"Approved for public release; distribution is unlimited."

\title{
Ecological Evaluation of
}

Proposed Dredged Material from St. Andrew Bay, Florida
H. L. Mayhew
M. R. Pinza
J. Q. Word
L. M. Karle
N. P. Kohn
J. A. Ward

Battelle/Maririe Sciences Laboratory

Sequim, Washington

October 1993

Prepared for

U.S. Army Corps of Engineers

under a Related Services Agreement

with the U.S. Department of Energy

Contract DE-AC06-76RLO 1830

Pacific Northwest Laboratory

Operated for the U.S. Department of Energy

by Battelle Memorial Institute 


\title{
DISCLAIMER
}

This report was prepared as an account of work sponsored by an agency of the United States Government. Neither the United States Government nor any agency thereof, nor Battelle Memorial Institute, nor any of their employees, makes any warranty, expressed or implied, or assumes any legal liability or responsibility for the accuracy, completeness, or usefulness of any information, apparatus, product, or process disclosed, or represents that its use would not infringe privately owned rights. Reference herein to any specific commercial product, process, or service by trade name, trademark, manufacturer, or ctherwise does not necessarily constitute or imply its endorsement, recommendation, or favoring by the United States Government or any agency thereof, or Battelle Memorial Institute. The views and opinions of authors expressed herein do not necessarily state or reflect those of the United States Government or any agency thereof.

\author{
PACIFIC NORTHWEST LABORATORY \\ operated by \\ BATTELLE MEMORIAL INSTITUTE \\ for the \\ UNITED STATES DEPARTMENT OF ENERGY \\ under Contract DE-AC06-76RLO 1830
}

Printed in the United States of America

Available to DOE and DOE contractors from the

Office of Scientific and Technical Information, P.O. Box 62, Oak Ridge, TN 37831; prices available from (615) 576-8401. FTS 626-8401.

Available to the public from the National Technical Information Service,

U.S. Department of Commerce, 5285 Port Royal Rd., Springfield, VA 22161. 
PNL-8894

UC-000

\title{
ECOLOGICAL EVALUATION OF PROPOSED DREDGED MATERIAL \\ FROM ST. ANDREW BAY, FLORIDA
}

\author{
H.L. Mayhew \\ J.Q. Word \\ N.P. Kohn \\ M.R. Pinza \\ L.M. Karle \\ J.A. Ward
}

Battelle/Marine Sciences Laboratory Sequim, Washington

October 1993

Prepared for the U.S. Army Corps of Engineers under a Related Services Agreement with the U.S. Department of Energy Contract DE-AC06-76RLO 1830

Pacific Northwest Laboratory

Richland, Washington 99352 


\section{SUMMARY}

Panama City Harbor is located in St. Andrew Bay, Florida, about 105 miles east of Pensacola, Florida. St. Andrew Bay is about 10 miles long and parallels the gulf coast. Natural depths range to about 50 feet, with about 7 square miles of the Bay measuring at least 30 feet deep. St. Andrew Bay is nearly landlocked, separated from the Gulf of Mexico by a barrier sand beach formally known as Lands End Peninsula (known locally as "Shell Island"). The Bay has two outlets to the Gulf, one of which is a natural inlet at the eastern end of Lands End Peninsula and the other a dredged channel 32 feet deep through the barrier peninsula about 4 miles west of the natural opening. The dredged cut is stabilized by twin rubble-mound jetties and serves as the harbor entrance from the Gulf.

The U.S. Army Corps of Engineers (USACE), Mobile District, requested that the Battelle/ Marine Sciences Laboratory (MSL) conduct field sampling and chemical and biological testing to determine the suitability of potential dredged material for open ocean disposal. Sediment from St. Andrew Bay was chemically characterized and evaluated for biological toxicity and bioaccumulation of contaminants following the guidelines in the 1991 Evaluation of Dredged Material Proposed for Ocean Disposal -- Testing Manual (EPA/USACE 1991a), referred to as the 1991 Implementation Manual, and in the 1991 Draft Regional Implementation Manual (EPAUSACE 1991b). These two manuals, hereinafter referred to as the 1991 Implementation Manuals, provide a tiered evaluation approach developed specifically for ocean disposal of dredged material at a selected site.

The Tier III guidance for ocean disposal testing requires tests of water column effects (following dredged material disposal), deposited sediment toxicity, and bioaccumulation of contaminants from deposited sediment (dredged material). To meet these requirements, the MSL conducted suspended-particulate-phase (SPP) toxicity tests, solid-phase toxicity tests, and bioaccumulation testing on sediment representing potential dredged material from Panama City Harbor. Physical and chemical characterization of sediment to support toxicity and bioaccumulation results was also conducted on both the test and reference sediments.

The MSL collected sediment samples from five sites in St. Andrew Bay and one reference site near Lands End Peninsula. The five test sediments and the reference sediment were analyzed for physical and chemical sediment characteristics, SPP chemical contaminants, solidphase toxicity, SPP toxicity, and bioaccumulation of contaminants. The SPP toxicity tests were conducted with the mysid shrimp ( $<48 \mathrm{~h}$ old) Mysidopsis bahia, the planktonic larvae of the bivalve Mytilus edulis, and the silverside minnow Menidia beryllina. Acute toxicity solid-phase tests were conducted with the deposit-feeding polychaete Nereis virens and the filter/depositfeeding infaunal amphipods Ampelisca abdita and Rhepoxynius abronius. Bioaccumulation of 
contaminants was evaluated through a 28-day exposure of the bent-nose clam Macoma nasuta and Nereis virens to the solid phase of the proposed dredged material, followed by chemical analyses of the tissues for the EPA priority pollutants and butyltins.

The maximum concentrations of contaminants of concern in the SPP samples were several orders of magnitude below the EPA Water Quality Criteria (WQC). The results of the SPP toxicity tests showed that there was no acute toxicity to any of the three species tested ( $M$. bahia, M. beryllina, and $M$. edulis). No $L C_{50}$ could be calculated because mortality did not exceed $50 \%$ of the population relative to the control.

The results of physical and chemical characterization of the sediment treatments show that, in general, the test treatments had higher concentrations of the majority of contaminants of concern relative to the reference sediment. Concentrations of TOC, total sulfides, PAHs, phthalate esters, chlorinated pesticides, metals, and butyltins were elevated in the test treatments relative to the reference sediment concentrations. The solid-phase tests of Panama City Harbor sediments showed solid-phase acute toxicity to $R$. abronius exposed to test treatment PC-2. when compared to the reference sediment using Dunnett's test (1964). There was no acute toxicity to either the A. abdita or N. virens solid-phase tests.

Tissue contaminant concentrations in $M$. nasuta and $N$. virens were orders of magnitude below the FDA action limits following exposure to Panama City Harbor sediments. Significant bioaccumulation of PAHs, pesticides, and PCBs were measured in $M$. nasuta tissues at levels between 2 and 21 times the concentrations observed in the tissues exposed to the reference sediment. Elevated metals concentrations in $M$. nasuta tissues exposed to the test treatments were generally at levels less than twice those found in the tissues exposed to the reference sediment, with the exception of Sb. Concentrations of Sb in M. nasuta tissues exposed to PC-4 were three times greater than in tissues exposed to the reference sediment. The tissues of $N$. virens exposed to the test treatments were statistically significantly different from the tissues exposed to the reference sediment, at levels less than 10 times the concentrations in the tissues exposed to the reference sediment for 6 of the 18 PAHs analyzed, and for 1 metal (Se).

There was no acute toxicity to water column organisms, and contaminant concentrations in SPP samples did not exceed WQC; therefore, the Panama City Harbor sediments meet water column criteria for ocean disposal. According to the 1991 Implementation Manuals, a proposed dredging area fails to meet the deposited sediment (solid-phase) criteria for ocean disposal if there is 1) statistically significant acute toxicity relative to reference and 2 ) a $>10 \%$ difference ( $>20 \%$ for amphipods) between the test treatment and reference. Following these criteria, test treatment PC-2 fails to comply with the deposited sediment criteria due to the acute toxicity to $R$. abronius. Compliance criteria for bioaccumulation are not as well-defined as for water column effects or 
deposited sediment toxicity. The scope of this project does not allow the MSL to make decisions regarding appropriate disposal of potential dredged material based on bioaccumulation results. Thus, bioaccumulation data are presented to assist the USACE and other resource agencies in providing a regional evaluation of disposal of proposed dredged material from St. Andrew Bay, Florida. 


\section{CONTENTS}

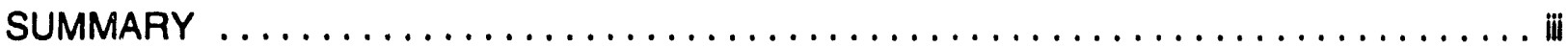

LIST OF ACRONYMS AND ABBREVIATIONS $\ldots \ldots \ldots \ldots \ldots \ldots \ldots \ldots \ldots \ldots$ Xi

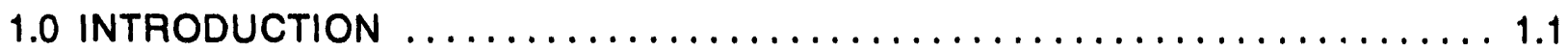

2.0 MATERIALS AND METHODS $\ldots \ldots \ldots \ldots \ldots \ldots \ldots \ldots \ldots \ldots \ldots \ldots \ldots \ldots \ldots \ldots$

2.1 SEDIMENT AND TEST ORGANISM COLLECTION $\ldots \ldots \ldots \ldots \ldots \ldots \ldots \ldots .1$

2.1.1 Test Sediment, Reference Sediment and Water Collection . . . . . . . . . 2.1

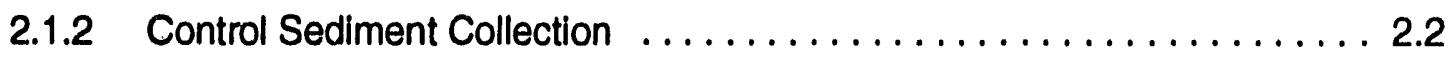

2.1.3 Test Organism Collection $\ldots \ldots \ldots \ldots \ldots \ldots \ldots \ldots \ldots \ldots \ldots \ldots . . \ldots \ldots$

2.2 SEDIMENT SAMPLE PREPARATION $\ldots \ldots \ldots \ldots \ldots \ldots \ldots \ldots \ldots \ldots$

2.2.1 Preparation of Laboratory Glassware and Equipment . . . . . . . . 2.3

2.2.2 Designation and Preparation of Sediment Treatments . . . . . . . . . 2.4

2.2.3 Preparation of Solid-Phase Treatments for Chemistry and Biological

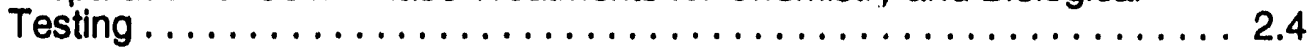

2.2.4 Preparation of Suspended-Particulate-Phase Samples for Chemistry

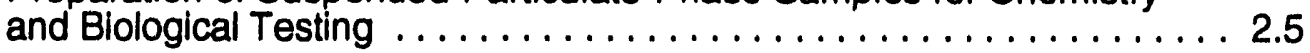

2.3 TOXICOLOGICAL TESTING PROCEDURES $\ldots \ldots \ldots \ldots \ldots \ldots \ldots \ldots$

2.3.1 10-Day Solid-Phase Flow-Through Test with A. abdita . . . . . . . . 2.6

2.3.2 10-Day Solid-Phase Static Test with $R$. abronius . . . . . . . . 2.8

2.3.3 10-Day Solld-Phase Flow-Through Test with $N$. virens . . . . . . . . . 2.9

2.3.4 28-Day Solid-Phase Flow-Through Test with $N$. virens . . . . . . . . . 2.11

2.3.5 28-Day Solid-Phase Flow-Through Test with M. nasuta . . . . . . . . . 2.12

2.3.6 96-h Suspended-Particulate-Phase Static Test with M. beryllina . . . . 2.12

2.3.7 96-h Suspended-Particulate-Phase Static Test with M. bahia . . . . . . . 2.13

2.3.8 72-h Suspended-Particulate-Phase Static Test with M. edulis . . . . . . . 2.13

2.4 SEDIMENT, WATER, AND TISSUE CHEMISTRY . . . . . . . . . . . . 2.15

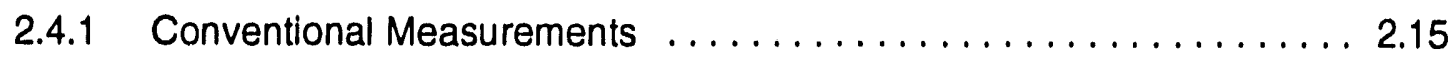

2.4.2 Polynuclear Aromatic Hydrocarbons (PAHs) . . . . . . . . . . . . . . . 2.19

2.4.3 Phenols, Substituted Phenols, and Phthalate Esters . . . . . . . . . . 2.19

$2.44 \quad \mathrm{PCB} /$ Pesticides . . . . . . . . . . . . . . . . . . . . . . . 2.20

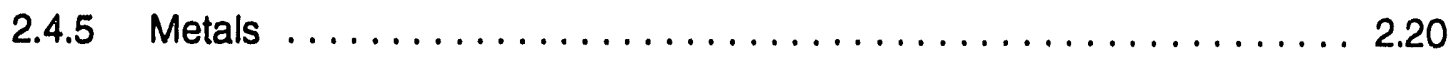

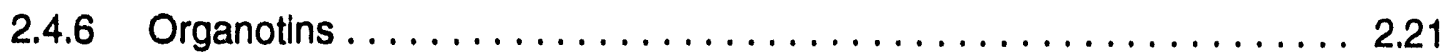

2.4 .7 Dioxins . . . . . . . . . . . . . . . . . . . . . . . . 2.22

2.5 DATA ANALYSIS AND INTERPRETATION $\ldots \ldots \ldots \ldots \ldots \ldots \ldots \ldots \ldots .22$

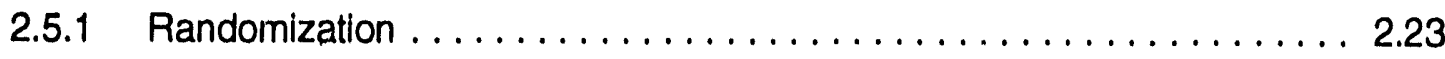

2.5.2 Statistical Analysis of Solid-Phase Tests . . . . . . . . . . . . . . 2.23

2.5.3 Statistical Analysis of Suspended-Particulate-Phase Tests . . . . . . . . 2.23 
2.5.4 Statistical Analysis of Bioaccumulation ................. 2.23

2.6 QUALITY ASSURANCE/QUALITY CONTROL (QAVQ) PROCEDURES . . 2.24

2.6.1 Sample Tracking and Storage $\ldots \ldots \ldots \ldots \ldots \ldots \ldots \ldots \ldots \ldots \ldots \ldots \ldots .2 .24$

2.6.2 Sediment and Tissue Chemistry Quality Control Procedures ...... 2.25

2.6.3 Toxicological Testing Quality Control Procedures ............. 2.26

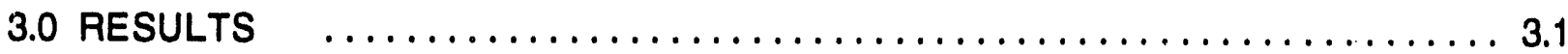

3.1 FIELD COLLECTION $\ldots \ldots \ldots \ldots \ldots \ldots \ldots \ldots \ldots \ldots \ldots \ldots \ldots \ldots \ldots . .1$

3.2 SEDIMENT SAMPLE PREPARATION $\ldots \ldots \ldots \ldots \ldots \ldots \ldots \ldots \ldots \ldots \ldots . .1$

3.3 SEDIMENT CHEMISTRY RESULTS $\ldots \ldots \ldots \ldots \ldots \ldots \ldots \ldots \ldots \ldots \ldots .2$

3.3.1 Conventional Measurements $\ldots \ldots \ldots \ldots \ldots \ldots \ldots \ldots \ldots \ldots . \ldots \ldots .2$

3.3.2 Polynuclear Aromatic Hydrocarbons $\ldots \ldots \ldots \ldots \ldots \ldots \ldots \ldots . \ldots .6$

3.3.3 Phenols, Substituted Phenols, and Phthalate Esters ............ 3.9

3.3.4 Chlorinated Pesticides and Polychlorinated Biphenyls .......... 3.10

3.3.5 Metals ...................................... 3.10

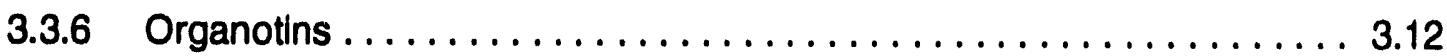

3.3.7 Dioxins ................................... 3.12

3.4 SUSPENDED-PARTICULATE-PHASE (SPP) CHEMISTRY RESULTS . . . 3.16

3.4.1 Polynuclear Aromatic Hydrocarbons (PAHs) $\ldots \ldots \ldots \ldots \ldots \ldots . \ldots .17$

3.4.2 Phenol, Substituted Phenols, and Phthalate Esters ............. 3.17

3.4.3 Chlorinated Pesticides and Polychlorinated Biphenyls ........... 3.19

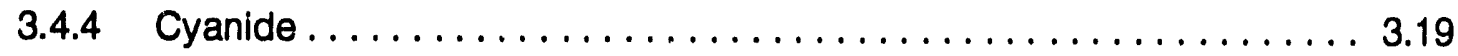

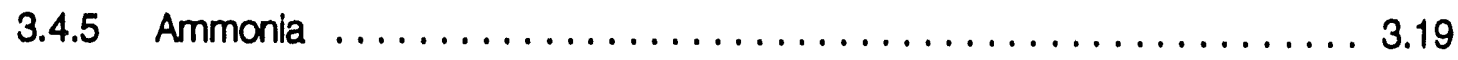

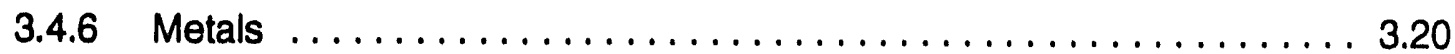

3.5 TOXICOLOGICAL TESTING RESULTS $\ldots \ldots \ldots \ldots \ldots \ldots \ldots \ldots \ldots . \ldots .20$

3.5.1 10-Day Solid-Phase Flow-Through Test with A. abdita .......... 3.21

3.5.2 10-Day Solid-Phase Static Test with R. abronius ............. 3.22

3.5.3 10-Day Solld-Phase Flow-Through Test with $N$. virens .......... 3.22

3.5.4 28-Day Solid-Phase Flow-Through Test with $N$. virens . .......... 3.23

3.5.5 28-Day Solid-Phase Flow-Through Test with $M$. nasuta .......... 3.23

3.5.6 96-h Suspended-Particulate-Phase Static Test with M. bahia . . . . . . . 3.23

3.5.7 96-h Suspended-Particulate-Phase Static Test with $M$. beryllina . . . . 3.24

3.5.8 72-h Suspended-Particulate-Phase Static Test with M. edulis . . . . . . 3.25

3.6 TISSUE CHEMISTRY $\ldots \ldots \ldots \ldots \ldots \ldots \ldots \ldots \ldots \ldots \ldots \ldots . \ldots \ldots . \ldots \ldots$

3.6.1 Bloaccumulation of Polynuclear Aromatic Hydrocarbons in M. nasuta .. 3.29

3.6.2 Bioaccumulation of Phenol, Substituted Phenols, and Phthalate Esters in $M$. nasuta .................................. 3.32

3.6.3 Bloaccumulation of Chlorinated Pesticides and Polychlorinated Biphenyls in $M$. nasuta ................................... 3.32 
3.6.4 Bloaccumulation of Metals in M. nasuta .................. 3.32

3.6.5 Bioaccumulation of Butyltins in $M$. nasuta ................. 3.35

3.6.6 Bloaccumulation of Dioxins in $M$. nasuta . ................ 3.35

3.6.7 Bloaccumulation of Polynuclear Aromatic Hydrocarbons in N. virens ... 3.36

3.6.8 Bloaccumulation of Phenol, Substituted Phenols, and Phthalate Esters in $N$. virens .................................... 3.37

3.6.9 Bioaccumulation Chlorinated Pesticides and Polychlorinated Biphenyls in $N$. virens ...................................... 3.37

3.6.10 Bloaccumulation of Metals in N. virens .................. 3.41

3.6.11 Bloaccumulation of Butyltins in $N$. virens ................. 3.41

4.0 CONCLUSIONS AND RECOMMENDATIONS $\ldots \ldots \ldots \ldots \ldots \ldots \ldots \ldots \ldots . . \ldots . . \ldots$

4.1 SEDIMENT CHARACTERISTICS ........................... 4.1

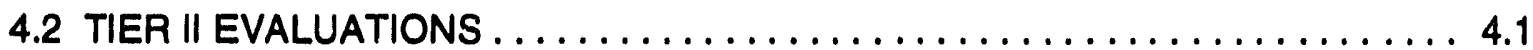

4.3 TIER III EVALUATIONS $\ldots \ldots \ldots \ldots \ldots \ldots \ldots \ldots \ldots \ldots \ldots \ldots \ldots . \ldots .2$

4.3.1 Water Column Effects . .......................... 4.2

4.3.2 Deposited Sediment (Solid-Phase) Acute Toxicity . . . . . . . . . . 4.3

4.3.3 Deposited Sediment Bloaccumulation .................... 4.3

4.4 CONCLUSIONS AND RECOMMENDATIONS $\ldots \ldots \ldots \ldots \ldots \ldots \ldots \ldots . .5$

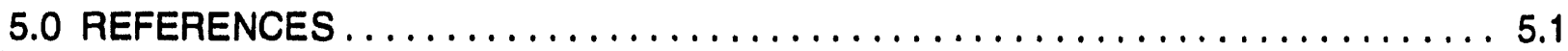

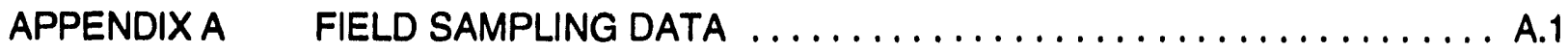

APPENDIX B SEDIMENT CHEMISTRY AND QUALITY ASSURANCE DATA ..... B.1

APPENDIX C SUSPENDED-PARTICULATE-PHASE (SPP) CHEMISTRY AND QUALITY ASSURANCE DATA $\ldots \ldots \ldots \ldots \ldots \ldots \ldots \ldots \ldots, \mathrm{C.} 1$

$\begin{array}{ll}\text { APPENDIX D } & \text { 10-DAY SOLID-PHASE TEST AND } 96-H O U R \text { REFERENCE } \\ \text { TOXICANT TEST WITH A. ABDITA .................... } .1\end{array}$

APPENDIXE 10-DAY SOLID-PHASE TEST AND 96-HOUR REFERENCE

TOXICANT TEST WITH R. ABRONIUS .................... E.1

APPENDIXF 10-DAY SOLID-PHASE TEST WITH N. VIRENS . . . . . . . . . . . F.1

APPENDIX G 28-DAY SOLID-PHASE TEST WITH N. VIRENS ............. .1

APPENDIXH 28-DAY SOLID-PHASE TEST WITH M. NASUTA .............. H. 1

APPENDIXI 96-HOUR SUSPENDED-PARTICULATE-PHASE TEST AND

96-HOUR REFERENCE TOXICANT TEST WITH M. BAHIA ........1.1

APPENDIXJ 96-HOUR SUSPENDED-PARTICULATE-PHASE TEST AND

96-HOUR REFERENCE TOXICANT TEST WITH M. BERYLLINA . . . J. J.1

APPENDIXK 72-HOUR SUSPENDED-PARTICULATE-PHASE TEST AND

72-HOUR REFERENCE TOXICANT TEST WITH M. EDULIS ....... K.1

APPENDIXL M. NASUTA TISSUE CHEMISTRY AND QUALITY CONTROL

DATA ........................................... L.1

APPENDIXM N. VIRENS TISSUE CHEMISTRY AND QUALITY CONTROL

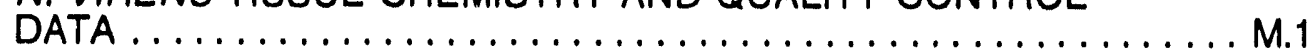

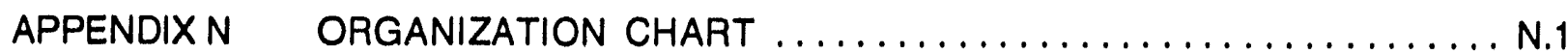

PANAMA CITY HARBOB ix 


\section{EIGURES}

1.1 Location of Panama City Harbor Study Area $\ldots \ldots \ldots \ldots \ldots \ldots \ldots \ldots \ldots \ldots$

2.1 Flow-Through and Static Testing Containers for A. abdita and R. abronius Toxicity

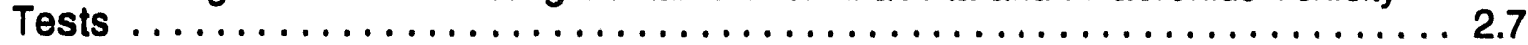

2.2 Flow-Through Aquaria for $M$. nasuta and $N$. virens Toxicity Tests . . . . . . . . . . 2.10

3.1 Location of Panama City Harbor Study Area $\ldots \ldots \ldots \ldots \ldots \ldots \ldots \ldots \ldots \ldots \ldots$

3.2 Location of $R$. abronius Control, West Beach, Whidbey Island, Washington ... . . 3.4

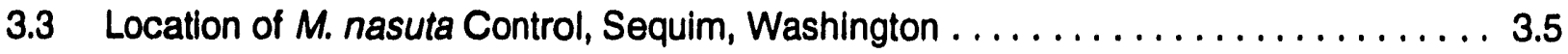

3.4 Regression Lines With 95\% Prediction Limits for Arsenic/Aluminum, Cadmium/Aluminum, Chromium/Aluminum, and Copper/Aluminum in

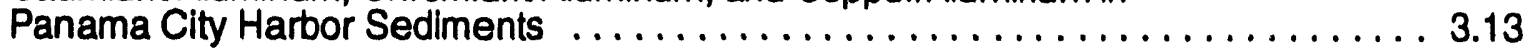

3.5 Regression Lines With 95\% Prediction Limits for Nickel'Aluminum, Lead/Aluminum, and Zinc/Aluminum in Panama City Harbor Sediments . . . . . . . . . . . . . . . 3.14

4.1 Panama City Harbor Sediment Treatments With Acute Toxicity and/or Bioaccumulation of at Least One Contaminant in the Tissues of at Least One Species (M. nasuta or N. virens) Compared to the Reference Treatment . . . . . . . . . . . . . . . . . 4.8

4.2 Matrix of Sediment Chemistry, Significant Acute Toxicity, and Bioaccumulation for Panama City Harbor Sediments Relative to the Reference Sediment 


\section{IABLES}

2.1 List of Analytes, Methods and Target Detection Limits $\ldots \ldots \ldots \ldots \ldots \ldots \ldots \ldots .16$

2.2 Analytical Methods for Analyzing Metals in Sediment, Water, and Tissue Matrices .. 2.21

3.1 Field Collection Summary for Test and Reference Sediment Treatments . . . . . . . . 3.2

3.2 Summary of Sediment Treatment Strategy for Chemical and Biological Testing . . . . . 3.6

3.3 Summary of Conventional Parameters in Panama City Harbor Sediment Treatments .

3.4 Summary of PAHs, Phenols, Substituted Phenols, and Phthalate Ester Concentrations in Panama City Harbor Sediment Samples $\ldots \ldots \ldots \ldots \ldots \ldots \ldots . . . .$.

3.5 Summary of Detected Pesticide and PCB Concentrations in Panama City Harbor Sediment Samples .................................. 3.11

3.6 Summary of Metals Concentrations in Panama City Harbor Sediment Samples . . . 3.12

3.7 Summary of Butyltins Concentrations in Panama City Harbor Sediment Samples . . 3.15

3.8 Summary of Dioxin Concentrations in Panama City Harbor Sediment Samples . . . 3.16

3.9 Summary of PAHs, Phenol, Substituted Phenols, and Phthalate Ester Concentrations in Panama City Harbor SPP Samples . . . . . . . . . . . . . . . 3.18

3.10 Summary of Cyanide and Ammonia in Panama City Harbor SPP Samples . . . . . . 3.19

3.11 Summary of Metals Concentrations in Panama City Harbor SPP Samples . . . . . . 3.21

3.12 Results of the 10-Day Solid-Phase Flow-Through Test with A. abdita . . . . . . . 3.22

3.13 ANOVA Results for the 10-Day Solid-Phase Flow-Through Test with A. abdita . . . 3.22

3.14 Results of the 10-Day Solid-Phase Static Test with $R$. abronius . . . . . . . . . 3.23

3.15 ANOVA Results for the 10-Day Solid-Phase Static Test with $R$. abronius . . . . . 3.23

3.16 Results of the 10-Day Solid-Phase Flow-Through Test with N. virens . . . . . . . 3.24

3.17 ANOVA Results for the 10-Day Solid-Phase Flow-Through Test with N. virens . . . 3.24

3.18 Results of the 28-Day Solid-Phase Flow-Through Test with N. virens and

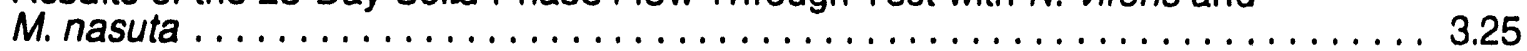

3.19 Results of the 96-h Suspended-Particulate-Phase Static Test with M. bahia . . . . 3.26

3.20 Results of the 96-h Suspended-Particulate-Phase Static Test with M. beryllina . . . 3.27

3.21 Results of the 72-h Suspended-Particulate-Phase Static Test with $M$. edulis . . . . 3.28

3.22 Mean Low PAH Concentrations in the Tissues of $M$. nasuta Exposed to Panama City Harbor Sediments ... . . . . . . . . . . . . . . . . . . . . . . . . . . 3.29

3.23 Mean High PAH Concentrations in the Tissues of $M$. nasuta Exposed to

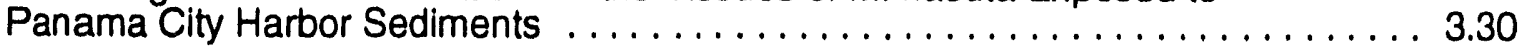

3.24 ANOVA Results for Chemical Parameters in the Tissues of $M$. nasuta Exposed to Test Treatments Compared to Tissues Exposed to the Reference Sediment ......... 3.31

3.25 Mean Concentrations of Chlorinated Pesticides and Polychlorinated Biphenyls (PCBs) in the Tissues of M. nasuta Exposed to Panama City Harbor Sediments .. 3.33

3.26 Mean Metal Concentrations in the Tissues of $M$. nasuta Exposed to Panama City

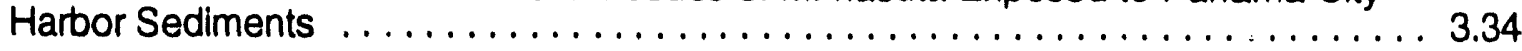


3.27 Mean Butyltin Concentrations in the Tissues of M. nasuta Exposed to Panama

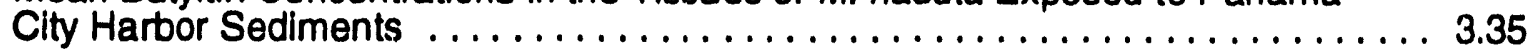

3.28 Summary of Dioxin Concentrations in M. nasuta Tissues Exposed to Panama City Harbor Sediments

3.29 Mean Low PAH Concentrations in the Tissues of N. virens Exposed to Panama City Harbor Sediments

3.30 Mean High PAH Concentrations in the Tissues of N. virens Exposed to Panama City Harbor Sediments

3.31 ANOVA Results for Chemical Parameters in Tissues of $N$. virens Exposed to Test Treatments Compared to Tissues Exposed to the Reference Sediment

3.32 Mean Concentrations of Chlorinated Pesticides and Polychlorinated Biphenyls (PCBs) in Tissues of $N$. virens Exposed to Panama City Harbor Sediments . . . . . 3.40

3.33 Mean Metal Concentrations in the Tissues of $N$. virens Exposed to Panama City

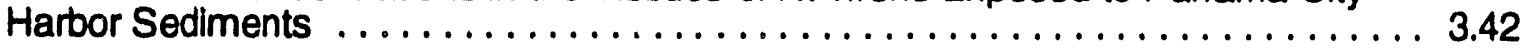

3.34 Mean Butyltin Concentrations in the Tissues of N. virens Exposed to Panama City Harbor Sediments

4.1 Comparison Between EPA Water Quality Criteria Levels and Panama City Harbor Suspended-Particulate-Phase (SPP) Samples $\ldots \ldots \ldots \ldots \ldots \ldots \ldots \ldots \ldots .2$

4.2 Suspended-Particulate-Phase Toxicity Test Results . . . . . . . . . . . . . . . 4.3

4.3 Comparison of Solid-Phase Acute Toxicity to the Reference Sediment . . . . . . . . 4.4

4.4 Comparison Between FDA Action Levels and Contaminant Levels in M. nasuta and $N$. virens Exposed to Panama City Harbor Sediments . . . . . . . . . . . . . . . . . 4.5

4.5 Summary of Acute Toxicity and Bioaccumulation for Panama City Harbor Sedirnent Treatments Relative to the Reference Sediment 


\section{UST OF ACRONYMS AND ABBREVIATIONS}

\begin{tabular}{|c|c|}
\hline$A A$ & atomic absorption \\
\hline ANOVA & analysis of variance \\
\hline BOS & Battelle Ocean Sciences, Duxbury, Massachusetts \\
\hline CVAA & cold vapor atomic absorption \\
\hline CVAF & cold vapor atomic fluorescence \\
\hline DO & dissolved oxygen \\
\hline$E_{50}$ & concentration causing abnormal effects to $50 \%$ of organisms tested \\
\hline EPA & U.S. Environmental Protection Agency \\
\hline FDA & Food and Drug Administration \\
\hline GC & gas chromatography \\
\hline GC-ECD & gas chromatography with electron capture detection \\
\hline GC/FPD & gas chromatography/flame photometric detection \\
\hline GC/MS & gas chromatography/mass spectrophotometry \\
\hline GFAA & graphite fumace atomic absorption \\
\hline GPC & gel permeation chromatography \\
\hline GPS & Gorman 100 Global Positioning System \\
\hline HAA & hydride atomic absorption \\
\hline HPAH & high-molecular-weight polynuclear aromatic hydrocarbons \\
\hline HPLC & high perfnmance liquid chromatography \\
\hline HRGC/HRMS & high-resolution gas chromatography and high-resolution mass spectrometry \\
\hline ICP/MS & inductively coupled plasma/mass spectroscopy \\
\hline IDL & instrument detection limit \\
\hline l-stat & industrial statistic \\
\hline$L C_{50}$ & concentration causing mortality to $50 \%$ of organisms tested \\
\hline LPAH & low-molecular-weight polynuclear aromatic hydrocarbons \\
\hline LPC & limiting permissible concentration \\
\hline MDL & method detection limit \\
\hline MS & matrix spike \\
\hline MSD & matrix spike duplicate \\
\hline MSL & Battelle/Marine Sciences Laboratory \\
\hline PAH & polynuclear aromatic hydrocarbons \\
\hline PCB & polychlorinated biphenyls \\
\hline PNL & Pacific Northwest Laboratory, Richland, Washington \\
\hline PSEP & Puget Sound Estuary Program \\
\hline PVC & polyvinyl chloride \\
\hline
\end{tabular}


RIS recovery intemal standard

RPD relative percent difference

RSD relative standard deviation

QA/QC quality assurance/quality control

SIM selective ion mode

SIS surrogate intemal standard

SOP standard operating procedure

SPP suspended-particulate-phase

SRM standard reference material

TEF toxicity equivalent factors

TOC total organic carbon

USACE U.S. Amy Corps of Engineers

WQC Water Quality Criteria

XRF $\quad x$-ray fluorescence 


\subsection{INTRODUCTION}

Panama City Harbor is located in St. Andrew Bay, Florida (Figure 1.1), about 105 miles east of Pensacola, Florida. The Bay is an arm of the Gulf of Mexico, about 10 miles long and parallel to the coast. Natural depths range to about 50 feet, with about 7 square miles of the Bay measuring at least 30 feet deep. St. Andrew Bay is nearly landlocked, separated from the Gulf of Mexico by a barrier sand beach formally known as Lands End Peninsula (known locally as "Shell Island"). The Bay has two outlets to the Gulf, one of which is a natural inlet at the eastern end of Lands End Peninsula and the other a dredged channel 32 feet deep through the barrier peninsula ibout 4 miles west of the natural opening. The dredged cut is stabilized by twin rubble-mound jetties and serves as the harbor entrance from the Gulf.

The U.S. Army Corps of Engineers (USACE), Mobile District, requested that the Battelle/ Marine Sciences Laboratory (MSL)(a) conduct field sampling and chemical and biological testing to determine the suitability of proposed dredged material for open ocean disposal. This testing is required by Section 103 of Public Law 92-532 [iMarine Protection, Research, and Sanctuaries Act of 1972 (MPRSA)] which regulates open ocean disposal of dredged material. Sediment from St. Andrew Bay was chemically characterized and evaluated for biological toxicity and bioaccumulation of contaminants following the guidelines in the 1991 Evaluation of Dredged Material Proposed for Ocean Disposal -- Testing Manual (EPAUSACE 1991a), referred to as the 1991 Implementation Manual, published jointly by the U.S. Environmental Protection Agency and the USACE, and in the 1991 Draft Regional Implementation Manual (EPAUSACE 1991b).

These testing manuals, hereinafter referred to as the 1991 Implementation Manuals, provide a tiered evaluation approach developed specifically for ocean disposal of dredged material at a selected site.

The Tier III guidance for ocean disposal testing requires tests of water column effects (following dredged material disposal), deposited sediment toxicity, and bioaccumulation of contaminants from deposited sediment (dredged material). To meet these requirements, the MSL conducted suspended-particulate-phase (SPP) toxicity tests, solid-phase toxicity tests, and bioaccumulation testing on sediment representing proposed dredged material from Panama City Harbor. Physical and chemical characterization of sediment to support toxicity and bioaccumulation results was also conducted on both the test and reference sediments.

The objectives of the Panama City Harbor Project were to collect and evaluate effects of the potentially contaminated sediment proposed for dredging and disposal. The results of analytical and toxicological measurements were compared to reference sediment results to

(a) The Battelle/Marine Sciences Laboratory is part of the Pacific Northwest Laboratory, which is operated for the U.S. Department of Energy by Battelle Memorial Institute. 


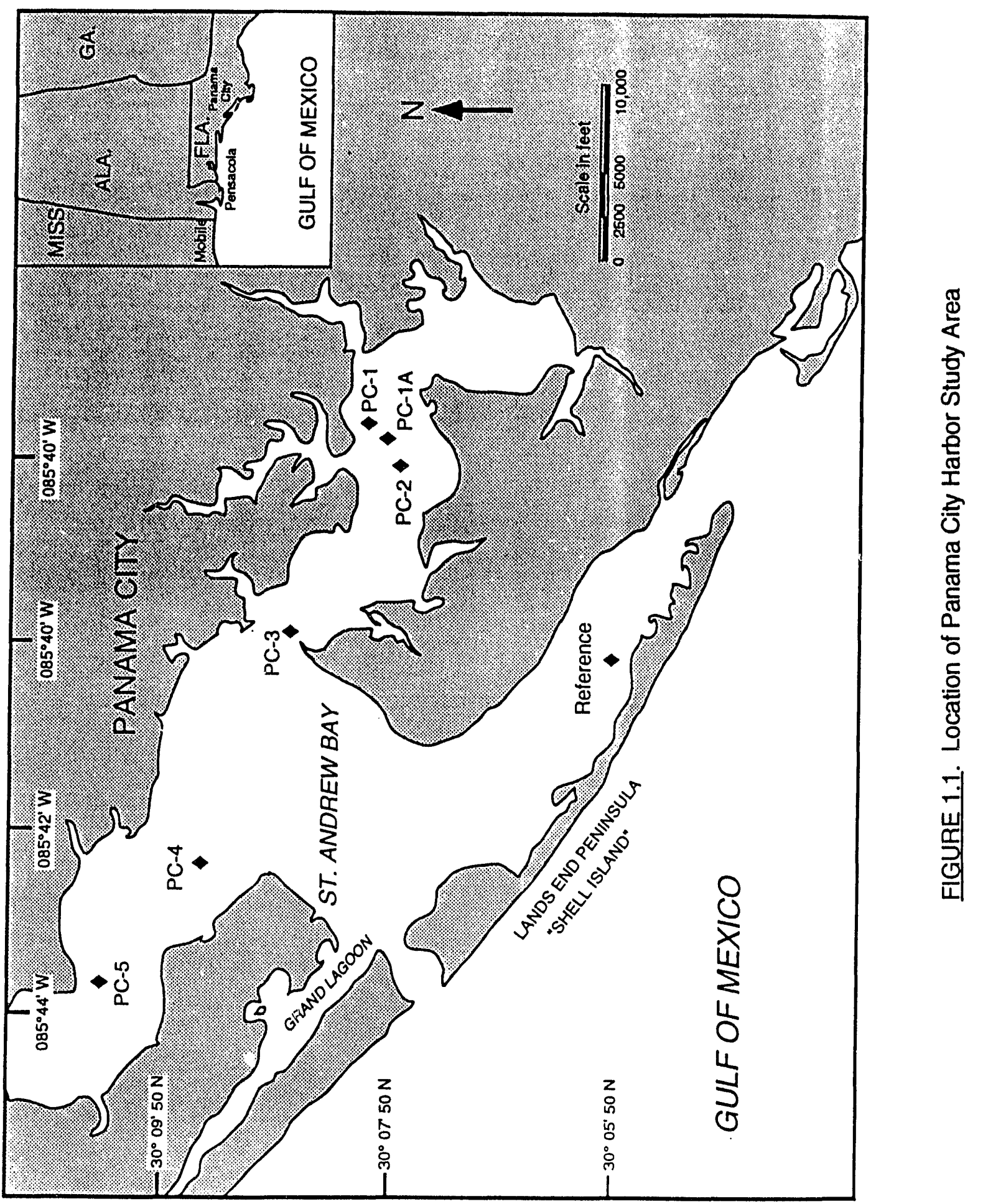


determine if the test sediments contained more bioavailable contaminants than the reference sediment. The use of reference sediment allows for comparison of biological responses and contaminant levels between a proposed dredged sediment sample and a proposed disposal area sample that is "...substantially free of contaminants and which...reflects conditions that would exist in the vicinity of the disposal site had no dredged-material disposal ever occurred..." Grab samples were collected from five sites in the harbor and one reference site near Lands End Peninsula. Reference site water was collected near Lands End Peninsula.

The five test sediments and the reference sediment were analyzed for physical and chemical sediment characteristics, SPP chemical contaminants, solid-phase toxicity, SPP toxicity, and bioaccumulation of contaminants. The chemical and biological tests were conducted following protocols in the 1991 Implementation Manuals. The SPP toxicity tests were designed to test the effects of dissolved contaminants plus those associated with suspended particulates in the water. The solid-phase toxicity and bioaccumulation tests examined effects of the settled portion of proposed dredged sediment on sensitive benthic organisms relative to sediment from a possible disposal site reference. Control sediment samples were also collected and tested following the same procedures to validate test results based upon survival of test organisms following exposure to their native sediment. Sediment treatment PC-3 was sampled and analyzed for grain size, specific gravity, and total percent solids only.

Test organism selection also followed guidance in the 1991 Implementation Manuals. Species proposed for acute toxicity solid-phase tests were the deposit-feeding polychaete Nereis virens, and the filter/deposit-feeding infaunal amphipods Ampelisca abdita and Rhispoxynius abronius. Species proposed for SPP toxicity tests were the mysid shrimp (<48 $\mathrm{h}$ old) Mysidopsis bahia, planktonic larvae of the bivalve Mytilus edulis, and the silverside minnow Menidia beryllina. Bioaccumulation of contaminants was evaluated through a 28-day exposure of the bent-nose clam Macoma nasuta and Nereis virens to the solid phase of the proposed dredged material followed by chemical analyses of the tissues for the EPA priority pollutants and butyltins. These species met the required selection criteria listed in the 1991 Implementation Manuals, and have been succsessfully used in similar testing programs conducted by the MSL.

Chemical analyses included measurements of EPA priority pollutant metals, polynuclear aromatic hydrocarbons (PAH), polychlorinated biphenyls (PCB), phenol and substituted phenols, phthalate esters, chlorinated pesticides, and dioxins as well as butyltins (tri- and dibutyltin) and conventional sediment parameters.

This report describes the evaluation of Panama City Harbor sediments relative to the Shell Island Reference Site. The report is divided into five sections. Following this introduction, Section 2.0 describes materials and methods used for sample collection and preparation for toxicological testing; sediment, water, and tissue chemistry; data analysis and interpretation; and 
quality assurance/quality control requirements. Section 3.0 presents the results of sediment chemistry, SPP chemistry, toxicological testing, and tissue chemistry. Section 4.0 is a discussion of analyses of sediment characteristics and Tier II and III evaluations, and presents conclusions and recommendations regarding the acceptability of dredged material for ocean disposal. Section 5.0 lists the literature cited in support of this document. The following appendixes contain detailed data listings:

\section{Appendix A Appendix $B$ Appendix $\mathbf{C}$ Appendixes $D \cdot K$ Appendixes L-M Appendix $\mathbf{N}$}

\author{
Field Sampling Data \\ Sediment Chemistry and Quality Control Data \\ Suspended-Particulate-Phase Chemistry and Quality Control Data \\ Toxicity Test Data \\ Tissue Chemistry and Quality Control Data \\ Organizational chart.
}




\subsection{MATERIALS AND METHODS}

\subsection{SEDIMENT ANL I TEST ORGANISM COLLECTION}

Sediment samples were collected from six test sites in St. Andrew Bay, Florida; one reference site located near Lands End Peninsula, also known as "Shell Island"; and four control sites in Sequim Bay, Washington (M. nasuta), Whidbey Island, Washington (R. abronius), San Pablo Bay, Califomia (A. abdita), and Newcastle, Maine (N. virens). All samples were collected using either a ponar grab, specially designed anchor or sand dredges, or a shovel. Control sediment and test organisms collected at Whidbey Island and Sequim Bay were collected by MSL personnel using a small boat; San Pablo Bay and Newcastle sediment and organisms collected at these sites were supplied to the MSL by private contractors. Specific locations of sediment sampling stations are presented with the sampling results in Section 3.1.

\subsubsection{Iest Sediment. Reference Sediment and Water Collection}

Sampling locations were selected by the USACE, based on proximity to industrial sites located in St. Andrew Bay and on depth and sediment type. Once the sampling location was Identified, a marker buoy was deployed from the vessel. Test and reference sediments were collected from specific locations using a sand dredge that penetrated approximately the top 15 to $20 \mathrm{~cm}$. The sand dredge and line were deployed until the dredge began to penetrate the surface of the sediment. Sediment entered the sand dredge through a box-like frame where it was contained in a reinforced canvas bag. The dredge was allowed to drag in the sampling area for $\sim 3$ min after which the sediment samples were transferred to clean, epoxy-coated 5-gal pails, sealed, and labeled with the study identifier, station name, date of collection, and number of buckets representing each station. Sampling records maintained in a logbook consisted of station position, date, time, replicate, water depth, sediment type, and comments. All samples were maintained at $-4 \pm 2^{\circ} \mathrm{C}$ in a refrigerated van until ready for shipment. Once all samples were obtained in the fleld, they were shipped in the refrigerated van from Panama Clty, Florida, to Sequim, Washington. Upon arrival at the MSL, sediment samples were transferred to a climatecontrolled cold room and maintained at $\sim 4^{\circ} \mathrm{C}$ until they were used for toxicity testing and chemical analysis.

Station positioning was accomplished through the use of a Gorman 100 Global Positioning System (GPS) provided and operated by USACE. Sampling depths were recorded using a calibrated fathometer (Raytheon).

The reference sediment sample located on the west end of "Shell Island" was collected with the sand dredge. Sediment samples were transferred to clean, epoxy-coated 5-gal pails, sealed, and labeled with the study identifier, station name, date of collection, and number of 
buckets representing the station. Sampling records maintained in a logbook consisted of station position, date, time, replicate, water depth, sediment type, and comments.

Water samples collected at the reference site prior to sediment sampling were taken from just below the water surface by submerging, filling, and capping a carboy while it was submerged. Samples were contained in 20-L polypropylene carboys that were soap-and-water washed, rinsed with deionized water, soaked at least $4 \mathrm{~h}$ in $10 \%$ nitric acid, rinsed again with deionized water, allowed to air dry, and then rinsed with methylene chloride. Water samples were stored in the refrigerated van along with sediment samples at $\sim 4^{\circ} \mathrm{C}$. Water samples were collected at the reference site $\sim 3$ wk after the initial field sampling and were sent to the MSL to complete toxicity testing.

\subsubsection{Control Sediment Collection}

The control sediment sampling sites were Sequim Bay, Washington ( $M$. nasuta), Whidbey Island, Washington ( $R$. abronius), San Pablo Bay, California ( $A$. abdita), and Newcastle, Maine (N. virens). Control sediment was collected using a variety of samplers. Control sediment and test organisms from Whidbey Island and Sequim Bay were collected by MSL personnel using a small boat at the same time and location at which test organisms were collected. Whidbey Island sediment was collected with a small, MSL-designed, anchor dredge sampler that also obtained sufficient quantitles of the organisms for test purposes. The dredge was deployed from the MSL's 17-ft Boston Whaler in $15 \mathrm{ft}$ of water. The Whidbey Island sampling location was determined by reference to known shoreline features. Control sediment from Sequim Bay was collected with a ponar grab deployed from an MSL research vessel. San Pablo Bay and Newcastle sediments and organisms collected at these sites were supplied to the MSL by private contractors.

\subsubsection{Test Oraanism Collection}

Seven species of organisms were used to evaluate sediment samples from the Panama City Harbor Project study area:

- amphipod Ampelisca abdita

- amphipod Rhepoxynius abronius

- polychaete Nereis virens

- bent-nose clam Macoma nasuta

- $\quad$ silverside fish Menidia beryllina

- $\quad$ mysid shrimp Mysidopsis bahia

- larvae of mussel Mytilus edulis

All test organisms (except mysids, silversides, and mussels) were wild-captured individuals collected either by a commercial supplier or by MSL personnel. The organisms were shipped in native sediment or in another way designed to ensure their viability. After receipt at the MSL, test organisms were gradually acclimated to test conditions. Animals acting abnormally 
were not used in toxicological tests. The amphipod $A$. abdita and the polychaete $N$. virens were supplied by Brezina and Assoclates, Dillon Beach, California. Samples of $A$. abdita and its native sediment were collected from San Pablo Bay, Callfomia, by dragging a large dipnet along the sediment surface. Test organisms were carefully removed from their tubes for enumeration, and then placed in clean native sediment for ovemight transport to the MSL. Samples of N. virens were collected from an intertidal region in Newcastle, Maine, using a bucket and shovel and transported in moist mats of seaweed packed in coolers via overnight mail. The $R$. abronius samples were collected by MSL personnel from Whidbey Island using an MSL-designed anchor dredge. Amphipods were transported in clean coolers containing $\sim 10 \mathrm{~cm}$ of sediment and $5 \mathrm{gal}$ of clean seawater at a temperature approximating natural conditions. Samples of M. nasuta were collected from intertidal zones in Discovery Bay, Washington, by Johnson and Gunstone (a commercial supplier) using a shovel, bucket, and sleve. Clams were kept cool prior to shipment by placing them in large containers filled with sediment and seawater from the collection site. The M. bery!lina samples were supplled by Aquatic Indicators, St. Augustine, Florida, shipped in large plastic bags containing seawater and maintained at $\sim 15^{\circ} \mathrm{C}$. Prior to shipment via overnight mail, seawater was supersaturated with oxygen to ensure test organism survival. Samples of M. bahia were obtained from Aquatic Biosystems, Fort Collins, Colorado, and shipped in plastic bags containing oxygen-supersaturated seawater maintained at $\sim 15^{\circ} \mathrm{C}$. The $M$. edulis samples were purchased from Taylor United, Inc. in Quilcene, Washington. These organisms were wrapped in moist paper towels and shipped in a styrofoam cooler containing blue ice to maintain an amblent temperature of $\sim 15^{\circ} \mathrm{C}$.

\subsection{SEDIMENT SAMPLE PREPARATION}

Sediment sample preparation involved all steps in the laboratory between delivery of the samples to the MSL and the preparation of samples for chemical and/or biological testing.

Sediment for biological testing was prepared and used within the 6-week holding period specified in the 1991 Implementation Manuals. During this holding time, the samples were recelved at the MSL, inventoried against chain-of-custody forms, processed for solid-phase and SPP testing, subsampled for sediment chemistry and water chemistry parameters, and used in the biological tests. The following sections describe equipment preparation, compositing strategy, preparation of sediments for chemistry and solid-phase biological testing, and preparation of SPP samples for chemistry and blological testing.

\subsubsection{Preparation of Laboraton Glassware and Equipment}

All glassware, stainless-steel or titanlum utensils, Nalgene, Teflon, and other laboratory containers and equipment underwent stringent cleaning procedures to avoid contamination of samples. Glassware (test containers, aquaria, and sediment transfer dishes) was washed with 
warm, soapy water, rinsed five times with deionized water, then soaked in a $5 \%$ reagent grade nitric acid bath for a minimum of $4 \mathrm{~h}$. After soaking, glassware was rinsed with deionized water five times and allowed to dry. Polyvinyl chloride (PVC), Nalgene, and Teflon tools were also washed and soaked in acid baths in the same manner as for glassware.

Stainless-steel bowls, spoons, spatulas, and other utensils were washed with warm, soapy water, rinsed five times with delonized water, and allowed to air dry. They were then rinsed with methylene chloride under a fume hood, and the methylene chloride was allowed to evaporate under the hood.

Neoprene stoppers and polyethylene sheets or other porous materials were washed with warm, soapy water and insed five times with delonized water. These items were then "seasoned" by continuous soaking in $0.45 \mu \mu \mathrm{m}$-filtered seawater for at least 2 days prior to use. Large pleces of laboratory equipment, such as the epoxy-coated sediment mixer, were washed with a dllute soap solution and thoroughly rinsed with tap water followed by delonized water.

Equlpment used to determine water quality--such as pH, dissolved oxygen (DO), temperature, and salinity--were calibrated according to the manufacturer's specifications and internal MSL Standard Operating Procedures (SOPs).

\subsubsection{Desionation and Preparation of Sediment Treatments}

A total of 11 sediment treatments were evaluated for the Panama City Harbor Project: six test treatments (PC-1, PC-2, PC-1A, PC-3, PC-4, and PC-5), one reference treatment, and four control treatments ( $M$. nasuta Control, $N$. virens Control, $A$. abdita Control, and $R$. abronius Control). Test sediment treatment PC-3 was originally included in the scope of work, but during the fleld sampling cruise there was concern that the materlal might be too coarse for the amphipod A. abdita; therefore, test sediment treatment PC-1A replaced PC-3. Sediment treatment PC-3 was sampled but was only tested for grain-size analysis and specific gravity. Station PC-1A, located midway between stations PC-1 and PC-2 (Figure 1.1), was chemically analyzed and used in the toxicological and bloaccumulation tests.

\subsubsection{Preparation of Solld-Phase Treatments for Chemistry and Blological Testing}

Solld phase refers to the sediment itself, in contrast to the suspended or dissolved phases. In blological tests, the solid phase of sediments represents 1) dredged material once it has settled at an aquatic disposal site (test sediment), 2) existing environmental conditions of a disposal site without dredged material (reference sediment), or 3) the environment of a benthic test organism ("native" control sediment). All solid-phase samples were thoroughly homogenized until constant color and texture were achieved before use in biological tests or chemical analysis.

Reference and control sediments were press-sleved through a $1.0-\mathrm{mm}$ screen to remove predators. After sleving, the reference or control sediment was mixed in a large epoxy-coated 
cement mixer. Between sleving of the reference and control sediments, all equipment was thoroughly rinsed with $0.45-\mu \mathrm{m}$-filtered seawater to avoid potential cross-contamination between samples. Test sediment samples were processed by compositing the sediment from a station in the epoxy-coated mixer until a homogenous color and texture were evident. After compositing, aliquots of each sediment were sampled for chemical analyses and placed in cleaned and labeled containers appropriate for the parameters to be measured. A subsample of each sediment treatment was also taken for archival purposes. All sediment treatments (test, reference, and control) were then placed in 5-gal epoxy-coated palls that were sealed, labeled, and maintained at $4 \pm 2^{\circ} \mathrm{C}$ untll needed for biological testing.

\subsubsection{Preparation of Suspended.Particulate-Phase Samples for Chemistry and Blological Testing}

The SPP of sediment samples was used to evaluate potential water column effects of open-water dredged material disposal. The SPP is the liquild supernatant that remains after mixing sediment with seawater and allowing heavler particles to settle to the bottom. Because SPP preparation does not involve filtration, this phase contains suspended particles as well as dissolved constituents. The SPP tests evaluate effects caused by both the physical presence of suspended particles and the chemical toxicity of contaminants associated with the particles or dissolved constituents. The process is intended to approximate exposure conditions created when materlals are discharged through the water column during dredged-material disposal operations.

The SPP was prepared by creating a 4:1 (volume:volume) water to sediment slurry in 1-L glass jars with Teflon-lined lids. The jars were marked at $200 \mathrm{~mL}$ and $400 \mathrm{~mL}$ and filled to the $200-\mathrm{mL}$ mark with $0.45-\mu \mathrm{m}$-filtered seawater. Homogenized sediment was then added until the water was dlsplaced to the $400-\mathrm{mL}$ mark. Each jar was filled to $1 \mathrm{~L}$ with filtered seawater. Twelve jars of sediment and water were placed on a shaker table and agitated for $30 \mathrm{~min}$ at a shaking rate of 120 to 150 cycles/min. After shaking, the slurry was poured into $500-\mathrm{mL}$ Teflon containers with tightly fitting llds. These containers were placed in a centrifuge and spun for 10 to $15 \mathrm{~min}$ at $\sim 1750 \mathrm{rmm}$. The 10 -min centrifugation was necessary to ensure that test organisms would be visible at the first observation following exposure to SPP test treatments. After centrifugation, the supernatant was poured into clean, labeled, 1-gal jars and used in the SPP tests as soon as possible (within $24 \mathrm{~h}$ ). The SPP produced for the water chemistry analysis was poured into appropriate chemistry jars for speciflc analysis. If the SPP was not used immediately for blological tests, the jars were stored at $4 \pm 2^{\circ} \mathrm{C}$. The Teflon Jars were rinsed after each use and the above process continued until an adequate amount of SPP was produced. Between SPP preparations, all glass and Teflon containers were appropriately cleaned according to procedures described in Section 2.2.1. 


\subsection{IOXICOLOGICAL TESTING PROCEDURES}

Biological tests to assess the ecological effects of aquatic disposal of dredged material from the Panama Clty Harbor Project area were conducted on the solid-phase and SPP of test sediments. Elght toxicological/bioaccumulation tests involving seven test species were conducted in support of the Panama Clty Harbor Project. Four species of marine organisms were exposed to test sediments from the Panama City Harbor Project area, reference area sediments, and control sediments. Three acute toxicity tests were conducted: 1) a 10-day solid-phase flowthrough acute toxicity test using the amphipod $A$. abdita, 2) a 10-day solld-phase static acute toxicity test using the amphipod $R$. abronius, and 3) a 10-day solld-phase flow-through acute toxicity test using the polychaete $N$. virens. The bioaccumulation test was a 28-day solid-phase exposure of $N$. virens and $M$. nasuta (tested separately). The purpose of the 28-day test was to assess the potential for bloaccumulation of contaminants from the sediment in tissues of the organisms. The 28-day bloaccumulation tests and procedures were similar to the 10-day test with the exception of a longer exposure period, larger test population, and a depuration process for surviving $M$. nasuta and $N$. virens. All solid-phase tests consisted of five replicate containers for each treatment and species tested. All test containers were placed in random positions in the water tables.

Three SPP tests were conducted: a $96-\mathrm{h}$ exposure using the silverside minnow M. beryllina, a 96-h exposure using the mysid shrimp M. bahia, and a 72-h exposure of larvae of the mussel M. edulls. The SPP treatments were prepared as described in Section 2.2.4. There were five replicates each of four SPP concentrations: $0 \%$ (seawater), $10 \%, 50 \%$, and $100 \%$ (SPP). All test containers were placed in random positions in the water tables.

The five test treatments and one reference treatment were evaluated for all toxicological tests. Since the SPP tests evaluated the difference in test organism survival idetween $0 \%$ (seawater) and 100\% SPP exposures, control tests were not required. The MSL facilities provided the required conditions for flow-through solid-phase tests, static solid-phase tests, and static SPP tests. Laboratory equipment included a controlled-temperature environment, flowthrough seawater supply, lighting control, and air supply.

\subsubsection{0-Dav Solid-Phase Elow-Throuah Test with A. abdita}

The A. abdita 'Nere held in a large holding tank containing their native sediment under flowthrough conditions at $\sim 20^{\circ} \mathrm{C}$ seawater. Organisms were not fed during the holding period, the $\sim 48 \mathrm{~h}$ preceding test initiation. The A. abdita test was conducted in 1-qt flow-through Mason jars (Figure 2.1) placed at random positions on a water table maintained at $20^{\circ} \mathrm{C}$. Prior to test initiation, sediment was added to the jars to a depth of $2 \mathrm{~cm}$, then each jar was allowed to slowly fill via the flow-through system to a total volume of $750 \mathrm{~mL}$. The flow-through Mason Jar was designed to allow a subsurface exit of seawater, thereby reducing the chance of test organism 


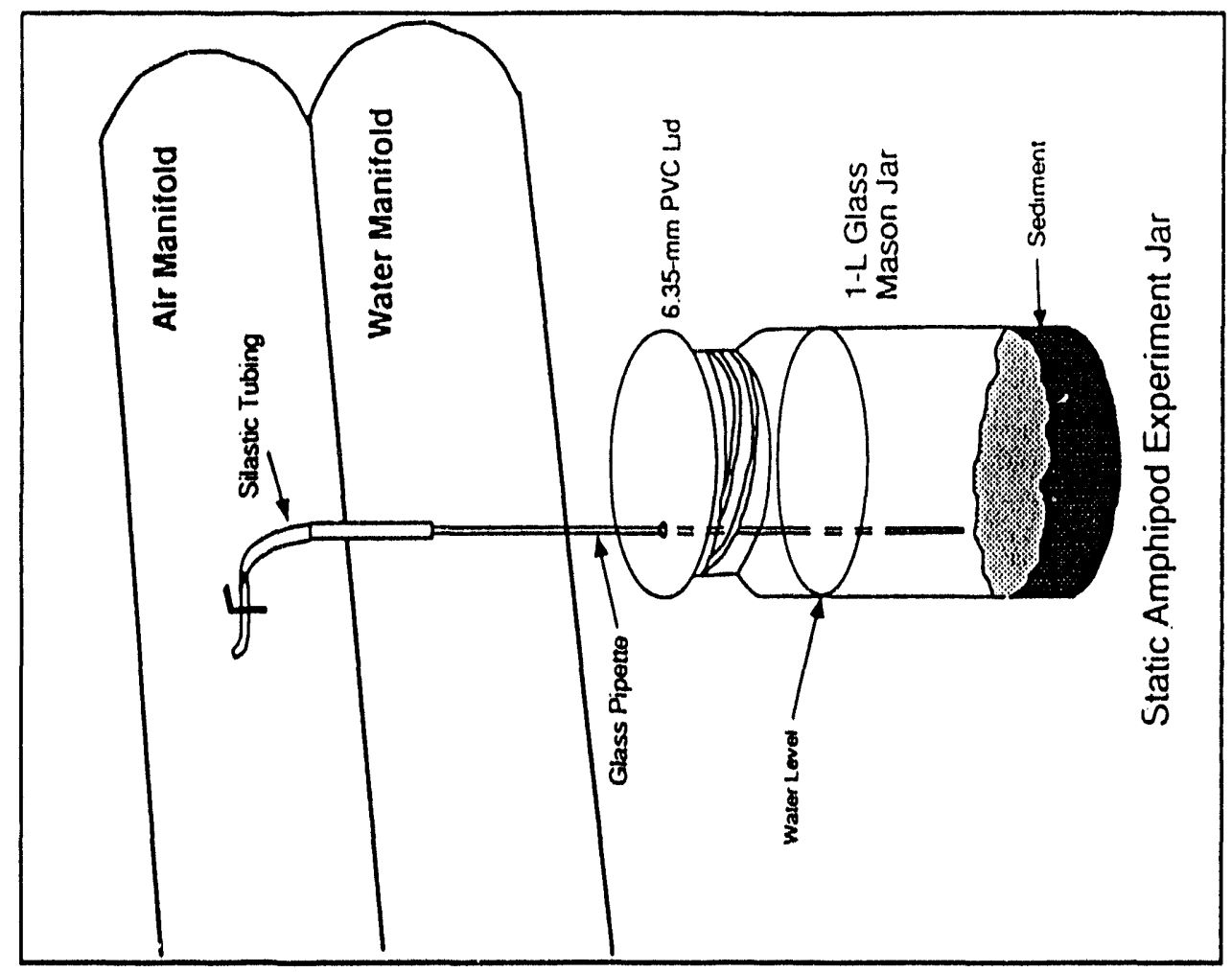

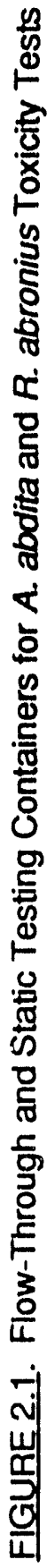


impingement on the screened discharge. Jars were placed on the water table overnight to stabilize the temperature to test conditions. After stabilization, initial water quality parameters were measured in each container and recorded on water quality forms. Gentle aeration was applied to each jar to provide adequate oxygenation of overlying water, and the test was conducted under a light regime of $16 \mathrm{~h}$ light/8 h dark.

The test was initlated by adding $20 \mathrm{~A}$. abdita to each test container. The amphipods were gently sieved from the holding tank into clean seawater and counted into small transfer containers. The number of organisms was then confirmed by a second observer before being transferred into the test container. The date and time of initiation were recorded on data forms and on the lids of test containers. The A. abdita were observed daily during the test, and the numbers of organisms elther floating on the water surface, swimming in the jar, or on the sediment surface were recorded on observation forms. Amphipods floating on the water surface were gently pushed below-surface with a pipet tip, and observations were made as to whether they remained on the sediment surface, were buried below the sediment, or returned to the water surface.

Water temperature, salinity, $\mathrm{pH}$, and $\mathrm{DO}$ were measured daily in one replicate of each sediment treatment and in all containers at initlation and termination of the test. Flow rate was measured daily in all test containers. Acceptable ranges for water quality parameters during the experiment were:

$\begin{array}{ll}\text { DO } & 26.0 \mathrm{mg} / \mathrm{L} \\ \text { pH } & 7.8 \pm 0.5 \text { units } \\ \text { Salinity } & 30 \pm 2.0 \% \circ \\ \text { Temperature } & 20 \pm 2.0^{\circ} \mathrm{C} . \\ \text { Flow Rate } & 45 \pm 10 \mathrm{~mL} / \mathrm{min} .\end{array}$

At the end of the test (Day 10), the contents of each jar were sieved through a $0.5-\mathrm{mm}$ Nytex screen to collect $A$. abdita. Organisms were placed in clean seawater in a glass dish labeled with the sediment treatment and replicate number, and the numbers of live, dead, and missing organisms were determined. If necessary, a dissecting microscope was used to examine moribund organisms for signs of life. The presence or absence of body parts recovered at the end of the test was also noted. The endpoint of this test was death, defined as the absence of pleopod movement in response to gentle probing. At least $10 \%$ of mortality counts were confirmed by a second observer. Test organism sensitivity was assessed through a 4-day reference toxicant test, which included a seawater control and four concentrations of cadmium $(0.25,0.5,1.0$, and $2.0 \mathrm{mg} / \mathrm{L})$.

\subsubsection{0-Dav Solid-Phase Static Test with $B$, abronius}

The R. abronius were held in a large holding tank containing their native sediment with flowing $15^{\circ} \mathrm{C}$ seawater. Organisms were not fed during the holding period, the $<2$ wk 
preceding test initiation. The $R$. abronius test was conducted in 1-qt static Mason jars (Figure 2.1) placed in random positions on a water table maintained at $-15^{\circ} \mathrm{C}$. Prior to test initiation, sediment was added to the jars to a depth of $2 \mathrm{~cm}$, then each jar was slowly filled with $0.45-\mu \mathrm{m}$-filtered seawater to a total volume of $750 \mathrm{~mL}$. Jars were placed on the water table overnight to stabilize the temperature to test conditions. After settling, initial water-quality parameters were measured in each container and recorded on water quality forms. Gentle aeration was applied to each jar to provide adequate oxygenation of overlying water, and the test was conducted under a 24-h illumination.

This test was conducted in a manner similar to the $A$. abdita test, except that it was a static rather than flow-through test. Acceptable ranges for water quality parameters for the static R. abronius test were:

$\begin{array}{ll}\text { DO } & -6.0 \mathrm{mg} / \mathrm{L} \\ \text { pH } & 7.8 \pm 0.5 \text { units } \\ \text { Salinity } & 30 \pm 2.0 \% \circ \\ \text { Temperature } & 15 \pm 2.0^{\circ} \mathrm{C} .\end{array}$

Test organism sensitivity was assessed through a 4-day reference toxicant test, which included a seawater control and four concentrations of cadmium $(0.5,1.0,2.0$, and $4.0 \mathrm{mg} / \mathrm{L})$.

\subsubsection{0-Day Solid-Phase Flow-Through Test with $N$. virens}

Prior to testing, $\boldsymbol{N}$. virens were held in their native sediment in shallow trays covered with well-aerated $15^{\circ} \mathrm{C}$ seawater provided by the laboratory's flow-through system. Temperature, $\mathrm{pH}, \mathrm{DO}$, and salinity of water in each holding tank were monitored daily. Organisms were not fed during the holding period. Test containers were aerated, and the test was conducted under a light regime of $16 \mathrm{~h}$ light/8 $\mathrm{h}$ dark.

The 10-day flow-through test with $N$. virens was conducted in 10-gal flow-through aquaria (Figure 2.2) placed in random positions on water tables. Each aquarium was filled with $\sim 8 \mathrm{~L}$ of sand-filtered seawater via the flow-through system. Sediment was then added to a depth of $3 \mathrm{~cm}$ by measuring the required amount $(3870 \mathrm{~mL})$ into a glass container and pouring the sediment evenly over the bottom of the aquarium.

The flow-through system was initiated and aquaria were allowed to fill to a total volume of $-36 \mathrm{~L}$. For $4 \mathrm{~h}$, suspended materials in the aquaria settled and the flow-through system was adjusted and calibrated to deliver $125 \pm 10 \mathrm{~mL} / \mathrm{min}$ of seawater flow to each aquarium. The system operated ovemight before adding the test organisms.

To initiate the test, $20 \mathrm{~N}$. virens were collected from the holding tanks and placed in each aquarium. The label on each test aquarium included initiation time/date and initials of the examiner who placed the organisms into each aquarium. Water quality parameters (noted below) were 


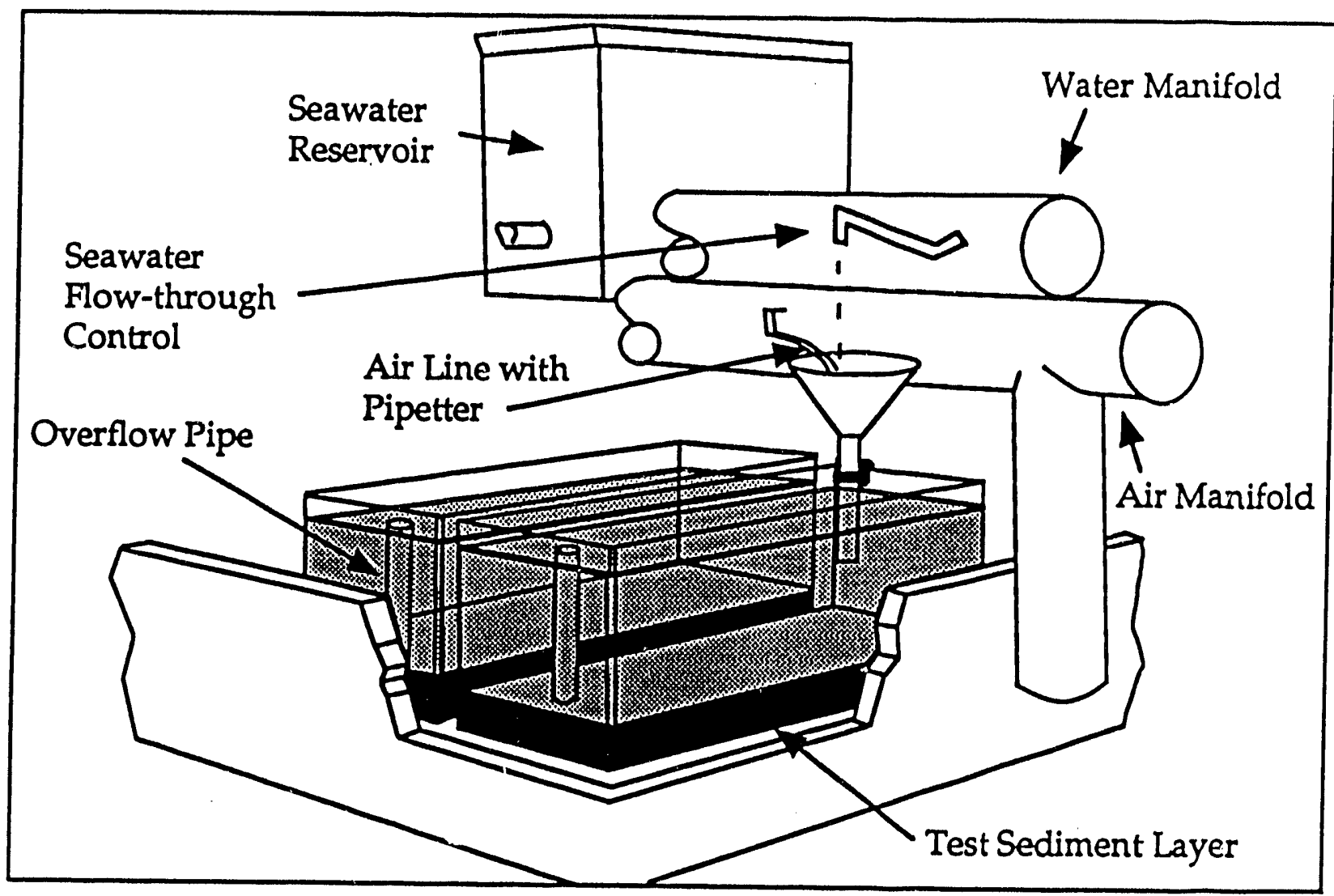

FIGURE 2.2. Flow-Through Aquaria for $M$. nasuta and $N$. virens Toxicity Tests 
measured daily in at least one replicate of each sediment treatment and recorded on water quality data sheets. Acceptable ranges of water quality parameters established for the tests were:

$\begin{array}{ll}\text { DO } & 26.0 \mathrm{mg} / \mathrm{L} \\ \text { pH } & 7.8 \pm 0.5 \text { units } \\ \text { Salinity } & 30 \pm 2.0 \% \\ \text { Temperature } & 15.0 \pm 2.0^{\circ} \mathrm{C} \\ \text { Flow Rate } & 125 \pm 10 \mathrm{~mL} / \mathrm{min} .\end{array}$

Daily observations of test animal behavior were made and recorded on data forms for each test. The number of $N$. virens on the sediment surface was noted daily in each aquarium. In addition to daily observations of behavior, the number of dead organisms in each aquarium was recorded on daily observation forms. Dead organisms were removed from the aquaria and destroyed by incineration. If and when a dead $N$. virens was removed, the specimen was identified as a whole animal or a portion of the animal (head or tail).

At the end of the 10-day test, water quality measurements were performed in all replicates and the contents of each aquarium were gently passed through a 1.0-mm Nytex screen to recover $N$. virens. Organisms were placed in glass baking dishes labeled with the sediment treatment number, and the numbers of dead versus live were determined. Death was determined by observing whether $N$. virens reacted to gentle probing; if there was no movement, the organism was considered dead. Mortality data were recorded on the termination forms and at least $10 \%$ of mortality counts were confirmed by a second observer. No reference toxicant test was run for this species.

\subsubsection{8-Day Solid-Phase Flow-Through Test with $N$. virens}

The procedure for conducting the 28-day solid-phase flow-through test with $N$. virens was identical to that of the 10-day test with three exceptions: 1) the exposure period was increased from 10 to 28 days; 2) surviving test organisms were depurated (voiding the digestive tract) in a flow-through seawater system for $48 \mathrm{~h}$, and 3) tissues were saved for chemical analysis. The ranges for water quality parameters, as well as for test conditions such as temperature and flow rate, were the same in both the 28-day and 10-day tests. Water quality measurements and mortality monitoring of test organisms were performed at the same frequency in both tests.

When the 28-day test was terminated, $N$. virens were collected for chemical evaluation of bioaccumulation. To ensure that tissue chemistry results would not be biased by contaminants associated with sediment grains in the digestive tract, the test organisms were allowed to depurate for $48 \mathrm{~h}$ in a flow-through seawater system following the 28-day exposure. After $48 \mathrm{~h}$ of depuration, $N$. virens were gently washed in clean seawater to remove external sediment 
grains and put in containers for future chemical analysis. No reference toxicant test was run for this species.

\subsubsection{8-Day Solid-Phase Flow-Through Test with $M$. nasuta}

The procedure for conducting the 28-day solid-phase flow-through test with $M$. nasuta was identical to that of the 28-day $N$. virens test, except that $25 \mathrm{M}$. nasuta were tested in each aquarium. As in the 28-day solid-phase flow-through $N$. virens test, $M$. nasuta were allowed to depurate for $48 \mathrm{~h}$ following the 28-day exposure to ensure that tissue chemistry results would not be biased by contaminants associated with sediment grains in the digestive tract. Surviving $M$. nasuta were placed in the depuration aquarium containing seawater-only. After $48 \mathrm{~h}$ of depuration, $M$. nasuta shells were cleaned with a scrub-brush and tissues were then removed using titanium knives, placed into pre-cleaned jars, and submitted for chemical analysis. No reference toxicant test was run for this species.

\subsubsection{6-h Suspended-Particulate-Phase Static Test with M. beryllina}

$M$. beryllina were held prior to testing in a 10-gal glass aquarium and fed $<24-h$-old brine shrimp nauplii Artemia salina twice daily. Temperature, $\mathrm{pH}, \mathrm{DO}$, and salinity of water in the aquaria were monitored daily. This $96-\mathrm{h}$ static SPP test was conducted in $400-\mathrm{mL}$ jars filled to a total volume of $300 \mathrm{~mL}$. Test containers were aerated, and the test was conducted under a light regime of $16 \mathrm{~h}$ light/8 $\mathrm{h}$ dark. The $M$. beryllina were gently pipetted from the holding tank into clean seawater and counted into small transfer containers. The test was initiated by transferring $10 \mathrm{M}$. beryllina to each test container. The number of organisms was then confirmed by a second observer, and the date and time of initiation were recorded on data forms and on the lid of each test container. The $M$. beryllina were observed daily during the test, and numbers of live and dead organisms were noted on the data forms. Dead animals were removed daily. Water temperature, salinity, $\mathrm{pH}$, and $\mathrm{DO}$ were measured daily in one replicate of each sediment treatment and in all containers at initiation and termination of the test. Acceptable ranges for water quality parameters during the experiment were:

$\begin{array}{ll}\text { DO } & 24.0 \mathrm{mg} / \mathrm{L} \\ \text { pH } & 7.8 \pm 0.5 \text { units } \\ \text { Salinity } & 30 \pm 2.0 \% \\ \text { Temperature } & 20 \pm 2.0^{\circ} \mathrm{C} .\end{array}$

At the end of the test $(96 \mathrm{~h})$, final observations were conducted. The endpoint of this test was death, defined as the absence of movement in response to gentle probing. At least $10 \%$ of mortality counts were confirmed by a second observer. Test organism sensitivity was assessed through a 96-h reference toxicant test, which included a seawater control and four concentrations of copper $(16,64,160$, and $400 \mu \mathrm{g} / \mathrm{L})$. 


\subsubsection{6-h Suspended-Particulate-Phase Static Test with M. bahia}

M. bahia were held prior to testing in a 10-gal glass aquarium and fed $<24-h$-old brine shrimp nauplii Artemia salina twice daily. Temperature, $\mathrm{pH}, \mathrm{DO}$, and salinity of water in the aquarium were monitored daily. This 96-h static SPP test was conducted in $400 \mathrm{~mL}$ glass jars filled to a total volume of $300 \mathrm{~mL}$. Test containers were placed in random positions, aerated, and the tesi was conducted under a light regime of $16 \mathrm{~h}$ light/ $8 \mathrm{~h}$ dark. Mysids were gently pipetted from the holding tank into clean seawater using large-bore pipettes and counted into small transfer contaliners. The test was initlated by adding $10 \mathrm{M}$. bahia to each test container. The number of organisms was then confimed by a second observer, and the date and time of initiation were recorded on data forms and the lid of each test container. The M. bahia were observed daily during the test, and numbers of live and dead organisms were noted on the data forms. Dead animals were removed dally. Water temperature, salinity, $\mathrm{pH}$, and $\mathrm{DO}$ were measured daily in one replicate of each sediment treatment and in all containers at initiation and termination of the test. Acceptable ranges for water quality parameters during the experiment were:

$\begin{array}{ll}\text { DO } & 24.0 \mathrm{mg} / \mathrm{L} \\ \text { pH } & 7.8 \pm 0.5 \text { units } \\ \text { Salinity } & 30 \pm 2.0 \% \\ \text { Temperature } & 20 \pm 2.0^{\circ} \mathrm{C} .\end{array}$

At the end of the test ( $96 \mathrm{~h})$, final observations were conducted. The endpoint of this test was death, defined as the absence of movement in response to gentle probing. At least $10 \%$ of mortality counts were confirmed by a second observer. Test organism sensitivity was assessed through a 96-h reference toxicant test, which included a seawater control and four concentrations of copper $(32,80,200$, and $500 \mu \mathrm{g} / \mathrm{L})$.

\subsubsection{2-h Suspended-Particulate-Phase Static Test with $M$. edulis}

Adult $M$. edulis were obtained from a commercial supplier and used for testing within a few days of receipt. Test chambers for the larval test were $400-\mathrm{mL}$ acid-washed, solvent-rinsed jars filled to a total volume of $300 \mathrm{~mL}$. Dilutions of SPP for the larval test $(0 \%, 10 \%, 50 \%$, and $100 \%)$ were prepared in clean, labeled glass jars, then distributed to the appropriate test containers. The dilution water (collected from the reference area in St. Andrew Bay) was filtered at $20 \mu \mathrm{m}$. Test chambers containing SPP were placed in random positions on a water table and aerated. The light regime for this test was $16 \mathrm{~h}$ light/8 $\mathrm{h}$ dark. Once the containers had reached test temperature $\left(16 \pm 2^{\circ} \mathrm{C}\right)$, initial water quality parameters were measured in all replicates.

Adult $M$. edulis were induced to spawn by placing individuals in $15^{\circ} \mathrm{C}$ seawater that was then rapidly elevated to $20^{\circ} \mathrm{C}$. Most adults spawned within $1 \mathrm{~h}$ and were removed from the $15^{\circ} \mathrm{C}$ holding container and placed in individual baking dishes containing site water for the collection of 
gametes. Egg solutions were filtered through a $75-\mu \mathrm{m}$ screen prior to the introduction of sperm. Sperm from up to three males was pooled and introduced to containers of egg suspension, where fertilization occurred. The egg suspensions were mixed frequently using a perforated plunger over a period of 90 to $140 \mathrm{~min}$, at which time fertilization (indicated by the presence of mult-cell embryos) of the embryos was assessed. Egg suspensions with a high percentage of fertllized embryos were pooled into a common stock for use in the test. This egg suspension was then rinsed on a 20- $\mu \mathrm{m}$ screen to clear away excess sperm, and embryos were rinsed from the 20- $\mu \mathrm{m}$ screen into a clean container filled with seawater.

To estimate fertilization success and embryo density, a $0.1-\mathrm{mL}$ sample was removed from the embryo stock and the number of developing embryos and non-fertilized eggs was scored using a Sedgewick-Rafter counting chamber on a compound microscope at low (4x) magnification. The mean number of embryos from the replicate counts was multiplied by 10 to estimate the density of embryos $/ \mathrm{mL}$ in the egg stock, resulting in a stock density of 23,000 embryos $/ \mathrm{mL}$.

To initiate the test, $1.2 \mathrm{~mL}$ of mussel larvae embryo stock solution was pipetted into each test container to yield a density of 23 embryos $/ \mathrm{mL}$. The test initlation date and time were recorded on data record forms. A 10-mL subsample was removed from all test containers $1 \mathrm{~h}$ after test initiation. Each test container was mixed with the perforated plunger and placed in a labeled vial, fixed with $1 \mathrm{~mL}$ of $50 \%$ formalin, and scored for the number of fertillized eggs.

Water quality parameters were measured in one repllcate of each dilution $24 \mathrm{~h}$ after test initiation. Acceptable ranges for water quality parameters during the experiment were:

$\begin{array}{ll}\mathrm{DO} & 24.0 \mathrm{mg} / \mathrm{L} \\ \mathrm{pH} & 7.8 \pm 0.5 \text { units } \\ \text { Salinity } & 30 \pm 2.0 \% \circ \\ \text { Temperature } & 16.0 \pm 2.0^{\circ} \mathrm{C}\end{array}$

The mussel test was terminated after $72 \mathrm{~h}$, when development of $\mathrm{D}$-shaped lavae was $>90 \%$ in control containers. Final water quality measurements were recorded for all replicates. Each chamber was then homogenized with the perforated plunger, and a 10-mL allquot was removed with a calibrated pipettor and placed in a labeled vial containing $1 \mathrm{~mL}$ of $50 \%$ formalin. Samples were scored for the appearance of normal $D$-shaped larvae, abnormally developed lanae, blastula-stage lanae, and total number of lavae. At least $10 \%$ of counts were confirmed by a second observer. Test organism sensitlvity was assessed through a 72-h reference toxicant test which included a seawater control and five concentrations of copper $(2.9,9.0,30$, and $100 \mu \mathrm{g} / \mathrm{L})$. 


\title{
2.4 SEDIMENT. WATER, AND TISSUE CHEMISTRY
}

Sediment samples collected in support of the Panama Clty Harbor Project were analyzed for conventional and other chemical parameters. Conventional parameters included grain size, specific gravity, total sollds, total organic carbon (TOC), ammonia, cyanide, and total sulfides. Sediments were also analyzed for PAHs, PCB/pesticides, dioxins, phenol and substituted phenols, phthalate esters, metals, and butyltins. Water samples (100\% SPP) were analyzed for PAHs, PCB/pesticides, phenols and substltuted phenols, phthalate esters, metals, cyanide and ammonia. Chemical analysis of $M$. nasuta and $N$. virens tissues was also conducted to determine bioaccumulation potential. Selected tissues were analyzed for total lipids, PAHs, PCBs, chlorinated pesticides, phenol and substituted phenols, phthalate esters, metals, dioxins, and organotins. Table 2.1 presents the analytical parameters measured in sediment, water, and tissue samples, the method used to perform each analysis, and the target analytical detection limits.

The following sections briefly describe the methods used for analysis of sediments, waters, and tissues within the required physical and chemical parameters. Analyses followed established EPA procedures where applicable. Quality control samples included method blanks, matrix spike (MS), standard reference materials (SRM), and analytical replicates. The MS and SRMs were used as a measurement of analytical accuracy. Analytical replicates were used to evaluate analytical precision.

\subsubsection{Conventienal Measurements}

Conventional parameters included grain size, specific gravity, total solids, TOC, ammonia, cyanide, and total sulfides. Grain size, specific gravity, and total solids analyses were conducted by Soil Technology, Bainbridge Island, Washington. Grain size and total solids analyses followed the procedures described in Plumb (1981); specific gravity analysis was consistent with ASTM Method D-854 (1991). Sixteen grain size fractions (in $\mu \mathrm{m}$ ) were quantified: 3350 , $2000,1000,250,125,62.5,48,31.2,23,15.6,7.8,3.9,1.9,0.9,0.4$, and $<0.4$. Because organic material is included in the analysis, these data are reported as "apparent" grain size. Grain size data are corrected for dissolved solids (salt) concentrations. Specific gravity determinations were made on the minus U.S. No. 40 sieve portion of the grain size samples. Total solids, reported as percent, were determined after oven drying at $90^{\circ} \mathrm{C}$.

Total organic carbon is the amount of non-volatile, partially volatile, volatile, and particulate organic carbon compounds in a sample. Analysis of TOC was performed by Global Geochem, Canoga Park, Callifomia, following modifled Method SW846 EPA 9060 (EPA 1986a). Each sediment treatment was dried and ball-milled to a fine powder. Before combustion, inorganic carbon in the sample was removed by acidification. The TOC in sediment was then determined by measuring the carbon dioxide released during combustion of the sample and reported as

\author{
PANAMA CITY HARBOB $\quad 2.15$
}


IABLE 21. List of Analytes, Methods and Target Detection Limits(a)

\begin{tabular}{l} 
Anglyte \\
\hline Grain $81 z e$ \\
8poolflo Oravity \\
T tal sollde \\
Toc \\
Ammonla \\
Cyanide \\
Total Sulfldes \\
Total Liplde
\end{tabular}

\begin{tabular}{|c|c|}
\hline $\begin{array}{c}\text { Relerence } \\
\text { Method }\end{array}$ & Sedimant \\
\hline $\begin{array}{l}\text { Plumb } 1981 \\
\text { D-854 (ASTM 1991) } \\
\text { Plumb 1981 } \\
9060 \text { (EPA 1986a) } \\
\text { Whitlodge of al. 1981 } \\
336.2 \text { (EPA 1979) } \\
\text { Plumb 1981 } \\
\text { 8290 (EPA 1990a) }\end{array}$ & $\begin{array}{l}1.0 \% \\
\mathrm{NA} \\
1.0 \% \\
0.1 \% \\
1.0 \mu \mathrm{moleh} \\
1.0 \mathrm{mg} \mathrm{kg} \\
0.2 \mathrm{mg} / \mathrm{kg} \\
\mathrm{NA}\end{array}$ \\
\hline
\end{tabular}

Dateation Limit

PAHe

Aconapthene
Aconaphthylene
Anthracene
Benzo(a)anthracene
Benzo(a)pyrene
Benzo(b)fluoranthene
Benzo(g,h,l)perylene
Benzo(k)fluoranthene
Chryeone
Dibenzo(a,h)anthracene
Fluoranthene
Fluesene
Indeno(1,2,3-cd)pyrene
Napthalene
Methlynapthalene
Phenanthrene
Pyrene

$\begin{array}{ll}8270 \text { (EPA 1986a) } & 30 \mu g / \mathrm{kg} \\ 8270 \text { (EPA 1986a) } & 30 \mu g / \mathrm{kg} \\ 8210 \text { (EPA 1986a) } & 30 \mu g / \mathrm{kg} \\ 8270 \text { (EPA 1986a) } & 30 \mu g / \mathrm{kg} \\ 8270 \text { (EPA 1986a) } & 30 \mu g / \mathrm{kg} \\ 8270 \text { (EPA 1986a) } & 30 \mu g / \mathrm{kg} \\ 8270 \text { (EPA 1986a) } & 30 \mu g / \mathrm{kg} \\ 8270 \text { (EPA 1986a) } & 30 \mu g / \mathrm{kg} \\ 8270 \text { (EPA 1986a) } & 30 \mu g / \mathrm{kg} \\ 8270 \text { (EPA 1986a). } & 30 \mu g / \mathrm{kg} \\ 8270 \text { (EPA 1986a) } & 30 \mu \mathrm{kg} \\ 8270 \text { (EPA 1986a) } & 30 \mu g / \mathrm{kg} \\ 8270 \text { (EPA 1986a) } & 30 \mu g / \mathrm{kg} \\ 8270 \text { (EPA 1986a) } & 30 \mu \mathrm{kg} \\ 8270 \text { (EPA 1986a) } & 30 \mu \mathrm{kg} / \mathrm{kg} \\ 8270 \text { (EPA 1986a) } & 30 \mu \mathrm{g} / \mathrm{kg} \\ 8270 \text { (EPA 1986a) } & 30 \mu \mathrm{g} / \mathrm{kg}\end{array}$

Phenol and Substltuted Phenols

Phenol
2,4-dimethylphenol

2,4,6-trichlorophenol

Para-chloro-meta-crosol

2-chlorophenol

2,4-dichlorophenol

2-nitrophenol

4-nitrophenol

2,4-dinitrophenol

4,6-dinitro-0-cresol

Pentachlorophenol

\section{Phthalate Estere}

B/s (2-ethylhexyl) phthalate

Butyl benzyl phthalate

Di-n-butyl phthalate

Di-n-octyl phthalate

Dlethyl phthalate

Dimethyl phthalate
8270 (EPA 1986a) $\quad 330 \mu \mathrm{g} / \mathrm{kg}$

8270 (EPA 1986a) $330 \mu \mathrm{g} / \mathrm{kg}$

8270 (EPA 1986a) $330 \mu \mathrm{g} / \mathrm{kg}$

8270 (EPA 1986a) $\quad 330 \mu \mathrm{g} / \mathrm{kg}$

8270 (EPA 1986a) $\quad 330 \mu g / k g$

8270 (EPA 1986a) $330 \mu \mathrm{g} / \mathrm{kg}$

8270 (EPA 1986a) $\quad 330 \mu g / k g$

8270 (EPA 1986a) $\quad 330 \mu \mathrm{g} / \mathrm{kg}$

8270 (EPA 1986a) $\quad 330 \mu g / k g$

8270 (EPA 1986a) $330 \mu g / k g$

8270 (EPA 1986a) $\quad 330 \mu g / k g$

$100 \mu \mathrm{g} / \mathrm{kg}$

$100 \mu \mathrm{g} / \mathrm{kg}$

$100 \mu \mathrm{g} / \mathrm{kg}$

$100 \mu \mathrm{g} / \mathrm{kg}$

$100 \mu \mathrm{g} / \mathrm{kg}$

$100 \mu \mathrm{g} / \mathrm{kg}$

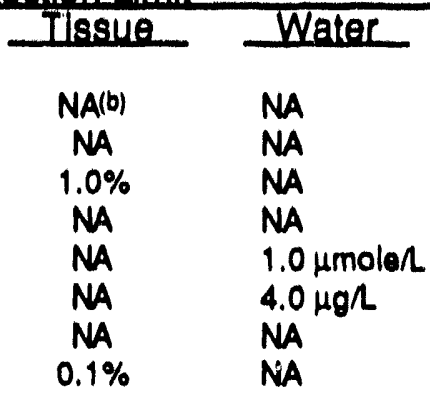

$\begin{array}{ll}30 \mu g / k g & 20 \mathrm{ng} / \mathrm{L} \\ 30 \mu g / \mathrm{kg} & 20 \mathrm{ng} / \mathrm{L} \\ 30 \mu g / \mathrm{kg} & 20 \mathrm{ng} / \mathrm{L} \\ 30 \mu g / \mathrm{kg} & 20 \mathrm{ng} / \mathrm{L} \\ 30 \mu g / \mathrm{kg} & 20 \mathrm{ng} / \mathrm{L} \\ 30 \mu g / \mathrm{kg} & 20 \mathrm{ng} / \mathrm{L} \\ 30 \mu \mathrm{g} / \mathrm{kg} & 20 \mathrm{ng} / \mathrm{L} \\ 30 \mu g / \mathrm{kg} & 20 \mathrm{ng} / \mathrm{L} \\ 30 \mu g / \mathrm{kg} & 20 \mathrm{Hg} / \mathrm{L} \\ 30 \mu g / \mathrm{kg} & 20 \mathrm{ng} / \mathrm{L} \\ 30 \mu g / \mathrm{kg} & 20 \mathrm{ng} / \mathrm{L} \\ 30 \mu g / \mathrm{kg} & 20 \mathrm{ng} / \mathrm{L} \\ 30 \mu g / \mathrm{kg} & 20 \mathrm{ng} / \mathrm{L} \\ 30 \mu \mathrm{g} / \mathrm{kg} & 20 \mathrm{ng} / \mathrm{L} \\ 30 \mu g / \mathrm{kg} & 20 \mathrm{ng} / \mathrm{L} \\ 30 \mu g / \mathrm{kg} & 20 \mathrm{ng} / \mathrm{L} \\ 30 \mu \mathrm{g} / \mathrm{kg} & 20 \mathrm{ng} / \mathrm{L}\end{array}$

$330 \mu \mathrm{g} / \mathrm{kg}$

$330 \mu \mathrm{g} / \mathrm{kg}$

$330 \mu \mathrm{g} / \mathrm{kg}$

$330 \mu \mathrm{g} / \mathrm{kg}$

$330 \mu \mathrm{g} / \mathrm{kg}$

$330 \mu \mathrm{g} / \mathrm{kg}$

$330 \mu \mathrm{g} / \mathrm{kg}$

$330 \mu \mathrm{g} / \mathrm{kg}$

$330 \mu \mathrm{g} / \mathrm{kg}$

$330 \mu \mathrm{g} / \mathrm{kg}$

$330 \mu \mathrm{g} / \mathrm{kg}$

$1000 \mathrm{ng} / \mathrm{L}$ $1000 \mathrm{ng} / \mathrm{L}$ $1000 \mathrm{ng} / \mathrm{L}$ $1000 \mathrm{ng} / \mathrm{L}$ $1000 \mathrm{ng} / \mathrm{L}$ $1000 \mathrm{ng} / \mathrm{L}$ $1000 \mathrm{ng} / \mathrm{L}$ $1000 \mathrm{ng} / \mathrm{L}$ i000 $\mathrm{ng} / \mathrm{L}$ $1000 \mathrm{ng} / \mathrm{L}$ $1000 \mathrm{ng} / \mathrm{L}$

$\begin{array}{ll}100 \mu g / k g & 200 \mathrm{ng} / \mathrm{L} \\ 100 \mu g / k g & 200 \mathrm{ng} / \mathrm{L} \\ 100 \mu g / k g & 200 \mathrm{ng} / \mathrm{L} \\ 100 \mu g / k g & 200 \mathrm{ng} / \mathrm{L} \\ 100 \mu g / k g & 200 \mathrm{ng} / \mathrm{L} \\ 100 \mu g / k g & 200 \mathrm{ng} / \mathrm{L}\end{array}$


IABLE21. Continued

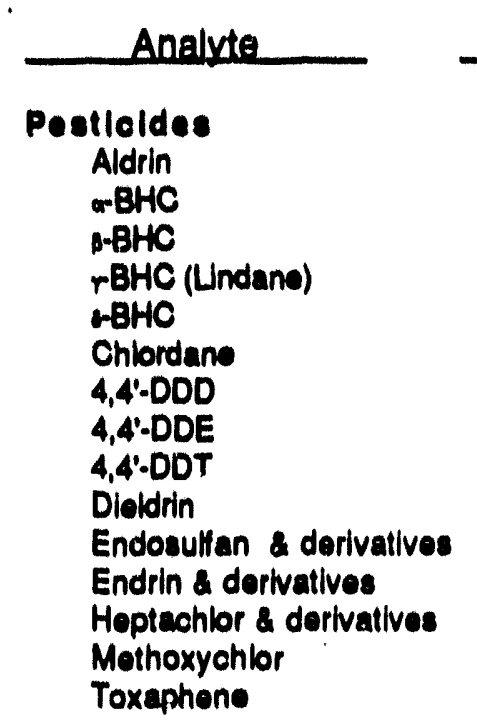

PCB.

Aroclor, 1016

Aroctor, 1221

Aroclor, 1232

Aroclor, 1242

Arocior, 1248

Aroclor, 1254

Aroclor, 1260

Motale

Aluminum

Antimony

Arsenic

Boryllium

Cadmium

Chromium

Copper

Lead

Mercury

Nickol

Solenium

Silver

Thallium

Zinc

\begin{tabular}{|c|c|}
\hline $\begin{array}{l}\text { Reference } \\
\text { Method }\end{array}$ & Sedlment \\
\hline $\begin{array}{l}8080 \text { (EPA 1986a) } \\
8080 \text { (EPA 1986a) } \\
8080 \text { (EPA 1986a) } \\
8080 \text { (EPA 1986a) } \\
8080 \text { (EPA 1986a) } \\
8080 \text { (EPA 1986a) } \\
8080 \text { (EPA 1986a) } \\
8080 \text { (EPA 1986a) } \\
8080 \text { (EPA 1986a) } \\
8080 \text { (EPA 1986a) } \\
8080 \text { (EPA 1986a) } \\
8080 \text { (EPA 1986a) } \\
8080 \text { (EPA 1986a) } \\
8080 \text { (EPA 1986a) } \\
8080 \text { (EPA 1986a) }\end{array}$ & $\begin{array}{l}10 \mu g / k g \\
10 \mu g / k g \\
10 \mu g / k g \\
10 \mu g / k g \\
10 \mu g / k g \\
30 \mu g / k g \\
10 \mu g / k g \\
10 \mu g / k g \\
10 \mu g / k g \\
10 \mu g / k g \\
20 \mu g / k g \\
10 \mu g / k g \\
20 \mu g / k g \\
20 \mu g / k g \\
30 \mu g / k g\end{array}$ \\
\hline
\end{tabular}

8080 (EPA 1986a)

8080 (EPA 1886a)

8080 (EPA 1986a)

8080 (EPA 1986a)

8080 (EPA 1986a)

8080 (EPA 1986a)

8080 (EPA 1986a)

ICPMS (EPA 1990b)

ICPMS (EPA 1990b)

ICP/MS (EPA 1990t;

ICPMS (EPA 199/J)

ICP/MS (EPA 19:10b)

ICPMS (EPA 1950b)

ICP/MS (EPA 1990b)

ICPMS (EPA 1990b)

CVAA (Bloom and Crgvollus 1984)

ICPMS (EPA 1990b)

ICPMS (EPA 1990b)

ICP/MS (EPA 1990b)

ICP/MS (EPA 1990b)

ICP/MS (EPA 1990b)

\section{$20 \mu g / k g$ \\ $20 \mu \mathrm{g} / \mathrm{kg}$ \\ $20 \mu \mathrm{g} / \mathrm{g}$ \\ $20 \mu \mathrm{g} / \mathrm{kg}$ \\ $20 \mu \mathrm{g} / \mathrm{kg}$ \\ $20 \mu \mathrm{g} / \mathrm{kg}$ \\ $20 \mu g / k g$}

$5.0 \mathrm{mg} / \mathrm{kg}$

$0.1 \mathrm{mg} / \mathrm{kg}$

$0.1 \mathrm{mg} / \mathrm{kg}$

$0.2 \mathrm{mg} k \mathrm{~kg}$

$0.1 \mathrm{mg} / \mathrm{kg}$

$0.6 \mathrm{mg} / \mathrm{kg}$

$0.1 \mathrm{mg} / \mathrm{kg}$

$0.1 \mathrm{mg} / \mathrm{kg}$

$0.01 \mathrm{mg} / \mathrm{kg}$

$0.1 \mathrm{mg} / \mathrm{kg}$

$0.2 \mathrm{mg} / \mathrm{kg}$

$0.1 \mathrm{mg} / \mathrm{kg}$

$0.1 \mathrm{mg} / \mathrm{kg}$

$0.3 \mathrm{mg} / \mathrm{kg}$
Detectlon Limit

\begin{tabular}{|c|c|}
\hline Iissue & Watar \\
\hline $\begin{array}{l}10 \mu g / \mathrm{kg} \\
10 \mu g / \mathrm{kg} \\
10 \mu g / \mathrm{kg} \\
10 \mu g / \mathrm{kg} \\
10 \mu g / \mathrm{kg} \\
30 \mu g / \mathrm{kg} \\
10 \mu g / \mathrm{kg} \\
10 \mu g / \mathrm{kg} \\
10 \mu \mathrm{g} / \mathrm{kg} \\
10 \mu g / \mathrm{kg} \\
20 \mu \mathrm{kg} \\
10 \mu g / \mathrm{kg} \\
20 \mu g / \mathrm{kg} \\
20 \mu \mathrm{g} / \mathrm{kg} \\
30 \mu \mathrm{g} / \mathrm{kg}\end{array}$ & $\begin{array}{l}5 n g / L \\
5 n g / L \\
5 n g / L \\
5 n g / L \\
5 n g / L \\
5 n g / L \\
5 n g / L \\
5 n g / L \\
5 n g / L \\
5 n g / L \\
5 n g / L \\
5 n g / L \\
5 n g / L \\
5 n g / L \\
50 n g / L\end{array}$ \\
\hline
\end{tabular}

$\begin{array}{ll}\text { NA } & \text { NA } \\ \text { NA } & \text { NA } \\ \text { NA } & \text { NA } \\ \text { NA } & \text { NA } \\ \text { NA } & \text { N/A } \\ \text { NA } & \text { NA } \\ \text { NA } & \text { NA } \\ \text { NA } & \text { NA } \\ \text { NA } & \text { NA } \\ \text { NA } & \text { NA } \\ \text { NA } & \text { NA } \\ \text { NA } & \text { NA } \\ \text { NA } & \text { NA } \\ \text { NA } & \text { NA }\end{array}$


IABLE21. Continued

\begin{tabular}{|c|c|c|c|c|}
\hline \multirow[b]{2}{*}{ Analvite } & \multirow{2}{*}{$\begin{array}{c}\text { Reference } \\
\text { Methed }\end{array}$} & \multicolumn{3}{|c|}{ Detection Lumit } \\
\hline & & edlment & Tlssue & Waler \\
\hline $\begin{array}{l}\text { Motale cont'd } \\
\text { Antimony } \\
\text { Arsonio } \\
\text { Boryllium } \\
\text { Cadmlum } \\
\text { Chromlum } \\
\text { Coppor } \\
\text { Load-M. nasuta } \\
\text { Load-N. virons } \\
\text { Morcury } \\
\text { Nlokol } \\
\text { Solonlum } \\
\text { Silvor } \\
\text { Thallium } \\
\text { Zino }\end{array}$ & $\begin{array}{l}\text { ICPMS (EPA 1090b) } \\
\text { XPF (PNL SOP) } \\
\text { ICPMS (EPA 1090b) } \\
\text { ICPMS (EPA 1090b) } \\
\text { ICPMS (EPA 1990b) } \\
\text { ICPMS (EPA 1090b) } \\
\text { OFAA (EPA 1986) } \\
\text { ICPMS (EPA 1900b) } \\
\text { CVAA (Bloom and Crecollus 1984) } \\
\text { ICPMS (EPA 1900b) } \\
\text { XRF (PNL SOP) } \\
\text { ICPMS (EPA 1900b) } \\
\text { ICPMS (EPA 1990b) } \\
\text { XRF (PNL SOP) }\end{array}$ & $\begin{array}{l}\text { NA } \\
N A \\
N A \\
N A \\
N A \\
N A \\
N A \\
N A \\
N A \\
N A \\
N A \\
N A \\
N A \\
N A\end{array}$ & $\begin{array}{l}0.1 \mathrm{mg} / \mathrm{kg} \\
0.1 \mathrm{mg} / \mathrm{kg} \\
0.2 \mathrm{mg} / \mathrm{kg} \\
0.1 \mathrm{mg} / \mathrm{kg} \\
0.6 \mathrm{mg} / \mathrm{kg} \\
0.1 \mathrm{mg} / \mathrm{kg} \\
0.1 \mathrm{mg} / \mathrm{kg} \\
0.1 \mathrm{mg} / \mathrm{kg} \\
0.01 \mathrm{mg} / \mathrm{kg} \\
1.0 \mathrm{mg} / \mathrm{kg} \\
0.3 \mathrm{mg} / \mathrm{kg} \\
0.1 \mathrm{mg} / \mathrm{kg} \\
0.1 \mathrm{mg} / \mathrm{kg} \\
0.3 \mathrm{mg} / \mathrm{kg}\end{array}$ & $\begin{array}{l}\text { NA } \\
\text { NA } \\
\text { NA } \\
\text { NA } \\
\text { NA } \\
\text { NA } \\
\text { NA } \\
\text { NA } \\
\text { NA } \\
\text { NA } \\
\text { NA } \\
\text { NA } \\
\text { NA } \\
\text { NA }\end{array}$ \\
\hline $\begin{array}{l}\text { Arsonic } \\
\text { Cadmium } \\
\text { Chromium } \\
\text { Coppor } \\
\text { Load } \\
\text { Moroury } \\
\text { Nilkel } \\
\text { Solonium } \\
\text { Silver } \\
\text { Zine }\end{array}$ & $\begin{array}{l}\text { HAA (EPA 1986a) } \\
\text { GFAA (EPA 1986a) } \\
\text { GFAA (EPA 1088a) } \\
\text { GFAA (EPA 1986a) } \\
\text { GFAA (EPA 1086a) } \\
\text { CVAF (Bloom and Crocollius 1983) } \\
\text { GFAA (EPA 1986a) } \\
\text { GFAA (EPA 1986a) } \\
\text { GFAA (EPA 1986a) } \\
\text { GFAA (EPA 1986a) }\end{array}$ & $\begin{array}{l}\text { NA } \\
\text { NA } \\
\text { NA } \\
\text { NA } \\
\text { NA } \\
\text { NA } \\
\text { NA } \\
\text { NA } \\
\text { NA } \\
\text { NA }\end{array}$ & $\begin{array}{l}\text { NA } \\
\text { NA } \\
\text { NA } \\
\text { NA } \\
\text { NA } \\
\text { NA } \\
\text { NA } \\
\text { NA } \\
\text { NA } \\
\text { NA }\end{array}$ & $\begin{array}{l}1.0 \mu g / L \\
0.1 \mu g / L \\
1.0 \mu g / L \\
0.1 \mu g / L \\
0.1 \mu g / L \\
0.001 \mu g / L \\
0.1 \mu g / L \\
2.0 \mu g / L \\
0.01 \mu g / L \\
2.0 \mu g / L\end{array}$ \\
\hline $\begin{array}{l}\text { utyltins } \\
\text { Tributyitin }\end{array}$ & Unger of al. (1986) & $0 \mu g / k g$ & $10 \mu g / k g$ & NA \\
\hline $\begin{array}{l}\text { xins } \\
\text { All congeners }\end{array}$ & 8290 (EPA 1990a) & $.0 \mathrm{ng} / \mathrm{kg}$ & $1.0 \mathrm{ng} / \mathrm{kg}$ & NA \\
\hline
\end{tabular}

(a) Detection limits are in dry weight for all sediment parameters and for metals in tissues. Detection limits are in wet woight for all organic tissue parameters.

(b) NA Not applicable.

percent of dry weight. Ammonia was analyzed by the University of Washington, Seattle, following the method described by Whitledge et al. (1981). Ammonlum is determined by hypochloride-citrate analysis in which hypochlorous acid and phenol react with ammonium in aqueous alkaline solution to form indophenol blue. Sediment from the flve test treatments and the reference sediment were placed into acid-cleaned teflon containers and centrifuged to release pore water from the sediment. This pore water was forced through a Gelman AE $0.03 \mu$ filter, frozen, and then analyzed for ammonlum concentrations. The data are reported as $\mathrm{NH}_{3}-\mathrm{N}$ (ammonia) and $\mathrm{NH}_{4}$ (ammonium) in $\mathrm{mg} / \mathrm{L}$. Cyanide was measured by Analytical Resources, Inc. (ARI), Seattle, 
using a colorimetric method described in EPA Method 335.2 (EPA 1979). This standard acid-reflux distllation measures free cyanide, simple cyanide, and most complexed cyanides. Released cyanides ( $\mathrm{HCN}$ or $\mathrm{CN}$ ) are trapped in a basic absorbing medlum (1M NaOH), which is then analyzed for oyanide by the colorimetric method. Total sulfides analyses were also measured by ARI following the methodology described in Plumb (1981). This method requires acidification and distllation to release sulfide from the sediment. Released sulfide is then trapped in zinc acetate, and this solution is then analyzed by the spectrophotometric methylene-blue procedure.

\subsubsection{Polynuclear Aromatio Hydrocartonns(PAHs)}

Analyses for $18 \mathrm{PAHs}$ in the Panama Clty Harbor sediment, water, and tlssue samples were pertormed by Battelle Ocean Sclences (BOS) In Duxbury, Massachusetts. Analysis of these compounds followed a modification to EPA SW. 846 Method 8270 (EPA 1986a). Sediment, water, and tissue samples were extracted two to three times consecutively using a roller technique. The extracts were dried over sodlum sulfate, passed through a cleanup column, and concentrated in preparation for further cleanup by llquid chromatography. Tissue extracts were run through gel-permeation-chromatography (GPC) prior to analysis to remove any additional interterences. The PAHs in sample extracts were analyzed via high-resolution capillary gas chromatography/mass spectrophotometry (GC/MS). A data system provided for Identiflcation and measurement of the selected PAHs listed in Table 2.1 using a selectlve lon mode (SIM). In the SIM mode, each PAH compound was monitored simultaneously for the presence of a parent lon and a confirming second ion.

\subsubsection{Ehenols. Substituted Phenols, and Phthalate Esters}

Phenols, substituted phenols, and phthalate esters in sediment, water, and tissue samples were analyzed by BOS in Duxbury, Massachusetts, following modifled EPA Method 8270 (EPA 1986a). This method is approprlate for the extraction of semivolatlle priority pollutants from sediment, water, and tlssue samples for analysis by gas chromatography (GC). In this procedure, $\sim 100 \mathrm{~g}$ of sediment was extracted using 2:1 ( $\mathrm{v}: \mathrm{v})$ dichloromethane/ methanol in a Soxhlet extractor. The extract was partitioned with water, then dried through a column of anhydrous sodium sulfate. Elemental sulfur was removed using metallic mercury. Blological macromolecules were removed by cleanup with GPC. A portion of the extract underwent alumina column chromatography to separate polar compounds from pesticides and PCBs prior to capillary gas chromatography with electron capture detection (GC-ECD) analysis. The remaining extract underwent reverse-phase column chromatography (bonded $\mathrm{C}_{18}$ solid phase) to reduce interferences from unresolved paraffinic hydrocarbons prior to capllary GC/MS analysis for acid, base, and neutral compounds. 


\subsubsection{RCB/Pestlaides}

The PCB and pesticide analyses for the Panama City Harbor sediment, water, and tissue samples were pertormed by BOS in Duxbury, Massachusetts. Chlorinated pesticides and PCB8 were quantilled by GC-ECD following modifled EPA SW-846 Method 8080 (EPA 1986a).

Chlorinated pestloldes and PCBs were extracted simultaneously with the PAH compounds using the roller technique as described for PAHs. The procedure involved a multiple methylene chloride extraction. A portion of the methylene chloride extract was solvent exchanged to hexane, and interterences were removed by passing the extract through a column packed with 100 of $2 \%$ deactlvated alumina and $20 \%$ of $2 \%$ deactivated sillica. Most samples required an additional cleanup treatment using high-performance llquid chromatography (HPLC) to remove other: interferences. Analytical quantiflcation was pertormed using GC/ECD analysis.

\subsubsection{Matala}

Metals in sediment, water, and tissue samples were analyzed at the MSL and at Paciflc Northwest Laboratory (PNL) in Richland, Washington. Six techniques were used for the analysis of metals: Induotively coupled plasma/mass spectroscopy (ICP/MS), energy-diffusive x-ray fluorescence (XRF), graphite fumace atomlo absorption (GFAA), cold vapor atomic absorption (CVAA), cold vapor atomic fluorescence (CVAF), and hydride atomic absorption (HAA). The ICP/MS procedure follows EPA 200.8 (EPA 1990b). The GFAA, CVAA, CVAF, and HAA methodologles are summarized in EPA SW846, 7000 Serles (1990 a) which were modifled into the MSL SOPs. Sediment samples were analyzed for a total of 14 metals: aluminum (Al), antimony (Sb), arsenic (As), beryllium (Be), cadmium (Cd), chromlum (Cr), copper (Cu), lead (Pb), mercury $(\mathrm{Hg})$, nickel (NI), selenium (Se), silver (Ag), thallium (TI), and zinc $(\mathrm{Zn})$. Water and tissue samples were analyzed for the same metals except aluminum. The analytical techniques used for these analyses are summarized in Table 2.2.

To prepare sediment and tissues for analysis, samples were freeze-drled and blended in a Spex mixer-mill. Approximately $5 \mathrm{~g}$ of mixed sample were ground in a ceramic ball mill. The XRF analysis was pertormed on a $0.5-g$ allquot of dried, ground material pressed into a pellet with a dlameter of $2 \mathrm{~cm}$. For ICP/MS, GFAA, and CVAA analyses, $0.2 \cdot$ to $0.5-9$ allquots of dried homogenous sample underwent an acid digestion process to separate and isolate the metals from the matix.

Water samples analyzed for metals were extracted according to several MSL SOPS, based on the particular metal. For $\mathrm{Cd}, \mathrm{Cu}, \mathrm{Pb}, \mathrm{NI}$, and $\mathrm{Ag}$, samples were extracted in accordance with the ammonium pyrrolidinedithiocarbamate (APDC) extraction method. Briefly, samples are chelated, precipitated out of solution, then filtered. The filter is digested in concentrated acid and the digestate analyzed by GFAA spectrometry. For $\mathrm{Cr}, \mathrm{Se}$, and $\mathrm{Zn}$, samples were analyzed 
IABLE22. Analytical Methods for Analyzing Metals in Sediment, Water, and Tissue Matrices

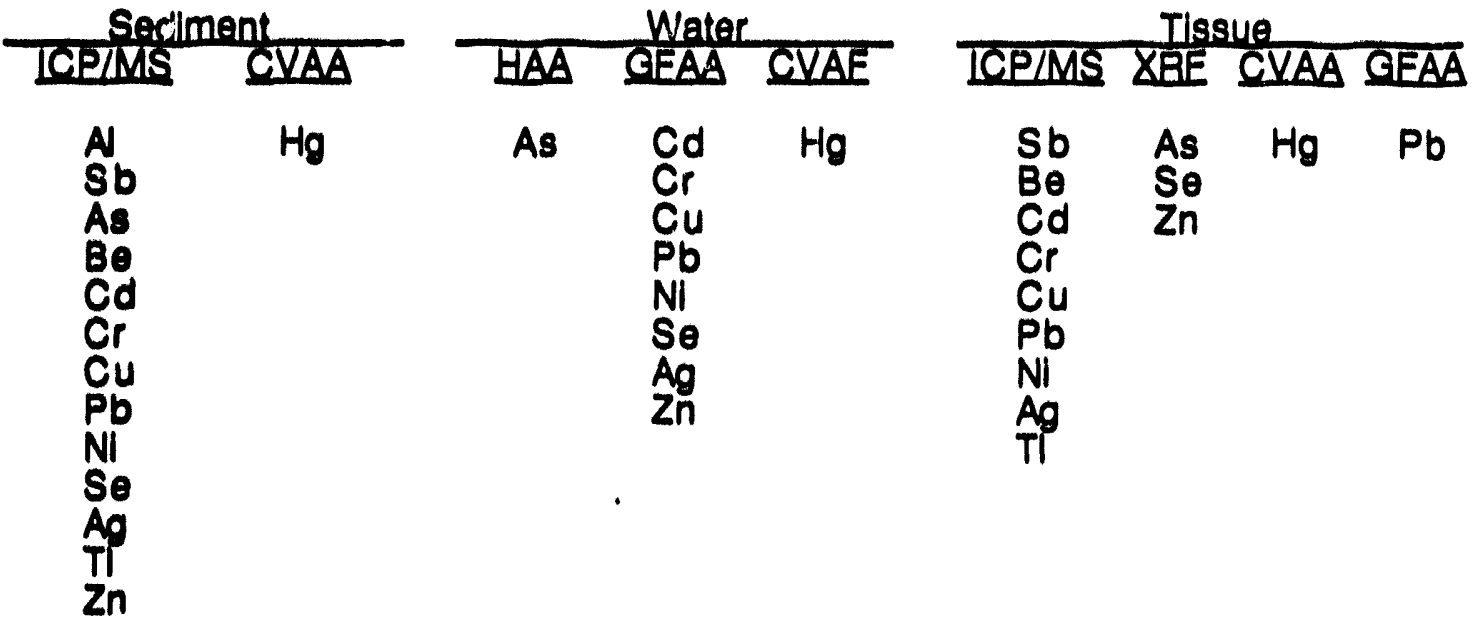

directly by GFAA spectrometry. For $\mathrm{Hg}$, samples were analyzed directly by CVAF. Briefly, this method is a CVAF technique based on emission of 254-nm radlation by excited $\mathrm{Hg}^{\circ}$ atoms in an inert gas stream. Mercuric lons in the oxidized sample are reduced to $\mathrm{Hg}^{\circ}$ with $\mathrm{SnCl}_{2}$, and then purged onto gold-coated sand traps as a means of preconcentration and interference removal. Mercury vapor is thermally desorbed to a second "analytical" gold trap, and from that into the fluorescence cell. Fluorescence (peak areas) is proportional to the quantity of mercury collected, which is quantfiled using a standard curve as a function of the quantity of sample purged. For As, the samples were analyzed by HAA. Briefly, arsenate, arsenite, methylarsonic acld, and dimethylaresinic acld are volatillzed from solution at a specific pH after reduction to the corresponding arsines with sodlum borohydride. The volatilized arsines are then swept onto a llquid-nitrogen-cooled chromatographic trap which, upon warming, allows for a separation of specles based on boiling points. The released arsines are swept by hellum carrier gas into a quartz cuvette bumer cell, where they are decomposed to atomic arsenic. Arsenic concentrations are then determined by atomic absorption spectroscopy. For all metals analyzed by atomic absorption, results were blank corrected by subtracting the blank absorbance readings prior to pertorming quantitation calculations.

\subsubsection{Oroanotins}

Organotins in sediment and tissue samples were analyzed at the MSL in Sequim, Washington. Butyltin compounds in sediments and tissues were analyzed using gas chromatography/flame photometric detection (GC/FPD) following the methods of Unger et al. (1986) and MSL-SOPs. Briefly, $20 \mathrm{~g}$ of sample were dried with $\mathrm{Na}_{2} \mathrm{SO}_{4}$ and extracted with methylene chloride. The sample was derivatized, cleaned with Florisil, then concentrated, and the concentrate analyzed by GC/FPD. Samples were quantifled using the recovery internal 
standard (RIS), with tripentyltin chloride added Just prior to extraction. The internal standard-inlpentylbutyltin, which was added to each sample just prior to instrument analysis--was used to measure recoveries of the RIS.

\subsubsection{Dioxins}

Dloxin analysis in sediment samples was performed by Battelle Columbus Operations, Columbus, Ohlo, following the proceduras summarized in EPA SW846, Method 8290 (EPA 1990a). This analytical method uses high-resolution gas chromatography and high-resolution mass spectrometry (HRGC/HRMS) on purfiled sample extracts. Samples were spiked with a solution containing nine isotoplcally labeled PCDD/PCDF compounds, and extracted according to a matrix-specific procedure. Sediment and soll samples underwent a toluene or benzene Soxhlet extraction; tlssue samples underwent a hexane/methylene chloride Soxhlet extraction. The extracts were subjected to an acid/base washing and dried. Following a solvent-exchange step, residues were cleaned by column chromatography and spiked with ${ }_{13} \mathrm{C}_{12}-1,2,3,4-T C D D$ to determine percent recoveries of tetra- and pentachloronated PCDD/PCDF congeners, and with ${ }_{13} \mathrm{C}_{12-1,2,37,8,9-H \times C D D}$ to determine percent recoveries of hexa-, hepta-, and octachloronated PCDD/PCDF congeners. The extracts were injected Into an HRCG/HRMS system capable of performing in the SIM mode. Significant revisions to Method 8290 were as follows:

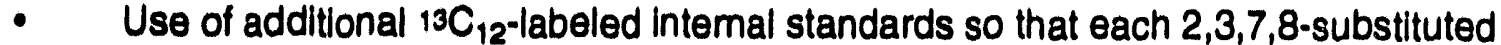
PCDD/PCDF isomer could be related to an intemal standard for identification and quantification purposes. Use of a complete range of Internal standards provided better accuracy than afforded by current EPA Method 8290 procedures.

- Use of $37 C_{14}$-labeled 2,3,7,8-tetra-CDD as a cleanup recovery standard added to sample extracts prior to cleanup to evaluate analyte recovery through cleanup procedures and provide an additional measure of quality control. Procedures similar to EPA Method 1613 were followed for this cleanup recovery standard.

- Routine calibration at only the beginning of the analytical period rather than at the beginning and end of the analytical period. This did not appear to affect data quality.

\subsection{DATAANALYSIS AND INTERPRETATION}

Statistical analyses were conducted to determine the magnitude and significance of toxicity and bloaccumulation in test treatments relative to reference treatments. Each statistical test was based on a completely random design that allowed unblased comparison between treatments. The 1991 Implementation Manuals recommend Dunnett's test (Dunnett 1964) for comparing test treatments to a single reference treatment. This test was used to evaluate all solid-phase tests, including toxicological and bioaccumulation exposures. Test design and specific statistical analysis procedures are discussed in the following sections. 


\subsubsection{Bandomization}

All solid-phase and SPP toxicity tests were designed as completely random tests. Organisms were randomly allocated to treatments, and treatments were randomly positioned on water tables. To determine the randomization, a random number table was generated for each toxicity test using the discrete uniform random number generator in the Excel 3.0 spreadsheet software. For the SPP tests, M. beryllina, M. bahia, and larval M. edulis tests were randomly allocated to SPP replicates for all concentrations.

\subsubsection{Statistical Analysis of Solid-Phase Tests}

Solid-phase toxicity of all sediment treatments was compared by analysis of variance (ANOVA) on the arcsine square-root of the proportion of organisms surviving the test. The arcsine square-root transformation stabilizes the within-class variances to meet assumptions of the ANOVA. All treatments were compared using Dunnett's test for comparison of all test treatments to the reference using an experiment-wise error rate of $\alpha=0.05$.

\subsubsection{Statistical Analysis of Suspended-Particulate-Phase Tests}

Two statistical tests are presented in the 1991 Implementation Manuals for the interpretation of SPP tests. The first test is a one-sided t-test between survival in control replicates and survival in the $100 \%$ SPP replicates. This test is to be performed only when survival in the $100 \%$ SPP is less than control (0\% SPP) survival and when control survival is $>90 \%$ for non-larval tests and $>\mathbf{7 0} \%$ for larval tests (indicating test validity). Prior to conducting the t-test, angular transformation (arcsine of the square root) of the proportion surviving in test replicates is performed to reduce possible heterogeneity of variance between control and $100 \%$ SPP mean survivals. The second test required by the 1991 Implementation Manuals is an LC Lo $_{50}$ or $\mathrm{EC}_{50}$ calculation, the concentration of SPP that is lethal to or affects $50 \%$ of organisms tested. The $L C_{50}$ or $E C_{50}$ values for these tests are calculated using the trimmed Spearman-Karber method (Finney 1971). The Spearman-Karber estimator is appropriate only if there is increasing mortality (or effect) with increasing concentration and if $\geq 50 \%$ or greater mortality (or effect) is observed in test solutions when normalized to control survival. If $50 \%$ mortality (or effect) does not occur in the $100 \%$ SPP dilutions for any treatments, then $\mathrm{LC}_{50}$ or $\mathrm{EC}_{50}$ values are reported as $>100 \%$ SPP.

\subsubsection{Statistical Analysis of Bioaccumulation}

Before statistical analysis of $M$. nasuta and $N$. virens tissue concentrations, a visual inspection of the tissue chemistry data was performed. If visual inspection showed that a compound was undetected in most replicate samples of test treatments, or that mean tissue concentration in the reference treatment was greater than that in the test treatments, no further analysis was performed. If the detected concentration of a compound exceeded that of the

\section{PANAMA CITYHABBOB $\quad 2.23$}


reference treatment, statistical analysis was performed. In all cases, detection limits were used in numerical calculations when a compound was undetected.

Treatments in which contaminants of concern were detected were compared to the reference treatment using ANOVA and Dunnett's test. Analytical detection limit values were used for replicates in which the compound was not detected ( $U$ flag). If a compound was detected at levels below the method detection limit ( $\mathrm{J}$ flag), then the associated value was used in the statistical analysis. If all replicates of a test treatment were flagged with $U, J$, or UJ qualifications (explained in Section 3.5) by the analytical laboratory, the data comprising that treatment were not analyzed. Significant bioaccumulation of a contaminant was determined by the statistical results of Dunnett's test at $\alpha=0.05$.

\subsection{QUALITY ASSURANCE/QUALITY CONTBOL (OA/OC) PROCEDURES}

The QAVC procedures for these studies were consistent with the 1991 Implementation Manuals and EPA protocols (PSEP 1986), and were documented by the PNL Quality Engineering Division as a QA Plan. A member of PNL's Quality Engineering staff was present throughout each phase of these studies to ensure that accepted procedures were followed. Laboratory notebooks (Data Accumulation Notebooks) were assigned to each portion of the study and served as records of day-to-day activities during the research. All entries in the laboratory notebooks were signed, dated, and reviewed by the project manager. The following discussion summarizes QAQC procedures followed for sediment sampling, biological testing, and chemical testing.

\subsubsection{Sample Tracking and Storage}

All sediment samples were accompanied by chain-of-custody forms from the time of collection to receipt at the MSL. After sample selection and compositing, a new set of custody forms was initiated for the sediment and water subsamples requiring chemical analyses. These accompanied the samples to the appropriate laboratory where the forms were signed and returned to the MSL project manager. Custody forms were also initiated for all tissue samples upon completion of the biological testing. These forms accompanied the samples to the appropriate laboratory for chemical analyses.

All sediment collected for these studies was stored in glass, cellulose acetate butyrate containers, or steel drums lined with 9-C-4-A-phenolic epoxy, a noncontaminating coating. Sediment samples were stored at $4^{\circ} \mathrm{C}$ prior to biological testing. Subsamples of sediment for chemical analyses and archiving were obtained prior to biological testing. These subsamples were stored frozen $\left(-20^{\circ} \mathrm{C}\right)$ until chemical analyses were performed. Samples for organic analyses were stored frozen up to 2 mo (PSEP 1986). Samples for metals were freeze-dried upon receipt at the laboratory and held up to 6 mo (PSEP 1986; EPA/USACE 1991a). 
Water samples were held at $4^{\circ} \mathrm{C}$ prior to chemical analysis. The water samples analyzed for organics were extracted within the 7-day holding period and analyzed within 40 days after extraction. Sediment and tissue samples were extracted within the 14-day holding period and analyzed within $\mathbf{4 0}$ days following extraction. Tissue samples were frozen immediately upon completion of the bloaccumulation tests. Samples for organic analyses were stored in precleaned glass jars with Teflon-lined lids. Samples for metals analyses were stored in precleaned plastic jars.

\subsubsection{Sediment and Tissue Chemisty Quality Control Procedures}

Chemical testing procedures require that specific QAVC protocols be followed. The QAQC guidelines specific to this project are provided in the PNL QA Plan. These guidelines include the following, where applicable:

analysis of a method blank with each batch of 20 samples

analysis of surrogate internal standards with each sample

analysis of matrix spikes on $10 \%$ of samples (where applicable) with appropriate compounds to assess accuracy

triplicate analyses on at least $10 \%$ of samples to assess analytical precision

analysis of SRMs at a frequency of $5 \%$, if available for the analytes of interest and sample matrix

archiving of all instrument printouts (e.g., raw data and chromatograms from AA and GC analyses) for future review.

In actual practice, some specific guidelines listed in the QA Plan for analytical precision and accuracy were modified for application to the most current laboratory methods. Guidelines for detection limits, range of recovery, and relative precision are listed in the Panama City Harbor QA Plan provided to USACE by the MSL.

Measurements of accuracy can be determined by analyzing the MSs of known concentrations and SRMs that have been certified for the presence of specific parameters. The MSs were analyzed for metals and organic parameters and generally consist of a subset of the analytes of interest. Percent recoveries were calculated based on differences between the amount spiked and the amount recovered in the sample. Metal spikes were analyzed at a frequency of $10 \%$, and organic compound spikes were generally analyzed at $10 \%$. Analytical accuracy is measured through the analysis of SRMs. In sediment, SRMs were analyzed for metals, PAHs, butyltins, and PCB congeners/pesticides (non-certified compounds); in tissues, SRMs were analyzed for PAHs, metals, and PCB congeners/pesticides (non-certified compounds); in waters, SRMs were analyzed for metals only. Surrogate compounds were a.jded in known amounts to samples analyzed for PCBs, pesticides, PAHs, dioxins, and 
butyltins. Surrogate compounds were added to samples prior to extraction, and their recoveries were a measurement of the efficiency or procedural accuracy of the analysis.

Measurements of precision were obtained through replicate analysis of selected sediment treatments. Analysis of replicates shows the precision and repeatability of the results. The measurements of precision include the industrial statistic (I-stat) and relative percent difference (RPD) for duplicate analyses, and the relative standard deviation (RSD) for triplicate analyses. The l-stat is defined as the absolute value of the difference between duplicate measurements divided by the sum of the duplicates. The RPD is defined as the absolute value of the clifference between two duplicate measurements, divided by the mean of the duplicates, multiplied by 100 . The RSD is defined as the sample standard deviation, divided by the mean, multiplied by 100 . All instrument printouts and other raw data generated using MSL analytical instruments are filed at the MSL for future reference. Procedures and related data were written into the appropriate Data Accumulation Notebooks. Copies of data generated by offsite analytical facilities are maintained at the MSL.

\subsubsection{Toxicological Testing Quality Control Procedures}

Appropriate procedures for organism care were maintained from collection through testing. Organisms shipped to the MSL were gradually equilibrated to ambient surroundings and kept in their native sediment whenever possible. Animals were fed if necessary before biological testing. Information on the collecting and handling of each test species is included in Section 2.1.3.

Selection of species was consistent with the 1991 Implementation Manuals and involved the use of juvenile forms, burrowing invertebrates, deposit-feeding organisms, and a larval (planktonic) form. Representatives of all test organisms were taxonomically identified by qualified experts at the MSL before use in testing. During testing, water quality parameters were measured to ensure that acceptable experimental conditions were maintained. These conditions included a stable temperature $\left( \pm 2.0^{\circ} \mathrm{C}\right.$ ), minimum DO representing at least $60 \%$ saturation in solid-phase tests (at least $40 \%$ in SPP tests), and controlled levels of light each day. Salinity was permitted to vary $\pm 2.0 \%$, and $\mathrm{pH}$ was allowed to vary \pm 0.5 units within each test container during the testing period. These limits and values are consistent with those outlined in the 1991 Implementation Manuals. Water quality instruments were calibrated according to the manufacturer's specification or PNL protocols. 


\subsection{RESULTS}

\subsection{EIELD COLLLECTION}

Sediment samples were collected from six test sites and one reference site in St. Andrew Bay, Florida. Table 3.1 and Appendix A summarize the test, reference, and control sediment collection information for the Panama City Harbor Project. Sediment samples were collected September 28-29, 1992. A sand dredge was used to collect the test and reference sediment samples in Panama City Harbor, Florida. This sampler was used to obtain the top 15 to $20 \mathrm{~cm}$ of sediment from each site. The site location was identifled through the use of a GPS that was provided and operated by the USACE. A marker buoy was deployed from the vessel to mark the site. The sand dredge was deployed near the buoy and dragged for $100 \mathrm{ft}$ before being retrieved. Once the sand dredge was onboard the vessel, the sediment was poured and/or scooped into labeled, epoxy-coated buckets. All samples were stored at $\sim 4^{\circ} \mathrm{C}$ and shipped to MSL via refrigerated van. Figure 3.1 shows the sampling locations for test and reference sediment collection. Water samples were collected at the reference site prior to sediment sampling by submerging, filling, and capping a clean, polypropylene carboy while it was submerged below the water surface. A second batch of water samples was collected $\sim 3$ wk following initlal field sampling and shipped to the MSL to complete toxicity testing. Water quality instruments were calibrated and used to determine the hydrographic measurements (conductivity, pH, turbidity, dissolved exygen, salinity, and water temperature) of water samples collected at the reference site. The following data were collected at the reference site:

$\begin{array}{ll}\text { conductivity } & 4200 \mu \text { mhos } \\ \text { pH } & 8.25 \\ \text { water transparency } & 3.3 \mathrm{~m} \text { (measured with a Secchi disk) } \\ \text { dissolved oxygen } & 8.7 \mathrm{mg} / \mathrm{L} \\ \text { salinity } & 28 \% \circ \\ \text { water temperature } & 26.1^{\circ} \mathrm{C}\end{array}$

Four control sediments were collected by MSL personnel or obtained from a commercial supplier for use in the blological toxicity tests. The $R$. abronius and $M$. nasuta control sediments (Figures 3.2 and 3.3) were collected by MSL personnel using a Battelle-designed anchor dredge and ponar grab, respectively. The $A$. abdita and $N$. virens control sediments were collected by a commercial supplier from San Pablo Bay, California, and Newcastle, Maine, respectiveily, during test organism collection.

\subsection{SEDIMENT SAMPLE PREPABATION}

The processing of sediment samples began once they were received at MSL. Each container of sediment was checked on the chain-of-custody form accompanying the samples. All sediment collected for each of the seven test treatrnents was homogenized thoroughly in a large, 
IABLE3.1. Field Collection Summary for Test and Reference Sediment Treatments

Station

PC-1

PC-1A

PC-2

PC-3

$P C-4$

PC-5

Reference
Latitude

$$
\begin{aligned}
& 30^{\circ} 08^{\prime} 03.4^{\prime \prime} N \\
& 30^{\circ} 07^{\prime} 54.6^{\prime \prime} N \\
& 30^{\circ} 07^{\prime} 46.2^{\prime \prime} N \\
& 30^{\circ} 08^{\prime} 38.1^{\prime \prime} N \\
& 30^{\circ} 09^{\prime} 31.6^{\prime \prime} \mathrm{N} \\
& 30^{\circ} 10^{\prime} 30.3^{\prime \prime} N \\
& 30^{\circ} 05^{\prime} 50.3^{\prime \prime} \mathrm{N}
\end{aligned}
$$

Lonoitude

$085^{\circ} 37^{\prime} 37.4^{\prime \prime} W$
$085^{\circ} 37^{\prime} 44.4^{\prime \prime} W$
$085^{\circ} 38^{\prime} 019^{\prime \prime} W$
$085^{\circ} 39^{\prime} 58.7^{\prime \prime} W$
$085^{\circ} 42^{\prime} 28.3^{\prime \prime} W$
$085^{\circ} 43^{\prime} 44.1^{\prime \prime} W$
$085^{\circ} 40^{\prime} 06.6^{\prime \prime} W$

Water Depth (ft)

$-30$

$-32$

$-33$

$-32$

.34

$-27$

$-14$

epoxy-coated cement-type mixer for sediment chemistry sampling and biological testing. Table 3.2 presents the sediment treatment strategy for the Panama City Harbor Project. This table summarizes sample designations and the appropriate chemistry and/or toxicity testing for each sediment treatment.

Suspended-particulate-phase samples were prepared for chemical analysis and blological testing. The homogenized sediment was mixed with the reference area site water in a 4:1 (v:v) water to sediment mixture and prepared according to the procedure in Section 2.2.4 to create a 100\% SPP mixture for each sediment treatment. This SPP was sampled for chemistry measurements and prepared and diluted for three SPP toxicity tests.

\subsection{SEDIMENT CHEMISTRY RESULTS}

Five test sediment treatments and one reference sediment were analyzed for a variety of contaminants. The sediment chemistry analyses consisted of measurements of conventional parameters (grain size, specific gravity, total solids, TOC, ammonia, cyanide, and total sulfides), PAHs, chlorinated pestlcides, PCBs, phenol and substituted phenols, phthalate esters, dioxins, metals, and butyltins. The purposes of these measurements were to provide an accurate characterization of contaminants associated with each sediment treatment and to compare test treatment characteristics with those of the reference area. This section addresses data quality, sediment chemistry results, and relationships between sediment treatments and the analytes. The complete sediment chemistry results and quality control data are presented in Appendix $B$.

\subsubsection{Cenventional Measurements}

Conventional parameters measured in sediment are summarized in Table 3.3. The data and associated quality control data for all the conventional parameters are presented in Appendix B, Tables B.1 through B.9. Quality control data for TOC, ammonia, cyanide, and total sulfide analyses met all requirements. Measurements of the four major grain size fractions (gravel, sand, silt, and clay) indicato that replicate precision was excellent. There were 4 of 16 grain size 


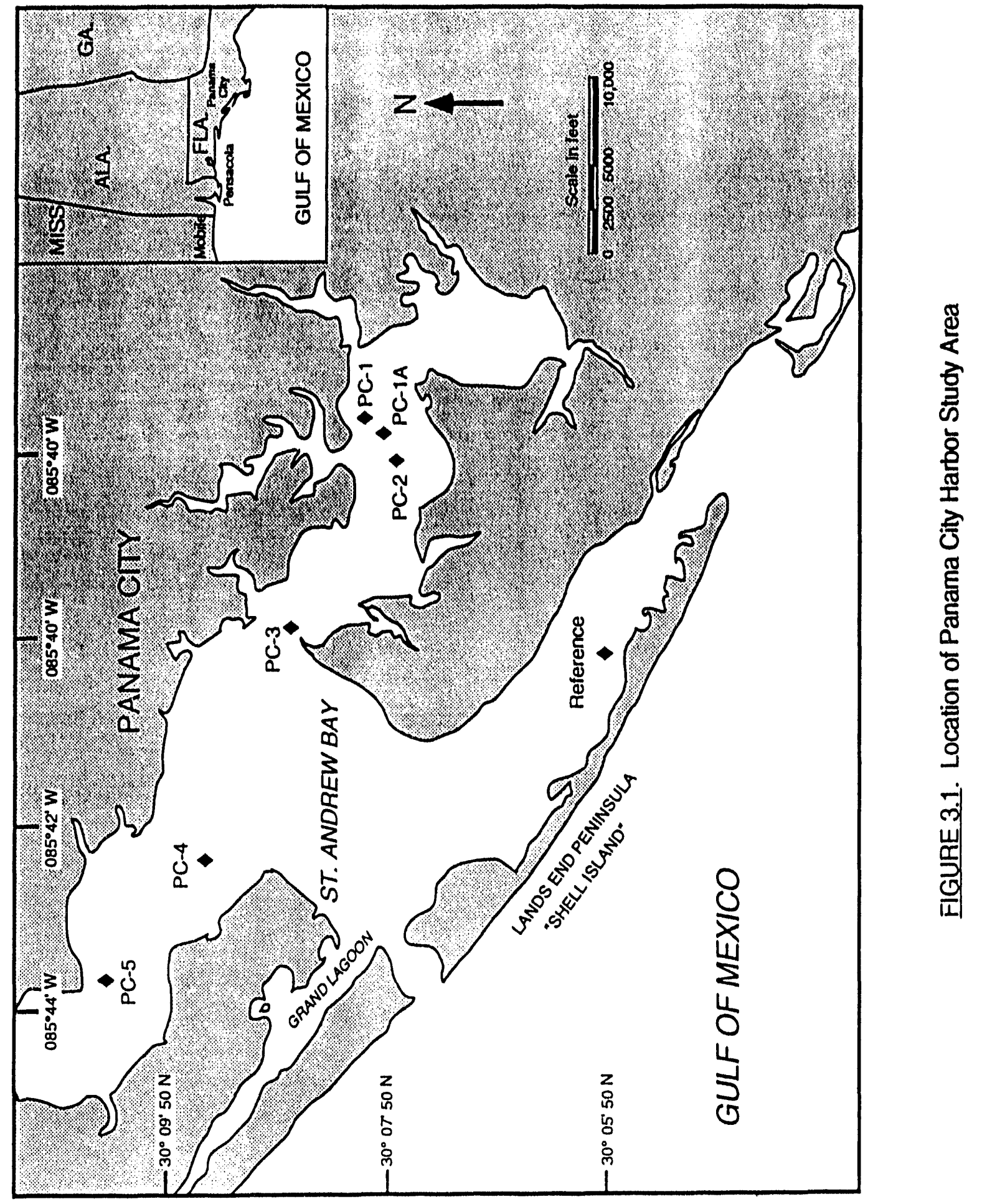

PANAMACITY HARBOB 


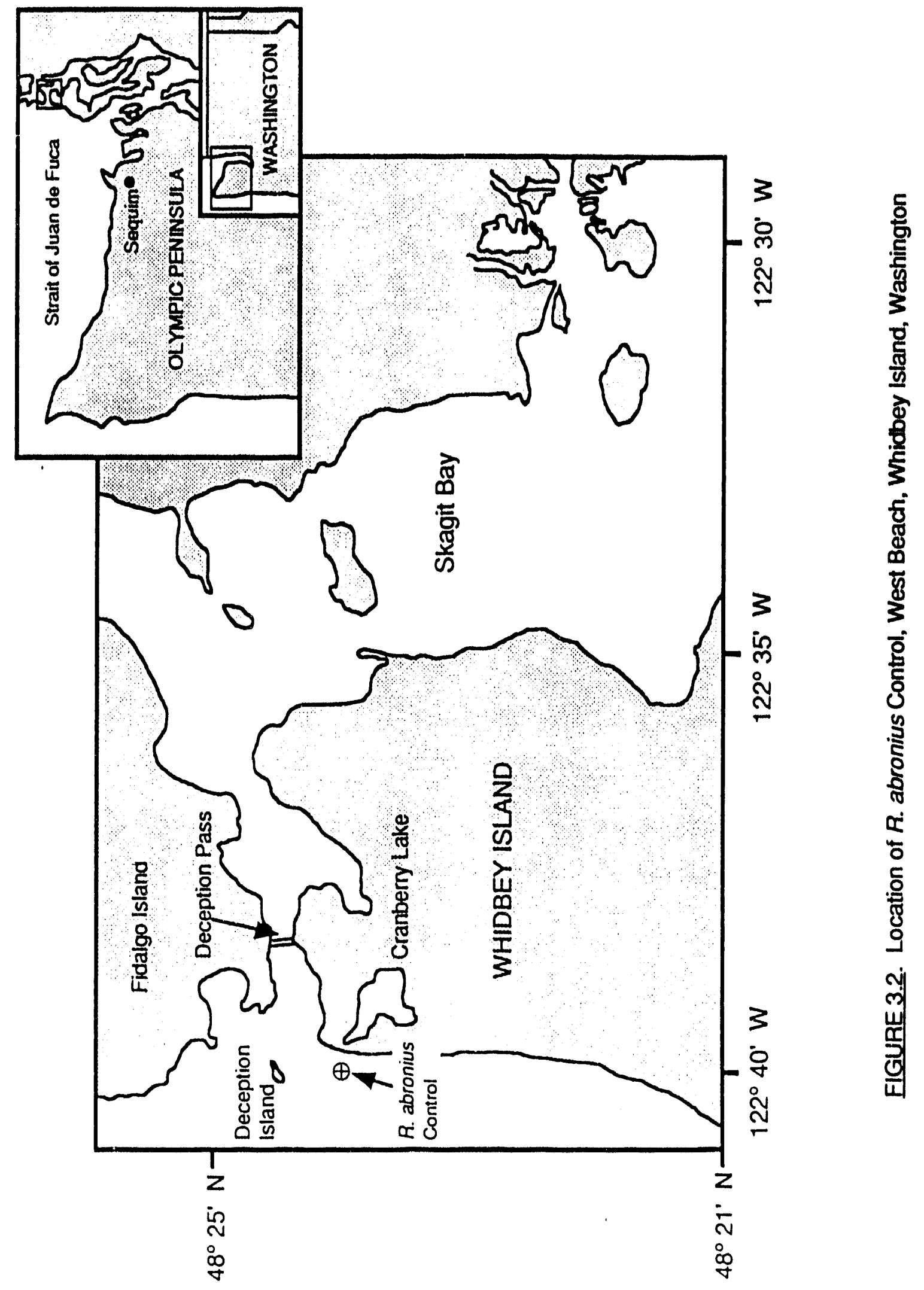




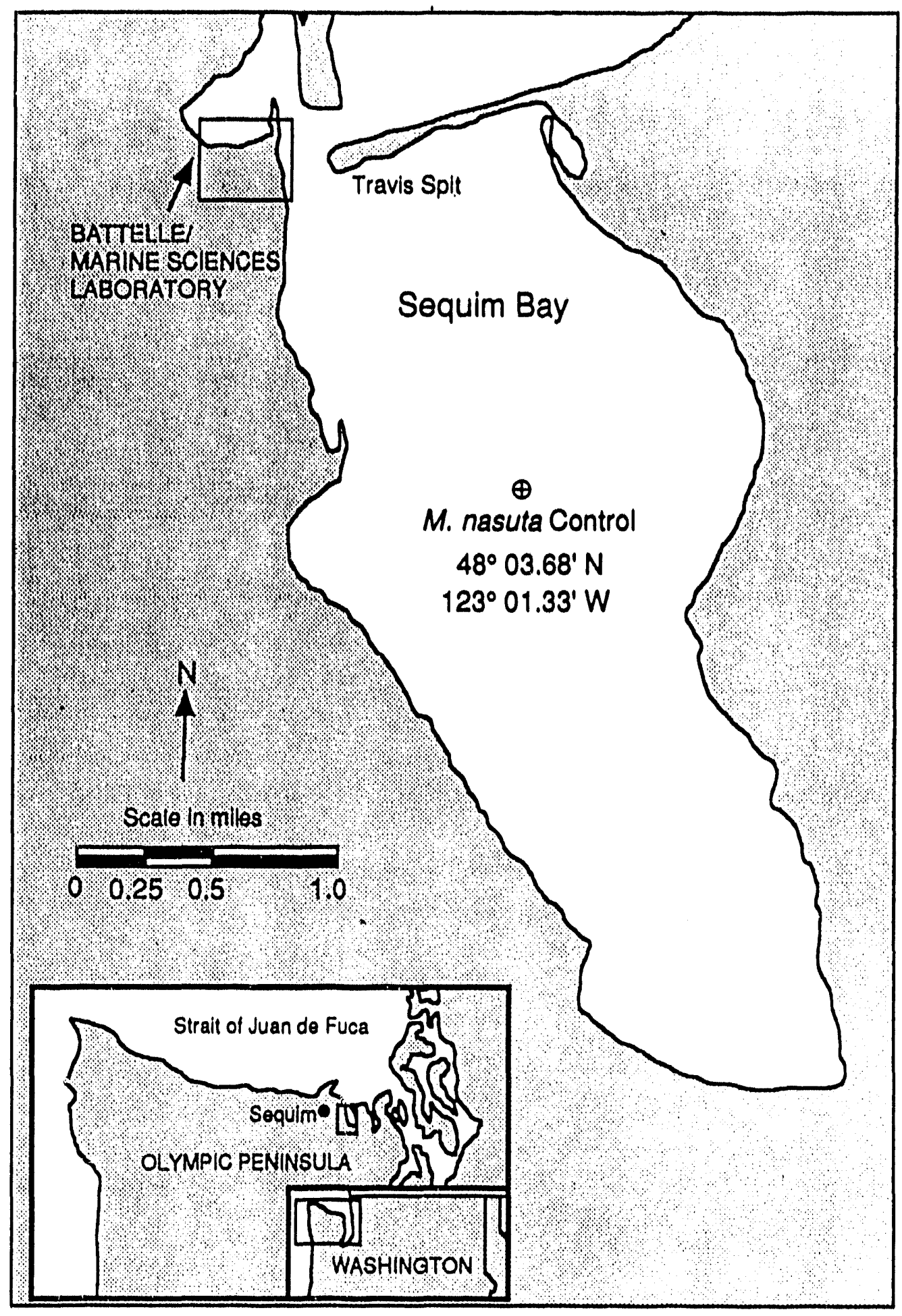

EIGURE 3.3. Location of M. nasuta Control, Sequim, Washington 
IABLE_32. Summary of Sediment Treatment Strategy for Chemical and Blological Testing

$\begin{array}{lccccc}\begin{array}{c}\text { Sediment } \\ \text { Ireatment }\end{array} & \begin{array}{c}\text { Sediment } \\ \text { Chemistry }\end{array} & \begin{array}{c}\text { Water } \\ \text { chemlstry }\end{array} & \begin{array}{c}\text { Solld-Phase } \\ \text { Acute } \\ \text { Ioxlality }\end{array} & \begin{array}{c}\text { SPP } \\ \text { Ioxidlty }\end{array} & \begin{array}{c}\text { Bloaccu- } \\ \text { mulation }\end{array} \\ \text { PC.-1 } & \text { YES } & \text { YES } & \text { YES } & \text { YES } & \text { YES } \\ \text { PC-2 } & \text { YES } & \text { YES } & \text { YES } & \text { YES } & \text { YES } \\ \text { PC-1A } & \text { YES } & \text { YES } & \text { YES } & \text { YES } & \text { YES } \\ \text { PC-3(a) } & \text { YES } & \text { NO } & \text { NO } & \text { NO } & \text { NO } \\ \text { PC-4 } & \text { YES } & \text { YES } & \text { YES } & \text { YES } & \text { YES } \\ \text { PC-5 } & \text { YES } & \text { YES } & \text { YES } & \text { YES } & \text { YES } \\ \text { Reference(b) } & \text { YES } & \text { YES } & \text { YES } & \text { YES } & \text { YES } \\ \text { M. nasuta Control(b) } & \text { NO } & \text { NO } & \text { NO } & \text { NO } & \text { YES } \\ \text { N. virens Control(b) } & \text { NO } & \text { NO } & \text { YES } & \text { NO } & \text { YES } \\ \text { A. abdita Controlb) } & \text { NO } & \text { NO } & \text { YES } & \text { NO } & \text { NO } \\ \text { R. abronius Control(b) } & \text { NO } & \text { NO } & \text { YES } & \text { NO } & \text { NO }\end{array}$

(a) Sediment sample for grain size and specific gravity analysis only.

(b) Sediment was dry-sleved to remove organisms before it was homogenized for testing.

fractions exceeding the relative standard deviation (RSD) that did not affect data interpretation, since the increased variation was due to fractions with low contributions to sediment coarseness.

Table 3.3 summarizes the specifle gravity, grain size, TOC, total ammonia, cyanide, total sulfides, and total sollds in sediment samples. Specific gravity was relatively consistent, ranging from 2.59 to 2.76. Grain size results show that all sediment treatments were composed primarily of sand, with values ranging from $63 \%$ dry weight in PC. 2 to $96 \%$ dry weight in the reference.

The percent solids in these sediment treatments ranged from $38 \%$ to $78 \%$, with the highest value recorded in the reference sediment. The TOC levels ranged from $0.11 \%$ dry weight in the reference to $2.14 \%$ dry weight in PC-2, increasing as the percentage of sand and percent solids decreased. Concentrations of ammonia in the pore water ranged from $1.86 \mathrm{mg} / \mathrm{L}$ in PC-1 to $5.26 \mathrm{mg} / \mathrm{L}$ in the reference. Cyanide was undetected in all treatments. Total sulfides ranged from undatected at $2.0 \mathrm{mg} / \mathrm{kg}$ dry weight in the reference, to $295 \mathrm{mg} / \mathrm{kg}$ dry weight in PC-2. Finegrained sediments and sediments with elevated TOC concentrations did not correspond to elevated concentrations of ammonia and total sulfides in the pore water samples.

\subsubsection{Polynuclear Aromatic Hydrocarbons}

Elghteen PAHs were analyzed in Panama Clty Harbor sediment treatments. The results are summarized in Table 3.4. The PAHs are reported as low-molecular-weight PAH compounds (LPAH) and high-molecular-weight PAH compounds (HPAH). The quality control data for PAH analysis (AppendlX B, Tables B.10 through B.14) show that the method blank analyzed for PAHs was free of contamination, with the exception of naphthalene which was present at 


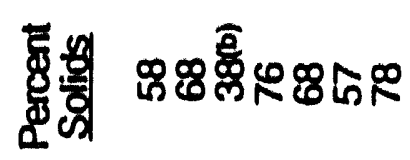

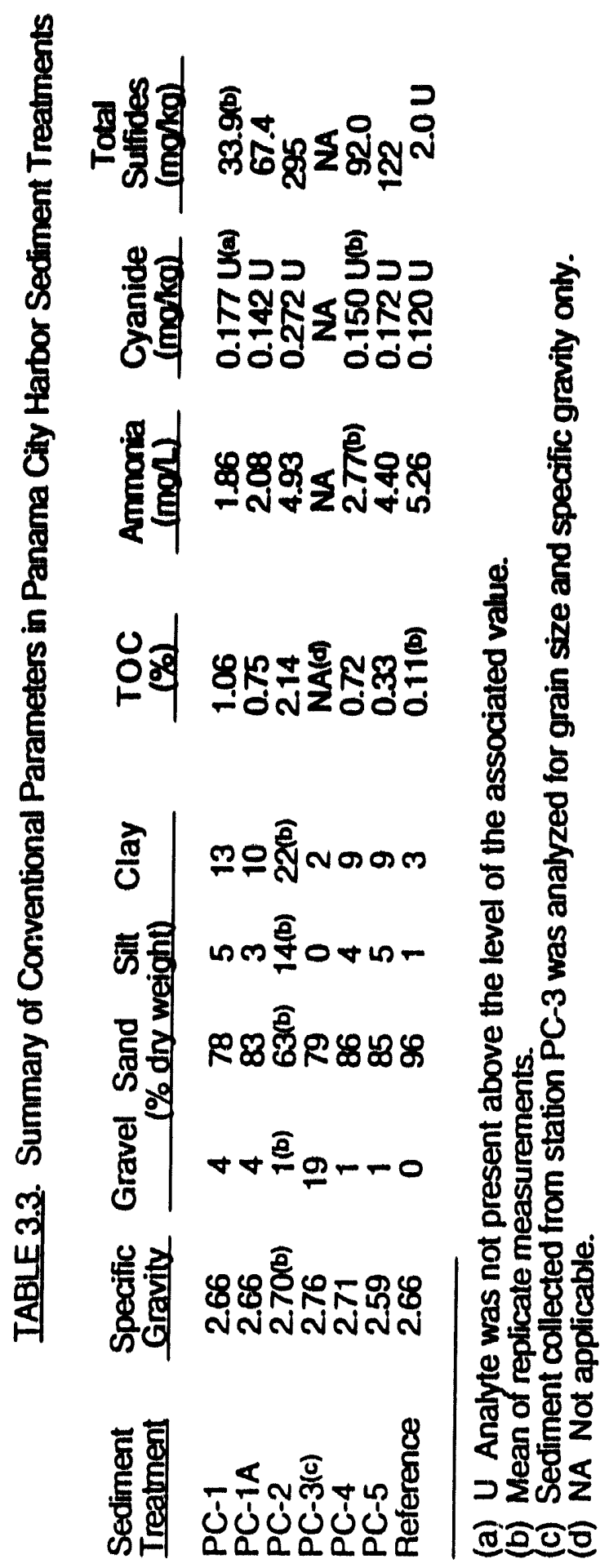


IABLEE 34. Summary of PAHs, Phenols, Substituted Phenols, and Phthalate Ester Concentrations in Panama Clity Harbor Sediment Samples

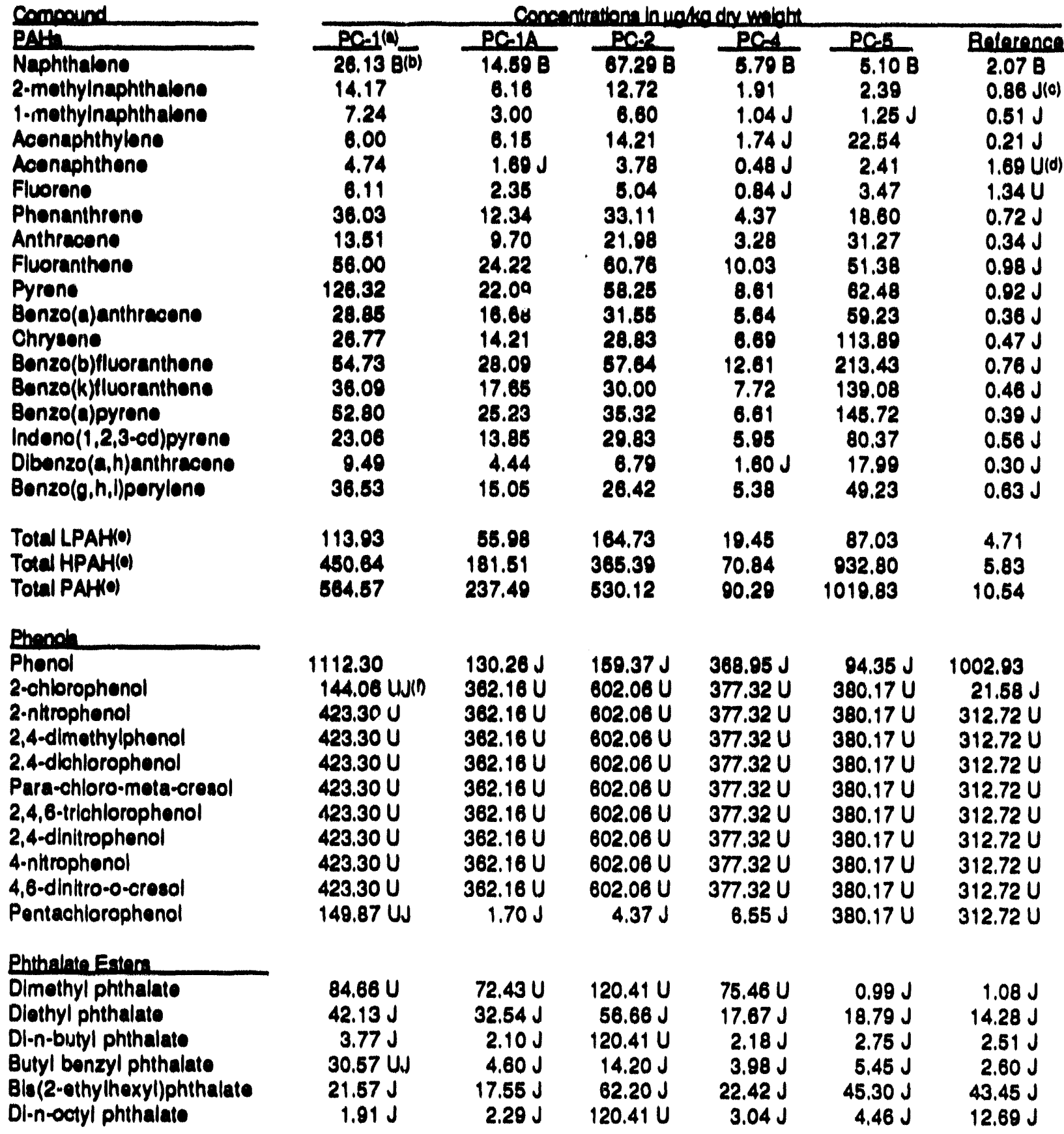

\footnotetext{
(a) Mean of replbate measurements.

(b) B Analyte was found in the method blank; results presented are not corrected for the amount in the blank.

(c) I Analyte was detected below the method detection limit (MDL) but above the instrument detection limit (IDL).

(d) U Analyte was not present above the level of the assoclated value.

(e) Values are the sum of dotected values.

(t) W Value is mean of replicates; analyte was elther undetected or detected below the method detection limit in all replicates.
} 
22 times the achieved detection limit. The data assoclated with thls sample were flagged with a "B." The achleved detection limits were all below target detection limits set in the QAQC plan. All of the percent recoveries calculated for the MS samples were within the $40 \%$ to $120 \%$ range set in the QAOC plan. The percent difference of certified PAHs in the sediment SRM was acceptable, with the exception of two PAHs [benzo(a)pyrene (34\%) and benzo(g,h,i)perylene $(41 \%)$ ). Analytical precision and intrasample variation were assessed through the analysis of tripllcate subsamples. Three of the eight LPAHs and all but one of the HPAHs had RSD values exceeding $30 \%$. Three PAH surrogate compounds, naphthalene-d, acenaphthene- $-d_{10}$, and benzo(a)pyrene-d $d_{12}$, were analyzed with the samples (Appendlx B, Table B.19). Recovery of these surrogate internal standard (SIS) compounds was acceptable. Adequate SRM precision and SIS compound recovery indicate that the larger variation observed with triplicate subsample measurements is due to intrasample variation of the relatively low concentrations of PAHs, and not to the precision of extraction and analyses.

The PAHs, phenol and substituted phenols, and phthalate ester concentrations in sediment samples are summarized in Table 3.4. This table shows that the highest total detected PAH concentrations occurred in PC.5 (1019.83 $\mu \mathrm{g} / \mathrm{kg} \mathrm{dry}$ weight) and the lowest levels were found in the reference sediment (10.54 $\mu \mathrm{g} / \mathrm{kg}$ dry weight). Where PAHs were detected, the majorty of measured PAHs were HPAH ( $>68 \%$ except for the reference sediment). The HPAH compounds are less volatile and tend to be more persistent in the environment.

\subsubsection{Phenols. Substituted Phenols, and Phthalate Esters}

Eleven phenol and substituted phenols and six phthalate esters were analyzed in Panama City Harbor sediment treatments (Table 3.4). The quality control data for phenol and substituted phenols (Appendix B, Tables B.16 and B.19) show that the method blank was uncontaminated. The surrogate percent recovery for 2-fluorophenol was poor. Achleved detection IImits were sllghtly elevated above target detection limits set in the QAQC plan. These elevated detection limits do not present a problem because all but two samples were undetected or detected below the target detection limit. Of the 11 phenol and substituted phenol compounds, 4 had MS recoveries beyond the $40 \%$ to $120 \%$ range set in the QAQC plan. Quality control data for phthalate esters are shown in Appendix B, Table B.18. The MS recoveries in phthalate ester compounds were all within the $40 \%$ to $120 \%$ range. No SRM sample was analyzed with these samples. Analytical precision and intrasample variablity were assessed through the analysis of triplicate subsamples. Two of six phthalate ester compounds had RSDs beyond the $30 \%$ range. The only calculable RSD for the phenol and substituted phenol analysis, the surrogate 2-fluorophenol, was $75 \%$, well outside the $30 \%$ range.

Substituted phenols were elther undetected, Indlcated by a "U" flag, or detected below the method detection limit, indicated by a "J" flag (Table 3.4). Phenol was detected in two 
sediment treatinents, with values of $1112.30 \mu \mathrm{g} / \mathrm{kg}$ dry weight in PC-1 and $1002.93 \mu \mathrm{g} / \mathrm{kg}$ dry weight in the reference sediment. Phthalate concentrations were either undetected or detected below the method detection limit.

\subsubsection{Chlorinated Pesticides and Polvchlorinated Biphenyls}

Chlorinated pesticide and PCB concentrations are summarized in Table 3.5. All data associated with these summaries and related quality assurance measurements may be found in Appendix B, Tables B.20 through B.26. The method blank analyzed for chlorinated pesticides and PCBs was uncontaminated, and achieved detection limits were below the target detection limits set in the QAQC plan. Of the 17 percent recoveries calculated for the MS samples, 5 exceeded the $40 \%$ to $120 \%$ range targeted in the QAVC plan. Analytical precision was assessed through the analysis of triplicate samples. All calculable RSDs were within the $30 \%$ range.

The majority of chlorinated pesticides and PCBs were either undetected, Indicated by a "U" flag, or detected below the method detection limit, Indicated by a "J" flag. Table 3.5 shows the compounds with detected concrintrations. The reference sediment had pesticlie and PCB concentrations that were either undetected or detected below the method detection limit. Concentrations of pesticides 4,4'-DDD, 4,4'-DDE, and 4,4'-DDT in sediment treatments PC- 1 and PC-2 ranged from 4 to 16 times higher than concentrations found in the reference sediment. All the PCBs except Aroclor 1254 were undetected in all sediment treatments. Aroclor 1254 was detected below the method detection limit, indicated by a "J" flag, or undetected above the method detection limit, indicated by a "U" flag, in all sediment treatments.

\subsubsection{Metals}

Fourteen metals were analyzed in sediment samples from Panama City Harbor. Metals concentrations are summarized in Table 3.6. All data associated with these summaries and related quality assurance measurements may be found in Appendix B, Tables B.27 through Tables B.30. The method blank analyzed for metals had low levels of $\mathrm{Al}, \mathrm{Cr}, \mathrm{Hg}, \mathrm{NI}, \mathrm{Pb}$, and $\mathrm{Zn}$. The detection limit goals for all metals were met. Of the $12 \mathrm{MS}$ recoveries, 3 ( $\mathrm{Ag}, \mathrm{Se}$, and $\mathrm{Sb}$ ) were outside the $75 \%$ to $125 \%$ range targeted in the QAQC plan. Analytical accuracy was assessed through analysis of an SRM and was within QAVC limits. Of the 14 RSD calculations, 5 exceeded $20 \%$.

Table 3.6 shows that all metals in the test treatments were elevated above metals concentrations in the reference sediment. Test treatment PC-2 exhibited the highest metals concentrations for all 14 metals analyzed. Concentrations of metals in PC-2 were 70 times higher than the reference sediment for $\mathrm{Be}, 26$ times higher for $\mathrm{Hg}, 16$ times higher for $\mathrm{Cr}$, and 15 times higher for Ag. Test treatment PC-5 produced the lowest metals concentrations of the five test treatments for 8 of the 14 metals analyzed. 
IABLE 3.5. Summary of Detected Pesticide and PCB Concentrations in Panama City Harbor Sediment Samples

\begin{tabular}{|c|c|c|c|c|c|c|}
\hline \multirow[b]{2}{*}{ Compound } & \multicolumn{6}{|c|}{ Concentrations in $u g / \mathrm{kg}$ dry weight } \\
\hline & $P C-1^{(a)}$ & PC-1A & PC-2 & $P C-4$ & $P C-5$ & Reference \\
\hline $\begin{array}{l}4,4^{\prime}-\mathrm{DDD} \\
4,4^{\prime}-\mathrm{DDE} \\
4,4^{\prime}-\mathrm{DDT} \\
\text { Aroclor-1254 }\end{array}$ & $\begin{array}{c}8.447 \\
2.418 \\
2.205 \\
36.224 \mathrm{~J}\end{array}$ & $\begin{array}{c}2.220 \\
0.998 \\
2.652 \\
11.308 \mathrm{~J}\end{array}$ & $\begin{array}{c}8.775 \\
3.259 \\
6.260 \\
24.158 \mathrm{~J}\end{array}$ & $\begin{array}{l}0.762 \mathrm{~J}(\mathrm{~b}) \\
0.555 \\
2.115 \\
38.916 \mathrm{U}\end{array}$ & $\begin{array}{c}1.082 \mathrm{~J} \\
0.640 \\
1.933 \\
39.210 \mathrm{U}\end{array}$ & $\begin{array}{l}0.545 \mathrm{~J} \\
0.411 \mathrm{U}(c) \\
0.556 \mathrm{~J} \\
32.253 \mathrm{U}\end{array}$ \\
\hline
\end{tabular}

(a) Mean of replicate measurements.

(b) I Analyte was detected below the method detection limit (MDL) but above the instrument detection limit (IDL).

(c) $U$ Analyte was not present above the level of the associated value.

The Florida Department of Environmental Regulation devised a technique by which sediment samples collected from coastal Florida waters can be compared with other Florida sediments based on concentrations of metals in the sediment. The concentration of $A l$ in the sediment treatments was compared with concentrations of $\mathrm{As}, \mathrm{Cd}, \mathrm{Cu}, \mathrm{Cr}, \mathrm{Pb}, \mathrm{Ni}$, and $\mathrm{Zn}$ by plotting the concentrations ( $\mathrm{mg} / \mathrm{kg}$ dry weight) on a log-log scale. These graphs were developed as an interpretive tool based on the relatively constant natural relationships existing between metals and aluminum (Florida Department of Environmental Regulation 1988). Sediments were collected from "clean" coastal areas throughout Florida and analyzed for their metals content. Metal/aluminum regressions and prediction limits were calculated, and Panama City Harbor metals data were plotted on the graphs. Sediment was judged to be "natural" or "meiai-enriched" depending on position of data points relative to the regression lines and $95 \%$ prediction limits. If a point fell within the $95 \%$ prediction limits, then the sediment metal concentration was considered within the expected natural range; if a point fell above the upper $95 \%$ prediction limit, then the sediment was considered to be metal-enriched. Some data points from "clean" sediments will fall below the lower prediction limit. By nomalizing metal concentrations to aluminum, an assessment of relative metal enrichment levels can be made, allowing estuaries to be ranked according to specific metal enrichment problems.

Metals data for the six sediment treatments were plotted on log-log scale graphs (Figures 3.4 and 3.5). These graphs show that, with the exception of a few points, the data fell within the $95 \%$ prediction limits for the calculated regression line. The $\mathrm{Cd}$ data for PC-4 and the Ni data for the reference area produced data points that fell slightly below the lower $95 \%$ prediction limit. To evaluate the $\mathrm{Hg}$ data, the maximum $\mathrm{Hg}$ values in the "clean" sediment data set $(0.21 \mathrm{mg} / \mathrm{kg})$ were assumed to represent the maximum $\mathrm{Hg}$ concentration found in natural sediments of Florida (Florida Department of Environmental Regulation 1988). Concentrations in the Panama City Harbor 
IABLE 3.6. Summary of Metals Concentrations in Panama City Harbor Sediment Samples

\begin{tabular}{|c|c|c|c|c|c|c|}
\hline \multirow[b]{2}{*}{ Compound } & \multicolumn{6}{|c|}{ Concentrations in mo/kg dry weight } \\
\hline & $P C-1$ & $P C-1 A$ & $\mathrm{PC}-2$ & $P C-4$ & $\mathrm{PC}-5$ & Reference (a) \\
\hline $\begin{array}{l}\mathrm{Ag} \\
\mathrm{A} \\
\mathrm{As} \\
\mathrm{Be} \\
\mathrm{Cd} \\
\mathrm{Cr} \\
\mathrm{Cu} \\
\mathrm{Hg} \\
\mathrm{Ni} \\
\mathrm{Pb} \\
\mathrm{Se} \\
\mathrm{Sb}\end{array}$ & $\begin{array}{c}0.05 \\
2,720 \\
4.86 \\
0.32 \\
0.03 \\
20.60 \\
5.80 \\
0.0594 \\
5.15 \\
8.32 \\
0.05 U \\
0.140 \\
0.15 \\
20.4\end{array}$ & $\begin{array}{c}0.07 \\
7,030 \\
3.46 \\
0.21 \\
0.02 \\
13.40 \\
4.75 \\
0.0320 \\
3.24 \\
6.18 \\
0.11 \\
0.065 \\
0.095 \\
14.3\end{array}$ & $\begin{array}{c}0.15 \\
14,000 \\
7.90 \\
0.7 \\
0.14 \\
33.70 \\
9.93 \\
0.0840 \\
9.55 \\
24.10 \\
0.7 \\
0.160 \\
0.27 \\
40.6\end{array}$ & $\begin{array}{c}0.06 \\
3,210 \\
3.09 \\
0.19 \\
0.01 \\
10.30 \\
2.97 \\
0.0235 \\
2.99 \\
6.86 \\
0.05 \mathrm{U} \\
0.057 \\
0.13 \\
13.8\end{array}$ & $\begin{array}{c}0.04 \\
4,070 \\
1.95 \\
0.14 \\
0.02 \\
9.82 \\
2.91 \\
0.0286 \\
2.39 \\
9.00 \\
0.05 \mathrm{U} \\
0.053 \\
0.035 \\
19.5\end{array}$ & $\begin{array}{c}0.01 \\
1,743 \\
0.69 \\
0.01 \\
0.01 \mathrm{U}(b) \\
2.13 \\
0.74 \\
0.0032 \\
0.71 \\
2.68 \\
0.05 \mathrm{U} \\
0.021 \\
0.03 \\
3.51\end{array}$ \\
\hline
\end{tabular}

(a) Mean of replicate measurements.

(b) $U$ Analyte was not present above the level of the associated value.

sediments were in the range 0.0032 to $0.0840 \mathrm{mg} / \mathrm{kg}$, well below the $0.21 \mathrm{mg} / \mathrm{kg} \mathrm{level}$, and were therefore considered typical of clean sediments.

\subsubsection{Organotins}

Organotin concentrations are summarized in Table 3.7. All data associated with these summaries and related quality assurance measurements may be found in Appendix $B$, Tables B.31 and B.32. The method blank analyzed with the samples was uncontaminated, and achieved detection limits were below the target detection limits. The MS recoveries were within the $40 \%$ to $120 \%$ range set in the QAVC plan. Analytical precision was assessed through the analysis of an SRM sample, and the results were within QAVC limits. Triplicate precision was acceptable.

Table 3.7 shows that dibutyltin was either undetected or detected below the method detection limit for all sediment treatments. Monobutyltin was undetected in five of the six sediment treatments. Tributyltin was detected above the method detection limit in three of the six sediment treatments at levels in the range 3.7 to $11.1 \mu \mathrm{g} / \mathrm{kg}$ dry weight.

\subsubsection{Dioxins}

Dibenzodioxin and dibenzofuran concentrations are summarized in Table 3.8. All data associated with these summaries and related quality assurance measurements may be found in Appendix B, Tables B.33 through B.39. The method blank analyzed for dioxins was uncontaminated for all dioxins and furans, with the exception of OCDD. The OCDD 

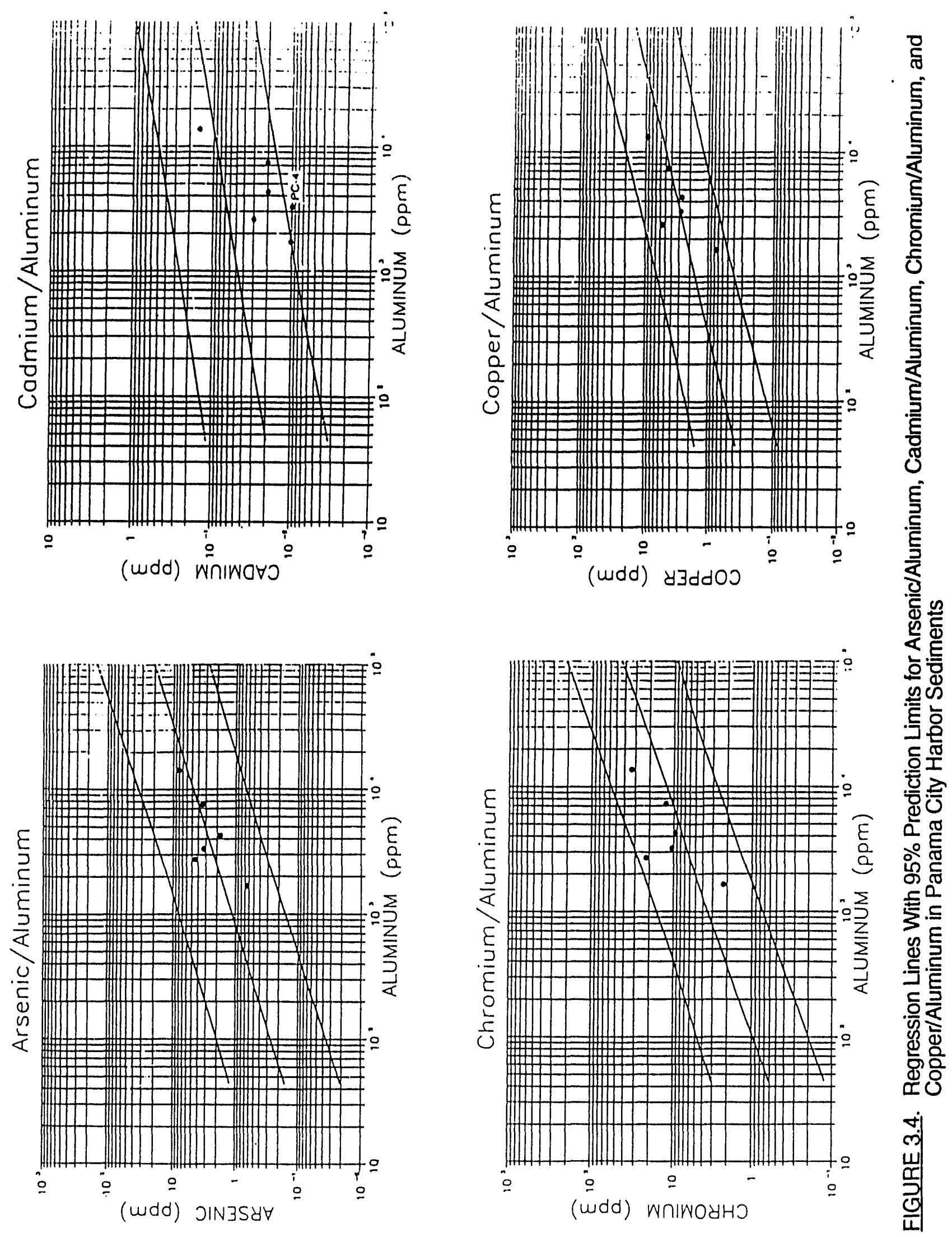

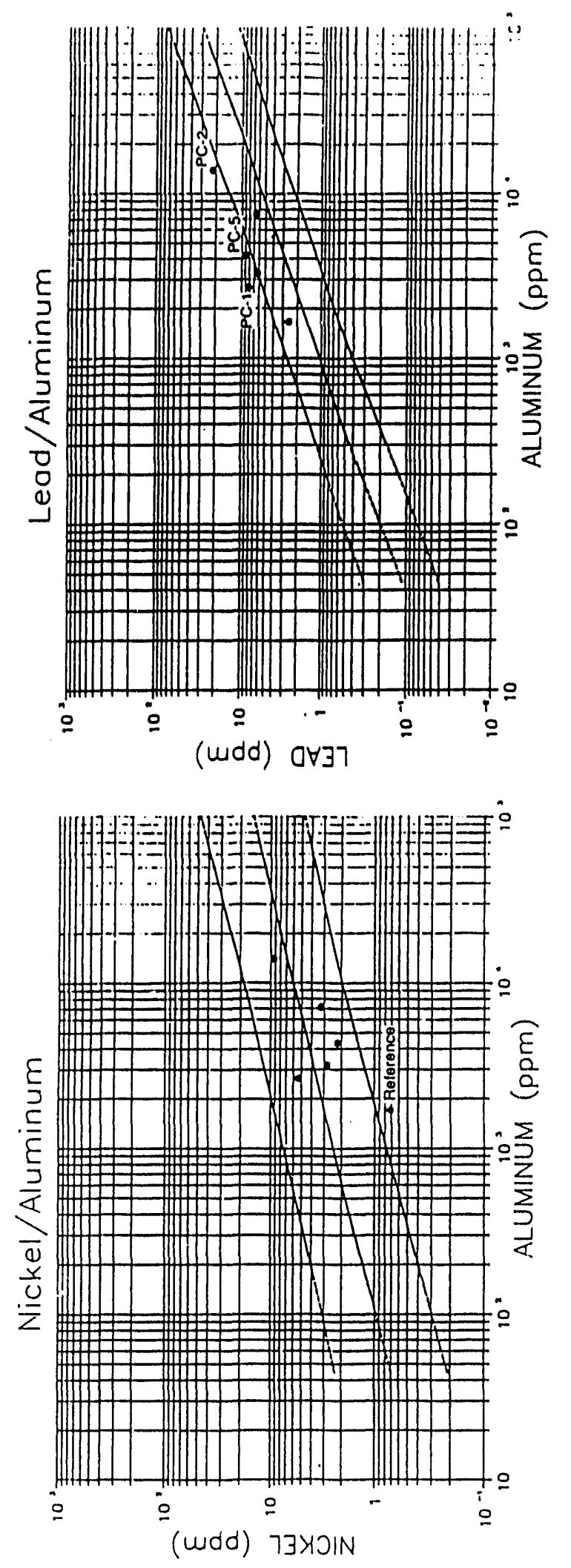

PANAMA CITY HARBOB

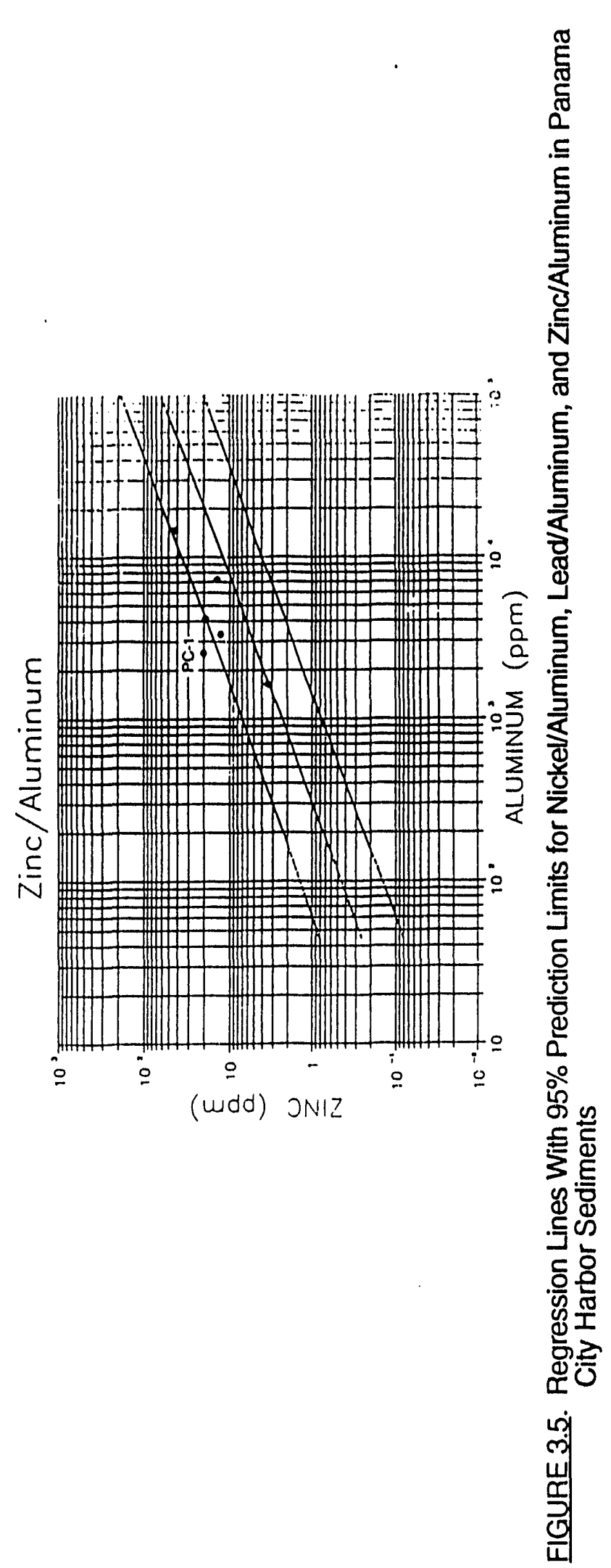

3.14 
IABLE 3.7. Summary of Butyltins Concentrations in Panama City Harbor Sediment Samples

Compound

Tributyltin

Dibutyltin

Monobutyltin

\begin{tabular}{|c|c|c|c|c|c|}
\hline$\overline{P C-1}$ & $\frac{\text { Mean }}{P C-1 A(a)}$ & $\frac{n c e n t r a}{\text { PC-2 }}$ & $\frac{(\mu \mathrm{gkgO}}{\mathrm{PC}-4}$ & $\frac{e \operatorname{lon}: 2}{P C-5}$ & $\theta$ \\
\hline $\begin{array}{l}3.7 \\
1.2 \mathrm{~J} \\
2.6 \mathrm{U}\end{array}$ & $\begin{array}{l}1.9 \cup J(b) \\
1.6 U J \\
3.5\end{array}$ & $\begin{array}{r}11.1 \\
2.6 \mathrm{U} \\
2.5 \mathrm{U}\end{array}$ & $\begin{array}{l}1.1 \mathrm{~J}(0) \\
1.3 U U \\
2.3 U\end{array}$ & $\begin{array}{l}5.1 \\
2.3 U \\
2.4 U\end{array}$ & $\begin{array}{l}1.8 U(d) \\
2.2 U^{(d)} \\
2.6 U\end{array}$ \\
\hline
\end{tabular}

(a) Mean of replicate measurements.

(b) UJ Analyte was elther undetected or detected below the method detection limit in all replicates; value is mean of detected values and dry weight detection limits.

(c) I Analyte was detected below the method detection limit (MDL) but above the instrument detection limit (IDL).

(d) $U$ Analyte was not present above the level of the associated value.

concentration of $2.45 \mathrm{ng} / \mathrm{kg}$ dry weight was footnoted because the mass ratio was outside the limits for that sample. Because this value is lower than the detection limit, the accuracy of quantification at levels lower than the detection limits cannot be guaranteed. Achleved detection limits for all dioxin congeners analyzed were lower than the target detection limits set in the QA plan, except for OCDF. The concentration of OCDF found in the blank was slightly higher than the target detection limit, but sample concentrations were elevated 58 to 89 times higher than the detection limit. Matrix spike/matrix spike duplicate (MS/MSD) recoveries for all the dioxin congener analyses were within the $40 \%$ to $120 \%$ range set in the QAQC plan. Analytical precision was determined by RPD calculations performed on the MS/MSD percent recoveries. These values are within the $30 \%$ limit set in the QAQC plan. The sediment samples were spiked with 15 labeled surrogate compounds and a clean-up standard. Of the 80 surrogate percent recoveries, 17 were outside the targeted recovery range of 40 to $120 \%$. All but one of the surrogate percent recoveries for station PC-1 (range from 19\% to $39 \%$ ) were below $40 \%$ to $120 \%$.

Table 3.8 shows the dioxin congeners analyzed in sediment treatments PC-1 and PC-2. The dioxin congener 2378-TCDD, considered the most toxic by EPA based on its Toxicity Equivalent Factors (TEF) ranking (EPA 1988), was detected at 0.86 and $1.45 \mathrm{ng} / \mathrm{kg}$ dry weight in PC-1 and PC-2, respectively. Two other dioxin congeners detected in sediment treatments, 12378-PeCDD and 23478-PeCDF, are considered one-half as toxic based on TEF rankings. The dioxin congener 12378-PeCDD was found in PC-1 and PC-2 at concentrations of 0.72 and $0.74 \mathrm{ng} / \mathrm{kg}$ dry weight, respectively. The dioxin congener 23478-PeCDF was undetected above the method detection limit in both PC-1 and PC-2. Other dioxin congeners were detected at elevated concentrations, but are considered much less toxic based upon TEFs. 
IABLE 3.8. Summary of Dloxin Concentrations in Panama Clty Harbor Sediment Samples

\begin{tabular}{l} 
Compound \\
\hline $2378-T C D D(a)$ \\
12378-PeCDD \\
$123478-H \times C D D(a)$ \\
$123678-H \times C D D(a)$ \\
$123789-H \times C D D(a)$ \\
$1234678-H p C D D$ \\
OCDD \\
$2378-T C D F(a)$ \\
$12378-P \theta C D F$ \\
$23478-P \theta C D F$ \\
$123478-H \times C D F$ \\
$123678-H \times C D F$ \\
$123789-H \times C D F$ \\
$234678-H \times C D F$ \\
$1234678-H p C D F(a)$ \\
$1234789-H p C D F$ \\
OCDF(a) \\
Total TCDD \\
Total PeCDD \\
Total HXCDD \\
Total HpCDD \\
Total TCDF \\
Total PeCDF \\
Total HXCDF \\
Total HpCDF \\
Tal
\end{tabular}

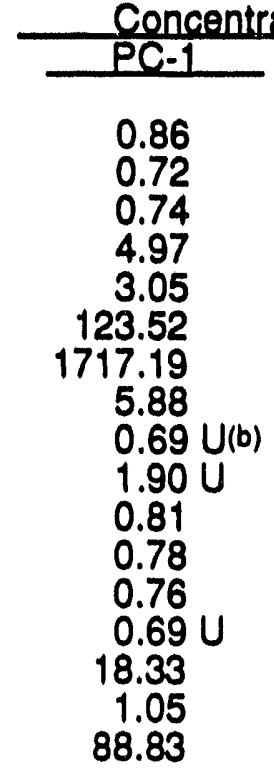

4.76

4.33

72.05

453.38

13.62

7.52

19.64

72.00

\section{encon}

PC-2

1.45

0.74

0.87

3.74

3.21

94.74

1026.32

9.21

0.45

$1.58 \mathrm{U}$

0.71

$1.32 \mathrm{U}$

$2.11 U$

$0.53 \mathrm{U}$

11.63

0.92

57.89

6.53

4.08

65.79

292.11

26.32

8.37

0.71

47.37

(a) Daily calibration response factors out of limits.

(b) $U$ Analyte was not present above the level of the associated value.

\subsection{SUSPENDED-PARTICULATE-PHASE (SPP) CHEMISTRY RESULTS}

Suspended-Particulate-Phase samples from the five test sediments and one reference sediment were analyzed for ammonia, cyanide, PAHs, chlorinated pesticides, PCBs, phenol and substituted phenols, phthalate esters, and metals. A procedural blank was processed in the same manner as the SPP samples to ensure that the SPP process was not contributing to the concentration of analytes. As stated in the 1991 Implementation Manuals, "the dredged-material impact in the water column must be within the applicable marine WQC for all contaminants of concern outside the boundary of the site at all times and within the site following the 4-h initialmixing period. When there are no WQC for all contaminants of concern, or when synergistic effects are suspected between the contaminants, water-column impact must also be investigated by toxicity testing..." This section of the report addresses data quality, SPP chemistry results, and relationships between sediment treatments and the analytes. The complete SPP chemistry results and quality control data are presented in Appendix $C$.

\section{PANAMA CITY HARBOB $\quad 3.16$}




\subsubsection{Polynuclear Aromatic Hydrocamons (PAHs)}

Eighteen PAHs were analyzed in the SPP samples. The results are summarized in Table 3.9, with PAHs reported as LPAH and HPAH. The data for PAH analysis (Appendix C, Tables C.3 through C.7) indicate contamination of naphthalene, 2-methylnaphthalene, and phenanthrene In the procedural blank. Data assoclated with this blank were flagged with a "B". No HPAHs were found in the procedural blank at levels above the detection limit. Of the 16 PAH, 5 MS recoveries were slightly outside the $40 \%$ to $120 \%$ range set in the QAVC plan. Analytical precision was within QA limits. Recovery of the SIS compounds, naphthalene- $d_{B}$ and acenaphthene- $d_{10}$, was acceptable in all SPP samples. Recovery of the SIS compound benzo(a)pyrene- $d_{12}$ was poor in all but one of the samples; however, the blank splke sample processed with the SPP samples showed acceptable recoveries of all SIS compounds. There is reason to belleve that matrix interference in the SPP samples resulted in poor recovery of benzo(a)pyrene-d $d_{12}$. No SRMs were analyzed for PAHs, phenol, substituted phenols, phthalate esters, chlorinated pesticides, or PCBs in the SPP samples.

Table 3.9 summarizes the PAHs, phenol and substituted phenols, and phthalate ester concentrations in SPP samples. This table shows that the lowest total PAH concentrations occurred in treatment PC-1 (71.74 ng/L) and the highest total PAH concentrations occurred in treatment PC-1A (141.17 ng/L). Concentrations of PAHs in the reference sediment were within the same range found in the test treatments.

\subsubsection{Phenol. Substliuted Phenols, and Phthalate Esters}

Eleven phenols and substituted phenols and six phthalate esters were analyzed in the SPP samples. The results are summarized in Table 3.9, and data for phenol and substituted phenol analysis and phthalate ester analysis are presented in Appendix C, Tables C.8 through C.12. No phenol or substituted phenols were found in the procedural blank at levels above the detection limit. There was contamination of diethyl phthalate and bis(2-ethylhexyl) phthalate in the procedural blank, and data associated with this blank were "B" flagged. Of the 11 phenol and substituted phenols, 6 had MS recoveries outside the $40 \%$ to $120 \%$ range. The MS recoveries for substituted phenols ranged from $1 \%$ to $15 \%$. Phenol had an MS recovery of $184 \%$. All phthalate ester MS recoveries were within the QA limits. There were no calculable RSDs because of the lack of detected values. Replicate precision between triplicates for the phthalate esters analysis showed two of the six RSDs to be out of range. The surrogate recovery of 2-fluorophenol was outside the quality control range of $40 \%$ to $120 \%$. The poor recovery of 2-fluorophenol was believed to be due to matrix interferences in the SPP samples.

Table 3.9 shows that all the phenol and substituted phenols analyzed were either undetected or detected below the method detection limit. The phthalate esters that were 
IABLE 3.9. Summary of PAHs, Phenol, Substituted Phenols, and Phthalate Ester Concentrations in Panama City Harbor SPP Samples

Commund

PAH

Naphthalene

2-mothylnephthalene

1-mothylnaphthalene

Acenaphthylene

Acenaphthene

Fluorene

Phenanthrono

Anthracene

Fluoranthene

Pyreno

Benzo(a)anthracene

Chrysene

Benzo(b)fluoranthene

Benzo(k)fluoranthene

Benzo(a)pyreno

Indeno(1,2,3-cd)pyrene

Dibenzo(a,h)anthracene

Benzo $(g, h, i)$ perylene

Total LPAH(O)

Total HPAH(a)

Total PAH(O)

\section{Phanol}

Phenol

2-chlorophenol

2-nitrophenol

2,4-dimethylphenol

2.4-dichlorophenol

Para-chloro-meta-cresol

2,4,6-trichlorophenol

2,4-dinitrophenol

4-nitrophenol

4,6-dinitro-0-cresol

Pentachlorophenol

Phthalate Esters

Dimethyl phthalate

Diethyl phthalate

Di-n-butyl phthalate

Butyl benzyl phthalate

Bis(2-ethylhexyl)phthalate

Di-n-octyl phthalate

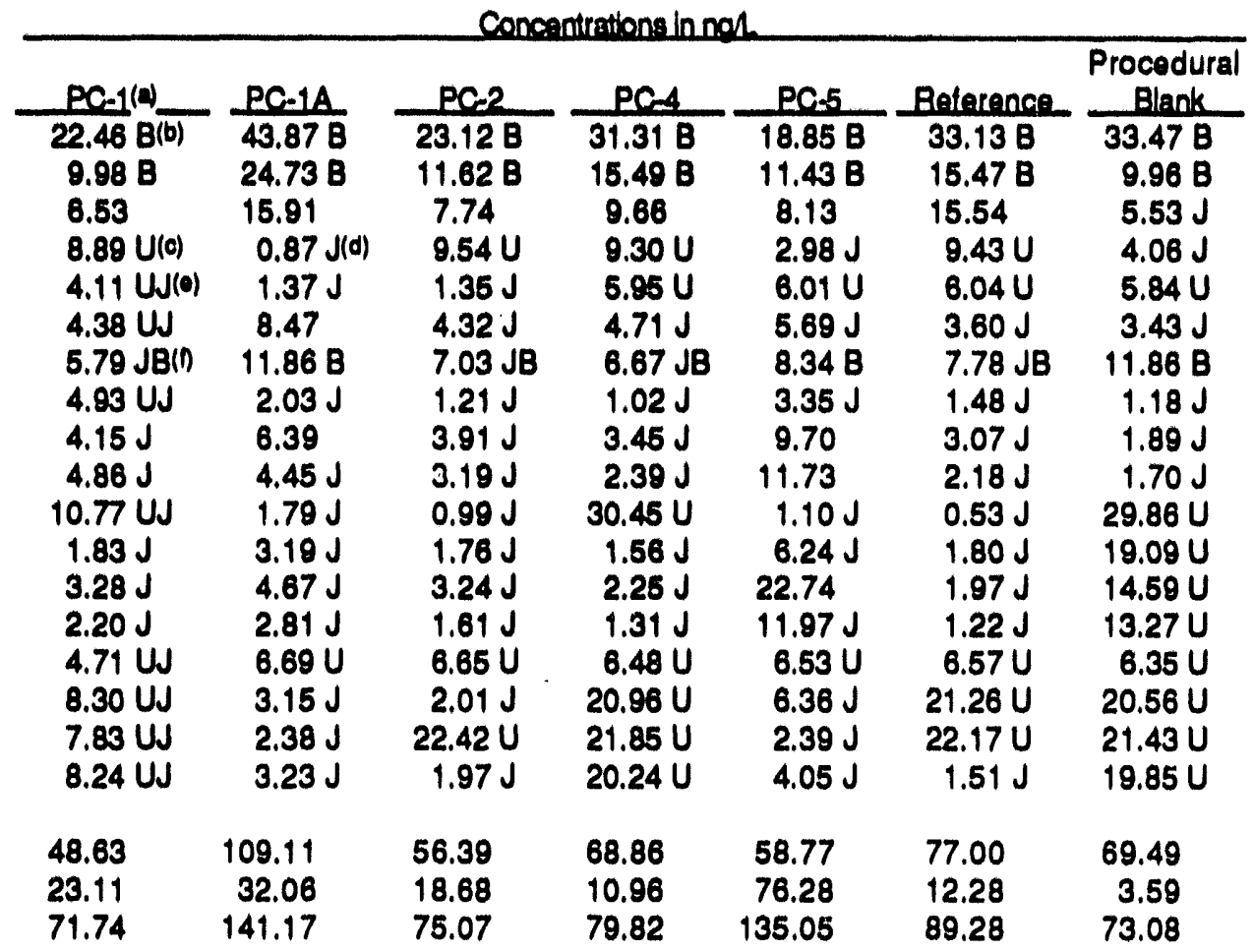

\begin{tabular}{|c|c|c|c|c|c|c|}
\hline $\begin{array}{c}1347.05 U \\
1347.05 U \\
442.55 U J \\
443.06 U J \\
1347.05 U \\
1347.05 U \\
1347.05 U \\
1347.05 U \\
1347.05 U \\
1347.05 U \\
442.48 U J\end{array}$ & $\begin{array}{r}1453.49 \mathrm{U} \\
1453.49 \mathrm{U} \\
9.53 \mathrm{~J} \\
23.64 \mathrm{~J} \\
1453.49 \mathrm{U} \\
1453.49 \mathrm{U} \\
1453.49 \mathrm{U} \\
1453.49 \mathrm{U} \\
1453.49 \mathrm{U} \\
1453.49 \mathrm{U} \\
6.16 \mathrm{~J}\end{array}$ & $\begin{array}{r}1445.09 \mathrm{U} \\
1445.09 \mathrm{U} \\
1445.09 \mathrm{U} \\
11.51 \mathrm{~J} \\
1445.09 \mathrm{U} \\
1445.09 \mathrm{U} \\
1445.09 \mathrm{U} \\
1445.09 \mathrm{U} \\
1445.09 \mathrm{U} \\
1445.09 \mathrm{U} \\
5.02 \mathrm{~J}\end{array}$ & $\begin{array}{r}1408.45 U \\
1408.45 U \\
8.34 \mathrm{~J} \\
14.83 \mathrm{~J} \\
1408.45 U \\
1408.45 U \\
1408.45 U \\
1408.45 U \\
1408.45 U \\
1408.45 U \\
1408.45 U\end{array}$ & $\begin{array}{r}1420.45 U \\
1420.45 \mathrm{U} \\
7.74 \mathrm{~J} \\
16.34 \mathrm{~J} \\
1420.45 \mathrm{U} \\
1420.45 \mathrm{U} \\
1420.45 \mathrm{U} \\
1420.45 \mathrm{U} \\
1420.45 \mathrm{U} \\
1420.45 \mathrm{U} \\
26.79 \mathrm{~J}\end{array}$ & $\begin{array}{l}1428.57 U \\
1428.57 U \\
1428.57 U \\
1428.57 U \\
1428.57 U \\
1428.57 U \\
1428.57 U \\
1428.57 U \\
1428.57 U \\
1428.57 U \\
1428.57 U\end{array}$ & $\begin{array}{r}388.5 \mathrm{~J} \\
1381.2 \mathrm{U} \\
1381.2 \mathrm{U} \\
4.9 \mathrm{~J} \\
3.9 \mathrm{~J} \\
10.2 \mathrm{~J} \\
1381.2 \mathrm{U} \\
1381.2 \mathrm{U} \\
21.8 \mathrm{~J} \\
1381.2 \mathrm{U} \\
25.5 \mathrm{~J}\end{array}$ \\
\hline
\end{tabular}

$\begin{array}{cccrrrr}118.79 \mathrm{~J} & 87.75 \mathrm{~J} & 95.22 \mathrm{~J} & 90.60 \mathrm{~J} & 102.11 \mathrm{~J} & 104.70 \mathrm{~J} & 137.96 \mathrm{~J} \\ 135.00 \mathrm{JB} & 146.71 \mathrm{JB} & 185.42 \mathrm{JB} & 155.80 \mathrm{JB} & 181.01 \mathrm{JB} & 174.98 \mathrm{JB} & 291.88 \mathrm{~B} \\ 93.75 \mathrm{~J} & 135.47 \mathrm{~J} & 124.65 \mathrm{~J} & 120.32 \mathrm{~J} & 93.47 \mathrm{~J} & 71.21 \mathrm{~J} & 253.21 \mathrm{~J} \\ 45.66 \mathrm{~J} & 65.09 \mathrm{~J} & 74.66 \mathrm{~J} & 57.13 \mathrm{~J} & 81.32 \mathrm{~J} & 27.25 \mathrm{~J} & 172.65 \mathrm{~J} \\ 218.43 \mathrm{JB} & 288.72 \mathrm{JB} & 222.60 \mathrm{JB} & 336.23 \mathrm{~B} & 377.17 \mathrm{~B} & 166.66 \mathrm{JB} & 2448.25 \mathrm{~B} \\ 12.38 \mathrm{~J} & 16.68 \mathrm{~J} & 23.79 \mathrm{~J} & 14.52 \mathrm{~J} & 39.66 \mathrm{~J} & 22.86 \mathrm{~J} & 37.85 \mathrm{~J}\end{array}$

(a) Mean of replicate measurements.

(b) B Analyte was found in the method blank; results presented are not corrected for the amount in the blank.

(c) U Analyte was not present above the level of the associated value.

(d) J Analyte was detected below the method detection limit (MDL) but above the instrument detection limit (IDL).

(e) UJ Analyte was either undetected or detected below the method detection limit in all replicates; value is mean of detected values and dry weight detection limits.

(f) JB Analyte was detected below the method detection limit (MDL) but above the instrument detection limit (IDL) and was found in the method blank; results presented are not corrected for the amount in the blank.

(g) Values are the sum of detected values. 
analyzed were all detected below the detection IImit of $290.70 \mathrm{ng} / \mathrm{L}$, except for bis(2-ethylhexyl)phthalate detected above the method detection limit in one replicate of test treatments PC.4 and PC-5.

\subsubsection{Chlorinated Pestlcides and Polvahlorinated Blohenyls}

Nineteen chlorinated pesticides and seven PCBs were analyzed in the SPP samples. The data for pesticides and PCB analysis (Appendix C, Tables C.13 through C.19) indicate no contamination of the procedural blank sample. All but 3 of the 17 pesticide MS recoveries were within the $40 \%$ to $120 \%$ range set in the QAVC plan. These three MS recoveries ranged from $121 \%$ to $148 \%$. The PCB Aroclor 1254 had an MS recovery of $108 \%$, within QA limits. One of the RSD8 (39\%), for pesticides and PCB analysis, was outside the QAQC goal of $\leq 30 \%$. The SIS compounds were all within the QA limits of $40 \%$ to $120 \%$. Pesticide and PCB concentrations were elther undetected or detected below the method detection IImit for all samples, except 4,4'-DDD detected at $5.981 \mathrm{ng} / \mathrm{L}$ in the reference treatment.

\subsubsection{Cyanide}

Cyanide was analyzed in the SPP samples. The results are summarized in Table 3.10, and data for cyanide analysis are presented in Appendix C, Tables C.1 and C.2. The quality control data indicate no blank contamination, the MS recovery was within the QAQC range, and replicate precision was excellent. The cyanide analysis showed that no SPP samples had detectable concentrations of cyanide.

\subsubsection{Ammonia}

Ammonla $\left(\mathrm{NH}_{3}-\mathrm{N}\right)$ was analyzed in the SPP samples. The results are summarized in Table 3.10, and data for ammonia analysis are presented in Appendix C, Tables C.1 and C.2. The quality control data for ammonia analysis indicate the blank was not contaminated and analytical precision was excellent.

IABLE 3.10. Summary of Cyanide and Ammonia in Panama City Harbor SPP Samples

\begin{tabular}{|c|c|c|c|}
\hline $\begin{array}{l}\text { Water } \\
\text { Ireatment }\end{array}$ & $\begin{array}{c}\text { Cyanide } \\
(40 / L)\end{array}$ & $\begin{array}{l}\text { Ammonium }\left(\mathrm{NH}_{4}\right) \\
(\mathrm{mo} / \mathrm{L})\end{array}$ & $\begin{array}{c}\text { Ammonia }\left(\mathrm{NH}_{3}-\mathrm{N}\right) \\
(\mathrm{mo} / \mathrm{L})\end{array}$ \\
\hline $\begin{array}{l}\text { PC-1 } \\
\text { PC-1A } \\
\text { PC-2 } \\
\text { PC-4 } \\
\text { PC-5 } \\
\text { Reference }\end{array}$ & $\begin{array}{l}4.0 U(a) \\
4.0 U(b) \\
4.0 U \\
4.0 U \\
4.0 U \\
4.0 U\end{array}$ & $\begin{array}{l}0.23 \\
0.20 \\
0.63 \\
0.24(\text { b) } \\
0.43 \\
0.82\end{array}$ & $\begin{array}{l}0.18 \\
0.16 \\
0.49 \\
0.18(b) \\
0.33 \\
0.64\end{array}$ \\
\hline
\end{tabular}

(a) $U$ Analyte was not present above the level of the associated value.

(b) Mean of replicate measurements. 
Ammonia concentrations in the SPP samples ranged from $0.16 \mathrm{mg} / \mathrm{L}$ In PC-1A to $0.64 \mathrm{mg} / \mathrm{L}$ in the reference treatment. Ammonia concentrations in the SPP samples were approximately 10 times less than concentrations in the sediment pore water samples. The concentrations of ammonium $\left(\mathrm{NH}_{4}\right)$ were calculated and are presented in Table 3.10.

\subsubsection{Matals}

Metals were analyzed in the SPP samples. The results are summarized in Table 3.11, and data for metals analysis are presented in Appendlx C, Tables C.20 and C.21. Some metals were detected slightly above the detection limit in the procedural and method blanks. The data associated with these blanks are corrected for the amount found in the method blank. Matrix splke recoveries were all within the QA limits of $75 \%$ to $125 \%$. The precision between analytical repllcates was excellent and within the $520 \%$ QAQC goal. Analytical accuracy was assessed through the analysis of an SRM and was within QAQC IImits.

Table 3.11 presents concentrations of metals in the SPP samples. SPP sample PC-1A had the lowest metals concentrations in five of the ten metals analyzed relative to the other test and reference treatments. PC-1 and PC-4 hiad the highest concentrations of $\mathrm{Zn}$ and $\mathrm{Hg}$, respectively, relative to the other test and reference treatments. PC-2 was highest in two metals concentrations ( $A s$ and $\mathrm{CP}$ ); the reference was highest in two metals concentrations ( $\mathrm{Ag}$ and $\mathrm{Ni}$ ); PC-5 was highest in three metals ( $\mathrm{Cd}, \mathrm{Cu}$, and $\mathrm{Pb})$ concentrations.

\subsection{IOXICOLOGICAL TESTING RESULTS}

Eight toxicological tests were conducted to assess the blological toxicity and bloaccumulation of contaminants from Panama Clty Harbor sediments. The complete results of water quality monitoring, test results, and the reference toxicant tests are contained in Appendixes $D$ through $K$.

Solid-phase toxicity tests were conducted to evaluate the six Panama City Harbor sediment treatments. The appropriate "natlve" control sediment for each species was also tested for toxicity. To assess acute toxicity of the sediment, three species of sensitive marine organisms were exposed for 10 days to the solid-phase treatments: the amphipod $R$. abronius, the amphipod A. abdita, and the polychaete $N$. virens. A 28-day exposure of $M$. nasuta and $N$. virens to the six sediment treatments was conducted to assess bloaccumulation of contaminants in test organism tissues. The results of each solid-phase test were examined to ensure test validation by $90 \%$ survival in the native control sediment. Data from the 10 -day solid-phase acute toxicity tests were then evalusted by ANOVA and Dunnett's test to determine any significant differences between test and reference treatments. 
IABLE3.11. Summary of Metals Concentrations in Panama Clty Harbor SPP Samples Concentrations in uod

\begin{tabular}{|c|c|c|c|c|c|c|c|}
\hline Compound & PC.1 & PC.1A & $P C=2(a)$ & PC.4 & PC.5 & Beference & $\begin{array}{l}\text { Procedural } \\
\text { Blank }\end{array}$ \\
\hline 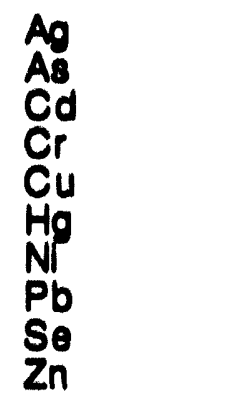 & $\begin{array}{l}0.001 U(b) \\
8.24 \\
0.015 U \\
0.719 \\
0.24 \\
0.00076 \\
0.93 \\
0.323 \\
2.6 U \\
2.14\end{array}$ & $\begin{array}{l}0.006 \\
7.98 \\
0.015 \mathrm{U} \\
0.745 \\
0.30 \\
0.00238 \\
1.07 \\
0.593 \\
2.6 \mathrm{U} \\
1.69\end{array}$ & $\begin{array}{l}0.003 \\
17.8 \\
0.031 \mathrm{U} \\
0.874 \\
0.36 \\
0.00190 \\
1.31 \\
0.826 \\
2.6 \mathrm{U} \\
1.77\end{array}$ & $\begin{array}{l}0.005 \\
7.23 \\
0.015 \mathrm{U} \\
0.694 \\
0.33 \\
0.00304 \\
1.1 \\
0.69 \\
2.6 \mathrm{U} \\
1.58\end{array}$ & $\begin{array}{l}0.004 \\
7.04 \\
0.018 \\
0.848 \\
0.39 \\
0.00158 \\
1.21 \\
1.09 \\
2.6 \mathrm{U} \\
2.03\end{array}$ & $\begin{array}{l}0.009 \\
1.49 \\
0.015 \mathrm{U} \\
0.848 \\
0.38 \\
0.0026 \\
2.11 \\
0.604 \\
2.6 \mathrm{U} \\
0.39 \mathrm{U}\end{array}$ & $\begin{array}{l}0.007 \\
1.14 \\
0.022 \\
0.257 \\
0.57 \\
0.00311 \\
0.86 \\
0.108 \\
2.6 U \\
3.61\end{array}$ \\
\hline
\end{tabular}

(a) Mean of replicate measurements.

(b) U Analyte was not present above the level of the assoclated value.

Suspended. particulate-phase toxicity tests were conducted on five test sediment treatments and one reference treatment. Three concentrations of $\operatorname{SPP}(10 \%, 50 \%$, and $100 \%)$, were prepared and tested along with a control (0\% SPP, reference slte water). Three specles of organisms were exposed to the six SPP treatments: the mysid shrimp M. bahla, the silverside minnow M. beryllina, and planktonic larvae of the blvalve M. odulls. Control survival and water quality data were evaluated to determine test vallilty. The data for the $0 \%$ (control) and $100 \%$ SPP treatments were statistically compared using a two-sample i-test. If the result was significant $(\alpha=0.05)$, and there was at least $50 \%$ reduction in survival relative to control, an LC 50 or $\mathrm{EC}_{80}$ estimate was made using the trimmed Spearman-Karber method.

\subsubsection{0-Dav Solld-Phase Flow-Through Test with A, abdita}

Results of the 10-day solid-phase flow-through test with $A$. abdita are presented in Tables 3.12 and 3.13, and water quality data and test results are presented in Appendix D. Water quality data for the 10-day test were all within range. The 96-h statlc reference toxicant test had some pH values sllghtly out of range on one of the four days, although this did not appear to affect the outcome due to adequate survival. The reference toxicant exposure resulted in an $L C_{50}$ to cadmium of $1.423 \mathrm{mg} / \mathrm{L}$, which is similar to previous tests conducted at MSL (range from 0.5 to $1.4 \mathrm{mg} / \mathrm{L}$ ). Test organism survival in the control treatment (San Pablo Bay) was $85 \%$. Statistical analyses were performed on the data, and the Dunnett's test and ANOVA test results are summarized in Tables 3.12 and 3.13. Survival of $A$. abdita ranged from $84 \%$ to $90 \%$, and there were no significant differences between test organism survival in test treatments relative to the reference treatment. 
IABLE.3.12. Results of the 10-Day Solld-Phase Flow-Through Test with A. abdita

Sediment Treatment

PC.1

PC. $1 \mathrm{~A}$

PC-2

PC. 4

PC.5

Relerence

A. abollta Control
Percent Survival

84.0

84.0

90.0

88.0

87.0

88.0

86.0
Statistlcal Sloniflicance

NS(a)

NS

NS

NS

NS

$N A(b)$

NA

(a) NS No significant difference from the reference at $\alpha=0.05$.

(b) NA Not applicable.

\subsubsection{0-Day Solld-Phase Static. Test with R, abronius}

Results of the 10.day solld-phase statlc test with $R$. abronlus are presented in Tables 3.14 and 3.15, and water quality data and test results are presented in Appendix E. Water quality data for the 10-day test were all within range, except for salinity in treatment PC-5, which exceeded the maximum range on one of the 10 days. However, this did not appear to affect validity of the test due to adequate survival. Water quality data for the 96 -h static reference toxicant test were all within range. The reference toxicant exposure resulted in an $L C_{B O}$ to cadmlum of $1.630 \mathrm{mg} / \mathrm{L}$, which is higher than the value clted in the recent ASTM (ASTM 1990) although similar to previous MSL studies (mean $L C_{B 0}$ of $1.46 \mathrm{mg} / \mathrm{L}, s d=0.50 \mathrm{mg} / \mathrm{L}$ ). The R. abronius test was valid, as indicated by $100 \%$ survival in the control treatment. Statistical analysis was performed on the data to compare test treatments to the reterence treatment (Table 3.14). Organisms exposed to sediment treatment PC-2 had a mean survival of $61 \%$, which was statistically significantly different from, and $>20 \%$ lower than, the reference treatment $(92 \%)$.

\subsubsection{0-Day Solld-Phase Flow-Through Test with $N$ w virens}

The 10-day solld-phase flow-through test with $N$. virens results are presented in Tables 3.16 and 3.17, and water quallty data and test results are presented in Appendix $F$. The water quality data indicate that all parameters were within range. The test is valld, as indicated by $96 \%$ survival in the control treatment. Survival in the test treatments ranged from $96 \%$ to $99 \%$. Statistical analyses were performed on the data, and the results are summarized in Table 3.16.

IABLE 3.13. ANOVA Results for the 10-Day Solid-Phase Flow-Through Test with A. abdita

\begin{tabular}{|c|c|c|c|c|c|}
\hline $\begin{array}{l}\text { Source of } \\
\text { Vardation }\end{array}$ & $\begin{array}{l}\text { Sum of } \\
\text { Squares }\end{array}$ & d.f. & $\begin{array}{c}\text { Mean } \\
\text { Square }\end{array}$ & E-Batlo & $\begin{array}{c}\text { Significance } \\
\text { Level }\end{array}$ \\
\hline $\begin{array}{l}\text { Treatment } \\
\text { Residual }\end{array}$ & $\begin{array}{l}0.030 \\
0.633\end{array}$ & $\begin{array}{r}5 \\
24\end{array}$ & $\begin{array}{l}0.006 \\
0.026\end{array}$ & 0.224 & 5 \\
\hline
\end{tabular}


IABLE 3.14. Results of the 10-Day Solld-Phase Statlc Test with R. abronlus

Sediment Treatment

PC-1

PC.1A

PC-2

PC.4

PC.5

Reference

R. abronius Control
Percent Survival

93.0

95.0

61.0

98.0

91.0

92.0
Statistical Slanificance

NS(a)
NS
S(b)
NS
NA
NA
NA

(a) NS No significant difference from the reference at $\alpha=0.05$.

b) $\mathrm{S}$ Significant difference from the reference.

c) NA Not applicable.

This table shows no significant differences between test organism survival in test treatments relative to the reference treatment. No reference toxicant test $\left(L C_{60}\right)$ was performed.

\subsubsection{8-Dav Solld-Phase Flow-Throuah Test with N. virens}

Results of the 28-day solid-phase flow-through test with $N$. virens are presented in Table 3.18, and water quality data and test results are presented in Appendix $G$. The water quality data Indicate that all parameters were within range. The test is valid, as indicated by $92 \%$ survival in the control treatment. Survival in the test treatments ranged from $88 \%$ to $98 \%$.

Statistical analysis was not conducted on this data, because the purpose of the 28-day solidphase test was to provide results regarding bioaccumulation potential of specific test treatments.

\subsubsection{8-Dav Solld-Phase Flow-Through Test with M. nasuta}

Results of the 28-day solid-phase flow-through test with $M$. nasuta are presented in Table 3.18, and water quality data and test results are presented in Appendix $H$. The water quality data indicate that all parameters were within range. The lest is valid, as indicated by $96 \%$ survival in the control treatment. Survival in the test treatments ranged from $95.2 \%$ to $100 \%$. Statistical analysis was not conducted on this data, because the purpose of the 28-day solidphase test was to provide results as to the bloaccumulation potentlal of specific test treatments.

\subsubsection{6-h Suspended-Particulate-Phase Static Test with $M$, bahia}

Results of the 96-h SPP static test with M. bahla are presented in Table 3.19, and water quality data and test results are presented in Appendix I. The water quality data indicate that a

IABLE 3.15. ANOVA Results for the 10-Day Solid-Phase Static Test with $R$. abronius

\begin{tabular}{|c|c|c|c|c|c|}
\hline $\begin{array}{l}\text { Source of } \\
\text { Veriation }\end{array}$ & $\begin{array}{l}\text { Sum of } \\
\text { Squares }\end{array}$ & d.f. & $\begin{array}{c}\text { Mean } \\
\text { Square }\end{array}$ & E. Ratio & $\begin{array}{c}\text { Significance } \\
\text { Level }\end{array}$ \\
\hline $\begin{array}{l}\text { Treatment } \\
\text { Residual }\end{array}$ & $\begin{array}{l}1.052 \\
0.807\end{array}$ & $\begin{array}{r}5 \\
24\end{array}$ & $\begin{array}{l}0.210 \\
0.034\end{array}$ & 6.257 & 0.0008 \\
\hline
\end{tabular}


IABLE 3.16. Results of the 10-Day Solld-Phase Flow-Through Test with N. virens

Sediment Treatment

PC-1

PC-1A

PC-2

$\mathrm{PC}-4$

PC-5

Reference

N. virens Control
Percent Sunvival

96.0

99.0

97.0

98.0

99.0

96.0

96.0
Statistlcal Slanificance

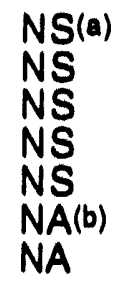

(a) NS No significant difference from the reference at $\alpha=0.05$.

(b) NA Not appllcable.

few pH and sailinity values exceeded the targeted range, although not affecting the valldity of the test. The reference toxicant water quality was within range, except for salinity measurements that exceeded the maximum range. However, these did not appear to affect validity of the test due to adequate survival. The reference toxicant exposure resulted in an $L C_{50}$ to copper of $340.0 \mu \mathrm{g} / \mathrm{L}$. This response is within control ranges for this species and indicates appropriate test organism sensitlvity. The test is validated by $>90 \%$ survival observed in the control ( $0 \%$ SPP) treatment. Table 3.19 indlcates that survival was $>90 \%$ in all test treatments. Since a $50 \%$ decrease in survival in the SPP treatments relative to the seawater control was not found, an LC 50 was not calculable. Therefore, there is no evidence of acute toxicity of the SPP prepared from these test treatments to this test species.

\subsubsection{6-h Suspended-Particulate-Phase Static Test with M. hexullina}

Results of the 96-h SPP test with M. beryllina are presented in Table 3.20, and water quality data and test results are presented in Appendix $\mathrm{J}$. The water quality data indicate that all parameters were within range, except for a slightly elevated sallinity (33.0\%) in one test jar on one of the four days. However, this did not seem to affect vallitity of the test. Water quality data for the reference toxicant test were within range, except for two salinity measurements (32.5\%) that slightly exceeded the maximum range. However, this did not appear to affect validity of the test due to adequate survival. The reference toxicant exposure resulted in an $L C_{50}$ to copper of $108.6 \mu \mathrm{g} / \mathrm{L}$. This response is within control ranges for this species and indicates appropriate test organism sensitivity. The test is validated by $>90 \%$ survival observed in the control ( $0 \%$ SPP)

IABLE 3.17. ANOVA Results for the 10-Day Solid-Phase Flow-Through Test with N. virens

\begin{tabular}{|c|c|c|c|c|c|}
\hline $\begin{array}{l}\text { Source of } \\
\text { Variation }\end{array}$ & $\begin{array}{l}\text { Sum of } \\
\text { Squares }\end{array}$ & dif & $\begin{array}{c}\text { Mean } \\
\text { Sauare }\end{array}$ & E-Ratio & $\begin{array}{c}\text { Significance } \\
\text { Level }\end{array}$ \\
\hline $\begin{array}{l}\text { Treatment } \\
\text { Residual }\end{array}$ & $\begin{array}{l}0.048 \\
0.454\end{array}$ & $\begin{array}{r}5 \\
24\end{array}$ & $\begin{array}{l}0.010 \\
0.019\end{array}$ & 0.509 & 3 \\
\hline
\end{tabular}


IABLE 3,18. Results of the 28-Day Solid-Phase Flow-Through Test with N. virens and M. nasuta

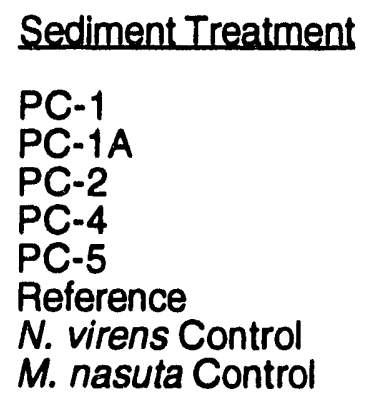

\begin{tabular}{cc}
\multicolumn{2}{c}{ Percent Survival } \\
\hline N. virens & $M$ nasuta \\
96.0 & 100.0 \\
96.0 & 100.0 \\
88.0 & 100.0 \\
98.0 & 99.2 \\
97.0 & 96.8 \\
98.0 & 95.2 \\
92.0 & NA(a) \\
NA & 96.0
\end{tabular}

(a) NA Not applicable.

treatment. Table 3.20 indicates that survival was $>90 \%$ in all test treatments. Since a $50 \%$ decrease in survival in the SPP treatments relative to the seawater control was not found, an $\mathrm{LC}_{50}$ is not calculable. Therefore, there is no evidence of acute toxicity of the SPP prepared from these test treatments to this test species.

\subsection{8 $72-h$ Suspended-Particulate-Phase Static Test with $M$. edulis}

Results of the 72-h SPP static test with $M$. edulis are summarized in Table 3.21, and water quality data and test results are presented in Appendix $K$. The water quality data indicate that all parameters were within range for the $72 \cdot h$ test and the reference toxicant test. The reference toxicant exposure resulted in an $L_{50}$ to copper of $17.00 \mu \mathrm{g} / \mathrm{L}$ and an $E_{50}$ of $16.34 \mu \mathrm{g} / \mathrm{L}$. This response is within control ranges for this species and indicates appropriate test organism sensitivity. Table 3.21 indicates that test organism survival and percent of normal larvae were $>74 \%$ and $69 \%$, respectively, for all the test treatments. The test was validated by the $>78 \%$ survival in the control (0\% SPP) treatments. Mean percent survival was calculated by adding the numbers of normal D-shaped larvae, the abnormal larvae, and the other larvae, and dividing the sum by the average stocking-density larval count ( 249 for the SPP test, and 245 for the reference toxicant test). The mean percent survival for the test treatments ranged from $75 \%$ in the $50 \%$ SPP from PC-2, to $91 \%$ in the $100 \%$ SPP from PC- 1 . The mean percent normal was calculated by dividing the normal $D$-shaped larvae by the average stocking-density larval count. All SPP sediment treatments had $>69 \%$ normality. The $L C_{50}$ or $E C_{50}$ values for SPP were not calculable. Therefore, there is no evidence of acute toxicity of the SPP prepared from these test treatments to this test species. 
IABLE 3.19. Results of the 96-h Suspended-Particulate-Phase Static Test with M. bahia

\section{Sediment Treatment}

PC-1

$\mathrm{PC}-1$

$\mathrm{PC}-1$

PC-1

$P C-1 A$

PC-1A

PC-1A

PC-1A

PC-2

PC-2

PC-2

PC-2

PC-4

PC-4

PC-4

PC-4

PC-5

PC-5

PC-5

PC-5

Reference

Reference

Reference

Reference

\section{Percent SPP}

0

10

50
100

0

10

50

100

0

10

100

0

10

50

100

0

10

50

100

0
10

50

100
Percent Survival

100.0

96.0

100.0

94.0

98.0

98.0

98.0

96.0

98.0

96.0

98.0

100.0

98.0

100.0

100.0

100.0

100.0

98.0

100.0

100.0

100.0

98.0

100.0

98.0

\subsection{IISSUE CHEMISTRY}

$M$. nasuta and $N$. virens were tested in a 28 -day solid-phase test by exposing these organisms to the test, reference, and control sediment treatments to evaluate bioaccumulation potential of these sediment treatments. The tissues of $M$. nasuta and $N$. virens were analyzed for PAHs, phenol and substituted phenols, phthalate esters, chlorinated pesticides, PCBs, metals, and organotins. The tissues of $M$. nasuta were also exposed to sediment treatments PC-1 and PC-2 and to the reference sediment for dioxin analysis. Complete tissue chemistry results in wet and dry weight, quality control data, and quality control summaries for these analyses are presented in Appendixes $L$ and $M$. Tissue chemistry results from these analyses, summarized in the following section, were statistically analyzed using Dunnett's test $(\alpha=0.05)$ for comparison of all test treatment means relative to the reference treatment. ii a contaminant was detected (no $U$ or $J$ qualifier) in tissues exposed to any replicate test treatment, and if the mean tissue concentration of the test replicates was greater than the mean tissue value of the reference treatment, a statistical comparison was made between test treatment and reference treatment 
IABLE 3.20. Results of the 96-h Suspended-Particulate-Phase Static Test with M. beryllina

$\begin{array}{lrr}\text { SedimentTreatment } & \text { Percent SPP } & \text { Percent Su } \\ \text { PC-1 } & 0 & 98.0 \\ \text { PC-1 } & 10 & 100.0 \\ \text { PC-1 } & 50 & 98.0 \\ \text { PC-1 } & 100 & 100.0 \\ \text { PC-1A } & 0 & 98.0 \\ \text { PC-1A } & 10 & 98.0 \\ \text { PC-1A } & 50 & 100.0 \\ \text { PC-1A } & 100 & 100.0 \\ \text { PC-2 } & 0 & 100.0 \\ \text { PC-2 } & 10 & 98.0 \\ \text { PC-2 } & 50 & 98.0 \\ \text { PC-2 } & 100 & 100.0 \\ \text { PC-4 } & 0 & 100.0 \\ \text { PC-4 } & 10 & 98.0 \\ \text { PC-4 } & 50 & 98.0 \\ \text { PC-4 } & 100 & 98.0 \\ \text { PC-5 } & 0 & 98.0 \\ \text { PC-5 } & 10 & 100.0 \\ \text { PC-5 } & 10 & 98.0 \\ \text { PC-5 } & 50 & 96.0 \\ \text { Reference } & 100 & 98.0 \\ \text { Reference } & & 98.0 \\ \text { Reference } & 0 & 96.0 \\ \text { Reference } & 10 & 98.0\end{array}$

concentrations. Reference treatments were used whether or not the values were detected or undetected. If a value was undetected ( $U$ flag), the detection limit value was used in the statistical analysis. If a compound was detected below the method detection limit ( $\mathrm{J}$ flag), then the associated value was used for statistical analysis. Background (pre-exposure) and control tissue concentrations were not included in the statistical analysis. The background tissues were taken from $M$. nasuta specimens that had been contained in clean sediment and then allowed to depurate prior to subsampling for chemical analysis. These tissues were then chemically analyzed to determine if $M$. nasuta were exposed to contaminants prior to biological testing. Mean contaminant concentrations and the results of statistical comparisons are presented in the following sections.

The individual replicate tissue samples analyzed for PAHs, PCBs, and chlorinated pesticides in M. nasuta tissues, and for PAHs in N. virens tissues, were contaminated in the analytical chemistry laboratory during analysis. As a result, archived and uncontaminated tissue samples from individual replicates were combined into a single composite for each sediment 
IABLE 3.21. Results of the 72-h Suspended-Particulate-Phase Static Test with M. edulis

\begin{tabular}{lrcc} 
SedimentTreatment & PercentsPP & $\begin{array}{c}\text { Mean } \\
\text { Percent Survival }\end{array}$ & $\begin{array}{c}\text { Mean } \\
\text { Percent Nomal }\end{array}$ \\
\cline { 2 - 2 } & 0 & 91.00 & 81.93 \\
PC-1 & 10 & 83.53 & 78.80 \\
PC-1 & 50 & 75.02 & 89.00 \\
PC-1 & 100 & 91.41 & 86.10 \\
PC-1A & 0 & 89.80 & 81.69 \\
PC-1A & 10 & 87.23 & 78.63 \\
PC-1A & 50 & 87.07 & 82.09 \\
PC-1A & 100 & 86.75 & 78.63 \\
PC-2 & 0 & 88.27 & 79.92 \\
PC-2 & 10 & 88.92 & 83.13 \\
PC-2 & 50 & 74.70 & 70.52 \\
PC-2 & 100 & 88.19 & 83.29 \\
PC-4 & 0 & 79.12 & 73.41 \\
PC-4 & 10 & 79.68 & 71.57 \\
PC-4 & 50 & 77.99 & 70.52 \\
PC-4 & 100 & 82.73 & 78.71 \\
PC-5 & 0 & 78.15 & 70.44 \\
PC-5 & 10 & 82.83 & 75.91 \\
PC-5 & 50 & 89.48 & 81.45 \\
PC-5 & 100 & 81.93 & 75.50 \\
Reference & 0 & 89.32 & 84.02 \\
Reference & 10 & 91.16 & 86.83 \\
Reference & 50 & 81.23 & 73.90 \\
Reference & 100 & 88.84 & 84.82 \\
Brine Control & NA(a) & 79.84 & 72.93 \\
& & &
\end{tabular}

(a) NA Not applicable.

treatment, and reanalyzed for the parameters listed above. After receipt of the composite data, the original and composite data sets were evaluated based on the following criteria. If the mean of the individual replicate concentrations was $\geq 2$ times the composite concentration, and if the individual replicate concentrations were detected (no $\cup$ qualifiers) and also $\geq 3$ times the composite concentration, then the data were footnoted in the Appendixes and the reanalyzed composite concentration was substituted for the anomalous value(s) prior to statistical analysis. The individual replicate concentrations and the composite concentrations are both reported in Appendixes $L$ and $M$. 


\subsubsection{Bioaccumulation of Polynuclear Aromatic Hydrocarbons in M. nasuta}

Tables 3.22 and 3.23 present the mean concentrations of LPAH and HPAH compounds in $M$. nasuta for test and reference treatments as well as background and control tissue concentrations. The results of Dunnett's test for the LPAH compounds indicate that $M$. nasuta tissues exposed to test treatment PC-5 were statistically significantly different from the tissues exposed to the reference, and at a level $>2$ times but $\leq 5$ times the reference for anthracene. Dunnett's test for the HPAH compounds indicates that nine of the ten HPAH compounds analyzed had statistically significant elevations in $M$. nasuta tissues in at least one of the test treatments. Fluoranthene, chrysene, indeno(1,2,3-c,d)pyrene, and benzo(g,h,i)perylene were statistically significantly elevated in $M$. nasuta tissues exposed to test treatment PC-5 at a magnitude of $>2$ times but $\leq 10$ times the reference. Pyrene was statistically significantly elevated in $M$. nasuta tissues exposed to test treatments PC-1 and PC-5, with concentrations in PC-5 >5 times but $\leq 10$ times the reference. Benzo(a)anthracene and benzo(b)fluoranthene were elevated in $M$. nasuta tissues exposed to all five test treatments. Benzo(k)fluoranthene and benzo(a)pyrene were statistically significantly elevated in $M$. nasuta tissues exposed to four test treatments and three test treatments, respectively. The four above mentioned compounds were measured in $M$. nasuta tissues exposed to PC-5 at concentrations $>10$ times the reference site. ANOVA data for those comparisons are presented in Table 3.24.

IABLE 3.22. Mean Low PAH Concentrations in the Tissues of M. nasuta Exposed to Panama City Harbor Sediments (bold type indicates value is significantly greater than the reference site when compared by Dunnett's test; box indicates value is $>2$ times but $\leq 5$ times the reference site)

Sediment

Treatment

Reference

PC-1

PC-1A

$P C-2$

$\mathrm{PC}-4$

PC-5

Naphtha-
lene

45.86

183.92

29.28

29.76

6.47

5.59

Mean Concentration ( $\mathrm{kg} / \mathrm{kg}$ dry weight)

$\begin{array}{llllll}\text { M. nasuta Control(d) } & 26.29 & 4.52 & 3.30 \mathrm{~J} & 13.30 & 2.25 \mathrm{~J}\end{array}$

(a) J Analyte was detected below the method detection limit (MDL) but above the instrument

(b) UJ Analyte was either undetected or detected below the method detection limit in all replicates; value is mean of detected values and dry weight detection limits.

(c) $\cup$ Analyte was not present above the level of the associated value.

(d) Treatment not included in Dunnett's test data set. 


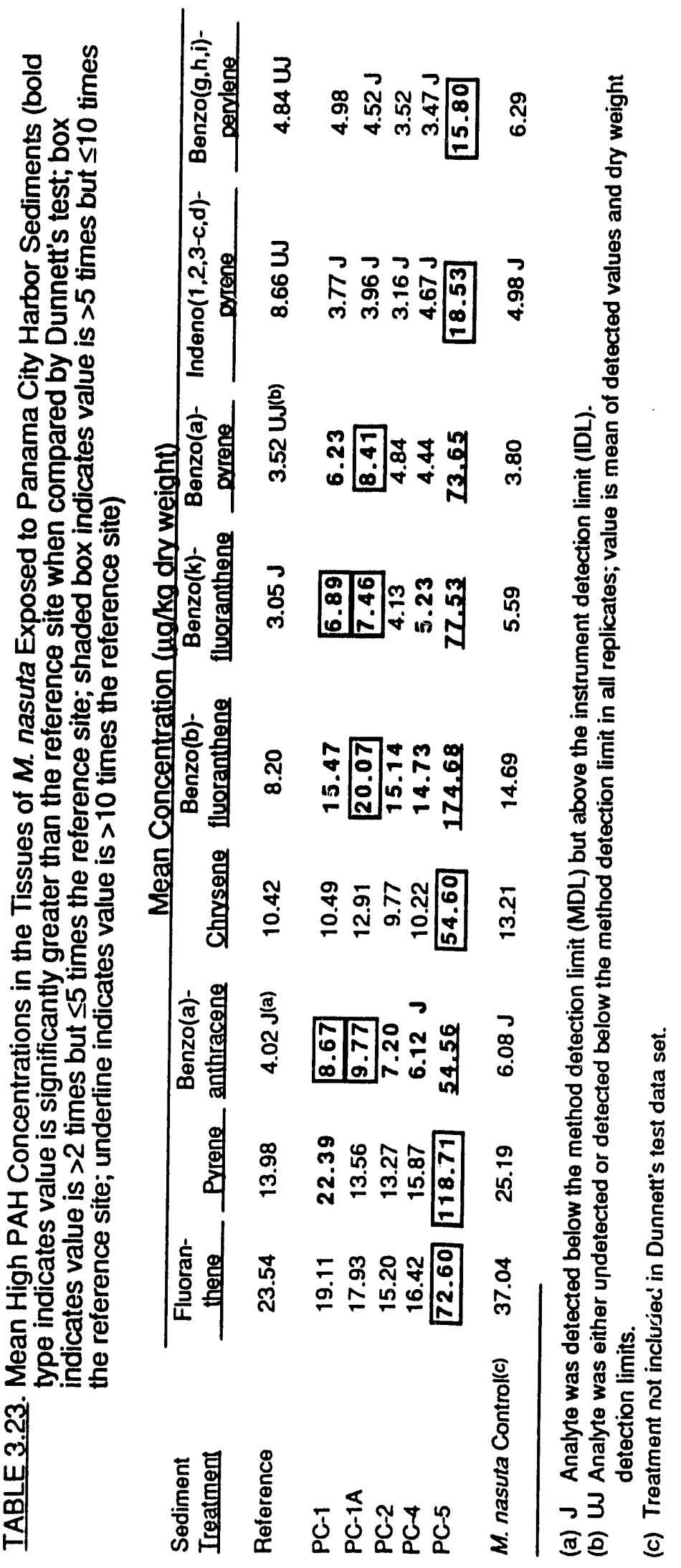

PANAMA CITY HARBOB 
IABLE 3.24. ANOVA Results for Chemical Parameters in Tissues of $M$. nasuta Exposed to Test Treatments Compared to Tissues Exposed to the Reference Sediment

Paramete

Polynuclear Aromatle Hydrocarbons

Naphthalene

2-methylnaphthalene

1-methylnaphthalene

Phenanthrene

Anthracene

Fluoranthene

Pyrene

Benzo(a)anthracene

Chrysene

Benzo(b)fluoranthene

Benzo(k)fluoranthene

Benzo(a)pyrene

Indeno(1,2,3-c,d)pyrene

Benzo(g,h,i)perylene

Phenol and Substituted Phenols

Phenol

11.138

Phthalate Esters

Bis (2-ethylhexyl) phthalate

Chlorinated Pesticides

Alpha-BHC
Lindane
Dieldrin
4,4'-DDD
4,4'-DDE
4,4'-DDT

Polychlorinated Biphenyls

Aroclor-1254

Metals

Silver

Arsenic

Beryllium

Cadmium

Chromium

Copper

Mercury

Nickel

Lead

Antimony

Selenium

Zinc

Butyltins

Tributyltin

5.271

0.551

0.307

0.182

16.888

6.461

0.584

4.890

0.806

0.022

0.348

0.359

0.301

0.100

0.099

0.523

0.506

5.401

0.192

0.310

0.151
Sum ot Squares

Ireatment

Residual

Degrees of Freedom

Treatment Residual

E-ratio

p-value

$\begin{array}{rr}24.858 & 20.833 \\ 0.609 & 3.354 \\ 0.778 & 3.562 \\ 5.717 & 10.589 \\ 16.358 & 4.879 \\ 8.667 & 1.509 \\ 18.621 & 2.178 \\ 20.144 & 0.554 \\ 11.183 & 0.884 \\ 28.412 & 0.601 \\ 31.454 & 2.625 \\ 32.103 & 1.907 \\ 10.086 & 4.577 \\ 7.673 & 5.130\end{array}$

\section{4}

20

5.727

0.0013

3.354

3.562

4.879

1.509

2.178

0.554

0.884

0.601

2.625

4.577

5.130

4
5
5
5
5
5
5
5
5
5
5
5
5

$$
24
$$$$
24
$$

0.908

1.048

2.591

16.094

27.564

41.043

174.678

60.704

227.037

57.519

80.799

10.578

7.179

0.4781

0.4130

0.0520

0.0001

0.0001

0.0001

0.0001

0.0001

0.0001

0.0001

0.0001

0.0001

0.0003

24

43.191

5

24

1.238

0.3225

31.666

5

24

0.799

0.5613

6.461

2.615

3.346

23.850

4.199

1.088

6.827

3.279

0.291

6.090

0.912

0.630

0.540

1.082

0.657

0.580

4.652

0.989

0.260

1.016

4

20

$0.745 \quad 0.5725$
$0.745 \quad 0.5725$

0.7173

0.7270

0.7280

0.0184

0.0003

0.0759

7.385

3.221

3.438

0.0175

1.179

0.3484

$0.366 \quad 0.8670$

$0.457 \quad 0.5179$

$1.892 \quad 0.1332$

2.293

0.0774

$0.888 \quad 0.5045$

$0.439 \quad 0.8170$

$3.819 \quad 0.0110$

$4.183 \quad 0.0071$

$5.573 \quad 0.0015$

$0.934 \quad 0.4767$

$5.731 \quad 0.0013$

PANAMA CITY HARBOB 


\subsubsection{Bloaccumulation of Phenol. Substituted Phenols, and Phthalate Esters in M. nasuta}

Concentrations of phenol, substituted phenols, and phthalate esters in M. nasuta tissues were either undetected or detected below the method detection limit for all compounds except phenol and bis (2-ethylhexyl) phthalate. However, there were no statistically significant differences between test treatments and the reference treatment for these two compounds. Bis (2-ethylhexyl) phthalate is a common laboratory contaminant that can be introduced into the sample or analytical procedure from materials such as plastics. ANOVA data for those comparisons are presented in Table 3.24. Complete $M$. nasuta tissue chemistry data in both wet and dry weight, quality control data, and quality control summaries are contained in Appendix L.

\subsubsection{Bloaccumulation of Chlorinated Pestlcides and Polychlorinated Biphenyls in M. nasuta}

Concentrations of pesticides and PCBs in M. nasuta tissues were either undetected or detected below the method detection limit for all compounds, except alpha-BHC, lindane, dieldrin, 4,4'-DDD, 4,4'-DDE, 4,4'-DDT, and Aroclor-1254. The data for these compounds were analyzed statistically, and the results of Dunnett's test are presented in Table 3.25. Concentrations of three compounds, 4,4'-DDD, 4,4'-DDE, and Aroclor-1254, were statistically significantly different between the test treatments and the reference treatment. $M$. nasuta tissues exposed to sediment treatment PC-1 were statistically significantly different for 4,4'-DDD when compared to tissues exposed to the reference treatment and at a magnitude of $>2$ times but $\leq 5$ times the reference. Tissues exposed to PC-1A and PC-2 were statistically significantly different for Aroclor-1254 when compared to tissues exposed to the reference treatment and at a magnitude of $>2$ times but $\leq 5$ times the reference. Concentrations of 4,4'-DDE in $M$. nasuta tissues were statistically significantly elevated in all the test treatments when compared to the tissues exposed to the reference treatment and at a magnitude of $>2$ times but $\leq 5$ times the reference. ANOVA data for these comparisons are in Table 3.24.

\subsubsection{Bioaccumulation of Metals in M. nasuta}

Results of Dunnett's test and concentrations of metals in the tissues of M. nasuta, expressed in $\mathrm{mg} / \mathrm{kg}$ dry weight, are presented in Table 3.26. The concentrations of TI were undetected in all test, reference, and control treatments. Concentrations of $\mathrm{Cr}$ in $M$. nasuta tissues were statistically significantly different in the test treatments PC-2, PC-4, and PC-5 when compared to the reference treatment. Concentrations of $\mathrm{Pb}$ in $\mathrm{M}$. nasuta tissues were statistically significantly different in the test treatment PC-5 when compared to the reference. Concentrations of $\mathrm{Sb}$ in $M$. nasuta tissues were statistically significantly different in test treatment PC-4 when compared to the reference treatment and at a magnitude of $>2$ times but $\leq 5$ times the reference. ANOVA data for these comparisons are presented in Table 3.24. 


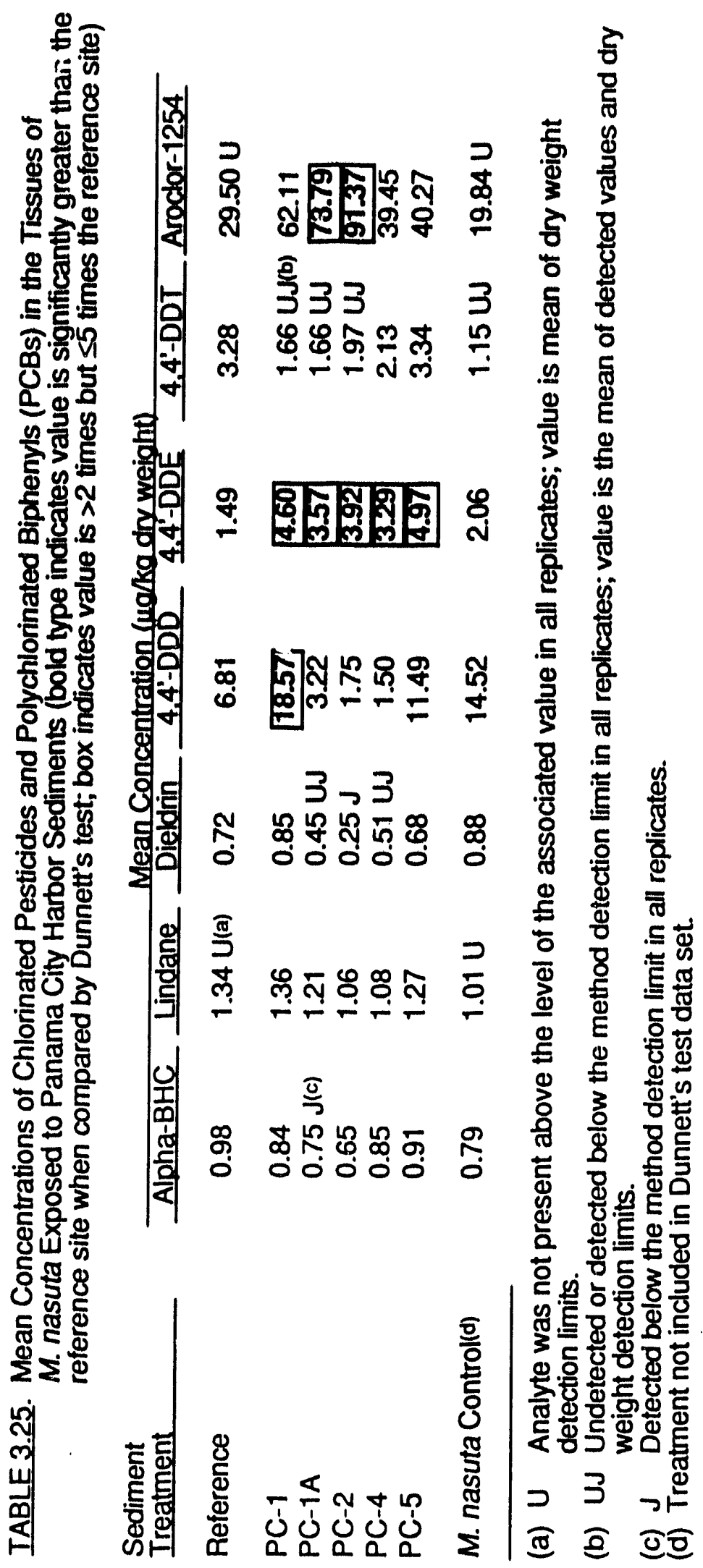

PANAMA CITY HARBOB 


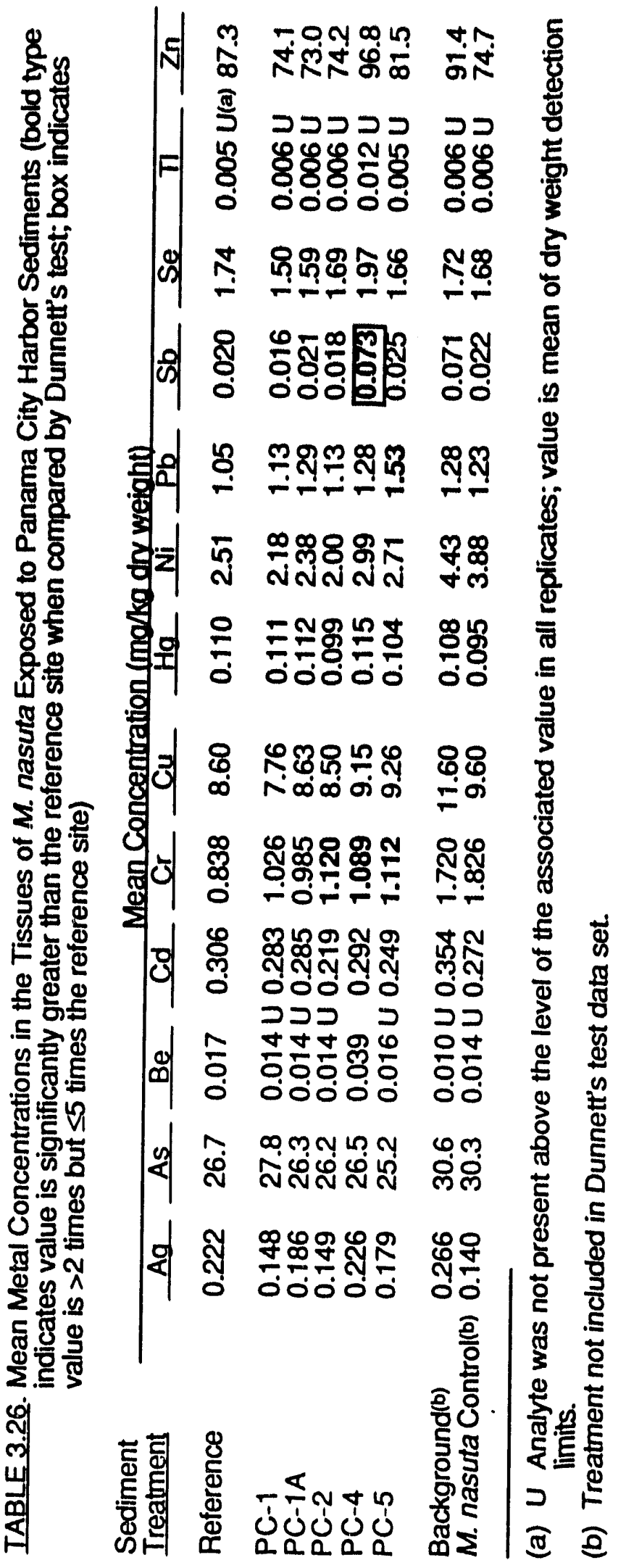

PANAMA CITY HARBOB 


\subsubsection{Bioaccumulation of Butyltins in M. nasuta}

Mean butyltin concentrations ( $\mu \mathrm{g} / \mathrm{kg}$ dry welght) in $M$. nasuta tissues exposed to test, reference, and control treatments are summarized in Table 3.27. Tributyltin was the only butyltin at detectable concentrations in the sediment treatments. No statistically significant difference occurred between test treatments and the reference treatment when data were analyzed using Dunnett's test. The ANOVA data for this statistical comparison are presented in Table 3.24.

\subsubsection{Bloaccumulation of Dloxins in M. nasuta}

Mean dibenzodioxins and dibenzofurans concentrations (ng/kg dry weight) in $M_{\text {. nasuta }}$ tissues exposed to test treatments PC- 1 and PC-2 and the reference treatment are summarized in Table 3.28. M. nasuta tissue samples for dioxin analysis were composite tissue samples from the five replicate aquaria per sediment treatment. The dloxin and furan congeners were undetected above the method detection limit in tissue samples for test treatments PC-1 and PC-2 with the exception of flve compounds (1231378-HpCDD, OCDD, 2378-TCDF, 123789-HxCDF, and OCDF). Concentrations of the compounds 1231378-HpCDD, OCDD, 123789-HXCDF, and OCDF were found in tissues exposed to both the test and reference treatments. These compounds were detected in relatively small concentrations and are belleved to be partlally the result of solvents used during laboratory glassware cleaning. Hepta- and octa- dloxin and furan compounds are determined to be ublqultous in the analytical laboratory (EPA 1990c); therefore, their presence in M. nasuta tissues should not be a concern. The presence of 2378-TCDF in M. nasuta tissues exposed to sediment treatments PC-1 and PC-2 were detected at respective concentrations of $0.39 \mathrm{ng} / \mathrm{kg}$ and $0.55 \mathrm{ng} / \mathrm{kg}$ wet weight, slightly above the method detection limit.

IABLE 3.27. Mean Butyltin Concentrations in the Tissues of $M$. nasuta Exposed to Panama Clty Harbor Sediments (no test treatments were statistically significantly different from the reference when compared by Dunnett's test)

Sediment

Ireatment

Reference

PC-1

PC-1A

$P C-2$

PC-4

PC-5

Background(b) M. nasuta Control(b)

\begin{tabular}{llc}
\multicolumn{3}{c}{ Mean Concentration (ua/ka dry weiaht) } \\
\hline Iributyltin & Dibutyltin & Monobutyltin \\
47.1 & $35.2 \mathrm{U}(\mathrm{a})$ & $56.4 \mathrm{U}$ \\
41.0 & $36.1 \mathrm{U}$ & $57.7 \mathrm{U}$ \\
$35.0 \mathrm{U}$ & $35.0 \mathrm{U}$ & $56.0 \mathrm{U}$ \\
39.7 & $35.6 \mathrm{U}$ & $56.9 \mathrm{U}$ \\
36.1 & $35.1 \mathrm{U}$ & $56.2 \mathrm{U}$ \\
36.4 & $34.4 \mathrm{U}$ & $55.0 \mathrm{U}$ \\
$27.5 \mathrm{U}$ & $27.5 \mathrm{U}$ & $43.9 \mathrm{U}$ \\
38.5 & $34.0 \mathrm{U}$ & $54.4 \mathrm{U}$
\end{tabular}

(a) $U$ Analyte was not present above the level of the associated value in all replicates; value is mean of dry weight detection limits.

(b) Treatment not included in Dunnett's test data set. 
IABLE 3.28. Summary of Dloxin Concentrations in M. nasuta Tissues Exposed to Panama Clty Harbor Sediments

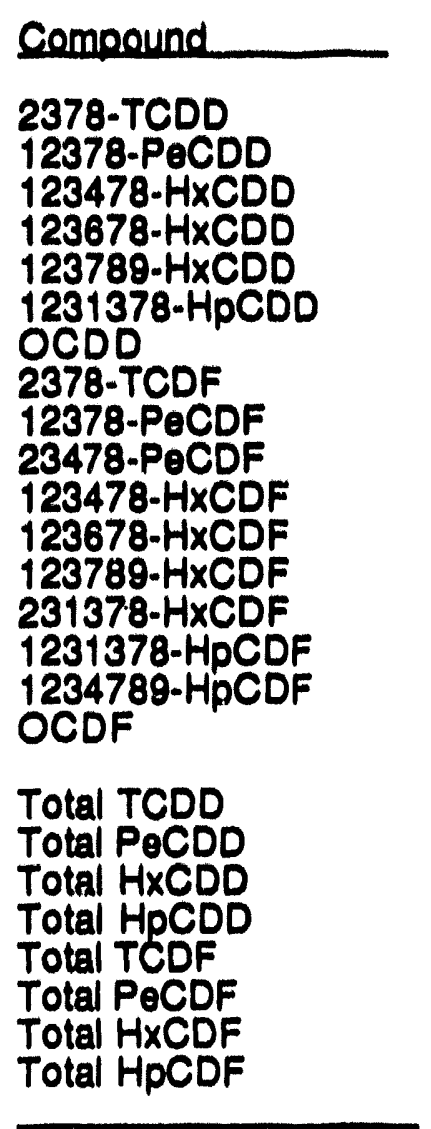

\begin{tabular}{|c|c|c|}
\hline PC.1 & 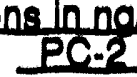 & Beference \\
\hline $\begin{array}{l}2.9 U(a) \\
1.5 U \\
0.7 U \\
2.9 U \\
2.2 U \\
10.68(b)(a) \\
90.42 \\
2.83 \\
1.5 U \\
0.7 U \\
0.7 U \\
0.7 U \\
1.38 \\
0.7 U \\
8.0 U \\
0.7 U \\
3.99\end{array}$ & $\begin{array}{c}2.1 U \\
1.4 U \\
1.4 U \\
2.1 U \\
2.1 U \\
20.6 U \\
67.82 \\
3.91 \\
1.4 U \\
0.7 U \\
0.7 U \\
0.7 U \\
2.8 U \\
0.7 U \\
5.0 U \\
0.7 U \\
1.78\end{array}$ & $\begin{array}{l}1.4 \mathrm{U} \\
1.4 \mathrm{U} \\
0.7 \mathrm{U} \\
0.7 \mathrm{U} \\
1.4 \mathrm{U} \\
3.58 \\
32.33 \\
2.1 \mathrm{U} \\
.0 .7 \mathrm{U} \\
0.7 \mathrm{U} \\
0.7 \mathrm{U} \\
0.7 \mathrm{U} \\
1.07 \\
0.7 \mathrm{U} \\
11.4 \mathrm{U} \\
0.7 \mathrm{U} \\
1.72\end{array}$ \\
\hline $\begin{array}{c}2.18 \\
N D \\
11.55 \\
40.31 \\
8.35 \\
N D \\
4.72 \\
3.12\end{array}$ & $\begin{array}{r}1.49 \\
\text { ND } \\
7.33 \\
25.62 \\
10.46 \\
\text { ND } \\
2.42 \\
1.92\end{array}$ & $\begin{array}{c}N D(d) \\
N D \\
5.15 \\
10.73 \\
N D \\
N D \\
1.65 \\
1.07\end{array}$ \\
\hline
\end{tabular}

(a) U Analyte was not present above the level of the associated value.

b) Calibration response factor at beginning of day out of limits.

c) Mass ratio out of limits.

(d) ND Not detected.

\subsubsection{Bloaccumulation of Polynuclear Aromatic Hydrocarbons in $N$ virens}

Tables 3.29 and 3.30 present the mean concentrations of LPAH and HPAH compounds in N. virens for test and reference treatments, as well as background and control tissue concentrations. The results of Dunnett's test for the LPAH compounds indicate that $N$. virens tissues were statistically significantly elevated in test treatment PC-4 for acenaphthylene and anthracene when compared to the reference, at a magnitude of $>2$ but $\leq 5$ times the reference treatment. Table 3.30 presents the HPAH compounds that were statistically analyzed using Dunnett's test. Pyrene and benzo(k)fluoranthene were statistically significantly elevated in $N$. virens tissues exposed to PC-5 when compared to the reference. Benzo(a)anthracene was statistically significantly elevated in $N$. virens tissues exposed to all five test treatments at magnitudes of $>2$ times but $\leq 10$ times the reference. Chrysene was statistically significantly 
IABLE 3.29. Mean Low PAH Concentrations in the Tissues of N. virens Exposed to Panama City Harbor Sediments (bold type indicates value is significantly greater than the reference site when compared by Dunnett's test; box indicates value is $>2$ times but $\leq 5$ times the reference site)

Sediment

Reference

$P C-1$

PC-1A

PC.2

PC.4

PC-5

N. virens Control(d)

\begin{tabular}{|c|c|c|c|c|}
\hline $\begin{array}{l}\text { Naphtha- } \\
\text { lene }\end{array}$ & $\begin{array}{c}\text { 2-methyl- } \\
\text { naphthalene }\end{array}$ & $\begin{array}{c}\text { 1-methyl- } \\
\text { naphthalene }\end{array}$ & $\begin{array}{l}\text { Acenaph- } \\
\text { thylene }\end{array}$ & $\begin{array}{l}\text { Anthra- } \\
\text { cene }\end{array}$ \\
\hline 48.83 & 4.62 & 3.74 & $3.10 \cup J(a)$ & $1.83 \mathrm{~J}(\mathrm{~b})$ \\
\hline $\begin{array}{r}49.70 \\
37.77 \\
30.34 \\
100.14 \\
42.04\end{array}$ & $\begin{array}{l}3.80 \cup J \\
4.66 \\
4.49 \cup J \\
7.86 \\
5.47\end{array}$ & $\begin{array}{l}4.42 \\
4.81 \\
5.64 \\
6.02 \\
6.11\end{array}$ & $\begin{array}{l}2.05 \mathrm{UJ} \\
0.98 \mathrm{~J} \\
3.11 \mathrm{UJ} \\
\frac{7.65}{0.71 \mathrm{~J}}\end{array}$ & $\begin{array}{l}0.51 \mathrm{~J} \\
0.59 \mathrm{~J} \\
3.10 \\
4.59 \\
3.77\end{array}$ \\
\hline
\end{tabular}

(a) UJ Analyte was elther undetected or detected below the method detection limit in all replicates; value is mean of detected values and dry weight detectlon limits.

(b) J Analyte was elther detected below the method detection limit (MDL) but above the instrument detection limit (IDL).

(c) U Analyte was not present above the level of the associated value in all replicates; value is mean of dry weight detection limits.

(d) Treatment not included in Dunnett's test data set.

elevated at a magnitude of $>2$ times but $\leq 5$ times the reference in $N$. virens tissues exposed to PC-4 and PC-5. ANOVA data for these comparisons are presented in Table 3.31.

\subsubsection{Bloaccumulation of Phenol, Substituted Phenols, and Phthalate Esters in N. virens}

Concentrations of phenol, substituted phenols, and phthalate esters in N. virens tissues were either undetected or detected below the method detection limit for all compounds, except dl-n-butyl phthalate and butyl benzyl phthalate. However, no statistlcally significant differences were found between the test and reference sediment treatments for these two compounds. ANOVA data for those comparisons are presented in Table 3.31. Complete N. virens tissue chemistry data in both wet and dry weight, quality control data, and quality control summaries are contained in Appendix $M$.

\subsubsection{Bloaccumulation of Chlorinated Pesticide and Polychlorinated Biphenyls in N. virens}

Concentrations of pesticides and PCBs in N. virens tissues were either undetected or detected below the method detection limit for all compounds, except alpha-BHC, dieldrin, $4,4^{\prime}-D D D$, and Aroclor-1260. The dry weight data for these compounds were analyzed statistically using Dunnett's test, and there were no statistically significant differences between test treatments and the reference (Table 3.32). ANOVA data for those comparisons are 


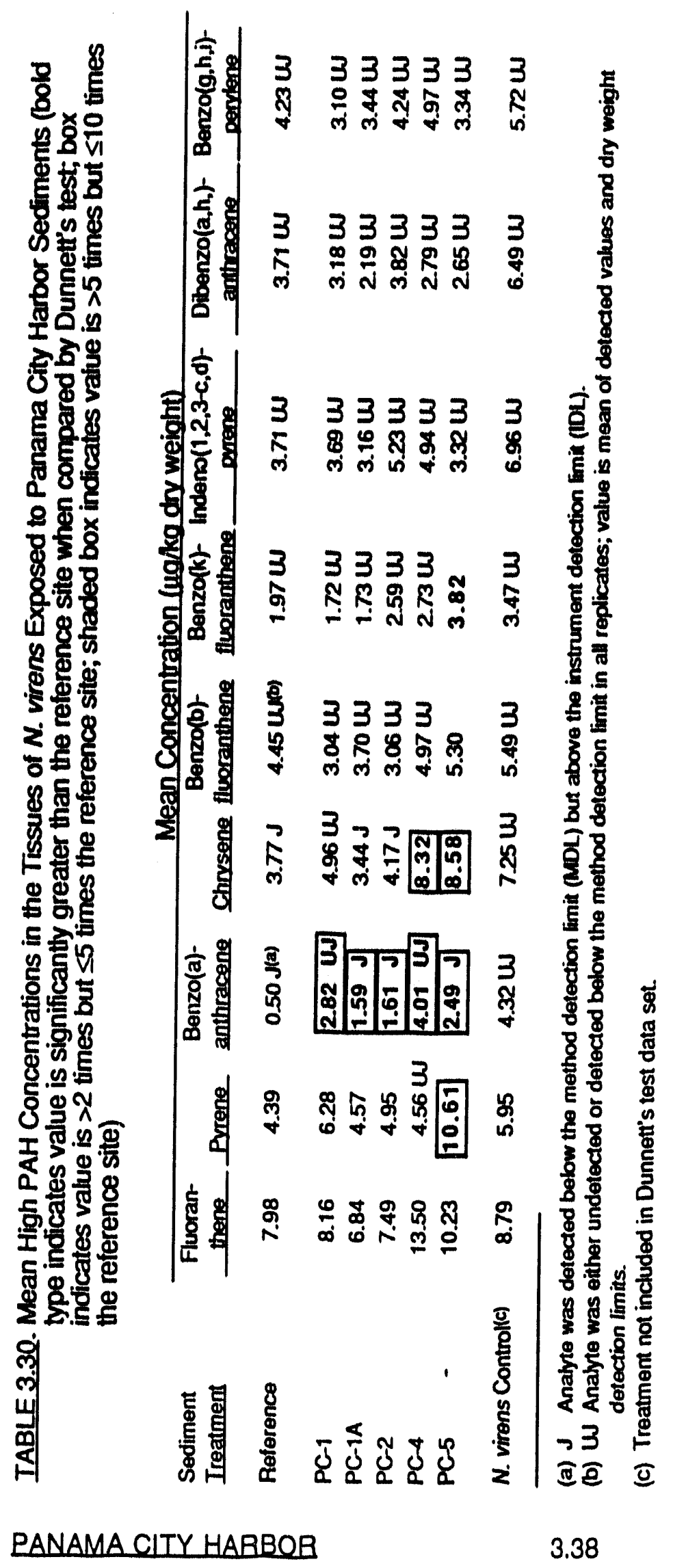


IABLE 3.31. ANOVA Results for Chemical Parameters in Tissues of $N$. virens Exposed to Test Treatments Compared to Tissues Exposed to the Reference Sediment

Parameter

Polynuclear Aromatic Hydrocarions

Naphthalene

2-methylnaphthalene

1-methylnaphthalene

Acenaphthylene

Anthracene

Fluoranthene

Pyrene

Benzo(a)anthracene

Chrysene

Benzo(b)fluoranthene

Benzo(k)fluoranthene

Indeno(1,2,3-c,d)pyrene

Dibenzo(a,h)anthracene

Benzo(g,h,i)perylene

Phthalate Esters

Di-n-butyl phthalate

Butyl benzyl phthalate

\section{Chlorinated Pesticides}

Alpha-BHC

Dieldrin

4, 4'-DDD

Polychlorinated Biphenyls

Aroclor-1260

\section{Metals}

Silver

Arsenic

Beryllium

Cadmium

Chromium

Copper

Mercury

Nickel

Lead

Antimony

Selenium

Thallium

Zinc

Butyltins

Dibutyltin

(a) NA Not applicable.

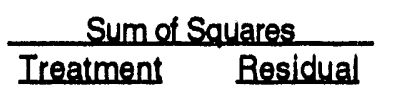

Degrees of Freedom

Ireatment Besidual E-ratio R-value

$\begin{array}{rr}3.697 & 7.905 \\ 1.455 & 3.865 \\ 0.714 & 2.614 \\ 14.854 & 18.067 \\ 18.740 & 5.374 \\ 0.826 & 3.052 \\ 2.841 & 2.484 \\ 11.475 & 4.233 \\ 3.668 & 2.917 \\ 2.453 & 8.828 \\ 3.680 & 7.559 \\ 1.791 & 7.789 \\ 1.707 & 26.615 \\ 0.996 & 4.862\end{array}$

7.672

33.273

0.717

13.291

$0.83 ?$

0.576

1.228

8.621

3.628

10.362

0.385

5.862

0.122

0.318

0.142

0.000

0.223

0.000

0.006

0.021

0.153

1.265

0.023

0.153

0.110

1.659

0.161

0.068

0.656

0.000

1.250

0.250

9.064

0.496

0.309

2.078

$-1.110 \mathrm{E}-16$

5.249

$7.732 E^{-5}$

0.183

2

12
$0.003 \quad 0.9975$

$0.003 \quad 0.9975$

0.0826

0.1497

0.2924

0.0094

0.0001

0.2974

0.0017

0.0001

0.0009

0.2839

0.0730

0.3843

0.9034

$0.984 \quad 0.4480$

$\begin{array}{ll}1.107 & 0.3829\end{array}$

$0.259 \quad 0.9311$

$\begin{array}{ll}0.464 & 0.7991 \\ 0.762 & 0.5858 \\ 0.569 & 0.7229\end{array}$

$0.315 \quad 0.8989$

12.470

0.0001

$3.051 \quad 0.0285$

NA(a) NA

i.278 0.3056

$0.580 \quad 0.7152$

$0.729 \quad 0.6087$

$2.101 \quad 0.1003$

$0.878 \quad 0.5104$

$1.555 \quad 0.2107$

$1.055 \quad 0.4092$

$\begin{array}{ll}1.515 & 0.2224\end{array}$

NA NA

$\begin{array}{ll}1.143 & 0.3654\end{array}$ 


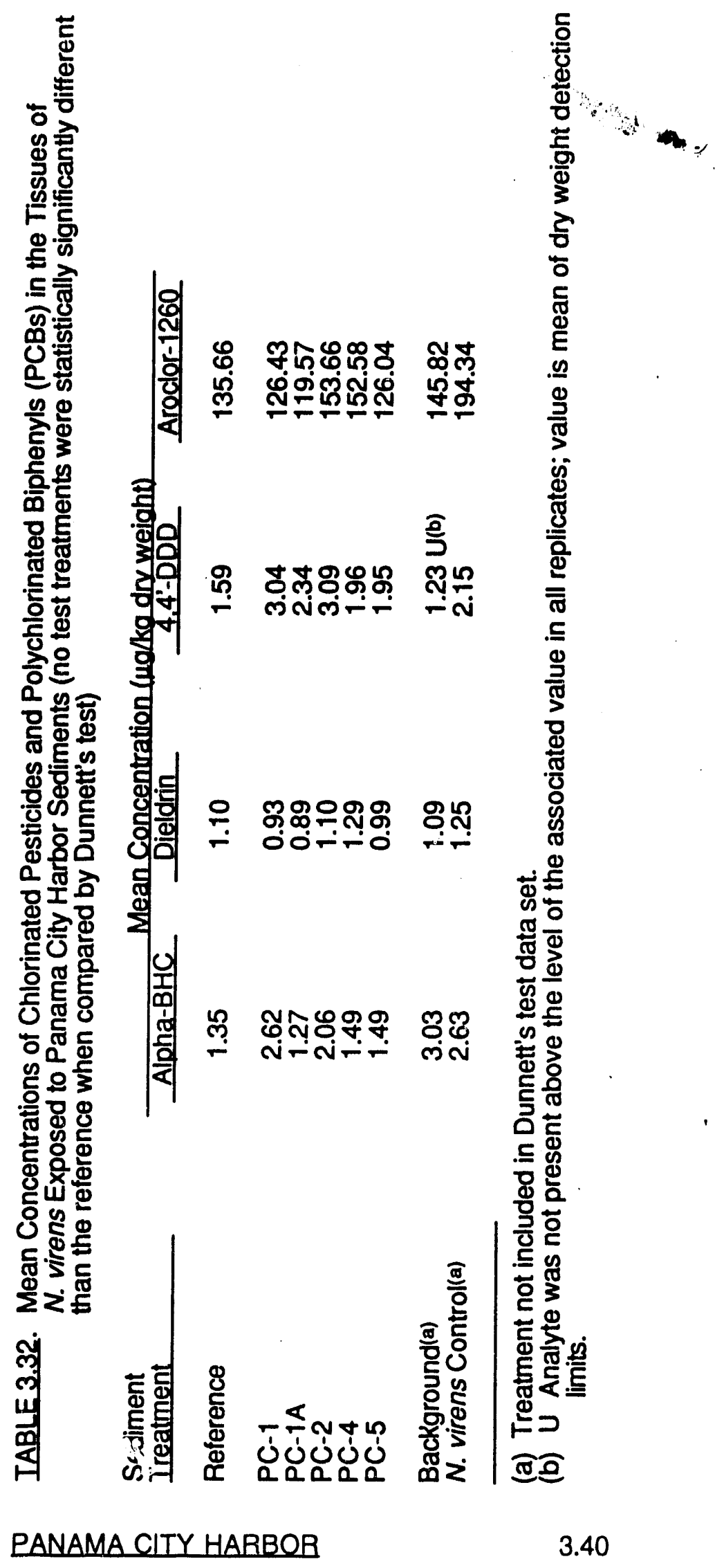


presented in Table 3.31. Complete N. virens tissue chemistry data in both wet and dry weight, quality control data, and quality control summaries are contained in Appendix $M$.

\subsubsection{Bioaccumulation of Metals in N. virens}

Results of Dunnett's test and concentrations of metals in the tissues of $N$. virens, expressed in $\mathrm{mg} / \mathrm{kg}$ dry weight, are presented in Table 3.33. The concentrations of $\mathrm{Be}$ and $\mathrm{TI}$ were undetected in all test, reference, and control treatments. Selenium was the only metal that was statistically significantly elevated, at a magnitude $<2$ times the reference in $N$. virens tissues exposed to sediment treatment PC-4 when compared to tissues exposed to the reference sediment. The ANOVA data for this statistical comparison are presented in Table 3.31.

\subsubsection{Bioaccumulation of Butyltins in N. virens}

Mean butyltin concentrations ( $\mu \mathrm{g} / \mathrm{kg}$ dry weight) in $N$. virens tissues exposed to test, reference, and control treatments are summarized in Table 3.34. Dibutyltin was the only butyltin found at detectable levels in the tissues of $N$. virens following exposure to the sediment treatments. Tissues exposed to sediment treatments PC-1A and PC-5 had detected values that were compared statistically to the reference. No statistically significant differences were found between the test and reference sediment treatments. The ANOVA data for this statistical comparison are presented in Table 3.31. 


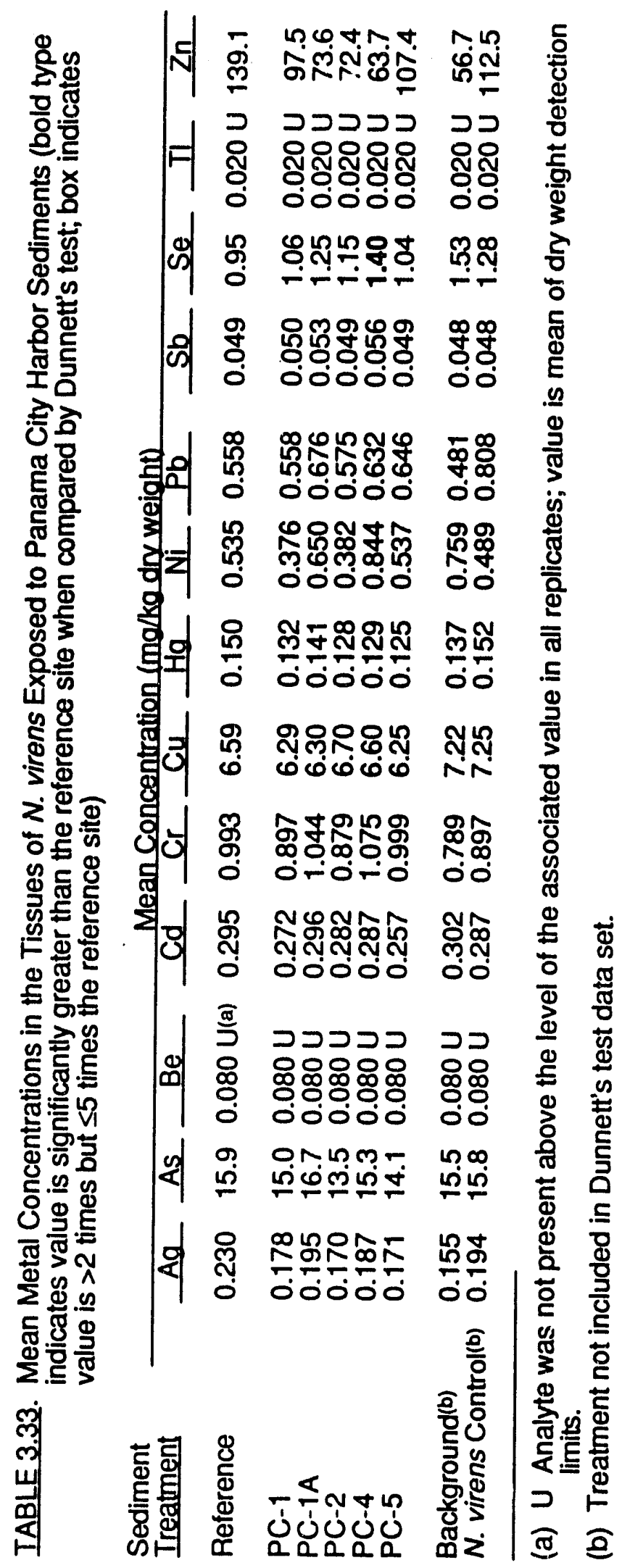


IABLE 3.34. Mean Butyltin Concentrations in the Tissues of N. virens Exposed to Panama City Harbor Sediments (no test treatments were statistically significantly different than the reference when compared by Dunnett's test)

\begin{tabular}{|c|c|c|c|}
\hline \multirow{2}{*}{$\begin{array}{l}\text { Sediment } \\
\text { Ireatment }\end{array}$} & \multicolumn{3}{|c|}{ Mean Concentration ( $u$ o/ka dw weiaht } \\
\hline & Iributyltin & Dibutvltin & Monobutyltin \\
\hline Reference & $34.3 U(a)$ & 37.1 & $54.8 \mathrm{U}$ \\
\hline $\begin{array}{l}\text { PC-1 } \\
\text { PC-1A } \\
\text { PC-2 } \\
\text { PC-4 } \\
\text { PC-5 }\end{array}$ & $\begin{array}{l}34.9 U \\
34.8 U \\
36.9 U \\
35.4 U \\
36.6 U\end{array}$ & $\begin{array}{l}34.9 U \\
37.2 \\
36.9 U \\
35.4 U \\
37.2\end{array}$ & $\begin{array}{l}55.9 U \\
55.7 U \\
59.0 U \\
56.6 U \\
58.5 U\end{array}$ \\
\hline $\begin{array}{l}\text { Background(b) } \\
\text { N. virens Control(b) }\end{array}$ & $\begin{array}{l}36.0 \mathrm{U} \\
36.9 \mathrm{U}\end{array}$ & $\begin{array}{l}43.7 \\
36.9 \mathrm{U}\end{array}$ & $\begin{array}{l}57.6 U \\
59.1 U\end{array}$ \\
\hline
\end{tabular}

(a) U Analyte was not present above the level of the associated value in all replicates; value is mean of dry weight detection limits.

(b) Treatment not included in Dunnett's test data set. 


\subsection{DISCUSSION}

In this section, the analyses and evaluations of Panama City Harbor sediments relative to the reference sediment are discussed in terms of compliance with the Tier II and Tier III guidelines given in Evaluation of Dredged Material for Ocean Disposal - Testing Manual (USACE/EPA 1991). Potential water-column effects of dredged material disposal are evaluated for compliance with the limiting permissible concentration (LPC) as set forth for Tier II (1991 Implementation Manua). According to the 1991 Implementation Manual, "the purpose of Tler II is to provide a reliable, rapid screen for potential impact and thereby eliminate the need for further testing." Tler III guidelines for determination of compliance with criteria for ocean disposal, defined under CFR 40, Section 227.13(c), include assessments of water column toxicity, deposited sediment (solidphase) toxicity, and deposited sediment bloaccumulation. Physical characterization and sediment chemistry analysis of Panama City Harbor sediments are used in support of toxicity tests and bioaccumulation results to evaluate appropriate disposal options.

\subsection{SEDIMENT CHARACTERISTICS}

The sediment chemistry results are intended to provide information about chemical contaminants of concem that could potentially cause toxicity or bioaccumulation. In general, the test treatments contained higher concentrations of most contaminants of concern relative to the reference sediment. Concentrations of TOC, total sulfides, PAHs, phthalate esters, chlorinated pesticides, metals, and butyltins were elevated in the test treatments relative to reference treatment concentrations.

\subsection{TIER}

As stated in the 1991 Implementation Manual, "the dredged-material impact in the water column must be within the applicable marine water quality criteria for all contaminants of concern outside the boundary of the site at all times and within the site following the 4-h initial-mixing period. When there are no WQC for all contaminants of concern, or when synergistic effects are suspected between the contaminants, water-column impact must also be investigated by toxicity testing..." Table 4.1 presents the EPA Marine Acute WQC for the contaminants of concern that were measured in the Panama City Harbor SPP samples (EPA 1986b). The maximum concentrations of contaminants of concern in the SPP samples were several orders of magnitude below the EPA WQC. 
IABLE 4.1. Comparison Between EPA Water Quality Criteria Levels and Panama City Harbor Suspended-Particulate-Phase (SPP) Samples

\begin{tabular}{l} 
Contaminant \\
Acenaphthene \\
Aldrin \\
Arsenic \\
BHC \\
Cadmium \\
Chlordane \\
Chromium (Hexa) \\
Copper \\
Cyanide \\
DbE \\
DDT \\
Dieldin \\
Endosulfan \\
Endrin \\
Fluoranthene \\
Heptachlor \\
Lindane \\
Lead \\
Mercury \\
Naphthalene \\
Nickel \\
Nitrophenols \\
PCB's \\
Pentachlorophenol \\
Phenol \\
Phthalate Esters \\
PAH's \\
Selenium \\
Silver \\
Toxaphene \\
Zinc \\
\hline
\end{tabular}

EPA Water Quality Criteria Marine Acute Criteria (uo/L)

$$
\begin{gathered}
970 \\
1.3 \\
2388 \\
0.34 \\
43 \\
0.09 \\
1,100 \\
2.9 \\
1 \\
14 \\
0.13 \\
0.71 \\
0.034 \\
0.037 \\
40 \\
0.053 \\
0.16 \\
140 \\
2.1 \\
2,350 \\
75 \\
4,850 \\
10 \\
13 \\
5,800 \\
2,944 \\
300 \\
410 \\
2.3 \\
0.21 \\
95
\end{gathered}
$$

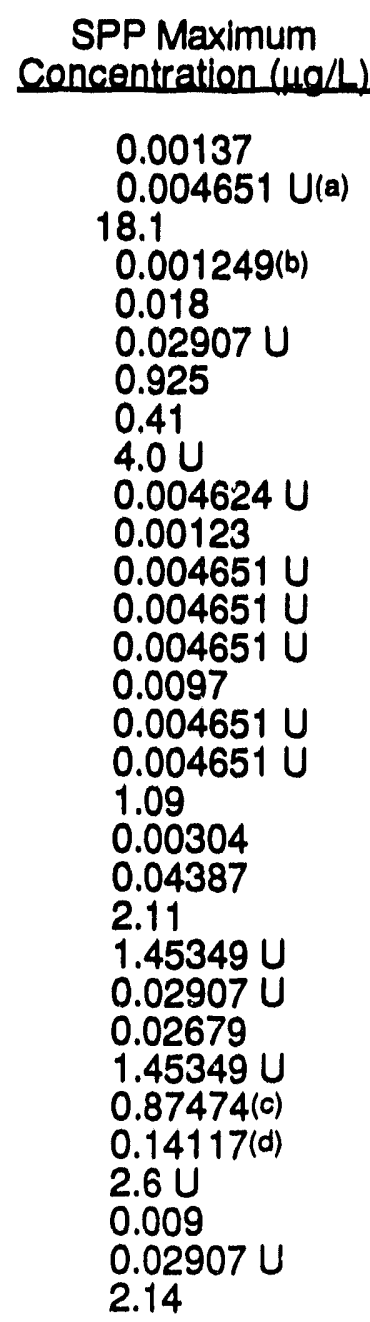

(a) $U$ Analyte was not present above the level of the associated value in all replicates of all test treatments.

(b) Value is for Alpha-BHC; Beta-BHC and Delta-BHC were undetected in the SPP samples.

c) Value is total of all phthalate ester compounds measured in the SPP samples.

(d) Value is total of detected low- and high-molecular-weight PAHs measured in the SPP samples.

\subsection{IIER IIIEVALUATIONS}

\subsubsection{Water Column Effects}

Estimates of toxicity in the water column were also evaluated by exposing three sensitive marine species ( $M$. bahia, $M$. beryllina, and $M$. edulis) to three concentrations of SPP and a dilution water control (reference site water). The results showed no acute toxicity to any of these three species (Table 4.2). No LC 50 could be calculated because mortality did not exceed $50 \%$ of 
IABLE 4.2. Suspended-Particulate-Phase Toxicity Test Results (no statistically significant differences when analyzed by t-test, $\alpha=0.5$ )

\begin{tabular}{|c|c|c|c|c|c|c|c|c|c|}
\hline \multirow[b]{2}{*}{ Ireatmant } & \multicolumn{3}{|c|}{ Musid Mi bahia } & \multicolumn{3}{|c|}{ Sllverside Minnow M. berrlling } & \multicolumn{3}{|c|}{ Musse/Lanae Medulis } \\
\hline & $\frac{\text { Means }}{0 \% \text { SPP }}$ & $\frac{\text { Inival } 1 \% \text { | }}{100 \% \text { SPF }}$ & $\begin{array}{l}\text { LC50 as } \\
\% \text { SPP }\end{array}$ & $\begin{array}{l}\text { MeanS } \\
0 \% \text { SPF }\end{array}$ & $\frac{\text { vival }(\%)}{100 \% \text { SPP }}$ & $\begin{array}{l}\text { LC50 as } \\
\% \text { SPP }\end{array}$ & $\frac{\text { Mean }}{0 \% \text { SPF }}$ & هـ & $\begin{array}{l}\text { LC50 as } \\
\% \text { SPP }\end{array}$ \\
\hline $\begin{array}{l}-1 \\
-1 A \\
-2 \\
-4\end{array}$ & $\begin{array}{r}100.0 \\
98.0 \\
98.0 \\
98.0 \\
100.0 \\
100.0\end{array}$ & $\begin{array}{r}94.0 \\
96.0 \\
100.0 \\
100.0 \\
100.0 \\
98.0\end{array}$ & $\begin{array}{l}>100 \\
>100 \\
>100 \\
>100 \\
>100 \\
>100\end{array}$ & $\begin{array}{r}98.0 \\
98.0 \\
100.0 \\
100.0 \\
98.0 \\
98.0\end{array}$ & $\begin{array}{r}100.0 \\
100.0 \\
100.0 \\
98.0 \\
96.0 \\
98.0\end{array}$ & $\begin{array}{l}>100 \\
>100 \\
>100 \\
>100 \\
>100 \\
>100\end{array}$ & $\begin{array}{l}91.0 \\
89.8 \\
88.3 \\
79.1 \\
78.2 \\
89.3\end{array}$ & $\begin{array}{l}91.4 \\
86.8 \\
88.2 \\
82.7 \\
81.9 \\
88.8\end{array}$ & $\begin{array}{l}>100 \\
>100 \\
>100 \\
>100 \\
>100 \\
>100\end{array}$ \\
\hline
\end{tabular}

the population relative to the control. Under 1991 Implementation Manua/ guidelines, the limiting permissible concentration (LPC) of dissolved plus suspended contaminants cannot exceed 0.01 of the acutely toxic concentration at the boundaries of the disposal site after allowing 4 hours for initial mixing. Based on the results of the SPP toxicity tests, disposal of the Panama City Harbor proposed dredged material would be acceptable according to this criteria.

\subsubsection{Depesited Sediment (Solid-Phase) Acute Toxicity}

Deposited sediment toxicity was determined by exposing three species of marine organisms ( $\boldsymbol{R}$. abronius, $\boldsymbol{A}$. abdita, and $\boldsymbol{N}$. virens) to test sediment treatments in 10-day solidphase tests. If the difference in mortality between proposed dredged material (test treatments) and the reference treatment is statistically significantly different, and if that difference exceeds $10 \%$ ( $20 \%$ for $R$. abronius), then the test material does not comply as stated in Appendix A of the 1991 Implementation Manual. The solid-phase tests of Panama City Harbor sediments (Table 4.3) showed solid-phase acute toxicity to R. abronius exposed to test treatment PC-2 when compared to the reference sediment using Dunnett's test. There were no detected statistically significant differences in acute toxicity to either the A. abdita or $N$. virens solid-phase tests. The Panama City Harbor sediments treatments, except PC-2, comply with the benthic bioassay criteria.

\subsubsection{Deposited Sediment Bloaccumulation}

The potential for bioaccumulation of contaminants was evaluated through 28-day solidphase exposures of $M$. nasuta and $N$. virens to Panama City Harbor sediments followed by chemical analysis of the tissues. The tissue contaminant concentrations were compared to existing Food and Drug Administration (FDA) limits. The tissue concentrations were statistically compared between tissues exposed to proposed dredged material and those exposed to reference sediment. Compliance criteria for bioaccumulation are not as well-defined as for water column or deposited sediment toxicity. If any statistically significant bioaccumulation is detected, other considerations are examined, such as number of compounds elevated, number of species 
IABLE 43. Comparison of Solid-Phase Acute Toxicity to the Reference Sediment (bold type would indicate mean survival statistically significantly lower than the reference based on Dunnett's test; shading would indicate $>26 \%$ difference)

Ireatment

PC-1

PC-1A

PC-2

PC-4

PC-5

Reference

A. abdita Control

R. abronius Control

N. virens Control
Mean Percent Sunvival in 10-day Solld-Phase Test

A. abdita B. abronius $N$ virens

84.0

84.0

90.0

88.0

87.0

93.0

95.0

61.0

98.0

91.0

92.0

$N A(a)$

100.0

NA

96.0

99.0

97.0

98.0

99.0

96.0

85.0

NA
NA

NA

96.0

(a) NA Not applicable.

showing elevated contaminant levels, magnitude of increase in contaminant concentrations, degree or magnitude of the elevations relative to tissues exposed to reference sediment, and related sediment toxicity.

M. nasuta and $N$. virens tissue contaminant concentrations were orders of magnitude below the FDA action limits following exposure to Panama City Harbor sediments (Table 4.4). Although most contaminants were not elevated in $M$. nasuta and $N$. virens tissues, statistically significant elevations of several contaminants were detected when compared to tissues exposed to reference sediment using Dunnett's test (Table 4.5).

One low-molecular-weight PAH (anthracene), several high-molecular-weight PAHs, the pesticides 4,4'-DDD and 4,4'-DDE, Aroclor-1254, and the metals $\mathrm{Cr}, \mathrm{Pb}$, and $\mathrm{Sb}$ were elevated in M. nasuta tissues exposed to some test treatments (Table 4.5). Actual concentrations of some of these compounds (anthracene, 4,4'-DDE, and $\mathrm{Sb}$ ) were low and below the target detection limits, although above the achieved detection limits. Four of the nine high-molecular-weight PAHs were elevated in $M$. nasuta tissues at magnitudes $>10$ times above the concentrations present in tissues exposed to the reference sediment. The PCB Aroclor-1254 was found to be statistically significantly elevated in $M$. nasuta tissues at magnitudes ranging from 2.7 to 3.1 times the concentrations present in tissues exposed to the reference sediment. Phenol and substituted phenols, phthalate esters, and butyltins were not statistically significantly elevated in $M$. nasuta tissues exposed to any of the test treatments relative to the tissues exposed to the reference sediment. 
IABLE 4.4. Comparison Between FDA Action Levels and Contaminant Levels in M. nasuta and N. virens Exposed to Panama Clty Harbor Sediments

\begin{tabular}{|c|c|c|c|}
\hline \multirow[b]{2}{*}{ Contaminant } & \multirow{2}{*}{$\begin{array}{l}\text { EDA Action Level } \\
\text { (ma/ka wet weiaht) }\end{array}$} & \multicolumn{2}{|c|}{ Maximum Concentration (ma/ka wet weiaht) } \\
\hline & & Mnasuta & Nuvirens \\
\hline Methyl Mercury & 1.0 & $0.025(a)$ & $0.026(a)$ \\
\hline $\begin{array}{l}\text { Benzene Hexachloride (BHC) } \\
\text { Chlordane } \\
\text { DDT + DDE } \\
\text { Dieldrin + Aldrin } \\
\text { Endrin } \\
\text { Heptachlor + Heptachlor Epoxide } \\
\text { Toxaphene }\end{array}$ & $\begin{array}{l}0.3 \\
0.3 \\
5.0 \\
0.3 \\
0.3 \\
0.3 \\
5.0\end{array}$ & $\begin{array}{l}0.00107(b) \\
0.00574 U(0) \\
0.00119 U J(d) \\
0.00115 \\
0.00024 U \\
0.00059 U \\
0.00574 U\end{array}$ & $\begin{array}{l}0.00615(b) \\
0.00496 U \\
0.00108 U \\
0.00058 \\
0.00021 U \\
0.00068 \\
0.00496 U\end{array}$ \\
\hline $\begin{array}{l}\text { PCBs } \\
\text { Dioxin }\end{array}$ & $\begin{array}{l}2.0 \\
0.025(\mu \mathrm{g} / \mathrm{kg})\end{array}$ & $\begin{array}{l}0.04669 \\
0.01245\end{array}$ & $\begin{array}{c}0.05593 \\
\text { NM(e) }\end{array}$ \\
\hline
\end{tabular}

(a) Value is for total mercury; methyl mercury is a fraction of the total but was not analyzed separately.

(b) Total BHCs (alpha-, beta-, delta-, and gamma-BHC).

(c) U Analyte was not present above the assoclated value.

(d) UJ Analyte was either undetected or detected below the method detection limit in the summation of 4,4'-DDT and 4,4'-DDE.

(e) NM Not measured.

Two low-molecular-weight PAHs (acenaphthylene and anthracene), four high-molecularweight PAHs (pyrene, benzo(a)anthracene, chrysene, and benzo(k)fluoranthene), and one metal (Se) were elevated in N. virens exposed to some test treatments. A few PAHs that were elevated in $N$. virens tissues could be attributed to the environmentally conservative approach of using values estimated below the achieved detection limit (J flagged). If the actual dry-weight detection limits for each replicate were substituted for J-flagged values, it is likely that fewer significant differences would have been found between test and reference treatments.

Chlorinated pesticides, PCBs, phenol and substituted phenols, phthalate esters, and butyltins were not statistically significantly elevated in $N$. virens tissues exposed to any of the test treatments relative to the tissues exposed to the reference sediment.

\subsection{CONCLUSIONS AND RECOMMENDATIONS}

Based on the Tier III evaluation of the results of this study, ocean disposal of proposed dredged material from the Panama City Harbor should not result in significant adverse watercolumn or deposited-sediment acute toxicity effects, with the exception of test treatment PC-2. Computer modeling should not be required because concentrations of contaminants in the SPP samples did not exceed WQC limits and there was no water column toxicity. Estimates of 


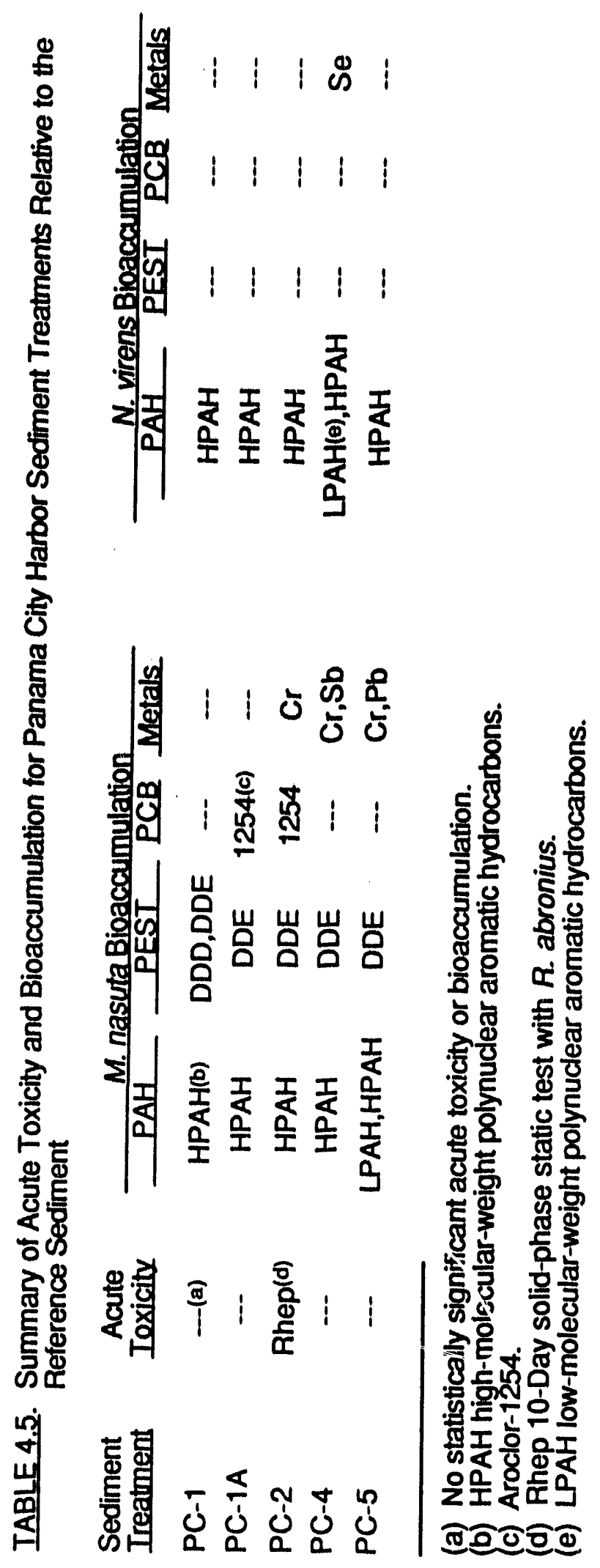

PANAMA CITY HARBOB $\quad 4.6$ 
water column toxicity were evaluated by exposing three marine species ( $M$ bahia, $M$. beryllina,

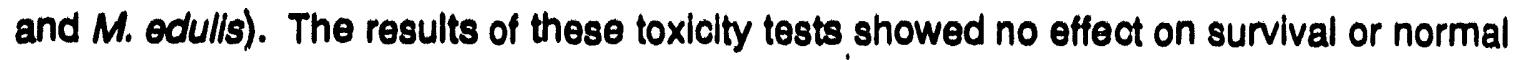
development of bivalve larvae from any of the test treatments or reference treatment. Evaluation of the concentrations of contaminants of concern in the SPP samples shows that concentrations of suspended and dissolved material from the Panama City Harbor test treatments did not exceed the EPA WQC IImits.

Deposited sediment toxicity was determined by exposing three species of marine organisms (A. abdita, R. abronius, and N. virens) to test sediment treatments. The 1991 Implementation Manuals guidelines conceming determination of compliance for deposited sediment toxicity are based on whether the mortality of organisms exposed to test treatments is statistically significantly different from the reference, and whether test organism mortality in test treatments exceeds the reference treatment by $20 \%$ (R. abronius) or $10 \%$ (other species). If mortality in test treatments is statistically significantly different from the reference mortality and exceeds the reference by the above percentages, the test material does not comply with the benthic bioassay criteria of Section 227.13(c) and Appendix A of the 1991 Implementation Manual.

Toxicological tests conducted by the MSL showed that one station, PC-2, was statistically significantly toxic to $R$. abronius compared to the reference sediment using Dunnett's test. The percent survival for this sediment treatment was $61 \%$, which was statistically significant and was $>20 \%$ below the reference sediment percent survival of $92 \%$.

The potential for bloaccumulation of contaminants was evaluated through 28-day solidphase flow-through tests with $M$. nasuta and $N$. virens. The concentrations of contaminants of concern were compared to existing FDA action limits and showed no evidence of bloaccumulation that would exceed FDA limits. The concentrations of contaminants were also compared to the reference sediment using Dunnett's test to determine the presence of statistically significant levels of contaminants relative to the reference sediment. In most cases, PAH, pesticide, and PCB levels in the tissues of organisms exposed to the test treatment were between 2 and 21 times the concentrations observed in tissues exposed to the reference treatment. Elevated metals concentrations in tissues exposed to the test treatments were generally at levels less than twice those found in tissues exposed to the reference treatment, with the exception of $\mathrm{Sb}$.

Concentrations of $\mathrm{Sb}$ in $M$. nasuta tissues exposed to PC-4 were three times greater than M. nasuta tissues exposed to the reference treatment.

The Panama City Harbor test treatments PC-1, PC-1A, and PC-2 are located in the eastern portion of St. Andrew Bay (Figure 4.1). These three test treatments had percentages of fine-grained sediments (silt and clay) ranging from $13 \%$ dry weight in PC-1A to $36 \%$ dry weight in PC-2. These fine-grained sediments were associated with concentrations of TOC that ranged 


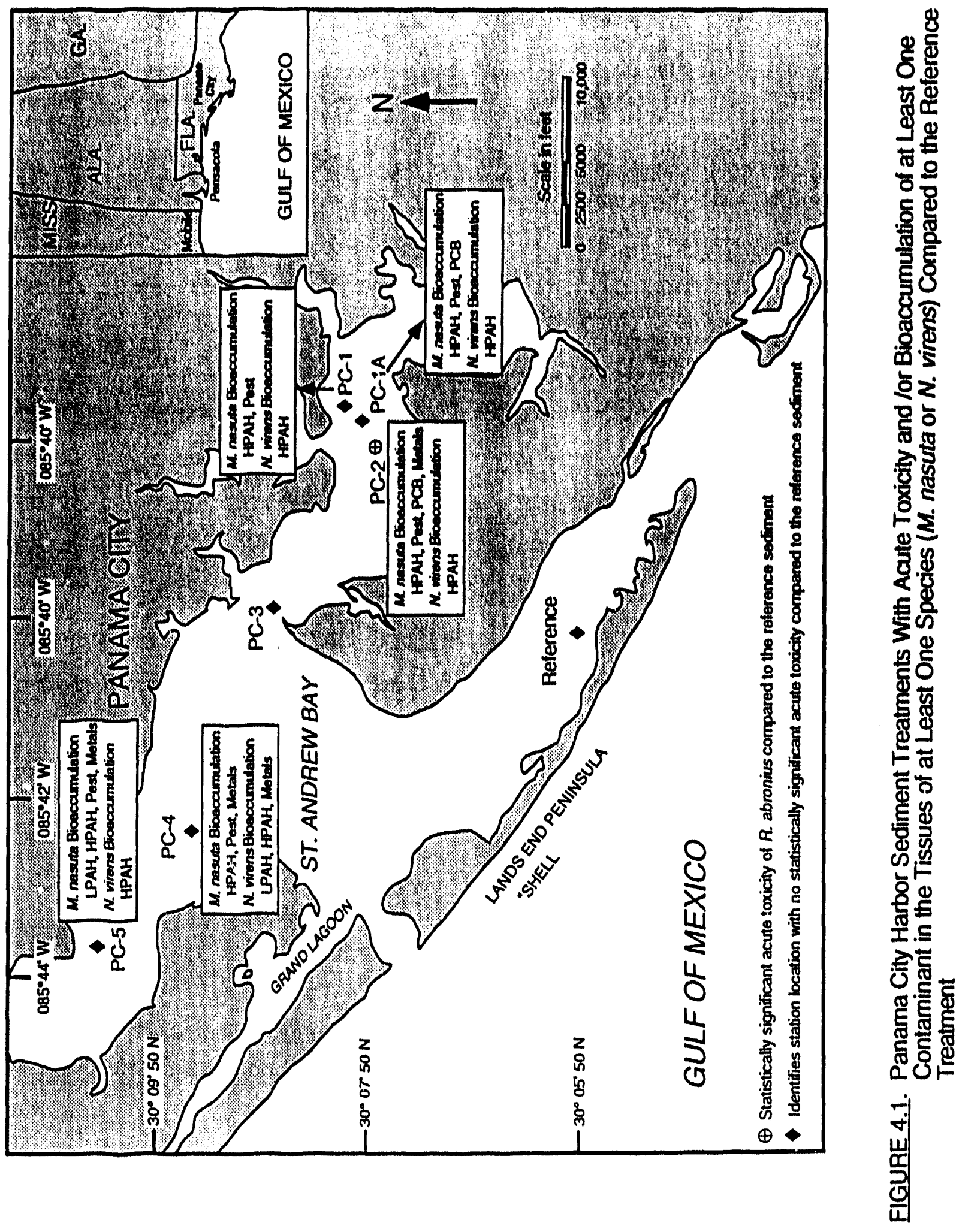


from $0.75 \%$ to $2.14 \%$ in these three test treatments. The fine-grained character and high TOC content in the sediments are assoclated with relatively low bloaccumulation potentlal, because organic compounds tend to bind to these sediments and are not as readlly avallable to the marine organisms. As a result of this relationship, test treatments PC-1, PC-1A, and PC-2 had no more than five high-molecular-weight PAHs, two pesticide/PCB compounds, and one metal that were statistically significantly elevated in M. nasuta tissues, and only one high-molecular-weight PAH was statistically significantly elevated in $N$. Virens tissues.

The Panama City Harbor sediment treatments PC-4 and PC-5 are located in the western arm of St. Andrew Bay (Flgure 4.1). The percentages of fine-grained sediment for PC.4 and PC.5 were $13 \%$ and $14 \%$ dry welght, respectively. The concentrations of TOC in these test treatments ranged from $0.33 \%$ to $0.72 \%$ dry weight. Due to the higher percentages of coarsegrained sediments (sand and gravel) and the relatively low TOC content, organic compounds such as PAHs may be more bloavallable to marine organisms such as $M$. nasuta and $N$. virens. The tssues of these two organisms exposed to test treatments PC-4 and PC-5 were statistically significantly elevated for two low-molecular-weight PAHs and nine high-molecular-weight PAH compounds, and at magnitudes ranging from 2 to 21 times the concentrations found in the reference treatment.

Proposed dredged material trom the Panama Clty Harbor was evaluated based on four criteria: 1) concentrations and magnifications of contaminants in the test sediment treatments relative to the reference sediment; 2) crncentrations of contaminants in the SPP samples and acute toxicity to SPP samples; 3) solid-phase acute toxicity of the test treatments compared to the reference sediment, and 4) concentrations and magnifications of contaminants in the tissues of both $M$. nasuta and $N$. virens exposed to the test treatments relative to tissues exposed to the reference sediment. The matrix in Figure 4.2 presents the results of these evaluations.

Panama City Harbor test treatments resulted in elevated levels of all the contaminants of concern relative to the reference sediment. There was no acute toxicity to water column organisms and contaminant concentrations in SPP samples did not exceed WQC; therefore, the Panama City Harbor sediments meet water column criteria for ocean disposal. According to the 1991 Implementation Manuals, a proposed dredging area falls to meet the deposited sediment (solld-phase) criteria for ocean disposal if there is 1) statistically significant acute toxicity relative to reference and 2) a $>10 \%$ difference (>20\% for amphipods) between the test treatment and reference. Following these criteria, test treatment PC-2 does not comply with the deposited sediment criteria due to the acute toxicity to $R$. abronius. However, the acute toxicity of test treatment PC-2 was not statistically significantly different for either the A. abdita or N. virens acute toxicity tests. Compliance criterla for bioaccumulation are not as well-defined as for water column effects or deposited sediment toxicity. Figure 4.2 lists contaminants showing statistically 
significant bioaccumulation, the number of compounds that were bioaccumulated, the number of species that bioaccumulated a compound, and the degree or magnitude of bioaccumulation

relative to the reference treatment. A summary of the bioaccumulation information (Figure 4.2) is included to assist the USACE and other resource agencies in providing a regional evaluation of dredged disposal material from Panama City Harbor. 


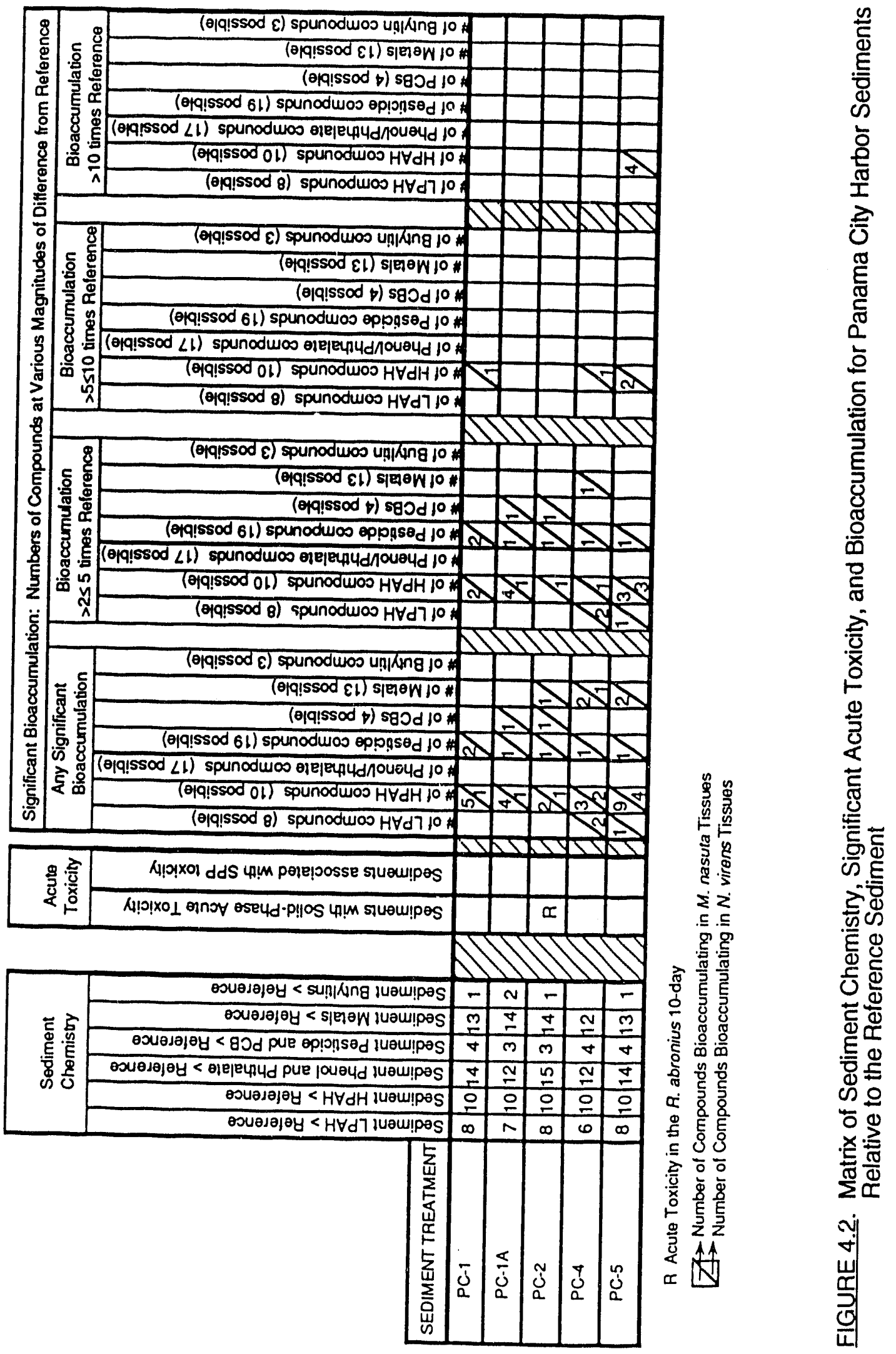




\subsection{REFERENCES}

ASTM (American Society for Testing and Materials). 1990. Standard Guide for Conducting 10-day Static Sediment Toxicity Tests with Marine and Estuarine Amphipods. ASTM

Designation: E 1367-90. American Society for Testing and Materials, Philadelphia.

ASTM (American Society for Testing and Materials). 1991. Standard Test Method for Specific Gravity of Soils. Method D-854-91. American Society for Testing and Materials, Philadelphia.

Bloom, N.S., and E.A. Crecelius. 1983. "Determination of Mercury in Seawater at Sub-Nanogram per Liter Levels." Marine Chemistry 14:49-59.

Bloom, N.S., and E.A. Crecelius. 1984. "Distribution of Silver, Mercury, Lead, Copper, and Cadmium in Central Puget Sound Sediments." Marine Chemistry 21:377-390.

Dunnett, C.W. 1964. "New tables for multiple comparisons with a control." Biometrics 20:482-491.

EPA (U.S. Environmental Protection Agency). 1979. Methods for Chemical Analysis of Water and Wastes. EPA-600 4-79-020, Environmental Monitoring and Support Laboratory, Cincinnati, $\mathrm{OH}$.

EPA (U.S. Environmental Protection Agency). 1986a. Test Methods for Evaluating Solid Waste:: PhysicallChemical Methods. EPA-955-001-00000, U.S. Government Printing Office, Washington, D.C.

EPA (U.S. Environmental Protection Agency). 1986b. Quality Criteria for Water. EPA 440/5-86-001, U.S. Government Printing Office, Washington, D.C.

EPA (U.S. Environmental Protection Agency). 1988. Integrated risk information system (IRIS). Vols. 1 and 2, EPA 600/8-88/032A,B. U.S. Environmental Protection Agency, Office of Healǐl and Environmental Assessment, Washington, D.C.

EPA (U.S. Environmental Protection Agency). 1990a. Method 8290 Analytical Procedures and Quality Assurance for Multimedia Analysis of Polychlorinated Dibenzo-p-Dioxins and Polychlorinated Dibenzofurans by High Resolution Gas Chromatography/High Resolution Mass Spectrometry. U.S. Environmental Protection Agency, Environmental Modeling Services Laboratory, Las Vegas, NV (draft).

EPA (U.S. Environmental Protection Agency). 1990b. Determination of Metals and Trace Elements by Inductively Coupled Plasma/Mass Spectrometry. Method 200.8. U.S. Environmental Protection Agency, Environmental Monitoring and Systems Laboratory, Office of Research and Development, Cincinnati, $\mathrm{OH}$ (draft).

EPA (U.S. Environmental Protection Agency). 1990c. Tetra Through Octa Chlorinated Dioxins and Furans by Isotope Dilution (HRGC/HRMS). Method 1613. U.S. Environmental Protection Agency, Office of Water Regulation and Standards Industrial Technology Division.

EPAUSACE (U.S. Environmental Protection Agency/U.S. Army Corps of Engineers). 1991a. Evaluation of Dredged Material Proposed for Ocean Disposal (Testing Manual).

EPA-68-C8-0105, U.S. Environmental Protection Agency, Office of Marine and Estuarine Protection, Washington, D.C. 
EPAUSACE (U.S. Environmental Protection Agency/U.S. Army Corps of Engineers). $1991 \mathrm{~b}$. Draft Regional Implementation Manual: Requirements and Procedures for Evaluation of the Ocean Disposal of Dredged Material in Southeastern Atlantic and Gulf Coastal Waters. U.S. Army Corps of Engineers, Mobile District, Mobile, AL.

Finney, D.J. 1971. Probit Analysis. Third ed., Cambridge University Press, Boston. 333 pp.

Florida Department of Environmental Regulation. 1988. A Guide to the Interpretation of Metal Concentrations in Estuarine Sediments. Coastal Zone Management Section, Department of Environmental Regulation, State of Florida, Tallahassee.

Plumb, R.H. Jr. 1981. Procedure for Handling and Chemical Analyses of Sediment and Water Samples. Technical Report EPAVE-81-1, prepared for Great Lakes Laboratory, State University College at Buffalo, NY, for the U.S. Environmental Protection Agency/U.S. Army Corps of Engineers Technical Committee on Criteria for Dredged and Fill Material. Published by U.S. Army Corps of Engineers Waterways Experiment Station, Vicksburg, MS.

PSEP (Puget Sound Estuary Program). 1986. Recommended Protocols for Measuring Selected Environmental Variables in Puget Sound. Vols. 1 and 2. Prepared by Tetra Tech, Inc. for the Puget Sound Estuary Program, Bellevue, WA.

Unger, M.A., W.G. Maclntyre, J. Greaves, and R.J. Huggett. 1986. "GC Determination of Butyltins in Natural Waters by Flame Photometric Detection of Hexyl Derivatives with Mass Spectrometric Confirmation." Chemosphere 15(4):461-470.

Whitledge, T.E., S.C. Malloy, C.J. Patton, and C.D. Wirick. 1981. Automated Nutrient Analysis in Seawater. BNL 51398, Brookhaven National Laboratory, Upton, NY. 


\section{APPENDIX A}

\section{FIELD SAMPLING DATA}


IABLE A.1. Field Collection Summary for the Test, Reference, and Control Sediment Treatments, Panama City Harbor Project

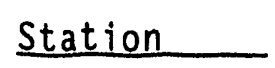

$P C-1$

$P C-1 A$

$\mathrm{PC}-2$

$P C-3$

$P C-4$

$P C-5$

Reference

A abdita Control

R. abronius Control

M. nasuta Control

$N$. virens Control

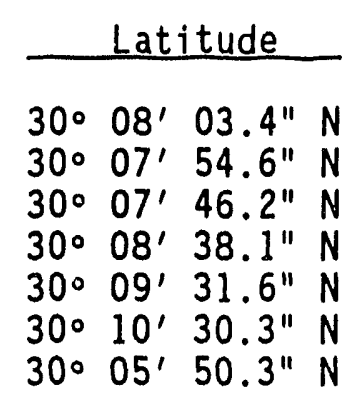

Longitude

$085^{\circ} 37^{\prime} 37.4^{\prime \prime} \mathrm{W}$

$085^{\circ} 37^{\prime} 44.4^{\prime \prime} W$

$085^{\circ} 38^{\prime} 01.9 " \mathrm{~W}$

$085^{\circ} 39^{\prime} 58.7^{\prime \prime} \mathrm{W}$

$085^{\circ} 42^{\prime} 28.3^{\prime \prime} \mathrm{W}$

$085^{\circ} 43^{\prime} 44.1 " \mathrm{~W}$

$085^{\circ} 40^{\prime} 06.6^{\prime \prime} \mathrm{W}$
Water Depth (ft)

$-30$

$-32$

$-33$

$-32$

$-34$

$-27$

$-14$

Sall Pablo Bay, California

West Beach, Whidbey Island, Washington

Sequim Bay, Washington

Newcastle, Maine 
APPENDIX B

SEDIMENT CHEMISTRY AND QUALITY ASSURANCE DATA 


\section{QA/QC SUMMARY}

$\begin{array}{ll}\text { PROGRAM: } & \text { Panama City Harbor Program } \\ \text { PARAMETER: } & \text { Grain Size and Total Solids } \\ \text { LABORATORY: } & \text { Soil Technology, Bainbridge Island, Washington } \\ \text { MATRIX: } & \text { Sediment }\end{array}$

QAVC DATA QUALITY OBJECTIVES

$\begin{array}{ccccc}\begin{array}{c}\text { Reference } \\ \text { Method }\end{array} & \begin{array}{c}\text { Range of } \\ \text { Recovery }\end{array} & \begin{array}{c}\text { SRM } \\ \text { Accuracy }\end{array} & \begin{array}{c}\text { Relative } \\ \text { Precision }\end{array} & \begin{array}{c}\text { Detection } \\ \text { Limit (dry wt) }\end{array} \\ \text { Plumb 1981 } & \text { NA } & \text { NA } & \leq 20 \% & 1.0 \%\end{array}$

HOLDING TIMES All samples were analyzed within the specified 6-month holding period.

DETECTION LIMITS The detection limit of $1.0 \%$ for both grain size and total solids analysis was met for all samples.

METHOD BLANKS NA

MATRIX SPIKES NA

SRMS NA

REPLICATES The requirement of triplicate analysis for every 10 samples was met. The relative standard deviation (RSD) between triplicates was performed on all 16 grain size fractions and the total gravel, sand, silt, and clay fractions. For the total gravel, sand, silt, and clay fractions, the RSDs ranged from $0 \%$ to $3 \%$ indicating excellent precision. Four of the 16 size fraction RSDs were outside the $\leq 20 \%$ limit because comparison of small values tends to exaggerate the RSD value. The RSD between triplicates for the total solids analysis was $0 \%$, which is within the QAVC limits. Overall, RSDs for grain size and total solids indicate acceptable precision of the methods.

SURROGATES NA

ADDITIONAL INFORMATION

All samples were corrected for salt interference.

NA Not applicable.

PANAMA CITY HARBOB B.iii 


\section{QAVC SUMMARY}

PROGRAM:

PARAMETER:

LABORATORY:

MATRIX:
Panama City Harbor Program

Specific Gravity

Soll Technology, Bainbridge Island, Washington

Sediment

\section{QAVQC DATA QUALITY OBJECTIVES}

\begin{tabular}{ccccc}
$\begin{array}{c}\text { Reference } \\
\text { Method }\end{array}$ & $\begin{array}{c}\text { Range of } \\
\text { Recovery }\end{array}$ & $\begin{array}{c}\text { SRM } \\
\text { Accuracy }\end{array}$ & $\begin{array}{c}\text { Relative } \\
\text { Precision }\end{array}$ & $\begin{array}{c}\text { Detection } \\
\text { Limit (dry wt) }\end{array}$ \\
\hline STM (1991) D-854 & NA & NA & $520 \%$ & NA
\end{tabular}

HOLDING TIMES All samples were analyzed within the specifled 6-month holding period.

DETECTION LIMITS NA

METHOD BLANKS NA

MATRIX SPIKES NA

SRMS NA

REPLICATES The requirement of triplicate analysis for every 10 samples was met. Precision was measured by Relative Standard Deviation (RSD) between replicates. The RSD between triplicates was $2 \%$, which is within the $20 \%$ established limit.

SURROGATES NA

NA Not applicable. 


\section{QA/QC SUMMARY}
PROGRAM:
Panama Clty Harbor Program
PARAMETER:
Total Organic Carbon
LABORATORY:
MATRIX:
Global Geochemistry Corporation, Canoga Park, California
Sediment

QAVC DATA QUALITY OBJECTIVES

\begin{tabular}{ccccc}
$\begin{array}{c}\text { Reference } \\
\text { Methed }\end{array}$ & $\begin{array}{c}\text { Range of } \\
\text { Becovery }\end{array}$ & $\begin{array}{c}\text { SRM } \\
\text { Accuracy }\end{array}$ & $\begin{array}{c}\text { Relative } \\
\text { Precislon }\end{array}$ & $\begin{array}{c}\text { Detection } \\
\text { Limit (dry wt) }\end{array}$ \\
\hline SW846 EPA 9060 (1986a) & NA & $520 \%$ & $510 \%$ & $0.1 \%$
\end{tabular}

HOLDING TIMES All samples were analyzed within the specifled 6-month holding period

DETECTION LIMITS The detection limit of $0.1 \%$ was met for all samples.

METHOD BLANKS The method blanks that were analyzed had concentrations of $0.004 \%$ and $0.012 \%$. Because these are less thari the detection limit, no blank correction is required.

MATRIX SPIKES NA

SRMs

The standard reference material (SRM) MESS-1, obtained from the National Research Council of Canada (NRCC), was analyzed with the sediment samples. The SRM had a concentration of 2.75 which is within $20 \%$ of the consensus value.

REPLICATES

Precision between triplicates was measured by Relative Standard Deviation (RSD). The RSD was $5 \%$, which is within the $10 \%$ value established in the QA plan.

SURROGATES

NA

NA Not applicable. 


\section{QA/QC SUMMARY}

PROGRAM: Panama City Harbor Program

PARAMETER: Total Sulfides and Cyanide

LABORATORY: Analytical Resources Incorporated, Seattle, Washington

MATRIX:

Sediment

QANQC DATA QUALITY OBJECTIVES

\begin{tabular}{|c|c|c|c|c|}
\hline M & $e$ of & $\begin{array}{c}\text { SRM } \\
\text { Accuracy }\end{array}$ & $\begin{array}{l}\text { Relative } \\
\text { Precision }\end{array}$ & $\begin{array}{r}\mathrm{De} \\
\text { Limi }\end{array}$ \\
\hline
\end{tabular}

$\begin{array}{llllll}\text { Total Sulfides Plumb } 1981 & N A & N A & s 30 \% & 0.2 \mathrm{mg} / \mathrm{kg}\end{array}$

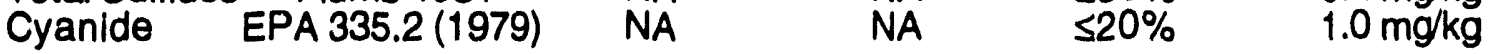

HOLDING TIMES All samples were analyzed within the specified 28-day holding period.

DETECTION LIMITS The achieved detection limit for the total sulfide analysis was $1.25 \mathrm{mg} / \mathrm{kg}$. Because concentrations in the samples were all well above the achieved detection limit, no corrective action was taken. The achieved detection limit for cyanide was $0.1 \mathrm{mg} / \mathrm{kg}$, which is below the target detection limit.

METHOD BLANKS The concentrations of total sulfide and cyanide measured in the method blank were less than the target detection limit; therefore, the data are acceptable.

MATRIX SPIKES Because matix spikes were not required for this project; no data quality objectives were established. Analytical Resources Incorporated analyzed matrix spikes for both total sulfides and cyanide, and the data are reported in Appendix B. The percent recoveries were $83 \%$ for the matrix spike sample analyzed for total sulfides and $95 \%$ for the matrix spike sample analyzed for cyanide.

SRMs NA

REPLICATES The relative standard deviation (RSD) between triplicates for total sulfide analysis was within the established QC limits. Precision between triplicates (RSD) for cyanide analysis could not be determined because all replicates were undetected.

SURROGATES NA

NA Not applicable. 


\section{QAVQC SUMMARY}

PROGR/AM:

PARAMETER:

LABORATORY:

MATRIX:
Panama City Harbor Program

Ammonia

University of Washington, Seattle, Washington

Sediment Porewater

\section{QANOC DATA QUALITY OBJECTIVES}

Reference Method

Whitledge et al. 1981

Range of
Recovery

NA
SRM

Accuracy

NA

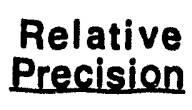

$\leq 30 \%$
Detection Limit (wet wt)

$0.01 \mathrm{mg} / \mathrm{L}$

HOLDING TIMES The samples were analyzed within the specifled 28-day holding period.

DETECTION LIMITS The achieved detection limit for the ammonia analysis was $0.04 \mathrm{mg} / \mathrm{L}$. The concentrations in the samples were all well above the achieved detection limit; therefore, no corrective action was taken.

METHOD BLANKS The concentration of ammonia in the method blank was undetected at a value slightly greater than the target detection linit. The concentrations in the samples were well above the target and achieved detection limits; therefore, no corrective action was taken.

\section{MATRIX SPIKES NA}

SRMS

NA

REPLICATES

The Relative Standard Deviation (RSD) between triplicates was $0.2 \%$, which was within the established QC limits.

SURROGATES

NA

NA Not applicable. 


\section{QA/QC SUMMARY}

PROGRAM:

PARAMETER:

\section{Panama City Harbor Program}

Polynuclear Aromatic Hydrocarbons (PAHs), Phenol, Substituted Phenols, and Phthalate Esters
LABORATORY:
Battelle Ocean Sciences, Duxbury, Massachusetts
MATRIX:
Sediment

QAQC DATA QUALITY OBJECTIVES

All samples were extracted within the 14-day holding period and analyzed within 30 days of extraction.

\section{Range of SRM Relativa Detection Recovery Accuracy Precision Limit (dry wt)}

$\begin{array}{llllll}\text { PAHs } & \text { EPA Method } 8270(1986 \mathrm{a}) & 40-120 \% & \leq 30 \% & \leq 30 \% & 30 \mu \mathrm{g} / \mathrm{kg} \\ \text { Phenol and } & & & & & \\ \text { Substituted Phenols } & \text { EPA Method } 8270 & 40-120 \% & \leq 30 \% & \leq 30 \% & 330 \mu \mathrm{g} / \mathrm{kg} \\ \text { Phthalate Esters } & \text { EPA Method 8270 } & 40-120 \% & \leq 30 \% & \leq 30 \% & 100 \mu \mathrm{g} / \mathrm{kg}\end{array}$

HOLDING TIMES

DETECTION LIMITS

METHOD BLANKS

MATRIX SPIKES

\author{
DETECTION LIMITS
}

The achieved detection limits for the samples analyzed for PAHs were all below the target detection limits. The achieved detection limits for phenol, substituted phenols, and phthalate esters were slightly elevated above the target detection limits set in the QA QC plan. These elevations do not present a problem because all but one analyte was either undetected or detected below the method detection limit.

The method blank analyzed with the samples was free of contamination, with the exception of naphthalene that was present at $<2$ times the method detection limit. The data associated with this sample was flagged with a "B."

The matrix spike recoveries for the low and high PAH compounds and the phthalate esters were all within the $40-120 \%$ range. Four of the 11 phenol and substituted phenol compounds had matrix spike recoveries that were out of range. The phenol and substituted phenols were outside the recovery range in the matrix spike samples due to high levels of phenol naturally present in the background sample.

SRMs
The percent differences of certified PAHs in the sediment SRM are acceptable, with the exception of two PAHs [benzo(a)pyrene (34\%) and benzo(g,h,i)perylene $(41 \%)]$ which were above the accuracy limit of $\leq 30 \%$. 
REPLICATES

SURROGATES
Precision was measured by relative standard deviation (RSD) between triplicates. Three of the eight low PAHs had RSDs that were outside the $30 \%$ range. All but one high PAH (fluoranthene) had RSDs outside the $30 \%$ range. Two of the six phthalate esters were out of range. No phenol or substituted phenols were detected in any of the replicates; therefore, no RSD values were calculated. In general, levels of the compound which exceeded the RSD limit were relatively low. Comparisons of low values tend to exaggerate the RSD values.

Four surrogate compounds were analyzed with the samples: 2-fluorophenol, naphthalene- $d_{8}$, acenaphthene- $d_{10}$, and benzo(a)pyrene- $d_{12}$. The recoveries of the surrogate internal standard (SIS) compounds were acceptable with the exception of 2-fluorophenol with a range of $3 \%$ to $54 \%$. 


\section{QA/QC SUMMARY}

PROGRAM:

PARAMETER:

LABORATORY:

MATRIX:
Panama City Harbor Program

Chlorinated Pesticides and Polychlorinated Biphenyls (PCBs)

Battelle Ocean Sciences, Duxbury, Massachusetts

Sediment

QAVC DATA QUALITY OBJECTIVES

\begin{tabular}{|c|c|c|c|c|}
\hline $\begin{array}{c}\text { Reference } \\
\text { Method }\end{array}$ & $\begin{array}{l}\text { Range of } \\
\text { Recovery }\end{array}$ & $\begin{array}{c}\text { SRM } \\
\text { Accuracy }\end{array}$ & $\begin{array}{c}\text { Relatlve } \\
\text { Precislon }\end{array}$ & $\begin{array}{c}\text { Detectlon } \\
\text { Limit (dry wt) }\end{array}$ \\
\hline EPA Method 8080 (1986a) & $40-120 \%$ & NA & $\leq 30 \%$ & $10-30 \mu \mathrm{g} / \mathrm{kg}$ \\
\hline
\end{tabular}

HQLDING TIMES

DETECTION LIMITS

METHOD BLANKS

MATRIX SPIKES

SRMs

REPLICATES

SURROGATES

NA Not applicable.
All samples were extracted within the specified 14-day holding period and analyzed within 30 days of extraction.

The detection limit of $10 \mu \mathrm{g} / \mathrm{kg}$ or $20 \mu \mathrm{g} / \mathrm{kg}$ was met for all the associated pesticides. Chlordane and toxaphene detection limits were elevated above the target detection limit of $30 \mu \mathrm{g} / \mathrm{kg}$, but all samples were undetected above the detection limit. All the PCBs analyzed had achieved detection limits that were abcve the target detection limits.

One method blank was analyzed with the samples. No pesticides were detected, indicating that the procedural blank is free of contamination.

Five of the 18 matrix spike recoveries were elevated above the target range of recovery $(40-120 \%)$. These five recoveries ranged from $122 \%$ to $183 \%$, due to coelution of PCB congeners present in Aroclor 1254.

Certified concentrations of target pesticides are not available for the sediment SRM; consequently, no pesticide/PCB data are submitted for the SRM.

Precision was measured by relative standard deviation (RSD) between triplicates. RSDs could be calculated only on the three pesticides and one PCB with detected values in all replicates. RSDs ranged from $6 \%$ to $16 \%$, which is well within the $30 \%$ established limit.

Surrogate percent recoveries for DBOFB and $\mathrm{CL}_{5}(112)$ ranged between $62 \%$ and $120 \%$, which were within the $40-120 \%$ acceptable recovery range. 


\section{QA/QC SUMMARY}

$\begin{array}{ll}\text { PROGRAM: } & \text { Panama City Harbor Program } \\ \text { PARAMETER: } & \text { Metals } \\ \text { LABORATORY: } & \text { Battelle/Marine Sciences Laboratory, Sequim, Washington } \\ \text { MATRIX: } & \text { Sediment }\end{array}$

\section{QAQC DATA QUALITY OBJECTIVES}

\begin{tabular}{llcccc} 
& \multicolumn{1}{c}{$\begin{array}{c}\text { Reference } \\
\text { Method }\end{array}$} & $\begin{array}{c}\text { Range of } \\
\text { Recevery }\end{array}$ & $\begin{array}{c}\text { SRM } \\
\text { Accuracy }\end{array}$ & $\begin{array}{c}\text { Relative } \\
\text { Precision }\end{array}$ & $\begin{array}{c}\text { Detection } \\
\text { Limit (dry wt) }\end{array}$ \\
\cline { 2 - 3 } Aluminum & ICP/MS (EPA 1990b) & $75-125$ & $\leq 30 \%$ & $\leq 20 \%$ & 5.0 \\
Antimony & ICP/MS & $75-125$ & $\leq 30 \%$ & $\leq 20 \%$ & 0.1 \\
Arsenic & ICP/MS & $75-125$ & $\leq 30 \%$ & $\leq 20 \%$ & 0.1 \\
Berylium & ICP/MS & $75-125$ & $\leq 30 \%$ & $\leq 20 \%$ & 0.2 \\
Cadmium & ICP/MS & $75-125$ & $\leq 30 \%$ & $\leq 20 \%$ & 0.1 \\
Chromium & ICP/MS & $75-125$ & $\leq 30 \%$ & $\leq 20 \%$ & 0.6 \\
Copper & ICP/MS & $75-125$ & $\leq 30 \%$ & $\leq 20 \%$ & 0.1 \\
Lead & ICP/MS & $75-125$ & $\leq 30 \%$ & $\leq 20 \%$ & 0.1 \\
Mercury & CVAA (Bloom et al. 1984) & $75-125$ & $\leq 30 \%$ & $\leq 20 \%$ & 0.01 \\
Nickel & ICP/MS & $75-125$ & $\leq 30 \%$ & $\leq 20 \%$ & 0.1 \\
Selenium & ICP/MS & $75-125$ & $\leq 30 \%$ & $\leq 20 \%$ & 0.2 \\
Silver & ICP/MS & $75-125$ & $\leq 30 \%$ & $\leq 20 \%$ & 0.1 \\
Thallium & ICP/MS & $75-125$ & $\leq 30 \%$ & $\leq 20 \%$ & 0.1 \\
Zinc & ICP/MS & $75-125$ & $\leq 30 \%$ & $\leq 20 \%$ & 0.3
\end{tabular}

HOLDING TIMES All samples analyzed for metals, except $\mathrm{Hg}$, were digested and analyzed within the specified 6-month holding period. All $\mathrm{Hg}$ samples were digested and analyzed within a holding time of 28 days.

DETECTION LIMITS The achieved detection limits for all the metals were below the target detection limit.

METHOD BLANKS LOW levels of $\mathrm{Al}, \mathrm{Cr}, \mathrm{Pb}, \mathrm{Hg}$, and $\mathrm{Ni}$ were detected in the method blank. The data associated with these blanks were corrected for the amount in the method blank; therefore, no corrective action was taken.

MATRIX SPIKES All matrix spike recoveries were within the criteria of $75-125 \%$, except for $\mathrm{Ag}(72 \%)$, Se (61\%), and $\mathrm{Sb}(44 \%)$.

SRMs

The standard reference material (SRM) 1646-1 was analyzed for all the metals except mercury (SRM 1646-2). The values were all within the $30 \%$ limit set in the QA plan.

REPLICATES Precision between triplicates was measured by Relative Standard Deviation (RSD). Five ( $\mathrm{Ag}, \mathrm{Be}, \mathrm{Cu}, \mathrm{Fb}$, and $\mathrm{Se}$ ) of the $11 \mathrm{RSD}$ calculations were out of the $20 \%$ range established as a data quality objective. All RSD exceedences, except for $\mathrm{Pb}$, were due to the comparison of small values which tends to exaggerate RSD values. 
ADDITIONAL INFORMATION

NA Not applicable.
The metals $\mathrm{Cd}$, Se, and $\mathrm{Ag}$ were analyzed by ICP/MS, and not by GFAA as required in the QA Plan, because of acceptable ICP/MS Quality Control (QC) data (matrix spike recoveries, RSDs, acceptable detection limits, and non-contaminated blanks). In the case of $\mathrm{Cd}$, the recovery of the SRM was also acceptable. 


\section{QA/QC SUMMARY}

PROGRAM:

PARAMETER:

LABORATORY:

MATRIX:
Panama City Harbor Program

Butyltins

Battelle/Marine Sciences Laboratory, Sequim, Washington

Sediment

QAVC DATA QUALI" " OBJECTIVES

Reference Method

Unger et al. 1986

HOLDING TIMES

DETECTION LIMITS

METHOD BLANKS

MATRIX SPIKES

SRMs

REPLICATES

SURROGATES
Range of

Recovery

$40-120 \%$

\section{SRM Accuracy}

$\leq 30 \%$

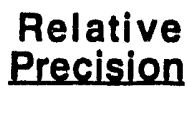

$\leq 30 \%$
Detection Limit (dry wt)

$10 \mu \mathrm{g} / \mathrm{kg}$

All samples were analyzed within the specified 14-day holding period.

The detection limit of $10 \mu \mathrm{g} / \mathrm{kg}$ was met for all samples.

No butyltins were detected in the method blank, indicating that the blank was free of contamination.

One sample was spiked with di-and tri-butyltin. Matrix spike recoveries were $116 \%$ and $110 \%$ for tributytin and dibutyltin, respectively, and were within the QC limits of $40-120 \%$.

The standard reference material (SRM) PACS- 1 was analyzed with the sediment samples. The SRM concentrations were within the $30 \%$ limit except for monobutyltin.

Precision between triplicates was measured by Relative Standard Deviation (RSD). No butyltins were detected; therefore, RSDs were not calculated.

One compound, tripentyltin chloride, is added prior to extraction to assess the efficiency of the method. Recoveries ranged from $57 \%$ to $111 \%$, which is within the QC limits of $40-120 \%$. 


\section{QA/QC SUMMARY}

PROGRAM:

PARAMETER:

LABORATORY:

MATRIX:
Panama City Harbor Program

Dloxins

Battelie Columbus Operations, Columbus, Ohio

Sediment

QAVQC DATA QUALITY OBJECTIVES

\begin{tabular}{ccccc}
$\begin{array}{c}\text { Reference } \\
\text { Method }\end{array}$ & $\begin{array}{c}\text { Range of } \\
\text { Recovery }\end{array}$ & $\begin{array}{c}\text { SRM } \\
\text { Accuracy }\end{array}$ & $\begin{array}{c}\text { Relative } \\
\text { Precision }\end{array}$ & $\begin{array}{c}\text { Detection } \\
\text { Limit (dry wt) }\end{array}$ \\
\hline EPA Method 8290 (1990a) & $40-120 \%$ & NA & $530 \%$ & $1.0 \mathrm{ng} / \mathrm{kg}$
\end{tabular}

HOLDING TIMES All samples were analyzed within the specified 14-day holding period.

DETECTION LIMITS The detection limit of $1.0 \mathrm{ng} / \mathrm{kg}$ was met for all samples, except the dioxin congener OCDF that had an achieved detection limit of $1.3 \mathrm{ng} / \mathrm{kg}$. The congener OCDD had an achieved detection limit of $<5.0 \mathrm{ng} / \mathrm{kg}$. The detection limit specified in EPA Method 8290 is $5 \mathrm{ng} / \mathrm{kg}$, and not $1.0 \mathrm{ng} / \mathrm{kg}$ as specified in the QA Plan.

METHOD BLANKS The method blank that was analyzed was undetected for all the dioxin congers, except for OCDD that was detected at $2.45 \mathrm{ng} / \mathrm{kg}$. This concentration was due to the mass ratio being out of limits. The concentrations in the samples were all well above the achieved detection limit; therefore, no corrective action was taken.

MATRIX SPIKES Matrix spike recoveries for the dioxin analysis ranged from $65 \%$ to $104 \%$, which were within the $40-120 \%$ acceptable range.

SRMs

NA

REPLICATES

Precision was measured by Relative Percent Difference (RPD) and I-STAT measurements between the percent recoveries of the matrix splke and matrix spike duplicate samples. All RPD values ranged from $1 \%$ to $12 \%$, which were well within the acceptable $30 \%$ limit.

\section{SURROGATES}

Fifteen labeled compounds and one clean-up standard were spiked into the sediment samples to assess the surrogate percent recovery of the compounds. Seventeen of the 80 surrogate percent recoveries were outside the targeted $40-120 \%$ range. All but one of the surrogate percent recoveries for PC- 1 were outside the 40-120\% range. These percent recoveries ranged from $19 \%$ to $39 \%$.

NA Not applicable. 
TABLE B.1. Summary of Grain Size Analys is of Sediment and Quality Control Data, Dry Weight, Panama City Harbor Project

Sediment

Ireatment

$P C-1$

$P C-1 A$

PC-2 Replicate 1

$P C-2$ Replicate 2

$P C-2$ Replicate 3

$P C-3$

$P C-4$

PC-5

Reference

Quality Control Data

Analytical Replicates

PC-2 Replicate 1

$P C-2$ Replicate 2

$P C-2$ Replicate 3 RSD

Gravel
$\geq 2000 \mu \mathrm{m}$

4
4
1
1
1
19
1
1
0

\begin{tabular}{c} 
Sand \\
$62.5-2000 \mu \mathrm{m}$ \\
\hline 78 \\
83 \\
63 \\
63 \\
62 \\
79 \\
86 \\
85 \\
96
\end{tabular}

63

63

62

$1 \%$

$\begin{array}{cc}\text { Silt } & \begin{array}{c}\text { Clay } \\ 3.9-62.5 \mu \mathrm{m}\end{array} \\ & \leq 3.9 \mu \mathrm{m} \\ 5 & 13 \\ 3 & 10 \\ 14 & 22 \\ 14 & 22 \\ 14 & 23 \\ 0 & 2 \\ 4 & 9 \\ 5 & 9 \\ 1 & 3\end{array}$

14

14

22

22

23

$0 \%$ 


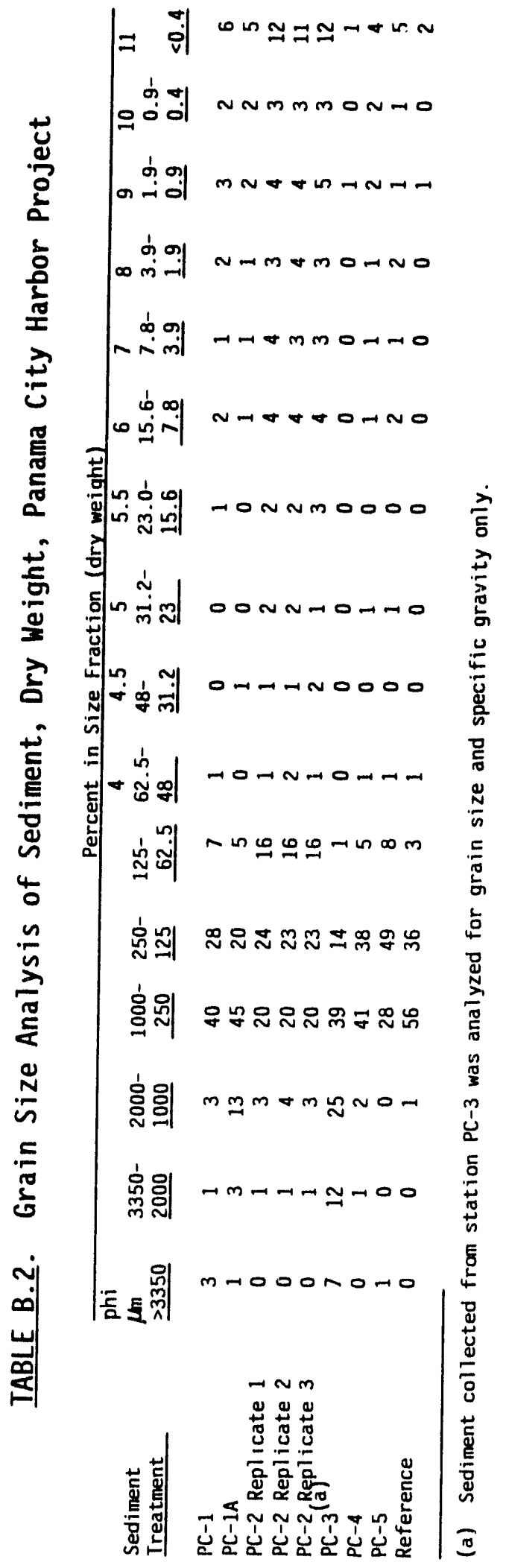

PANAMA CITY HARBOR 


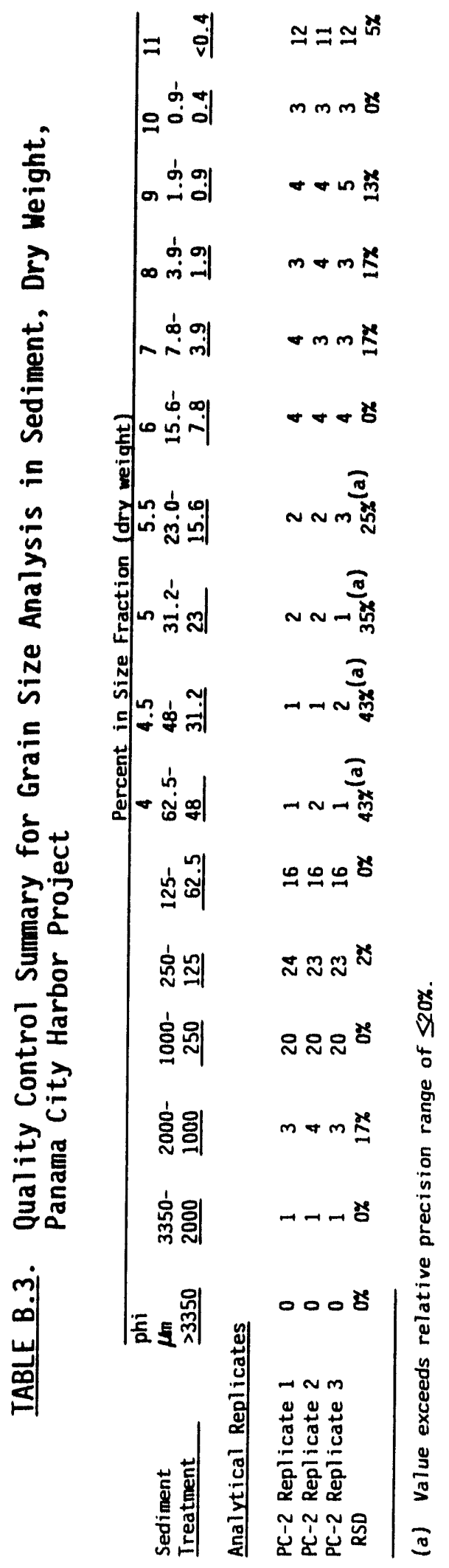

PANAMA CITY HARBOR

B. 3 
IABLE B.4. Specific Gravity, Total Solids and Total Organic Carbons (TOC) Analysis of Sediment, Dry Weight, Panama City Harbor Project

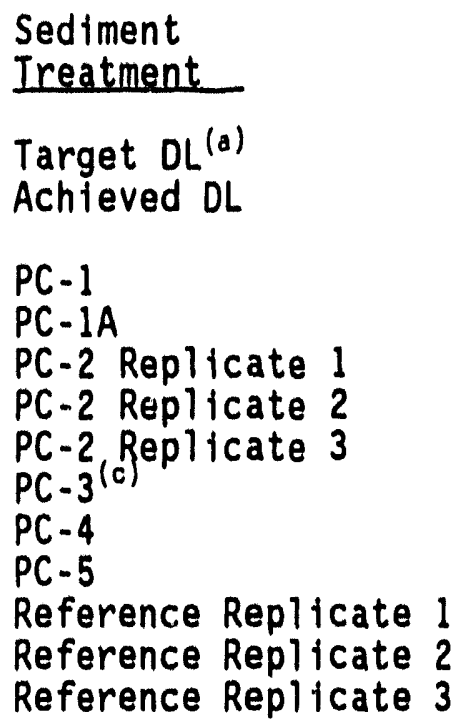

Specific
Gravity
NA(b)
NA

2.66
2.66
2.74
2.65
2.70
2.76
2.71
2.59
2.66
NA
NA

TOC (percent)

0.1

0.1

1.0

1.0

Solids

(percent)

1.06

0.75

2.14

38

NA $\quad 38$

NA $\quad 76$

$0.72 \quad 68$

$0.33 \quad 57$

0.11

0.12

78

NA

NA

(a) DL Detection limit.

(b) NA Not applicable.

(c) Sediment collected from station PC-3 was analyzed for grain size and specific gravity only. 
IABLE B.5. Quality Control Summary for Specific Gravity, Total Solids and Total Organic Carbons (TOC) in Sediment, Dry Weight, Panama City Harbor Project

Sediment

Ireatment

Method Blanks

Blank

Blank
Specific

Gravity

$N A^{(a)}$
$N A$

$N C^{(b)}$

NA

MESS - 1

Analytical Replicates

PC-2 Replicate 1

PC-2 Replicate 2

PC-2 Replicate 3

RSD

Reference Replicate 1

Reference Replicate 2

Reference Replicate 3

RSD

(a) NA Not applicable.

(b) NC Not certified.
2.74

2.65

2.70

$2 \%$

\subsection{6}

$N A$

NA

NA
TOC

(percent)

0.004

0.012

NA

NA
Total

Solids

(percent)
$2.6 \pm 0.2 \quad N C$

$2.75 \quad N A$
2.14

NA

NA

NA

0.11

0.12

0.11

$5 \%$
38

38

38

$0 \%$

78

NA

NA

NA 

TABLE B.6. Cyanide and Total Sulfides Analysis of Sediment, Dry Weight,
Panama City Harbor Project

Sediment

Ireatment

Target $D L^{(a)}$

Achieved DL

PC-1 Replicate 1

PC-1 Replicate 2

PC-1 Replicate 3

PC-1A

$P C-2$

PC-4 Replicate 1

PC-4 Replicate 2

PC-4 Replicate 3

$P C-5$

Reference

\section{Cyanide}

$\mathrm{mg} / \mathrm{kg}$

1.0

0.1

$0.177{ }_{N A}(c)^{(b)}$

NA

$0.142 \mathrm{U}$

$0.272 \mathrm{U}$

$0.149 \mathrm{U}$

$0.151 \mathrm{U}$

$0.150 \mathrm{U}$

$0.172 \mathrm{U}$

$0.120 \mathrm{U}$
Total

Sulfides

$\mathrm{mg} / \mathrm{kg}$

0.2

1.25

28.3

29.8

43.7

67.4

295

92.0

NA

122

$2.0 \mathrm{U}$

(a) DL Detection limit.

(b) U Analyte was not present above the associated value.

(c) NA Not applicable. 
IABLE B.7. Quality Control Sumrary for Cyanide and Total Sulfide Analysis in Sediment, Dry Weight, Panama City Harbor Project

Sediment

Ireatment

Method Blank

B1 ank

Matrix Spikes

PC-4 MS

Concentration Recovered Amount Spiked

Percent Recovery

PC-1 Replicate 1

$P C-1$ MS

Concentration Recovered

Percent Recovery
Cyanide $\mathrm{mg} / \mathrm{kq}$

$0.1 U^{(a)}$

$0.149 U$

103

103

109

$95 \%$

$0.177 \mathrm{U}$

NA

NA

NS

NA
Total

Sulfide

$\mathrm{mg} / \mathrm{kg}$
PC-4 Replicate 1

Amount Spiked

\section{Analytical Replicates}

PC-1 Replicate 1

PC-1 Replicate 2

PC-1 Replicate 3

RSD

$0.177 U$

NA

NA

NA

$1.25 U$

PC-4 Replicate 1

PC-4 Replicate 2

PC-4 Replicate 3

RSD

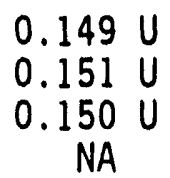

$0.149 U$

$0.150 \mathrm{U}$

NA

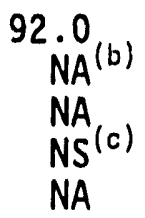

28.3

474

445.7

537

$83 \%$
28.3

29.8

43.7 $25 \%$

92.0

NA

NA

NA

(a) $U$ Analyte was not present above the associated value.

(b) NA Not applicable.

(c) NS Not spiked. 
TABLE B.8. Ammonia Analysis of Sediment Porewater, Panama City Harbor Project

Sediment

Ireatment

Target $D L^{(a)}$

Achieved DL

$P C-1$

PC-1A

$P C-2$

PC-4 Replicate 1

PC-4 Replicate 2

PC-4 Replicate 3

PC-5

Reference
$\mathrm{NH}_{4}$

Ammonium

$(\mathrm{mg} / \mathrm{L})$

$$
\begin{aligned}
& N A^{(b)} \\
& N A
\end{aligned}
$$

2.39

2.67

6.34

3.56

3.56

3.58

5.66

6.76
$\mathrm{NH}_{3}-\mathrm{N}$

Ammonia

$(m g / L)$

0.01

0.04

1.86

2.08

4.93

2.77

2.77

2.78

4.40

5.26

(a) DL Detection limit.

(b) NA Not applicable. 
TABLE B.9. Quality Control Summary for Ammonia Analysis of Sediment Porewater, Panama City Harbor Project

Sediment

Treatment

Method Blank

Bl ank

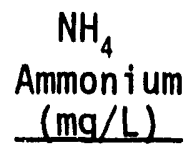

$N A^{(a)}$

Analytical Replicates

PC-4 Replicate 1

PC-4 Replicate 2

PC-4 Rep 1 icate 3

RSD

\subsection{6}

3.56

3.58

$0.3 \%$
$\mathrm{NH}_{3}-\mathrm{N}$

Ammonia

$(\mathrm{mg} / \mathrm{L})$

$0.04 U^{(b)}$

(a) NA Not applicable.
(b) U Analyte was not

(b) $U$ Analyte was not present above the associated value. 
TABLE B.10. Total Polynuclear Aromatic Hydrocarbons (PAH) Analys is of Sediment, Dry Weight, Panama City Harbor Project

Sediment

Ireatment

PC-1 Replicate 1

PC-1 Replicate 2

PC-1 Replicate 3

$P C-1 A$

$P C-2$

$P C-4$

PC-5

Reference
Total

Low Molecular

Weight PAH

131.27

96.83

113.70

55.98

164.73

19.45

87.03

4.71
Total

High Molecular

Weight PAH

310.47

273.98

767.47

181.51

365.39

70.84

932.80

5.83
Total

PAH

441.74

370.81

881.17

237.49

530.12

90.29

1019.83

10.54 
IABLE B.11. Low Molecular Weight Polynuclear Aromatic Hydrocarbons (LPAH) Analysis of Sediment, Dry Weight, Panama City Harbor Project

\begin{tabular}{|c|c|c|c|c|c|c|c|c|}
\hline \multirow[b]{2}{*}{$\begin{array}{l}\text { Sediment } \\
\text { Ireatment }\end{array}$} & \multicolumn{8}{|c|}{ LPAH $(\mu \mathrm{g} / \mathrm{kg}$ dry weight $)$} \\
\hline & $\begin{array}{l}\text { Naphtha- } \\
\text { lene }\end{array}$ & $\begin{array}{l}\text { 2-Methyl- } \\
\text { naphtha- } \\
\text { lene }\end{array}$ & $\begin{array}{l}\text { 1-Methyl- } \\
\text { naphtha- } \\
\text { lene }\end{array}$ & $\begin{array}{l}\text { Acenaph- } \\
\text { thylene }\end{array}$ & $\begin{array}{l}\text { Acenaph- } \\
\text { thene }\end{array}$ & Eluorene & $\begin{array}{l}\text { Phenan- } \\
\text { threne }\end{array}$ & $\begin{array}{l}\text { Anthra- } \\
\text { cene }\end{array}$ \\
\hline $\begin{array}{l}\text { Target OL (a) } \\
\text { Achieved OL Low } \\
\text { Achieved OL High }\end{array}$ & $\begin{array}{l}30 \\
0.77 \\
1.48\end{array}$ & $\begin{array}{l}30 \\
1.40 \\
2.70\end{array}$ & $\begin{array}{l}30 \\
1.40 \\
2.70\end{array}$ & $\begin{array}{l}30 \\
2.19 \\
4.23\end{array}$ & $\begin{array}{l}30 \\
1.69 \\
3.25\end{array}$ & $\begin{array}{l}30 \\
1.34 \\
2.58\end{array}$ & $\begin{array}{l}30 \\
2.27 \\
4.37\end{array}$ & $\begin{array}{l}30 \\
2.12 \\
4.09\end{array}$ \\
\hline $\begin{array}{l}\text { PC-1 Replicate } 1 \\
P C-1 \text { Replicate } 2 \\
P C-1 \text { Replicate } 3 \\
P C-1 A \\
P C-2 \\
P C-4 \\
P C-5 \\
\text { Reference }\end{array}$ & $\begin{array}{l}29.69 \mathrm{~B}(\mathrm{~b}) \\
25.14 \mathrm{~B} \\
23.55 \mathrm{~B} \\
14.59 \mathrm{~B} \\
67.29 \mathrm{~B} \\
5.79 \mathrm{~B} \\
5.10 \mathrm{~B} \\
2.07 \mathrm{~B}\end{array}$ & $\begin{array}{r}14.69 \\
13.79 \\
14.04 \\
6.16 \\
12.72 \\
1.91 \\
2.39 \\
0.86 \mathrm{~J}\end{array}$ & $\begin{array}{l}7.77 \\
6.62 \\
7.33 \\
3.00 \\
6.60 \\
1.04 \mathrm{~J} \\
1.25 \mathrm{~J} \\
0.51 \mathrm{~J}\end{array}$ & $\begin{array}{r}4.58 \\
5.16 \\
8.26 \\
6.15 \\
14.21 \\
1.74 \mathrm{~J} \\
22.54 \\
0.21 \mathrm{~J}\end{array}$ & $\begin{array}{l}6.75 \\
3.83 \\
3.65 \\
1.69 \mathrm{~J}(\mathrm{c}) \\
3.78 \\
0.48 \mathrm{~J} \\
2.41 \mathrm{u}^{(\mathrm{d})} \\
1.69\end{array}$ & $\begin{array}{l}7.30 \\
5.55 \\
5.49 \\
2.35 \\
5.04 \\
0.84 \mathrm{~J} \\
3.47 \\
1.34 \mathrm{U}\end{array}$ & $\begin{array}{r}48.13 \\
24.80 \\
35.15 \\
12.34 \\
33.11 \\
4.37 \\
18.60 \\
0.72 \mathrm{~J}\end{array}$ & $\begin{array}{r}12.36 \\
11.94 \\
16.23 \\
9.70 \\
21.98 \\
3.28 \\
31.27 \\
0.34\end{array}$ \\
\hline
\end{tabular}

\footnotetext{
(a) OL Detection limit.

(b) B Analyte found in the procedural blank; results presented are not corrected for the amount in the blank.

(c) J Analyte detected below method detection limit (MDL), but above instrument detection limit (IDL).

(d) $U$ Analyte was not present above the associated value.
} 


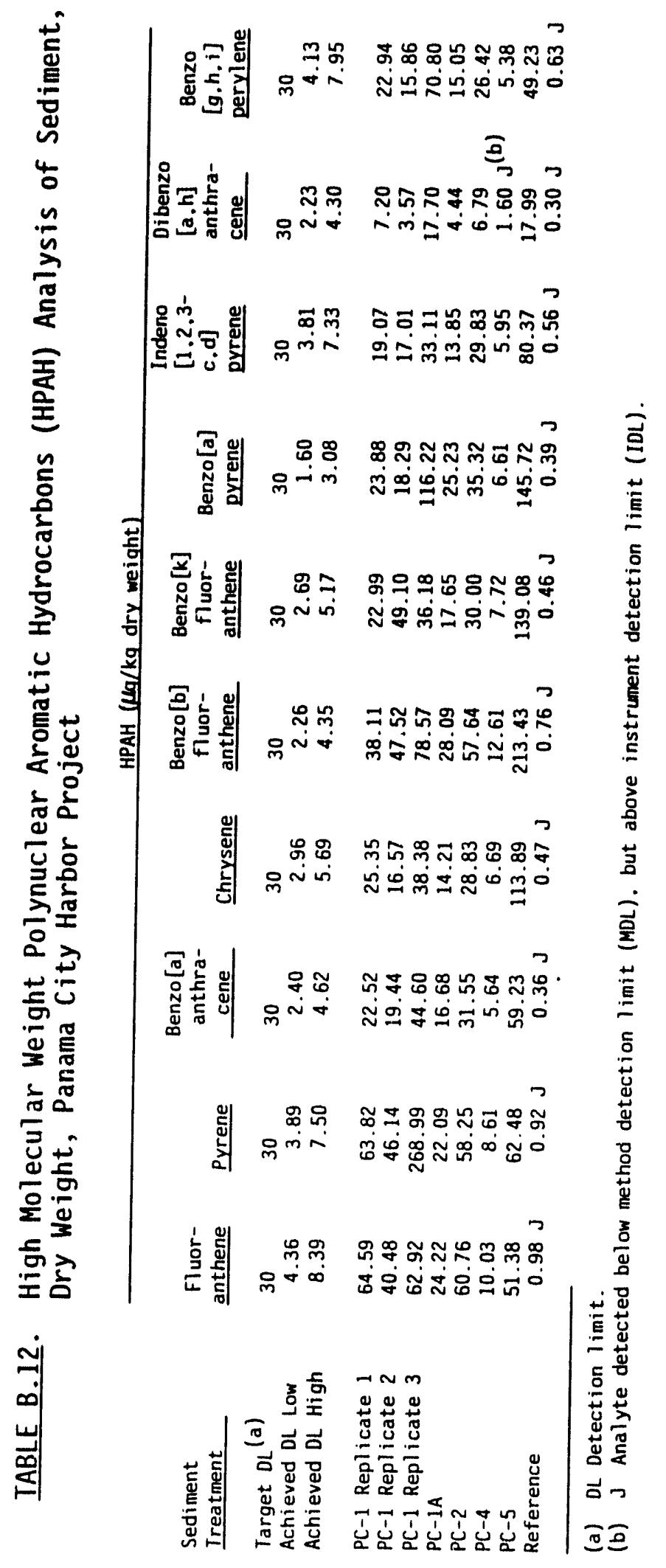

PANAMA CITY HARBOR

B. 12 
IABLE B.13. Quality Control Summary for Low Molecular Weight Polynuclear Aromatic Hydrocarbons (LPAH) Analys is in Sediment, Dry Weight, Panama City Harbor Project

\begin{tabular}{|c|c|c|c|c|c|c|c|c|}
\hline \multirow[b]{2}{*}{$\begin{array}{l}\text { Sediment } \\
\text { Ireatment }\end{array}$} & \multicolumn{8}{|c|}{ LPAH $(\mu \mathrm{g} / \mathrm{kg}$ dry weight) } \\
\hline & $\begin{array}{l}\text { Naphtha- } \\
\text { lene }\end{array}$ & $\begin{array}{l}\text { 2-Methyl- } \\
\text { naphtha- } \\
\text { lene }\end{array}$ & $\begin{array}{l}\text { 1-Methyl- } \\
\text { naphtha- } \\
\text { lene } \\
\end{array}$ & $\begin{array}{l}\text { Acenaph- } \\
\text { thrlene }\end{array}$ & $\begin{array}{l}\text { Acenaph- } \\
\text { thene }\end{array}$ & Eluorene & $\begin{array}{l}\text { Phenan- } \\
\text { threne }\end{array}$ & $\begin{array}{l}\text { Anthra- } \\
\text { cene }\end{array}$ \\
\hline \multicolumn{9}{|l|}{ Method Blank } \\
\hline Blank & $1.77 \mathrm{~B}^{(\mathrm{a})}$ & $0.70 \mathrm{~J}^{(b)}$ & $1.77 u^{(c)}$ & $2.81 \mathrm{U}$ & $2.16 \mathrm{U}$ & $1.71 \mathrm{U}$ & $2.91 \mathrm{U}$ & $2.72 \mathrm{U}$ \\
\hline \multicolumn{9}{|l|}{ Matrix Spike } \\
\hline $\begin{array}{l}\text { Reference } \\
\text { Reference MS } \\
\text { Concentration Recovered } \\
\text { Amount Splked } \\
\text { Percent Recovery }\end{array}$ & $\begin{array}{r}2.07 \text { B } \\
84.78 \\
82.71 \\
84.32 \\
98 \%\end{array}$ & $\begin{array}{l}0.86 \\
N A \\
N A \\
N S \\
N A \\
N A\end{array}$ & $\begin{array}{l}0.51 \mathrm{~J} \\
N A \\
N A \\
N S \\
N A\end{array}$ & $\begin{array}{r}0.21 \mathrm{~J} \\
80.48 \\
80.27 \\
84.32 \\
95 \%\end{array}$ & $\begin{array}{l}1.69 \mathrm{U} \\
81.17 \\
81.17 \\
84.32 \\
96 \%\end{array}$ & $\begin{array}{c}1.34 U \\
87.44 \\
87.44 \\
84.32 \\
104 \%\end{array}$ & $\begin{array}{l}0.72 \mathrm{~J} \\
92.96 \\
92.24 \\
84.32 \\
109 \%\end{array}$ & $\begin{array}{r}0.34 \mathrm{~J} \\
87.44 \\
87.10 \\
84.32 \\
103 \%\end{array}$ \\
\hline \multicolumn{9}{|l|}{ Standard Reference Material } \\
\hline $\begin{array}{l}\text { Certified } \\
\text { Value }\end{array}$ & $N C^{(f)}$ & NC & NC & NC & NC & NC & $\begin{array}{l}577 \\
\pm 59\end{array}$ & $\begin{array}{l}202 \\
\pm 42\end{array}$ \\
\hline NIST 1941 & NA & NA & NA & NA & NA & NA & 594.66 & 191.24 \\
\hline \multicolumn{9}{|l|}{ Analytical Replicates } \\
\hline $\begin{array}{l}P C-1 \text { Replicate } 1 \\
\text { PC-1 Replicate } 2 \\
\text { PC-1 Repl icate } 3 \\
\text { RSD }\end{array}$ & $\begin{array}{c}29.69 \mathrm{~B} \\
25.14 \mathrm{~B} \\
23.55 \mathrm{~B} \\
12 \%\end{array}$ & $\begin{array}{r}14.69 \\
13.79 \\
14.04 \\
3 \%\end{array}$ & $\begin{array}{r}7.77 \\
6.62 \\
7.33 \\
8 \%\end{array}$ & $\begin{array}{l}4.58 \\
5.16 \\
8.26 \\
33 \%(g)\end{array}$ & $\begin{array}{l}6.75 \\
3.83 \\
3.65 \\
37 \%(g)\end{array}$ & $\begin{array}{l}7.30 \\
5.55 \\
5.49 \\
17 \%\end{array}$ & $\begin{array}{l}48.13 \\
24.80 \\
35.15 \\
32 \%(g)\end{array}$ & $\begin{array}{l}12.36 \\
11.94 \\
16.23 \\
18 \%\end{array}$ \\
\hline
\end{tabular}

(a) B Analyte found in the procedural blank: results presented are not corrected for the amount in the blank.

(b) J Analyte detected below method detection limit (MDL), but above instrument detection limit (IOL).

(c) U Analyte was not present above the associated value.

(d) NA Not applicable.

(e) NS Not spiked.

(f) NC Not certified.

(g) Value exceeds relative precision range of $\leq 30 \%$. 


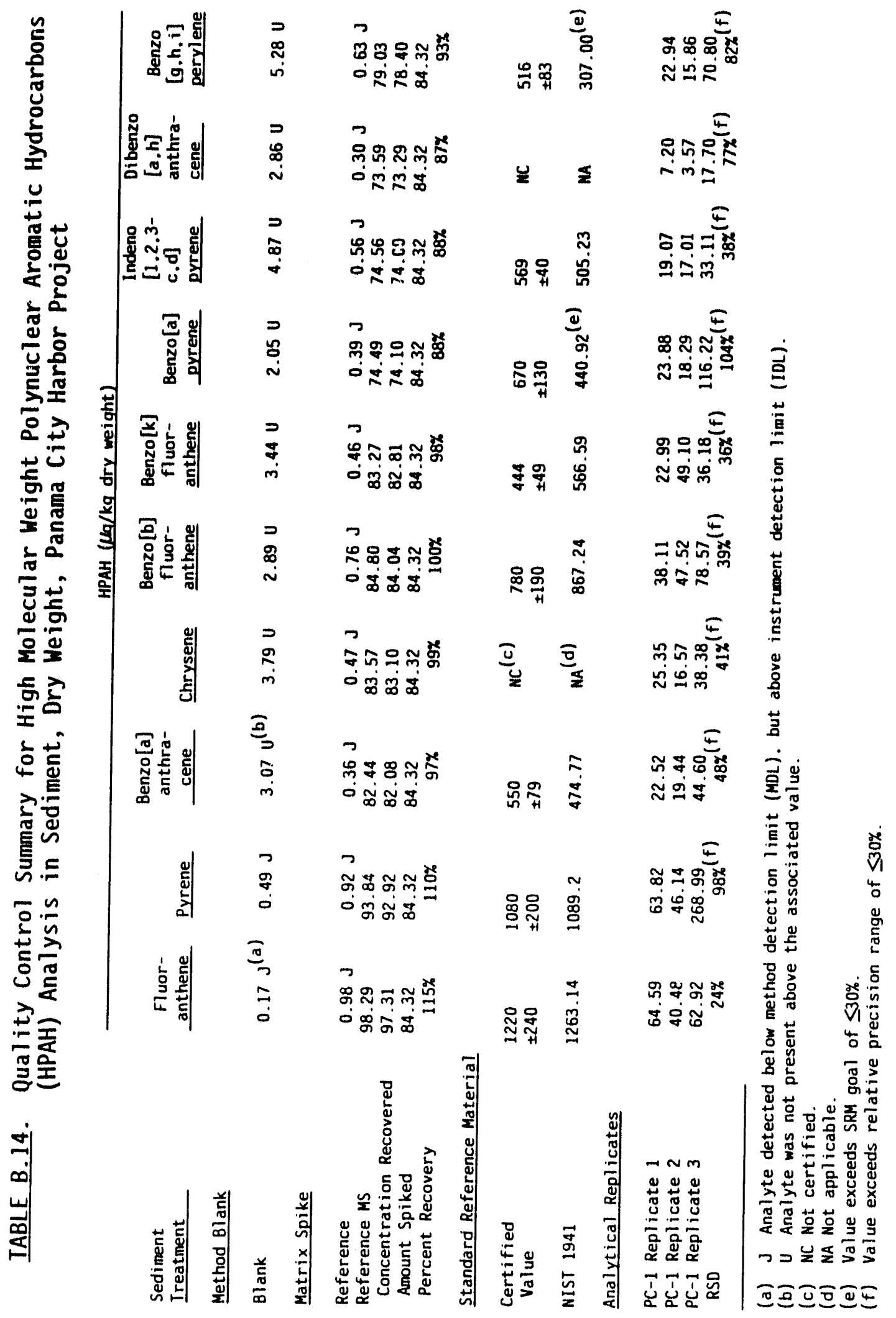

PANAMA CITY HARBOR

B. 14 


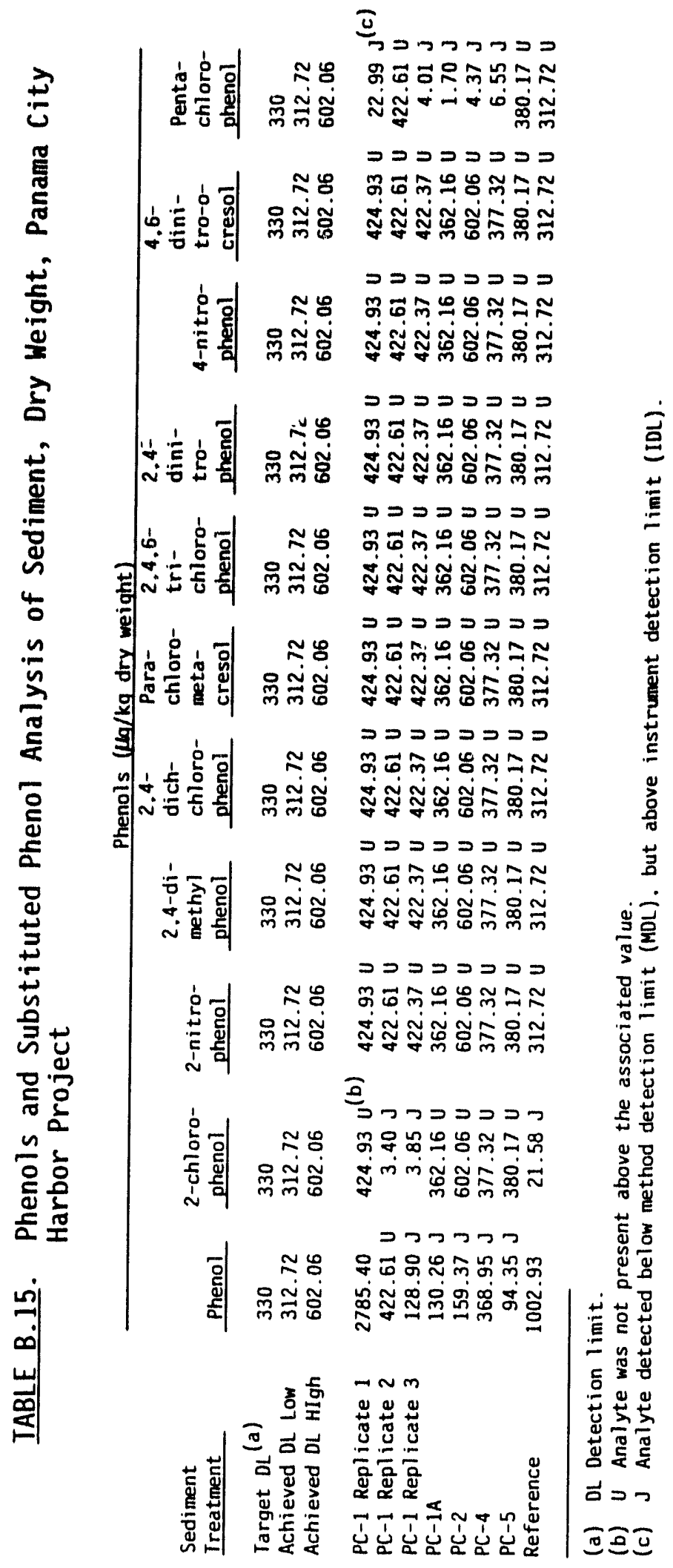

PANAMA CITY HARBOR 


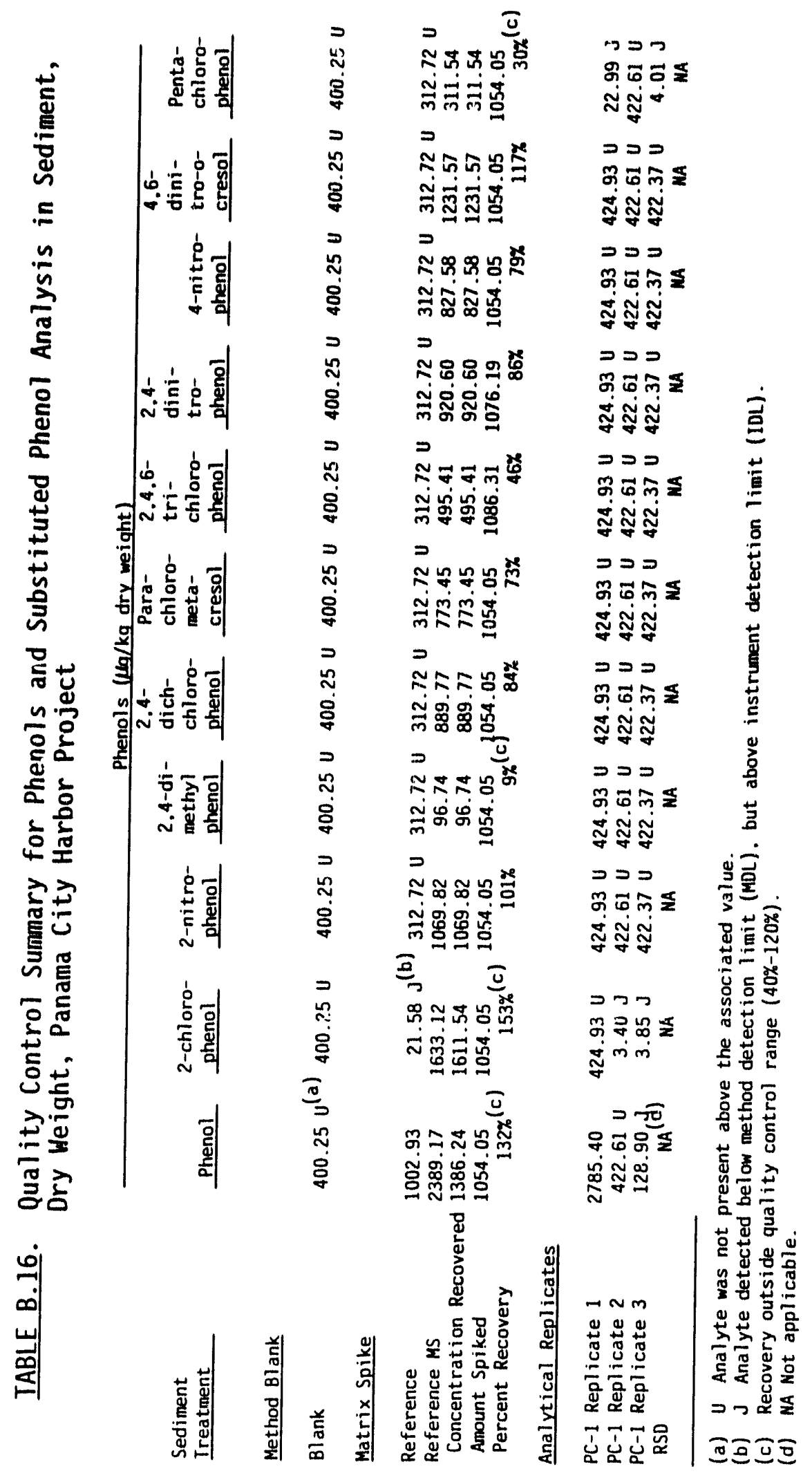

PANAMA CITY HARBOR

B. 16 
IABLE B.17. Phthalate Ester Analysis of Sediment, Dry Weight, Panama City Harbor Project

\begin{tabular}{|c|c|c|c|c|c|c|}
\hline \multirow[b]{2}{*}{$\begin{array}{l}\text { Sudiment } \\
\text { Ireatment }\end{array}$} & \\
\hline & $\begin{array}{r}\text { Dimethyl } \\
\text { phthelete }\end{array}$ & $\begin{array}{c}\text { Diethyl } \\
\text { phthelate }\end{array}$ & $\begin{array}{l}\text { Di-n-butyl } \\
\text { phthalate }\end{array}$ & $\begin{array}{l}\text { Butyl } \\
\text { benzyl } \\
\text { phthelate }\end{array}$ & $\begin{array}{c}\text { Bis } \\
(2-e t h y 1 \text { hexyl) } \\
\text { phthalate }\end{array}$ & $\begin{array}{l}01-n \text {-octyl } \\
\text { ohthalate }\end{array}$ \\
\hline $\begin{array}{l}\text { Target OL (a) } \\
\text { Achleved OL Low } \\
\text { Achleved OL High }\end{array}$ & $\begin{array}{l}100 \\
62.54 \\
120.41\end{array}$ & $\begin{array}{c}100 \\
62.54 \\
120.41\end{array}$ & $\begin{array}{l}100 \\
62.54 \\
120.41\end{array}$ & $\begin{array}{l}100 \\
62.54 \\
120.41\end{array}$ & $\begin{array}{l}100 \\
62.54 \\
120.41\end{array}$ & $\begin{array}{l}100 \\
62.54 \\
120.41\end{array}$ \\
\hline $\begin{array}{l}\text { PC-1 Replicate } 1 \\
\text { PC-1 Replicate } 2 \\
\text { PC-1 Replicate } 3 \\
\text { PC-1A } \\
\text { PC-2 } \\
\text { PC-4 } \\
\text { PC-5 } \\
\text { Reference }\end{array}$ & $\begin{array}{r}84.99 U^{(b)} \\
84.52 U \\
84.47 \mathrm{U} \\
72.43 \mathrm{U} \\
120.41 \mathrm{U} \\
75.46 \mathrm{U} \\
0.99 \mathrm{~J} \\
1.08 \mathrm{~J}\end{array}$ & $\begin{array}{l}21.06 \mathrm{~J}(\mathrm{c}) \\
66.16 \mathrm{~J} \\
39.16 \mathrm{~J} \\
32.54 \mathrm{~J} \\
56.66 \mathrm{~J} \\
17.67 \mathrm{~J} \\
18.79 \mathrm{~J} \\
14.28 \mathrm{~J}\end{array}$ & $\begin{array}{r}6.60 \mathrm{~J} \\
1.95 \mathrm{~J} \\
2.77 \mathrm{~J} \\
2.10 \mathrm{~J} \\
120.41 \mathrm{U} \\
2.18 \mathrm{~J} \\
2.75 \mathrm{~J} \\
2.51 \mathrm{~J}\end{array}$ & $\begin{array}{r}5.65 \mathrm{~J} \\
1.59 \mathrm{~J} \\
84.47 \mathrm{U} \\
4.60 \mathrm{~J} \\
14.20 \mathrm{~J} \\
3.98 \mathrm{~J} \\
5.45 \mathrm{~J} \\
2.60 \mathrm{~J}\end{array}$ & $\begin{array}{l}27.42 \mathrm{~J} \\
18.37 \mathrm{~J} \\
18.93 \mathrm{~J} \\
17.55 \mathrm{~J} \\
62.20 \mathrm{~J} \\
22.42 \mathrm{~J} \\
45.30 \mathrm{~J} \\
43.45 \mathrm{~J}\end{array}$ & $\begin{array}{r}1.81 \mathrm{~J} \\
2.00 \mathrm{~J} \\
1.92 \mathrm{~J} \\
2.29 \mathrm{~J} \\
120.41 \mathrm{U} \\
3.04 \mathrm{~J} \\
4.46 \mathrm{~J} \\
12.69 \mathrm{~J}\end{array}$ \\
\hline
\end{tabular}

(a) DL Detection limit.

(b) U Analyte was not present above the associated value.

(c) J Analyte detected below method detection 1 imit (MDL), but above instrument detection 1 Imit (IOL). 
IABLE B.18. Quality Control Summary for Phthalate Ester Analysis In Sediment, Dry Woight, Panama City Harbor Project

\begin{tabular}{|c|c|c|c|c|c|c|}
\hline \multirow[b]{2}{*}{$\begin{array}{l}\text { Sediment } \\
\text { Irentment }\end{array}$} & \multicolumn{6}{|c|}{ Phthalates (Ma/ko dry welaht) } \\
\hline & $\begin{array}{l}\text { Dimethyl } \\
\text { ohthalate }\end{array}$ & $\begin{array}{c}\text { Olathyl } \\
\text { phthalate }\end{array}$ & $\begin{array}{l}\text { D1-n-butyl } \\
\text { phthalate }\end{array}$ & $\begin{array}{l}\text { Butyl } \\
\text { benzyl } \\
\text { phthalate }\end{array}$ & $\begin{array}{c}\text { B/s } \\
(2-\text { thylhexy1) } \\
\text { ohthalate }\end{array}$ & $\begin{array}{l}\text { Di-n-octyl } \\
\text { phthalate }\end{array}$ \\
\hline \multicolumn{7}{|l|}{ Method Blenk } \\
\hline Blank & $80.05 U^{(a)}$ & $18.02 J^{(b)}$ & $1.18 \mathrm{~J}$ & $1.74 \mathrm{~J}$ & $5.67 \mathrm{~J}$ & $0.26 \mathrm{~J}$ \\
\hline \multicolumn{7}{|l|}{ Matrix Solks } \\
\hline $\begin{array}{l}\text { Reference } \\
\text { Reference MS } \\
\text { Concentratlon Recovered } \\
\text { Anount Splked } \\
\text { Percent Recovery }\end{array}$ & $\begin{array}{c}1.08 \mathrm{~J} \\
1083.75 \\
1082.67 \\
1054.05 \\
103 \%\end{array}$ & $\begin{array}{r}14.28 \mathrm{~J} \\
1164.72 \\
1150.44 \\
1081.04 \\
1064\end{array}$ & $\begin{array}{r}2.51 \mathrm{~J} \\
1095.48 \\
1092.97 \\
1054.05 \\
104 x\end{array}$ & $\begin{array}{r}2.60 \mathrm{~J} \\
1150.39 \\
1147.79 \\
1054.05 \\
109 \%\end{array}$ & $\begin{array}{r}43.45 \mathrm{~J} \\
1210.08 \\
1167.53 \\
1054.05 \\
111 \times\end{array}$ & $\begin{array}{r}12.69 \mathrm{~J} \\
991.20 \\
978.51 \\
1054.05 \\
93 \%\end{array}$ \\
\hline \multicolumn{7}{|l|}{ Analytical Reolicates } \\
\hline $\begin{array}{l}\text { PC-1 Repl lcate } 1 \\
\text { PC-1 Repl Icate } 2 \\
\text { PC-1 Repl lcate } 3 \\
\text { RSD }\end{array}$ & $\begin{array}{l}84.99 U \\
84.52 U \\
84.47 \text { ( U) } \\
N A\end{array}$ & $\begin{array}{l}21.06 \mathrm{~J} \\
66.16 \mathrm{~J} \\
39.16 \mathrm{~J} \\
54 \times(d)\end{array}$ & $\begin{array}{l}6.60 \mathrm{~J} \\
1.95 \mathrm{~J} \\
2.77 \mathrm{~J} \\
66 \times(\mathrm{d})\end{array}$ & $\begin{array}{r}5.65 \mathrm{~J} \\
1.59 \mathrm{~J} \\
84.47 \mathrm{U} \\
\mathrm{NA}\end{array}$ & $\begin{array}{c}27.42 \mathrm{~J} \\
18.37 \mathrm{~J} \\
18.93 \mathrm{~J} \\
24 \mathrm{x}\end{array}$ & $\begin{array}{l}1.81 \mathrm{~J} \\
2.00 \mathrm{~J} \\
1.92 \mathrm{~J} \\
5 \%\end{array}$ \\
\hline
\end{tabular}

(a) U Analyte was not present above the associated value.

(b) J Analyte detected below mathod detection 1 ImIt (MOL), but above instrument detection $1 / \mathrm{mIt}$ (IOL).

(c) NA Not appl lcable.

(d) Value exceeds relative precision range of $\leq 30 \%$. 
IABLE B.19. Surrogate Recoveries and Quality Control Data for Polynuclear Aromatic Hydrocarbons (PAH), Phenols, and Phthalate Ester in Sediment, Dry Weight, Panama City Harbor Project

Sediment

Ireatment.

$P C-1$ Replicate 1

PC-1 Replicate 2

PC-1 Replicate 3

$P C-1 A$

$P C-2$

$P C-4$

$P C-5$

Reference
Surrogate Percent Recovery

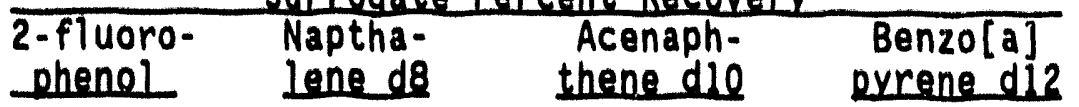

$\begin{array}{cc}3^{(a)} & 55 \\ 32^{(a)} & 59 \\ 32^{(a)} & 62 \\ 54 & 65 \\ 35^{(a)} & 64 \\ 10^{(a)} & 57 \\ 30^{(a)} & 57 \\ 8^{(a)} & 54\end{array}$

57

69

75

77

68

71

77

63

Quality Control Data

Method Blank

Bl ank

48

71

67

45

Matrix Solke

Reference

Reference MS

$8^{(a)}$

$26^{(4)}$
54

54
70

71

63

67

Analytical Replicates

PC-1 Replicate 1

PC.1 Replicate 2

PC-1 Replicate 3 RSD

$$
\begin{aligned}
& 3^{(a)} \\
& 32^{(a)} \\
& 32^{(a)} \\
& 75 \%
\end{aligned}
$$

55
59
62

$6 \%$
74
76
78

$3 \%$
57

69

75

(a) Recovery outside of qualtty control range (40\%-120\%).

(b) Value exceeds relative precision range of $530 \%$. 


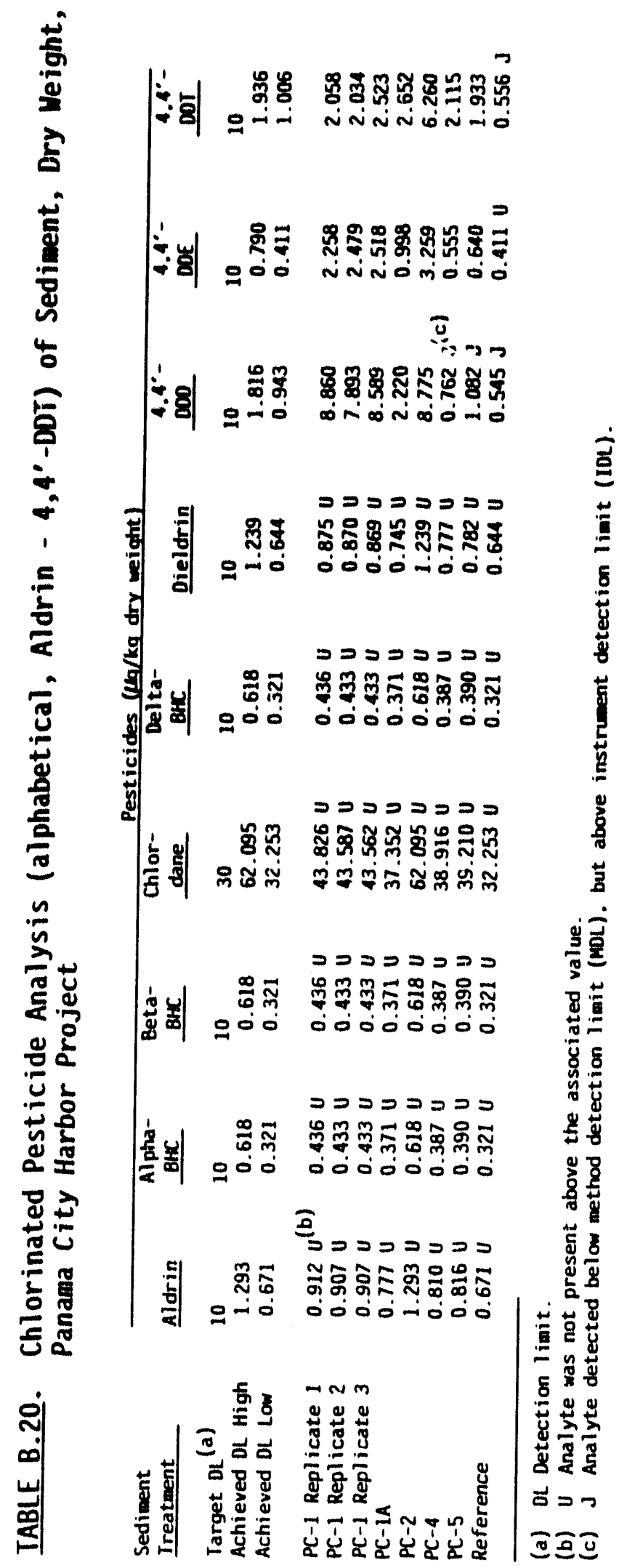

PANAMA CITY HARBOR 


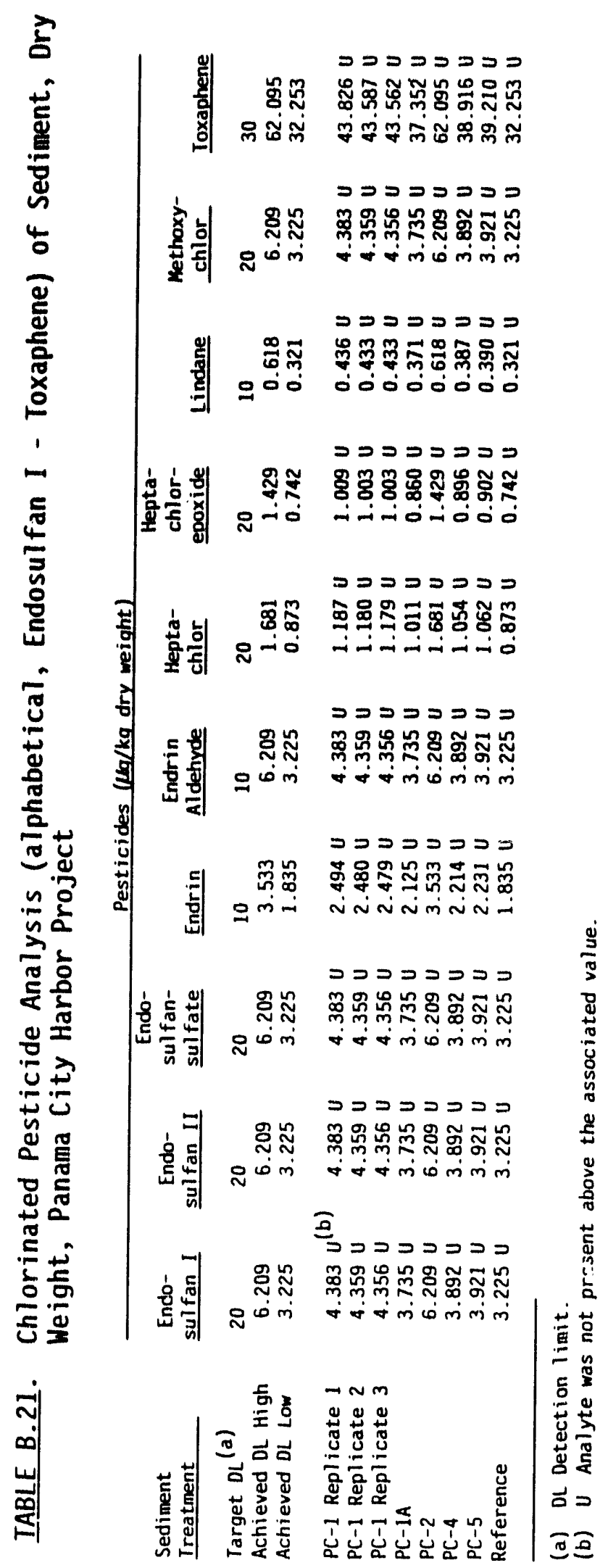




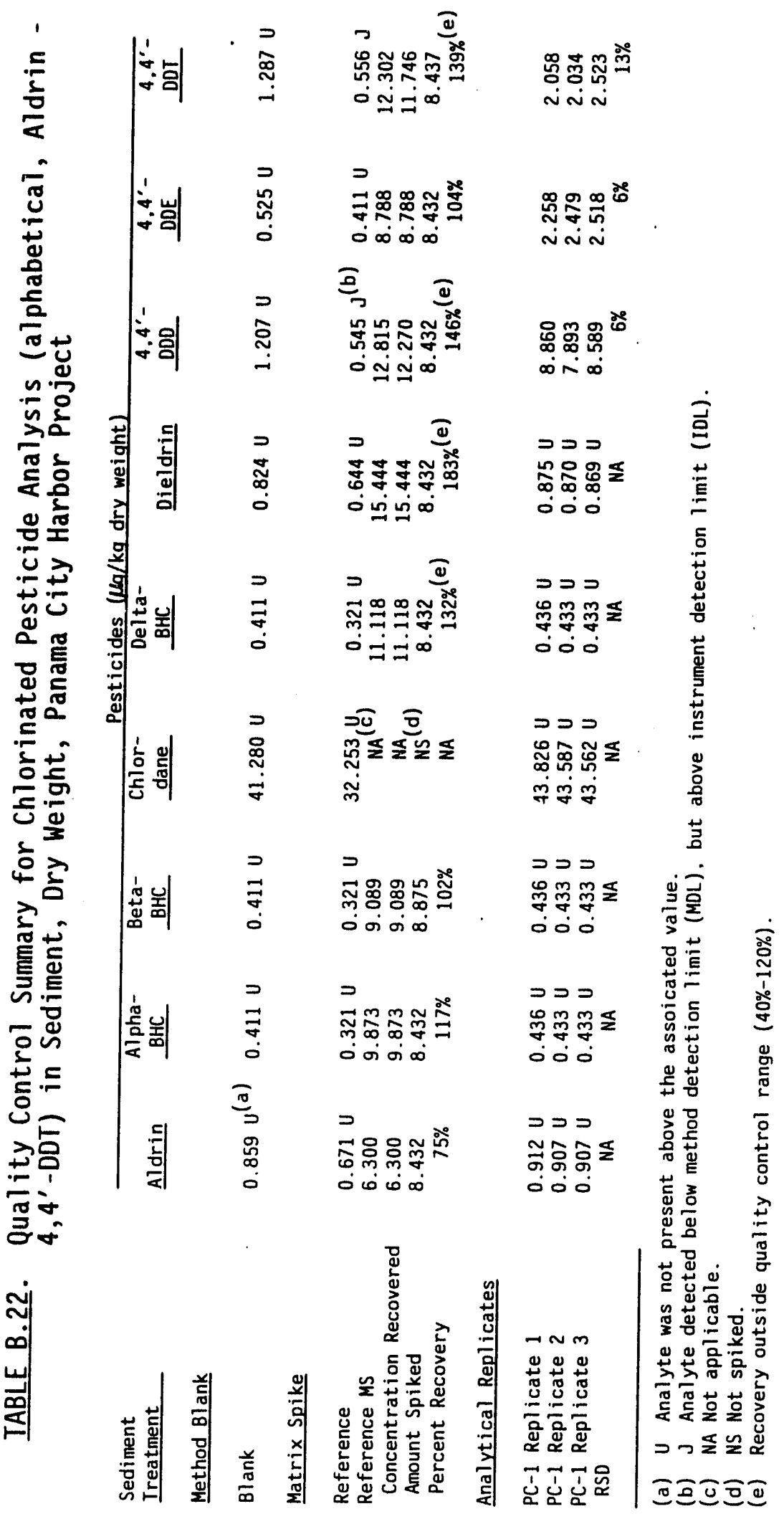

PANAMA CITY HARBOR 


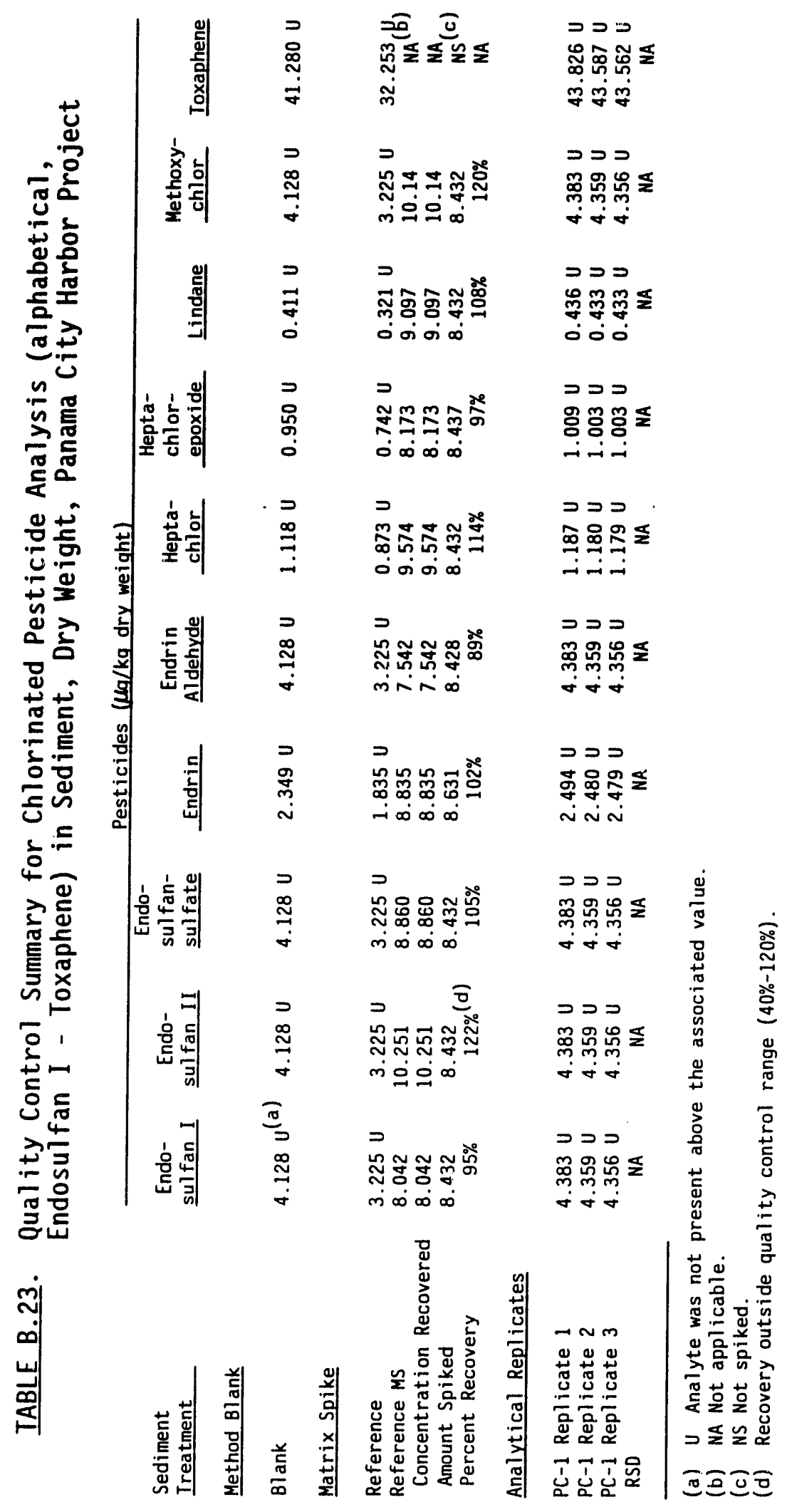

PANAMA CITY HARBOR

B. 23 
TABLE B.24. Polychlorinated Biphenyls (PCB) Analysis of Sediment, Dry Weight, Panama City Harbor Project

Sediment

Treatment

Target DL (a)

Achieved DL High

Achieved DL Low

\begin{tabular}{|c|c|}
\hline $\begin{array}{l}\text { Aroclor } \\
1221\end{array}$ & $\begin{array}{c}\text { Aroclor } \\
1232 \\
\end{array}$ \\
\hline $\begin{array}{l}20 \\
62.095 \\
32.253\end{array}$ & $\begin{array}{l}20 \\
62.095 \\
32.253\end{array}$ \\
\hline $\begin{array}{l}43.826 U^{(b)} \\
43.587 U \\
43.562 U \\
37.352 U \\
62.095 U \\
38.916 U \\
39.210 U \\
32.253 U\end{array}$ & $\begin{array}{l}43.826 U \\
43.587 U \\
43.562 U \\
37.352 U \\
62.095 U \\
38.916 U \\
39.210 U \\
32.253 U\end{array}$ \\
\hline
\end{tabular}

PCBs $(\mu \mathrm{g} / \mathrm{kg}$ dry weight)

Aroclor Aroclor

$1242 / 1016 \quad 1248$

Aroclor Aroclor

20

62.095

20

62.095

1254

1260

PC-1 Replicate 1

PC-1 Replicate 2

PC-1 Replicate 3

$P C-1 A$

32.253

32.253

62.095

20

$43.826 \mathrm{U}$

$43.826 \mathrm{U}$

$43.587 U$

$43.587 \mathrm{U}$

$43.562 \mathrm{U}$

$37.352 \mathrm{U}$

$43.562 U$

$37.352 U$

$62.095 \mathrm{U}$

$38.916 U$

$62.095 \mathrm{U}$

$38.916 \mathrm{U}$

$39.210 \mathrm{U}$

$39.210 \mathrm{U}$

32.253

62.095

PC-4

$P C-5$
Reference

$32.253 \mathrm{U}$

$32.253 \mathrm{U}$

$32.253 \mathrm{U}$

$38.266 \mathrm{~J}(\mathrm{c})$

$40.891 \mathrm{~J}$

$29.514 \mathrm{~J}$

$11.308 \mathrm{~J}$

$24.158 \mathrm{~J}$

$38.916 \mathrm{U}$

$39.210 \mathrm{U}$

$32.253 U$

32.253

(a) OL Detection limit.

(b) $U$ Analyte was not present above the associated value.

(c) J Analyte detected below method detection limit (MOL), but above instrument detection 1 imit (IDL). 
TABLE B.25. Quality Control Summary for Polychlorinated Biphenyls (PCB) Analysis of Sediment, Dry Weight, Panama City Harbor Project

Sediment

Ireatment

Method Blank

Blank

Matrix Spike

\begin{tabular}{llllll}
\multicolumn{8}{c}{ PCBs $(\mu \mathrm{g} / \mathrm{kg}$ dry weight $)$} \\
\hline Aroclor & Aroclor & Aroclor & Aroclor & Aroclor & Aroclor \\
1221 & 1232 & $1242 / 1016$ & 1248 & -1254 & 1260 \\
\hline
\end{tabular}

$41.280 U^{(a)} \quad 41.280 U$

$41.280 \mathrm{U}$

$41.280 U$

$41.280 \mathrm{U}$

$41.280 \mathrm{U}$

$32.253 \mathrm{U}$
NA
NA
NS
NA

$43.826 \cup$
$43.587 \cup$
$43.562 U$
NA

$32.253 U$
$N A$
$N A$
$N S$
$N A$

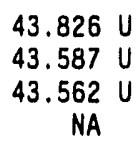

NA

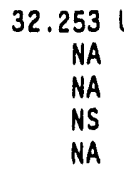

$43.826 U$
$43.587 U$
$43.562 U$
NA
$32.253 \mathrm{U}$

174.902

174.902

179.189

$98 \%$
$32.253 \mathrm{U}$

NA

NA

NS

NA

\title{
Analytical Replicates
}

\begin{abstract}
PC-1 Replicate 1
PC-1 Replicate ?

RSD
\end{abstract}

$43.826 U$
$43.587 U$
$43.562 U$

NA

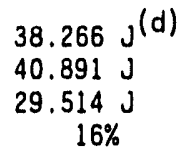

$43.826 \mathrm{U}$ $43.587 \mathrm{U}$ $43.562 U$ NA

(a) U Analyte was not present above the associated value.

(b) NA Not applicable.

(c) NS Not spiked.

(d) J Analyte detected below method detection limit (MOL), but above instrument detection limit (IDL). 
IABLE B.26. Surrogate Recoveries and Quality Control Data for Chlorinated Pesticides and Polychlorinated Biphenyls (PCB) in Sediment, Dry Weight, Panama City Harbor Project

Sediment

Treatment

PC-1 Replicate 1

$P C-1$ Replicate 2

$P C-1$ Replicate 3

PC - $1 A$

$P C-2$

$\mathrm{PC}-4$

PC-5

Reference

Quality Control Data

Method Blank

Bl ank

Matrix Spike

Reference

Reference MS

Analytical Replicates

PC-1 Replicate 1

PC-1 Replicate 2

PC-1 Replicate 3

RSD
Surrogate

Percent Recoveries

DBOFB

CL5(112)

37
93
120
108
105
92
87
74

67

80

80

69

71

78

75

77

62

68

74

77

75

85

97

67

93

80

120

80

$14 \%$

$10 \%$ 
IABLE B.27. Metals Analysis (alphabetical, Ag - $\mathrm{Hg}$ ) of Sediment, Dry Weight, Panama City Harbor Project

Sediment

Ireatment

Target $O L^{(a)}$

Achieved DL

$P C-1$

PC- $1 A$

PC-2

$P C-4$

$\mathrm{PC}-5$

Reference Replicate 1

Reference Replicate 2

Reference Replicate 3

\begin{tabular}{|c|c|}
\hline $\mathrm{Aq}$ & Al \\
\hline $\begin{array}{l}0.1 \\
0.01\end{array}$ & $\begin{array}{l}5.0 \\
0.1\end{array}$ \\
\hline $\begin{array}{l}0.05 \\
0.07 \\
0.15 \\
0.06 \\
0.04 \\
0.01 \\
0.01 \\
0.02\end{array}$ & $\begin{array}{r}2720 \\
7030 \\
14000 \\
3210 \\
4070 \\
1680 \\
1800 \\
1750\end{array}$ \\
\hline
\end{tabular}

Metals (ma $/ \mathrm{kg}$ dry weight)

(a) DL Detection 1 imit.

(b) U Analyte was not present above the associated value.

$\mathrm{Cd} \quad \mathrm{Cr}$

0.1

0.1

0.2

0.01

4.86

3.46

0.01

0.03

0.02

0.21

0.7

0.19

3.09

0.14

0.01

0.02

$0.01 u^{(b)}$

0.01

0.02

0.65

$0.01 \mathrm{U}$

$0.01 \mathrm{U}$

$\mathrm{Cr}$

$\mathrm{Cu}$

$\mathrm{Ha}$

0.6

0.1

0.01

0.71

0.01

0.01

0.01

0.0016

20.60

13.40

5.80

4.75

33.70

9.93

2.97

9.82

2.11

2.19

2.91

0.95

0.83

0.45

0.0594

0.0320

0.0840

0.0235

0.0286

0.0031

0.0033

0.0032 
IABLE B.28. Metals Analysis (alphabetical, Ni - Zn) of Sediment, Dry Weight, Panama City Harbor Project

Sediment Ireatment

Target $D L$ (a)

Achieved DL

$P C-1$

PC- 1 A

$\mathrm{PC}-2$

$P C-4$

$P C-5$

Reference Replicate 1

Reference Replicate 2

Reference Replicate 3

\begin{tabular}{lr}
\hline$N L$ & $P b$ \\
0.1 & 0.1 \\
0.01 & 0.01 \\
5.15 & \\
3.24 & 8.32 \\
9.55 & 6.18 \\
2.99 & 24.10 \\
2.39 & 6.86 \\
0.71 & 9.00 \\
0.70 & 1.76 \\
0.71 & 1.09 \\
& 5.19
\end{tabular}

Metals (ma/kg dry welaht)

Se Il Il

0.2

0.05

0.1

0.01

0.1

0.3

$0.05 u^{(b)}$

0.11

0.7

$0.05 U$

$0.05 U$

$0.05 \mathrm{U}$

$0.05 U$

0.140

0.01

0.05

(a) OL Detection IImit.

(b) U Analyte was not present above the associated value. 
IABLE B.29. Quality Control Summary for Metals (alphabetical, $\mathrm{Ag}-\mathrm{Hg}$ ) in Sediment, Dry Weight, Panama City Harbor Project

Sediment Ireatment

Method Blank

Blank

Matrix Soike

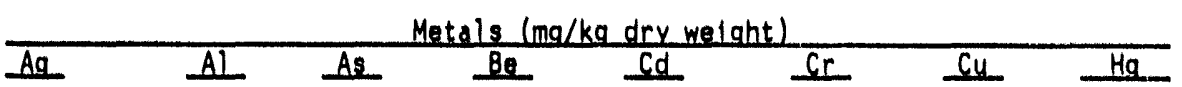
$0.01 u^{(a)}$
30
$0.01 \mathrm{U}$
$0.01 \mathrm{U}$
$0.01 U$
0.20
$0.01 U$
0.0008

$$
\begin{aligned}
& 0.07 \\
& 0.78 \\
& 0.71 \\
& 0.99
\end{aligned}
$$

Amount Spiked

Percent Recovery

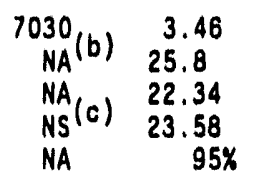

0.21

2.87

2.66

2.36

$113 \%$

0.02
0.96
0.94
0.99
$95 \%$

13.4

61.8

48.4

58.96

4.75

0.032

56.0

51.25

58.96

0.102

$82 \%$

$87 \%$

Standard Reference Material

Certified

Value

$1646-1$

$1646-2$

Analytical Replicates

$$
\mathrm{NC}(\mathrm{e})
$$

$$
62500
$$$$
\pm 2000
$$

11.6
\pm 1.3

NC

0.36
\pm 0.07

76
\pm 3

18

0.063

$0.4 \quad 63000$

11.2

${ }_{N A}^{11.2}$

2.03

NA

0.36

NA

$69.2 \quad 17.5$

17.5

$\pm 0.012$

0.0667

0.0654

$\begin{array}{lll}0.65 & 0.01 & 0.01 U \\ 0.71 & 0.02 & 0.01 U \\ 0.72 & 0.01 & 0.01 U \\ 5 \% & { }_{43 \%}(f) & \text { NA }\end{array}$

2.11
2.19
2.08
$3 \%$

$\begin{array}{lr}0.95 & 0.0031 \\ 0.83 & 0.0033 \\ 0.45 & 0.0032 \\ 35 \% & \end{array}$

(a) U Analyte was not present above the assoclated value.

(b) NA Not applicable.

(c) NS Not spiked.

(d) Recovery outside quality control range (75\%-125\%).

(e) NC Not certified.

(f) Value exceeds relative precision range of $\leq 20 \%$. 
IABLE B,30. Quality Control Summary for Metals (alphabetical, Ni - $\mathrm{Zn}$ ) in Sediment, Dry Weight, Panama City Harbor Project

Sediment

Iroatment

Mothod Blank

Blank

Matrix Soike

$P C-1 A$

PC-1A MS

Concentration Recovered

Amount Splked

Percent Recovery

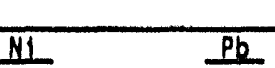

1.10

0.092

3.24
51.4
48.16
58.96
$82 x$

6.18

67.9

61.72

58.96

$105 \%$

Standard Reference Material

Certifled
Value
$1646-1$
$1646-2$

32

$\pm 3$

24.9

NA

28.2

$\pm 1.8$

29.9

NA

Analytical Replicates

$\begin{array}{ccccccc}\text { Reference Replicate 1 } & 0.71 & 1.76 & 0.05 U & 0.020 & 0.01 U & 3.83 \\ \text { Reforence Replicate 2 } & 0.70 & 1.09 & 0.05 U & 0.016 & 0.01 U & 3.87 \\ \text { Reforence Replicate 3 } & 0.71 & 5.19 & 0.05 U & 0.027 & 0.06 & 2.83 \\ \text { RSD } & 1 \% & 82 X(f) & \text { NA } & 27 \%(f) & \text { NA } & 17 \%\end{array}$

Metals (ma/ka dry weiaht)

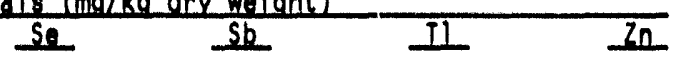

(a) U Analyte was not present above the associated value.

(b) NA Not applicable.

(c) NS Not spiked.

(d) Recovery outside quality control range $(75 \%-125 \%)$.

(e) NC Not certified.

(f) Value exceeds relative precision range of $\leq 20 \%$.
0.11

4.88

4.77

7.88

$61 x^{(d)}$

0.58

0.52

1. 18 (d)

2.81

2.715

2.36

$115 x$

NC(e)

NC

NC

0.71

NA

0.24

NA

0.63

NA

108

$$
\begin{aligned}
& 14.3 \\
& N A \\
& N A \\
& N S \\
& N A \\
& N A
\end{aligned}
$$


IABLE B.31. Butyltin Analysis of Sediment, Dry Weight, Panama City Harbor Project

\begin{tabular}{|c|c|c|c|c|}
\hline \multirow[b]{2}{*}{$\begin{array}{l}\text { Sediment } \\
\text { Ireatment }\end{array}$} & \multirow{2}{*}{$\begin{array}{c}\text { Surrogate } \\
\text { Percent } \\
\text { Recovery } \\
\text { Tri- } \\
\text { Dentyltin }\end{array}$} & \multicolumn{3}{|c|}{ Butyltins (ug/kg dry weight) } \\
\hline & & $\begin{array}{c}\text { Tri- } \\
\text { butyltin }\end{array}$ & $\begin{array}{l}\text { Di- } \\
\text { butyltin }\end{array}$ & $\begin{array}{l}\text { Mono- } \\
\text { butylt in }\end{array}$ \\
\hline $\begin{array}{l}\text { Target } D L(a) \\
\text { Achleved High DL } \\
\text { Achieved Low DL }\end{array}$ & $\begin{array}{l}N A^{(b)} \\
N A \\
N A\end{array}$ & $\begin{array}{l}10 \\
2.7 \\
1.6\end{array}$ & $\begin{array}{l}10 \\
2.2 \\
1.3\end{array}$ & $\begin{array}{l}10 \\
3.8 \\
2.3\end{array}$ \\
\hline $\begin{array}{l}P C-1 \\
P C-1 A \text { Repl icate } 1 \\
P C-1 A \text { Repl icate } 2 \\
P C-1 A \text { Replicate } 3 \\
P C-2 \\
P C-4 \\
P C-5 \\
\text { Reference }\end{array}$ & $\begin{array}{r}107 \\
57 \\
101 \\
96 \\
99 \\
103 \\
102 \\
105\end{array}$ & $\begin{aligned} & 3.7 \\
& 1.6 \mathrm{~J} \\
& 2.0 \mathrm{U} \\
& 2.0 \mathrm{U} \\
& 11.1 \\
& 1.1 \mathrm{~J} \\
& 5.1 \mathrm{U} \\
& 1.8 \mathrm{U}\end{aligned}$ & $\begin{array}{l}1.2 \mathrm{~J}^{(\mathrm{c})} \\
2.2 \mathrm{U} \\
1.5 \mathrm{U} \\
1.6 \mathrm{~J} \\
2.6 \mathrm{U} \\
1.3 \mathrm{U} \\
2.3 \mathrm{U} \\
2.2 \mathrm{U}\end{array}$ & $\begin{array}{l}2.6 U^{(d)} \\
3.8 U \\
2.6 U \\
4.0 \\
2.5 U \\
2.3 U \\
2.4 U \\
2.6 U\end{array}$ \\
\hline
\end{tabular}
(a) OL Detection 1 imit.
(b) NA Not applicable.
(c) J Analyte detected below method detection 1 imit (MDL), but above instrument detection 1 imit (IDL).
(d) U Analyte was not present above the associated value. 
IABLE B.32. Quality Control Summary for Butyltins in Sediment, Dry Weight, Panama City Harbor Project

Sediment

Ireatment

\section{Surrogate \\ Percent}

Recovery

Tri-

pentyltin

$\frac{\text { Butyltins (ug/kg dry weight) }}{\text { Tri- }}$

Method Blank

Blank

111

$1.9 U^{(a)}$

$1.5 \mathrm{U}$

$2.7 \mathrm{U}$

Matrix Solke

$P C-5$

PC-5 MS

Concentration Recovered

Amount Splked

Percent Recovery

Standard Reference Material
102

104

NA.

$N S^{(c)}$

NA

$\begin{array}{ll}N C^{(d)} & 1270 \\ N A & \pm 220 \\ 108 & 1114 \\ & \\ & \\ 57 & 1.6 \mathrm{~J}^{(f)} \\ 101 & 2.0 \mathrm{U} \\ 96 & 2.0 \mathrm{U} \\ 28 \% & N A\end{array}$

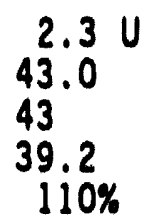

2.4 (b)

50.5

45.4

39.2

$116 \%$
NA

NS

NA
Certified

Value

PACS - 1

Analytical Replicates

PC-3 Replicate 1

PC-3 Replicate 2

PC-3 Replicate 3

RSD

(a) U Analyte was not present above the associated value.

(b) NA Not applicable.

(c) NS Not spiked.

(d) NC Not certified.

(e) Value exceeds SRM goal of $\leq 30 \%$.

(f) J Analyte detected below method detection limit (MDL), but above instrument detection limit (IDL).

1160

$\pm 180$

280

$\pm 170$

858

$565^{(\bullet)}$ 
IABIEB.33. Total Polychlorinated Dibenzodioxins (PCDD) and Dibenzofurans (PCDF) Analysis of Sediment, Dry Weight, Panama City Harbor Project

Sediment

PC-1

$P C-2$

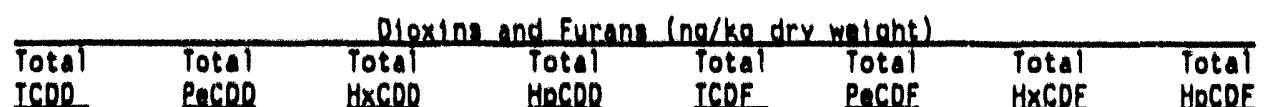

4.76

$6.53 \quad 4.08$

72.05

65.79

453.38

292.11

13.62

26.32

7.52

8.37

19.64

0.71

72.00

47.37 
IABLE B.34. Polychlorinated Dibenzodioxins (PCDD) Analysis of Sediment (2378-TCDD - OCDD), Dry Weight, Panama City Harbor Project

Sediment

PC-1

$P C-2$

\begin{tabular}{lll}
\hline $2378-$ & $12378-$ & 1234 \\
ICDD & POCDD & HXCD \\
& & \\
0.86 & 0.72 & 0.74 \\
1.45 & 0.74 & 0.87
\end{tabular}

Dloxing (no/ka dry welaht)

23478- 123678- 123789$\mathrm{HxCDO} \quad \mathrm{HXCDO}$

OCDD

1.45

0.74

4.97

3.74

3.05

3.21

123.52

1717.19

1026.32 
IABLE B.35. Quality Control Summary for Polychlorinated Dibenzodioxins (PCDD) Analys is of Sediment (2378-TCDD - OCDD), Wet Weight, Panama City Harbor Project

Sediment

Ireatment

Target OL (a)

Achieved OL.

\begin{tabular}{|c|c|c|c|c|c|c|}
\hline \multicolumn{7}{|c|}{ Dioxing (ng/kg wet weight) } \\
\hline $\begin{array}{l}2378- \\
\text { ICDD }\end{array}$ & $\begin{array}{l}12378- \\
\text { PeCDD }\end{array}$ & $\begin{array}{l}123478- \\
\mathrm{H} \times \mathrm{CDOD}\end{array}$ & $\begin{array}{l}123678- \\
\mathrm{H} \times \mathrm{CDO}\end{array}$ & $\begin{array}{l}123789- \\
\mathrm{H} \times \mathrm{CDD}\end{array}$ & $\begin{array}{l}1234678- \\
\mathrm{HDCDD}\end{array}$ & $O C D$ \\
\hline $\begin{array}{l}1.0 \\
0.3\end{array}$ & $\begin{array}{l}1.0 \\
0.3\end{array}$ & $\begin{array}{l}1.0 \\
0.9\end{array}$ & $\begin{array}{l}1.0 \\
0.5\end{array}$ & $\begin{array}{l}1.0 \\
0.8\end{array}$ & $\begin{array}{l}1.0 \\
0.7\end{array}$ & \\
\hline
\end{tabular}

Mathod Blank

Blank

$0.3 u^{(b)}$

$0.3 \mathrm{U}$

$0.9 U$

$0.5 U$

$0.8 U$

$0.7 \mathrm{U}$

$2.45^{(c)}$

\section{Matrix Spikes}

$P C-1$

PC-1 MS

0.50

Amount Splked
Percent Recovery (d)

17

20

\begin{tabular}{|c|}
\hline $\begin{array}{l}0.42 \\
97 \\
100\end{array}$ \\
\hline $97 x$ \\
\hline
\end{tabular}
$7^{2.88}$
100

PC-1

PC-1 MSD

Amount Spiked

Percent Recovery (d)

0.50

16

$2078 \%$

\begin{tabular}{cc}
0.42 & 0.43 \\
93 & $7^{78}$ \\
100 & 100 \\
$93 \%$ & \multicolumn{100}{c}{$78 \%$}
\end{tabular}

2.88
$76^{100} 74 \%$

1.77
100

71.64

140

100

$82 \%$

995.97

889

200

RPO

0.03

$0.02^{4 x}$

0.03

$0.01^{1 \%}$

1.77
86
100
$85 \%$

71.64

149

100

$87 \%$

995.97

809

200

$68 \%$

1-Stat

0.01

0.03

0.04

\footnotetext{
(a) OL Detection Iimit.

(b) $U$ Analyte was not present above the associated value.

(c) Mass ratio out of limtts. This value is lower than the detection 1 imit, howerer, the accuracy of the quantification at levels lower than the detection limits cannot be guarenteed.

(d) Percent recovery - [(matrix spike concentration)/(amount spiked + original sample concentration)]*100.
} 


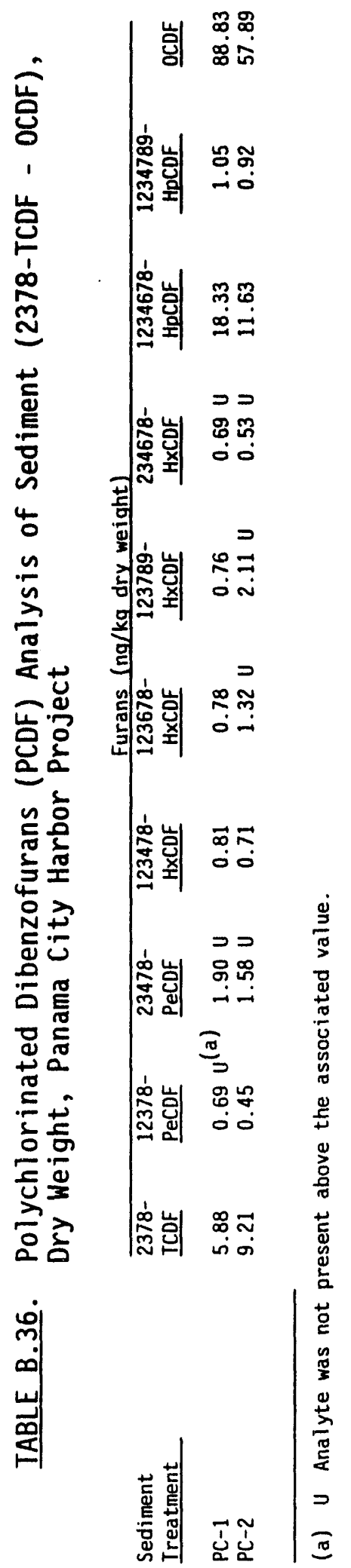

PANAMA CITY HARBOR 


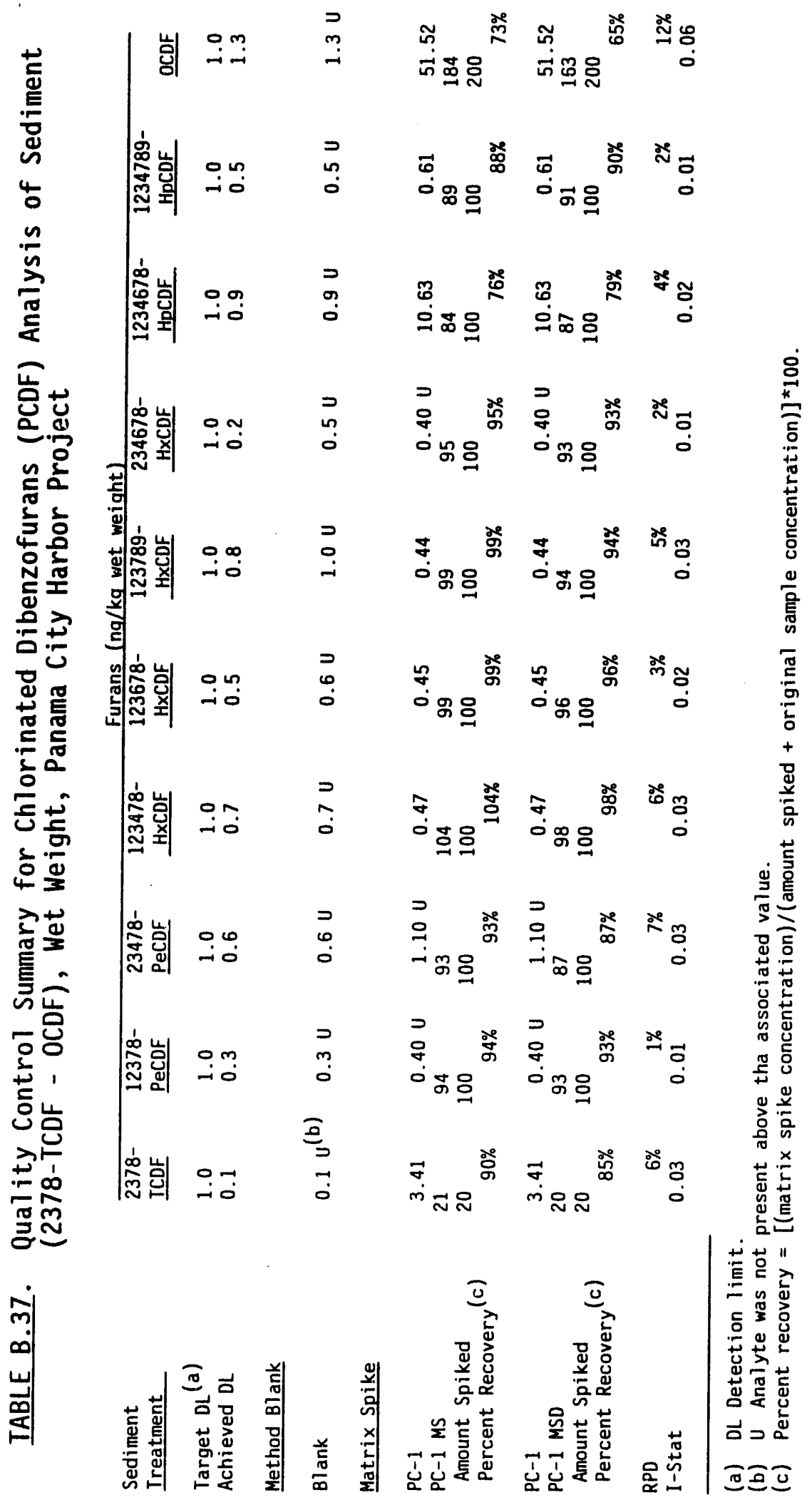

PANAMA CITY HARBOR

B. 37 
TABLE B.38. Surrogate Percent Recovery and Quality Control Data of Polychlorinated Dibenzodioxins (PCDD), Wet Weight, Panama City Harbor Project

\begin{tabular}{|c|c|c|c|c|c|c|}
\hline \multirow[b]{2}{*}{$\begin{array}{l}\text { Sediment } \\
\text { Ireatment }\end{array}$} & \multicolumn{6}{|c|}{ Dioxin Labelled Compounds (ng/kg wet weight) } \\
\hline & $\begin{array}{c}2378- \\
T C D D-C 13 \\
\end{array}$ & $\begin{array}{c}12378- \\
\text { PeCDD-C13 }\end{array}$ & $\begin{array}{r}123478- \\
\mathrm{H} \times \mathrm{COD}-\mathrm{C} 13 \\
\end{array}$ & $\begin{array}{r}123678- \\
H \times C D D-C 13 \\
\end{array}$ & $\begin{array}{r}1234678- \\
\text { HDCDD-C13 }\end{array}$ & OCDD-C13 \\
\hline $\begin{array}{l}P C-1 \\
P C-2\end{array}$ & $\begin{array}{l}35^{(a)} \\
82\end{array}$ & $\begin{array}{l}41 \\
84\end{array}$ & $\begin{array}{l}35^{(a)} \\
81\end{array}$ & $\begin{array}{l}37^{(a)} \\
86\end{array}$ & $\begin{array}{l}26^{(a)} \\
66\end{array}$ & $\begin{array}{l}21(a) \\
49\end{array}$ \\
\hline \multicolumn{7}{|c|}{ Qual ity Control Data } \\
\hline \multicolumn{7}{|c|}{ Method Blank } \\
\hline Blank & 56 & 72 & 64 & 61 & 58 & 41 \\
\hline \multicolumn{7}{|c|}{ Matrix Splke } \\
\hline $\begin{array}{l}P C-1 \quad \text { MS } \\
P C-1 \quad \text { MSD }\end{array}$ & $\begin{array}{l}59 \\
95\end{array}$ & $\begin{array}{l}59 \\
99\end{array}$ & $\begin{array}{l}58 \\
78\end{array}$ & $\begin{array}{l}56 \\
87\end{array}$ & $\begin{array}{l}49 \\
69\end{array}$ & $\begin{array}{l}39^{(a)} \\
55\end{array}$ \\
\hline
\end{tabular}

(a) Recovery outside quality control range (40\%-120\%). 


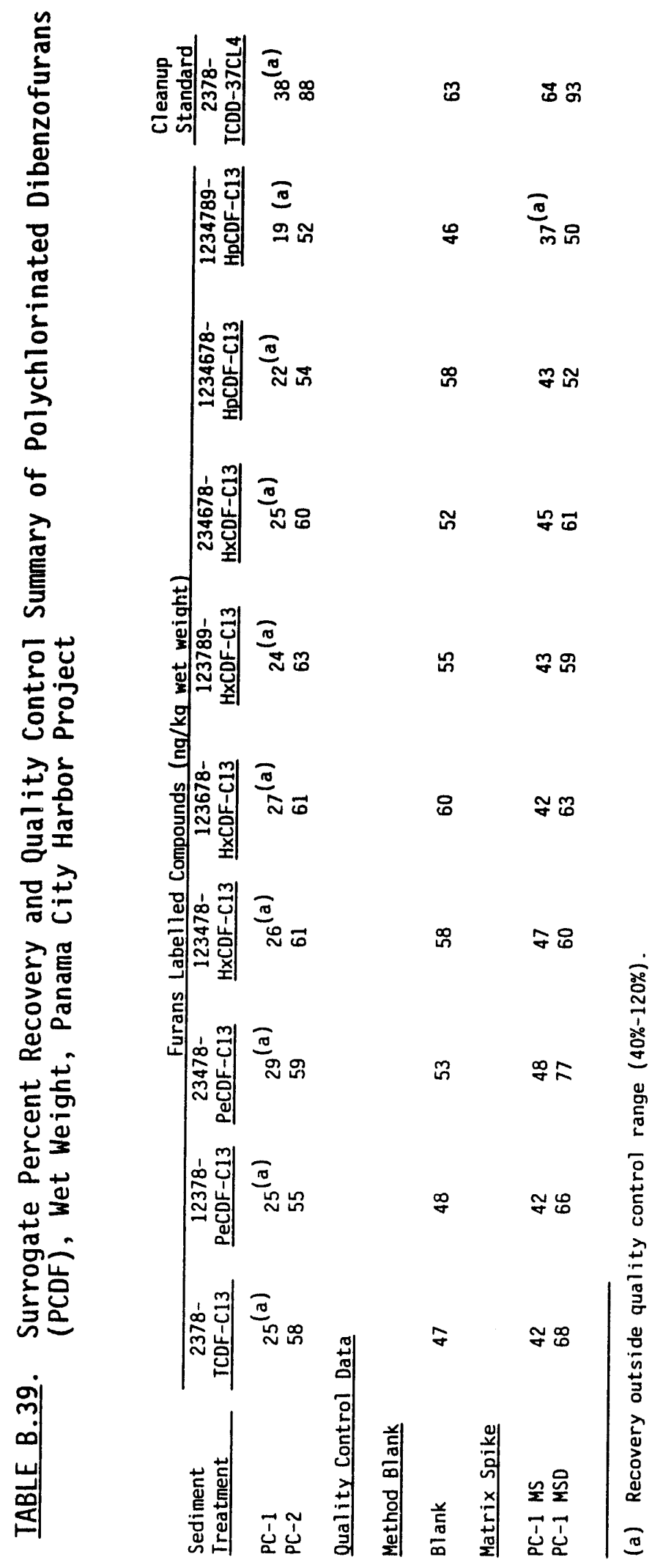

PANAMA CITY HARBOR

B. 39 
APPENDIX C

SUSPENDED-PARTICULATE-PHASE (SPP) CHEMISTRY AND QUALITY ASSURANCE DATA 


\section{QA/QC SUMMARY}

PROGRAM:

PARAMETER:

LABORATORY:

MATRIX:
Panama Clty Harbor Program

Cyanide

Analytical Resources Incorporated, Seattle, Washington

Suspended-Particulate-Phase (SPP) Water

\section{QAVC DATA QUALITY OBJECTIVES}

Reference Method

EPA $335.2(1979)$

HOLDING TIMES

DETECTION LIMITS

METHOD BLANKS

MATRIX SPIKES

SRMs

REPLICATES

SURROGATES

Range of

Recovery

NA

NA

NA
SRM

Accuracy

NA

\section{Relative}

$\leq 20 \%$

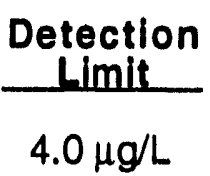

All samples were analyzed within the speclfied 28-day holding period.

The detection limit of $4.0 \mu \mathrm{g} / \mathrm{L}$ was met for all samples.

The concentration of cyanide in the method blank was less than the target detection limit; therefore, the data are acceptable.

Matrix spikes were not required for this project; therefore, no data quality objectives were established. Analytical Resources Incorporated analyzed a matrix spike for cyanide analysis; the percent recovery for the matrix splke sample analyzed was $77 \%$.

Precision between replicates was assessed by the Relative Standard Deviation (RSD) between triplicates. RSD for cyanide could not be determined because all replicates were undetected.

NA Not applicable. 


\section{QAVQC SUMMARY}

PROGRAM:

PARAMETER:

LABORATORY:

MATRIX:
Panama City Harbor Program

Ammonia

University of Washington, Seattle, Washington

Suspended-Particulate-Phase (SPP) Water

QAVC DATA QUALITY OBJECTIVES

\begin{tabular}{ccccc}
$\begin{array}{c}\text { Reference } \\
\text { Method }\end{array}$ & $\begin{array}{c}\text { Range of } \\
\text { Recovery }\end{array}$ & $\begin{array}{c}\text { SRM } \\
\text { Accuracy }\end{array}$ & $\begin{array}{c}\text { Relative } \\
\text { Precision }\end{array}$ & $\begin{array}{c}\text { Detection } \\
\text { Limili }\end{array}$ \\
\hline NA & NA & $\leq 30 \%$ & $0.01 \mathrm{mg} / \mathrm{L}$
\end{tabular}

HOLDING TIMES All samples were analyzed within the specified 28-day holding perlod.

DETECTION LIMITS The achleved detection limit for the ammonla analysis was $0.04 \mathrm{mg} / \mathrm{L}$. The concentrations in the samples were all well above the achieved detection limit; therefore, no corrective action was taken.

METHOD BLANKS The concentration of ammonia in the method blank was undetected at a value slightly greater than the target detection limit. The concentrations in the samples were well above the target and achleved detection limits; therefore, no corrective action was taken.

MATRIX SPIKES NA

SRMs $\quad$ NA

REPLICATES The Relative Standard Deviation (RSD) between triplicates was $8 \%$, which was within the established QC limits.

SURROGATES NA

NA Not applicable. 


\section{QAVOC SUMMARY}

PROGRAM:

PARAMETER:

LABORATORY:

MATRIX:
Panama Clty Harbor Program

Polynuclear Aromatlc Hydrocarbons (PAHs), Phenol, Substituted Phenols, and Phthalate Esters

Battelle Ocean Sciences, Duxbury, Massachusetts

Suspended-Particulate-Phase (SPP) Water

QANQC DATA QUALITY OBJECTIVES

\begin{tabular}{|c|c|c|c|c|c|}
\hline & $\begin{array}{c}\text { Reference } \\
\text { Method }\end{array}$ & $\begin{array}{l}\text { Range of } \\
\text { Recovery }\end{array}$ & $\begin{array}{c}\text { SRM } \\
\text { Accuracy }\end{array}$ & $\begin{array}{l}\text { Relative } \\
\text { Preclalon }\end{array}$ & $\begin{array}{c}\text { Detection } \\
\text { Limit }\end{array}$ \\
\hline $\begin{array}{l}\text { PAHs } \\
\text { Phenols } \\
\text { Phthalate Esters }\end{array}$ & $\begin{array}{l}\text { EPA Method } 8270 \text { (1986a) } \\
\text { EPA Method } 8270 \\
\text { EPA Method } 8270\end{array}$ & $\begin{array}{l}40.120 \% \\
40.120 \% \\
40.120 \%\end{array}$ & $\begin{array}{l}\text { NA } \\
\text { NA } \\
\text { NA }\end{array}$ & $\begin{array}{l}\leq 30 \% \\
\leq 30 \% \\
\leq 30 \%\end{array}$ & $\begin{array}{l}20 \mathrm{ng} / \mathrm{l} \\
1000 \mathrm{ng} / \mathrm{L} \\
200 \mathrm{ng} / \mathrm{L}\end{array}$ \\
\hline
\end{tabular}

HOLDING TIMES All samples were extracted within the 7-day holding period and analyzed within 40 days of extraction.

DETECTION LIMITS

The achieved detection limits for PAHs were generally within the target detection limits. The achleved detection limits for phenol, substituted phenols, and phthalate esters were slightly elevated above the target detection limits set in the QAQC plan. These elevations do not present a problem due to the majority of samples being undetected.

METHOD BLANKS

The procedural blank analyzed with the samples had detected levels of naphthalene, 2-methylnaphthalene, phenanthrene, diethyl phthalate, and bis(2-ethylhexyl)phthalate in the blank. The data associated with this sample were flagged with a " $B$. ."

MATRIX SPIKES The recoveries of target PAHs and phthalate esters in the matrix spike are good, ranging from $26 \%$ to $140 \%$. Five of the 16 PAHs and none of the 6 phthalate ester matrix spike recoveries were outside the $40-120 \%$ acceptable range. The recoveries of target phenol and substituted phenols in the matrix spike were poor, ranging from $1 \%$ to $184 \%$. The recovery of the phenol and substituted phenol compounds are acceptable in the blank spike (Milli-Q water) processed with the water samples, indicating that matrix interferences resulted in the poor recovery of the phenol and substituted phenol compounds.

SRMs

REPLICATES
NA

Precision was measured by relative standard deviation (RSD) between triplicates. Precision between replicates analyzed for PAHs was excellent, with no RSD values outside the $30 \%$ range. RSDs for phenol and substituted phenols could not be determined because all replicates were undetected. Two of the six RSDs from the phthalate analysis were out of range. 
SURROGATES

Four surrogate compounds were analyzed with the samples: 2-fluorophenol, naphthalene-d $d_{8}$ acenaphthten $\theta-d_{10}$, and benzo(a)pyrene-d $d_{12}$. Two of these surrogates (acenaphthene-d $d_{10}$ and naphthalene-d $d_{12}$ ) showed acceptable recovery of the surrogate intemal standard (SIS) compounds. The recoveries of 2-fluorophenol and benzo(a)pyrene-d $d_{12}$ were poor, and believed to be due to matrix interferences of the water samples.

NA Not applicable. 


\title{
QAVQC SUMMARY
}

\author{
PROGRAM: Panama Cly Harbor Program \\ PARAMETER: Chlorinated Pesticides and Polychlorinated Biphenyls (PCBs) \\ LABORATORY: Battelle Ocean Sciences, Duxbury, Massachusetts \\ MATRIX: $\quad$ Suspended-Partlculate-Phase (SPP) Water
}

QANQC DATA QUALITY OBJECTIVES

\begin{tabular}{|c|c|c|c|c|c|}
\hline & $\begin{array}{l}\text { Reference } \\
\text { Method }\end{array}$ & Range of & $\begin{array}{c}\text { SRM } \\
\text { Acouracy }\end{array}$ & $\begin{array}{l}\text { Relative } \\
\text { Precinion }\end{array}$ & $\begin{array}{l}\text { Detection } \\
\text { Limit }\end{array}$ \\
\hline $\begin{array}{l}\text { asticides } \\
\text { Xaphene } \\
\text { CBs }\end{array}$ & $\begin{array}{l}\text { EPA Method } 8080 \text { (1986a) } \\
\text { EPA Method } 8080 \\
\text { EPA Method } 8080\end{array}$ & $\begin{array}{l}40.120 \% \\
40.120 \% \\
40.120 \%\end{array}$ & $\begin{array}{l}\text { NA } \\
\text { NA } \\
\text { NA }\end{array}$ & $\begin{array}{l}\leq 30 \% \\
\leq 30 \% \\
\leq 30 \%\end{array}$ & $\begin{array}{l}5 \mathrm{ng} / \mathrm{l} \\
50 \mathrm{ng} / \mathrm{L} \\
50 \mathrm{ng} / \mathrm{L}\end{array}$ \\
\hline
\end{tabular}

HOLDING TIMES All samples were extracted within the 7-day holding perlod and analyzed within 40 days of extraction.

DETECTION LIMITS The achleved detection limits for all analytes were within the target detection limits except for chlordane and methoxyclor. These elevations do not present a problem because all the samples were undetected for these analytes.

METHOD BLANKS The procedural blank analyzed with the samples was free of contamination.

MATRIX SPIKES Three of the 18 matrlx spike recoveries had values outside the $40-120 \%$ range set in the QAVC plan. These three recoveries ranged from $121 \%$ to $148 \%$, due to coelution of $P C B$ congeners present in Aroclor 1254.

SRMs NA

REPLICATES Precision was measured by relative standard deviation (RSD) between triplicates. RSDs could be calculated only on the two pesticides with detected values in all replicates. RSDs were $15 \%$ and $39 \%$ and were calculated from " $\mathrm{J}$ " values detected below the method detection limit. This tends to exaggerate the RSD values due to comparison of small values.

SURROGATES Two surrogate compounds were analyzed with the samples: DBOFB and $\mathrm{CL}_{6}(11$ ?). The 22 surrogate recoveries ranged from $34 \%$ to $116 \%$. Only three of these were below the established range of $40-120 \%$, and were associated with the method blank and matrix splke sample.

NA Not applicable.

PANAMA CITYHARBOB C.VII 


\section{QAVOC SUMMARY}

PROQRAM:

PARAMETER:

LABORATORY: MATRIX:
Panama Clty Harbor Program

Motals

Battelle/Marine Sclences Laboratory, Sequim, Washington

Suspended-Particulate-Phase (SPP) Water

QAQC DATA QUALITY OBJECTIVES

\begin{tabular}{|c|c|c|c|c|c|}
\hline & $\begin{array}{c}\text { Reference } \\
\text { Method }\end{array}$ & $\begin{array}{l}\text { Range of } \\
\text { Becovery }\end{array}$ & $\begin{array}{c}\text { SRM } \\
\text { Acauracy }\end{array}$ & $\begin{array}{l}\text { Relative } \\
\text { Preclalon }\end{array}$ & $\begin{array}{c}\text { Detection } \\
\text { Limit }\end{array}$ \\
\hline $\begin{array}{l}\text { Arsenic } \\
\text { Cadmium } \\
\text { Chromium } \\
\text { Copper } \\
\text { Lead } \\
\text { Mercury } \\
\text { Nickel } \\
\text { Selenium } \\
\text { Silver } \\
\text { Zinc }\end{array}$ & $\begin{array}{l}\text { HAA (EPA 1986a) } \\
\text { GFAA (EPA 1986a) } \\
\text { GFAA } \\
\text { GFAA } \\
\text { GFAA } \\
\text { CVAF } \\
\text { GFAA } \\
\text { GFAA } \\
\text { GFAA } \\
\text { GFAA }\end{array}$ & $\begin{array}{l}75-125 \\
75-125 \\
75-125 \\
75-125 \\
75-125 \\
75-125 \\
75-125 \\
75-125 \\
75-125 \\
75-125\end{array}$ & $\begin{array}{l}\leq 30 \% \\
\leq 30 \% \\
\leq 30 \% \\
\leq 30 \% \\
\leq 30 \% \\
\leq 30 \% \\
\leq 30 \% \\
\leq 30 \% \\
\leq 30 \% \\
\leq 30 \%\end{array}$ & $\begin{array}{l}\leq 20 \% \\
\leq 20 \% \\
\leq 20 \% \\
\leq 20 \% \\
\leq 20 \% \\
\leq 20 \% \\
\leq 20 \% \\
\leq 20 \% \\
\leq 20 \% \\
\leq 20 \%\end{array}$ & $\begin{array}{l}1.0 \mu g / L \\
0.1 \mu g / L \\
1.0 \mu g / L \\
0.1 \mu g / L \\
0.1 \mu g / L \\
0.001 \mu g / L \\
0.1 \mu g / L \\
2.0 \mu g / L \\
0.01 \mu g / L \\
2.0 \mu g / L\end{array}$ \\
\hline
\end{tabular}

HOLDING TIMES All samples analyzed for metals, except $\mathrm{Hg}$, were analyzed within the specifled 6-month holding period. All $\mathrm{Hg}$ samples were analyzed within the holding time of 28 days.

DETECTION LIMITS

The achieved detection limits for all the metals were below the target detection limit, except for selenium. The concentrations in the samples were undetected; therefore, no correctlve actlon was taken.

METHOD BLANKS The procedural blank analyzed with the water samples had low concentrations of all the metals except selenium. The method blank analyzed with the samples had low levels of silver, cadmlum, chromium, mercury, nickel, and zinc. The data associated with these blanks were corrected for the amount in the method blank; therefore, no corrective action was taken.

\section{MATRIX SPIKES}

SRMs

REPLICATES
Matrix splke recoveries ranged between $79 \%$ and $114 \%$, which is within the $75-125 \%$ range.

The standard reference material (SRM) 1641b was analyzed for mercury. SRM CASS-2 was analyzed for all the other metals. The values were all within the $30 \%$ limit set in the QA plan.

Precision between triplicates was measured by Relative Standard Deviation (RSD). Calculable RSDs ranged from $2 \%$ to $18 \%$, which were within the $20 \%$ range set in the data quality objectives. 
IABLE C.l. Ammonia and Cyanide Analysis of Suspended-Particulate-Phase (SPP) Samples, Panama City Harbor Project

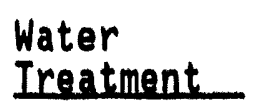

Target $D L^{(a)}$

Achieved DL

$P C-1$

PC-1A Replicate 1

$P C-1 A$ Replicate 2

PC-IA Replicate 3

$P C-2$

PC-4 Replicate 1

PC-4 Replicate 2

PC-4 Replicate 3

PC-5

Reference

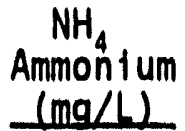

$N A^{(b)}$

NA

0.23

0.20

NA

NA

0.63

0.22

0.24

0.25

0.43

0.82
$\mathrm{NH}_{3}-\mathrm{N}$
Ammon la

(ma/h)

0.01

0.04

0.18

0.16

NA

NA

0.49

0.17

0.18

0.20

0.33

0.64
Cyanide $(u g / L)$

4.0

4.0

$4.0 U^{(0)}$

$4.0 \mathrm{U}$

$4.0 \mathrm{U}$

$4.0 \mathrm{U}$

$4.0 \mathrm{U}$

$4.0 \mathrm{U}$

NA

NA

$4.0 \mathrm{U}$

$4.0 \mathrm{U}$

(a) DL Detection 1 imit.

(b) NA Not applicable.

(c) U Analyte was not present above the assoctated value. 
IABLEC.2. Quality Control Summary for Ammonia and Cyanide in SuspendedParticulate-Phase (SPP) Samples, Panama City Harbor Project

Water

Ireatment

Blank

Method Blank

Matrix Solke

$P C-1 A$

PC-1A MS

Concentration Recovered

Amount Splked

Percent Recovery

\section{Analytical Replicates}

PC-1A Replicate 1

PC-IA Replicate 2

PC-1A Replicate 3

RSD

PC-4 Replicate 1

PC-4 Replicate 2

PC-4 Replicate 3

RSD

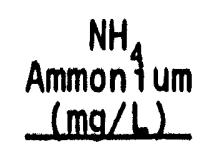

$N A^{(a)}$

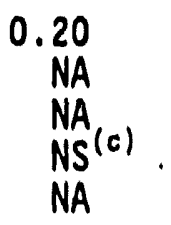

NA

NA

NA

NA
0.22
0.24
0.25
$6 \%$

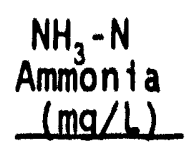

Cyanide

$(\mu \mathrm{g} / \mathrm{L})$

$4.0 \mathrm{U}$

$0.04 U^{(b)}$

0.16
$N A$
$N A$
$N S$
$N A$

$4.0 \mathrm{U}$

56.0

56.0

73.0

$77 \%$
$4.0 \mathrm{U}$

$4.0 \mathrm{U}$

$4.0 \mathrm{U}$

NA

4. 0

NA

NA

NA

(a) NA Not applicable.

(b) $U$ Analyte was not present above the associated value.

(c) NS Not spiked. 
IABLE C.3. Total Polynuclear Aromatic Hydrocarbons (PAH) Analys is of Suspended-Particulate-Phase (SPP) Samples, Panama City Harbor Project

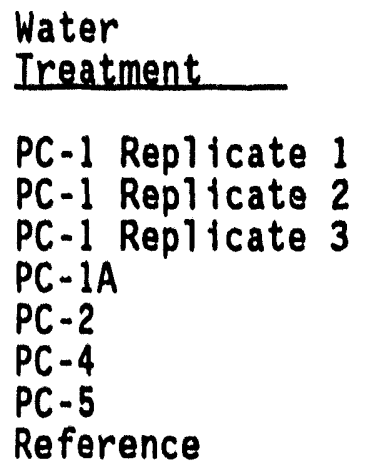

Water

PC-1 Replicate 1

$P C-1$ Replicate 2

PC-1 Replicate 3

$P C-5$

Reference

\begin{tabular}{ccr}
\multicolumn{3}{c}{ Total PAH (ng/L) } \\
\hline $\begin{array}{c}\text { Total } \\
\text { Low Molecular } \\
\text { Weight PAH }\end{array}$ & $\begin{array}{c}\text { Total } \\
\text { High Molecular } \\
\text { Weight PAH }\end{array}$ & $\begin{array}{r}\text { Total } \\
\text { PAH }\end{array}$ \\
\cline { 2 - 3 } 36.16 & & \\
56.54 & 16.52 & 52.68 \\
53.20 & 25.97 & 82.51 \\
109.11 & 26.84 & 80.04 \\
56.39 & 32.06 & 141.17 \\
68.86 & 18.68 & 75.07 \\
58.77 & 10.96 & 79.82 \\
77.00 & 76.28 & 135.05 \\
& 12.28 & 89.28
\end{tabular}


TABLE C.4. Low Molecular Weight Polynuclear Aromatic Hydrocarbons (LPAH) Analys is of Suspended-Particulate-Phase (SPP) Samples, Panama City Harbor Project

Water

Treatment

Target DL (a)

Achieved High DL

Achieved Low DL

PC-1 Replicate 1

PC-1 Replicate 2

PC-1 Replicate 3

$P C-1 A$

$P C-2$

$P C-4$

PC-5

Reference

\begin{tabular}{|c|c|c|c|c|c|c|c|}
\hline $\begin{array}{l}\text { Naphtha- } \\
\text { lene } \\
\end{array}$ & $\begin{array}{l}\text { 2-Methyl- } \\
\text { naphtha- } \\
\text { lene } \\
\end{array}$ & $\begin{array}{l}\text { 1-Methyl- } \\
\text { naphtha- } \\
\text { lene } \\
\end{array}$ & $\begin{array}{l}\text { Acenaph- } \\
\text { thylene }\end{array}$ & $\begin{array}{l}\text { Acenaph- } \\
\text { thene }\end{array}$ & Eluorene & $\begin{array}{l}\text { Phenan- } \\
\text { threne }\end{array}$ & $\begin{array}{l}\text { Anthra- } \\
\text { cene }\end{array}$ \\
\hline $\begin{array}{r}20 \\
7.64 \\
6.88\end{array}$ & $\begin{array}{r}20 \\
7.64 \\
6.88\end{array}$ & $\begin{array}{r}20 \\
7.64 \\
6.88\end{array}$ & $\begin{array}{r}20 \\
9.65 \\
8.64\end{array}$ & $\begin{array}{r}20 \\
6.14 \\
5.53\end{array}$ & $\begin{array}{r}20 \\
7.21 \\
6.49\end{array}$ & $\begin{array}{l}20 \\
8.19 \\
7.37\end{array}$ & $\begin{array}{r}20 \\
12.03 \\
10.84\end{array}$ \\
\hline $\begin{array}{l}19.18 \mathrm{~B}^{(\mathrm{b})} \\
25.43 \mathrm{~B} \\
22.78 \mathrm{~B} \\
43.87 \mathrm{~B} \\
23.12 \mathrm{~B} \\
31.31 \mathrm{~B} \\
18.85 \mathrm{~B} \\
33.13 \mathrm{~B}\end{array}$ & $\begin{array}{l}6.87 \mathrm{JB}^{(\mathrm{C})} \\
11.85 \mathrm{~B} \\
11.23 \mathrm{~B} \\
24.73 \mathrm{~B} \\
11.62 \mathrm{~B} \\
15.49 \mathrm{~B} \\
11.43 \mathrm{~B} \\
15.47 \mathrm{~B}\end{array}$ & $\begin{array}{c}4.99 \mathrm{~J}^{(\mathrm{d})} \\
7.89 \\
6.70 \mathrm{~J} \\
15.91 \\
7.74 \\
9.66 \\
8.13 \\
15.54\end{array}$ & $\begin{array}{l}8.64 U^{(e)} \\
9.02 U \\
9.02 U \\
0.87 \mathrm{~J} \\
9.54 \mathrm{U} \\
9.30 \mathrm{U} \\
2.98 \mathrm{~J} \\
9.43 \mathrm{U}\end{array}$ & $\begin{array}{l}5.53 \mathrm{U} \\
5.78 \mathrm{U} \\
1.03 \mathrm{~J} \\
1.37 \mathrm{~J} \\
1.35 \mathrm{~J} \\
5.95 \mathrm{U} \\
6.01 \mathrm{U} \\
6.04 \mathrm{U}\end{array}$ & $\begin{array}{l}6.49 \mathrm{U} \\
3.56 \mathrm{~J} \\
3.08 \mathrm{~J} \\
8.47 \\
4.32 \mathrm{~J} \\
4.71 \mathrm{~J} \\
5.69 \mathrm{~J} \\
3.60 \mathrm{~J}\end{array}$ & $\begin{array}{rl}5.12 & \mathrm{JB} \\
6.21 & \mathrm{JB} \\
6.04 & \mathrm{JB} \\
11.86 & \mathrm{~B} \\
7.03 & \mathrm{JB} \\
6.67 & \mathrm{JB} \\
8.34 & \mathrm{~B} \\
7.78 & \mathrm{JB}\end{array}$ & $\begin{array}{r}10.84 \mathrm{U} \\
1.60 \mathrm{~J} \\
2.34 \mathrm{~J} \\
2.03 \mathrm{~J} \\
1.21 \mathrm{~J} \\
1.02 \mathrm{~J} \\
3.35 \mathrm{~J} \\
1.48 \mathrm{~J}\end{array}$ \\
\hline
\end{tabular}

(a) OL Detection 1 imit.

(b) B Analyte found in the procedural blank; results presented are not corrected for the amount in the blank.

(c) JB Analyte detected below method detection limit (MDL), but above instrument detection limit (IDL), and found in the procedural blank; results presented are not corrected for the amount in the blank.

(d) J Analyte detected below method detection limit (MOL), but above instrument detection limit (IDL).

(e) U Analyte was not present above the associated value. 


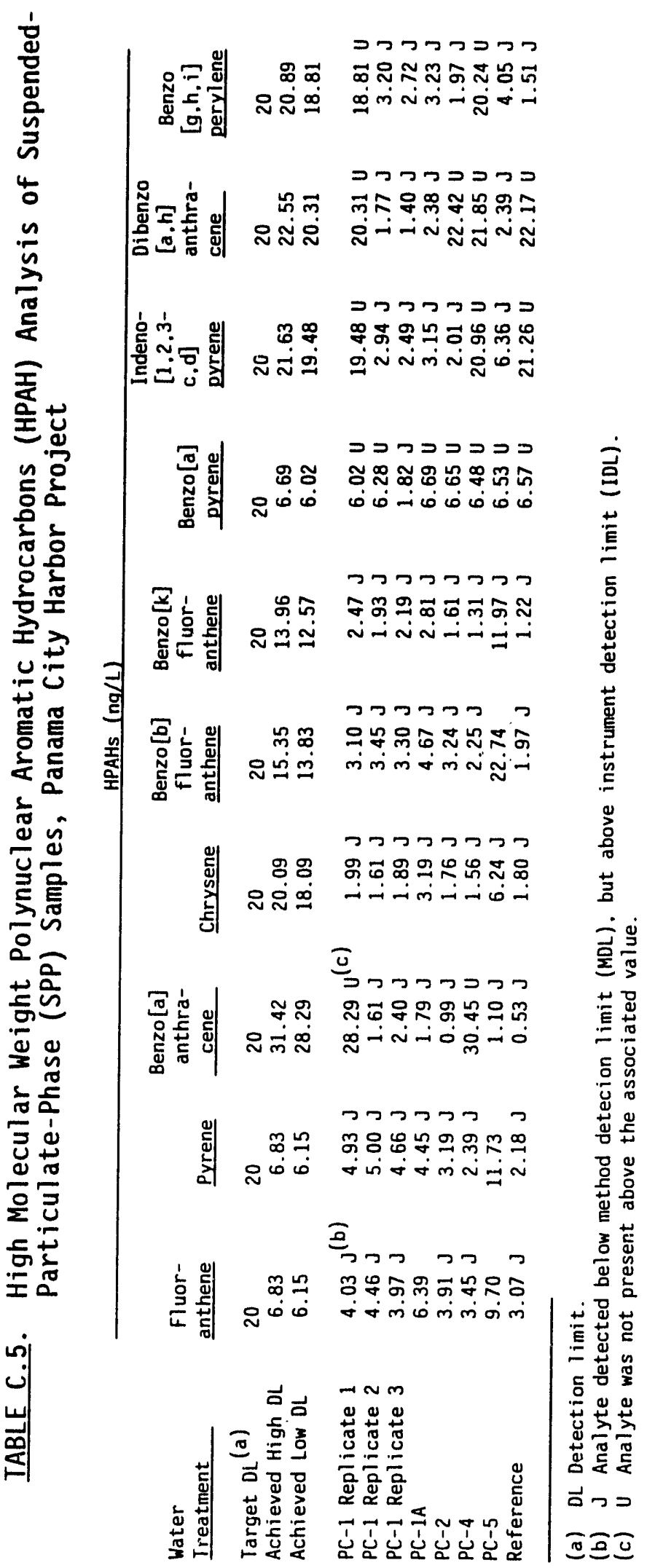

PANAMA CITY HARBOR

C. 5 
TABLE C.6. Quality Control Summary for Analys is of Low Molecular Weight Polynuclear Aromatic Hydrocarbons (LPAH) in SuspendedParticulate-Phase (SPP) Samples, Panama City Harbor Project

Water
Treatment

Blanks

Method Blank (a)

Procedural

Matrix Spike

\begin{tabular}{lll}
\hline & LPAH $(n g / L)$ \\
Naphtha- & $\begin{array}{l}\text { naphtha- naphtha- Acenaph- Acenaph- } \\
\text { lene }\end{array}$ & $\begin{array}{l}\text { 1-Methyl- } \\
\text { lene }\end{array}$ lene Phenan- Anthra- \\
lenylene thene Fluorene threne cene
\end{tabular}

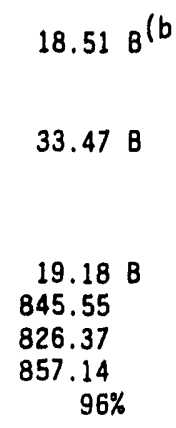

$18.51 B^{(b)}$

$33.47 \mathrm{~B}$

19.18 B
845.55
826.37
857.14
$\quad 96 \%$

$7.34 \mathrm{j}^{(\mathrm{c})}$

$18.55 u^{(d)}$

$29.38 \mathrm{U}$

$22.62 U$

$17.94 \cup \quad 30.42 \cup \quad 28.43 \cup$

$9.96 \mathrm{~B}$

$5.53 \mathrm{~J}$

$4.06 \mathrm{~J} \quad 5.84 \mathrm{U}$

$3.43 \mathrm{~J} \quad 11.86 \mathrm{~B} \quad 1.18 \mathrm{~J}$

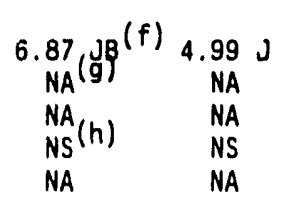

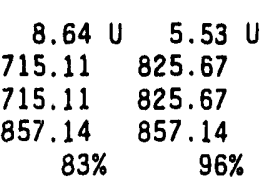

Analytical Replicates

PC-1 Replicate 1

PC-1 Replicate 2

PC-1 Replicate 3 RSD

$19.18 \mathrm{~B}$

$25.43 \mathrm{~B}$

22.788

$14 \%$

$\begin{array}{cc}6.87 \mathrm{JB} & 4.99 \mathrm{~J} \\ 11.85 \mathrm{~B} & 7.89 \\ 11.23 \mathrm{~B} & 6.70 \mathrm{~J} \\ 27 \% & 22 \%\end{array}$

$8.64 U$
$9.02 U$
$9.02 U$
$5.53 \mathrm{U}$
$5.78 \mathrm{U}$
$1.03 \mathrm{~J}$
$\mathrm{NA}$

\begin{tabular}{|c|c|c|}
\hline $\begin{array}{c}6.49 U \\
903.46 \\
903.46 \\
857.14 \\
105 \%\end{array}$ & $\begin{array}{r}5.12 \\
947.62 \\
942.5 \\
857.14 \\
110 \%\end{array}$ & $\begin{array}{r}\text { JB } 10.84 \\
330.19 \\
330.19 \\
857.14 \\
\% \quad 39 \%\end{array}$ \\
\hline
\end{tabular}

$6.49 \mathrm{U}$

$3.56 \mathrm{~J}$

$3.08 \mathrm{~J}$

NA
5.12 JB $10.84 \mathrm{U}$

$6.21 \mathrm{JB} \quad 1.60 \mathrm{~J}$

$6.04 \mathrm{JB} \quad 2.34 \mathrm{~J}$

$10 \%$ NA

(a) Method water blank concentrations were determined by using the sediment method blank values in (ng) and dividing by the average volume size of the water samples. The sediment and water samples were extracted together.

(b) B Analyte found in the procedural blank: results presented are not corrected for the amount in the blank.

(c) J Analyte detected below method detection limit (MDL), but above instrument detection level (IDL).

(d) U Analyte was not present above the associated value.

(e) Procedural blank was processed and analyzed following the same procedures as the water samples.

(f) JB Analyte detected below method detection limit (MOL), but above the instrument detection limit

(IDL), and found in the procedural blank: results presented are not corrected for the amount in the blank.

(g) NA Not applicable.

(h) NS Not spiked.

(i) Value outside of quality control range $(40 \%-120 \%)$. 


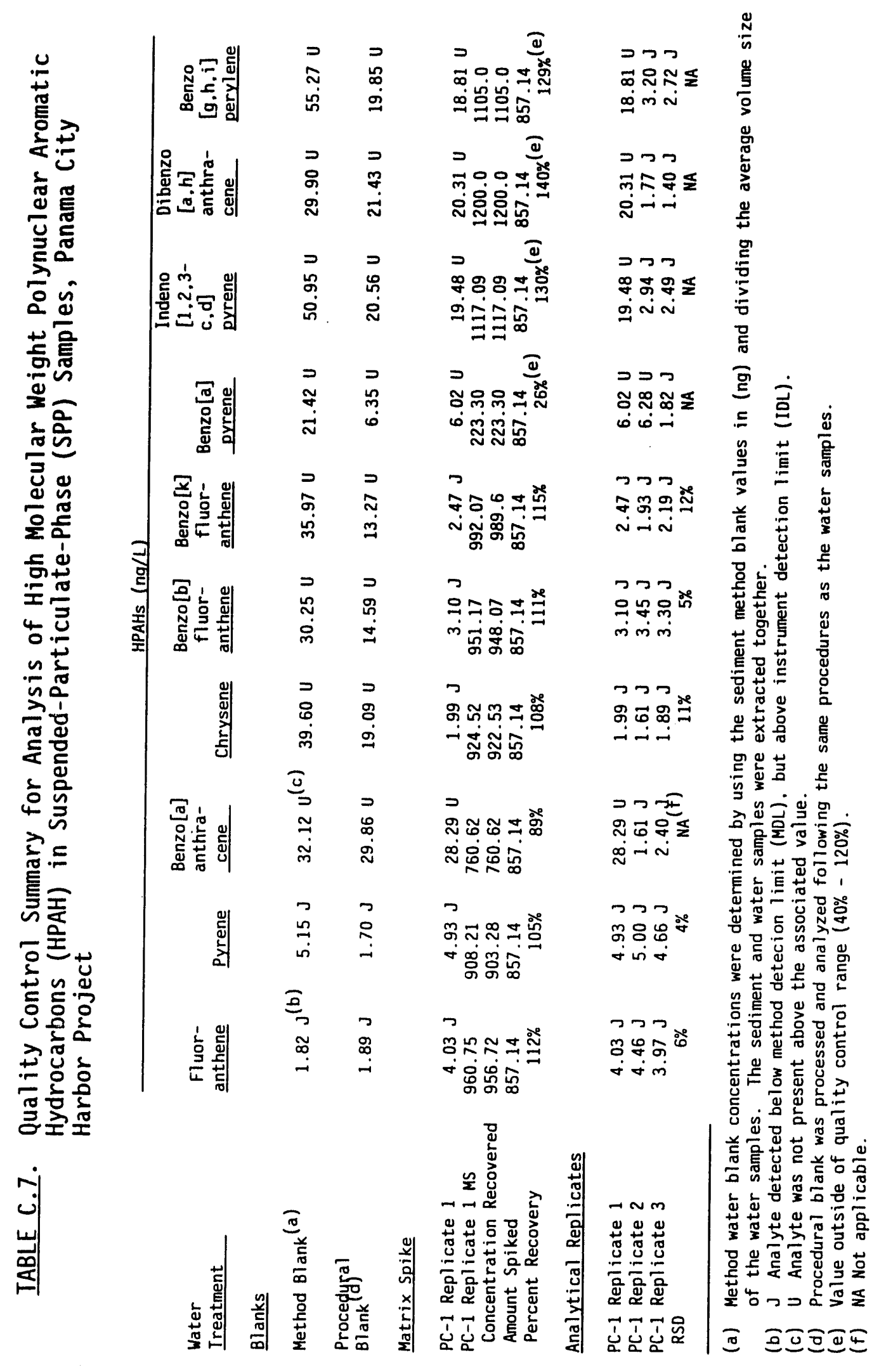




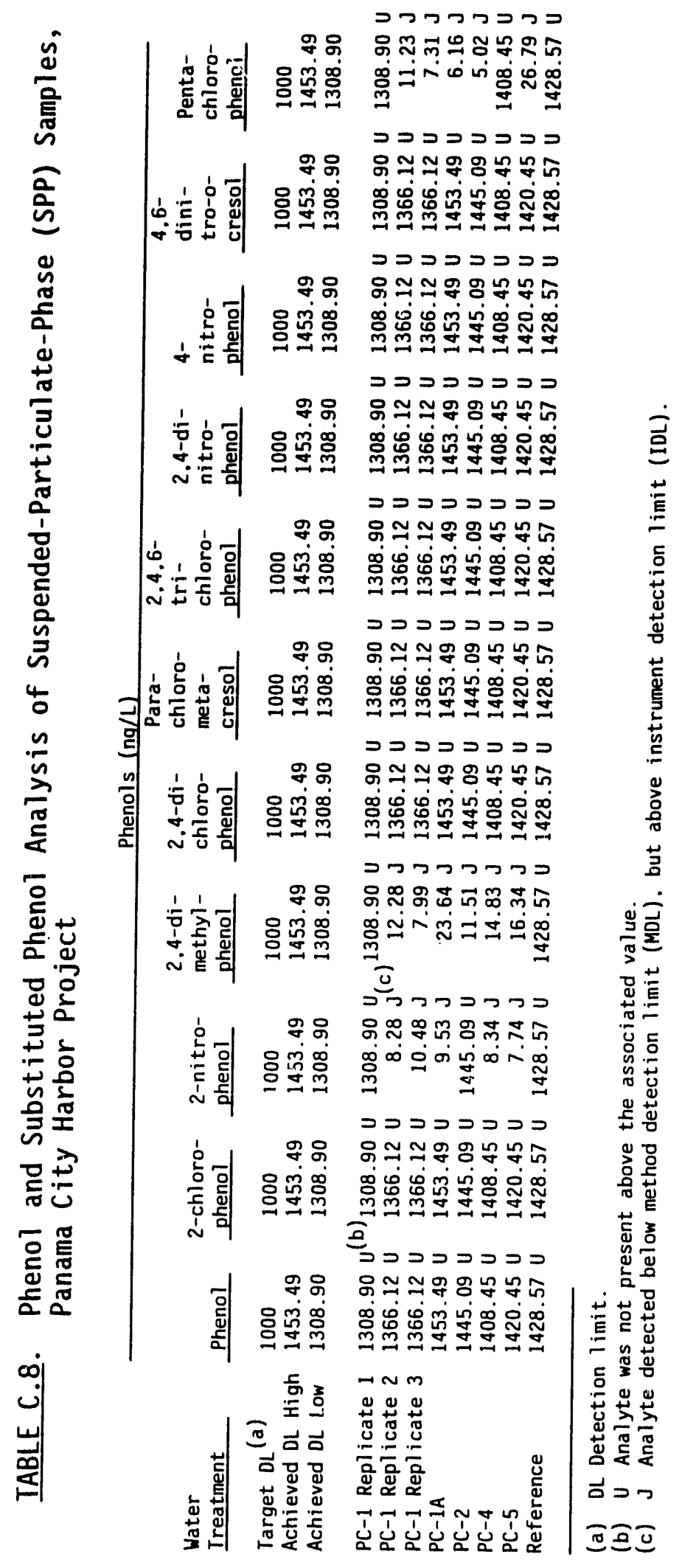




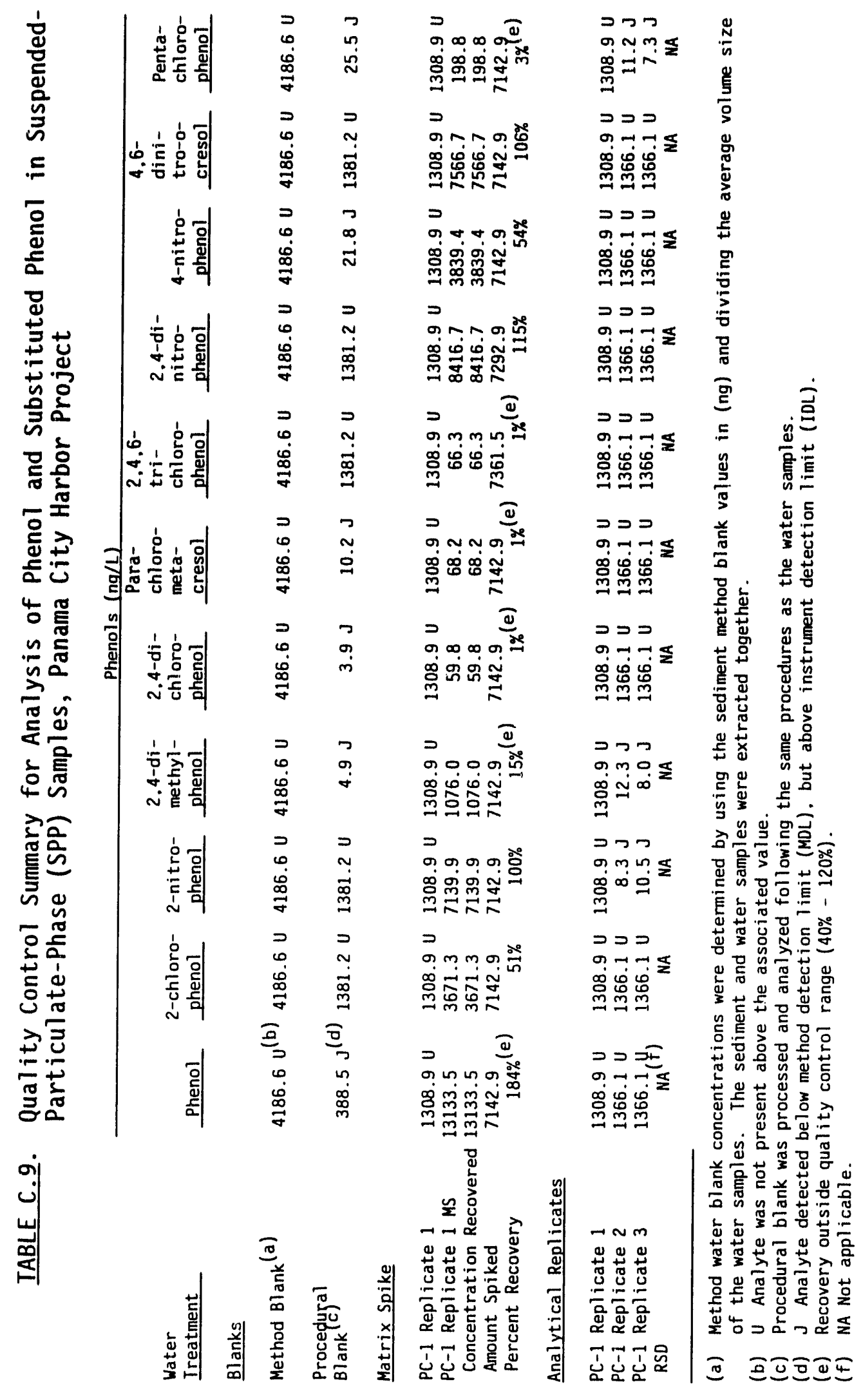


IABLE C.10. Phthalate Ester Analysis of Suspended-Particulate-Phase (SPP) Samples, Panama City Harbor Project

Phthalate Esters (ng/h)

Water
Ireatment

Target OL (a)

Achieved OL High

Achieved OL LOW

PC-1 Replicate 1

$P C-1$ Replicate 2

PC-1 Replicate 3

$P C-1 A$

$P C-2$

$P C-4$

PC-5

Reference

\begin{tabular}{|c|c|c|c|c|c|}
\hline $\begin{array}{l}\text { Dimethyl } \\
\text { phthalate }\end{array}$ & $\begin{array}{l}\text { Diethyl } \\
\text { ohthalate }\end{array}$ & $\begin{array}{l}\text { Di-n-butyi } \\
\text { ohthalate }\end{array}$ & $\begin{array}{l}\text { Butyl } \\
\text { benzyl } \\
\text { phthalate }\end{array}$ & $\begin{array}{l}\text { bis } \\
\text { (2-ethyl- } \\
\text { hexyl) } \\
\text { phthalate }\end{array}$ & $\begin{array}{l}\text { Di-n-octy\} } \\
\text { phthalate }\end{array}$ \\
\hline $\begin{array}{r}200 \\
290.70 \\
261.78\end{array}$ & $\begin{array}{r}200 \\
290.70 \\
261.78\end{array}$ & $\begin{array}{r}200 \\
290.70 \\
261.78\end{array}$ & $\begin{array}{r}200 \\
290.70 \\
261.78\end{array}$ & $\begin{array}{r}200 \\
290.70 \\
261.78\end{array}$ & $\begin{array}{r}200 \\
290.70 \\
261.78\end{array}$ \\
\hline $\begin{array}{r}74.56 \mathrm{~J}^{(b)} \\
93.38 \mathrm{~J} \\
188.42 \mathrm{~J} \\
87.75 \mathrm{~J} \\
95.22 \mathrm{~J} \\
90.60 \mathrm{~J} \\
102.11 \mathrm{~J} \\
104.70 \mathrm{~J}\end{array}$ & $\begin{array}{l}99.49 \mathrm{JB}(\mathrm{c}) \\
161.40 \mathrm{JB} \\
144.10 \mathrm{JB} \\
146.71 \mathrm{JB} \\
185.42 \mathrm{JB} \\
155.80 \mathrm{JB} \\
181.01 \mathrm{JB} \\
174.98 \mathrm{JB}\end{array}$ & $\begin{array}{r}97.14 \mathrm{~J} \\
100.58 \mathrm{~J} \\
83.52 \mathrm{~J} \\
135.47 \mathrm{~J} \\
124.65 \mathrm{~J} \\
120.32 \mathrm{~J} \\
93.47 \mathrm{~J} \\
71.21 \mathrm{~J}\end{array}$ & $\begin{array}{l}31.84 \mathrm{~J} \\
71.93 \mathrm{~J} \\
33.22 \mathrm{~J} \\
65.09 \mathrm{~J} \\
74.66 \mathrm{~J} \\
57.13 \mathrm{~J} \\
81.32 \mathrm{~J} \\
27.25 \mathrm{~J}\end{array}$ & $\begin{array}{l}206.38 \mathrm{JB} \\
253.27 \mathrm{JB} \\
195.65 \mathrm{JB} \\
288.72 \mathrm{JB} \\
222.60 \mathrm{JB} \\
336.23 \mathrm{~g}(\mathrm{~d}) \\
377.17 \mathrm{~B} \\
166.66 \mathrm{JB}\end{array}$ & $\begin{array}{r}9.45 \mathrm{~J} \\
16.42 \mathrm{~J} \\
11.28 \mathrm{~J} \\
16.68 \mathrm{~J} \\
23.79 \mathrm{~J} \\
14.52 \mathrm{~J} \\
39.66 \mathrm{~J} \\
22.86 \mathrm{~J}\end{array}$ \\
\hline
\end{tabular}

\footnotetext{
(a) OL Detection 1/mit.

(b) J Analyte detected below method detection 1 imit (MOL), but above instrument detection 1 imit (IDL).

(c) JB Analyte detected below method detection limit (MOL), but above instrument detection limit (IDL), and found in the procedural blank: results presented are not corrected for the amount in the blank.

(d) B Analyte was found in the procedural blank; results presented are not corrected for the amount in the blank.
} 


\section{IABLE C.11. Quality Control Summary for Analysis of Phthalate Ester in Suspended-Particulate-Phase (SPP) Samples, Panama City Harbor Project}

\section{Water}

Ireatment

Blanks

Method Blank (a)

Procedyyal
Blank

\section{Matrix Solke}

PC-1 Replicate 1 PC-1 Replicate I MS Concentration Recovered Amount Spiked

Percent Recovery

Analytical Replicates

$\begin{array}{cccccc}74.56 \mathrm{~J} & 99.49 \mathrm{JB} & 97.14 \mathrm{~J} & 31.84 \mathrm{~J} & 206.38 \mathrm{JB} & 9.45 \mathrm{~J} \\ 93.38 \mathrm{~J} & 161.40 \mathrm{JB} & 100.58 \mathrm{~J} & 71.93 \mathrm{~J} & 253.27 \mathrm{JB} & 16.42 \mathrm{~J} \\ 188.42 \mathrm{~J} & 144.10 \mathrm{JB} & 83.52 \mathrm{~J} & 33.22 \mathrm{~J} & 195.65 \mathrm{JB} & 11.28 \mathrm{~J} \\ 51 \%(\mathrm{~g}) & 24 \% & 10 \% & 50 \%(\mathrm{~g}) & 14 \% & 29 \%\end{array}$

Phthalate Esters (ng/h)

\begin{tabular}{|c|c|c|c|c|c|}
\hline $\begin{array}{l}\text { Oimethyl } \\
\text { phthalate }\end{array}$ & $\begin{array}{l}\text { Diethyl } \\
\text { phthalate }\end{array}$ & $\begin{array}{l}01-n \text {-butyl } \\
\text { phthalate }\end{array}$ & $\begin{array}{l}\text { Butyl } \\
\text { benzyl } \\
\text { phthalate }\end{array}$ & $\begin{array}{l}\text { Bis } \\
\text { (2-ethyl- } \\
\text { hexyl) } \\
\text { phthalate }\end{array}$ & $\begin{array}{l}\text { Di-n-octyl } \\
\text { phthalate }\end{array}$ \\
\hline
\end{tabular}

$\begin{array}{lllllll}837.31 \mathrm{U}^{(\mathrm{b})} & 188.47 \mathrm{~J}(\mathrm{c}) & 12.34 \mathrm{~J} & 18.20 \mathrm{~J} & 59.29 \mathrm{~J} & 2.74 \mathrm{~J} \\ 137.96 \mathrm{~J} & 291.88 \mathrm{8}^{(\mathrm{e})} & 253.21 \mathrm{~J} & 172.65 \mathrm{~J} & 2448.25 \mathrm{~B} & 37.85 \mathrm{~J}\end{array}$

$\begin{array}{cccccr}74.56 \mathrm{~J} & 99.49 \mathrm{JB}(\mathrm{f}) & 97.14 \mathrm{~J} & 31.84 \mathrm{~J} & 206.38 \mathrm{JB} & 9.45 \mathrm{~J} \\ 7280.79 & 7645.61 & 4188.67 & 7407.85 & 6968.62 & 3290.36 \\ 7206.23 & 7546.12 & 4091.53 & 7376.01 & 6762.24 & 3280.91 \\ 7142.87 & 7325.70 & 7142.87 & 7142.87 & 7142.87 & 7142.87 \\ 101 \% & 103 \% & 57 \% & 103 \% & 95 \% & 46 \%\end{array}$

(a) Method water blank concentrations were determined by using the sediment method blank values in (ng) and dividing by the average volume size of the water samples. The sediment and water samples were extracted together.

(b) $U$ Analyte was not present above the associated value.

(c) J Analyte detected below method detection limit (MDL), but above instrument detection limit (IDL).

(d) Procedural blank was processed and analyzed following the same procedures as the water samples.

(e) B Analyte was found in the procedural blank: results presented are not corrected for the amount in the blank.

(f) JB Analyte detected below method detection limit (MDL), but above instrument detection Iimit (IDL), and found in the procedural blank; results presented are nct corrected for the amount in the blank.

(g) Value exceeds relative precision goal of $\leq 30 \%$. 


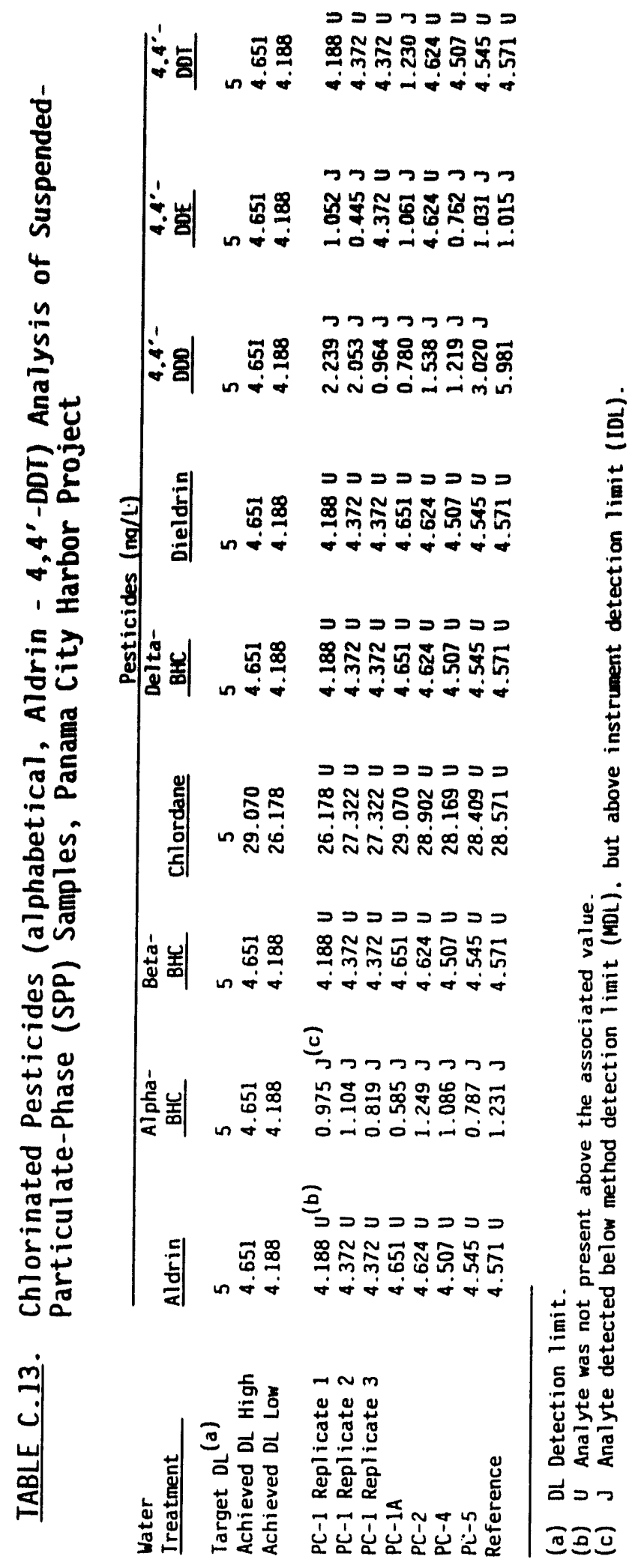

PANAMA CITY HARBOR

C. 13 


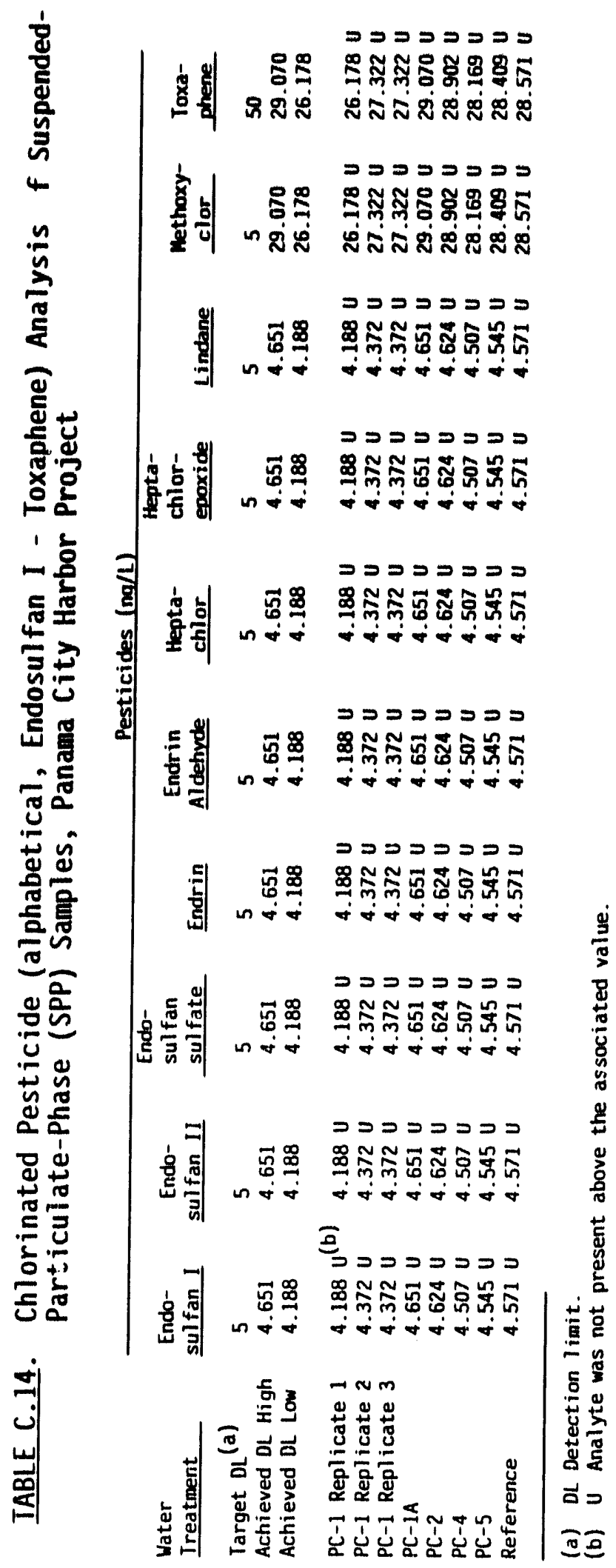

PANAMA CITY HARBOR

C. 14 


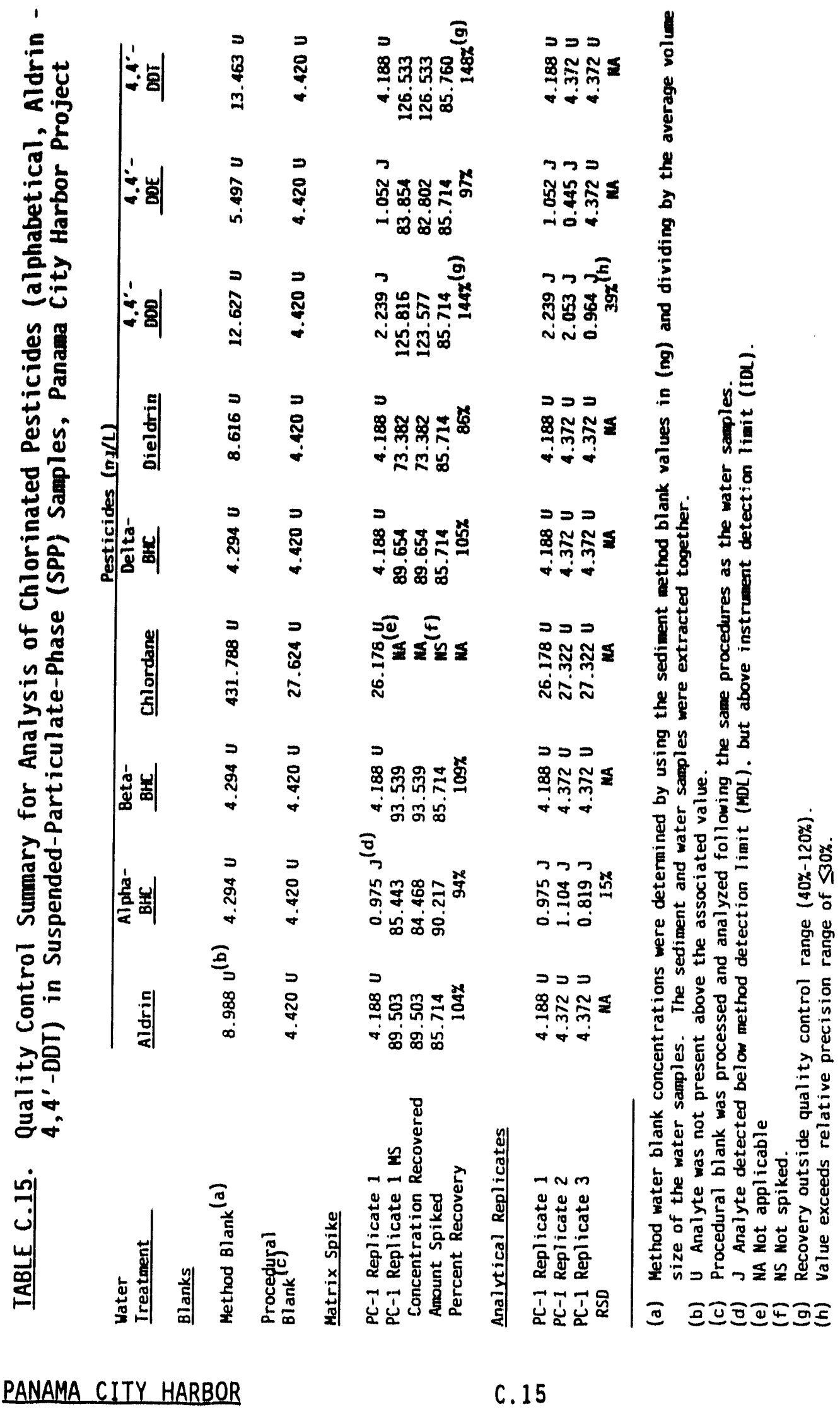




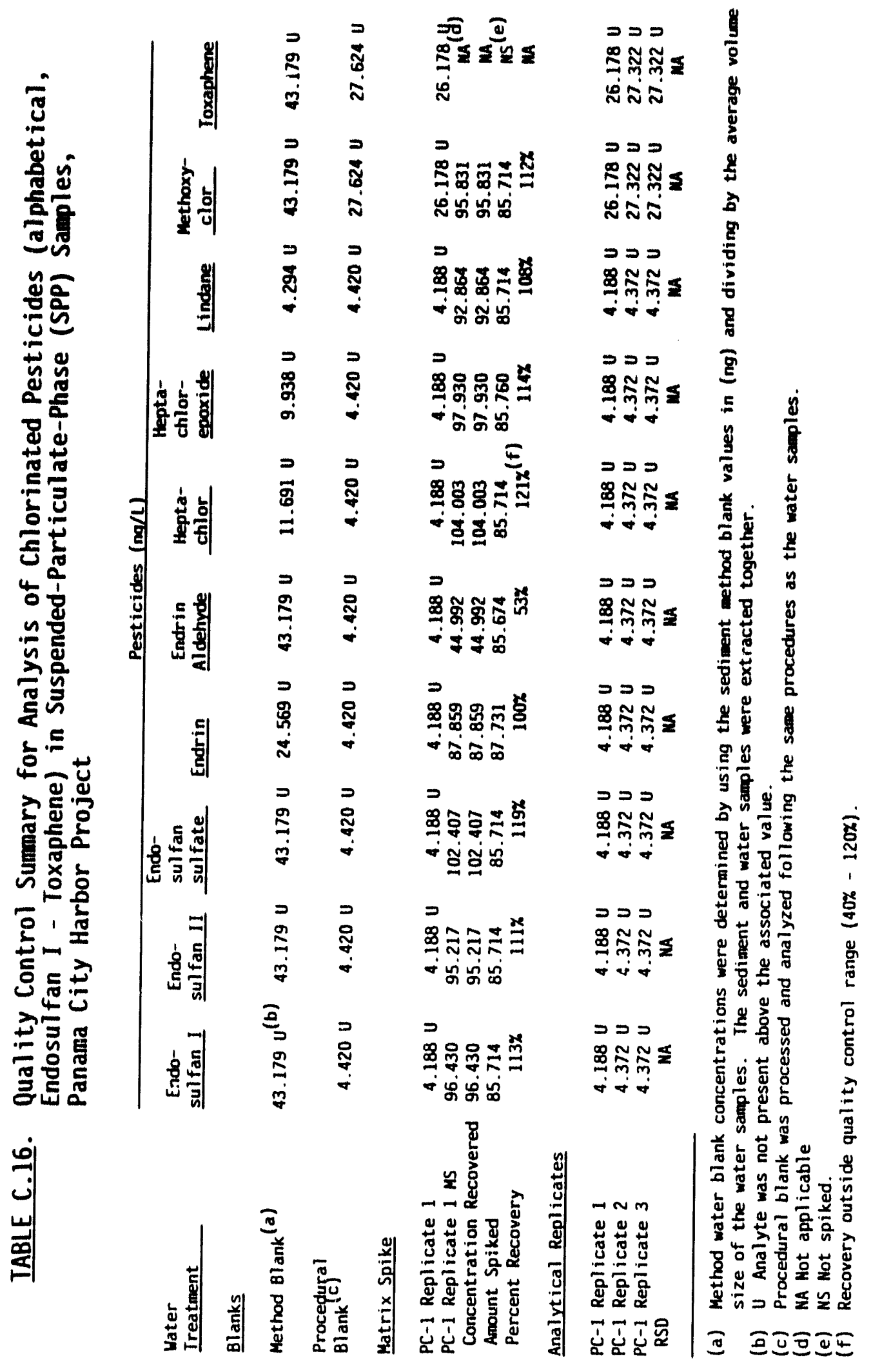

PANAMA CITY HARBOR

C. 16 
IABLE C.17. Polychlorinated Biphenyls (PCB) Analysis of SuspendedParticulate-Phase (SPP) Samples, Panama City Harbor Project

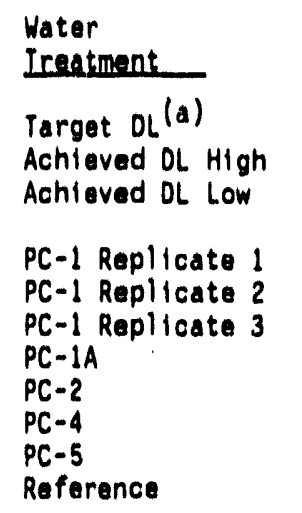

\begin{tabular}{|c|c|c|c|c|c|}
\hline \multicolumn{6}{|c|}{ PCBs (na $/ b)$} \\
\hline $\begin{array}{l}\text { Aroclor } \\
1221\end{array}$ & $\begin{array}{l}\text { Aroclor } \\
1232 \\
\end{array}$ & $\begin{array}{l}\text { Aroclor } \\
1242 / 1016\end{array}$ & $\begin{array}{l}\text { Aroclor } \\
1248 \\
\end{array}$ & $\begin{array}{l}\text { Aroclor } \\
1254 \\
\end{array}$ & $\begin{array}{l}\text { Aroclor } \\
1260 \\
\end{array}$ \\
\hline $\begin{array}{l}50 \\
29.070 \\
26.178\end{array}$ & $\begin{array}{l}50 \\
29.070 \\
26.178\end{array}$ & $\begin{array}{l}50 \\
29.070 \\
26.178\end{array}$ & $\begin{array}{l}50 \\
29.070 \\
26.178\end{array}$ & $\begin{array}{l}50 \\
29.070 \\
26.178\end{array}$ & $\begin{array}{l}50 \\
29.070 \\
26.178\end{array}$ \\
\hline $\begin{array}{l}26.178 U^{(b)} \\
27.322 U \\
27.322 U \\
29.070 U \\
28.902 U \\
28.169 U \\
28.409 U \\
28.571 U\end{array}$ & $\begin{array}{l}26.178 U \\
27.322 U \\
27.322 U \\
29.070 U \\
28.902 U \\
28.169 U \\
28.409 U \\
28.571 U\end{array}$ & $\begin{array}{l}26.178 U \\
27.322 U \\
27.322 U \\
29.070 U \\
28.902 U \\
28.169 U \\
28.409 U \\
28.571 U\end{array}$ & $\begin{array}{l}26.178 U \\
27.322 U \\
27.322 U \\
29.070 U \\
28.902 U \\
28.169 U \\
28.409 U \\
28.571 U\end{array}$ & $\begin{array}{l}26.178 U \\
27.322 U \\
27.322 U \\
29.070 U \\
28.902 U \\
28.169 U \\
28.409 U \\
28.571 U\end{array}$ & $\begin{array}{l}26.178 U \\
27.322 U \\
27.322 U \\
29.070 U \\
28.902 U \\
28.169 U \\
28.409 U \\
28.571 U\end{array}$ \\
\hline
\end{tabular}

(a) OL Detection limit.

(b) U Analyte was not present above the assoclated value. 
TABLE C.18. Quality Control Summary for Analysis of Polychlorinated Biphenyls (PCB) in Suspended-Particulate-Phase (SPP) Samples, Panama City Harbor Project

\begin{tabular}{|c|c|c|c|c|c|c|}
\hline $\begin{array}{l}\text { Water } \\
\text { Treatment }\end{array}$ & \multicolumn{6}{|c|}{ PCBs (ng/L) } \\
\hline Method Blank $(a)$ & $431.788 u^{(b)}$ & $431.788 U$ & $431.788 U$ & $431.788 \mathrm{U}$ & $431.788 \mathrm{U}$ & 431.788 \\
\hline $\begin{array}{l}\text { Procedural } \\
\text { Blank }\end{array}$ & $27.624 \mathrm{U}$ & $27.624 \mathrm{U}$ & $27.624 \mathrm{U}$ & $27.624 \mathrm{U}$ & $27.624 \mathrm{U}$ & $27.624 \mathrm{~L}$ \\
\hline \multicolumn{7}{|l|}{ Matrix Spike } \\
\hline $\begin{array}{l}\text { PC-1 Replicate } 1 \\
\text { PC-1 Replicate } 1 \text { MS } \\
\text { Concentration Recovered } \\
\text { Amount Spiked } \\
\text { Percent Recovery }\end{array}$ & $\begin{array}{l}26.178 \mathrm{~d}) \\
N A \\
N A \\
N S \\
N A\end{array}$ & $\begin{array}{l}26.178 \text { U } \\
\text { NA } \\
\text { NA } \\
\text { NS } \\
\text { NA. }\end{array}$ & $\begin{array}{l}26.178 \mathrm{U} \\
\text { NA } \\
\text { NA } \\
\text { NS } \\
\text { NA }\end{array}$ & $\begin{array}{l}26.178 \mathrm{U} \\
\text { NA } \\
\text { NA } \\
\text { NS } \\
\text { NA }\end{array}$ & $\begin{array}{r}26.178 \mathrm{U} \\
1348.750 \\
1348.750 \\
1250.017 \\
108 \%\end{array}$ & $\begin{array}{l}26.178 \mathrm{~L} \\
\text { NA } \\
\text { NA } \\
\text { NS } \\
\text { NA }\end{array}$ \\
\hline $\begin{array}{l}\text { PC-1 Repl icate } 1 \\
\text { PC-1 Repl icate } 2 \\
\text { PC-1 Repl icate } 3 \\
\text { RSD }\end{array}$ & $\begin{array}{l}26.178 U \\
27.322 U \\
27.322 U \\
N A\end{array}$ & $\begin{array}{l}26.178 U \\
27.322 U \\
27.322 U \\
\text { NA }\end{array}$ & $\begin{array}{l}26.178 U \\
27.322 U \\
27.322 U \\
\text { NA }\end{array}$ & $\begin{array}{l}26.178 U \\
27.322 U \\
27.322 U \\
N A\end{array}$ & $\begin{array}{l}26.178 U \\
27.322 U \\
27.322 U \\
N A\end{array}$ & $\begin{array}{l}26.178 \mathrm{~L} \\
27.322 \mathrm{~L} \\
27.322 \mathrm{~L} \\
\text { NA }\end{array}$ \\
\hline
\end{tabular}

(a) Method water blank conceiıtralions were determined by using the sediment method blank values in (ng) and dividing the average voli,ne size of the water samples. The sediment and water samples were extracted together.

(b) $U$ Analyte was not present above the associated value.

(c) Procedural blank was processed and analyzed following the same procedures as the water sample.

(d) NA Not applicable.

(e) NS Not spiked. 
IABLE C.19. Surrogate Recoveries and Quality Control Summary for Analys is of Chlorinated Pesticides and Polychlorinated Biphenyls (PCB) in Suspended-Particulate-Phase (SPP) Samples, Panama City Harbor Project

Water

Ireatment

PC-1 Replicate 1

PC-1 Replicate 2

$P C-1$ Replicate 3

$P C-1 A$

$P C-2$

$P C-4$

$P C-5$

Reference

\begin{tabular}{lc} 
Surrogate \\
& Percent Recoveries \\
\hline DBOFB &
\end{tabular}

102

106

105

91

115

99

94

116
90

91

90

79

91

84

77

83

Quality Control Data

Blanks

Method Blank(a) $35^{(b)}$ $38^{(b)}$

Procedural

Blank ${ }^{\text {c }}$

Matrix Spike

PC-1 Replicate 1

PC-1 Replicate 1 MS

\section{Analytica? Replicates}

PC-1 Replicate 1

102

90

$P C-1$ Replicate 2

PC-1 Replicate 3

106

91

105

90

$2 \%$

RSD

(a) Method water blank concentrations were determined by using the sediment method blank values in (ng) and dividing by the average volume size of the water samples. The sediment and water samples were extracted together.

(b) Recovery outside of quality control range (40\%-120\%).

(c) Procedural blank was processed and analyzed following the same procedure as the water samples. 


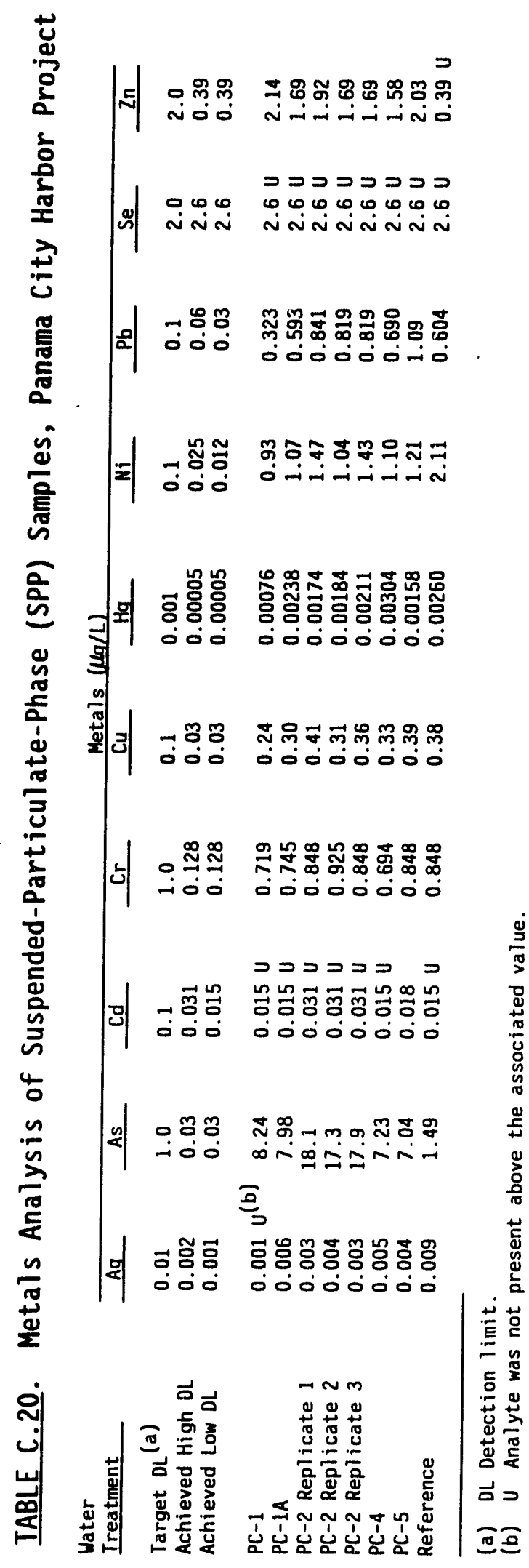

PANAMA CITY HARBOR 


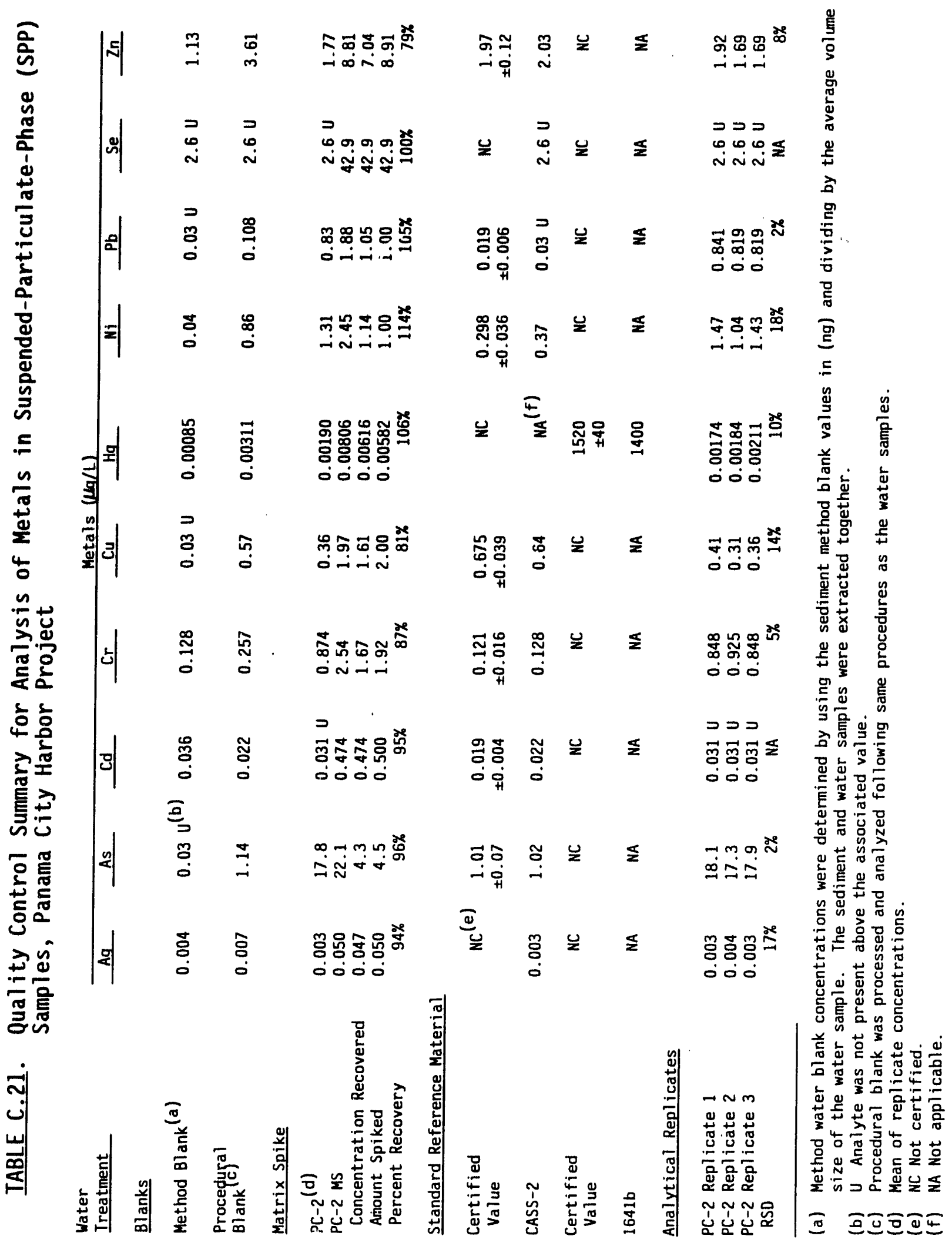

PANAMA CITY HARBOR

C. 21 
APPENDIX D

10-DAY SOLID-PHASE TEST

96-HOUR REFERENCE TOXICANT TEST

WITH A. ABDITA 
Table D.1. Results for All Replicates in 10-Day A. abdita Solid-Phase Test, Panama City Harbor Froject

Sediment

Treatment

$P C-1$

$P C-1$

$P C-1$

$P C-1$

$P C-1$

$P C-1 A$

$P C-1 A$

$P C-1 A$

$P C-1 A$

$P C-1 A$

$\mathrm{PC}-2$

$\mathrm{PC}-2$

$P C-2$

$P C-2$

$\mathrm{PC}-2$

PC -4

PC- 4

PC -4

PC -4

PC - 4

$P C-5$

$P C-5$

$P C-5$

$P C-5$

$P C-5$

Re:erence

Reference

Reference

Reference

Reference

A. abdita Control

A. abdita Control

A. abdita Control

A. abdita Control

A. abdita Control

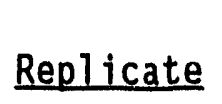

1

2

3

4
5

1

2

3

5

1

2

4

5

1

2

3

4
5

5

1

2

3

4

5

1

2

3

4

5

1
2
3
4
5

$\begin{array}{lll}\text { A. abdita } & \begin{array}{c}\text { Mean } \\ \text { Percent }\end{array} \\ \text { Live } & \text { Mead or } & \begin{array}{c}\text { Proportion } \\ \text { Missing }\end{array}\end{array}$

16

19

13

18

18

18

17

15

14

20

18

19

18

17

18

16

17

20

18

17

18

18

18

16

17

20

16

19

16

17

18

19

17

13

18

$\begin{array}{ll}4 & 0.80 \\ 1 & 0.95 \\ 7 & 0.65 \\ 2 & 0.90 \\ 2 & 0.90\end{array}$

84.0

0.90

0.85

0.75

0.70

1.00

84.0

0.90

0.95

0.90

0.85

0.90

90.0

0.80

0.85

1.00

0.90

0.85

88.0

0.90

0.90

0.90

0.80

0.85

87.0

1.00

0.80

0.95

0.80

0.85

88.0

0.90

0.95

0.85

0.65

0.90

85.0 
IABLE D.2. Water Quality Summary for 10-Day A. abdita Solid-Phase Test, Panama City Harbor Project

Sediment

Treatment

Acceptable

range

PC- 1

$P C-1 A$

$P C-2$

$P C-4$

PC-5

Reference

A. abdica Control

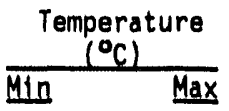

18.0

18.2

18.1

18.2

18.2

18.2

18.2

18.2

21.2

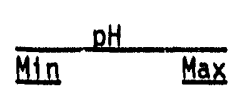

7.30

7.46

7.64

7.65

7.64

7.70

7.60

7.59
8.30

8.08

8.07

8.07

8.07

8.09

8.12

8.07

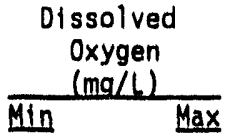

26.0

$\begin{array}{ll}6.3 & 7.5 \\ 6.1 & 7.4 \\ 6.1 & 7.4 \\ 6.1 & 7.5 \\ 6.2 & 7.4 \\ 6.0 & 7.4 \\ 6.0 & 7.4\end{array}$

6.0

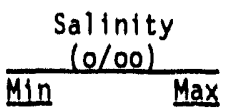

28.0

32.0

7.4

30.5

$30.5 \quad 32.0$

$30.5 \quad 32.0$

$30.0 \quad 32.0$

$31.0 \quad 32.0$

$31.0 \quad 32.0$

$30.5 \quad 32.0$ 
IABLE D.3. Results for All Replicates in 96-Hour $A$. abdita Reference Toxicant Test, Panama City Harbor Project

\begin{tabular}{|c|c|c|c|c|c|}
\hline \multirow{2}{*}{$\begin{array}{c}\text { Cadmium } \\
\text { Concentration } \\
\text { (mg/L) }\end{array}$} & \multirow[b]{2}{*}{ Replicate } & \multicolumn{3}{|c|}{ A. abdita } & \multirow{2}{*}{$\begin{array}{c}\text { Mean } \\
\text { Percent } \\
\text { Surviving } \\
\end{array}$} \\
\hline & & Live & $\begin{array}{l}\text { Dead or } \\
\text { Missing }\end{array}$ & $\begin{array}{l}\text { Proportion } \\
\text { Surviving }\end{array}$ & \\
\hline $\begin{array}{l}0.0 \\
0.0 \\
0.0\end{array}$ & $\begin{array}{l}1 \\
2 \\
3\end{array}$ & $\begin{array}{l}19 \\
19 \\
16\end{array}$ & $\begin{array}{l}1 \\
1 \\
4\end{array}$ & $\begin{array}{l}0.95 \\
0.95 \\
0.80\end{array}$ & 90.0 \\
\hline $\begin{array}{l}0.5 \\
0.5 \\
0.5\end{array}$ & $\begin{array}{l}1 \\
2 \\
3\end{array}$ & $\begin{array}{l}18 \\
18 \\
19\end{array}$ & $\begin{array}{l}2 \\
2 \\
1\end{array}$ & $\begin{array}{l}0.90 \\
0.90 \\
0.95\end{array}$ & 91.7 \\
\hline $\begin{array}{l}1.0 \\
1.0 \\
1.0\end{array}$ & $\begin{array}{l}1 \\
2 \\
3\end{array}$ & $\begin{array}{l}15 \\
15 \\
12\end{array}$ & $\begin{array}{l}5 \\
5 \\
8\end{array}$ & $\begin{array}{l}0.75 \\
0.75 \\
0.60\end{array}$ & 70.0 \\
\hline $\begin{array}{l}2.0 \\
2.0 \\
2.0\end{array}$ & $\begin{array}{l}1 \\
2 \\
3\end{array}$ & $\begin{array}{l}5 \\
1 \\
6\end{array}$ & $\begin{array}{l}15 \\
19 \\
14\end{array}$ & $\begin{array}{l}0.25 \\
0.05 \\
0.30\end{array}$ & 20.0 \\
\hline $\begin{array}{l}4.0 \\
4.0 \\
4.0\end{array}$ & $\begin{array}{l}1 \\
2 \\
3\end{array}$ & $\begin{array}{l}0 \\
0 \\
0\end{array}$ & $\begin{array}{l}20 \\
20 \\
20\end{array}$ & $\begin{array}{l}0.00 \\
0.00 \\
0.00\end{array}$ & 0.0 \\
\hline
\end{tabular}


IABLE 0.4. Water Quality Summary for 96-Hour A. abdita Reference Toxicant Test, Panama City Harbor Project

\begin{tabular}{|c|c|c|c|c|c|c|c|c|}
\hline \multirow{2}{*}{$\begin{array}{l}\text { Cadmilum } \\
\text { Concentration } \\
\text { (ma/L) }\end{array}$} & \multicolumn{2}{|c|}{$\begin{array}{l}\text { Temperature } \\
\left({ }^{\circ} \mathrm{C}\right)\end{array}$} & \multicolumn{2}{|c|}{$\mathrm{pH}$} & \multicolumn{2}{|c|}{$\begin{array}{l}\text { Oissolved } \\
\text { Oxygen } \\
(\mathrm{mg} / \mathrm{L})\end{array}$} & \multicolumn{2}{|c|}{$\begin{array}{c}\text { Salinity } \\
(0 / 00)\end{array}$} \\
\hline & Minn & Max & $\overline{\operatorname{Min}}$ & $\underline{\text { Max }}$ & $\overline{M 1 n}$ & Max & in & $\operatorname{Max}$ \\
\hline $\begin{array}{l}\text { Acceptable } \\
\text { range }\end{array}$ & 18.0 & 22.0 & 7.30 & 8.30 & & & 28.0 & 32.0 \\
\hline $\begin{array}{l}0.0 \\
0.25 \\
0.5 \\
1.0 \\
2.0\end{array}$ & $\begin{array}{l}18.4 \\
18.4 \\
18.3 \\
18.4 \\
18.4\end{array}$ & $\begin{array}{l}19.5 \\
19.5 \\
19.6 \\
19.7 \\
19.5\end{array}$ & $\begin{array}{l}8.01 \\
8.01 \\
8.00 \\
8.00 \\
7.98\end{array}$ & $\begin{array}{l}8.35(a) \\
8.35(a) \\
8.33(a) \\
8.33(a) \\
8.28\end{array}$ & $\begin{array}{l}6.8 \\
7.2 \\
7.1 \\
7.0 \\
7.2\end{array}$ & $\begin{array}{l}7.5 \\
7.5 \\
7.4 \\
7.6 \\
7.4\end{array}$ & $\begin{array}{l}31.0 \\
30.5 \\
31.0 \\
31.0 \\
31.0\end{array}$ & $\begin{array}{l}32.0 \\
32.0 \\
32.0 \\
32.0 \\
32.0\end{array}$ \\
\hline
\end{tabular}

(a) Value outside of acceptable range. 
APENDIXE

10-DAY SOLID-PHASE TEST

96-HOUR REFERENCE TOXICANT TEST

WITH $R$. ABRONIUS 
Iable E.d. Results for All Replicates in 10-Day R. abronius

Solid-Phase Test, Panama City Harbor Project

\section{Sediment}

Ireatment

$P C-1$

$P C-1$

$P C-1$

$P C-1$

$P C-1$

$P C-1 A$

PC-1A

PC-1A

$P C-1 A$

PC-1A

$P C-2$

$\mathrm{PC}-2$

$\mathrm{PC}-2$

$P C-2$

$\mathrm{PC}-2$

PC- 4

$P C-4$

$P C-4$

PC- 4

PC- 4

PC -5

$P C-5$

$P C-5$

$P C-5$

PC-5

Reference

Reference

Reference

Reference

Reference

$R$. abronius Control

$R$. abronius Control

$R$. abronius Control

$R$. abronius Control

$R$. abronius Control
Replicate

1
2
3
4
5

1

2

3

4
5

1

2

3

4
5

120

218

3

4

119

$2 \quad 17$

320

$4 \quad 19$

$5 \quad 16$

$1 \quad 19$

$2 \quad 19$

320

$4 \quad 15$

$5 \quad 19$

120

20

20

20

20
R. abronius

Dead or Proportion Percent

Missing surviving surviving

$\begin{array}{lll}20 & 0 & 1.00\end{array}$

$\begin{array}{lll}16 & 4 & 0.80\end{array}$

$\begin{array}{lll}9 & 1 & 0.95\end{array}$

$\begin{array}{lll}18 & 2 & 0.90\end{array}$

$\begin{array}{lll}2 & 0 & 1.00\end{array}$

93.0

18

9

18

20

2

0.90

1.00

0.95

0.90

1.00

95.0

0.45

0.70

0.50

0.90

0.50

61.0

1.00

0.90

1.00

1.00

1.00

98.0

0.95

0.85

1.00

0.95

0.80

91.0

0.95

0.95

1.00

0.75

0.95

92.0

1.00

1.00

1.00

1.00

1.00

100.0 
IABLEE.2. Water Quality Summary for R. abronius 10-Day Solid-Phase Test, Panama City Harbor Project

Sediment

Irestment.

Acceptable

range

$P C-1$

PC-1A

$P C-2$

PC-4

PC-5

Reference

$R$ abronius control

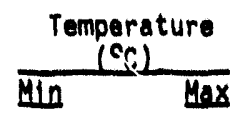

13.0

17.0
15.7
15.7
15.9
15.8
15.7
15.7
15.6

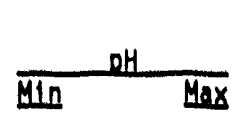

7.30

7.86

8.05

8.02

8.00

8.04

7.92

7.79
8.30

8.18

8.25

8.22

8.23

8.23

8.27

8.18

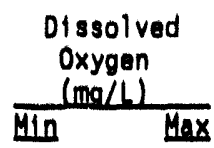

26.0

7.2

7.3

7.3

7.4

7.0

6.8

7.5
8.1

8.1

8.3

8.0

8.1

8.2

8.3 $\begin{gathered}\text { Salinity } \\ (0 / 00)\end{gathered}$
Min Max

$28.0 \quad 32.0$

$31.5 \quad 32.0$

$30.5 \quad 32.0$

$31.0 \quad 32.0$

$31.5 \quad 32.0$ (a)

$31.0 \quad 32.5(a)$

$31.5 \quad 32.0$

$31.5 \quad 32.0$

(a) Value outside of acceptable range. 
IABLEE.3. Results for All Replicates in 96-Hour R. abronius Reference Toxicant Test, Panama City Harbor Project

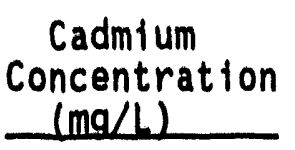

0.0

0.0

0.0

0.5

0.5

0.5

1.0

1.0

1.0

2.0

2.0

2.0

4.0

4.0

4.0
Reolicate

1
2
3

1
2
3

1

3

1
3

1
2
3

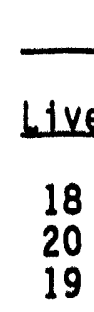

18

18

19

13

12

14

9
7
8

0

3
R. abrenius Dead or Missing Surviving

0.90

1.00

0.95

0.90

0.90

0.95

0.65

0.60

0.70

65.0

11

13

12

0.45

0.35

0.40

40.0

20

17

0.00

0.15

0.05

95.0

91.7

Percent

Surviving

19

6.7 
IABLEE.4. Water Quality Summary for R. abronius 96-Hour Reference Toxicant Test, Panama City Harbor Project

\begin{tabular}{|c|c|c|c|c|c|c|c|c|}
\hline \multirow{2}{*}{$\begin{array}{l}\text { Cadmi um } \\
\text { Concentration } \\
\text { (mos/le) } \\
\end{array}$} & \multicolumn{2}{|c|}{$\begin{array}{c}\text { Temperature } \\
\left(0^{\circ} \mathrm{C}\right)^{-1}\end{array}$} & & & \multicolumn{2}{|c|}{$\begin{array}{l}01 \text { ssolved } \\
\text { Oxygen } \\
(\mathrm{mg} / \mathrm{L})\end{array}$} & \multicolumn{2}{|c|}{$\begin{array}{c}\text { Salinity } \\
(0 / 00)\end{array}$} \\
\hline & In & Max & Min & Max & Min & $\operatorname{Max}$ & Min & Max \\
\hline $\begin{array}{l}\text { Acceptable } \\
\text { range }\end{array}$ & 13.0 & 17.0 & 7.30 & 8.30 & & & 28.0 & 32.0 \\
\hline $\begin{array}{l}0.0 \\
0.5 \\
1.0 \\
2.0 \\
4.0\end{array}$ & $\begin{array}{l}14.4 \\
14.3 \\
14.5 \\
14.4 \\
14.4\end{array}$ & $\begin{array}{l}14.8 \\
14.7 \\
14.7 \\
14.7 \\
14.7\end{array}$ & $\begin{array}{l}8.02 \\
8.07 \\
7.90 \\
7.91 \\
7.87\end{array}$ & $\begin{array}{l}8.28 \\
8.28 \\
8.26 \\
8.21 \\
8.14\end{array}$ & $\begin{array}{l}7.7 \\
7.8 \\
7.7 \\
7.9 \\
7.5\end{array}$ & $\begin{array}{l}8.2 \\
8.2 \\
8.1 \\
8.4 \\
8.5\end{array}$ & $\begin{array}{l}31.5 \\
32.0 \\
32.0 \\
31.5 \\
32.0\end{array}$ & $\begin{array}{l}32.0 \\
32.0 \\
32.0 \\
32.0 \\
32.0\end{array}$ \\
\hline
\end{tabular}




\section{APPENDIX F}

10-DAY SOLID-PHASE TEST

WITH N. VIRENS 
TABLE F.1. Results for Al1 Replicates in 10-Day N. virens Solid-Phase Test, Panama City Harbor Project

\section{Sediment \\ Treatment}

$P C-1$

$P C-1$

$P C-1$

$P C-1$

$\mathrm{PC}-1$

$P C-1 A$

$P C-1 A$

$P C-1 A$

$P C \cdot 1 A$

$P C-1 A$

$P C-2$

$P C-2$

$P C-2$

$P C-2$

$P C-2$

PC -4

$P C-4$

$P C-4$

$P C-4$

PC - 4

PC -5

$P C-5$

$P C-5$

$P C-5$

$P C-5$

Reference

Reference

Reference

Reference

Reference

N. virens Control

N. virens Control

N. virens Control

N. virens Control

N. virens Control

\section{Replicate}

1

2

3

4

5

1

2

3

4
5

5

1

2

3

4

5

1

2

3

4

1
2
3
4
5

1

2

3
4

5

1
2
3
4
5

N. virens Dead or Missing

19

20

20

19

18

20

19

20

20

20

20

19

20

20

18

20

20

20

19

19

19

20

20

20

20

20

17

20

20

19

19

20

20

18

19

$\begin{array}{ll}1 & 0.95 \\ 0 & 1.00 \\ 0 & 1.00 \\ 1 & 0.95 \\ 2 & 0.90\end{array}$

0.95

96.0

1.00

0.95

1.00

1.00

1.00

99.0

1.00

0.95

1.00

1.00

0.90

97.0

1.00

1.00

1.00

0.95

0.95

98.0

0.95

1.00

1.00

1.00

1.00

99.0

1.00

0.85

1.00

1.00

0.95

96.0

0.95

1.00

1.00

0.90

0.95

96.0

F.1

PANAMA CITY HARBOR 
IABLE F.2. Water Quality Summary for N. virens 10-Day Solid-Phase Test, Panama City Harbor Project

\begin{tabular}{|c|c|c|c|c|c|c|c|c|}
\hline \multirow{2}{*}{$\begin{array}{l}\text { Sediment } \\
\text { Ireatment }\end{array}$} & \multicolumn{2}{|c|}{$\begin{array}{l}\text { Temperature } \\
\left({ }^{\circ} \mathrm{C}\right)\end{array}$} & \multicolumn{2}{|c|}{$\mathrm{pH}$} & \multicolumn{2}{|c|}{$\begin{array}{l}\text { Dissolved } \\
\text { Oxygen } \\
(\mathrm{mg} / \mathrm{L})\end{array}$} & \multicolumn{2}{|c|}{$\begin{array}{c}\text { Salinity } \\
(0 / 00)\end{array}$} \\
\hline & Min & Max & Min & $\underline{\operatorname{Max}}$ & Min & Max & Min & Max \\
\hline $\begin{array}{l}\text { Acceptable } \\
\text { Range }\end{array}$ & 13.0 & 17.0 & 7.30 & 8.30 & & & 28.0 & 32.0 \\
\hline $\begin{array}{l}P C-1 \\
P C-1 A \\
P C-2 \\
P C-4 \\
P C-5 \\
\text { Reference } \\
N . \text { virens Control }\end{array}$ & $\begin{array}{l}14.8 \\
14.7 \\
14.8 \\
14.9 \\
14.8 \\
14.9 \\
14.8\end{array}$ & $\begin{array}{l}15.8 \\
16.1 \\
16.0 \\
16.1 \\
15.9 \\
16.0 \\
15.9\end{array}$ & $\begin{array}{l}7.77 \\
7.71 \\
7.73 \\
7.73 \\
7.71 \\
7.74 \\
7.69\end{array}$ & $\begin{array}{l}8.04 \\
8.02 \\
7.95 \\
8.01 \\
7.99 \\
7.96 \\
7.92\end{array}$ & $\begin{array}{l}7.0 \\
6.7 \\
7.0 \\
7.0 \\
7.1 \\
6.2 \\
7.1\end{array}$ & $\begin{array}{l}8.1 \\
7.9 \\
7.8 \\
7.7 \\
7.9 \\
7.8 \\
7.7\end{array}$ & $\begin{array}{l}31.0 \\
30.5 \\
31.0 \\
30.5 \\
30.5 \\
30.5 \\
31.0\end{array}$ & $\begin{array}{l}32.0 \\
32.0 \\
32.5 \\
32.0 \\
32.0 \\
32.0 \\
32.0\end{array}$ \\
\hline
\end{tabular}


APPENDIX G

28-DAY SOLID-PHASE TEST

WITH N. VIRENS 
TABLE G.1. Results for All Replicates in 23-Day M. virens Solid-Phase Test, Panama City Harbor Project

\section{Sediment}

Ireatment

$P C-1$

$P C-1$

$\mathrm{PC}-1$

$P C-1$

$P C-1$

$P C-1 A$

$P C-1 A$

$P C-1 A$

$P C-1 A$

$P C-1 A$

PC-2

$P C-2$

$P C-2$

PC-2

PC-2

PC - 4

PC- 4

PC- 4

PC- 4

PC - 4

PC - 5

$P C-5$

$P C-5$

$P C-5$

$P C-5$

Reference

Reference

Reference

Reference

Reference
Replicate

1

3

4

5

1

2

3

4

5

1

2

3

4

5

1

2

3

4
5

1

2

3

4
5

5

1

2

3

4

5

$\begin{array}{ll}\text { N. virens Control } & 1 \\ N \text {. virens Control } & 2 \\ \text { N. virens Control } & 3 \\ \text { N. virens Control } & 4 \\ \text { N. virens Control } & 5\end{array}$

\begin{tabular}{|c|c|c|c|}
\hline \multicolumn{3}{|c|}{ N. virens } & Mean \\
\hline Live & $\begin{array}{l}\text { Dead or } \\
\text { Missing }\end{array}$ & $\begin{array}{l}\text { Proportion } \\
\text { Surviving }\end{array}$ & $\begin{array}{c}\text { Percent } \\
\text { Surviving }\end{array}$ \\
\hline
\end{tabular}

19

20

19

18

20

19

20

20

17

20

19

18

19

19

13

20

20

19

19

20

20

$\cdot 19$

19

20

19

20

20

19

19

20

19

19

17

19

18

$\begin{array}{ll}1 & 0.95 \\ 0 & 1.00 \\ 1 & 0.95 \\ 2 & 0.90 \\ 0 & 1.00\end{array}$

96.0

0.95

1.00

1.00

0.85

1.00

96.0

0.95

0.90

0.95

0.95

0.65

88.0

1.00

1.00

0.95

0.95

1.00

98.0

1.00

0.95

0.95

1.00

0.95

97.0

1.00

1.00

0.95

0.95

1.00

98.0

0.95

0.95

0.85

0.95

0.90

92.0 
TABLE G.2. Water Quality Summary for N. virens 28-Day Solid-Phase Test, Panama City Harbor Project

\begin{tabular}{|c|c|c|c|c|c|c|c|c|}
\hline \multirow{2}{*}{$\begin{array}{l}\text { Sediment } \\
\text { Ireatment }\end{array}$} & \multicolumn{2}{|c|}{$\begin{array}{c}\text { Temperature } \\
\left({ }^{\circ} \mathrm{C}\right)\end{array}$} & \multicolumn{2}{|c|}{$\mathrm{pH}$} & \multicolumn{2}{|c|}{$\begin{array}{l}\text { Dissolved } \\
\text { Oxygen } \\
(\mathrm{mg} / \mathrm{L})\end{array}$} & \multicolumn{2}{|c|}{$\begin{array}{c}\text { Salinity } \\
(0 / 00)\end{array}$} \\
\hline & Min & $\overline{\mathrm{Max}}$ & Min & Max & Min & Max & Min & Max \\
\hline $\begin{array}{l}\text { Acceptable } \\
\text { Range }\end{array}$ & 13.0 & 17.0 & 7.30 & 8.30 & & & 28.0 & 32.0 \\
\hline $\begin{array}{l}P C-1 \\
P C-1 A \\
P C-2 \\
P C-4 \\
P C-5 \\
\text { Reference } \\
N \text {. virens Control }\end{array}$ & $\begin{array}{l}14.8 \\
14.8 \\
14.7 \\
14.8 \\
14.8 \\
14.8 \\
14.8\end{array}$ & $\begin{array}{l}16.5 \\
16.5 \\
16.4 \\
16.4 \\
16.6 \\
16.2 \\
16.3\end{array}$ & $\begin{array}{l}7.73 \\
7.73 \\
7.61 \\
7.60 \\
7.60 \\
7.53 \\
7.61\end{array}$ & $\begin{array}{l}7.99 \\
7.96 \\
7.99 \\
7.99 \\
8.00 \\
7.98 \\
7.94\end{array}$ & $\begin{array}{l}7.0 \\
7.0 \\
6.6 \\
7.0 \\
7.0 \\
6.7 \\
7.0\end{array}$ & $\begin{array}{l}8.1 \\
8.0 \\
8.1 \\
8.1 \\
8.2 \\
8.0 \\
8.1\end{array}$ & $\begin{array}{l}31.0 \\
30.5 \\
30.0 \\
30.5 \\
31.0 \\
31.0 \\
30.5\end{array}$ & $\begin{array}{l}32.0 \\
32.0 \\
32.0 \\
32.0 \\
32.0 \\
32.0 \\
32.0\end{array}$ \\
\hline
\end{tabular}


APPENDIX H

28-DAY SOLID-PHASE TEST

WITH M. NASUTA 
TABLE H.1. Results for All Replicates in 28-Day M. nasuta Solid-Phase Test, Panama City Harbor Project

\begin{tabular}{|c|c|c|c|c|c|}
\hline \multirow{2}{*}{$\begin{array}{l}\text { Sediment } \\
\text { Ireatment }\end{array}$} & \multirow[b]{2}{*}{ Replicate } & & \multirow{2}{*}{$\begin{array}{c}\text { Mean } \\
\text { Percent } \\
\text { Surviving } \\
\end{array}$} \\
\hline & & Live & $\begin{array}{l}\text { Dead or } \\
\text { Missing }\end{array}$ & $\begin{array}{l}\text { Proportion } \\
\text { Surviving }\end{array}$ & \\
\hline $\begin{array}{l}P C-1 \\
P C-1 \\
P C-1 \\
P C-1 \\
P C-1\end{array}$ & $\begin{array}{l}1 \\
2 \\
3 \\
4 \\
5\end{array}$ & $\begin{array}{l}25 \\
25 \\
25 \\
25 \\
25\end{array}$ & $\begin{array}{l}0 \\
0 \\
0 \\
0 \\
0\end{array}$ & $\begin{array}{l}1.00 \\
1.00 \\
1.00 \\
1.00 \\
1.00\end{array}$ & 100.0 \\
\hline $\begin{array}{l}P C-1 A \\
P C-1 A \\
P C-1 A \\
P C-1 A \\
P C-1 A\end{array}$ & $\begin{array}{l}1 \\
2 \\
3 \\
4 \\
5\end{array}$ & $\begin{array}{l}25 \\
25 \\
25 \\
25 \\
25\end{array}$ & $\begin{array}{l}0 \\
0 \\
0 \\
0 \\
0\end{array}$ & $\begin{array}{l}1.00 \\
1.00 \\
1.00 \\
1.00 \\
1.00\end{array}$ & 100.0 \\
\hline $\begin{array}{l}P C-2 \\
P C-2 \\
P C-2 \\
P C-2 \\
P C-2\end{array}$ & $\begin{array}{l}1 \\
2 \\
3 \\
4 \\
5\end{array}$ & $\begin{array}{l}25 \\
25 \\
25 \\
25 \\
25\end{array}$ & $\begin{array}{l}0 \\
0 \\
0 \\
0 \\
0\end{array}$ & $\begin{array}{l}1.00 \\
1.00 \\
1.00 \\
1.00 \\
1.00\end{array}$ & 100.0 \\
\hline $\begin{array}{l}P C-4 \\
P C-4 \\
P C-4 \\
P C-4 \\
P C-4\end{array}$ & $\begin{array}{l}1 \\
2 \\
3 \\
4 \\
5\end{array}$ & $\begin{array}{l}25 \\
25 \\
24 \\
25 \\
25\end{array}$ & $\begin{array}{l}0 \\
0 \\
1 \\
0 \\
0\end{array}$ & $\begin{array}{l}1.00 \\
1.00 \\
0.96 \\
1.00 \\
1.00\end{array}$ & 99.2 \\
\hline $\begin{array}{l}P C-5 \\
P C-5 \\
P C-5 \\
P C-5 \\
P C-5\end{array}$ & $\begin{array}{l}1 \\
2 \\
3 \\
4 \\
5\end{array}$ & $\begin{array}{l}25 \\
24 \\
23 \\
24 \\
25\end{array}$ & $\begin{array}{l}0 \\
1 \\
2 \\
1 \\
0\end{array}$ & $\begin{array}{l}1.00 \\
0.96 \\
0.92 \\
0.96 \\
1.00\end{array}$ & 96.8 \\
\hline $\begin{array}{l}\text { Reference } \\
\text { Reference } \\
\text { Reference } \\
\text { Reference } \\
\text { Reference }\end{array}$ & $\begin{array}{l}1 \\
2 \\
3 \\
4 \\
5\end{array}$ & $\begin{array}{l}24 \\
24 \\
24 \\
23 \\
24\end{array}$ & $\begin{array}{l}1 \\
1 \\
1 \\
2 \\
1\end{array}$ & $\begin{array}{l}0.96 \\
0.96 \\
0.96 \\
0.92 \\
0.96\end{array}$ & 95.2 \\
\hline $\begin{array}{l}\text { M. nasuta Control } \\
\text { M. nasuta Control } \\
\text { M. nasuta Control } \\
\text { M. nasuta Control } \\
\text { M. nasuta Control }\end{array}$ & $\begin{array}{l}1 \\
2 \\
3 \\
4 \\
5\end{array}$ & $\begin{array}{l}23 \\
24 \\
25 \\
23 \\
25\end{array}$ & $\begin{array}{l}2 \\
1 \\
0 \\
2 \\
0\end{array}$ & $\begin{array}{l}0.92 \\
0.96 \\
1.00 \\
0.92 \\
1.00\end{array}$ & 96.0 \\
\hline
\end{tabular}


IABLE H.2. Water Quality Summary for M. nasuta 28-Day Solid-Phase Test, Panama City Harbor Project

\begin{tabular}{|c|c|c|c|c|c|c|c|c|}
\hline \multirow{2}{*}{$\begin{array}{l}\text { Sediment } \\
\text { Ireatment }\end{array}$} & \multicolumn{2}{|c|}{$\begin{array}{c}\text { Temperature } \\
\left({ }^{\circ} \mathrm{C}\right)\end{array}$} & \multicolumn{2}{|c|}{$\mathrm{pH}$} & \multicolumn{2}{|c|}{$\begin{array}{c}\text { Dissolved } \\
\text { Oxygen } \\
(\mathrm{mg} / \mathrm{L})\end{array}$} & \multicolumn{2}{|c|}{$\begin{array}{c}\text { Salinity } \\
(0 / 00)\end{array}$} \\
\hline & Min & $\overline{\text { Max }}$ & Min & $\underline{\operatorname{Max}}$ & Min & Max & Min & Max \\
\hline $\begin{array}{l}\text { Acceptable } \\
\text { range }\end{array}$ & 13.0 & 17.0 & 7.30 & 8.30 & & & 28.0 & 32.0 \\
\hline $\begin{array}{l}P C-1 \\
P C-1 A \\
P C-2 \\
P C-4 \\
P C-5 \\
\text { Reference } \\
\text { M. nasuta Control }\end{array}$ & $\begin{array}{l}14.8 \\
14.8 \\
14.8 \\
14.8 \\
14.9 \\
14.8 \\
14.9\end{array}$ & $\begin{array}{l}16.4 \\
16.3 \\
16.2 \\
16.2 \\
16.4 \\
16.5 \\
16.9\end{array}$ & $\begin{array}{l}7.75 \\
7.73 \\
7.73 \\
7.73 \\
7.76 \\
7.71 \\
7.69\end{array}$ & $\begin{array}{l}8.00 \\
8.00 \\
7.96 \\
8.10 \\
7.98 \\
8.00 \\
7.98\end{array}$ & $\begin{array}{l}7.1 \\
7.1 \\
7.1 \\
7.1 \\
7.1 \\
7.0 \\
6.9\end{array}$ & $\begin{array}{l}8.3 \\
8.1 \\
8.1 \\
8.1 \\
8.1 \\
8.1 \\
8.3\end{array}$ & $\begin{array}{l}30.5 \\
31.0 \\
30.5 \\
30.5 \\
30.5 \\
30.5 \\
30.5\end{array}$ & $\begin{array}{l}32.0 \\
32.0 \\
32.0 \\
32.0 \\
32.0 \\
32.0 \\
32.0\end{array}$ \\
\hline
\end{tabular}


APPENDIX I

96-HOUR SUSPENDED-PARTICULATE-PHASE TEST 96-HOUR REFERENCE TOXICANT TEST

WITH M. BAHIA 
TABLE 1.1. Results for All Replicates in 96-Hour M. bahia SuspendedParticulate-Phase Test, Panama City Harbor Project

\begin{tabular}{|c|c|c|c|c|c|c|}
\hline & Concentration & & & M. bahl & & \\
\hline $\begin{array}{l}\text { Sediment } \\
\text { Ireatment }\end{array}$ & $\begin{array}{c}\text { Percent } \\
\text { SPP } \\
\end{array}$ & Replicate & Live & $\begin{array}{l}\text { Dead or } \\
\text { Missing }\end{array}$ & $\begin{array}{l}\text { Proportion } \\
\text { Surviving }\end{array}$ & $\begin{array}{c}\text { Percent } \\
\text { Surviving }\end{array}$ \\
\hline $\begin{array}{l}P C-1 \\
P C-1 \\
P C-1 \\
P C-1 \\
P C-1\end{array}$ & $\begin{array}{l}0 \\
0 \\
0 \\
0 \\
0\end{array}$ & $\begin{array}{l}1 \\
2 \\
3 \\
4 \\
5\end{array}$ & $\begin{array}{l}10 \\
10 \\
10 \\
10 \\
10\end{array}$ & $\begin{array}{l}0 \\
0 \\
0 \\
0 \\
0\end{array}$ & $\begin{array}{l}1.00 \\
1.00 \\
1.00 \\
1.00 \\
1.00\end{array}$ & 100.0 \\
\hline $\begin{array}{l}P C-1 \\
P C-1 \\
P C-1 \\
P C-1 \\
P C-1\end{array}$ & $\begin{array}{l}10 \\
10 \\
10 \\
10 \\
10\end{array}$ & $\begin{array}{l}1 \\
2 \\
3 \\
4 \\
5\end{array}$ & $\begin{array}{r}10 \\
10 \\
9 \\
10 \\
9\end{array}$ & $\begin{array}{l}0 \\
0 \\
1 \\
0 \\
1\end{array}$ & $\begin{array}{l}1.00 \\
1.00 \\
0.90 \\
1.00 \\
0.90\end{array}$ & 96.0 \\
\hline $\begin{array}{l}P C-1 \\
P C-1 \\
P C-1 \\
P C-1 \\
P C-1\end{array}$ & $\begin{array}{l}50 \\
50 \\
50 \\
50 \\
50\end{array}$ & $\begin{array}{l}1 \\
2 \\
3 \\
4 \\
5\end{array}$ & $\begin{array}{l}10 \\
10 \\
10 \\
10 \\
10\end{array}$ & $\begin{array}{l}0 \\
0 \\
0 \\
0 \\
0\end{array}$ & $\begin{array}{l}1.00 \\
1.00 \\
1.00 \\
1.00 \\
1.00\end{array}$ & 100.0 \\
\hline $\begin{array}{l}P C-1 \\
P C-1 \\
P C-1 \\
P C-1 \\
P C-1\end{array}$ & $\begin{array}{l}100 \\
100 \\
100 \\
100 \\
100\end{array}$ & $\begin{array}{l}1 \\
2 \\
3 \\
4 \\
5\end{array}$ & $\begin{array}{r}9 \\
10 \\
9 \\
9 \\
10\end{array}$ & $\begin{array}{l}1 \\
0 \\
1 \\
1 \\
0\end{array}$ & $\begin{array}{l}0.90 \\
1.00 \\
0.90 \\
0.90 \\
1.00\end{array}$ & 94.0 \\
\hline $\begin{array}{l}P C-1 A \\
P C-1 A \\
P C-1 A \\
P C-1 A \\
P C-1 A\end{array}$ & $\begin{array}{l}0 \\
0 \\
0 \\
0 \\
0\end{array}$ & $\begin{array}{l}1 \\
2 \\
3 \\
4 \\
5\end{array}$ & $\begin{array}{r}10 \\
9 \\
10 \\
10 \\
10\end{array}$ & $\begin{array}{l}0 \\
1 \\
0 \\
0 \\
0\end{array}$ & $\begin{array}{l}1.00 \\
0.90 \\
1.00 \\
1.00 \\
1.00\end{array}$ & 98.0 \\
\hline $\begin{array}{l}P C-1 A \\
P C-1 A \\
P C-1 A \\
P C-1 A \\
P C-1 A\end{array}$ & $\begin{array}{l}10 \\
10 \\
10 \\
10 \\
10\end{array}$ & $\begin{array}{l}1 \\
2 \\
3 \\
4 \\
5\end{array}$ & $\begin{array}{r}10 \\
9 \\
10 \\
10 \\
10\end{array}$ & $\begin{array}{l}0 \\
1 \\
0 \\
0 \\
0\end{array}$ & $\begin{array}{l}1.00 \\
0.90 \\
1.00 \\
1.00 \\
1.00\end{array}$ & 98.0 \\
\hline $\begin{array}{l}P C-1 A \\
P C-1 A \\
P C-1 A \\
P C-1 A \\
P C-1 A\end{array}$ & $\begin{array}{l}50 \\
50 \\
50 \\
50 \\
50\end{array}$ & $\begin{array}{l}1 \\
2 \\
3 \\
4 \\
5\end{array}$ & $\begin{array}{r}10 \\
10 \\
10 \\
10 \\
9\end{array}$ & $\begin{array}{l}0 \\
0 \\
0 \\
0 \\
1\end{array}$ & $\begin{array}{l}1.00 \\
1.00 \\
1.00 \\
1.00 \\
0.90\end{array}$ & 98.0 \\
\hline
\end{tabular}


IABLE 1.1. (contd)

\begin{tabular}{|c|c|c|c|c|c|c|}
\hline \multirow[b]{2}{*}{$\begin{array}{l}\text { Sediment } \\
\text { Ireaatment }\end{array}$} & \multirow{2}{*}{$\begin{array}{c}\text { Concentration } \\
\text { Percent } \\
\text { SPP }\end{array}$} & \multirow[b]{2}{*}{ Replicate } & \multicolumn{3}{|c|}{ M. bahia } & \multirow{2}{*}{$\begin{array}{c}\text { Mean } \\
\text { Percent } \\
\text { Surviving }\end{array}$} \\
\hline & & & Live & $\begin{array}{l}\text { Dead or } \\
\text { Missing }\end{array}$ & $\begin{array}{l}\text { Proportion } \\
\text { Surviving }\end{array}$ & \\
\hline $\begin{array}{l}P C-1 A \\
P C-1 A \\
P C-1 A \\
P C-1 A \\
P C-1 A\end{array}$ & $\begin{array}{l}100 \\
100 \\
100 \\
100 \\
100\end{array}$ & $\begin{array}{l}1 \\
2 \\
3 \\
4 \\
5\end{array}$ & $\begin{array}{r}10 \\
9 \\
10 \\
10 \\
9\end{array}$ & $\begin{array}{l}0 \\
1 \\
0 \\
0 \\
1\end{array}$ & $\begin{array}{l}1.00 \\
0.90 \\
1.00 \\
1.00 \\
0.90\end{array}$ & 96.0 \\
\hline $\begin{array}{l}P C-2 \\
P C-2 \\
P C-2 \\
P C-2 \\
P C-2\end{array}$ & $\begin{array}{l}0 \\
0 \\
0 \\
0 \\
0\end{array}$ & $\begin{array}{l}1 \\
2 \\
3 \\
4 \\
5\end{array}$ & $\begin{array}{r}10 \\
10 \\
10 \\
10 \\
9\end{array}$ & $\begin{array}{l}0 \\
0 \\
0 \\
0 \\
1\end{array}$ & $\begin{array}{l}1.00 \\
1.00 \\
1.00 \\
1.00 \\
0.90\end{array}$ & 98.0 \\
\hline $\begin{array}{l}P C-2 \\
P C-2 \\
P C-2 \\
P C-2 \\
P C-2\end{array}$ & $\begin{array}{l}10 \\
10 \\
10 \\
10 \\
10\end{array}$ & $\begin{array}{l}1 \\
2 \\
3 \\
4 \\
5\end{array}$ & $\begin{array}{r}10 \\
9 \\
9 \\
10 \\
10\end{array}$ & $\begin{array}{l}0 \\
1 \\
1 \\
0 \\
0\end{array}$ & $\begin{array}{l}1.00 \\
0.90 \\
0.90 \\
1.00 \\
1.00\end{array}$ & 96.0 \\
\hline $\begin{array}{l}P C-2 \\
P C-2 \\
P C-2 \\
P C-2 \\
P C-2\end{array}$ & $\begin{array}{l}50 \\
50 \\
50 \\
50 \\
50\end{array}$ & $\begin{array}{l}1 \\
2 \\
3 \\
4 \\
5\end{array}$ & $\begin{array}{r}10 \\
10 \\
10 \\
10 \\
9\end{array}$ & $\begin{array}{l}0 \\
0 \\
0 \\
0 \\
1\end{array}$ & $\begin{array}{l}1.00 \\
1.00 \\
1.00 \\
1.00 \\
0.90\end{array}$ & 98.0 \\
\hline $\begin{array}{l}P C-2 \\
P C-2 \\
P C-2 \\
P C-2 \\
P C-2\end{array}$ & $\begin{array}{l}100 \\
100 \\
100 \\
100 \\
100\end{array}$ & $\begin{array}{l}1 \\
2 \\
3 \\
4 \\
5\end{array}$ & $\begin{array}{l}10 \\
10 \\
10 \\
10 \\
10\end{array}$ & $\begin{array}{l}0 \\
0 \\
0 \\
0 \\
0\end{array}$ & $\begin{array}{l}1.00 \\
1.00 \\
1.00 \\
1.00 \\
1.00\end{array}$ & 100.0 \\
\hline $\begin{array}{l}P C-4 \\
P C-4 \\
P C-4 \\
P C-4 \\
P C-4\end{array}$ & $\begin{array}{l}0 \\
0 \\
0 \\
0 \\
0\end{array}$ & $\begin{array}{l}1 \\
2 \\
3 \\
4 \\
5\end{array}$ & $\begin{array}{r}10 \\
10 \\
10 \\
9 \\
10\end{array}$ & $\begin{array}{l}0 \\
0 \\
0 \\
1 \\
0\end{array}$ & $\begin{array}{l}1.00 \\
1.00 \\
1.00 \\
0.90 \\
1.00\end{array}$ & 98.0 \\
\hline $\begin{array}{l}P C-4 \\
P C-4 \\
P C-4 \\
P C-4 \\
P C-4\end{array}$ & $\begin{array}{l}10 \\
10 \\
10 \\
10 \\
10\end{array}$ & $\begin{array}{l}1 \\
2 \\
3 \\
4 \\
5\end{array}$ & $\begin{array}{l}10 \\
10 \\
10 \\
10 \\
10\end{array}$ & $\begin{array}{l}0 \\
0 \\
0 \\
0 \\
0\end{array}$ & $\begin{array}{l}1.00 \\
1.00 \\
1.00 \\
1.00 \\
1.00\end{array}$ & 100.0 \\
\hline
\end{tabular}


TABLE I.1. (contd)

\begin{tabular}{|c|c|c|c|c|c|c|}
\hline & Concentration & & & M. bahi & & \\
\hline $\begin{array}{l}\text { Sediment } \\
\text { Treatment }\end{array}$ & $\begin{array}{c}\text { Percent } \\
\text { SPP }\end{array}$ & Replicate & Live & $\begin{array}{l}\text { Dead or } \\
\text { Missing }\end{array}$ & $\begin{array}{l}\text { Proportion } \\
\text { Surviving }\end{array}$ & $\begin{array}{c}\text { Percent } \\
\text { Surviving }\end{array}$ \\
\hline $\begin{array}{l}P C-4 \\
P C-4 \\
P C-4 \\
P C-4 \\
P C-4\end{array}$ & $\begin{array}{l}50 \\
50 \\
50 \\
50 \\
50\end{array}$ & $\begin{array}{l}1 \\
2 \\
3 \\
4 \\
5\end{array}$ & $\begin{array}{l}10 \\
10 \\
10 \\
10 \\
10\end{array}$ & $\begin{array}{l}0 \\
0 \\
0 \\
0 \\
0\end{array}$ & $\begin{array}{l}1.00 \\
1.00 \\
1.00 \\
1.00 \\
1.00\end{array}$ & 100.0 \\
\hline $\begin{array}{l}\text { PC }-4 \\
\text { PC-4 } \\
\text { PC-4 } \\
\text { PC-4 } \\
\text { PC-4 }\end{array}$ & $\begin{array}{l}100 \\
100 \\
100 \\
100 \\
100\end{array}$ & $\begin{array}{l}1 \\
2 \\
3 \\
4 \\
5\end{array}$ & $\begin{array}{l}10 \\
10 \\
10 \\
10 \\
10\end{array}$ & $\begin{array}{l}0 \\
0 \\
0 \\
0 \\
0\end{array}$ & $\begin{array}{l}1.00 \\
1.00 \\
1.00 \\
1.00 \\
1.00\end{array}$ & 100.0 \\
\hline $\begin{array}{l}P C-5 \\
P C-5 \\
P C-5 \\
P C-5 \\
P C-5\end{array}$ & $\begin{array}{l}0 \\
0 \\
0 \\
0 \\
0\end{array}$ & $\begin{array}{l}1 \\
2 \\
3 \\
4 \\
5\end{array}$ & $\begin{array}{l}10 \\
10 \\
10 \\
10 \\
10\end{array}$ & $\begin{array}{l}0 \\
0 \\
0 \\
0 \\
0\end{array}$ & $\begin{array}{l}1.00 \\
1.00 \\
1.00 \\
1.00 \\
1.00\end{array}$ & 100.0 \\
\hline $\begin{array}{l}P C-5 \\
P C-5 \\
P C-5 \\
P C-5 \\
P C-5\end{array}$ & $\begin{array}{l}10 \\
10 \\
10 \\
10 \\
10\end{array}$ & $\begin{array}{l}1 \\
2 \\
3 \\
4 \\
5\end{array}$ & $\begin{array}{r}9 \\
10 \\
10 \\
10 \\
10\end{array}$ & $\begin{array}{l}1 \\
0 \\
0 \\
0 \\
0\end{array}$ & $\begin{array}{l}0.90 \\
1.00 \\
1.00 \\
1.00 \\
1.00\end{array}$ & 98.0 \\
\hline $\begin{array}{l}P C-5 \\
P C-5 \\
P C-5 \\
P C-5 \\
P C-5\end{array}$ & $\begin{array}{l}50 \\
50 \\
50 \\
50 \\
50\end{array}$ & $\begin{array}{l}1 \\
2 \\
3 \\
4 \\
5\end{array}$ & $\begin{array}{l}10 \\
10 \\
10 \\
10 \\
10\end{array}$ & $\begin{array}{l}0 \\
0 \\
0 \\
0 \\
0\end{array}$ & $\begin{array}{l}1.00 \\
1.00 \\
1.00 \\
1.00 \\
1.00\end{array}$ & 100.0 \\
\hline $\begin{array}{l}P C-5 \\
P C-5 \\
P C-5 \\
P C-5 \\
P C-5\end{array}$ & $\begin{array}{l}100 \\
100 \\
100 \\
100 \\
100\end{array}$ & $\begin{array}{l}1 \\
2 \\
3 \\
4 \\
5\end{array}$ & $\begin{array}{l}10 \\
10 \\
10 \\
10 \\
10\end{array}$ & $\begin{array}{l}0 \\
0 \\
0 \\
0 \\
0\end{array}$ & $\begin{array}{l}1.00 \\
1.00 \\
1.00 \\
1.00 \\
1.00\end{array}$ & 100.0 \\
\hline $\begin{array}{l}\text { Reference } \\
\text { Reference } \\
\text { Reference } \\
\text { Reference } \\
\text { Reference }\end{array}$ & $\begin{array}{l}0 \\
0 \\
0 \\
0 \\
0\end{array}$ & $\begin{array}{l}1 \\
2 \\
3 \\
4 \\
5\end{array}$ & $\begin{array}{l}10 \\
10 \\
10 \\
10 \\
10\end{array}$ & $\begin{array}{l}0 \\
3 \\
0 \\
0 \\
0\end{array}$ & $\begin{array}{l}1.00 \\
1.00 \\
1.00 \\
1.00 \\
1.00\end{array}$ & 100.0 \\
\hline
\end{tabular}


IABLE I.1. (contd)

\begin{tabular}{|c|c|c|c|c|c|c|}
\hline & Concentration & & & M. bah & & Mean \\
\hline $\begin{array}{l}\text { Sediment } \\
\text { Ireatment }\end{array}$ & $\begin{array}{c}\text { Percent } \\
\text { SPP }\end{array}$ & Replicate & Live & $\begin{array}{l}\text { Dead or } \\
\text { Missing }\end{array}$ & $\begin{array}{l}\text { Proportion } \\
\text { Surviving } \\
\end{array}$ & $\begin{array}{c}\begin{array}{c}\text { Percent } \\
\text { Surviving }\end{array} \\
\end{array}$ \\
\hline $\begin{array}{l}\text { Reference } \\
\text { Reference } \\
\text { Reference } \\
\text { Reference } \\
\text { Reference }\end{array}$ & $\begin{array}{l}10 \\
10 \\
10 \\
10 \\
10\end{array}$ & $\begin{array}{l}1 \\
2 \\
3 \\
4 \\
5\end{array}$ & $\begin{array}{r}10 \\
10 \\
9 \\
10 \\
10\end{array}$ & $\begin{array}{l}0 \\
0 \\
1 \\
0 \\
0\end{array}$ & $\begin{array}{l}1.00 \\
1.00 \\
0.90 \\
1.00 \\
1.00\end{array}$ & 98.0 \\
\hline $\begin{array}{l}\text { Reference } \\
\text { Reference } \\
\text { Reference } \\
\text { Reference } \\
\text { Reference }\end{array}$ & $\begin{array}{l}50 \\
50 \\
50 \\
50 \\
50\end{array}$ & $\begin{array}{l}1 \\
2 \\
3 \\
4 \\
5\end{array}$ & $\begin{array}{l}10 \\
10 \\
10 \\
10 \\
10\end{array}$ & $\begin{array}{l}0 \\
0 \\
0 \\
0 \\
0\end{array}$ & $\begin{array}{l}1.00 \\
1.00 \\
1.00 \\
1.00 \\
1.00\end{array}$ & 100.0 \\
\hline $\begin{array}{l}\text { Reference } \\
\text { Reference } \\
\text { Reference } \\
\text { Reference } \\
\text { Reference }\end{array}$ & $\begin{array}{l}100 \\
100 \\
100 \\
100 \\
100\end{array}$ & $\begin{array}{l}1 \\
2 \\
3 \\
4 \\
5\end{array}$ & $\begin{array}{r}10 \\
10 \\
10 \\
10 \\
9\end{array}$ & $\begin{array}{l}0 \\
0 \\
0 \\
0 \\
1\end{array}$ & $\begin{array}{l}1.00 \\
1.00 \\
1.00 \\
1.00 \\
0.90\end{array}$ & 98.0 \\
\hline
\end{tabular}


IABLE I.2. Water Quality Summary for 96-Hour M. bahia SuspendedParticulate-Phase Test, Panama City Harbor Project

\begin{tabular}{|c|c|c|c|c|c|c|c|c|c|}
\hline \multirow{2}{*}{$\begin{array}{l}\text { Sediment } \\
\text { Ireatment }\end{array}$} & \multirow{2}{*}{$\begin{array}{c}\text { Concentration } \\
\text { Percent } \\
\text { SPP } \\
\end{array}$} & \multicolumn{2}{|c|}{$\begin{array}{c}\text { Temperature } \\
\left({ }^{\circ} \mathrm{C}\right)\end{array}$} & \multicolumn{2}{|c|}{$\mathrm{pH}$} & \multicolumn{2}{|c|}{$\begin{array}{c}\text { Dissolved } \\
\text { Oxygen } \\
\text { (mg/L) }\end{array}$} & \multicolumn{2}{|c|}{$\begin{array}{l}\text { Salinity } \\
(0 / 00)\end{array}$} \\
\hline & & Min & $\underline{\operatorname{Max}}$ & Min & Max & Min & Max & Min. & Max \\
\hline $\begin{array}{l}\text { Acceptable } \\
\text { range }\end{array}$ & & 18.0 & 22.0 & 7.30 & 8.30 & & & 28.0 & 32.0 \\
\hline $\begin{array}{l}P C-1 \\
P C-1 \\
P C-1 \\
P C-1\end{array}$ & $\begin{array}{r}0 \\
10 \\
50 \\
100\end{array}$ & $\begin{array}{l}19.2 \\
19.3 \\
19.2 \\
19.3\end{array}$ & $\begin{array}{l}20.3 \\
20.2 \\
20.1 \\
20.4\end{array}$ & $\begin{array}{l}7.88 \\
8.06 \\
8.01 \\
7.96\end{array}$ & $\begin{array}{l}8.35(a) \\
8.35(a) \\
8.28 \\
8.25\end{array}$ & $\begin{array}{l}6.8 \\
6.7 \\
6.7 \\
6.7\end{array}$ & $\begin{array}{l}7.8 \\
7.8 \\
7.9 \\
8.0\end{array}$ & $\begin{array}{l}28.0 \\
27.0(a) \\
28.0 \\
28.0\end{array}$ & $\begin{array}{l}30.5 \\
31.0 \\
30.5 \\
40.0(a)\end{array}$ \\
\hline $\begin{array}{l}P C-1 A \\
P C-1 A \\
P C-1 A \\
P C-1 A\end{array}$ & $\begin{array}{r}0 \\
10 \\
50 \\
100\end{array}$ & $\begin{array}{l}19.1 \\
19.3 \\
19.2 \\
19.4\end{array}$ & $\begin{array}{l}20.2 \\
20.1 \\
20.4 \\
20.1\end{array}$ & $\begin{array}{l}7.69 \\
7.95 \\
7.89 \\
8.01\end{array}$ & $\begin{array}{l}8.27 \\
8.26 \\
8.27 \\
8.27\end{array}$ & $\begin{array}{l}6.3 \\
6.7 \\
6.5 \\
6.7\end{array}$ & $\begin{array}{l}8.1 \\
8.0 \\
7.9 \\
7.7\end{array}$ & $\begin{array}{l}30.0 \\
30.0 \\
29.0 \\
28.0\end{array}$ & $\begin{array}{l}31.5 \\
32.0 \\
31.5 \\
30.5\end{array}$ \\
\hline $\begin{array}{l}P C-2 . \\
P C-2 \\
P C-2 \\
P C-2\end{array}$ & $\begin{array}{r}0 \\
10 \\
.30 \\
100\end{array}$ & $\begin{array}{l}19.1 \\
19.1 \\
19.1 \\
19.3\end{array}$ & $\begin{array}{l}20.3 \\
20.5 \\
20.4 \\
20.4\end{array}$ & $\begin{array}{l}7.87 \\
7.92 \\
8.05 \\
7.99\end{array}$ & $\begin{array}{l}8.36^{(a)} \\
8.36 \\
8.27 \\
8.30\end{array}$ & $\begin{array}{l}6.7 \\
6.6 \\
6.6 \\
6.6\end{array}$ & $\begin{array}{l}7.9 \\
8.1 \\
8.0 \\
7.7\end{array}$ & $\begin{array}{l}28.0 \\
28.5 \\
29.0 \\
28.0\end{array}$ & $\begin{array}{l}30.0 \\
33.0(a) \\
31.5 \\
30.0\end{array}$ \\
\hline $\begin{array}{l}P C-4 \\
P C-4 \\
P C-4 \\
P C-4\end{array}$ & $\begin{array}{r}0 \\
10 \\
50 \\
100\end{array}$ & $\begin{array}{l}19.2 \\
19.3 \\
19.2 \\
19.2\end{array}$ & $\begin{array}{l}20.2 \\
20.1 \\
20.2 \\
20.3\end{array}$ & $\begin{array}{l}7.82 \\
7.81 \\
7.92 \\
7.77\end{array}$ & $\begin{array}{l}8.23 \\
8.29 \\
8.26 \\
8.19\end{array}$ & $\begin{array}{l}6.3 \\
6.5 \\
6.4 \\
6.3\end{array}$ & $\begin{array}{l}8.0 \\
7.8 \\
7.6 \\
7.5\end{array}$ & $\begin{array}{l}28.0 \\
28.0 \\
28.0 \\
28.0\end{array}$ & $\begin{array}{l}30.5 \\
32.0 \\
33.5(a) \\
32.0\end{array}$ \\
\hline $\begin{array}{l}P C-5 \\
P C-5 \\
P C-5 \\
P C-5\end{array}$ & $\begin{array}{r}0 \\
10 \\
50 \\
100\end{array}$ & $\begin{array}{l}18.8 \\
19.0 \\
18.9 \\
19.2\end{array}$ & $\begin{array}{l}20.3 \\
20.3 \\
20.4 \\
20.2\end{array}$ & $\begin{array}{l}7.95 \\
7.87 \\
7.75 \\
8.03\end{array}$ & $\begin{array}{l}8.17(a) \\
8.34 \\
8.28 \\
8.22\end{array}$ & $\begin{array}{l}6.5 \\
6.3 \\
6.0 \\
6.4\end{array}$ & $\begin{array}{l}7.9 \\
7.7 \\
7.6 \\
7.5\end{array}$ & $\begin{array}{l}30.0 \\
29.0 \\
28.0 \\
29.0\end{array}$ & $\begin{array}{l}30.5 \\
30.0 \\
31.5 \\
32.0\end{array}$ \\
\hline $\begin{array}{l}\text { Reference } \\
\text { Reference } \\
\text { Reference } \\
\text { Reference }\end{array}$ & $\begin{array}{r}0 \\
10 \\
50 \\
100\end{array}$ & $\begin{array}{l}19.4 \\
19.3 \\
19.2 \\
19.1\end{array}$ & $\begin{array}{l}20.0 \\
20.1 \\
20.3 \\
20.5\end{array}$ & $\begin{array}{l}7.98 \\
7.95 \\
7.86 \\
7.87\end{array}$ & $\begin{array}{l}8.36^{(a)} \\
8.32^{(a)} \\
8.19 \\
8.19\end{array}$ & $\begin{array}{l}6.4 \\
6.4 \\
6.4 \\
6.2\end{array}$ & $\begin{array}{l}7.7 \\
7.7 \\
7.5 \\
7.3\end{array}$ & $\begin{array}{l}29.0 \\
29.0 \\
29.0 \\
29.0\end{array}$ & $\begin{array}{l}30.5 \\
32.5(a) \\
31.0 \\
45.0^{(a)}\end{array}$ \\
\hline
\end{tabular}

(a) Value outside of acceptable range. 
TABLE I.3. Results for A11 Replicates in 96-Hour M. bahia Reference Toxicant Test, Panama City Harbor Project

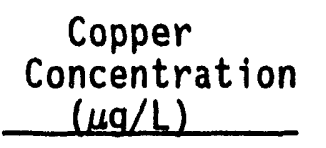

0

0
0

32

32

32

80

80

80

200

200

200

500

500

500

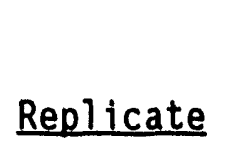

1
2
3

1

3

1

1
3

1
2
3

1
2
3

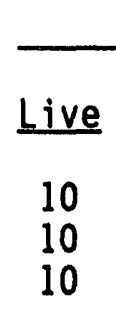

10

10

10

10

10

9

7
9
10

2
3
2
M. bahia Dead or Missing

\section{0}

0

0

0

0

0

0

0

1

3

1

0

8

7

8
Mean

Percent

Proportion

Surviving Surviving

1.00

1.00

1.00

100.0

1.00

1.00

1.00

100.0

1.00

1.00

0.90

96.7

0.70

0.90

1.00

86.7

0.20

0.30

0.20

23.3 
IABLE I.4. Water Quality Summary for 96-Hour M. bahia Reference Toxicant Test, Panama City Harbor Project

\begin{tabular}{|c|c|c|c|c|c|c|c|c|}
\hline \multirow{2}{*}{$\begin{array}{c}\text { Copper } \\
\text { Concentration } \\
(\mu \mathrm{g} / \mathrm{L}) \\
\end{array}$} & \multicolumn{2}{|c|}{$\begin{array}{c}\text { Temperature } \\
\left({ }^{\circ} \mathrm{C}\right)\end{array}$} & \multicolumn{2}{|c|}{$\mathrm{pH}$} & \multicolumn{2}{|c|}{$\begin{array}{l}\text { Dissolved } \\
\text { Oxygen } \\
\text { (mg/L) }\end{array}$} & \multicolumn{2}{|c|}{$\begin{array}{c}\text { Salinity } \\
(0 / 00)\end{array}$} \\
\hline & Min & Max & Min & Max & Min & $\underline{\text { Max }}$ & Min & Max \\
\hline $\begin{array}{l}\text { Acceptable } \\
\text { range }\end{array}$ & 18.0 & 22.0 & 7.30 & 8.30 & & & 28.0 & 32.0 \\
\hline $\begin{array}{r}0 \\
32 \\
80 \\
200 \\
500\end{array}$ & $\begin{array}{l}19.7 \\
19.7 \\
19.6 \\
19.4 \\
19.5\end{array}$ & $\begin{array}{l}20.1 \\
20.2 \\
20.2 \\
20.2 \\
20.3\end{array}$ & $\begin{array}{l}7.78 \\
7.78 \\
7.79 \\
7.77 \\
7.76\end{array}$ & $\begin{array}{l}8.27 \\
8.27 \\
8.26 \\
8.26 \\
8.26\end{array}$ & $\begin{array}{l}6.3 \\
6.3 \\
6.4 \\
6.4 \\
6.3\end{array}$ & $\begin{array}{l}7.5 \\
7.5 \\
7.3 \\
7.3 \\
7.2\end{array}$ & $\begin{array}{l}31.0 \\
31.0 \\
31.0 \\
31.0 \\
31.0\end{array}$ & 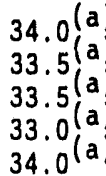 \\
\hline
\end{tabular}

(a) Value outside of acceptable range. 
A.PEENDIX J

96-HOUR SUSPENDED-PARTICULATE-PHASE TEST 96-HOUR REFERENCE TOXICANT TEST

WITH M. BERYLLINA 
IABLE J.1. Results for A11 Replicates in 96-Hour M. beryllina SuspendedParticulate-Phase Test, Panama City Harbor Project

\begin{tabular}{|c|c|c|c|c|c|c|}
\hline \multirow[b]{2}{*}{$\begin{array}{l}\text { Sediment } \\
\text { Ireatment }\end{array}$} & \multirow{2}{*}{$\begin{array}{l}\text { Concentration } \\
\text { Percent } \\
\text { SPP } \\
\end{array}$} & \multirow[b]{2}{*}{ Replicate } & \multicolumn{3}{|c|}{ M. beryllina } & \multirow{2}{*}{$\begin{array}{c}\text { Mean } \\
\text { Percent } \\
\text { Surviving }\end{array}$} \\
\hline & & & Live & $\begin{array}{l}\text { Dead or } \\
\text { Missing }\end{array}$ & $\begin{array}{l}\text { Proportion } \\
\text { Surviving }\end{array}$ & \\
\hline $\begin{array}{l}P C-1 \\
P C-1 \\
P C-1 \\
P C-1 \\
P C-1\end{array}$ & $\begin{array}{l}0 \\
0 \\
0 \\
0 \\
0\end{array}$ & $\begin{array}{l}1 \\
2 \\
3 \\
4 \\
5\end{array}$ & $\begin{array}{r}10 \\
10 \\
9 \\
10 \\
10\end{array}$ & $\begin{array}{l}0 \\
0 \\
1 \\
0 \\
0\end{array}$ & $\begin{array}{l}1.00 \\
1.00 \\
0.90 \\
1.00 \\
1.00\end{array}$ & 98.0 \\
\hline $\begin{array}{l}P C-1 \\
P C-1 \\
P C-1 \\
P C-1 \\
P C-1\end{array}$ & $\begin{array}{l}10 \\
10 \\
10 \\
10 \\
10\end{array}$ & $\begin{array}{l}1 \\
2 \\
3 \\
4 \\
5\end{array}$ & $\begin{array}{l}10 \\
10 \\
10 \\
10 \\
10\end{array}$ & $\begin{array}{l}0 \\
0 \\
0 \\
0 \\
0\end{array}$ & $\begin{array}{l}1.00 \\
1.00 \\
1.00 \\
1.00 \\
1.00\end{array}$ & 100.0 \\
\hline $\begin{array}{l}P C-1 \\
P C-1 \\
P C-1 \\
P C-1 \\
P C-1\end{array}$ & $\begin{array}{l}50 \\
50 \\
50 \\
50 \\
50\end{array}$ & $\begin{array}{l}1 \\
2 \\
3 \\
4 \\
5\end{array}$ & $\begin{array}{r}10 \\
10 \\
10 \\
9 \\
10\end{array}$ & $\begin{array}{l}0 \\
0 \\
0 \\
1 \\
0\end{array}$ & $\begin{array}{l}1.00 \\
1.00 \\
1.00 \\
0.90 \\
1.00\end{array}$ & 98.0 \\
\hline $\begin{array}{l}P C-1 \\
P C-1 \\
P C-1 \\
P C-1 \\
P C-1\end{array}$ & $\begin{array}{l}100 \\
100 \\
100 \\
100 \\
100\end{array}$ & $\begin{array}{l}1 \\
2 \\
3 \\
4 \\
5\end{array}$ & $\begin{array}{l}10 \\
10 \\
10 \\
10 \\
10\end{array}$ & $\begin{array}{l}0 \\
0 \\
0 \\
0 \\
0\end{array}$ & $\begin{array}{l}1.00 \\
1.00 \\
1.00 \\
1.00 \\
1.00\end{array}$ & 100.0 \\
\hline $\begin{array}{l}P C-1 A \\
P C-1 A \\
P C-1 A \\
P C-1 A \\
P C-1 A\end{array}$ & $\begin{array}{l}0 \\
0 \\
0 \\
0 \\
0\end{array}$ & $\begin{array}{l}1 \\
2 \\
3 \\
4 \\
5\end{array}$ & $\begin{array}{r}10 \\
10 \\
9 \\
10 \\
10\end{array}$ & $\begin{array}{l}0 \\
0 \\
1 \\
0 \\
0\end{array}$ & $\begin{array}{l}1.00 \\
1.00 \\
0.90 \\
1.00 \\
1.00\end{array}$ & 98.0 \\
\hline $\begin{array}{l}P C-1 A \\
P C-1 A \\
P C-1 A \\
P C-1 A \\
P C-1 A\end{array}$ & $\begin{array}{l}10 \\
10 \\
10 \\
10 \\
10\end{array}$ & $\begin{array}{l}1 \\
2 \\
3 \\
4 \\
5\end{array}$ & $\begin{array}{r}9 \\
10 \\
10 \\
10 \\
10\end{array}$ & $\begin{array}{l}1 \\
0 \\
0 \\
0 \\
0\end{array}$ & $\begin{array}{l}0.90 \\
1.00 \\
1.00 \\
1.00 \\
1.00\end{array}$ & 98.0 \\
\hline $\begin{array}{l}P C-1 A \\
P C-1 A \\
P C-1 A \\
P C-1 A \\
P C-1 A\end{array}$ & $\begin{array}{l}50 \\
50 \\
50 \\
50 \\
50\end{array}$ & $\begin{array}{l}1 \\
2 \\
3 \\
4 \\
5\end{array}$ & $\begin{array}{l}10 \\
10 \\
10 \\
10 \\
10\end{array}$ & $\begin{array}{l}0 \\
0 \\
0 \\
0 \\
0\end{array}$ & $\begin{array}{l}1.00 \\
1.00 \\
1.00 \\
1.00 \\
1.00\end{array}$ & 100.0 \\
\hline
\end{tabular}

PANAMA CITY HARBOR 
TABLE J.1. (contd)

\begin{tabular}{|c|c|c|c|c|c|c|}
\hline & Concentration & & & M. beryll & ina & \\
\hline $\begin{array}{l}\text { Sediment } \\
\text { Ireatment }\end{array}$ & $\begin{array}{c}\text { Percent } \\
\text { SPP }\end{array}$ & Replicate & Live & $\begin{array}{l}\text { Dead or } \\
\text { Missing }\end{array}$ & $\begin{array}{l}\text { Proportion } \\
\text { Surviving }\end{array}$ & $\begin{array}{c}\text { Percent } \\
\text { Surviving } \\
\end{array}$ \\
\hline $\begin{array}{l}P C-1 A \\
P C-1 A \\
P C-1 A \\
P C-1 A \\
P C-1 A\end{array}$ & $\begin{array}{l}100 \\
100 \\
100 \\
100 \\
100\end{array}$ & $\begin{array}{l}1 \\
2 \\
3 \\
4 \\
5\end{array}$ & $\begin{array}{l}10 \\
10 \\
10 \\
10 \\
10\end{array}$ & $\begin{array}{l}0 \\
0 \\
0 \\
0 \\
0\end{array}$ & $\begin{array}{l}1.00 \\
1.00 \\
1.00 \\
1.00 \\
1.00\end{array}$ & 100.4 \\
\hline $\begin{array}{l}P C-2 \\
P C-2 \\
P C-2 \\
P C-2 \\
P C-2\end{array}$ & $\begin{array}{l}0 \\
0 \\
0 \\
0 \\
0\end{array}$ & $\begin{array}{l}1 \\
2 \\
3 \\
4 \\
5\end{array}$ & $\begin{array}{l}10 \\
10 \\
10 \\
10 \\
10\end{array}$ & $\begin{array}{l}0 \\
0 \\
0 \\
0 \\
0\end{array}$ & $\begin{array}{l}1.00 \\
1.00 \\
1.00 \\
1.00 \\
1.00\end{array}$ & 100.0 \\
\hline $\begin{array}{l}P C-2 \\
P C-2 \\
P C-2 \\
P C-2 \\
P C-2\end{array}$ & $\begin{array}{l}10 \\
10 \\
10 \\
10 \\
10\end{array}$ & $\begin{array}{l}1 \\
2 \\
3 \\
4 \\
5\end{array}$ & $\begin{array}{r}10 \\
10 \\
10 \\
9 \\
10\end{array}$ & $\begin{array}{l}0 \\
0 \\
0 \\
1 \\
0\end{array}$ & $\begin{array}{l}1.00 \\
1.00 \\
1.00 \\
0.90 \\
1.00\end{array}$ & 98.0 \\
\hline $\begin{array}{l}P C-2 \\
P C-2 \\
P C-2 \\
P C-2 \\
P C-2\end{array}$ & $\begin{array}{l}50 \\
50 \\
50 \\
50 \\
50\end{array}$ & $\begin{array}{l}1 \\
2 \\
3 \\
4 \\
5\end{array}$ & $\begin{array}{r}9 \\
10 \\
10 \\
10 \\
10\end{array}$ & $\begin{array}{l}1 \\
0 \\
0 \\
0 \\
0\end{array}$ & $\begin{array}{l}0.90 \\
1.00 \\
1.00 \\
1.00 \\
1.00\end{array}$ & 98.0 \\
\hline $\begin{array}{l}P C-2 \\
P C-2 \\
P C-2 \\
P C-2 \\
P C-2\end{array}$ & $\begin{array}{l}100 \\
100 \\
100 \\
100 \\
100\end{array}$ & $\begin{array}{l}1 \\
2 \\
3 \\
4 \\
5\end{array}$ & $\begin{array}{l}10 \\
10 \\
10 \\
10 \\
10\end{array}$ & $\begin{array}{l}0 \\
0 \\
0 \\
0 \\
0\end{array}$ & $\begin{array}{l}1.00 \\
1.00 \\
1.00 \\
1.00 \\
1.00\end{array}$ & 100.0 \\
\hline $\begin{array}{l}P C-4 \\
P C-4 \\
P C-4 \\
P C-4 \\
P C-4\end{array}$ & $\begin{array}{l}0 \\
0 \\
0 \\
0 \\
0\end{array}$ & $\begin{array}{l}1 \\
2 \\
3 \\
4 \\
5\end{array}$ & $\begin{array}{l}10 \\
10 \\
10 \\
10 \\
10\end{array}$ & $\begin{array}{l}0 \\
0 \\
0 \\
0 \\
0\end{array}$ & $\begin{array}{l}1.00 \\
1.00 \\
1.00 \\
1.00 \\
1.00\end{array}$ & 100.0 \\
\hline $\begin{array}{l}P C-4 \\
P C-4 \\
P C-4 \\
P C-4 \\
P C-4\end{array}$ & $\begin{array}{l}10 \\
10 \\
10 \\
10 \\
10\end{array}$ & $\begin{array}{l}1 \\
2 \\
3 \\
4 \\
5\end{array}$ & $\begin{array}{r}10 \\
10 \\
10 \\
10 \\
9\end{array}$ & $\begin{array}{l}0 \\
0 \\
0 \\
0 \\
1\end{array}$ & $\begin{array}{l}1.00 \\
1.00 \\
1.00 \\
1.00 \\
0.90\end{array}$ & 98.0 \\
\hline
\end{tabular}


IABLE U.1. (contd)

\begin{tabular}{|c|c|c|c|c|c|c|}
\hline & Concentration & & & M. beryll & ina & Mean \\
\hline $\begin{array}{l}\text { Sediment } \\
\text { Ireatment }\end{array}$ & $\begin{array}{c}\begin{array}{c}\text { Percent } \\
\text { SPP }\end{array} \\
\end{array}$ & Replicate & Live & $\begin{array}{l}\text { Dead or } \\
\text { Missing }\end{array}$ & $\begin{array}{l}\text { Proportion } \\
\text { Surviving }\end{array}$ & $\begin{array}{c}\text { Percent } \\
\text { Surviving }\end{array}$ \\
\hline $\begin{array}{l}P C-4 \\
P C-4 \\
P C-4 \\
P C-4 \\
P C-4\end{array}$ & $\begin{array}{l}50 \\
50 \\
50 \\
50 \\
50\end{array}$ & $\begin{array}{l}1 \\
2 \\
3 \\
4 \\
5\end{array}$ & $\begin{array}{r}10 \\
10 \\
10 \\
9 \\
10\end{array}$ & $\begin{array}{l}0 \\
0 \\
0 \\
1 \\
0\end{array}$ & $\begin{array}{l}1.00 \\
1.00 \\
1.00 \\
0.90 \\
1.00\end{array}$ & 98.0 \\
\hline $\begin{array}{l}P C-4 \\
P C-4 \\
P C-4 \\
P C-4 \\
P C-4\end{array}$ & $\begin{array}{l}100 \\
100 \\
100 \\
100 \\
100\end{array}$ & $\begin{array}{l}1 \\
2 \\
3 \\
4 \\
5\end{array}$ & $\begin{array}{r}10 \\
10 \\
10 \\
10 \\
9\end{array}$ & $\begin{array}{l}0 \\
0 \\
0 \\
0 \\
1\end{array}$ & $\begin{array}{l}1.00 \\
1.00 \\
1.00 \\
1.00 \\
0.90\end{array}$ & 98.0 \\
\hline $\begin{array}{l}P C-5 \\
P C-5 \\
P C-5 \\
P C-5 \\
P C-5\end{array}$ & $\begin{array}{l}0 \\
0 \\
0 \\
0 \\
0\end{array}$ & $\begin{array}{l}1 \\
2 \\
3 \\
4 \\
5\end{array}$ & $\begin{array}{r}10 \\
9 \\
10 \\
10 \\
10\end{array}$ & $\begin{array}{l}0 \\
1 \\
0 \\
0 \\
0\end{array}$ & $\begin{array}{l}1.00 \\
0.90 \\
1.00 \\
1.00 \\
1.00\end{array}$ & 98.0 \\
\hline $\begin{array}{l}P C-5 \\
P C-5 \\
P C-5 \\
P C-5 \\
P C-5\end{array}$ & $\begin{array}{l}10 \\
10 \\
10 \\
10 \\
10\end{array}$ & $\begin{array}{l}1 \\
2 \\
3 \\
4 \\
5\end{array}$ & $\begin{array}{l}10 \\
10 \\
10 \\
10 \\
10\end{array}$ & $\begin{array}{l}0 \\
0 \\
0 \\
0 \\
0\end{array}$ & $\begin{array}{l}1.00 \\
1.00 \\
1.00 \\
1.00 \\
1.00\end{array}$ & 100.0 \\
\hline $\begin{array}{l}P C-5 \\
P C-5 \\
P C-5 \\
P C-5 \\
P C-5\end{array}$ & $\begin{array}{l}50 \\
50 \\
50 \\
50 \\
50\end{array}$ & $\begin{array}{l}1 \\
2 \\
3 \\
4 \\
5\end{array}$ & $\begin{array}{r}10 \\
9 \\
10 \\
10 \\
10\end{array}$ & $\begin{array}{l}0 \\
1 \\
0 \\
0 \\
0\end{array}$ & $\begin{array}{l}1.00 \\
0.90 \\
1.00 \\
1.00 \\
1.00\end{array}$ & 98.0 \\
\hline $\begin{array}{l}P C-5 \\
P C-5 \\
P C-5 \\
P C-5 \\
P C-5\end{array}$ & $\begin{array}{l}100 \\
100 \\
100 \\
100 \\
100\end{array}$ & $\begin{array}{l}1 \\
2 \\
3 \\
4 \\
5\end{array}$ & $\begin{array}{r}9 \\
9 \\
10 \\
10 \\
10\end{array}$ & $\begin{array}{l}1 \\
1 \\
0 \\
0 \\
0\end{array}$ & $\begin{array}{l}0.90 \\
0.90 \\
1.00 \\
1.00 \\
1.00\end{array}$ & 96.0 \\
\hline $\begin{array}{l}\text { Reference } \\
\text { Reference } \\
\text { Reference } \\
\text { Reference } \\
\text { Reference }\end{array}$ & $\begin{array}{l}0 \\
0 \\
0 \\
0 \\
0\end{array}$ & $\begin{array}{l}1 \\
2 \\
3 \\
4 \\
5\end{array}$ & $\begin{array}{r}10 \\
10 \\
10 \\
10 \\
9\end{array}$ & $\begin{array}{l}0 \\
0 \\
0 \\
0 \\
1\end{array}$ & $\begin{array}{l}1.00 \\
1.00 \\
1.00 \\
1.00 \\
0.90\end{array}$ & 98.0 \\
\hline
\end{tabular}

PANAMA CITY HARBOR

J. 3 
IABLE J,1. (contd)

\begin{tabular}{|c|c|c|c|c|c|c|}
\hline \multirow[b]{2}{*}{$\begin{array}{l}\text { Sediment } \\
\text { Ireatment }\end{array}$} & \multirow{2}{*}{$\begin{array}{c}\text { Concentration } \\
\text { Percent } \\
\text { SPP } \\
\end{array}$} & \multirow[b]{2}{*}{ Replicate } & \multicolumn{3}{|c|}{ M. beryllina } & \multirow{2}{*}{$\begin{array}{c}\text { Mean } \\
\text { Perccint } \\
\text { Surviving }\end{array}$} \\
\hline & & & Live & $\begin{array}{l}\text { Dead or } \\
\text { Missing }\end{array}$ & $\begin{array}{l}\text { Proportion } \\
\text { Surviving }\end{array}$ & \\
\hline $\begin{array}{l}\text { Reference } \\
\text { Reference } \\
\text { Reference } \\
\text { Reference } \\
\text { Reference }\end{array}$ & $\begin{array}{l}10 \\
10 \\
10 \\
10 \\
10\end{array}$ & $\begin{array}{l}1 \\
2 \\
3 \\
4 \\
5\end{array}$ & $\begin{array}{l}10 \\
10 \\
10 \\
10 \\
9\end{array}$ & $\begin{array}{l}0 \\
0 \\
0 \\
0 \\
1\end{array}$ & $\begin{array}{l}1.00 \\
1.00 \\
1.00 \\
1.00 \\
0.90\end{array}$ & 98.0 \\
\hline $\begin{array}{l}\text { Reference } \\
\text { Reference } \\
\text { Reference } \\
\text { Reference } \\
\text { Reference }\end{array}$ & $\begin{array}{l}50 \\
50 \\
50 \\
50 \\
50\end{array}$ & $\begin{array}{l}1 \\
2 \\
3 \\
4 \\
5\end{array}$ & $\begin{array}{r}9 \\
9 \\
10 \\
10 \\
10\end{array}$ & $\begin{array}{l}1 \\
1 \\
0 \\
0 \\
0\end{array}$ & $\begin{array}{l}0.90 \\
0.90 \\
1.00 \\
1.00 \\
1.00\end{array}$ & 96.0 \\
\hline $\begin{array}{l}\text { Reference } \\
\text { Reference } \\
\text { Reference } \\
\text { Reference } \\
\text { Reference }\end{array}$ & $\begin{array}{l}100 \\
100 \\
100 \\
100 \\
100\end{array}$ & $\begin{array}{l}1 \\
2 \\
3 \\
4 \\
5\end{array}$ & $\begin{array}{r}10 \\
10 \\
9 \\
10 \\
10\end{array}$ & $\begin{array}{l}0 \\
0 \\
1 \\
0 \\
0\end{array}$ & $\begin{array}{l}1.00 \\
1.00 \\
0.90 \\
1.00 \\
1.00\end{array}$ & 98.0 \\
\hline
\end{tabular}


IABLE 0.2. Water Quality Summar'y for 96-Hour M. beryllina SuspendedParticulate-Phase Test, Panama City Harbor Project

\begin{tabular}{|c|c|c|c|c|c|c|c|c|c|}
\hline \multirow{2}{*}{$\begin{array}{l}\text { Sediment } \\
\text { Ireatment }\end{array}$} & \multirow{2}{*}{$\begin{array}{c}\text { Concentration } \\
\text { Percent } \\
\text { SPP }\end{array}$} & \multicolumn{2}{|c|}{$\begin{array}{c}\text { Temperature } \\
\left({ }^{\circ} \mathrm{C}\right)\end{array}$} & \multicolumn{2}{|c|}{$\mathrm{pH}$} & \multicolumn{2}{|c|}{$\begin{array}{c}\text { Oissol ved } \\
\text { Oxygen } \\
(\mathrm{mg} / \mathrm{L}) \\
\end{array}$} & \multicolumn{2}{|c|}{$\begin{array}{c}\text { Salinfty } \\
(0 / 00)\end{array}$} \\
\hline & & Min & $\operatorname{Max}$ & Min & Max & Min & Max & Min & $\operatorname{Max}$ \\
\hline $\begin{array}{l}\text { Acceptable } \\
\text { range }\end{array}$ & & 18.0 & 22.0 & 7.30 & 8.30 & & & 28.0 & 32.0 \\
\hline $\begin{array}{l}P C-1 \\
P C-1 \\
P C-1 \\
P C-1\end{array}$ & $\begin{array}{r}0 \\
10 \\
50 \\
100\end{array}$ & $\begin{array}{l}19.3 \\
19.7 \\
19.9 \\
19.7\end{array}$ & $\begin{array}{l}20.8 \\
20.8 \\
20.7 \\
20.8\end{array}$ & $\begin{array}{l}7.93 \\
8.00 \\
7.89 \\
7.84\end{array}$ & $\begin{array}{l}8.21 \\
8.18 \\
8.17 \\
8.19\end{array}$ & $\begin{array}{l}6.5 \\
6.6 \\
6.5 \\
6.2\end{array}$ & $\begin{array}{l}8.1 \\
8.2 \\
7.7 \\
7.5\end{array}$ & $\begin{array}{l}30.0 \\
29.5 \\
30.0 \\
30.0\end{array}$ & $\begin{array}{l}31.5 \\
31.5 \\
32.0 \\
32.0\end{array}$ \\
\hline $\begin{array}{l}P C-1 A \\
P C-1 A \\
P C-1 A \\
P C-1 A\end{array}$ & $\begin{array}{r}0 \\
10 \\
50 \\
100\end{array}$ & $\begin{array}{l}19.9 \\
19.7 \\
20.0 \\
19.9\end{array}$ & $\begin{array}{l}20.9 \\
20.9 \\
21.0 \\
20.8\end{array}$ & $\begin{array}{l}7.70 \\
7.87 \\
7.84 \\
7.88\end{array}$ & $\begin{array}{l}8.17 \\
8.16 \\
8.17 \\
8.17\end{array}$ & $\begin{array}{l}6.0 \\
6.3 \\
6.5 \\
6.4\end{array}$ & $\begin{array}{l}7.7 \\
7.8 \\
7.7 \\
7.5\end{array}$ & $\begin{array}{l}30.5 \\
30.5 \\
30.5 \\
30.5\end{array}$ & $\begin{array}{l}32.0 \\
32.0 \\
33.0(a) \\
32.0\end{array}$ \\
\hline $\begin{array}{l}P C-2 \\
P C-2 \\
P C-2 \\
P C-2\end{array}$ & $\begin{array}{r}0 \\
10 \\
50 \\
100\end{array}$ & $\begin{array}{l}19.7 \\
19.7 \\
20.0 \\
19.7\end{array}$ & $\begin{array}{l}20.8 \\
20.8 \\
20.8 \\
20.8\end{array}$ & $\begin{array}{l}7.92 \\
7.49 \\
7.95 \\
7.92\end{array}$ & $\begin{array}{l}8.17 \\
8.18 \\
8.16 \\
8.22\end{array}$ & $\begin{array}{l}6.3 \\
4.5 \\
6.4 \\
6.3\end{array}$ & $\begin{array}{l}8.3 \\
8.2 \\
7.7 \\
7.5\end{array}$ & $\begin{array}{l}28.0 \\
28.5 \\
30.0 \\
30.5\end{array}$ & $\begin{array}{l}29.5 \\
30.5 \\
31.5 \\
32.0\end{array}$ \\
\hline $\begin{array}{l}P C-4 \\
P C-4 \\
P C-4 \\
P C-4\end{array}$ & $\begin{array}{r}0 \\
10 \\
50 \\
100\end{array}$ & $\begin{array}{l}19.5 \\
19.5 \\
19.6 \\
19.6\end{array}$ & $\begin{array}{l}20.8 \\
20.8 \\
20.8 \\
20.8\end{array}$ & $\begin{array}{l}7.73 \\
7.91 \\
7.89 \\
7.98\end{array}$ & $\begin{array}{l}8.18 \\
8.17 \\
8.26 \\
8.19\end{array}$ & $\begin{array}{l}5.6 \\
6.1 \\
6.3 \\
6.3\end{array}$ & $\begin{array}{l}7.9 \\
7.6 \\
7.6 \\
7.6\end{array}$ & $\begin{array}{l}30.5 \\
30.5 \\
30.5 \\
30.0\end{array}$ & $\begin{array}{l}32.0 \\
32.0 \\
32.0 \\
32.0\end{array}$ \\
\hline $\begin{array}{l}P C-5 \\
P C-5 \\
P C-5 \\
P C-5\end{array}$ & $\begin{array}{r}0 \\
10 \\
50 \\
100\end{array}$ & $\begin{array}{l}19.4 \\
19.4 \\
19.5 \\
19.4\end{array}$ & $\begin{array}{l}20.8 \\
20.8 \\
20.8 \\
20.8\end{array}$ & $\begin{array}{l}7.77 \\
7.61 \\
7.99 \\
7.46\end{array}$ & $\begin{array}{l}8.17 \\
8.17 \\
8.16 \\
8.16\end{array}$ & $\begin{array}{l}6.0 \\
4.5 \\
6.2 \\
4.7\end{array}$ & $\begin{array}{l}7.6 \\
7.6 \\
7.5 \\
7.2\end{array}$ & $\begin{array}{l}29.5 \\
30.5 \\
30.5 \\
30.5\end{array}$ & $\begin{array}{l}31.5 \\
31.5 \\
32.0 \\
32.0\end{array}$ \\
\hline $\begin{array}{l}\text { Reference } \\
\text { Reference } \\
\text { Reference } \\
\text { Reference }\end{array}$ & $\begin{array}{r}0 \\
10 \\
50 \\
100\end{array}$ & $\begin{array}{l}19.2 \\
19.1 \\
19.2 \\
19.2\end{array}$ & $\begin{array}{l}20.8 \\
20.8 \\
20.8 \\
20.9\end{array}$ & $\begin{array}{l}7.97 \\
7.96 \\
7.58 \\
7.54\end{array}$ & $\begin{array}{l}8.18 \\
8.17 \\
8.08 \\
8.16\end{array}$ & $\begin{array}{l}6.1 \\
6.4 \\
5.9 \\
4.7\end{array}$ & $\begin{array}{l}7.9 \\
7.7 \\
7.1 \\
7.2\end{array}$ & $\begin{array}{l}30.5 \\
30.5 \\
30.5 \\
30.5\end{array}$ & $\begin{array}{l}32.0 \\
32.0 \\
32.0 \\
32.0\end{array}$ \\
\hline
\end{tabular}

(a) Value outside of acceptable range.

PANAMA CITY HARBOR DRAFT $\quad J .5$ 
IABLE J.3. Results for All Replicates in 96-Hour M. beryllina Reference Toxicant Test, Panama City Harbor Project

\begin{tabular}{|c|c|c|c|c|c|}
\hline \multirow{2}{*}{$\begin{array}{c}\text { Copper } \\
\text { Concentration } \\
(\mu \mathrm{g} / \mathrm{L})\end{array}$} & \multirow[b]{2}{*}{ Replicate } & \multicolumn{3}{|c|}{ M. beryllina } & \multirow{2}{*}{$\begin{array}{c}\text { Mean } \\
\text { Percent } \\
\text { Surviving } \\
\end{array}$} \\
\hline & & Live & $\begin{array}{l}\text { Dead or } \\
\text { Missing }\end{array}$ & $\begin{array}{l}\text { Proportion } \\
\text { Surviving }\end{array}$ & \\
\hline $\begin{array}{l}0 \\
0 \\
0\end{array}$ & $\begin{array}{l}1 \\
2 \\
3\end{array}$ & $\begin{array}{l}10 \\
10 \\
10\end{array}$ & $\begin{array}{l}0 \\
0 \\
0\end{array}$ & $\begin{array}{l}1.00 \\
1.00 \\
1.00\end{array}$ & 100.0 \\
\hline $\begin{array}{l}16 \\
16 \\
16\end{array}$ & $\begin{array}{l}1 \\
2 \\
3\end{array}$ & $\begin{array}{r}10 \\
10 \\
9\end{array}$ & $\begin{array}{l}0 \\
0 \\
1\end{array}$ & $\begin{array}{l}1.00 \\
1.00 \\
0.90\end{array}$ & 96.7 \\
\hline $\begin{array}{l}64 \\
64 \\
64\end{array}$ & $\begin{array}{l}1 \\
2 \\
3\end{array}$ & $\begin{array}{r}10 \\
9 \\
10\end{array}$ & $\begin{array}{l}0 \\
0 \\
0\end{array}$ & $\begin{array}{l}1.00 \\
0.90 \\
1.00\end{array}$ & 96.7 \\
\hline $\begin{array}{l}160 \\
160 \\
160\end{array}$ & $\begin{array}{l}1 \\
2 \\
3\end{array}$ & $\begin{array}{l}1 \\
1 \\
1\end{array}$ & $\begin{array}{l}9 \\
9 \\
9\end{array}$ & $\begin{array}{l}0.10 \\
0.10 \\
0.10\end{array}$ & 10.0 \\
\hline $\begin{array}{l}400 \\
400 \\
400\end{array}$ & $\begin{array}{l}1 \\
2 \\
3\end{array}$ & $\begin{array}{l}0 \\
0 \\
0\end{array}$ & $\begin{array}{l}10 \\
10 \\
10\end{array}$ & $\begin{array}{l}0.00 \\
0.00 \\
0.00\end{array}$ & 0.0 \\
\hline
\end{tabular}


IABLE 3.4. Water Quality Summary for 96-Hour M. beryllina Reference Toxicant Test, Panama City Harbor Project

\begin{tabular}{|c|c|c|c|c|c|c|c|c|}
\hline \multirow{2}{*}{$\begin{array}{c}\text { Copper } \\
\text { Concentration } \\
\text { (ma/L) }\end{array}$} & \multicolumn{2}{|c|}{$\begin{array}{c}\text { Temperature } \\
\left({ }^{\circ} \mathrm{C}\right)\end{array}$} & & & \multicolumn{2}{|c|}{$\begin{array}{l}\text { Dissolved } \\
\text { Oxygen } \\
\text { (mg/h) }\end{array}$} & \multicolumn{2}{|c|}{$\begin{array}{c}\text { Salinity } \\
(0 / 00)\end{array}$} \\
\hline & Min & Max & Min & $\overline{M a x}$ & Min & $\overline{M a x}$ & Min & $\overline{M a x}$ \\
\hline $\begin{array}{l}\text { Acceptable } \\
\text { range }\end{array}$ & 18.0 & 22.0 & 7.30 & 8.30 & & & 28.0 & 32.0 \\
\hline $\begin{array}{r}0 \\
16 \\
64 \\
160 \\
640\end{array}$ & $\begin{array}{l}18.1 \\
18.1 \\
18.2 \\
18.1 \\
18.1\end{array}$ & $\begin{array}{l}19.5 \\
19.4 \\
19.5 \\
19.6 \\
19.5\end{array}$ & $\begin{array}{l}7.73 \\
7.75 \\
7.75 \\
7.75 \\
7.74\end{array}$ & $\begin{array}{l}8.16 \\
8.15 \\
8.09 \\
8.25 \\
8.23\end{array}$ & $\begin{array}{l}6.5 \\
6.8 \\
6.8 \\
7.0 \\
6.9\end{array}$ & $\begin{array}{l}7.5 \\
7.6 \\
7.5 \\
7.4 \\
7.5\end{array}$ & $\begin{array}{l}32.0 \\
32.0 \\
32.0 \\
32.0 \\
32.0\end{array}$ & $\begin{array}{l}32.5^{(a)} \\
32.5^{(a)} \\
32.0 \\
32.0 \\
32.0\end{array}$ \\
\hline
\end{tabular}

(a) Value outside of acceptable range. 
APPENDIX K

72-HOUR SUSPENDED-PARTICULATE-PHASE TEST

72-HOUR REFERENCE TOXICANT TEST

WITH M. EDULIS 
TABLE K.1. Results for All Replicates in 72-Hour M. edulis SuspendedParticulate-Phase Test, Panama City Harbor Project

\begin{tabular}{|c|c|c|c|c|c|c|c|c|c|}
\hline $\begin{array}{l}\text { Sediment } \\
\text { Ireatment }\end{array}$ & $\begin{array}{c}\text { Concentration } \\
\text { Percent } \\
\text { SPP }\end{array}$ & Replicate & $\begin{array}{c}\text { Normal } \\
\text { D-Shaped } \\
\text { Shell } \\
\end{array}$ & $\begin{array}{l}\text { Abnormal } \\
\text { with } \\
\text { Shell } \\
\end{array}$ & Other & $\begin{array}{l}\text { Percent } \\
\text { Normal }(a)\end{array}$ & $\begin{array}{l}\text { Mean } \\
\text { Percent } \\
\text { Normal } \\
\end{array}$ & $\begin{array}{l}\text { Percent } \\
\text { Survival (a) }\end{array}$ & $\begin{array}{l}\text { Mean } \\
\text { Percent } \\
\text { Survival } \\
\end{array}$ \\
\hline $\begin{array}{l}P C-1 \\
P C-1 \\
P C-1 \\
P C-1 \\
P C-1\end{array}$ & $\begin{array}{l}0 \\
0 \\
0 \\
0 \\
0\end{array}$ & $\begin{array}{l}1 \\
2 \\
3 \\
4 \\
5\end{array}$ & $\begin{array}{l}199 \\
185 \\
222 \\
219 \\
195\end{array}$ & $\begin{array}{r}11 \\
26 \\
23 \\
1 \\
12\end{array}$ & $\begin{array}{r}6 \\
13 \\
6 \\
11 \\
6\end{array}$ & $\begin{array}{l}79.92 \\
74.30 \\
89.16 \\
87.95 \\
78.31\end{array}$ & 81.93 & $\begin{array}{c}86.75 \\
89.96(b) \\
100.00(b) \\
92.77 \\
85.54\end{array}$ & 91.00 \\
\hline $\begin{array}{l}P C-1 \\
P C-1 \\
P C-1 \\
P C-1 \\
P C-1\end{array}$ & $\begin{array}{l}10 \\
10 \\
10 \\
10 \\
10\end{array}$ & $\begin{array}{l}1 \\
2 \\
3 \\
4 \\
5\end{array}$ & $\begin{array}{l}162 \\
190 \\
216 \\
164 \\
263\end{array}$ & $\begin{array}{l}2 \\
2 \\
1 \\
2 \\
3\end{array}$ & $\begin{array}{r}1 \\
19 \\
10 \\
22 \\
2\end{array}$ & $\begin{array}{c}65.06 \\
76.31 \\
86.75 \\
65.86 \\
100.00(\mathrm{~b})\end{array}$ & 78.80 & $\begin{array}{c}66.27 \\
84.74 \\
91.16 \\
75.50(\mathrm{~h}) \\
100.00(\mathrm{~s})\end{array}$ & 83.53 \\
\hline $\begin{array}{l}P C-1 \\
P C-1 \\
P C-1 \\
P C-1 \\
P C-1\end{array}$ & $\begin{array}{l}50 \\
50 \\
50 \\
50 \\
50\end{array}$ & $\begin{array}{l}1 \\
2 \\
3 \\
4 \\
5\end{array}$ & $\begin{array}{l}190 \\
180 \\
181 \\
156 \\
152\end{array}$ & $\begin{array}{r}1 \\
3 \\
3 \\
11 \\
7\end{array}$ & $\begin{array}{r}9 \\
4 \\
14 \\
12 \\
11\end{array}$ & $\begin{array}{l}76.31 \\
72.29 \\
72.69 \\
62.65 \\
61.04\end{array}$ & 69.00 & $\begin{array}{l}80.32 \\
75.10 \\
79.52 \\
71.89 \\
68.27\end{array}$ & 75.02 \\
\hline $\begin{array}{l}P C-1 \\
P C-1 \\
P C-1 \\
P C-1 \\
P C-1\end{array}$ & $\begin{array}{l}100 \\
100 \\
100 \\
100 \\
100\end{array}$ & $\begin{array}{l}1 \\
2 \\
3 \\
4 \\
5\end{array}$ & $\begin{array}{l}234 \\
174 \\
209 \\
221 \\
234\end{array}$ & $\begin{array}{l}5 \\
8 \\
9 \\
5 \\
9\end{array}$ & $\begin{array}{r}9 \\
7 \\
10 \\
0 \\
4\end{array}$ & $\begin{array}{l}93.98 \\
69.88 \\
83.94 \\
88.76 \\
93.98\end{array}$ & 86.10 & $\begin{array}{l}99.60 \\
75.90 \\
91.57 \\
90.76 \\
99.20\end{array}$ & 91.41 \\
\hline $\begin{array}{l}P C-1 A \\
P C-1 A \\
P C-1 A \\
P C-1 A \\
P C-1 A\end{array}$ & $\begin{array}{l}0 \\
0 \\
0 \\
0 \\
0\end{array}$ & $\begin{array}{l}1 \\
2 \\
3 \\
4 \\
5\end{array}$ & $\begin{array}{l}230 \\
174 \\
193 \\
180 \\
240\end{array}$ & $\begin{array}{r}14 \\
30 \\
10 \\
7 \\
4\end{array}$ & $\begin{array}{r}7 \\
2 \\
16 \\
8 \\
5\end{array}$ & $\begin{array}{l}92.37 \\
69.88 \\
77.51 \\
72.29 \\
96.39\end{array}$ & 81.69 & $\begin{array}{c}100.00^{(b)} \\
82.73 \\
87.95 \\
78.31 \\
100.00\end{array}$ & 89.80 \\
\hline $\begin{array}{l}P C-1 A \\
P C-1 A \\
P C-1 A \\
P C-1 A \\
P C-1 A\end{array}$ & $\begin{array}{l}10 \\
10 \\
10 \\
10 \\
10\end{array}$ & $\begin{array}{l}1 \\
2 \\
3 \\
4 \\
5\end{array}$ & $\begin{array}{l}180 \\
197 \\
179 \\
210 \\
213\end{array}$ & $\begin{array}{r}6 \\
4 \\
6 \\
10 \\
2\end{array}$ & $\begin{array}{l}17 \\
11 \\
25 \\
13 \\
13\end{array}$ & $\begin{array}{l}72.29 \\
79.12 \\
71.89 \\
84.34 \\
85.54\end{array}$ & 78.63 & $\begin{array}{l}81.53 \\
85.14 \\
84.34 \\
93.57 \\
91.57\end{array}$ & 87.23 \\
\hline $\begin{array}{l}P C-1 A \\
P C-1 A \\
P C-1 A \\
P C-1 A \\
P C-1 A\end{array}$ & $\begin{array}{l}50 \\
50 \\
50 \\
50 \\
50\end{array}$ & $\begin{array}{l}1 \\
2 \\
3 \\
4 \\
5\end{array}$ & $\begin{array}{l}217 \\
205 \\
240 \\
166 \\
194\end{array}$ & $\begin{array}{r}1 \\
10 \\
2 \\
5 \\
6\end{array}$ & $\begin{array}{r}11 \\
1 \\
16 \\
5 \\
14\end{array}$ & $\begin{array}{l}87.15 \\
82.33 \\
96.39 \\
66.67 \\
77.91\end{array}$ & 82.09 & $\begin{array}{c}91.97 \\
86.75 \\
100.00(b) \\
70.68 \\
85.94\end{array}$ & 87.07 \\
\hline $\begin{array}{l}P C-1 A \\
P C-1 A \\
P C-1 A \\
P C-1 A \\
P C-1 A\end{array}$ & $\begin{array}{l}100 \\
100 \\
100 \\
100 \\
100\end{array}$ & $\begin{array}{l}1 \\
2 \\
3 \\
4 \\
5\end{array}$ & $\begin{array}{l}196 \\
192 \\
227 \\
173 \\
191\end{array}$ & $\begin{array}{r}1 \\
22 \\
2 \\
6 \\
5\end{array}$ & $\begin{array}{r}23 \\
15 \\
6 \\
10 \\
11\end{array}$ & $\begin{array}{l}78.71 \\
77.11 \\
91.16 \\
69.48 \\
76.71\end{array}$ & 78.63 & $\begin{array}{l}88.35 \\
91.97 \\
94.38 \\
75.90 \\
83.13\end{array}$ & 86.75 \\
\hline $\begin{array}{l}P C-2 \\
P C-2 \\
P C-2 \\
P C-2 \\
P C-2\end{array}$ & $\begin{array}{l}0 \\
0 \\
0 \\
0 \\
0\end{array}$ & $\begin{array}{l}1 \\
2 \\
3 \\
4 \\
5\end{array}$ & $\begin{array}{l}215 \\
211 \\
204 \\
184 \\
181\end{array}$ & $\begin{array}{r}15 \\
21 \\
6 \\
12 \\
6\end{array}$ & $\begin{array}{r}16 \\
6 \\
1 \\
5 \\
16\end{array}$ & $\begin{array}{l}86.35 \\
84.74 \\
81.93 \\
73.90 \\
72.69\end{array}$ & 79.92 & $\begin{array}{l}98.80 \\
95.58 \\
84.74 \\
80.72 \\
81.53\end{array}$ & 88.27 \\
\hline
\end{tabular}


TABLE K.1. (contd)

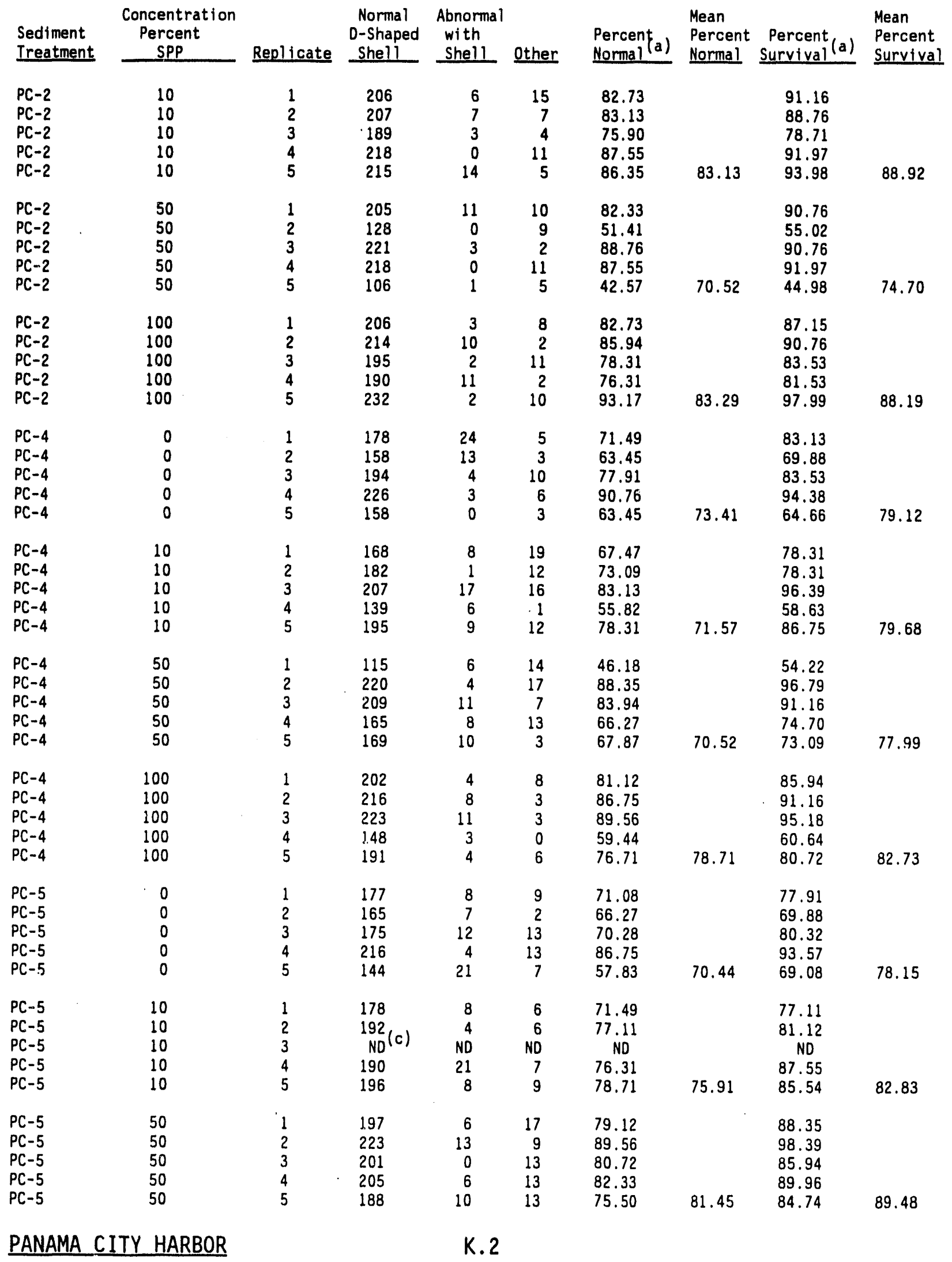


IABLE K.1. (contd)

\begin{tabular}{|c|c|c|c|c|c|c|c|c|c|}
\hline $\begin{array}{l}\text { Sediment } \\
\text { Ireatment }\end{array}$ & $\begin{array}{c}\text { Concentration } \\
\text { Percent } \\
\text { SPP } \\
\end{array}$ & Replicate & $\begin{array}{c}\text { Normal } \\
\text { D-Shaped } \\
\text { Shell } \\
\end{array}$ & $\begin{array}{l}\text { Abnormal } \\
\text { with } \\
\text { Shell } \\
\end{array}$ & Other & $\begin{array}{l}\text { Percent } \\
\text { Normal a) }\end{array}$ & $\begin{array}{l}\text { Mean } \\
\text { Percent } \\
\text { Normal }\end{array}$ & $\begin{array}{l}\text { Percent } \\
\text { Survival (a) }\end{array}$ & $\begin{array}{l}\text { Mean } \\
\text { Percent } \\
\text { Survival } \\
\end{array}$ \\
\hline $\begin{array}{l}P C-5 \\
P C-5 \\
P C-5 \\
P C-5 \\
P C-5\end{array}$ & $\begin{array}{l}100 \\
100 \\
100 \\
100 \\
100\end{array}$ & $\begin{array}{l}1 \\
2 \\
3 \\
4 \\
5\end{array}$ & $\begin{array}{l}195 \\
192 \\
160 \\
183 \\
210\end{array}$ & $\begin{array}{r}15 \\
2 \\
6 \\
16 \\
1\end{array}$ & $\begin{array}{r}3 \\
9 \\
7 \\
0 \\
21\end{array}$ & $\begin{array}{l}78.31 \\
77.11 \\
64.26 \\
73.49 \\
84.34\end{array}$ & 75.50 & $\begin{array}{l}85.54 \\
81.53 \\
69.48 \\
79.92 \\
93.17\end{array}$ & 81.93 \\
\hline $\begin{array}{l}\text { Reference } \\
\text { Reference } \\
\text { Reference } \\
\text { Reference } \\
\text { Reference }\end{array}$ & $\begin{array}{l}0 \\
0 \\
0 \\
0 \\
0\end{array}$ & $\begin{array}{l}1 \\
2 \\
3 \\
4 \\
5\end{array}$ & $\begin{array}{l}184 \\
222 \\
237 \\
205 \\
198\end{array}$ & $\begin{array}{r}10 \\
13 \\
13 \\
7 \\
8\end{array}$ & $\begin{array}{l}1 \\
5 \\
0 \\
6 \\
4\end{array}$ & $\begin{array}{l}73.90 \\
89.16 \\
95.18 \\
82.33 \\
79.52\end{array}$ & 84.02 & $\begin{array}{l}78.31 \\
96.39 \\
100.00(b) \\
87.55 \\
84.34\end{array}$ & 89.32 \\
\hline $\begin{array}{l}\text { Reference } \\
\text { Reference } \\
\text { Reference } \\
\text { Reference } \\
\text { Reference }\end{array}$ & $\begin{array}{l}10 \\
10 \\
10 \\
10 \\
10\end{array}$ & $\begin{array}{l}1 \\
2 \\
3 \\
4 \\
5\end{array}$ & $\begin{array}{l}241 \\
288 \\
205 \\
224 \\
162\end{array}$ & $\begin{array}{l}3 \\
1 \\
4 \\
3 \\
6\end{array}$ & $\begin{array}{r}27 \\
17 \\
19 \\
12 \\
2\end{array}$ & $\begin{array}{c}96.79 \\
100.00(b) \\
82.33 \\
89.96 \\
65.06\end{array}$ & 86.83 & $\begin{array}{c}100.00(\mathrm{~b}) \\
100.00^{(b)} \\
91.57 \\
95.98 \\
68.27\end{array}$ & 91.16 \\
\hline $\begin{array}{l}\text { Reference } \\
\text { Reference } \\
\text { Reference } \\
\text { Reference } \\
\text { Reference }\end{array}$ & $\begin{array}{l}50 \\
50 \\
50 \\
50 \\
50\end{array}$ & $\begin{array}{l}1 \\
2 \\
3 \\
4 \\
5\end{array}$ & $\begin{array}{r}189 \\
\text { ND } \\
180 \\
173 \\
194\end{array}$ & $\begin{array}{r}1 \\
\text { ND } \\
4 \\
10 \\
1\end{array}$ & $\begin{array}{r}26 \\
\text { ND } \\
7 \\
13 \\
11\end{array}$ & $\begin{array}{c}75.90 \\
\text { ND } \\
72.29 \\
69.48 \\
77.91\end{array}$ & 73.90 & $\begin{array}{c}86.75 \\
\text { ND } \\
76.71 \\
78.71 \\
82.73\end{array}$ & 81.23 \\
\hline $\begin{array}{l}\text { Reference } \\
\text { Reference } \\
\text { Reference } \\
\text { Reference } \\
\text { Reference }\end{array}$ & $\begin{array}{l}100 \\
100 \\
100 \\
100 \\
100\end{array}$ & $\begin{array}{l}1 \\
2 \\
3 \\
4 \\
5\end{array}$ & $\begin{array}{l}238 \\
201 \\
200 \\
190 \\
227\end{array}$ & $\begin{array}{l}1 \\
3 \\
0 \\
7 \\
1\end{array}$ & $\begin{array}{r}6 \\
8 \\
11 \\
7 \\
6\end{array}$ & $\begin{array}{l}95.58 \\
80.72 \\
80.32 \\
76.31 \\
91.16\end{array}$ & 84.82 & $\begin{array}{l}98.39 \\
85.14 \\
84.74 \\
81.93 \\
93.98\end{array}$ & 88.84 \\
\hline \multicolumn{2}{|c|}{$\begin{array}{l}\text { Brine Control } \\
\text { Brine Control } \\
\text { Brine Control } \\
\text { Brine Control } \\
\text { Brine Control }\end{array}$} & $\begin{array}{l}1 \\
2 \\
3 \\
4 \\
5\end{array}$ & $\begin{array}{l}214 \\
150 \\
204 \\
146 \\
194\end{array}$ & $\begin{array}{l}2 \\
0 \\
7 \\
0 \\
9\end{array}$ & $\begin{array}{l}10 \\
12 \\
10 \\
18 \\
18\end{array}$ & $\begin{array}{l}85.94 \\
60.24 \\
81.93 \\
58.63 \\
77.91\end{array}$ & 72.93 & $\begin{array}{l}90.76 \\
65.06 \\
88.76 \\
65.86 \\
88.76\end{array}$ & 79.84 \\
\hline
\end{tabular}

(a) Percent normal and percent survival based on stocking density (average of multicell larvae) of 249 larvae per $10 \mathrm{~mL}$.

(b) A percent survival of 100.00 was used when the number surviving was greater than the stocking density.

(c) ND No data. 
IABLE K.2. Water Quality Summary for M. edulis 72-Hour SuspendedParticulate-Phase Test, Panama City Harbor Project

\begin{tabular}{|c|c|c|c|c|c|c|c|c|c|}
\hline \multirow{2}{*}{$\begin{array}{l}\text { Sediment } \\
\text { Ireatment }\end{array}$} & \multirow{2}{*}{$\begin{array}{c}\text { Concentration } \\
\text { Percent } \\
\text { SPP } \\
\end{array}$} & \multicolumn{2}{|c|}{$\begin{array}{c}\text { Temperature } \\
\left({ }^{\circ} \mathrm{C}\right)\end{array}$} & \multicolumn{2}{|c|}{$\mathrm{DH}$} & \multicolumn{2}{|c|}{$\begin{array}{l}\text { Dissolved } \\
\text { Oxygen } \\
\text { (ma/L) }\end{array}$} & \multicolumn{2}{|c|}{$\begin{array}{c}\text { Salinity } \\
(0 / 00)\end{array}$} \\
\hline & & Min & Max & Min & Max & Min & Max & Min & Max \\
\hline $\begin{array}{l}\text { Acceptable } \\
\text { Range }\end{array}$ & & 14.0 & 18.0 & 7.30 & 8.30 & & & 28.0 & 32.0 \\
\hline $\begin{array}{l}P C-1 \\
P C-1 \\
P C-1 \\
P C-1\end{array}$ & $\begin{array}{r}0 \\
10 \\
50 \\
100\end{array}$ & $\begin{array}{l}15.0 \\
15.0 \\
15.0 \\
15.0\end{array}$ & $\begin{array}{l}15.4 \\
15.5 \\
15.7 \\
15.7\end{array}$ & $\begin{array}{l}8.11 \\
8.09 \\
8.13 \\
8.09\end{array}$ & $\begin{array}{l}8.27 \\
8.26 \\
8.24 \\
8.24\end{array}$ & $\begin{array}{l}7.4 \\
7.5 \\
7.4 \\
7.5\end{array}$ & $\begin{array}{l}8.4 \\
8.2 \\
8.4 \\
8.4\end{array}$ & $\begin{array}{l}30.0 \\
30.0 \\
30.0 \\
30.0\end{array}$ & $\begin{array}{l}31.5 \\
31.5 \\
32.0 \\
32.0\end{array}$ \\
\hline $\begin{array}{l}P C-1 A \\
P C-1 A \\
P C-1 A \\
P C-1 A\end{array}$ & $\begin{array}{r}0 \\
10 \\
50 \\
100\end{array}$ & $\begin{array}{l}15.0 \\
15.0 \\
15.1 \\
15.0\end{array}$ & $\begin{array}{l}15.5 \\
15.4 \\
15.6 \\
15.4\end{array}$ & $\begin{array}{l}8.16 \\
8.16 \\
8.15 \\
8.15\end{array}$ & $\begin{array}{l}8.25 \\
8.27 \\
8.24 \\
8.25\end{array}$ & $\begin{array}{l}7.3 \\
7.4 \\
7.4 \\
7.4\end{array}$ & $\begin{array}{l}8.3 \\
8.1 \\
8.2 \\
8.5\end{array}$ & $\begin{array}{l}29.5 \\
30.0 \\
30.0 \\
30.0\end{array}$ & $\begin{array}{l}32.0 \\
32.0 \\
31.0 \\
32.0\end{array}$ \\
\hline $\begin{array}{l}P C-2 \\
P C-2 \\
P C-2 \\
P C-2\end{array}$ & $\begin{array}{r}0 \\
10 \\
50 \\
100\end{array}$ & $\begin{array}{l}15.0 \\
15.1 \\
15.0 \\
15.0\end{array}$ & $\begin{array}{l}15.4 \\
15.6 \\
15.5 \\
15.4\end{array}$ & $\begin{array}{l}8.13 \\
8.16 \\
8.13 \\
8.14\end{array}$ & $\begin{array}{l}8.27 \\
8.26 \\
8.24 \\
8.27\end{array}$ & $\begin{array}{l}7.1 \\
7.4 \\
7.4 \\
7.4\end{array}$ & $\begin{array}{l}8.5 \\
8.1 \\
8.3 \\
8.4\end{array}$ & $\begin{array}{l}30.0 \\
30.0 \\
30.0 \\
30.0\end{array}$ & $\begin{array}{l}32.0 \\
31.0 \\
32.0 \\
31.0\end{array}$ \\
\hline $\begin{array}{l}P C-4 \\
P C-4 \\
P C-4 \\
P C-4\end{array}$ & $\begin{array}{r}0 \\
10 \\
50 \\
100\end{array}$ & $\begin{array}{l}15.1 \\
15.0 \\
15.0 \\
15.0\end{array}$ & $\begin{array}{l}15.5 \\
15.4 \\
15.6 \\
15.4\end{array}$ & $\begin{array}{l}8.11 \\
8.16 \\
8.14 \\
8.12\end{array}$ & $\begin{array}{l}8.27 \\
8.25 \\
8.25 \\
8.26\end{array}$ & $\begin{array}{l}7.4 \\
7.4 \\
7.4 \\
7.3\end{array}$ & $\begin{array}{l}8.4 \\
8.1 \\
8.3 \\
8.4\end{array}$ & $\begin{array}{l}30.0 \\
30.0 \\
30.0 \\
30.0\end{array}$ & $\begin{array}{l}32.0 \\
31.0 \\
31.5 \\
31.0\end{array}$ \\
\hline $\begin{array}{l}P C-5 \\
P C-5 \\
P C-5 \\
P C-5\end{array}$ & $\begin{array}{r}0 \\
10 \\
50 \\
100\end{array}$ & $\begin{array}{l}15.0 \\
15.0 \\
15.1 \\
15.0\end{array}$ & $\begin{array}{l}15.5 \\
15.5 \\
15.7 \\
15.4\end{array}$ & $\begin{array}{l}8.15 \\
8.16 \\
8.15 \\
8.15\end{array}$ & $\begin{array}{l}8.27 \\
8.26 \\
8.26 \\
8.29\end{array}$ & $\begin{array}{l}7.4 \\
7.3 \\
7.3 \\
7.4\end{array}$ & $\begin{array}{l}8.4 \\
8.2 \\
8.3 \\
8.3\end{array}$ & $\begin{array}{l}30.0 \\
30.0 \\
30.0 \\
30.0\end{array}$ & $\begin{array}{l}32.0 \\
32.0 \\
31.0 \\
32.0\end{array}$ \\
\hline $\begin{array}{l}\text { Reference } \\
\text { Reference } \\
\text { Reference } \\
\text { Reference }\end{array}$ & $\begin{array}{r}0 \\
10 \\
50 \\
100\end{array}$ & $\begin{array}{l}15.0 \\
15.1 \\
15.1 \\
15.1\end{array}$ & $\begin{array}{l}15.4 \\
15.4 \\
15.6 \\
15.9\end{array}$ & $\begin{array}{l}8.15 \\
8.14 \\
8.14 \\
8.09\end{array}$ & $\begin{array}{l}8.26 \\
8.25 \\
8.24 \\
8.22\end{array}$ & $\begin{array}{l}7.4 \\
7.5 \\
7.4 \\
7.5\end{array}$ & $\begin{array}{l}8.2 \\
8.1 \\
8.3 \\
8.5\end{array}$ & $\begin{array}{l}30.0 \\
30.0 \\
30.0 \\
30.0\end{array}$ & $\begin{array}{l}32.0 \\
32.0 \\
32.0 \\
32.0\end{array}$ \\
\hline
\end{tabular}


IABLEKK.3. Results for All Replicates in 72-Hour M. edulis Reference Toxicant Test, Panama City Harbor Project

\begin{tabular}{|c|c|c|c|c|c|c|c|c|}
\hline $\begin{array}{c}\text { Copper } \\
\text { Concentration }\end{array}$ & Repl lcate & $\begin{array}{c}\text { Normal } \\
\text { D-Shaped } \\
\text { Shell } \\
\end{array}$ & $\begin{array}{c}\text { Abnormal } \\
\text { with } \\
\text { Shell } \\
\end{array}$ & Other & $\begin{array}{l}\text { Percent } \\
\text { Normal (a) }\end{array}$ & $\begin{array}{l}\text { Mean } \\
\text { Percent } \\
\text { Normal }\end{array}$ & $\begin{array}{l}\text { Percent } \\
\text { Survival (a) } \\
\end{array}$ & $\begin{array}{l}\text { Mean } \\
\text { Percent } \\
\text { Survival } \\
\end{array}$ \\
\hline $\begin{array}{l}0 \\
0 \\
0\end{array}$ & $\begin{array}{l}1 \\
2 \\
3\end{array}$ & $\begin{array}{l}133 \\
262 \\
255\end{array}$ & $\begin{array}{l}0 \\
0 \\
1\end{array}$ & $\begin{array}{r}8 \\
28 \\
24\end{array}$ & $\begin{array}{l}54.29 \\
100.00(b) \\
100.00\end{array}$ & 84.76 & $\begin{array}{l}57.55(b) \\
100.00(b) \\
100.00(b)\end{array}$ & 85.85 \\
\hline $\begin{array}{l}2.9 \\
2.9 \\
2.9\end{array}$ & $\begin{array}{l}1 \\
2 \\
3\end{array}$ & $\begin{array}{l}263 \\
233 \\
209\end{array}$ & $\begin{array}{l}0 \\
1 \\
0\end{array}$ & $\begin{array}{l}17 \\
13 \\
19\end{array}$ & $\begin{array}{l}100.00^{(b)} \\
95.10 \\
85.31\end{array}$ & 93.47 & $\begin{array}{l}100.00(\mathrm{~b}) \\
100.00^{(\mathrm{b})} \\
93.06\end{array}$ & 97.69 \\
\hline $\begin{array}{l}9.0 \\
9.0 \\
9.0\end{array}$ & $\begin{array}{l}1 \\
2 \\
3\end{array}$ & $\begin{array}{l}237 \\
194 \\
210\end{array}$ & $\begin{array}{l}5 \\
1 \\
2\end{array}$ & $\begin{array}{l}29 \\
33 \\
54\end{array}$ & $\begin{array}{l}96.73 \\
79.18 \\
85.71\end{array}$ & 87.21 & $\begin{array}{l}100.00^{(b)} \\
93.06 \\
100.00^{(b)}\end{array}$ & 97.69 \\
\hline $\begin{array}{l}30.0 \\
30.0 \\
30.0\end{array}$ & $\begin{array}{l}1 \\
2 \\
3\end{array}$ & $\begin{array}{l}4 \\
0 \\
0\end{array}$ & $\begin{array}{l}0 \\
0 \\
0\end{array}$ & $\begin{array}{l}2 \\
5 \\
4\end{array}$ & $\begin{array}{l}1.63 \\
0.00 \\
0.00\end{array}$ & 0.54 & $\begin{array}{l}2.45 \\
2.04 \\
1.63\end{array}$ & 2.04 \\
\hline $\begin{array}{l}100.0 \\
100.0 \\
100.0\end{array}$ & $\begin{array}{l}1 \\
2 \\
3\end{array}$ & $\begin{array}{l}0 \\
0 \\
1\end{array}$ & $\begin{array}{l}0 \\
0 \\
0\end{array}$ & $\begin{array}{l}0 \\
0 \\
5\end{array}$ & $\begin{array}{l}0.00 \\
0.00 \\
0.41\end{array}$ & 0.14 & $\begin{array}{l}0.00 \\
0.00 \\
2.45\end{array}$ & 0.82 \\
\hline
\end{tabular}

(a) Percent normal and percent survival based on stocking density (average of multicell larvae) of 245 larvae per $10 \mathrm{~mL}$.

(b) A percent survival of 100.00 was used when the number surviving was greater than the stocking density. 
IABLE K.4. Water Quality Summary for 72-Hour M. edulis Reference Toxicant Test, Panama City Harbor Project

\begin{tabular}{|c|c|c|c|c|c|c|c|c|}
\hline \multirow{2}{*}{$\begin{array}{c}\text { Copper } \\
\text { Concentration } \\
(1 \mathrm{~g} / \mathrm{L})\end{array}$} & \multicolumn{2}{|c|}{$\begin{array}{c}\text { Temperature } \\
\left({ }^{\circ} \mathrm{C}\right)\end{array}$} & \multicolumn{2}{|c|}{$\mathrm{pH}$} & \multicolumn{2}{|c|}{$\begin{array}{l}\text { Dissolved } \\
\text { Oxygen } \\
\text { (ma/h) }\end{array}$} & \multicolumn{2}{|c|}{$\begin{array}{c}\text { Salinity } \\
(0 / 00)\end{array}$} \\
\hline & Min & Max & Min & Max & Min & Max & Min & $\operatorname{Max}$ \\
\hline $\begin{array}{l}\text { Acceptable } \\
\text { Range }\end{array}$ & 14.0 & 18.0 & 7.30 & 8.30 & & & 28.0 & 32.0 \\
\hline $\begin{array}{r}0.0 \\
2.9 \\
9.0 \\
30.0 \\
100.0\end{array}$ & $\begin{array}{l}15.0 \\
15.0 \\
15.1 \\
15.0 \\
15.0\end{array}$ & $\begin{array}{l}15.3 \\
15.3 \\
15.3 \\
15.3 \\
15.2\end{array}$ & $\begin{array}{l}8.11 \\
8.14 \\
8.14 \\
8.08 \\
8.14\end{array}$ & $\begin{array}{l}8.23 \\
8.17 \\
8.22 \\
8.19 \\
8.20\end{array}$ & $\begin{array}{l}7.5 \\
7.6 \\
7.6 \\
7.2 \\
7.6\end{array}$ & $\begin{array}{l}8.3 \\
8.3 \\
8.2 \\
8.0 \\
8.3\end{array}$ & $\begin{array}{l}30.0 \\
30.0 \\
30.0 \\
30.0 \\
30.0\end{array}$ & $\begin{array}{l}31.0 \\
31.0 \\
31.0 \\
31.0 \\
31.0\end{array}$ \\
\hline
\end{tabular}




\section{APPENDIX L}

M. NASUTA TISSUE CHEMISTRY

AND QUALITY CONTROL DATA 
QA/QC SUMMARY

PROGRAM:

PARAMETER:

LABORATORY:

MATRIX:
Panama Clty Harbor Program

Polynuclear Aromatic Hydrocarbons (PAHs)

Battelle Ocean Sclences, Duxbury, Massachusetts

M. nasuta Tissue

\section{QANC DATA QUALITY OBJECTIVES

\begin{tabular}{ccccc}
$\begin{array}{c}\text { Reference } \\
\text { Method }\end{array}$ & $\begin{array}{c}\text { Range of } \\
\text { Recovery }\end{array}$ & $\begin{array}{c}\text { SRM } \\
\text { Accuracy }\end{array}$ & $\begin{array}{c}\text { Relative } \\
\text { Preclslon }\end{array}$ & $\begin{array}{c}\text { Detection } \\
\text { Limit (wet wt) }\end{array}$ \\
\hline EPA Method $8270(1986 a)$ & $40-120 \%$ & $\leq 30 \%$ & $\leq 30 \%$ & $30 \mu \mathrm{g} / \mathrm{kg}$
\end{tabular}

HOLDING TIMES All samples were stored frozen $\left(-20^{\circ} \mathrm{C}\right)$ in sealed containers until ready for extraction. The tissue samples were extracted within 2 months of receipt at the laboratory and were analyzed within the 40-day holding period.

DETECTION LIMITS The achieved detection limits for PAHs were all well below the target detection limits.

METHOD BLANKS The four method blanks analyzed with the samples were contaminated in at least one of the blanks, by all but one of the low-molecular-weight PAHs and all but three of the high-molecular-weight PAHs. The data associated with these blanks were flagged with a "B" If the amount in the blank was $>1 / 5$ the target detection limit.

MATRIX SPIKES The recovery of target PAHs in the matrix spikes ranged from $43 \%$ to $151 \%$. Seven of the 29 low-molecular-weight PAH matrix spike recoveries ranged from $121 \%$ to $125 \%$. One of the matrix spike recoveries of naphthalene could not be calculated due to the elevated concentration of naphthalene in the sample. Twenty-eight of the 50 high-molecular-weight PAH matrix spike recoveries ranged from $121 \%$ to $151 \%$. The matrix spike recoveries of PC-1 COMP MS and MSD sample were all outside the $40 \%$ to $120 \%$ acceptable range, but precision between the matrix spike recoveries (RPD) was $\leq 10 \%$.

\section{SRMs}

The standard reference material NIST 1974 was analyzed with the PAH samples. The percent differences of certifled PAHs in the tissue SRMs were acceptable in 22 of the 32 reported SRM values. 
REPLICATES

SURROQATES
Precision was measured by relative standard deviation (RSD) between triplicates. All but three of the low-molecular-weight PAH calculable RSD values exceeded the $30 \%$ goal. These elevated RSD values ranged from $50 \%$ to $164 \%$, generally due to one of the replicates being suspect or associated with contamination from the blank sample. Seven of the $25 \mathrm{high}$-molecular-welght PAH calculable RSD values exceeded the $30 \% \mathrm{goal}$ and ranged from $34 \%$ to $109 \%$. These elevated RSD values were generally due to one of the replicates being suspect or several of the replicates being detected below the target detection 11 mit.

Three surrogate compounds were analyzed with the samples: naphthalene- $d_{8}$, acenaph thene- $d_{10}$, and benzo(a)pyrene-d $d_{12}$. The recoveries of the surrogate internal standard (SIS) compound for 32 of the 144 tissue samples were outside the $40 \%$ to $120 \%$ acceptable range.

The individual replicate tissue samples analyzed for PAHs, PCBs, and chlorinated pesticides in the M. nasuta tissues were contaminated in the analytical laboratory during analysis. Existing leftover uncontaminated tissue samples were combined into a single composite for each sediment treatment and reanalyzed. The composite and original data are presented in Appendix $L$. 


\section{QA/QC SUMMARY}

PROQRAM:

PARAMETER:

LABORATORY:

MATRIX:

\section{Panama Clty Harbor Program}

Phenols, Substituted Phenols, and Phthalate Esters

Battelle Ocean Sciences, Duxbury, Massachuselts

M. nasuta Tissue

\section{QANC DATA QUALITY OBJECTIVES Reference Method}

\section{Phenols \\ Phthalate Esters EPA Method 8270(1986a) EPA Method 8270}

\section{Range of SRM Recovery Accuracy}

Relatlve Detection Rrecislon uimit (wet wit)
HOLDING TIMES

DETECTION LIMITS

METHOD BLANKS

MATRIX SPIKES
All samples were stored frozen $\left(-20^{\circ} \mathrm{C}\right)$ in sealed containers untll ready for extraction. The tissue samples were extracted within 2 months of receipt at the laboratory and were analyzed within the 40-day holding period.

The samples analyzed for phenols and phthalate esters were slightly elevated above the target detection limits. These elevations do not present a problem, due to all but two samples having concentrations of phenols or phthalate esters elther undetected or detected below the method detection limit.

The method blanks analyzed with the samples had concentrations of phenols and phthalate esters either undetected or detected below the method detection limit; therefore, no correctlve action was taken.

Matrix spike recovery criteria for phenols and phthalate esters in tissues have not been established by the EPA. This may be due to the difflculty involved with recovering phenols both from the extraction procedures as well as from the gas chromatograph. Fifteen of the 43 matrix spike recoveries ranged from $121 \%$ to $1133 \%$, exceeding the target range of $40 \%$ to $120 \%$ and were gerierally due to relatively high concentrations of phenols and phthalate esters that were spiked into the samples.

NA

Precision was measured by relative standard devlation (RSDs) between triplicates. The concentrations of phenols and phthalate esters were either undetected or detected below the MDL; thus the RSDs could not be calculated. 
SURROQATES

NA Not applicable.
The surrogate compound 2-fluorophenol was analyzed with the samples. The recovery of 7 of the 48 surrogate internal standard (SIS) compounds 2-fluorophenol ranged from $124 \%$ to $148 \%$ and from $2 \%$ to $8 \%$, exceeding the target range of $40 \%$ to $120 \%$. 


\section{QA/OC SUMMARY}

PROQRAM:

PARAMETER:

LABORATOAY:

MATRIX:
Panama Cly Harbor Program

Chlorinated Pesticides and Polychlorinated Biphenyls (PCBs)

Battelle Ocean Sciences, Duxbury, Massachusetts

M. nasuta Tissue

QANOC DATA QUALITY OBJECTIVES

\begin{tabular}{|c|c|c|c|c|}
\hline $\begin{array}{l}\text { Reforence } \\
\text { Methed }\end{array}$ & $\begin{array}{l}\text { Range of } \\
\text { Becovery }\end{array}$ & $\begin{array}{c}\text { SRM } \\
\text { Acouracy }\end{array}$ & $\begin{array}{l}\text { Relattive } \\
\text { Preclalon }\end{array}$ & $\begin{array}{l}\text { Detectlon } \\
\text { Limil (wet wt) }\end{array}$ \\
\hline PA Method 808 & $40.120 \%$ & NA & $\$ 30 \%$ & $10.30 \mu \mathrm{g} / \mathrm{kg}$ \\
\hline
\end{tabular}

HOLDING TIMES

All samples were stored frozen $\left(-20^{\circ} \mathrm{C}\right)$ in sealed contalners untll ready for extraction. The tissue samples were extracted within 2 months of recelpt at the laboratory and were analyzed within 40 days.

DETECTION LIMITS

METHOD BLANKS

MATRIX SPIKES

SRMB

REPLICATES

SURROGATES

NA Not applicable.
The achleved detection limits for pesticides and PCBs were all well below the target detection limits.

The method blanks analyzed with the composite samples and Batches 3 and 4 of the individual replicate samples were free of contamination. The method blank analyzed with the Batch 5 samples was slightly contaminated with dieldrin, 4, ' - DDD, 4, $4^{\prime} \cdot$-DDE, and 4,4'-DDT. The amount of 4,4'-DDD and 4,4'-DDT in the method blank was >i/5 the target detection limit; therefore, the data assoclated with this batch were flagged with a "B."

Recoverles of 17 of the 54 matrlx splkes were outside of the $40 \%$ to $120 \%$ acceptable range. These 17 matrix spike recoverles ranged from $121 \%$ to $246 \%$ and from $4 \%$ to $9 \%$, most due to concentrations of pestlcides and PCBs in the samples that were either undetected or detected below the target detection limit.

NA

Precision was measured by relative standard deviation (RSDs) between triplicates. Four of the calculable 19 RSD values exceeded the relative precision goal of $30 \%$, ranging from $35 \%$ to $64 \%$ and generally due to concentrations of pesticides and PCBs detected below the target detection limit.

Three surrogate compounds were analyzed with the samples: DBOFB, $\mathrm{Cl}_{B}(103)$, and $\mathrm{Cl}_{5}(112)$. The recovery of the surrogate internal standard (SIS) compounds was acceptable, with the exception of 12 of the 120 tissue samples. 


\section{QAVQC SUMMARY}

PROGRAM:

PARAMETER:

LABORATORY: MATAIX:
Panama Clty Harbor Program

Metals

Battelle/Marine Sclences Laboratory, Sequim, Washington

M. nasuta Tissues

QANON DATA QUALITY OBJECTIVES

\begin{tabular}{|c|c|c|c|c|c|}
\hline & $\begin{array}{c}\text { Reference } \\
\text { Method }\end{array}$ & $\begin{array}{l}\text { Range of } \\
\text { Recovery }\end{array}$ & $\begin{array}{l}\text { SRM } \\
\text { gouracy }\end{array}$ & $\begin{array}{l}\text { Relative } \\
\text { Preclalon }\end{array}$ & $\begin{array}{l}\text { Detection } \\
\text { Mimit (dry wi) }\end{array}$ \\
\hline $\begin{array}{l}\text { Antimony } \\
\text { Arsenio } \\
\text { Beryllium } \\
\text { Cadmlum } \\
\text { Chromium } \\
\text { Copper } \\
\text { Lead } \\
\text { Mercury } \\
\text { Nickel } \\
\text { Selenlum } \\
\text { Silver } \\
\text { Thallum } \\
\text { Zinc }\end{array}$ & $\begin{array}{l}\text { ICP/MS (EPA 1990b) } \\
\text { XRF (PNL SOP) } \\
\text { ICP/MS } \\
\text { ICP/MS } \\
\text { ICP/MS } \\
\text { ICP/MS } \\
\text { GFAA (EPA 1986a) } \\
\text { CVAA (Bloom Crecellus 1984) } \\
\text { ICP/MS } \\
\text { XPF } \\
\text { ICP/MS } \\
\text { ICP/MS } \\
\text { XRF }\end{array}$ & $\begin{array}{l}75-125 \\
75-125 \\
75-125 \\
75-125 \\
75-125 \\
75-125 \\
75-125 \\
75-125 \\
75-125 \\
75-125 \\
75-125 \\
75-125 \\
75-125\end{array}$ & $\begin{array}{l}\leq 30 \% \\
\leq 30 \% \\
\leq 30 \% \\
\leq 30 \% \\
\leq 30 \% \\
\leq 30 \% \\
\leq 30 \% \\
\leq 30 \% \\
\leq 30 \% \\
\leq 30 \% \\
\leq 30 \% \\
\leq 30 \% \\
\leq 30 \%\end{array}$ & $\begin{array}{l}\leq 20 \% \\
\leq 20 \% \\
\leq 20 \% \\
\leq 20 \% \\
\leq 20 \% \\
\leq 20 \% \\
\leq 20 \% \\
\leq 20 \% \\
\leq 20 \% \\
\leq 20 \% \\
\leq 20 \% \\
\leq 20 \% \\
\leq 20 \%\end{array}$ & $\begin{array}{l}0.1 \mathrm{mg} / \mathrm{kg} \\
0.1 \mathrm{mg} / \mathrm{kg} \\
0.2 \mathrm{mg} / \mathrm{kg} \\
0.1 \mathrm{mgkg} \\
0.6 \mathrm{mg} / \mathrm{kg} \\
0.1 \mathrm{mg} / \mathrm{kg} \\
0.1 \mathrm{mgkg} \\
0.01 \mathrm{mg} / \mathrm{kg} \\
1.0 \mathrm{mgkg} \\
0.3 \mathrm{mgkg} \\
0.1 \mathrm{mg} / \mathrm{kg} \\
0.1 \mathrm{mgkg} \\
0.3 \mathrm{mg} / \mathrm{kg}\end{array}$ \\
\hline
\end{tabular}

HOLDING TIMES

Recommended holding times for metals in tissues based on the 1991 Implementation Manual (EPAUSACE 1991) are 6 months $\left(<20^{\circ} \mathrm{C}\right.$ ) for all metals, except $\mathrm{Hg}$ which is 28 days. After recelpt at MSL, $M$. nasuta tissue samples were held frozen and then freeze-dried and stored in sealed containers until ready for analysis.

DETECTION LIMITS

METHOD BLANKS

MATRIX SPIKES

SRMs
Achleved detection limits based on dry weight concentrations were lower than the target detection limits for all metals except As, $\mathrm{Hg}, \mathrm{Se}$, and $\mathrm{Zn}$. These four metals were detected in all the tissue samples at concentrations above the target detection limits. Sample concentrations of these four metals were well above the achieved detection limits; therefore, no corrective action was taken.

The method blank analyzed for metals had low levels of $\mathrm{Ag}, \mathrm{Cd}, \mathrm{Cr}$, $\mathrm{Cu}, \mathrm{Hg}, \mathrm{Pb}$, and $\mathrm{Sb}$. The data assoclated with these blanks were corrected for the amount in the method blank.

Recovery of 12 of the 50 calculable matrix splkes were outside the $75 \%$ to $125 \%$ range, ranging from $126 \%$ to $182 \%$, with one matrix spike recovery at $68 \%$. Nine of these 12 exceedences were matrix spikes of $\mathrm{Be}$ and $\mathrm{TI}$.

The oyster tissue standard reference material (SRM) 1566a was analyzed for all the metals. The values were all within the acceptable limit of $30 \%$. 

Deviation (RSDs). Two of the calculable 42 RSD values were $35 \%$ and $52 \%$, exceeding the target limit of $20 \%$. 


\section{QA/QC SUMMARY}

PROGRAM:

PARAMETER:

LABORATORY:

MATRIX:
Panama City Harbor Program

Butyltins

Battelle/Marine Sciences Laboratory, Sequim, Washington

M. nasuta Tissues

QAVC JATA QUALITY OBJECTIVES

\begin{tabular}{|c|c|}
\hline & $\begin{array}{c}\text { Reference } \\
\text { Method }\end{array}$ \\
\hline $\begin{array}{l}\text { ibutyltin } \\
\text { butyltin } \\
\text { onobutyltin }\end{array}$ & $\begin{array}{l}\text { Unger et al. } 1986 \\
\text { Unger et al. } 1986 \\
\text { Unger et al. } 1986\end{array}$ \\
\hline
\end{tabular}

\section{Range of Recovery}

40-120

40-120

40-120

\section{SRM \\ Accuracy}

NA

NA

NA

\section{Relative Precision}

$$
\begin{aligned}
& \leq 30 \% \\
& \leq 30 \% \\
& \leq 30 \%
\end{aligned}
$$

Detectlon Limit (wet wt)

$10 \mu \mathrm{g} / \mathrm{kg}$ $10 \mu \mathrm{g} / \mathrm{kg}$ $10 \mu \mathrm{g} / \mathrm{kg}$

HOLDING TIMES Samples were extracted within the 14-day holding period and analyzed within $\mathbf{4 0}$ days after extraction.

DETECTION LIMITS The detection limit of $10 \mu \mathrm{g} / \mathrm{kg}$ was met for all samples.

METHOD BLANKS The method blanks analyzed with the samples were free of contamination.

MATRIX SPIKES

Two of the four tributyltin matrix spike percent recovery values were slightly above (124\% and $147 \%$ ) the target range of $40 \%$ to $120 \%$. The matrix spike recoveries for monobutyltin ranged from $24 \%$ to $31 \%$ and were all below the target $Q C$ range. Low recoveries for monobutyltin are standard due to the ineffiency of the method used to extract this compound.

SRMs

NA

REPLICATES

Precision between triplicates was measured by Relative Standard Deviation (RSDs). There was at least one replicate that was undetected; therefore, no RSDs could be calculated.

\section{SURROGATES}

The surrogate internal standard (SIS) compound tripentyltin was analyzed with the samples. Two of the 42 percent recovery values were $39 \%$ and $126 \%$, and these values were outside the target range of $40 \%$ to $120 \%$.

NA Not applicable. 


\title{
QA/QC SUMMARY
}

\author{
PROGRAM: \\ Panama City Harbor Program \\ PARAMETER: \\ Dioxins \\ LABORATORY: Battelle Columbus Operations, Columbus, Ohio \\ MATRIX: \\ M. nasuta Tissue
}

\begin{tabular}{|c|c|c|c|c|}
\hline $\begin{array}{l}\text { Reference } \\
\text { Method }\end{array}$ & $\begin{array}{l}\text { Range of } \\
\text { Recovery }\end{array}$ & $\underset{\text { Accuracy }}{\text { SRM }}$ & $\begin{array}{l}\text { Relative } \\
\text { Precislon }\end{array}$ & $\begin{array}{c}\text { Detectlon } \\
\text { Limit (wet wt) }\end{array}$ \\
\hline EPA Method 8290 (1990a) & $40-120 \%$ & NA & $\leq 30 \%$ & $1.0 \mathrm{ng} / \mathrm{kg}$ \\
\hline
\end{tabular}

HOLDING TIMES All samples were extracted and analyzed within 30 days of sample receipt at the laboratory. Samples were stored frozen $\left(-20^{\circ} \mathrm{C}\right)$ until ready for analysis.

DETECTION LIMITS The target detection limit of $1.0 \mathrm{ng} / \mathrm{kg}$ wet weight for dioxin analysis was met for all samples except one compound, OCDD, with an achieved detection limit of $2.27 \mathrm{ng} / \mathrm{g}$ wet weight. The concentration found in the samples was detected above the target detection limit; therefore, no corrective action was taken.

METHOD BLANKS The method blank analyzed with the samples was undetected for all the dioxin congeners except for OCDD and OCDF, detected at $2.27 \mathrm{ng} / \mathrm{kg}$ and $0.24 \mathrm{ng} / \mathrm{kg}$, respectively. The concentrations of OCDD in the samples were all well above the achieved detection limit, and the concentrations of OCDF in the samples were all below the target detection limit; therefore, no corrective action was taken.

MATRIX SPIKES

Matrix spike recoveries for the dioxin analysis ranged from $41 \%$ to $114 \%$, within the $40 \%$ to $120 \%$ acceptable range as set in the QA/QC plan.

SRMs NA

REPLICATES Precision was measured by Relative Percent Difference (RPD) and I-STAT measurement between the percent recoveries of the matrix spike and matrix spike duplicate samples. All RPD values ranged from $0 \%$ to $26 \%$, which were well within the acceptable $30 \%$ limit.

SURROGATES Fifteen labeled compounds and one clean-up standard were spiked into the $M$. nasuta tissue samples to assess the surrogate percent recovery of the compounds. One of the 96 surrogate percent recoveries had a value of $35 \%$, which is outside the targeted $40 \%$ to $120 \%$ range. 
ADDITIONAL INFORMATION

NA Not applicable.
The hepta- and octa- dioxin and furan compounds are determined to be ubiquitous in the analytical laboratory; therefore, their presence in the $M$. nasuta tissues should not be a concern. 
IABLE L.1. Total Polynuclear Aromatic Hydrocarbon (PAH) Results, Wet Weight, in Tissue of M. nasuta, Panama City Harbor Project

Sediment

Ireatment

PC-1 COMP

$\mathrm{PC}-1$

$P C-1$

$P C-1$

$P C-1$

PC-1

$P C-1 A$ COMP

$P C-1 A$

$P C-1 A$

PC-1A Rep 1

PC-1A Rep 2

PC-1A Rep 3

PC- $1 A$

PC-1A

$P C-2$ COMP

$\mathrm{PC}-2$

$\mathrm{PC}-2$

$\mathrm{PC}-2$

$\mathrm{PC}-2$

PC-2

PC -4 COMP

PC- 4

PC- 4

$P C-4$

$P C-4$

$\mathrm{PC}-4$

PC-5 COMP

PC-5

PC-5

PC -5

PC -5

PC-5

Reference COMP

Reference

Reference

Reference Rep 1

Reference Rep 2

Reference Rep 3

Reference

Reference

PANAMA CITY HARBOR
Total Low Total High Molecular Molecular Total Replicate Batch Weight PAH Weight PAH PAH

$\begin{array}{rrrrr} & & 19 & 11 & 30 \\ 1 & 5 & 4 & 13 & 17 \\ 2 & 5 & 7 & 15 & 22 \\ 3 & 5 & 74 & 11 & 85 \\ 4 & 4 & 4 & 10 & 14 \\ 5 & 3 & 77 & 14 & 91\end{array}$

$\begin{array}{ll}1 & 5 \\ 2 & 4 \\ 3 & 4 \\ 3 & 4 \\ 3 & 4 \\ 4 & 4 \\ 5 & 5\end{array}$

9
4
47
9
11
118
96
4

1120

$10 \quad 14$

$14 \quad 61$

$15 \quad 24$

$14 \quad 25$

$15 \quad 133$

$13 \quad 109$

1216

$\begin{array}{rrr}8 & 8 & 16 \\ 5 & 9 & 14 \\ 95 & 12 & 107 \\ 81 & 11 & 92 \\ 5 & 10 & 15 \\ 102 & 11 & 113\end{array}$

$\begin{array}{rrr}3 & 7 & 10 \\ 53 & 9 & 62 \\ 5 & 10 & 15 \\ 219 & 11 & 230 \\ 82 & 10 & 92 \\ 230 & 14 & 244\end{array}$

$4 \quad 91 \quad 95$

7

173

9

64

283

101

67

108

240

$88 \quad 97$

$94 \quad 158$

$102 \quad 385$

10

38

85

293

6

155

147
15

45

93

318

18

15

166

158 
IABLE L.1. (contd)

Sediment

Ireatment

M. nasuta Background Rep 1

M. nasuta Background Rep 2

M. nasuta Background Rep 3

M. nasuta Control COMP

M. nasuta Control

M. nasuta Control

M. nasuta Control

M. nasuta Control

M. nasuta Control
Total Low Total High

Molecular Molecular

Replicate Batch Weight PAH Weight PAH PAH

$\begin{array}{rrrrr}1 & 5 & 6 & 17 & 23 \\ 2 & 5 & 18 & 17 & 35 \\ 3 & 5 & 7 & 17 & 24\end{array}$

$\begin{array}{ll}1 & 3 \\ 2 & 3 \\ 3 & 5 \\ 4 & 5 \\ 5 & 5\end{array}$

13

24

15

17

16

12

24
122
172
24
21
16




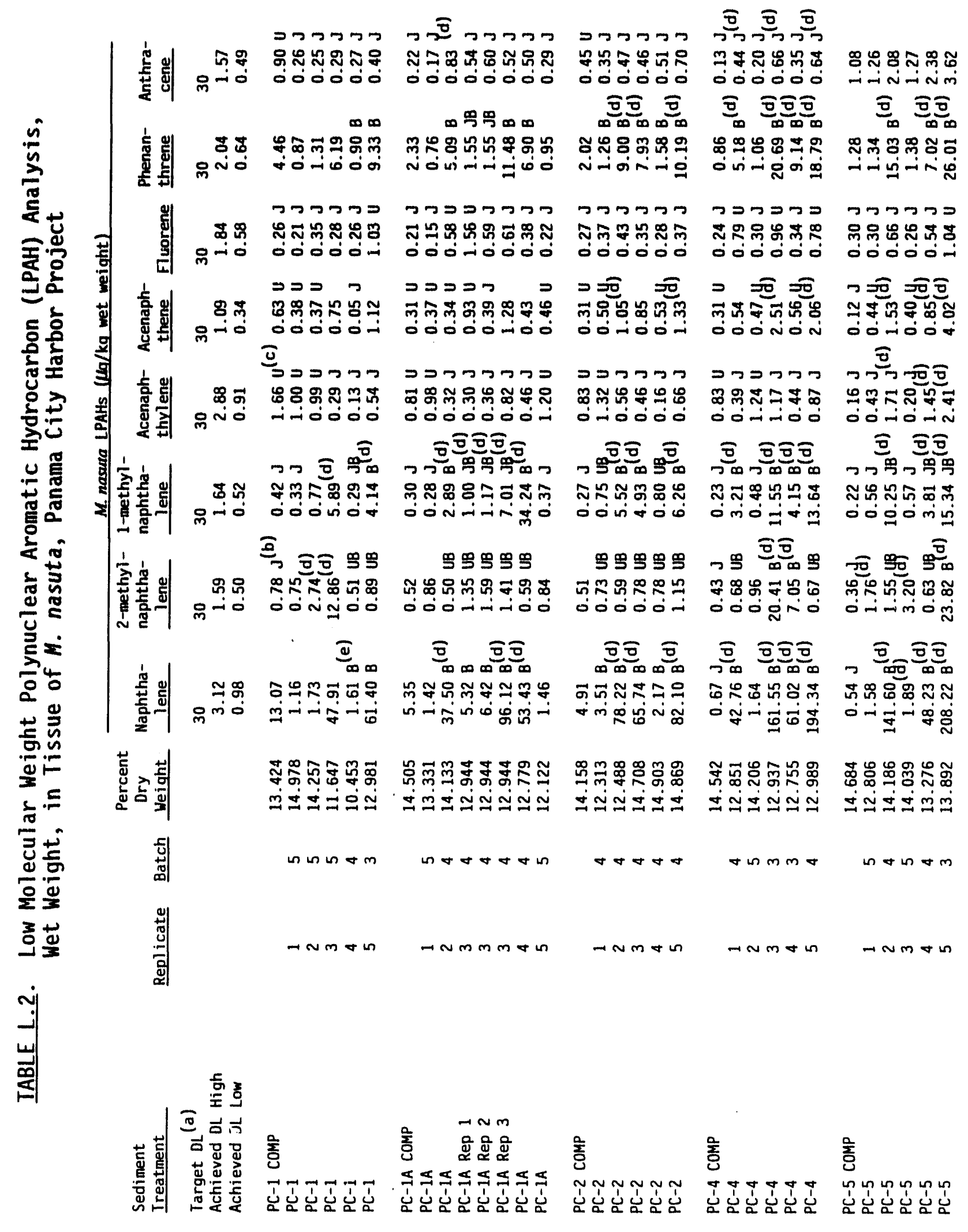




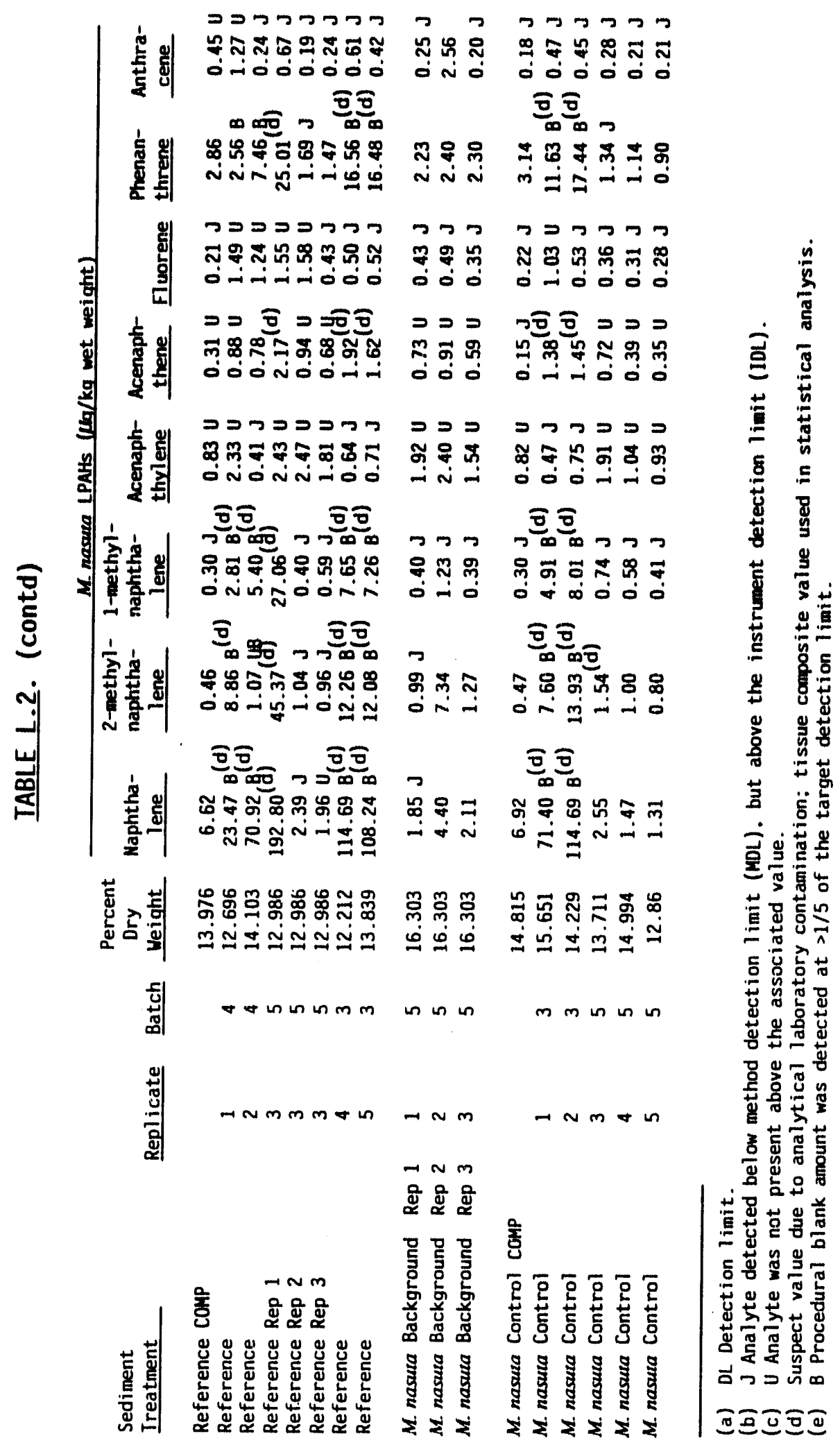




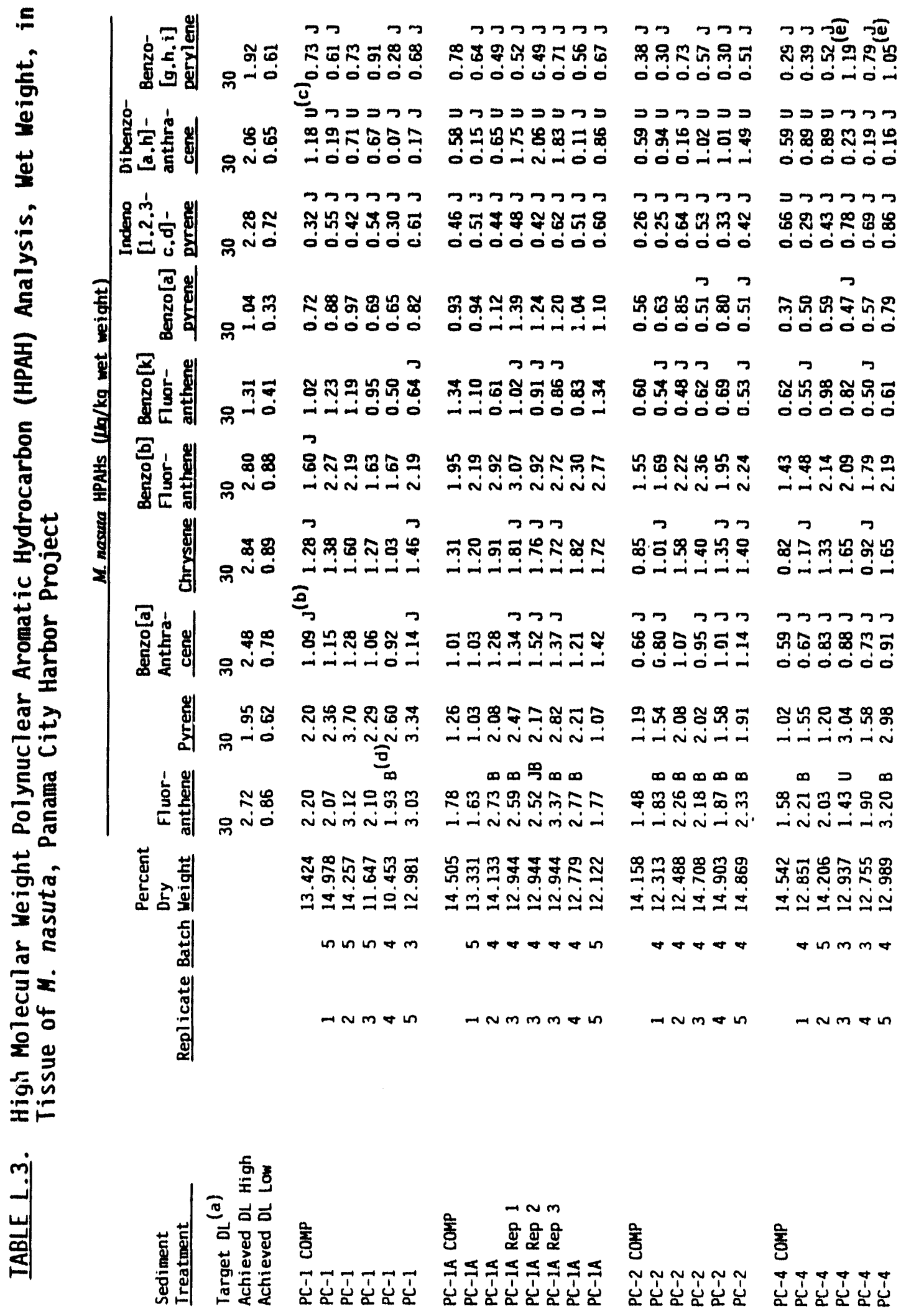

PANAMA CITY HARBOR

L. 5 


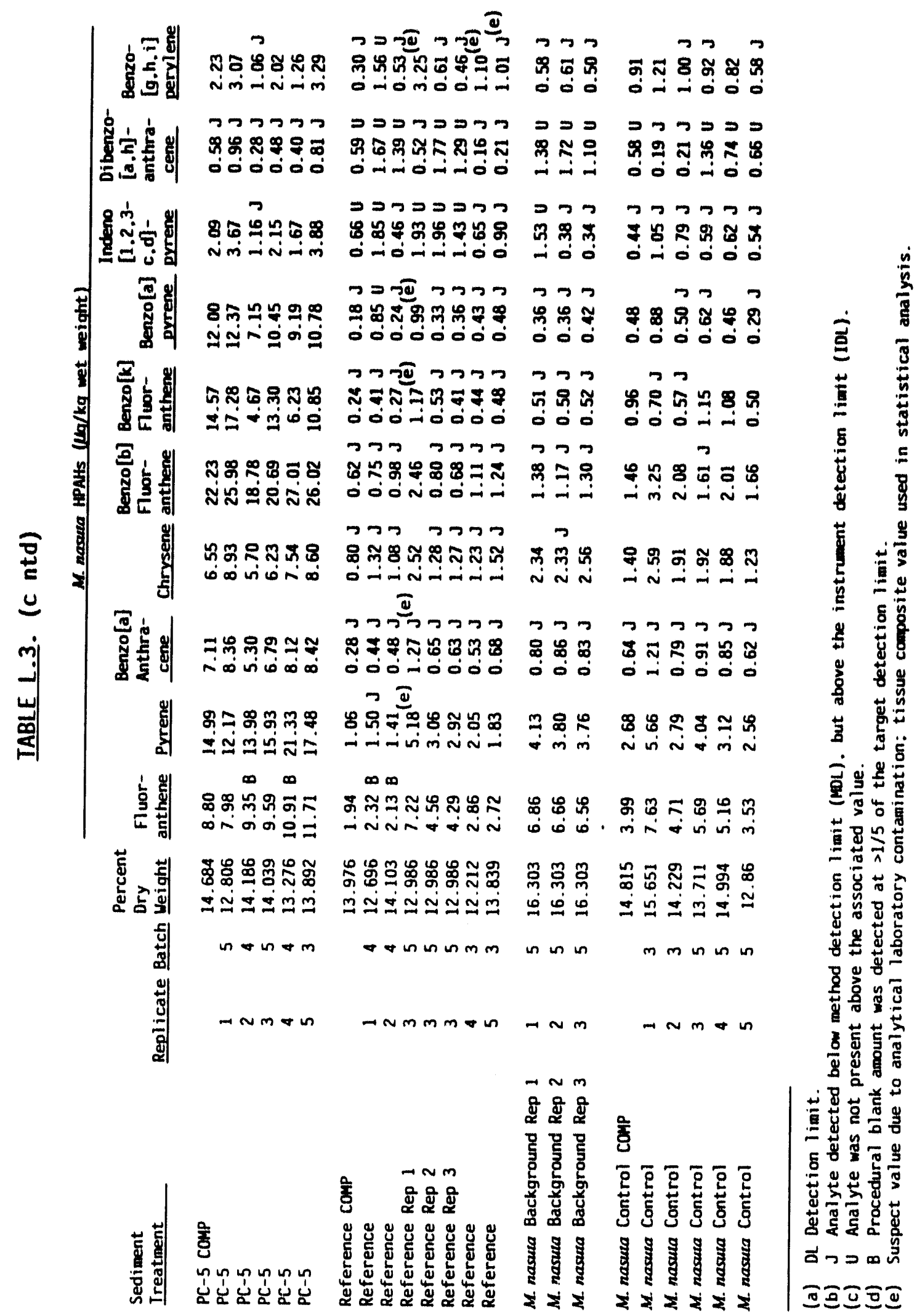


IABLELL4. Total Polynuclear Aromatic Hydrocarbon (PAH) Results, Dry Weight, in Tissue of M. nasuta, Panama City Harbor Project

Sediment

Ireatment

$P C-1$ COMP

$P C-1$

$P C-1$

$P C-1$

$P C-1$

$P C-1$

PC-1A COMP

$P C-1 A$

$P C-1 A$

PC-1A Rep 1

PC-1A Rep 2

PC-1A Rep 3

$P C-1 A$

$P C-1 A$

PC-2 COMP

$P C-2$

$P C-2$

$P C-2$

$P C-2$

$P C-2$

PC- 4 COMP

PC -4

$P C-4$

$P C-4$

$P C-4$

PC -4

PC - 5 COMP

$P C-5$

$P C-5$

$P C-5$

$P C-5$

$P C-5$

Reference COMP

Reference

Reference

Reference Rep 1

Reference Rep 2

Reference Rep 3

Reference

Reference
Total Low Total High Molecular Molecular Total

Replicate Batch Weight PAH Weight PAH PAH.

141

24

50

639

34

593

62
27

330

67

86

910

754

34

56

45

763

549

32

683

18

409

33

1689

647

1773

28

56

1219

62

484

2040

75
297

604

2257

44

28

1268

1065

$\begin{array}{rr}83 & 224 \\ 85 & 109 \\ 107 & 157 \\ 98 & 737 \\ 95 & 129 \\ 108 & 701\end{array}$

$\begin{array}{rr}75 & 136 \\ 78 & 105 \\ 96 & 426 \\ 113 & 180 \\ 108 & 194 \\ 119 & 1029 \\ 105 & 859 \\ 103 & 137\end{array}$

53

70

97

76

66

74

46

69

71

86

76

111

621

787

475

624

705

733

39

53

54

189

105

85

86

80
109

115

860

625

98

757

64

478

104

1775

723

1884

649

843

1694

686

1189

2773

114

350

658

2446

149

113

1354

1145

PANAMA CITY HARBOR

L.7 
IABLE L.4. (contd)

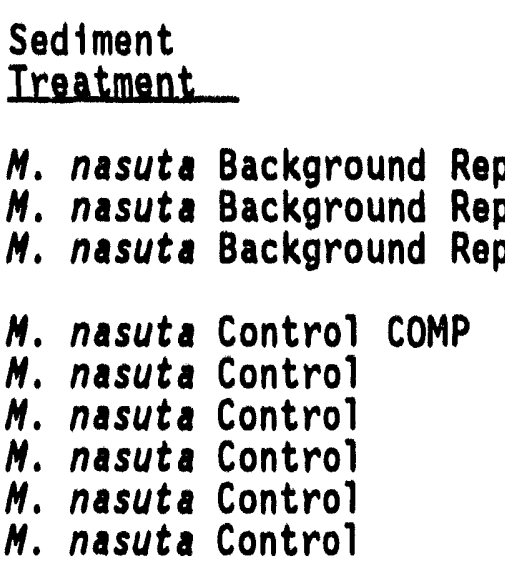

\begin{tabular}{|c|c|c|c|c|}
\hline Replicate & Batch & $\begin{array}{l}\text { Total Low } \\
\text { Molecular } \\
\text { Weiaht PAH }\end{array}$ & $\begin{array}{l}\text { Total High } \\
\text { Molecular } \\
\text { Welaht PAH }\end{array}$ & $\begin{array}{c}\text { Total } \\
\text { PAH } \\
\end{array}$ \\
\hline $\begin{array}{l}1 \\
2 \\
3\end{array}$ & $\begin{array}{l}5 \\
5 \\
5\end{array}$ & $\begin{array}{r}38 \\
113 \\
41\end{array}$ & $\begin{array}{l}104 \\
102 \\
103\end{array}$ & $\begin{array}{l}142 \\
215 \\
144\end{array}$ \\
\hline $\begin{array}{l}1 \\
2 \\
3 \\
4 \\
5\end{array}$ & $\begin{array}{l}3 \\
3 \\
5 \\
5 \\
5\end{array}$ & $\begin{array}{r}77 \\
625 \\
1105 \\
50 \\
31 \\
30\end{array}$ & $\begin{array}{r}88 \\
156 \\
108 \\
127 \\
107 \\
90\end{array}$ & $\begin{array}{r}165 \\
781 \\
1213 \\
177 \\
138 \\
120\end{array}$ \\
\hline
\end{tabular}




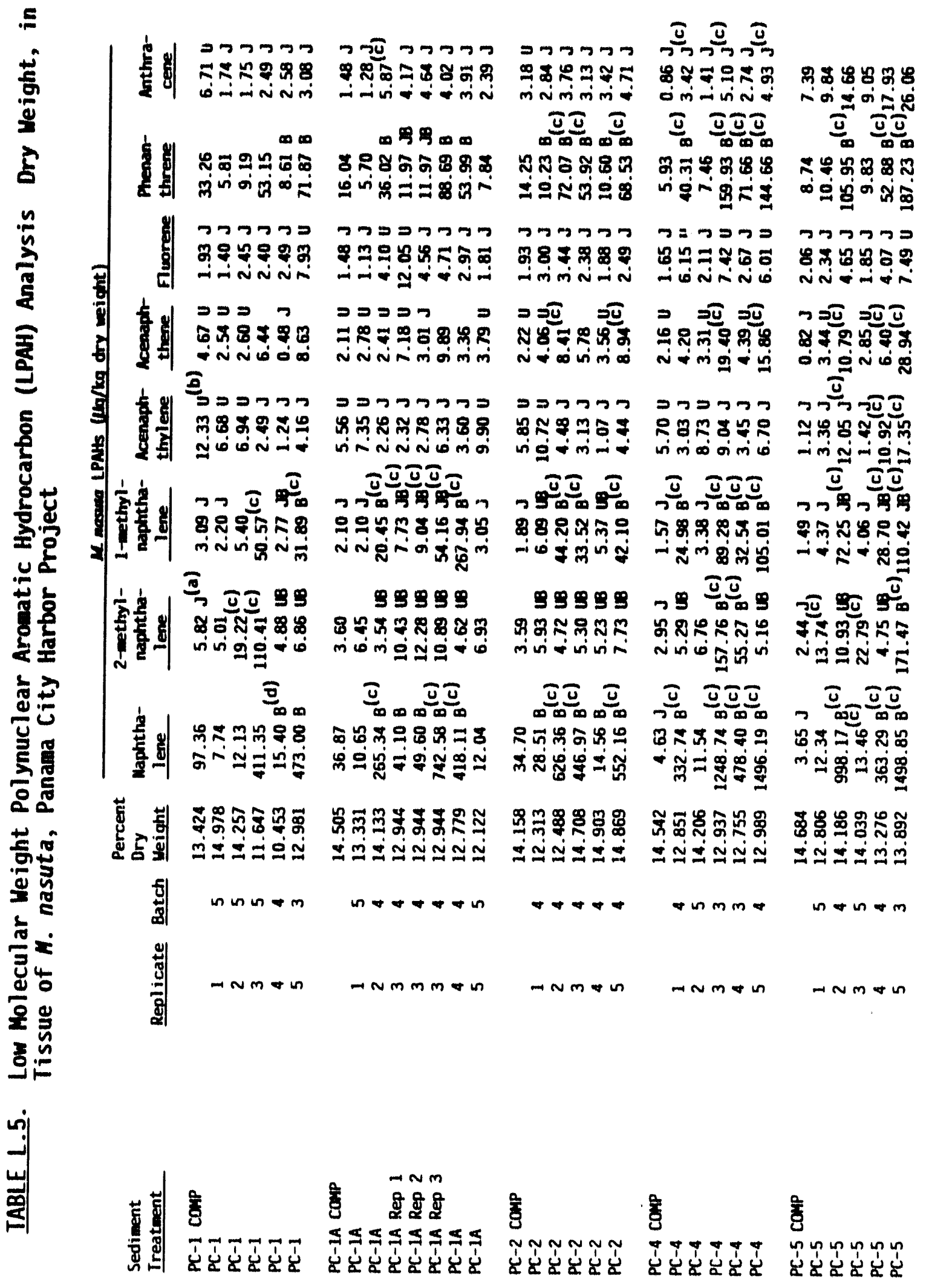

PANAMA CITY HARBOR L.9 


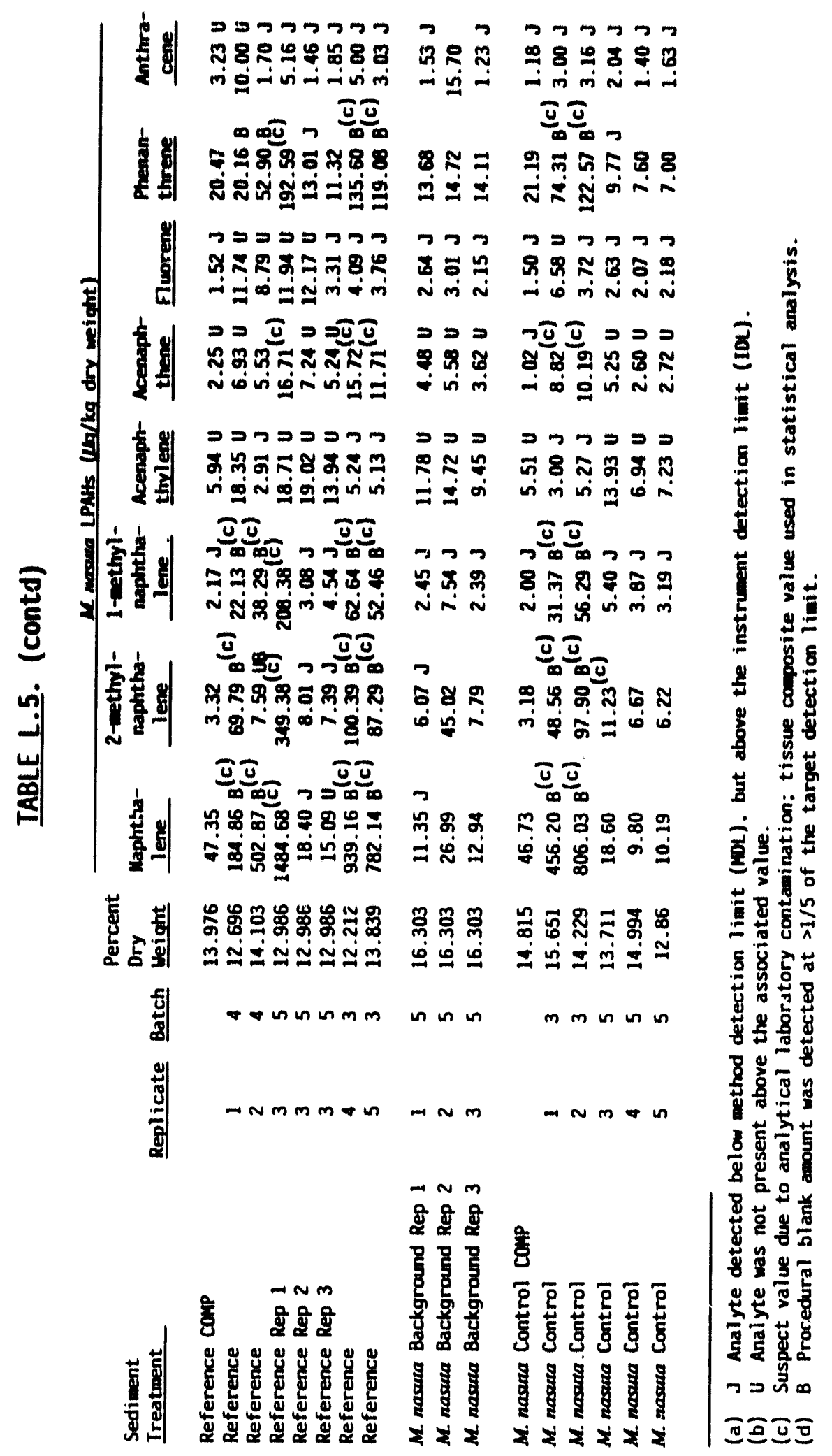




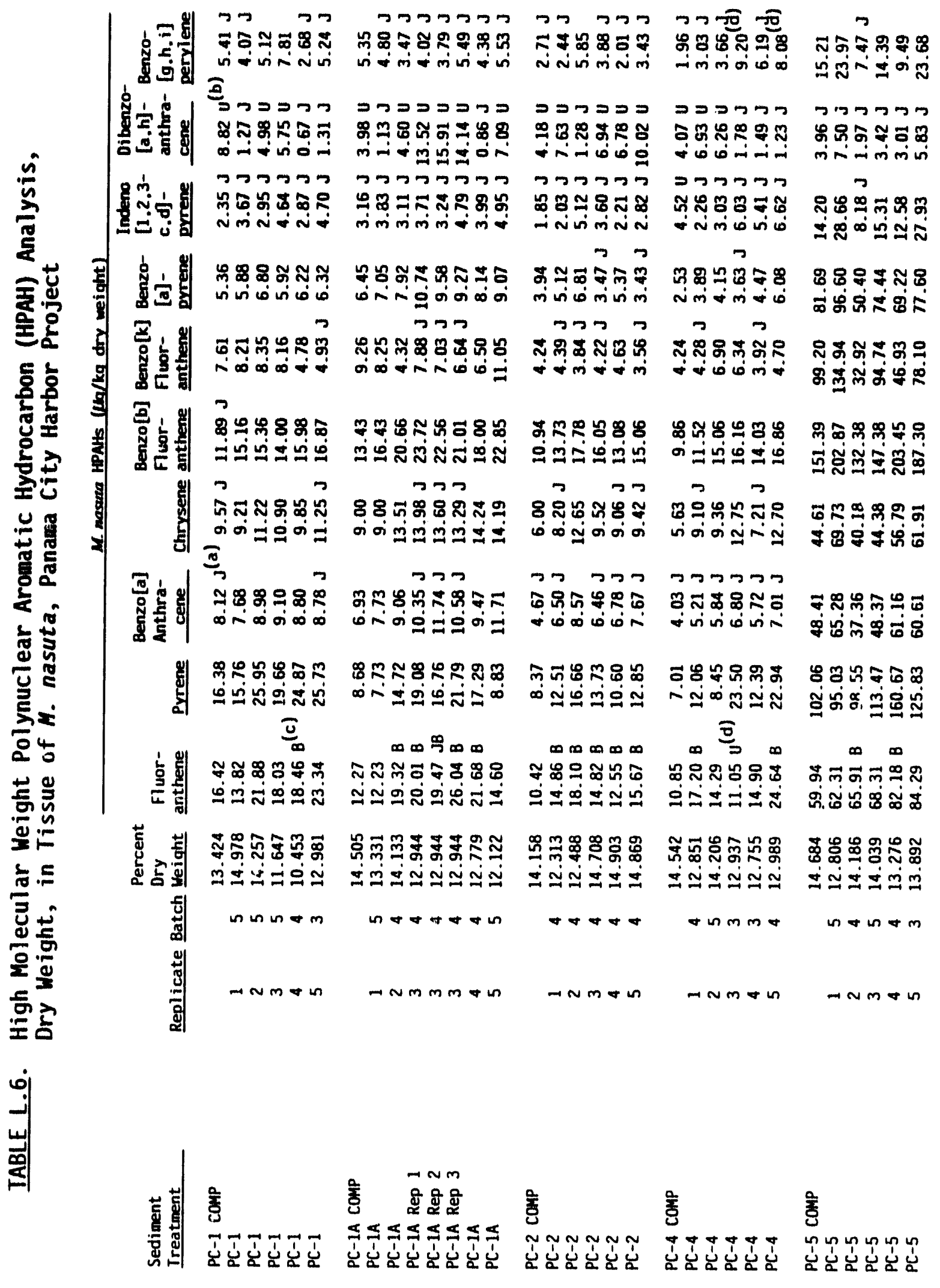




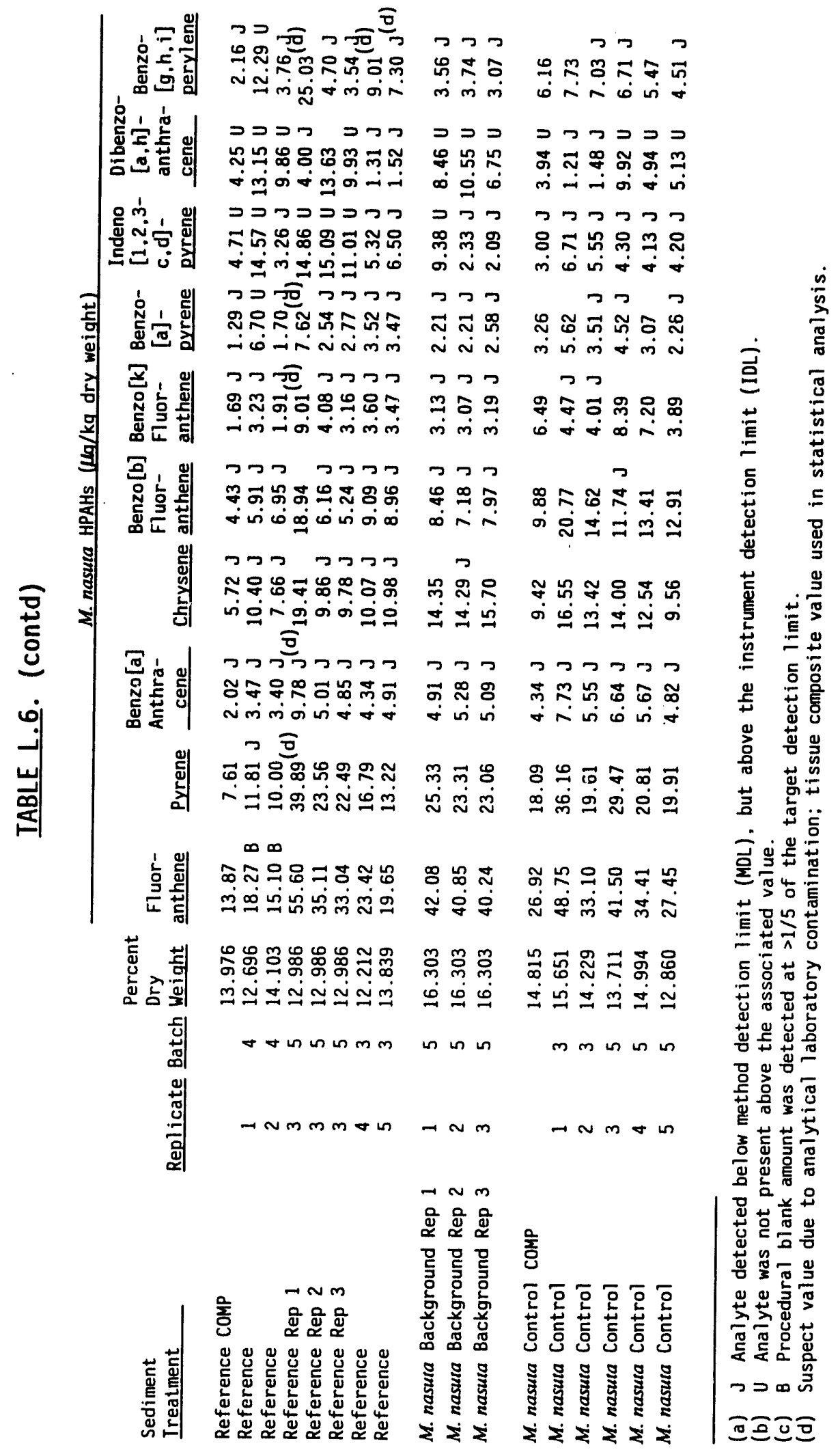

PANAMA CITY HARBOR

L. 12 


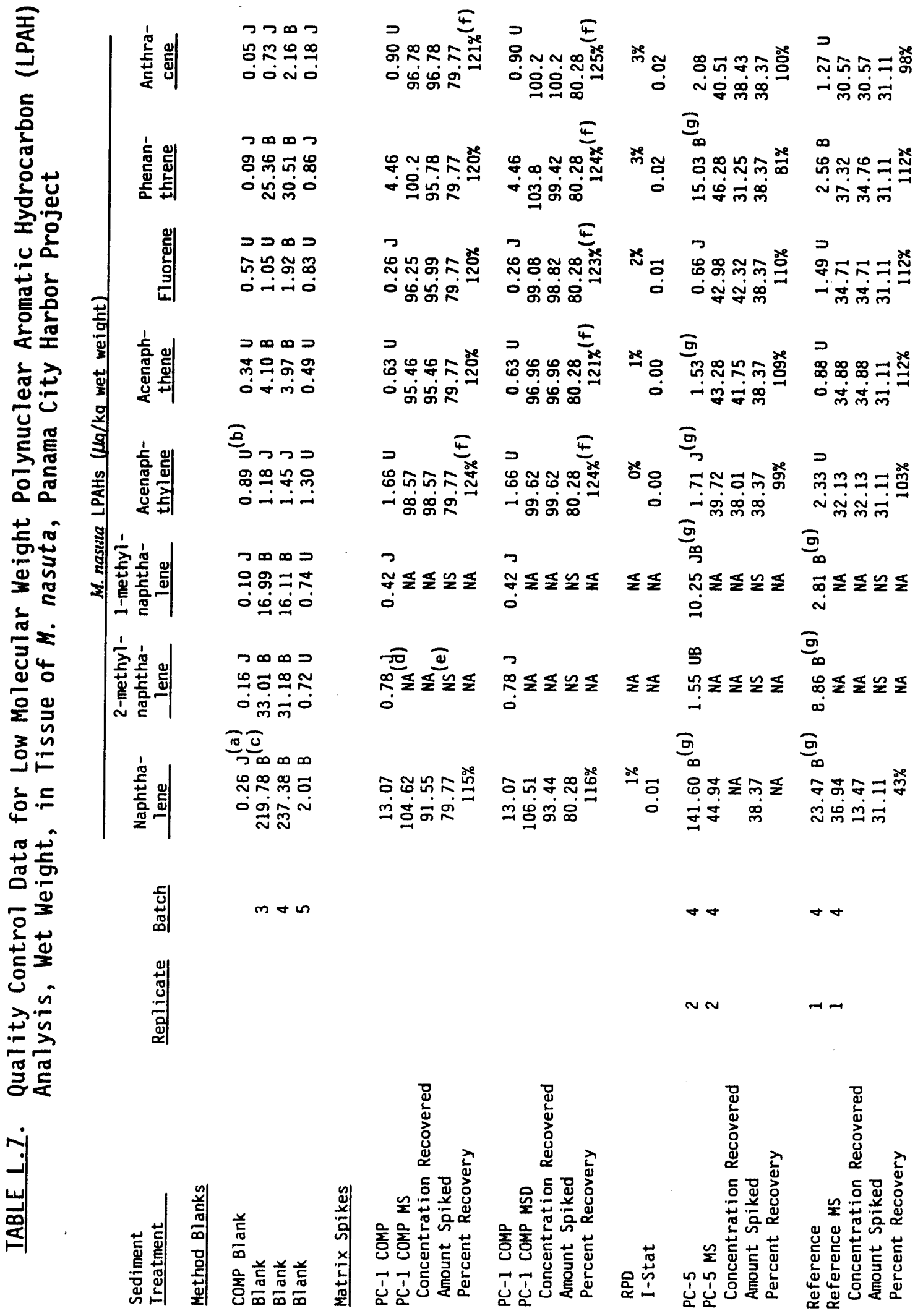




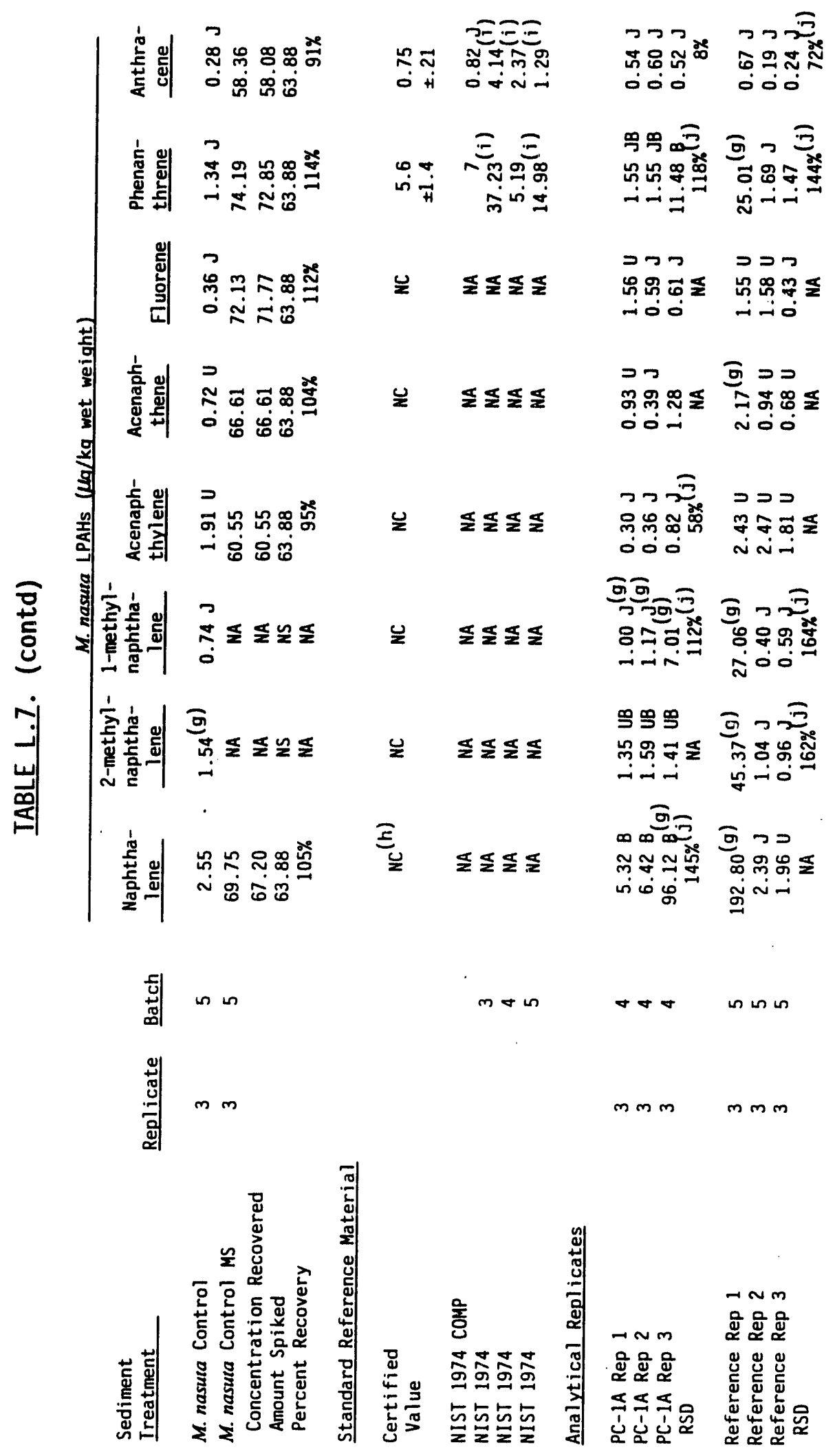

PANAMA CITY HARBOR

L. 14 


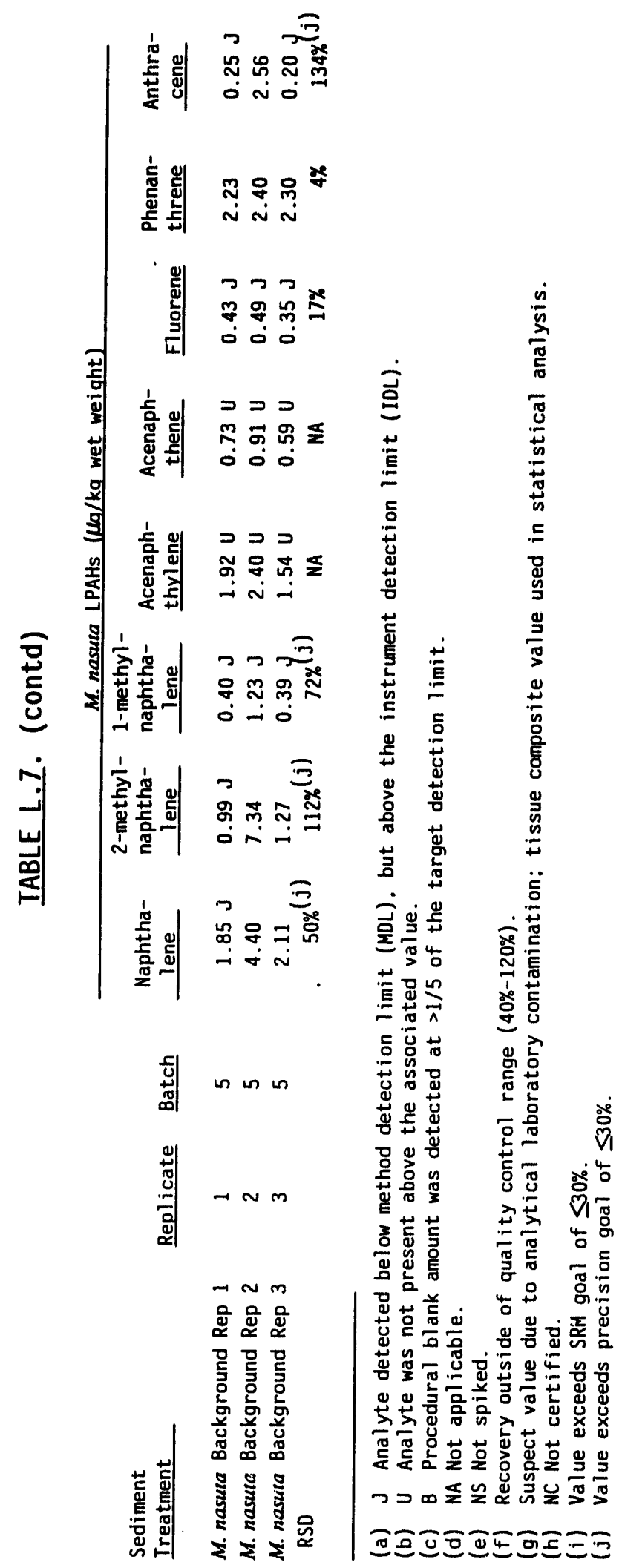

PANAMA CITY HARBOR 


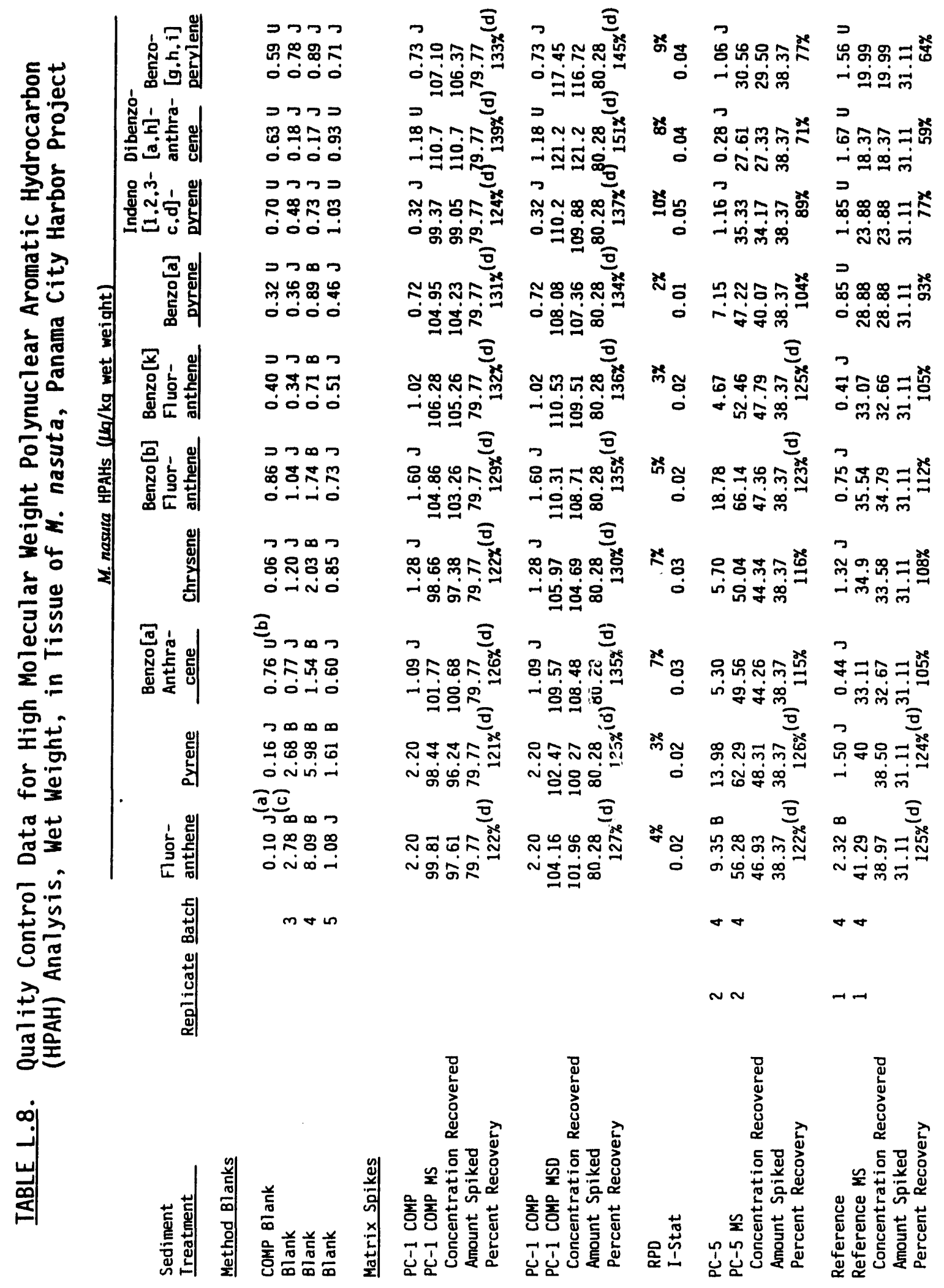




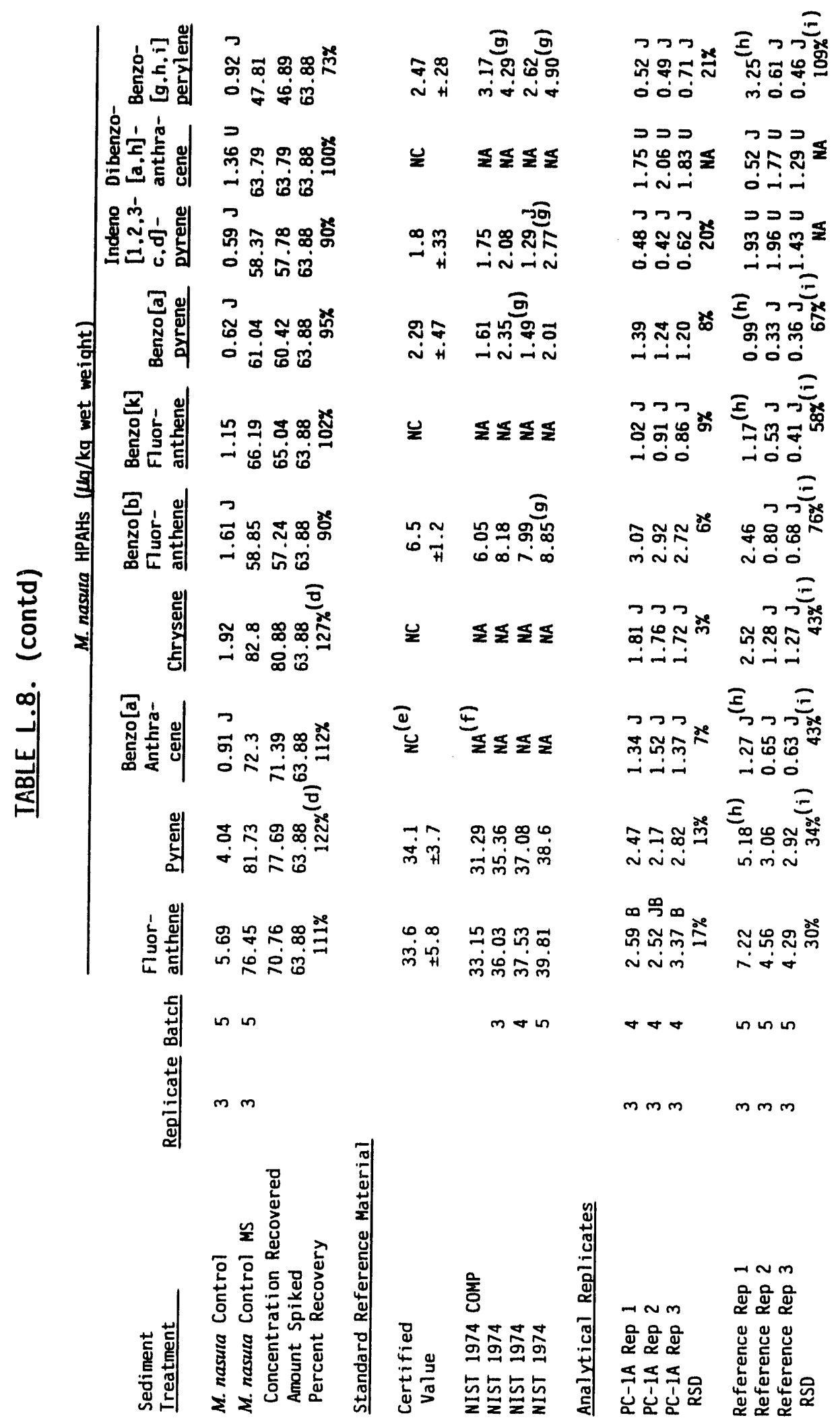

PANAMA CITY HARBOR

L. 17 


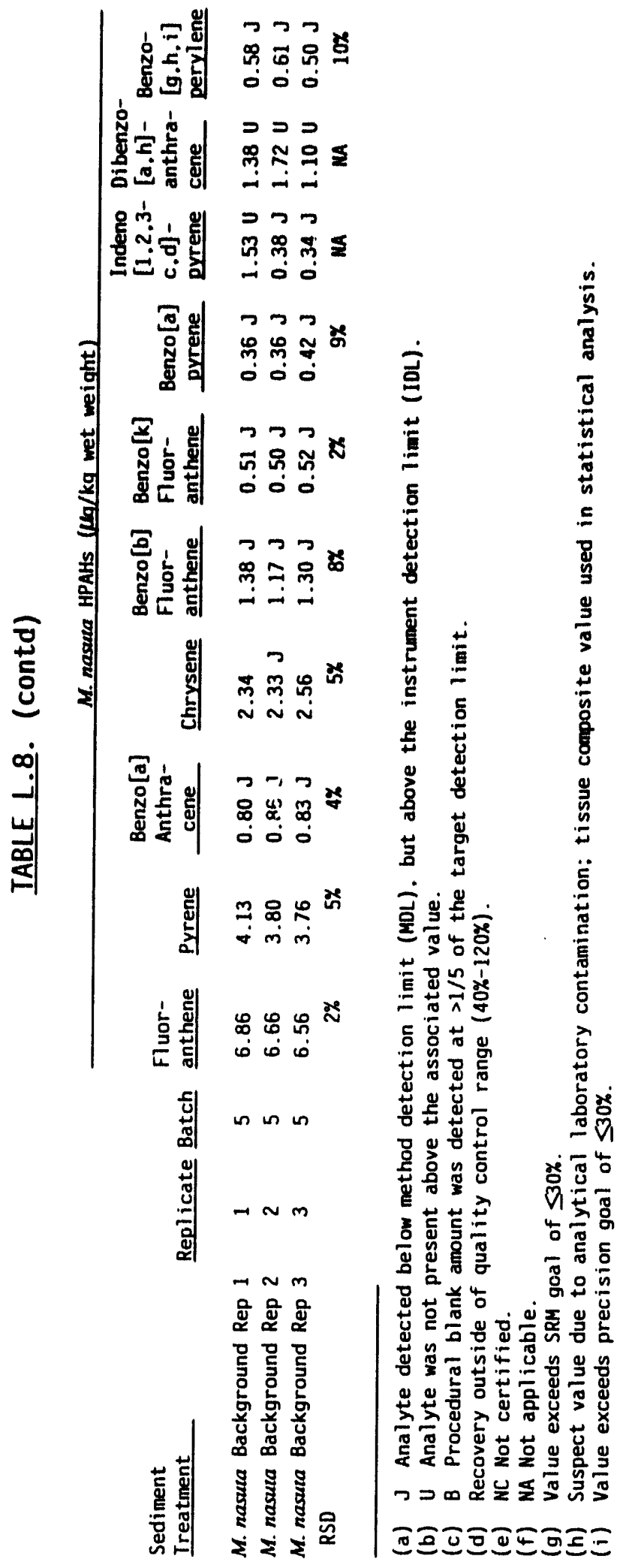

PANAMA CITY HARBOR

L. 18 
IABLEL.9. Phenol and Substituted Phenol Analysis, Wet Weight, in Tissue of M. nasuta, Panama City Harbor Project

Sediment

Ireatment

Target OL (a)

Achieved OL High

Achieved DL Low

$P C-1$

$P C-1$

$P C-1$

$P C-1$

$P C-1$

PC-1A

$P C-1 A$

PC-1A Rep 1

PC-1A Rep 2

PC-1A Rep 3

$P C-1 A$

$P C-1 A$

$P C-2$
$P C-2$
$P C-2$
$P C-2$
$P C-2$

PC -4

$P C-4$

$P C-4$

$P C-4$

$P C-4$

PC-5

$P C-5$

$P C-5$

$P C-5$

$P C-5$

Reference

Reference

Reference Rep 1

Reference Rep 2

Reference Rep 3

Reference

Reference

M. nasuta Background Rep 1

M. nasuta Background Rep 2

M. nasuta Background Rep 3

\begin{tabular}{|c|c|c|c|c|c|c|c|}
\hline \multirow{3}{*}{ Reolicate } & \multirow{3}{*}{ Batch } & \multirow{3}{*}{$\begin{array}{l}\text { Percent } \\
\text { Ory } \\
\text { Weiaht }\end{array}$} & \multicolumn{5}{|c|}{ M. nasuta } \\
\hline & & & Phenol & $\begin{array}{l}\text { 2,4-di- } \\
\text { methyl- } \\
\text { phonol- }\end{array}$ & $\begin{array}{l}2,4,6- \\
\text { tri- } \\
\text { chloro- } \\
\text { phenol }\end{array}$ & $\begin{array}{l}\text { Para- } \\
\text { chloro- } \\
\text { mata- } \\
\text { cresol }\end{array}$ & $\begin{array}{l}\text { 2-chloro- } \\
\text { phenol }\end{array}$ \\
\hline & & & $\begin{array}{l}330 \\
1155.00 \\
364.19\end{array}$ & $\begin{array}{l}330 \\
1155.00 \\
364.19\end{array}$ & $\begin{array}{l}330 \\
1155.00 \\
364.19\end{array}$ & $\begin{array}{l}330 \\
1155.00 \\
364.19\end{array}$ & $\begin{array}{l}330 \\
1155.00 \\
364.19\end{array}$ \\
\hline $\begin{array}{l}1 \\
2 \\
3 \\
4 \\
5\end{array}$ & $\begin{array}{l}5 \\
5 \\
5 \\
4 \\
3\end{array}$ & $\begin{array}{l}14.978 \\
14.257 \\
11.647 \\
10.453 \\
12.981\end{array}$ & $\begin{array}{r}36.30 \mathrm{~J} \\
396.79 \mathrm{U} \\
23.20 \mathrm{~J} \\
41.24 \mathrm{~J} \\
142.96 \mathrm{~J}\end{array}$ & 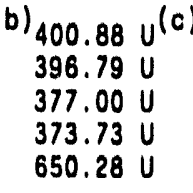 & $\begin{array}{l}1400.88 l \\
396.79 \\
377.00 \\
373.73 \\
650.28\end{array}$ & $\begin{array}{l}400.88 U \\
396.79 U \\
377.00 U \\
373.73 U \\
650.28 U\end{array}$ & $\begin{array}{l}400.88 U \\
396.79 U \\
377.00 U \\
373.73 U \\
650.28 U\end{array}$ \\
\hline $\begin{array}{l}1 \\
2 \\
3 \\
3 \\
3 \\
4 \\
5\end{array}$ & $\begin{array}{l}5 \\
4 \\
4 \\
4 \\
4 \\
4 \\
5\end{array}$ & $\begin{array}{l}13.331 \\
14.133 \\
12.944 \\
12.944 \\
12.944 \\
12.779 \\
12.122\end{array}$ & $\begin{array}{r}391.68 \mathrm{U} \\
89.69 \mathrm{~J} \\
72.42 \mathrm{~J} \\
125.58 \mathrm{~J} \\
70.06 \mathrm{~J} \\
75.05 \mathrm{~J} \\
482.49 \mathrm{U}\end{array}$ & $\begin{array}{r}391.68 \mathrm{U} \\
364.19 \mathrm{U} \\
979.62 \mathrm{U} \\
1155.00 \mathrm{U} \\
1027.85 \mathrm{U} \\
426.06 \mathrm{U} \\
482.49 \mathrm{U}\end{array}$ & $\begin{array}{r}391.68 \\
364.19 \\
979.62 \\
1155.00 \\
1027.85 \\
426.06 \\
482.49\end{array}$ & $\begin{array}{r}391.68 \mathrm{U} \\
364.19 \mathrm{U} \\
979.62 \mathrm{U} \\
1155.00 \mathrm{U} \\
1027.85 \mathrm{U} \\
426.06 \mathrm{U} \\
482.49 \mathrm{U}\end{array}$ & $\begin{array}{r}391.68 U \\
364.19 U \\
979.62 U \\
1155.00 U \\
1027.85 U \\
0.49 \mathrm{~J} \\
482.49 U\end{array}$ \\
\hline $\begin{array}{l}1 \\
2 \\
3 \\
4 \\
5\end{array}$ & $\begin{array}{l}4 \\
4 \\
4 \\
4 \\
4\end{array}$ & $\begin{array}{l}12.313 \\
12.488 \\
14.708 \\
14.903 \\
14.869\end{array}$ & $\begin{array}{r}146.35 \mathrm{~J} \\
103.24 \mathrm{~J} \\
112.29 \mathrm{~J} \\
167.44 \mathrm{~J} \\
87.87 \mathrm{~J}\end{array}$ & $\begin{array}{l}529.30 U \\
426.42 U \\
569.67 U \\
564.49 U \\
836.19 U\end{array}$ & $\begin{array}{l}529.30 U \\
426.42 U \\
569.67 U \\
564.49 U \\
836.19 U\end{array}$ & $\begin{array}{l}529.30 U \\
426.42 U \\
569.67 U \\
564.49 U \\
836.19 U\end{array}$ & $\begin{array}{l}529.30 U \\
426.42 U \\
569.67 U \\
564.49 U \\
836.19 U\end{array}$ \\
\hline $\begin{array}{l}1 \\
2 \\
3 \\
4 \\
5\end{array}$ & $\begin{array}{l}4 \\
5 \\
3 \\
3 \\
4\end{array}$ & $\begin{array}{l}12.851 \\
14.206 \\
12.937 \\
12.755 \\
12.989\end{array}$ & $\begin{array}{r}58.27 \mathrm{~J} \\
497.51 \mathrm{U} \\
161.75 \mathrm{~J} \\
91.64 \mathrm{~J} \\
51.07 \mathrm{~J}\end{array}$ & $\begin{array}{l}497.44 U \\
497.51 U \\
606.24 U \\
592.08 U \\
487.66 U\end{array}$ & $\begin{array}{l}497.44 U \\
497.51 U \\
606.24 U \\
593.08 U \\
487.66 U\end{array}$ & $\begin{array}{l}497.44 U \\
497.51 U \\
606.24 U \\
593.08 U \\
487.66 U\end{array}$ & $\begin{array}{l}497.14 U \\
497.51 U \\
606.24 U \\
593.08 U \\
487.66 U\end{array}$ \\
\hline $\begin{array}{l}1 \\
2 \\
3 \\
4 \\
5\end{array}$ & $\begin{array}{l}5 \\
4 \\
5 \\
4 \\
3\end{array}$ & $\begin{array}{l}12.806 \\
14.186 \\
14.039 \\
13.276 \\
13.892\end{array}$ & $\begin{array}{r}39.86 \mathrm{~J} \\
215.72 \mathrm{~J} \\
0.37 \mathrm{~J} \\
110.81 \mathrm{~J} \\
110.60 \mathrm{~J}\end{array}$ & $\begin{array}{r}0.17 \mathrm{~J} \\
1128.29 \mathrm{U} \\
428.08 \mathrm{U} \\
456.64 \mathrm{U} \\
653.64 \mathrm{U}\end{array}$ & $\begin{array}{r}462.60 U \\
1128.29 U \\
428.08 U \\
456.64 U \\
653.64 U\end{array}$ & $\begin{array}{r}462.60 \mathrm{U} \\
1128.29 \mathrm{U} \\
428.08 \mathrm{U} \\
456.64 \mathrm{U} \\
653.64 \mathrm{U}\end{array}$ & $\begin{array}{r}462.60 U \\
1128.29 U \\
428.08 \mathrm{U} \\
456.64 \mathrm{U} \\
653.64 \mathrm{U}\end{array}$ \\
\hline $\begin{array}{l}1 \\
2 \\
3 \\
3 \\
3 \\
4 \\
5\end{array}$ & $\begin{array}{l}4 \\
4 \\
5 \\
5 \\
5 \\
3 \\
3\end{array}$ & $\begin{array}{l}12.696 \\
14.103 \\
12.986 \\
12.986 \\
12.986 \\
12.212 \\
13.839\end{array}$ & $\begin{array}{r}1108.86 \\
230.18 \mathrm{~J} \\
64.75 \mathrm{~J} \\
58.77 \mathrm{~J} \\
59.70 \mathrm{~J} \\
148.09 \mathrm{~J} \\
173.00 \mathrm{~J}\end{array}$ & $\begin{array}{l}936.50 \mathrm{U} \\
778.03 \mathrm{U} \\
976.47 \mathrm{U} \\
991.57 \mathrm{U} \\
724.38 \mathrm{U} \\
643.83 \mathrm{U} \\
641.15 \mathrm{U}\end{array}$ & $\begin{array}{l}936.50 U \\
778.03 U \\
976.47 U \\
991.57 U \\
724.38 U \\
643.83 U \\
641.15 U\end{array}$ & $\begin{array}{l}936.50 U \\
778.03 U \\
976.47 U \\
991.57 U \\
724.38 U \\
643.83 U \\
641.15 U\end{array}$ & $\begin{array}{l}936.50 \cup \\
778.03 U \\
976.47 U \\
991.57 U \\
724.38 U \\
643.83 U \\
641.15 U\end{array}$ \\
\hline 1 & 5 & 16.303 & $771.90 \mathrm{U}$ & $771.90 \mathrm{U}$ & $771.90 \mathrm{U}$ & $771.90 \mathrm{U}$ & $771.90 \mathrm{U}$ \\
\hline 2 & 5 & 16.303 & $1.67 \mathrm{~J}$ & $964.23 \mathrm{U}$ & $964.23 \mathrm{U}$ & $964.23 \mathrm{U}$ & $964.23 \mathrm{U}$ \\
\hline 3 & 5 & 16.303 & $40.04 \mathrm{~J}$ & $619.62 \mathrm{U}$ & $619.62 U$ & $619.62 \mathrm{U}$ & $619.62 \mathrm{U}$ \\
\hline
\end{tabular}


IABLE L.9. (contd)

Sediment

Ireatment.

M. nasuta Control

$M$. nasuta Control

$M$. nasuta Control

M. nasuta Control

$M$. nasula Control

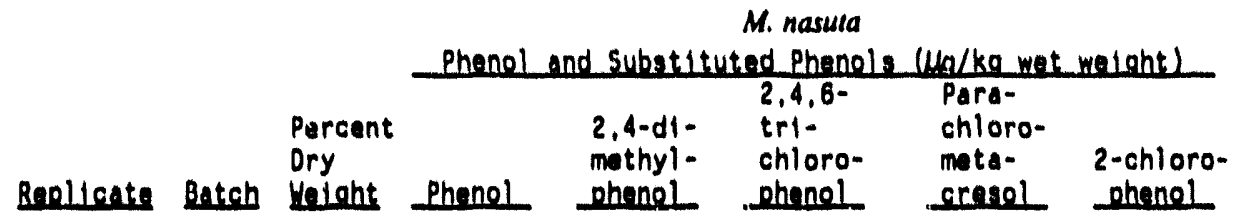

$\begin{array}{lll}1 & 3 & 15.651 \\ 2 & 3 & 14.229 \\ 3 & 5 & 13.711 \\ 4 & 5 & 14.994 \\ 5 & 5 & 12.860\end{array}$

$86.91 \mathrm{~J} 644.50 \mathrm{U}$

$124.24 \mathrm{~J} 655.52 \mathrm{U}$

$50.28 \mathrm{~J} 764.64 \mathrm{U}$

$415.37 \mathrm{U} \quad 415.37 \mathrm{U}$

$31.13 \mathrm{~J} \quad 372.01 \mathrm{U}$

$644.50 \cup \quad 644.50 \mathrm{U}$

$655.52 \cup \quad 655.52 \mathrm{U}$

$764.64 U \quad 764.64 U$

$415.37 \mathrm{U} \quad 415.37 \mathrm{U}$

$372.01 \mathrm{U} \quad 372.01 \mathrm{U}$

$644.50 \mathrm{U}$

$655.52 \mathrm{U}$

$764.64 \mathrm{U}$

$415.37 \mathrm{U}$

$372.01 \mathrm{U}$

(a) DL Detection Iimit.

(b) I Analyte detected below mathod detection 1 Imit (MDL), but above the instrument detection IImit (IDL).

(c) U Analyte was not present above the assoclated value. 


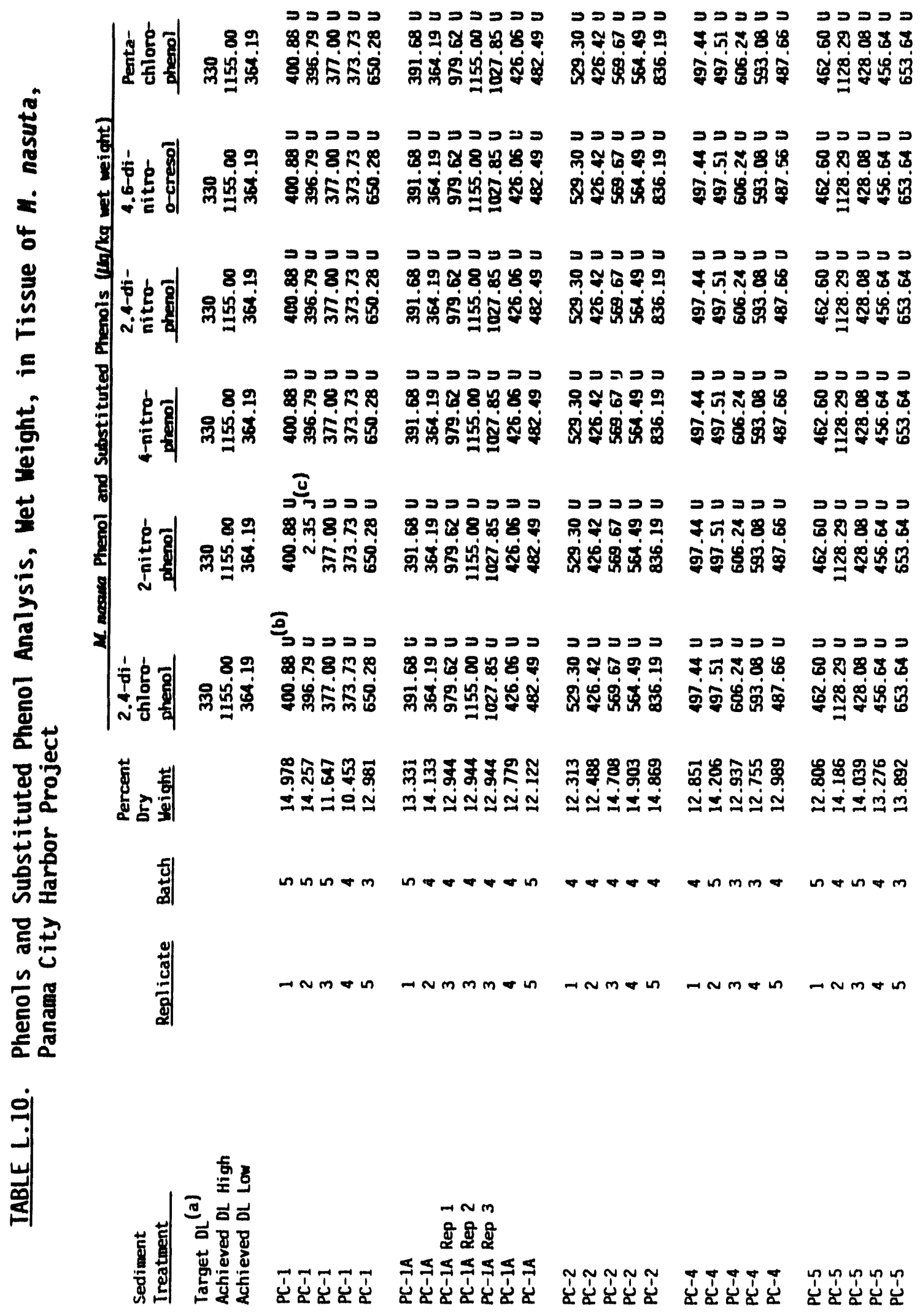

PANAMA CITY HARBOR

L. 21 


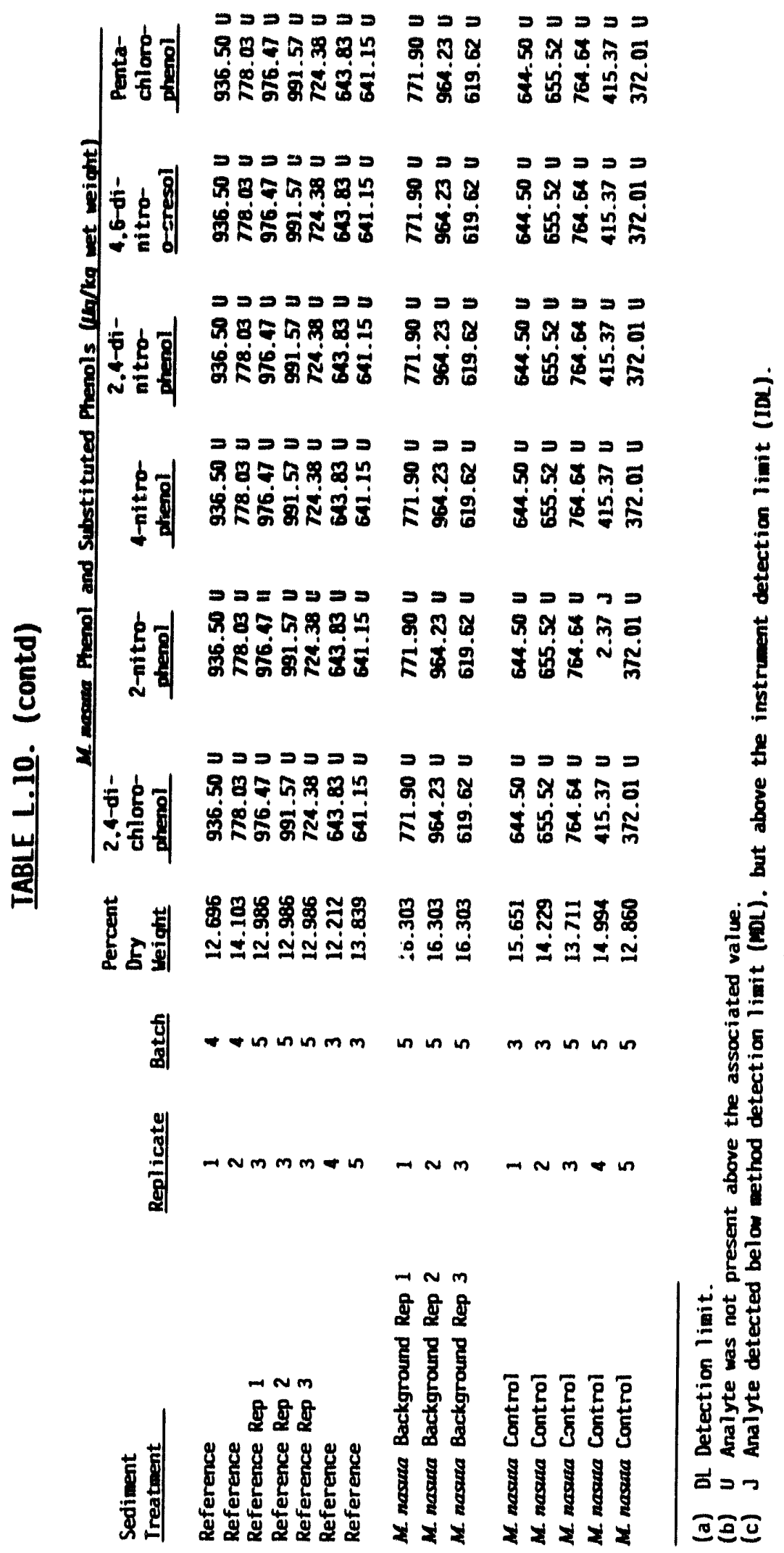

PANAMA CITY HARBOR

L. 22 
IABLE_Ldl. Phenol and Substituted Phenol Analysis, Dry Weight, in Tissue of M. nasuta, Panama City Harbor Project

\begin{tabular}{|c|c|c|c|c|c|c|c|c|}
\hline $\begin{array}{l}\text { Sediment } \\
\text { Ireatmant }\end{array}$ & Repllaten & Batch & $\begin{array}{l}\text { Percent } \\
\text { Ory } \\
\text { Selont }\end{array}$ & Phonola & $\begin{array}{l}\text { 1d Subatitut } \\
\text { 2.4-di- } \\
\text { mathyl- } \\
\text { phenol }\end{array}$ & $\begin{array}{l}\text { M. nasuta } \\
\text { od Phnnole } \\
2,4,6- \\
\text { tri- } \\
\text { chloro- } \\
\text { ohenol }\end{array}$ & $\begin{array}{l}(1 \mathrm{ga} / \mathrm{kg} \text { dry } \\
\text { Para- } \\
\text { chloro- } \\
\text { mata- } \\
\text { arnsol }\end{array}$ & $\begin{array}{l}\text { 2-chloro- } \\
\text { phenol }\end{array}$ \\
\hline $\begin{array}{l}P C-1 \\
P C-1 \\
P C-1 \\
P C-1 \\
P C-1\end{array}$ & $\begin{array}{l}1 \\
2 \\
3 \\
4 \\
5\end{array}$ & $\begin{array}{l}5 \\
5 \\
5 \\
4 \\
3\end{array}$ & $\begin{array}{l}14.978 \\
14.257 \\
11.647 \\
10.453 \\
12.981\end{array}$ & $\begin{array}{r}242.36 \mathrm{~J} \\
2783.12 \mathrm{U} \\
199.19 \mathrm{~J} \\
394.53 \mathrm{~J} \\
1101.30 \mathrm{~J}\end{array}$ & $\begin{array}{l}2676.46 U^{\prime} \\
2783.12 \mathrm{U} \\
3236.89 \mathrm{U} \\
3575.34 \mathrm{U} \\
5009.48 \mathrm{U}\end{array}$ & $\begin{array}{r}12876.46 U \\
2783.12 U \\
3236.89 U \\
3575.34 U \\
5009.48 U\end{array}$ & $\begin{array}{l}2676.46 U \\
2783.12 U \\
3236.89 U \\
3575.34 U \\
5009.48 U\end{array}$ & $\begin{array}{l}2676.46 U \\
2783.12 U \\
3236.89 U \\
3575.34 U \\
5009.48 U\end{array}$ \\
\hline $\begin{array}{l}P C-1 A \\
P C-1 A \\
P C-1 A \text { Rep } 1 \\
P C-1 A \text { Rap } 2 \\
P C-1 A \text { ReP } 3 \\
P C-1 A \\
P C-1 A\end{array}$ & $\begin{array}{l}1 \\
2 \\
3 \\
3 \\
3 \\
4 \\
5\end{array}$ & $\begin{array}{l}5 \\
4 \\
4 \\
4 \\
4 \\
4 \\
5\end{array}$ & $\begin{array}{l}13.331 \\
14.133 \\
12.944 \\
12.944 \\
12.944 \\
12.719 \\
12.122\end{array}$ & $\begin{array}{r}2938.11 \mathrm{U} \\
634.61 \mathrm{~J} \\
559.49 \mathrm{~J} \\
970.18 \mathrm{~J} \\
541.25 \mathrm{~J} \\
587.29 \mathrm{~J} \\
3980.28 \mathrm{U}\end{array}$ & $\begin{array}{l}2938.11 U \\
2576.88 U \\
7568.14 U \\
8923.05 U \\
7940.74 U \\
3334.08 U \\
3980.28 U\end{array}$ & $\begin{array}{l}2938.11 U \\
2576.88 U \\
7568.14 U \\
8923.05 U \\
7940.74 U \\
3334.06 U \\
3980.28 U\end{array}$ & $\begin{array}{l}2938.11 U \\
2578.88 U \\
7588.14 U \\
8923.05 U \\
7940.74 U \\
3334.06 U \\
3980.28 U\end{array}$ & $\begin{array}{r}2938.11 U \\
2576.88 \mathrm{U} \\
7568.14 \mathrm{U} \\
8923.05 \mathrm{U} \\
7940.74 \mathrm{U} \\
3.83 \mathrm{~J} \\
3980.28 \mathrm{U}\end{array}$ \\
\hline $\begin{array}{l}P C-2 \\
P C-2 \\
P C-2 \\
P C=2 \\
P C-2\end{array}$ & $\begin{array}{l}1 \\
2 \\
3 \\
4 \\
5\end{array}$ & $\begin{array}{l}4 \\
4 \\
4 \\
4 \\
4\end{array}$ & $\begin{array}{l}12.313 \\
12.488 \\
14.708 \\
14.903 \\
14.869\end{array}$ & $\begin{array}{r}1188.58 \mathrm{~J} \\
826.71 \mathrm{~J} \\
763.46 \mathrm{~J} \\
1123.53 \mathrm{~J} \\
590.96 \mathrm{~J}\end{array}$ & $\begin{array}{l}4298.71 U \\
3414.64 U \\
3873.20 \cup \\
3787.76 \cup \\
5623.71 \cup\end{array}$ & $\begin{array}{l}4298.71 \mathrm{U} \\
3414.64 \mathrm{U} \\
3873.20 \mathrm{U} \\
3787.76 \mathrm{U} \\
5623.71 \mathrm{U}\end{array}$ & $\begin{array}{l}4298.71 U \\
3414.64 U \\
3873.20 U \\
3787.76 U \\
5623.71 U\end{array}$ & $\begin{array}{l}4298.71 U \\
3414.64 U \\
3873.20 U \\
3787.76 U \\
5623.71 U\end{array}$ \\
\hline $\begin{array}{l}P C-4 \\
P C-4 \\
P C-4 \\
P C-4 \\
P C=4\end{array}$ & $\begin{array}{l}1 \\
2 \\
3 \\
4 \\
5\end{array}$ & $\begin{array}{l}4 \\
5 \\
3 \\
3 \\
4\end{array}$ & $\begin{array}{l}12.851 \\
14.206 \\
12.937 \\
12.755 \\
12.989\end{array}$ & $\begin{array}{r}453.43 \mathrm{~J} \\
3502.11 \mathrm{U} \\
1250.29 \mathrm{~J} \\
718.46 \mathrm{~J} \\
393.18 \mathrm{~J}\end{array}$ & $\begin{array}{l}3870.83 U \\
3502.11 U \\
4686.09 U \\
4649.78 U \\
3754.41 U\end{array}$ & $\begin{array}{l}3870.83 U \\
3502.11 U \\
4686.09 \mathrm{U} \\
4649.78 \mathrm{U} \\
3754.41 \mathrm{U}\end{array}$ & $\begin{array}{l}3870.83 U \\
3502.11 U \\
4686.09 U \\
4649.78 U \\
3754.41 U\end{array}$ & $\begin{array}{l}3870.83 U \\
3502.11 U \\
4686.09 U \\
4649.78 U \\
3754.41 U\end{array}$ \\
\hline $\begin{array}{l}P C-5 \\
P C-5 \\
P C-5 \\
P C-5 \\
P C-5\end{array}$ & $\begin{array}{l}1 \\
2 \\
3 \\
4 \\
5\end{array}$ & $\begin{array}{l}5 \\
4 \\
5 \\
4 \\
3\end{array}$ & $\begin{array}{l}12.806 \\
14.186 \\
14.039 \\
13.276 \\
13.892\end{array}$ & $\begin{array}{r}311.26 \mathrm{~J} \\
1520.65 \mathrm{~J} \\
2.64 \mathrm{~J} \\
834.66 \mathrm{~J} \\
796.14 \mathrm{~J}\end{array}$ & $\begin{array}{r}1.33 \mathrm{~J} \\
7953.55 \mathrm{U} \\
3049.22 \mathrm{U} \\
3439.59 \mathrm{U} \\
4705.15 \mathrm{U}\end{array}$ & $\begin{array}{l}3612.37 \mathrm{U} \\
7953.55 \mathrm{U} \\
3049.22 \mathrm{U} \\
3439.59 \mathrm{U} \\
4705.15 \mathrm{U}\end{array}$ & $\begin{array}{l}3612.37 U \\
7953.55 U \\
3049.22 U \\
3439.59 U \\
4705.15 U\end{array}$ & $\begin{array}{l}3612.37 U \\
7953.55 U \\
3049.22 U \\
3439.59 U \\
4705.15 U\end{array}$ \\
\hline $\begin{array}{l}\text { Reforence } \\
\text { Reference } \\
\text { Reference Rep } 1 \\
\text { Reference Rep } 2 \\
\text { Reference Rep } 3 \\
\text { Reference } \\
\text { Reference }\end{array}$ & $\begin{array}{l}1 \\
2 \\
3 \\
3 \\
3 \\
4 \\
5\end{array}$ & $\begin{array}{l}4 \\
4 \\
5 \\
5 \\
5 \\
3 \\
3\end{array}$ & $\begin{array}{l}12.696 \\
14.103 \\
12.986 \\
12.986 \\
12.986 \\
12.212 \\
13.839\end{array}$ & $\begin{array}{r}8733.93 \\
1632.14 \mathrm{~J} \\
498.61 \mathrm{~J} \\
452.56 \mathrm{~J} \\
459.73 \mathrm{~J} \\
1212.66 \mathrm{~J} \\
1250.09 \mathrm{~J}\end{array}$ & $\begin{array}{l}7376.34 U \\
5516.77 U \\
7519.41 U \\
7635.68 U \\
5578.16 U \\
5272.11 U \\
4632.92 U\end{array}$ & $\begin{array}{l}7376.34 \mathrm{U} \\
5516.77 \mathrm{U} \\
7519.41 \mathrm{U} \\
7635.68 \mathrm{U} \\
5578.16 \mathrm{U} \\
5272.11 \mathrm{U} \\
4632.92 \mathrm{U}\end{array}$ & $\begin{array}{l}7376.34 U \\
5516.77 U \\
7519.41 U \\
7635.68 U \\
5578.16 U \\
5272.11 U \\
4632.92 U\end{array}$ & $\begin{array}{l}7376.34 U \\
5516.77 U \\
7519.41 U \\
7635.68 U \\
5578.16 U \\
5272.11 U \\
4632.92 U\end{array}$ \\
\hline M. nasuta Background Rep I & 1 & 5 & 16.303 & $4734.71 \mathrm{U}$ & $4734.71 \mathrm{U}$ & $4734.71 \mathrm{U}$ & $4734.71 \mathrm{U}$ & $4734.71 U$ \\
\hline M. nasula Background Rep 2 & 2 & 5 & 16.303 & $10.24 \mathrm{~J}$ & $5914.43 \mathrm{U}$ & $5914.43 \mathrm{U}$ & $5914.43 \mathrm{U}$ & $5914.43 \mathrm{U}$ \\
\hline M. nasuta Background Rep 3 & 3 & 5 & 16.303 & $245.60 \mathrm{~J}$ & $3800.65 \mathrm{U}$ & $3800.65 \mathrm{U}$ & $3800.65 \mathrm{U}$ & $3800.65 \mathrm{U}$ \\
\hline M. nasula Control & 1 & 3 & 15.651 & $555.30 \mathrm{~J}$ & $4117.95 \mathrm{U}$ & $4117.95 \mathrm{U}$ & $4117.95 \mathrm{U}$ & $4117.95 \mathrm{U}$ \\
\hline M. nasula Control & 2 & 3 & 14.229 & $873.15 \mathrm{~J}$ & $4606.93 \mathrm{U}$ & $4606.93 \mathrm{U}$ & $4606.93 \mathrm{U}$ & $4606.93 \mathrm{U}$ \\
\hline M. nasura Control & 3 & 5 & 13.711 & $366.71 \mathrm{~J}$ & $5576.84 \mathrm{U}$ & $5576.84 \mathrm{U}$ & $5576.84 \mathrm{U}$ & $5576.84 \mathrm{U}$ \\
\hline M. nasuta Control & 4 & 5 & 14.994 & $2770.24 \mathrm{U}$ & $2770.24 \mathrm{U}$ & $2770.24 \mathrm{U}$ & $2770.24 \mathrm{U}$ & $2770.24 U$ \\
\hline M. nasuta Control & 5 & 5 & 12.86 & $242.07 \mathrm{~J}$ & $2892.77 \mathrm{U}$ & $2892.77 \mathrm{U}$ & $2892.77 \mathrm{U}$ & $2892.77 \mathrm{U}$ \\
\hline
\end{tabular}

(a) J Analyte detected below method detection limit (MOL), but above the instrument detection limit (IDL). (b) $U$ Analyte was not present above the associated value.

PANAMA CITY HARBOR L.23 


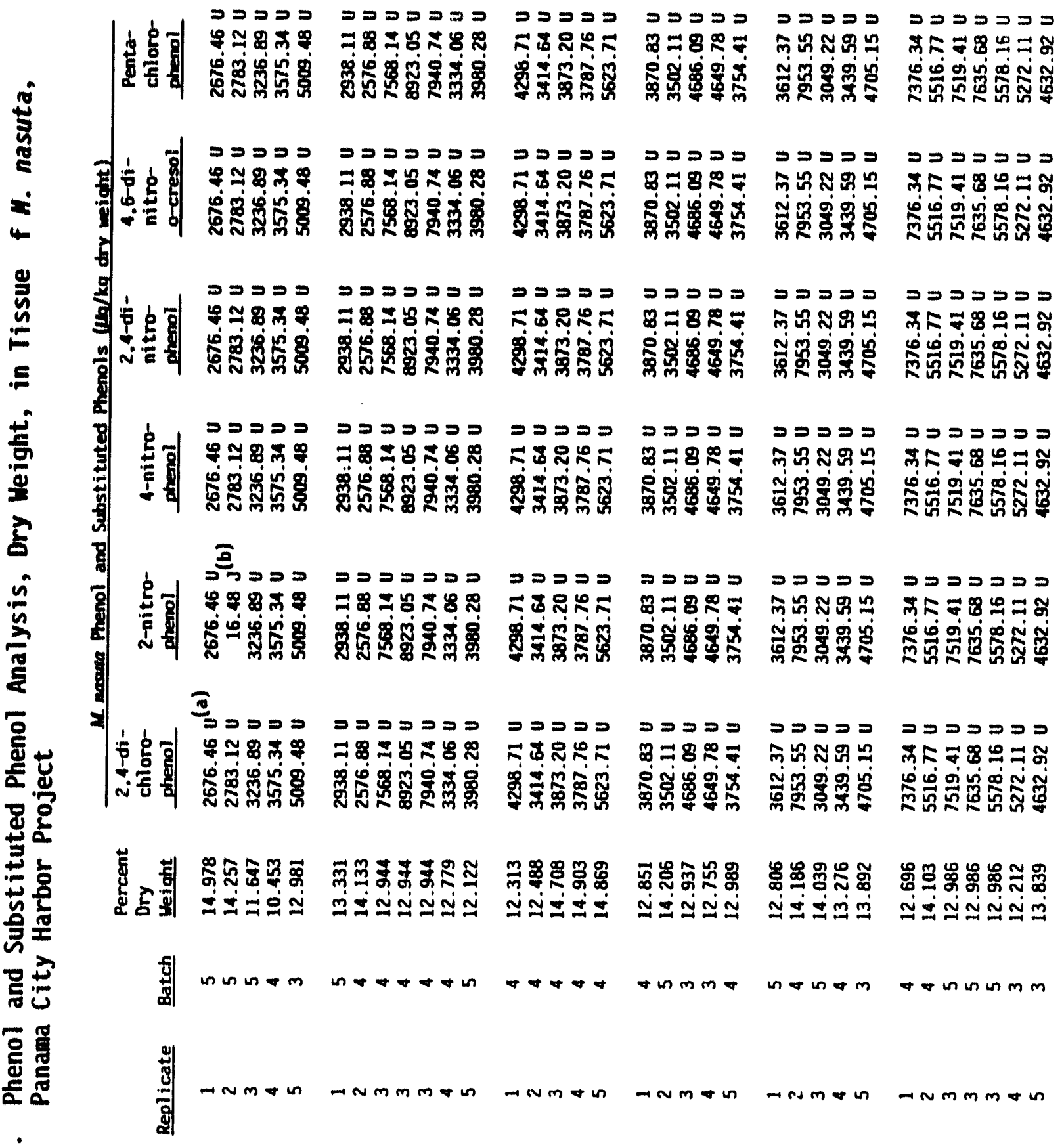

荘

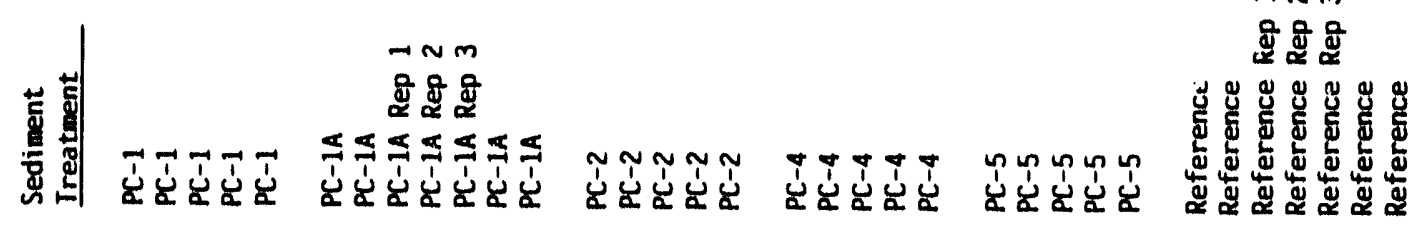




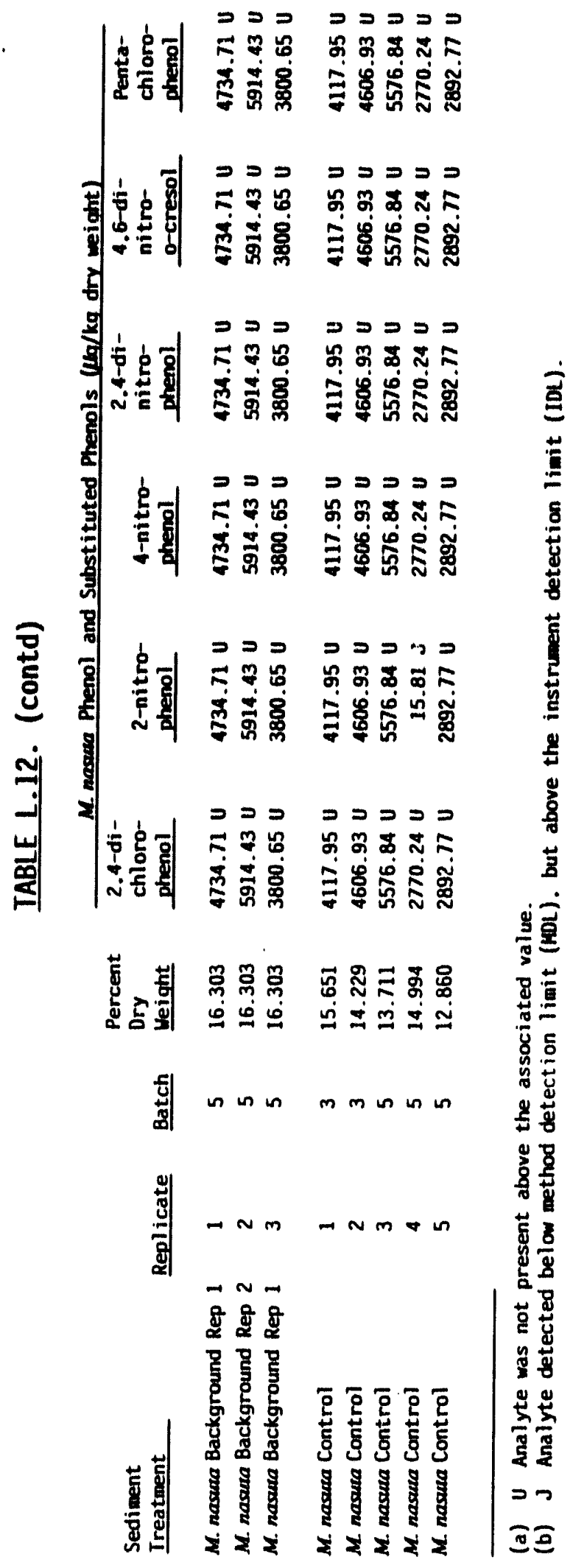




\section{TABLE L.13. Quality Control Data for Phenol and Substituted Phenol Analysis, Wet Weight, in Tissue of $M$. nasuta, Panama City Harbor Project}

\begin{tabular}{|c|c|c|c|c|c|c|c|}
\hline \multirow[b]{2}{*}{$\begin{array}{l}\text { Sediment } \\
\text { Treatment }\end{array}$} & \multirow[b]{2}{*}{ Replicate } & \multirow[b]{2}{*}{ Batch } & \multicolumn{5}{|c|}{$\begin{array}{l}\text { M. nasuta } \\
\text { Phenol and Substituted Phenols ( } \mu \mathrm{g} / \mathrm{kg} \text { wet weight) }\end{array}$} \\
\hline & & & Phenol & $\begin{array}{l}\text { 2,4-di- } \\
\text { methyl- } \\
\text { phenol } \\
\end{array}$ & $\begin{array}{l}2.4,6- \\
\text { tri- } \\
\text { chloro- } \\
\text { phenol }\end{array}$ & $\begin{array}{l}\text { Para- } \\
\text { chloro- } \\
\text { meta- } \\
\text { cresol } \\
\end{array}$ & $\begin{array}{l}\text { 2-chloro- } \\
\text { phenol }\end{array}$ \\
\hline \multicolumn{8}{|l|}{ Method Blanks } \\
\hline $\begin{array}{l}\text { Blank } \\
\text { Blank } \\
\text { Blank }\end{array}$ & & $\begin{array}{l}3 \\
4 \\
5\end{array}$ & $\begin{array}{l}59.04 \mathrm{~J}^{(\mathrm{a})} \\
62.16 \mathrm{~J} \\
522.06 \mathrm{U}\end{array}$ & $\begin{array}{l}659.89 U^{(b)} \\
584.69 U \\
522.06 U\end{array}$ & $\begin{array}{l}659.89 \mathrm{U} \\
584.69 \mathrm{U} \\
522.06 \mathrm{U}\end{array}$ & $\begin{array}{l}659.89 U \\
584.69 U \\
522.06 U\end{array}$ & $\begin{array}{l}659.89 \mathrm{U} \\
584.69 \mathrm{U} \\
522.06 \mathrm{U}\end{array}$ \\
\hline \multicolumn{8}{|l|}{ Matrix Spikes } \\
\hline $\begin{array}{l}\text { Reference } \\
\text { Reference MS } \\
\text { Concentration Recovered } \\
\text { Amount Spiked } \\
\text { Percent Recovery }\end{array}$ & $\begin{array}{l}1 \\
1\end{array}$ & $\begin{array}{l}4 \\
4\end{array}$ & $\begin{array}{r}1108.86 \\
3349.87 \\
2241.01 \\
2837.23 \\
79 \%\end{array}$ & $\begin{array}{c}936.50 \mathrm{U} \\
3219.17 \\
3219.17 \\
2837.23 \\
113 \%\end{array}$ & $\begin{array}{l}936.50 \mathrm{U} \\
8267.78 \\
8267.78 \\
2923.84 \\
283 \%(\mathrm{c})\end{array}$ & $\begin{array}{r}936.50 \mathrm{U} \\
2865.57 \\
2865.57 \\
2837.23 \\
101 \%\end{array}$ & $\begin{array}{l}936.50 \mathrm{U} \\
3594.26 \\
3594.26 \\
2837.23 \\
127 \%(\mathrm{c})\end{array}$ \\
\hline $\begin{array}{l}\text { PC-5 } \\
\text { PC-5 MS } \\
\text { Concentration Recovered } \\
\text { Amount Spiked } \\
\text { Percent Recovery }\end{array}$ & $\begin{array}{l}2 \\
2\end{array}$ & $\begin{array}{l}4 \\
4\end{array}$ & $\begin{array}{c}215.72 \mathrm{~J} \\
3774.23 \\
3558.51 \\
3499.34 \\
102 \%\end{array}$ & $\begin{array}{l}1128.29 \mathrm{U} \\
4161.16 \\
4161.16 \\
3499.35 \\
119 \%\end{array}$ & $\begin{array}{l}1128.29 \mathrm{U} \\
5107.92 \\
5107.92 \\
3606.17 \\
\quad 142 \%(\mathrm{c})\end{array}$ & $\begin{array}{r}1128.29 U \\
2882.35 \\
2882.35 \\
3499.35 \\
82 \%\end{array}$ & $\begin{array}{l}1128.29 \mathrm{U} \\
4368.89 \\
4368.89 \\
3499.35 \\
125 \%(\mathrm{c})\end{array}$ \\
\hline M. nasuta Control & 3 & 5 & $50.28 \mathrm{~J}$ & $764.64 \mathrm{U}$ & $764.64 \mathrm{U}$ & $764.64 \mathrm{U}$ & $764.64 U$ \\
\hline M. nasuta Control & 3 & 5 & 2963.81 & 3539.06 & 11075.88 & 2586.38 & 3350.10 \\
\hline $\begin{array}{l}\text { Concentration Recovered } \\
\text { Amount Spiked } \\
\text { Percent Recovery }\end{array}$ & & & $\begin{array}{r}2913.53 \\
3066.31 \\
95 \%\end{array}$ & $\begin{array}{r}3539.06 \\
3066.31 \\
115 \%\end{array}$ & $\begin{array}{r}11075.88 \\
3159.83 \\
351 \%(c)\end{array}$ & $\begin{array}{r}2586.38 \\
3066.31 \\
84 \%\end{array}$ & $\begin{array}{r}3350.10 \\
3066.31 \\
109 \%\end{array}$ \\
\hline \multicolumn{8}{|l|}{ Analytical Replicates } \\
\hline $\begin{array}{l}\text { PC-1A Rep } 1 \\
\text { PC-1A Rep } 2 \\
\text { PC-1A Rep } 3 \\
\text { RSD }\end{array}$ & $\begin{array}{l}3 \\
3 \\
3\end{array}$ & $\begin{array}{l}4 \\
4 \\
4\end{array}$ & $\begin{array}{r}72.42 \mathrm{~J} \\
125.58 \mathrm{~J} \\
70.06 \mathrm{j} \\
35 \%\end{array}$ & $\begin{array}{r}979.62 U \\
1155.00 U \\
1027.85(U) \\
{ }_{N A}(e)\end{array}$ & $\begin{array}{r}979.62 U \\
1155.00 \mathrm{U} \\
1027.85 \mathrm{U} \\
\text { NA }\end{array}$ & $\begin{array}{r}979.62 U \\
1155.00 U \\
1027.85 U \\
\text { NA }\end{array}$ & $\begin{array}{r}979.62 U \\
1155.00 U \\
1027.85 U \\
\text { NA }\end{array}$ \\
\hline $\begin{array}{l}\text { Reference Rep } 1 \\
\text { Reference Rep } 2 \\
\text { Reference Rep } 3 \\
\text { RSD }\end{array}$ & $\begin{array}{l}3 \\
3 \\
3\end{array}$ & $\begin{array}{l}5 \\
5 \\
5\end{array}$ & $\begin{array}{c}64.75 \mathrm{~J} \\
58.77 \mathrm{~J} \\
59.70 \mathrm{~J} \\
5 \%\end{array}$ & $\begin{array}{c}976.47 \mathrm{U} \\
991.57 \mathrm{U} \\
724.38 \mathrm{U} \\
\text { NA }\end{array}$ & $\begin{array}{c}976.47 U \\
991.57 \mathrm{U} \\
724.38 \mathrm{U} \\
N A\end{array}$ & $\begin{array}{c}976.47 U \\
991.57 U \\
724.38 U \\
\text { NA }\end{array}$ & $\begin{array}{c}976.47 U \\
991.57 U \\
724.38 U \\
N A\end{array}$ \\
\hline M. nasuta Background Rep 1 & 1 & 5 & $771.90 \mathrm{U}$ & $771.90 \mathrm{U}$ & $771.90 \mathrm{U}$ & $771.90 \mathrm{U}$ & $771.90 \mathrm{U}$ \\
\hline M. nasuta Background Rep 2 & 2 & 5 & $1.67 \mathrm{~J}$ & $964.23 \mathrm{U}$ & $964.23 \mathrm{U}$ & $964.23 \mathrm{U}$ & $964.23 \mathrm{U}$ \\
\hline $\begin{array}{l}\text { M. nasuta Background Rep } 3 \\
\text { RSD }\end{array}$ & 3 & 5 & $\begin{array}{c}40.04 \mathrm{~J} \\
\mathrm{NA}\end{array}$ & $\begin{array}{c}619.62 U \\
\text { NA }\end{array}$ & $\begin{array}{c}619.62 U \\
N A\end{array}$ & $\begin{array}{c}619.62 U \\
N A\end{array}$ & $\begin{array}{c}619.62 \mathrm{U} \\
\mathrm{NA}\end{array}$ \\
\hline
\end{tabular}

(a) J Analyte detected below method detection limit (MOL), but above the instrument detection limit (IDL).

(b) U Analyte was not present above the associated value.

(c) Recovery outside of quality control range $(40 \%-120 \%)$.

(d) Value exceeds relative precision goal of $\leq 30 \%$.

(e) NA Not applicable. 


\section{TABLE L.14. Quality Control Data for Phenol and Substituted Phenol Analysis, Wet Weight, in Tissue of M. nasuta, Panama City Harbor Project}

Sediment

Treatment

\begin{tabular}{|c|c|c|c|c|c|c|c|}
\hline \multirow[b]{2}{*}{ eplicate } & \multirow[b]{2}{*}{ Batch } & \multicolumn{6}{|c|}{$\begin{array}{r}M . \text { nasuta } \\
\text { Phenol and Substituted Phe }\end{array}$} \\
\hline & & $\begin{array}{l}\text { 2.4-di- } \\
\text { chloro- } \\
\text { phenol }\end{array}$ & $\begin{array}{l}\text { 2-nitro- } \\
\text { phenol }\end{array}$ & $\begin{array}{l}\text { 4-nitro- } \\
\text { phenol }\end{array}$ & $\begin{array}{l}\text { 2,4-di- } \\
\text { nitro- } \\
\text { phenol }\end{array}$ & $\begin{array}{l}4,6-d i- \\
\text { nitro- } \\
\text { o-cresol }\end{array}$ & $\begin{array}{l}\text { Penta- } \\
\text { chloro- } \\
\text { phenol }\end{array}$ \\
\hline
\end{tabular}

Method Blanks

Blank

Blank

Blank

$\begin{array}{lll}3 & 659.89 U^{(a)} & 659.89 U \\ 4 & 584.69 U & 584.69 U \\ 5 & 522.06 U & 522.06 U\end{array}$

659.89 U $\quad 659.89 \mathrm{U}$ $584.69 \mathrm{U} \quad 584.69 \mathrm{U}$

$659.89 \mathrm{U}$

$522.06 \mathrm{U}$

$522.06 \mathrm{U}$

5

Matrix Spikes

Reference
Reference MS
Concentration Recovered
Amount Spiked
Percent Recovery
PC-5
PC-5 MS
Concentration Recovered
Amount Spiked
Percent Recovery
M. nasuta Control
M. nasuta Control
Concentration Recovered
Amount Spiked
Percent Recovery
Analytical Replicates
PC-1A Rep 1
PC-1A Rep 2
PC-1A Rep 3
RSD
Reference Rep 1
Reference Rep 2
Reference Rep 3
RSD
M. nasuta Background Rep 1
M. nasuta Background Rep 2
M. nasuta Background Rep 3
RSD

14

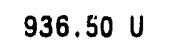

$\begin{array}{rrr}3 & 4 & 979.62 \mathrm{U} \\ 3 & 4 & 1155.00 \mathrm{U} \\ 3 & 4 & 1027.85 \mathrm{U}\end{array}$
$1027.85 \mathrm{U}$

$979.62 \mathrm{U}$ 1155.00 $1027.85 \mathrm{U}$

NA

$976.47 \mathrm{U}$ $991.57 \mathrm{U}$ $724.38 U$ NA $991.57 \mathrm{U}$ NA

$771.90 \mathrm{U}$ $964.23 \mathrm{U}$ $619.62 \mathrm{U}$ NA
$979.62 \mathrm{U}$ $1027.85 \mathrm{U}$

NA

$976.47 \mathrm{U}$ $991.57 \mathrm{U}$ $724.38 U$ NA

$771.90 \mathrm{U}$ $964.23 U$ $619.62 \mathrm{U}$

NA
$979.62 \mathrm{U}$ $1155.00 \mathrm{U}$ 1027.85

NA

$976.47 \mathrm{U}$ $991.57 \mathrm{U}$ $724.38 \mathrm{U}$

$$
\text { NA }
$$

$771.90 \mathrm{U}$ $964.23 \mathrm{U}$ $619.62 \mathrm{U}$

NA
$979.62 \mathrm{U} \quad 979.62 \mathrm{U}$ $1155.00 \mathrm{U} 1155.00 \mathrm{U}$ $1027.85 \mathrm{U} \quad 1027.85 \mathrm{U}$

NA NA

$976.47 \cup \quad 976.47 \cup$ $991.57 \mathrm{U} \quad 991.57 \mathrm{U}$ 724.38 U $724.38 \mathrm{U}$

$$
\text { NA NA }
$$

$771.90 \mathrm{U} \quad 771.90 \mathrm{U}$ $964.23 \cup \quad 964.23 U$ $619.62 \cup \quad 619.62 U$

(a) $U$ Analyte was not present above the associated value.

(b) NA Not applicable.

(c) Recovery outside of quality control range $(40 \%-120 \%)$.

$\begin{array}{ll}\text { PANAMA CITY HARBOR } & \text { L.27 }\end{array}$ 


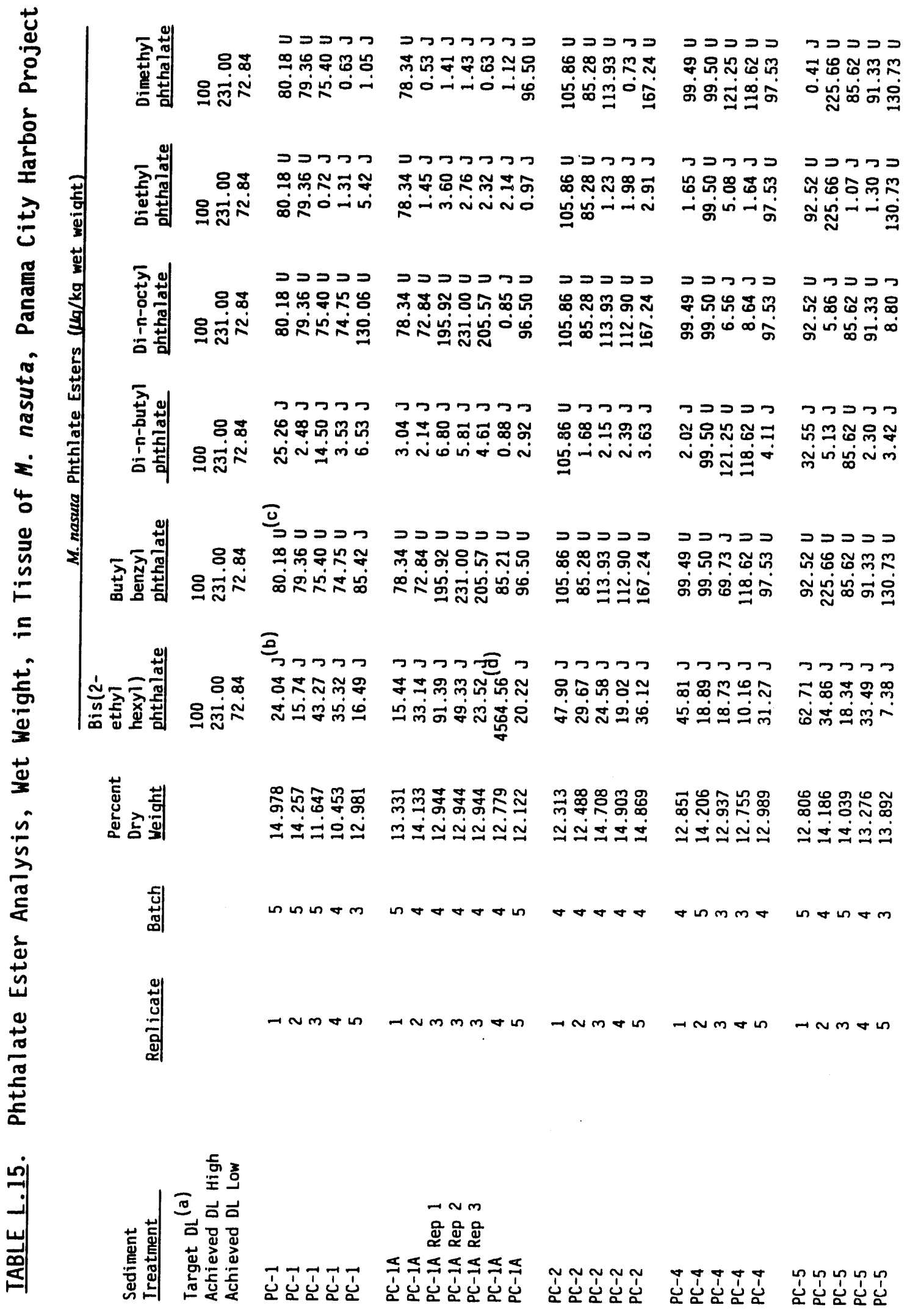

PANAMA CITY HARBOR L.28 


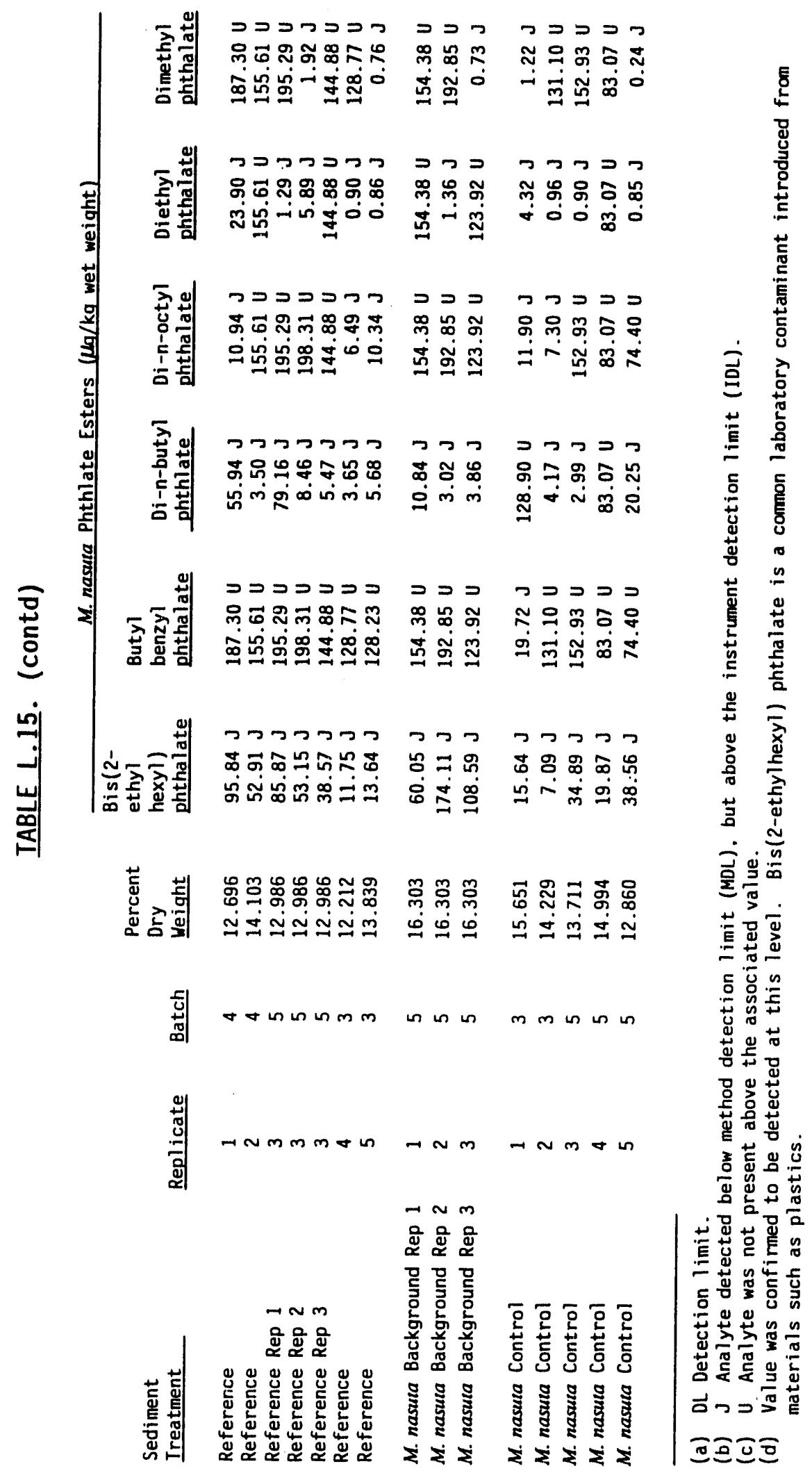

PANAMA CITY HARBOR 


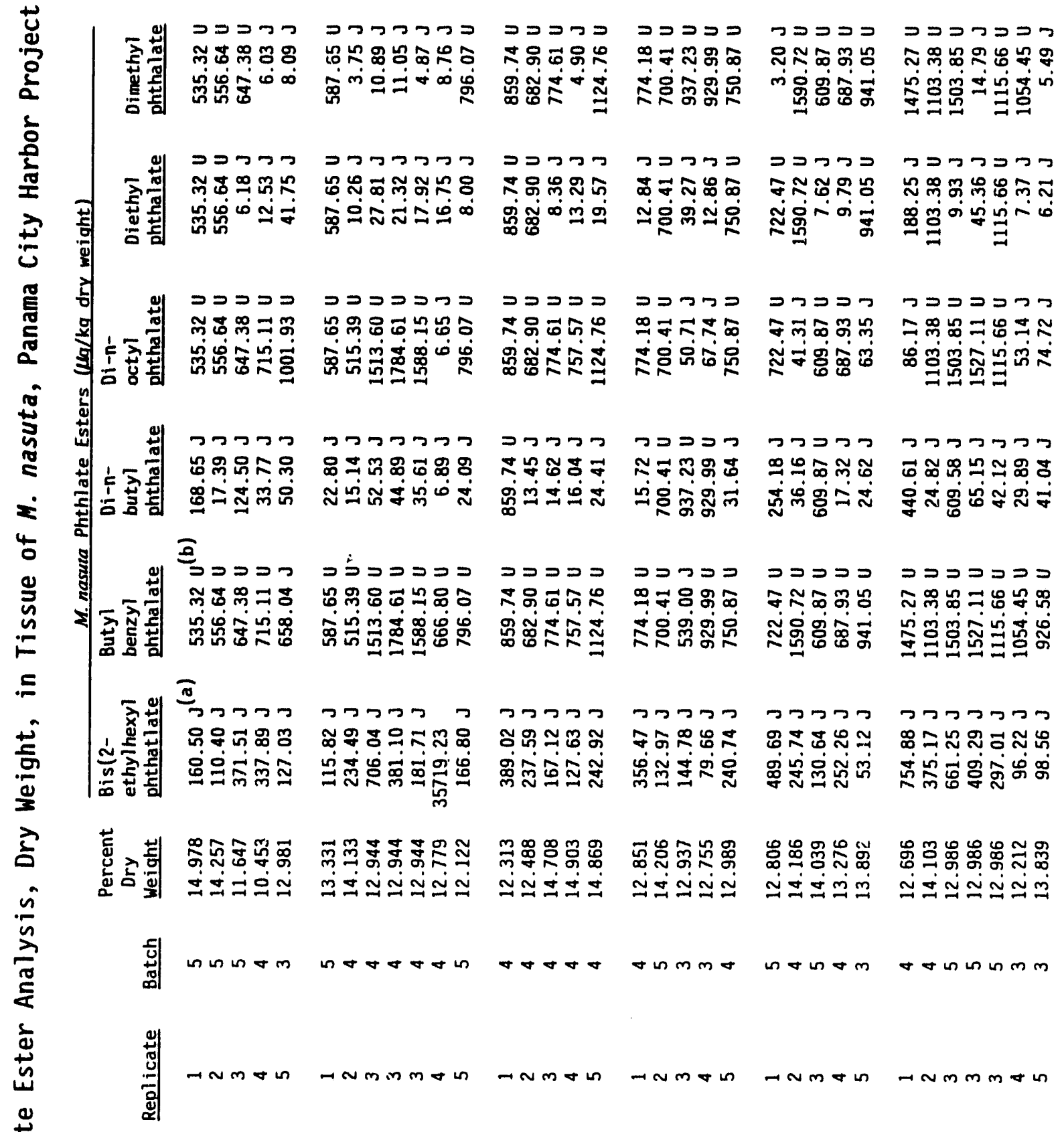

竞

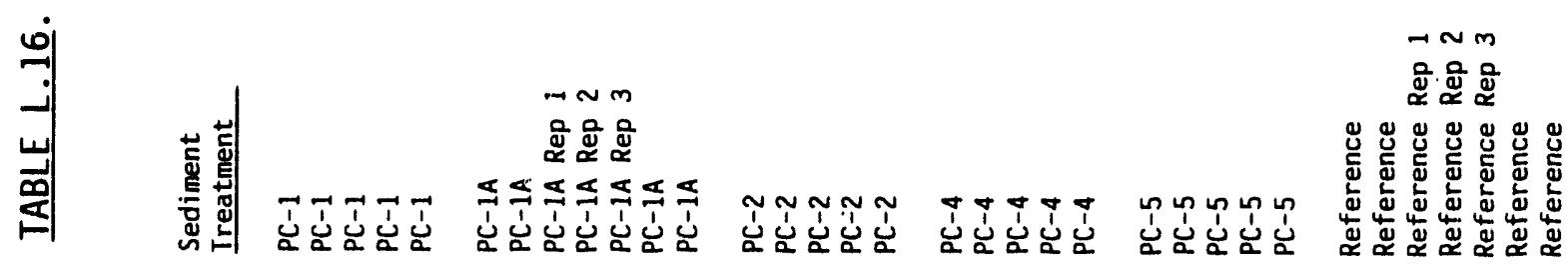




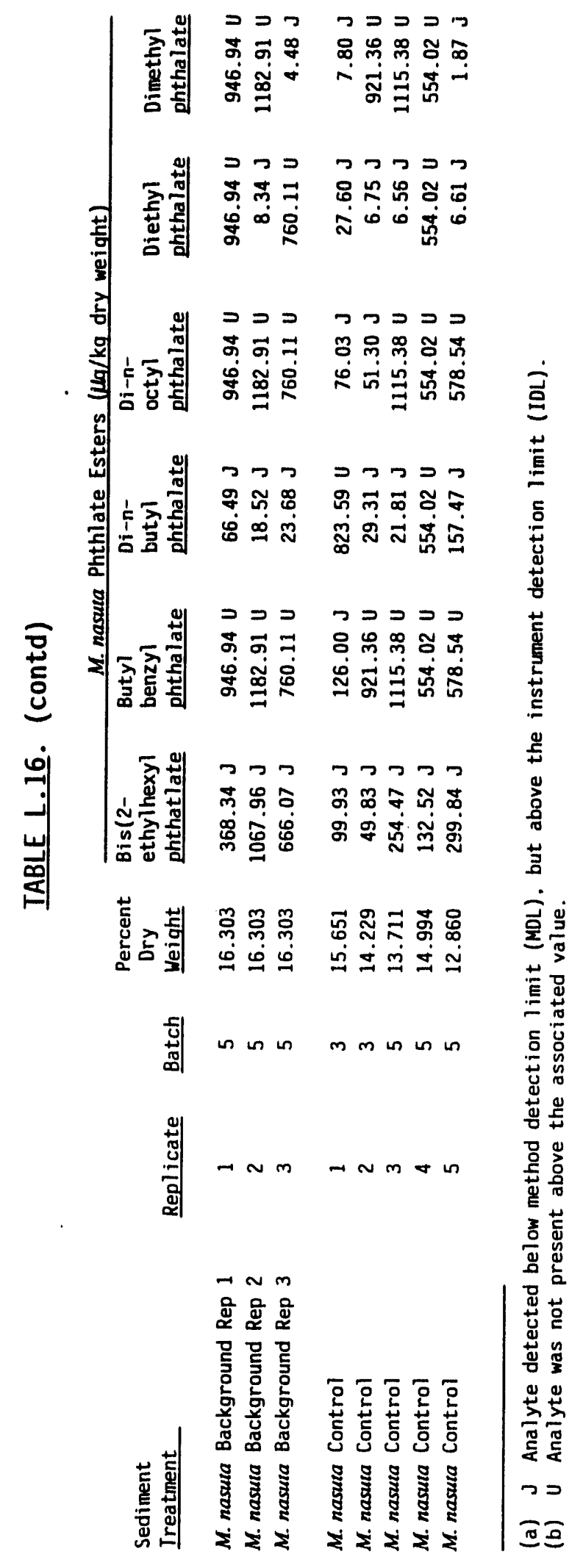


IABLE L.17. Quality Control Summary for Phthalate Ester Analysis, Wet Weight, in Tissue of M. nasuta, Panama City Harbor Project

Sediment

Treatment

Method 8lanks

Blank

Blank

Blank

Matrix Spikes

Reference

Reference MS

Concentration Recovered

Amount Spiked

Percent Recovery

$P C-5$

PC-5 MS

Concentration Recovered

Amount Spiked

Percent Recovery

M. nasuia Control

$M$. nasuta Control

Concentration Recovered

Amount Spiked

Percent Recovery

Analytical Replicates

PC-1A Rep 1

PC-1A Rep 2

PC-IA Rep 3

RSD

\section{Reference Rep 1 \\ Reference Rep 2 \\ Reference Rep 3 \\ RSD}

M. nasuta Background Rep 1

$M$. nasuta Background Rep 2

M. nasuta Background Rep 3 RSD

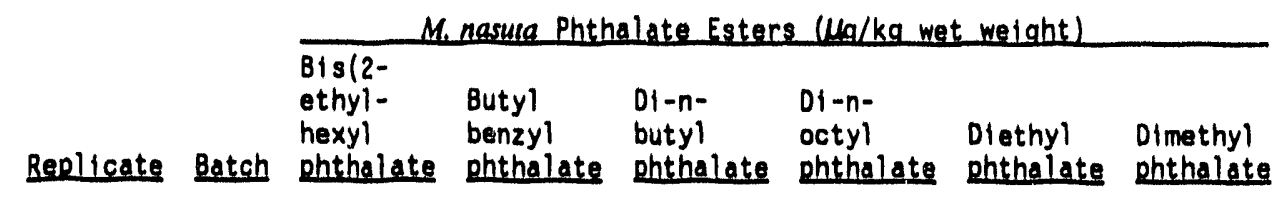

\begin{tabular}{|c|c|c|c|c|c|c|c|}
\hline 1 & $\begin{array}{l}4 \\
4\end{array}$ & $\begin{array}{r}95.84 \mathrm{~J} \\
1380.28 \\
1284.44 \\
1306.62 \\
98 \%\end{array}$ & $\begin{array}{c}187.30 \mathrm{U} \\
1431.14 \\
1431.14 \\
1306.62 \\
110 \%\end{array}$ & $\begin{array}{c}55.94 \mathrm{~J} \\
1554.75 \\
1498.81 \\
1306.62 \\
115 \%\end{array}$ & $\begin{array}{c}10.94 \mathrm{~J} \\
1703.46 \\
1692.52 \\
1306.62 \\
130 \% \text { (c }\end{array}$ & $\begin{array}{c}23.90 \mathrm{~J} \\
1712.32 \\
1688.42 \\
1340.03 \\
126 \%(\mathrm{c}\end{array}$ & $\begin{array}{c}187.30 \mathrm{U} \\
1715.07 \\
1715.07 \\
1306.62(\mathrm{c}) \\
131 \%(\mathrm{c})\end{array}$ \\
\hline & $\begin{array}{l}4 \\
4\end{array}$ & $\begin{array}{r}34.86 \mathrm{~J} \\
1213.57 \\
1178.71 \\
1611.54 \\
73 \%\end{array}$ & $\begin{array}{r}225.66 \mathrm{U} \\
1285.77 \\
1285.77 \\
1611.54 \\
80 \%\end{array}$ & $\begin{array}{c}5.13 \mathrm{~J} \\
1738.41 \\
1733.28 \\
1611.54 \\
108 \%\end{array}$ & $\begin{array}{r}5.86 \mathrm{~J} \\
1483.36 \\
1477.50 \\
1611.54 \\
92 \%\end{array}$ & $\begin{array}{c}225.66 \mathrm{U} \\
1995.54 \\
1995.54 \\
1652.75 \\
121 \% \text { (c }\end{array}$ & $\begin{array}{c}225.66 U \\
2076.84 \\
2076.84 \\
1611.54 \mathrm{lc}) \\
129 \%(\mathrm{c})\end{array}$ \\
\hline & 5 & $34.89 \mathrm{~J}$ & $152.93 \mathrm{U}$ & $2.99 \mathrm{~J}$ & $152.93 \mathrm{U}$ & $0.90 \mathrm{~J}$ & $152.93 \mathrm{U}$ \\
\hline & 5 & 651.77 & 497.85 & 762.73 & 1072.47 & 1229.14 & 1397.92 \\
\hline & & $\begin{array}{r}616.88 \\
1149.86 \\
54 \%\end{array}$ & $\begin{array}{r}497.85 \\
1149.86 \\
43 \%\end{array}$ & $\begin{array}{r}759.74 \\
1149.86 \\
66 \%\end{array}$ & $\begin{array}{r}1072.47 \\
1149.86 \\
93 \%\end{array}$ & $\begin{array}{l}1228.24 \\
1179.19 \\
104 \%\end{array}$ & $\begin{array}{l}1397.92 \\
1149.87 \\
122 \%(c)\end{array}$ \\
\hline
\end{tabular}

$\begin{array}{ll}3 & 4 \\ 3 & 4 \\ 3 & 4\end{array}$

$$
\begin{aligned}
& 91.39 \mathrm{~J} \\
& 49.33 \mathrm{~J} \\
& 23.52 \mathrm{~J} \\
& 63 \%
\end{aligned}
$$

$195.92 \mathrm{U}$

$231.00 \mathrm{U}$

$6.80 \mathrm{~J} 195.92 \mathrm{U}$

$5.81 \mathrm{~J} 231.00 \mathrm{U}$

$4.61 \mathrm{~J} 205.57 \mathrm{U}$

$3.60 \mathrm{~J}$

$2.76 \mathrm{~J}$

$2.32 \mathrm{~J}$
$22 \%$

$1.41 \mathrm{~J}$

$1.43 \mathrm{~J}$

NA ${ }^{(\mathrm{e})}$

$19 \%$ NA

0.63 j (d)

3
3
3

5
5
5

$\begin{array}{lc}85.87 \mathrm{~J} & 195.29 \mathrm{U} \\ 53.15 \mathrm{~J} & 198.31 \mathrm{U} \\ 38.57 \mathrm{~J} & 144.88 \mathrm{U} \\ 41 \% & \mathrm{NA}\end{array}$

$79.16 \mathrm{~J} 195.29 \mathrm{U}$

$8.46 \mathrm{~J} 198.31 \mathrm{U}$

$5.47 \mathrm{~d}(\mathrm{~d}) 144.88 \mathrm{U}$

$1.29 \mathrm{~J}$

$5.89 \mathrm{~J}$

$144.88 \mathrm{U}$

$195.29 \mathrm{U}$

$1.92 \mathrm{~J}$

$144.88 \mathrm{U}$

NA

$\begin{array}{ccc}5 & 60.05 \mathrm{~J} & 154.38 \mathrm{U} \\ 5 & 174.11 \mathrm{~J} & 192.85 \mathrm{U} \\ 5 & 108.59 \mathrm{~J} & 123.92 \mathrm{U} \\ & 50 \%(\mathrm{~d}) & \text { NA }\end{array}$

$10.84 \mathrm{~J} \quad 154.38 \mathrm{U}$

$3.02 \mathrm{~J} \quad 192.85 \mathrm{U}$

$3.86 \mathrm{~J} 123.92 \mathrm{U}$

$154.38 U$

$1.36 \mathrm{~J}$

$154.38 \mathrm{U}$

$192.85 \mathrm{U}$

$0.73 \mathrm{~J}$

NA

NA

(a) U Analyte was not present above the associated value.

(b) J Analyte detected below method detection limit (MDL), but above the instrument detection limit (IDL).

(c) Recovery outside of quality control range $(40 \%-120 \%)$.

(d) Value exceeds relative precision goal of $\leq 30 \%$.

(e) NA Not applicable. 
IABLE L.18. Surrogate Recoveries and Quality Control Data for Polychlorinated Aromat ic Hydrocarbons (PAH) and Phenol Analysis, Wet Weight, in Tissue of M. nasuta, Panama City Harbor Project

Sediment

Ireatment

\section{$P C-1$}

$P C-1$

$P C-1$

$P C-1$

$P C-1$

$P C-1 A$

$P C-1 A$

PC-1A Rep 1

PC-1A Rep 2

$P C-1 A$ Rep 3

$P C-1 A$

$P C-1 A$

$P C-2$

$P C-2$

$P C-2$

PC-2

PC-2

PC -4

$P C-4$

PC -4

PC -4

PC- 4

$P C-5$

$P C-5$

$P C-5$

$P C-5$

PC-5

Reference

Reference

Reference Rep 1

Reference Rep 2

Reference Rep 3

Reference

Reference
M. nasuta

Surrogate Percent Recoverjes

2- Naph- Acenaph-Benzo[a]-
fluoro- thalene thene
phenol d8yrene

Replicate Batch phenol d8 d10 d12

$\begin{array}{rrrrrr}1 & 5 & 81 & 90 & 161^{(a)} & 101 \\ 2 & 5 & 83 & 105 & 216^{(a)} & 91 \\ 3 & 5 & 105 & 90 & 205^{(a)} & 79 \\ 4 & 4 & 117 & 72 & 87 & 90 \\ 5 & 3 & 80 & 69 & 84 & 76\end{array}$

1
2
3

$5 \quad 96$

445

$4 \quad 127^{(a)}$

$\begin{array}{ll}4 & 144^{(a)} \\ 4 & 148^{(a)}\end{array}$

496

5106

90

43

58

81

77

66

109

$185^{(a)}$

120

65

88

105

108

$\begin{array}{cc}70 & 70 \\ 191^{(a)} & 66\end{array}$

$\begin{array}{ll}4 & 90 \\ 4 & 72 \\ 4 & 68 \\ 4 & 81 \\ 4 & 75\end{array}$

49

62

56

68

65

$56 \quad 55$

142 (a) 75

$138^{\text {(a) }} \quad 68$

$\begin{array}{ll}149(a) & 80 \\ 139 & (a)\end{array}$

473

$\begin{array}{rrr}4 & 13 & 62 \\ 3 & 125^{(a)} & 106\end{array}$

$78 \quad 77$

ن9

81
78

58

107

78

85

71

95

89
61
101
66
83

$\begin{array}{cc}141^{(a)} & 90 \\ 381^{(a)} & 125^{(a)} \\ 87 & 69\end{array}$

83

$130^{(a)} \quad 83$

$141^{(a)} \quad 94$

$121^{(a)} \quad 66$

$195^{(a)} \quad 99$

$124^{(a)} \quad 71$

$83 \quad 101 \quad 83$

1
2
3
3
3
4
5

4
4
5
5
5
3
3

$7^{(a)}$
51
81
103
101
76
79

$\begin{array}{cc}11^{(a)} & 0^{(a)} \\ 153^{(a)} & 87 \\ 128^{(a)} & 58 \\ 199^{(a)} & 103 \\ 139^{(a)} & 78 \\ 92 & 77 \\ 90 & 69\end{array}$

PANAMA CITY HARBOR 
IABLELL.18. (contd)

\begin{tabular}{|c|c|c|c|c|c|c|}
\hline \multirow[b]{2}{*}{$\begin{array}{l}\text { Sediment } \\
\text { Ireatment }\end{array}$} & \multirow[b]{2}{*}{ Replicate } & \multirow[b]{2}{*}{ Batch } & \multicolumn{4}{|c|}{$\begin{array}{c}\text { M. nasuta } \\
\text { Surrogate Percent Recovertes }\end{array}$} \\
\hline & & & $\begin{array}{l}\text { 2- } \\
\text { fluoro- } \\
\text { phenol }\end{array}$ & $\begin{array}{l}\text { Naph- } \\
\text { thalene } \\
\text { d8 } \\
\end{array}$ & $\begin{array}{l}\text { Acenaph- } \\
\text { thene } \\
\text { d } 10 \\
\end{array}$ & $\begin{array}{c}\text { Benzo[a]- } \\
\text { pyrene } \\
\text { d12 } \\
\end{array}$ \\
\hline $\begin{array}{l}\text { M. nasuta Background Rep } 1 \\
\text { M. nasuta Background Rep } 2 \\
\text { M. nasuta Background Rep } 3\end{array}$ & $\begin{array}{l}1 \\
2 \\
3\end{array}$ & $\begin{array}{l}5 \\
5 \\
5\end{array}$ & $\begin{array}{l}111 \\
102 \\
117\end{array}$ & $\begin{array}{r}95 \\
104 \\
119\end{array}$ & $\begin{array}{l}232^{(a)} \\
194^{(a)} \\
227^{(a)}\end{array}$ & $\begin{array}{l}93 \\
95 \\
99\end{array}$ \\
\hline $\begin{array}{l}\text { M. nasuta Control } \\
\text { M. nasuta Control } \\
\text { M. nasuta Control } \\
\text { M. nasuta Control } \\
M . \text { nasuta Control }\end{array}$ & $\begin{array}{l}1 \\
2 \\
3 \\
4 \\
5\end{array}$ & $\begin{array}{l}3 \\
3 \\
5 \\
5 \\
5\end{array}$ & $\begin{array}{r}88 \\
88 \\
119 \\
101 \\
107\end{array}$ & $\begin{array}{r}74 \\
82 \\
106 \\
108 \\
90\end{array}$ & $\begin{array}{l}91 \\
94 \\
176^{(a)} \\
205^{(a)} \\
173^{(a)}\end{array}$ & $\begin{array}{r}74 \\
67 \\
95 \\
111 \\
98\end{array}$ \\
\hline \multicolumn{7}{|l|}{ Method Blanks } \\
\hline $\begin{array}{l}\text { Blank } \\
\text { Blank } \\
\text { Blank }\end{array}$ & & $\begin{array}{l}3 \\
4 \\
5\end{array}$ & $\begin{array}{l}75 \\
90 \\
2^{(a)}\end{array}$ & $\begin{array}{l}64 \\
61 \\
39^{(a)}\end{array}$ & $\begin{array}{l}65 \\
67 \\
49\end{array}$ & $\begin{array}{l}85 \\
67 \\
52\end{array}$ \\
\hline \multicolumn{7}{|l|}{ Matrix Spikes } \\
\hline Reference MS & & 4 & 119 & 89 & 104 & 89 \\
\hline$P C-5$ MS & & 4 & $124^{(a)}$ & 90 & 112 & 86 \\
\hline M. nasuta Control MS & & 5 & 110 & 90 & $174^{(a)}$ & 94 \\
\hline
\end{tabular}

(a) Recovery outside of qualtty control range $(40 \%-120 \%)$. 


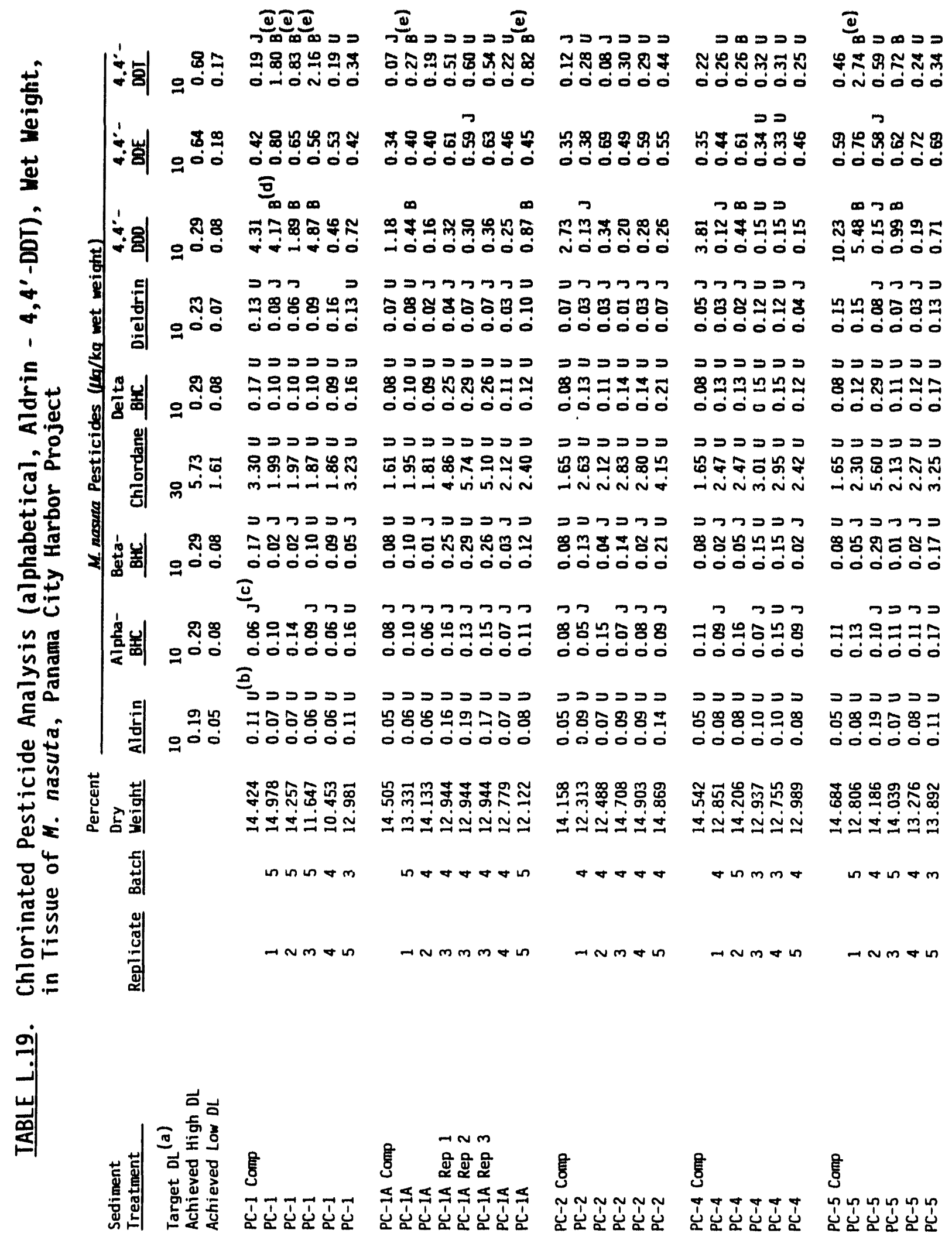

PANAMA CITY HARBOR

L. 35 


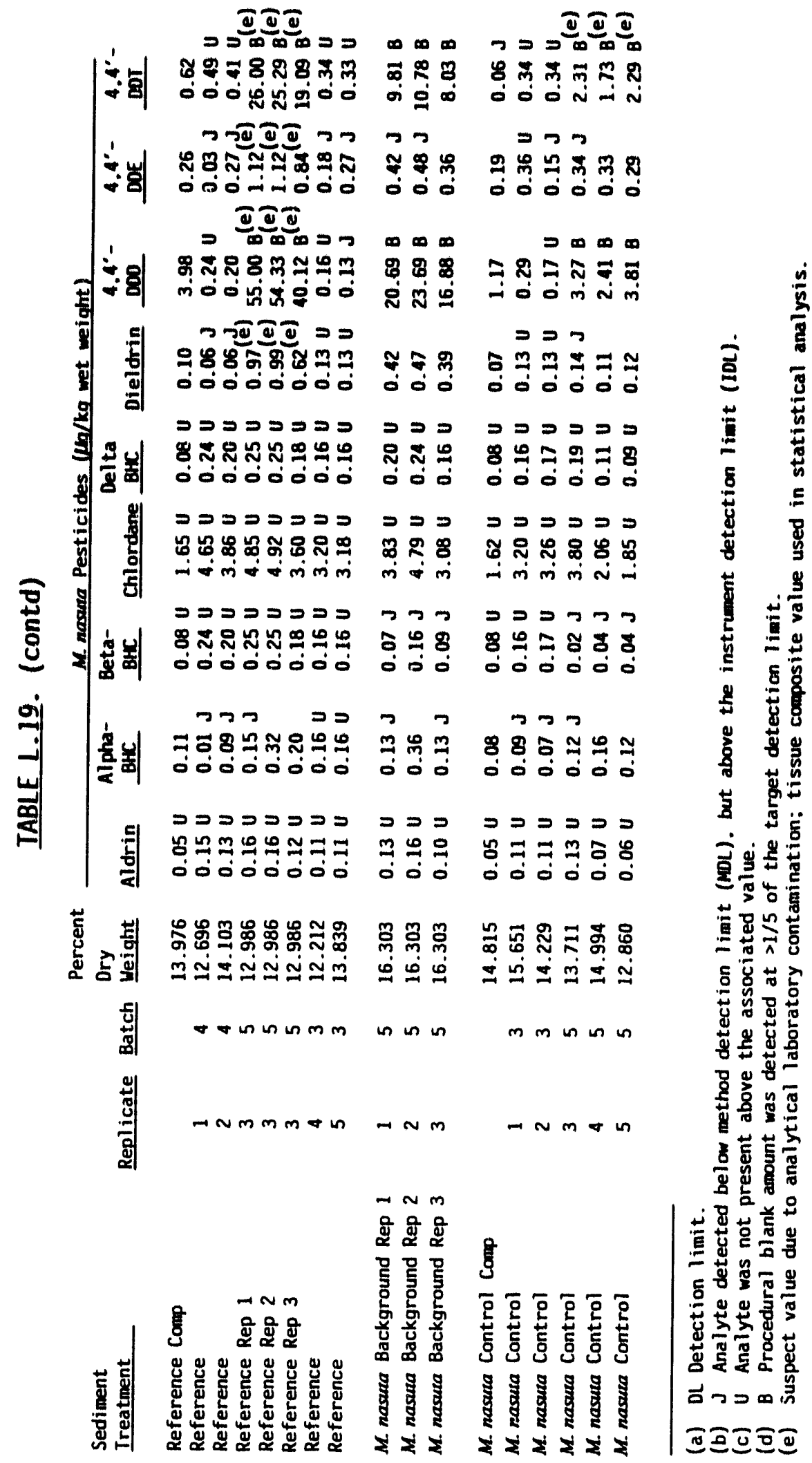

PANAMA CITY HARBOR 
모로

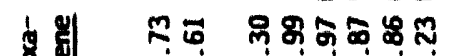

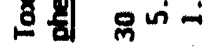
हो항

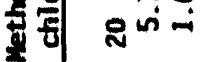

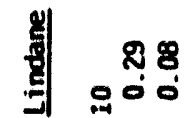

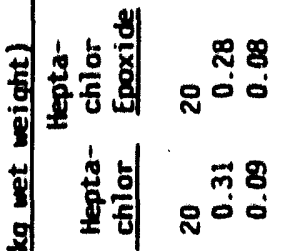

단

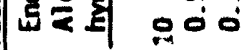

青 충 goio

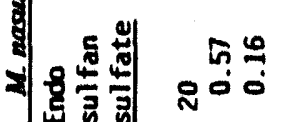

5은 安点

约

$=$

40

$\sum_{\text {जै }}^{4}$

들

วาว บว ตำำำ 00000 을

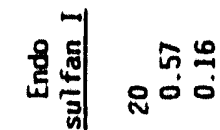
葍者言

응요

ơơं

莳界高角恋

可的可

$n \operatorname{mn} \otimes m$
บ고고

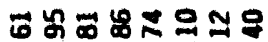

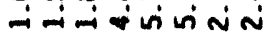

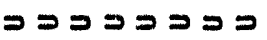

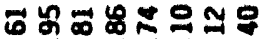
- - i-ivini $\Rightarrow \overline{\mathrm{z}}>\mathrm{D}$

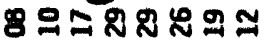
0ं00000

บ $⿻ コ 一 ⿻ 上$

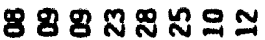

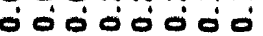

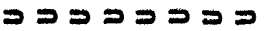

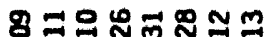
0000000

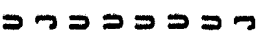

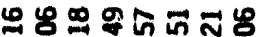

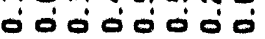
ว $\neg コ ⿻ コ 一 ⿻ 上$

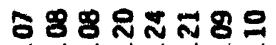
00000000

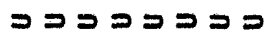
ำ里司踣 00000000

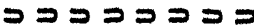
ํำำด约 สี 00000000

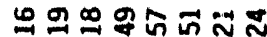

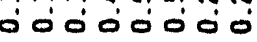

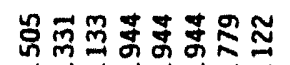

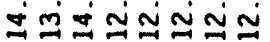

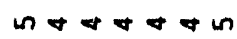

- NmMm

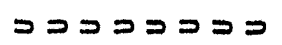

D

뉴 స న :

00000

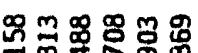

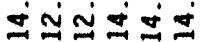

$\Rightarrow$ 可

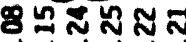
000000

8 m우요

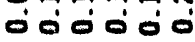
ว $ว \pi=2$ $8=8 \simeq \simeq$ 000000

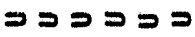

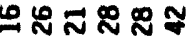
000000 כ $2 \geq 3$

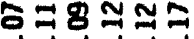
000000 00 0.0000

ว $\geq \geq \geq$

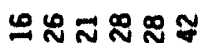
0.0000

ว $ว \geq \geq=$ 는듬ำ존 00000

(1)

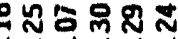
0ं000 ว $ว \geq \geq \geq$ 노오으므눙 ธ0ं000 D $0 \geq 0$

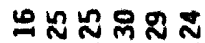
00000

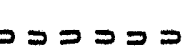

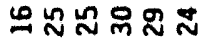
ơơó0 ニ 00000。

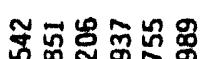

范岕品号怘芯

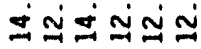

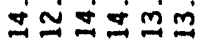

$\Delta \sin \rightarrow$

n $\forall n<m$

- Nm*m

$-N m+n$

- Nm 4

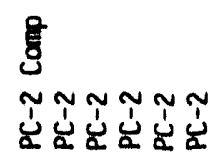<smiles>[BH2]</smiles>

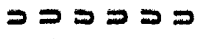
出品吅ล - ivinim D $\supset \geq \geq 0$

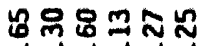
MUNNM PDD $D$ $8 \simeq 20 \div$ 00000

ב 20

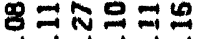
000000 ב $>\geq$ $8 ㅍ ㅛ ㄷ ㅗ$ 000000

二8내요 엉ㅇㅇ 구국

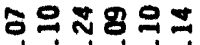
200000 จ $\supset \supset$ ล กัน ว $ว \geq \geq 2$

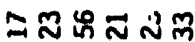
ócóó

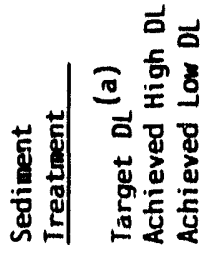

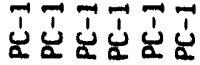

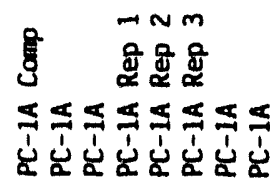

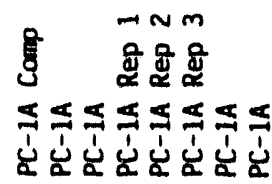

PANAMA CITY HARBOR 


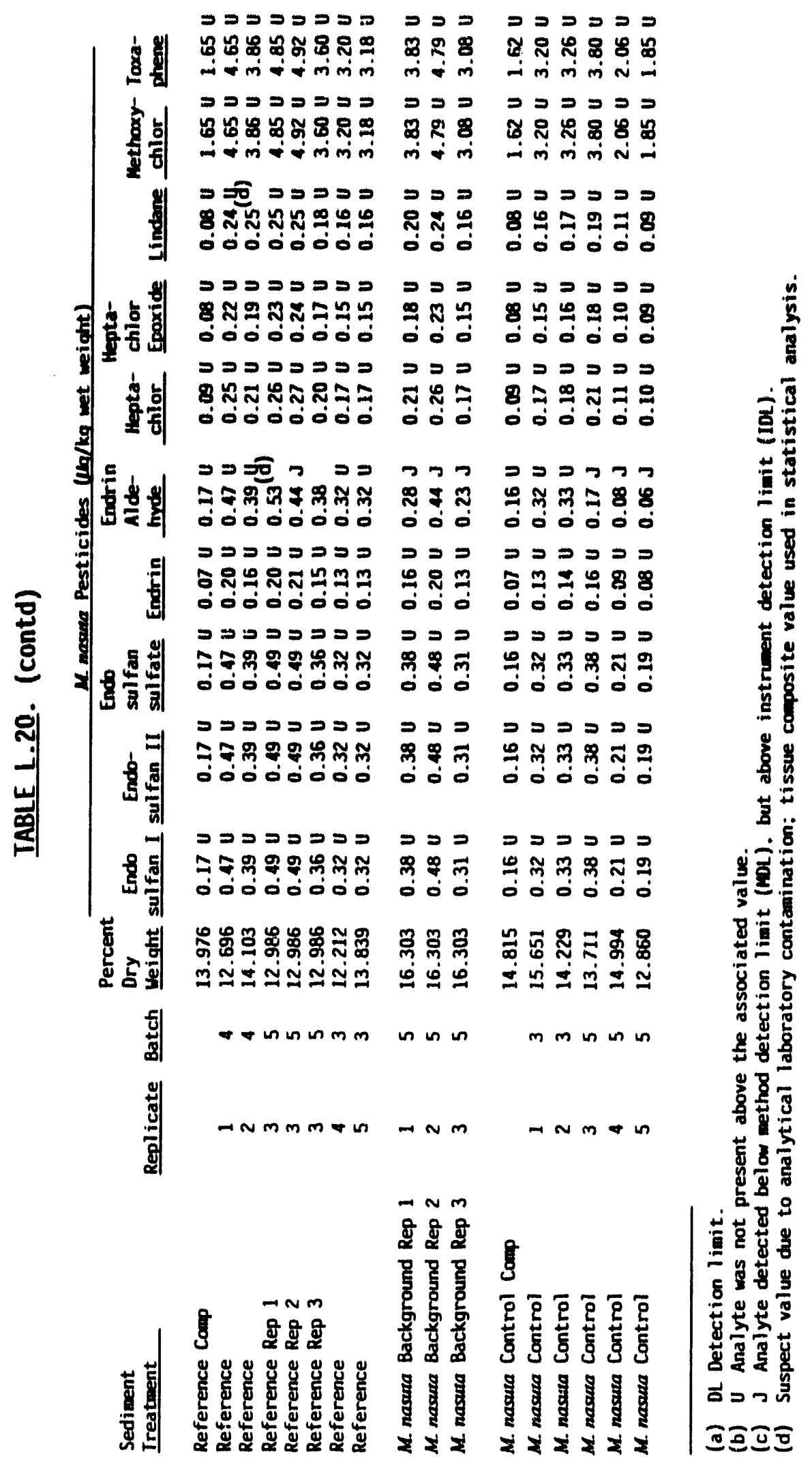




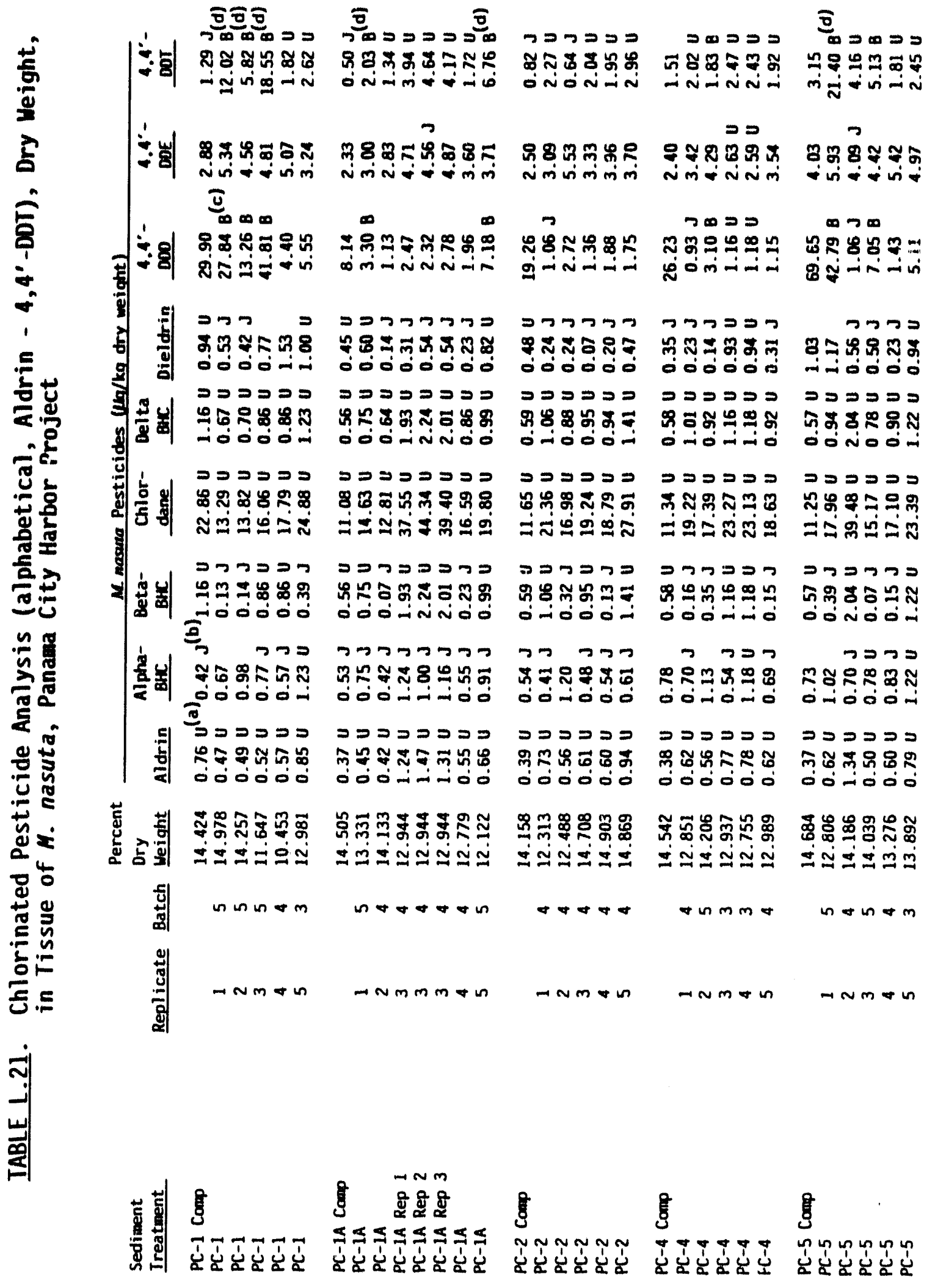




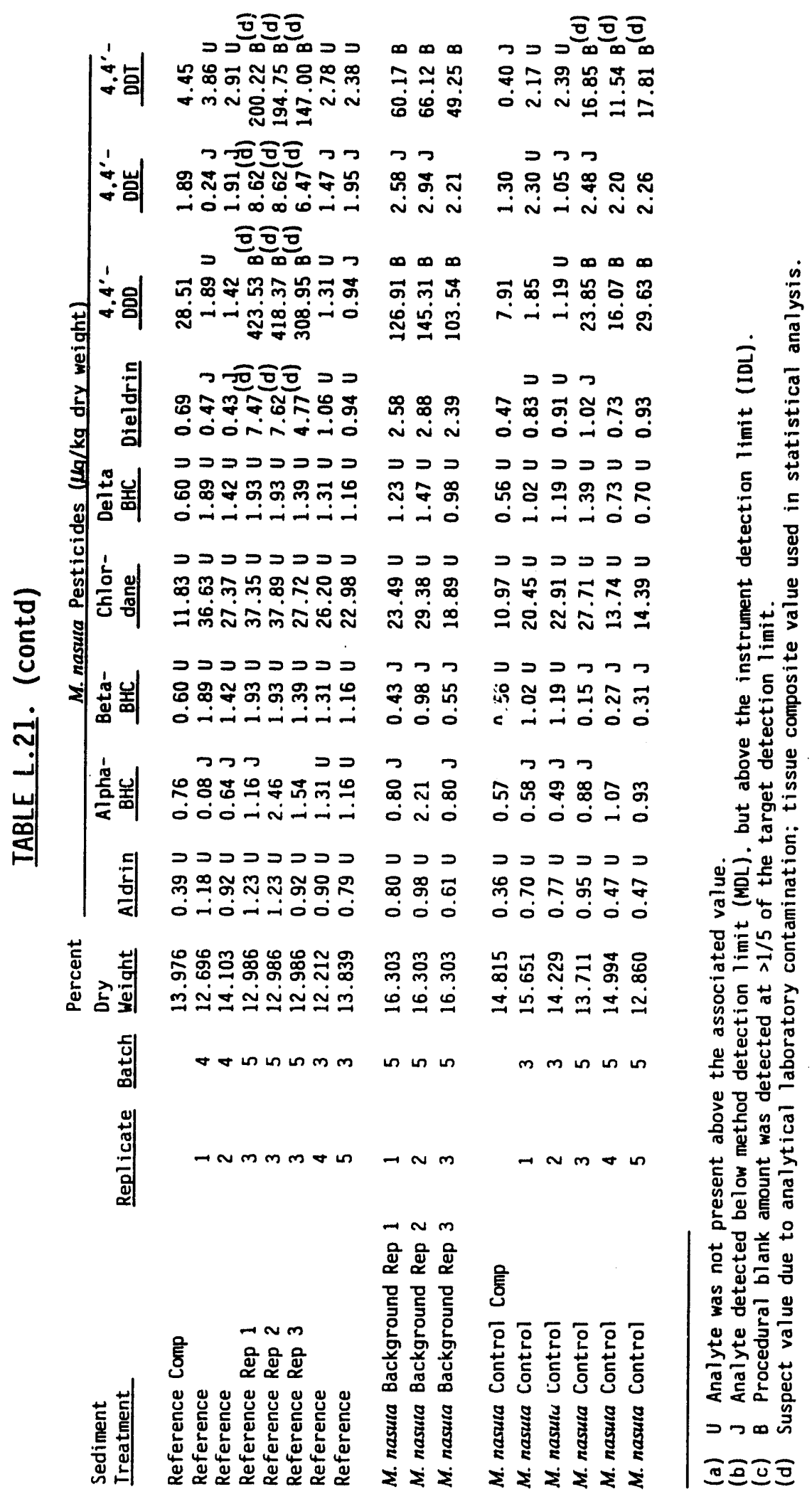




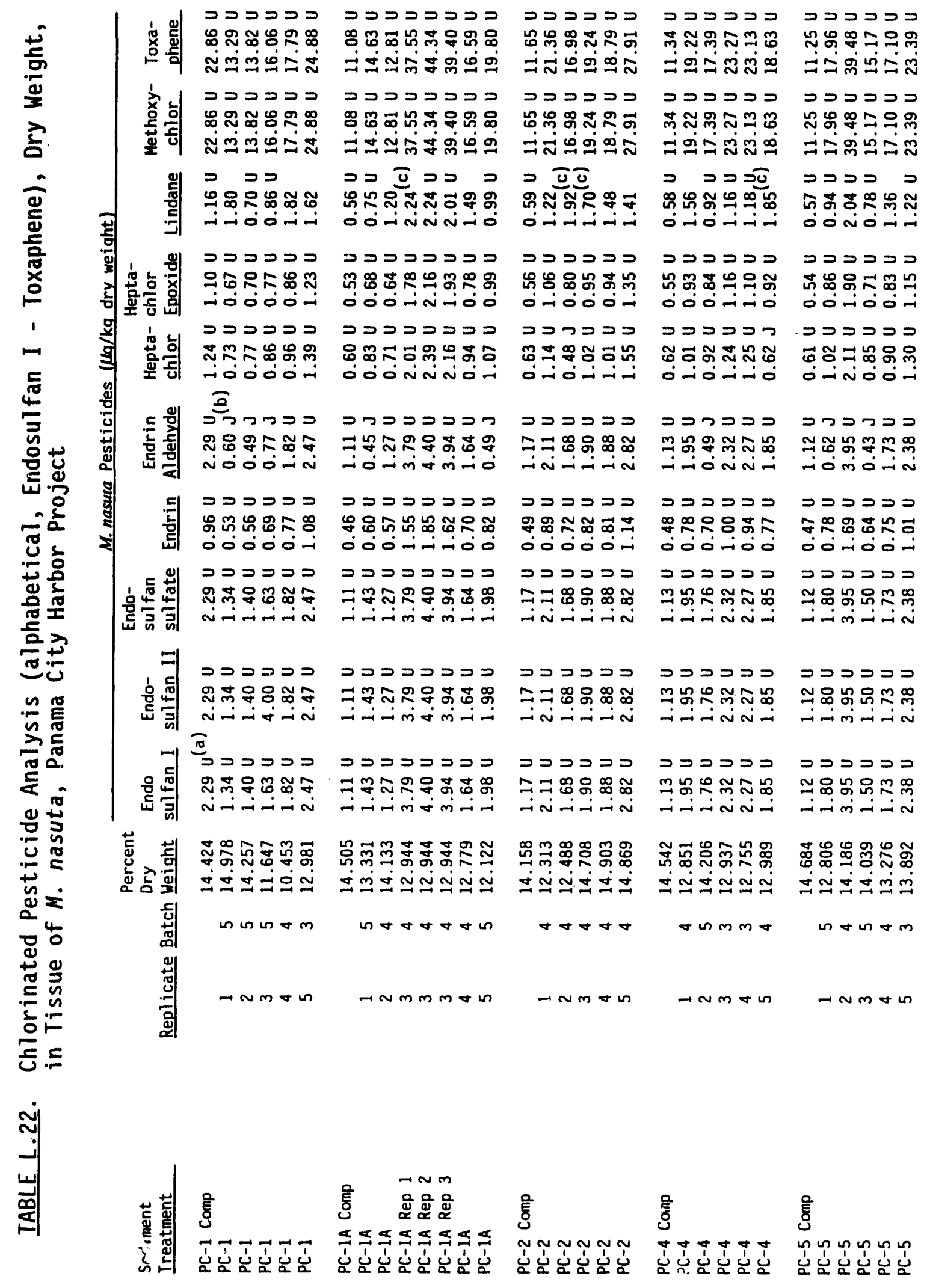

PANAMA CITY HARBOR 


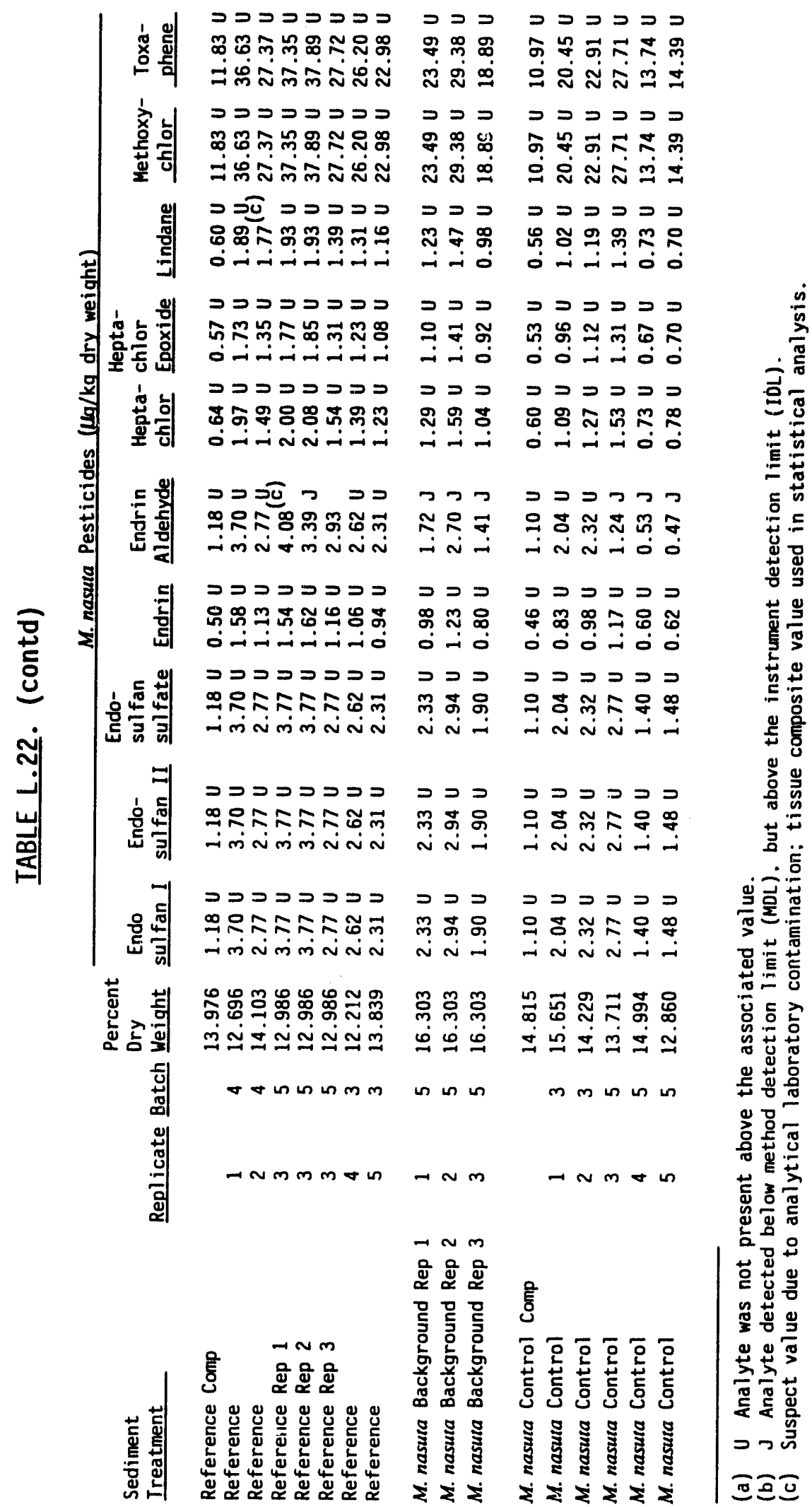

PANAMA CITY HARBOR 


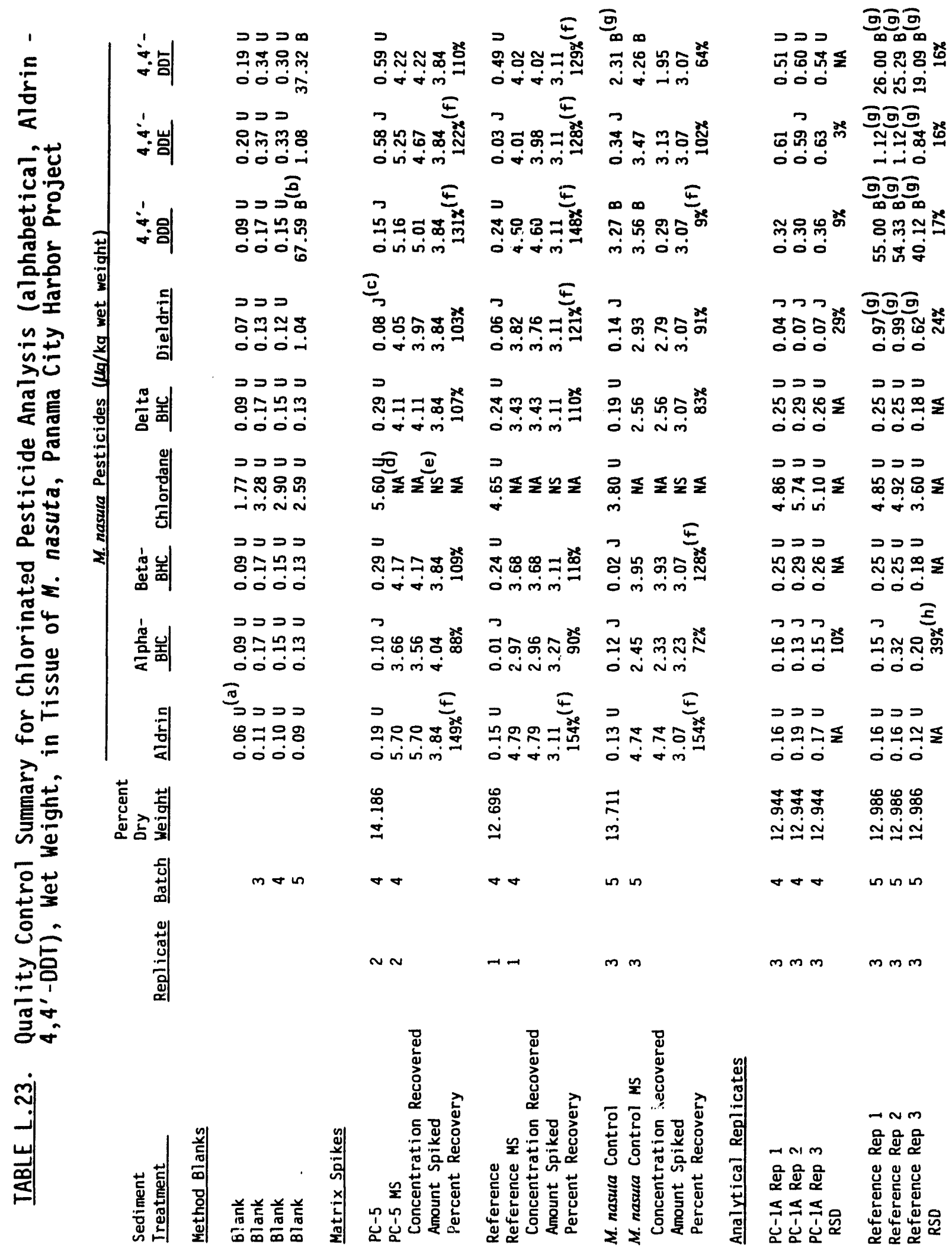

PANAMA CITY HARBOR 


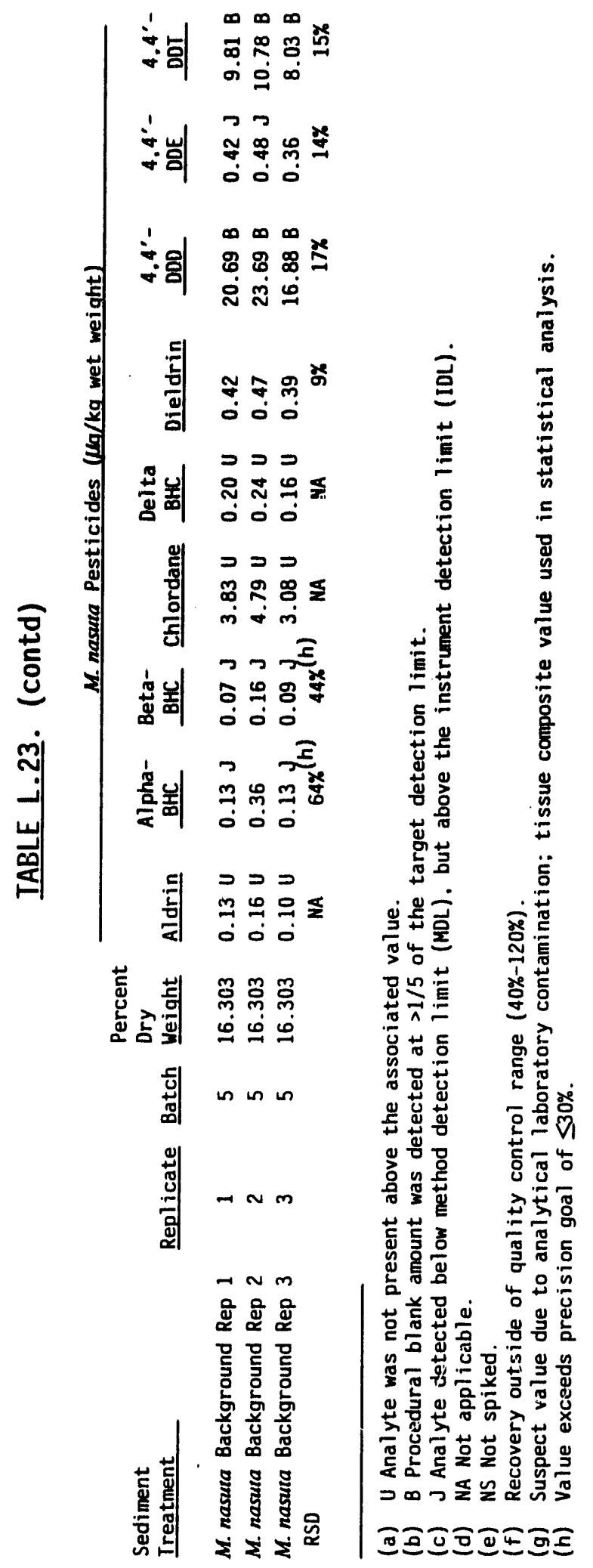

PANAMA CITY HARBOR 

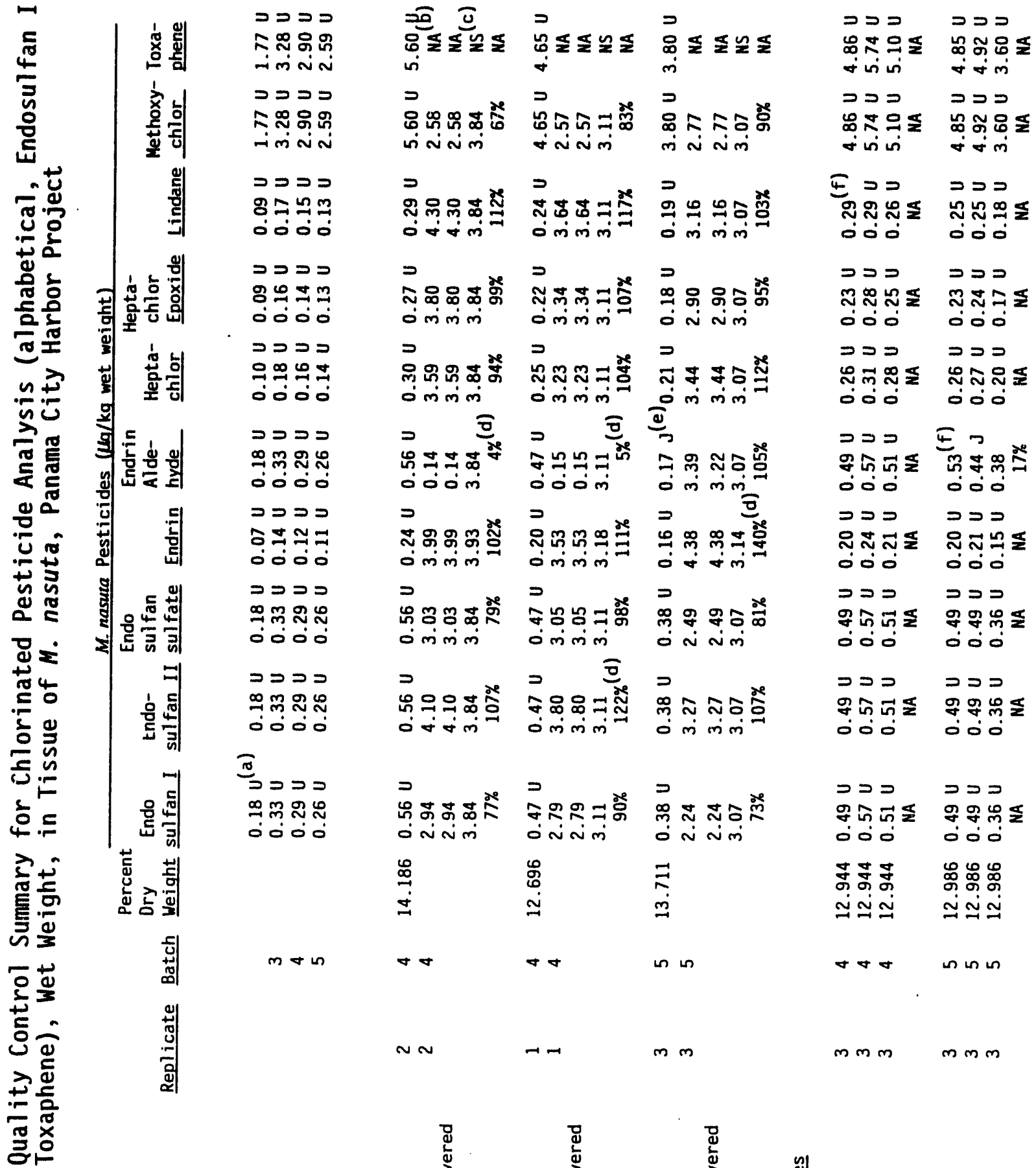

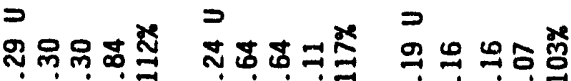

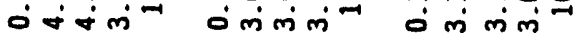

సิ요용

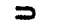
०ंmंn

ำ

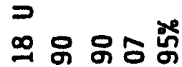

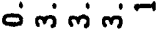
○ั $\sim$ in

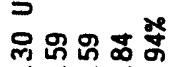

ก $m m=$ 年

I

वंmं

$\Rightarrow \quad \overline{0}=$ के

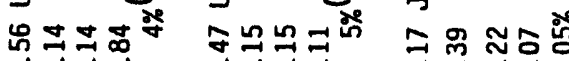

वं०்

वंōं

○ं mं mं

$>$

ํํ요ำ

$>$

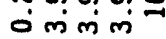

กิ๊

$\Rightarrow$ है

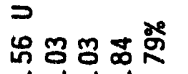

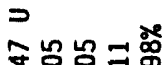

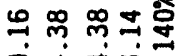

○ंmंn்

○ं किं कि

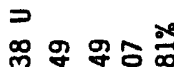

$\Rightarrow$

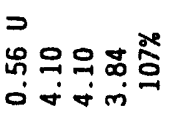

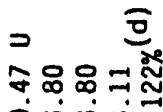

०ं तं

000

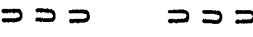

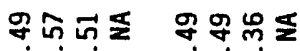

0ं0

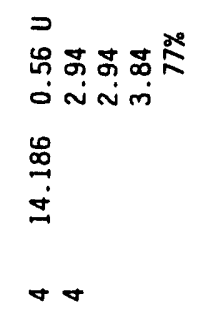

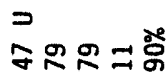

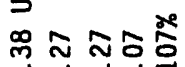

o

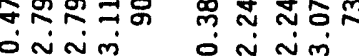

号

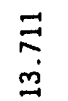

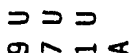

$\supset \supset$

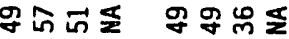

0ं0 0ं0

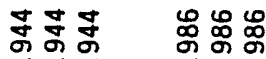

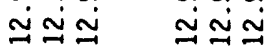

$\sim \sim$

$\rightarrow$

$m m$

$m m m$

mm

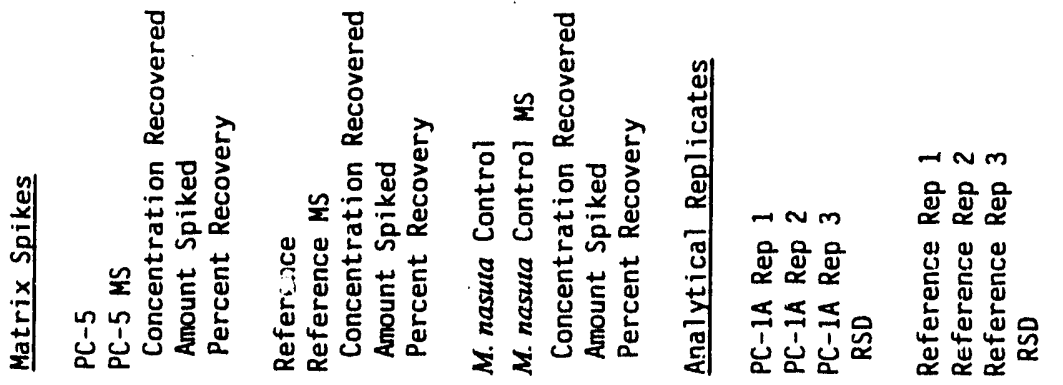

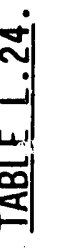

善

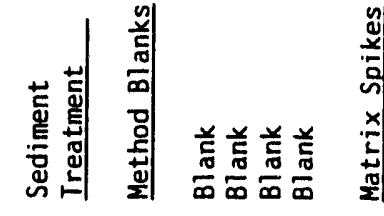

ن̀ 


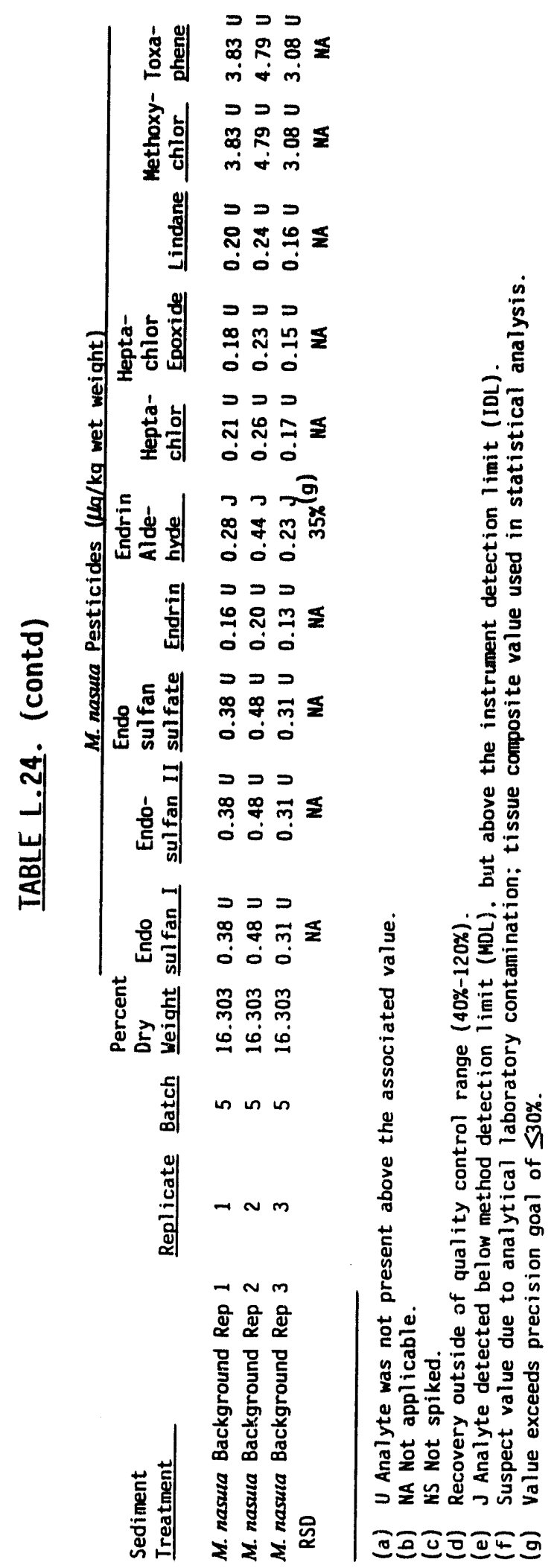

PANAMA CITY HARBOR 
TABLE L.25. Polychlorinated Biphenyl (PCB) Analysis, Wet Weight, in Tissue of $M$. nasuta, Panama City Harbor Project

\begin{tabular}{|c|c|c|c|c|c|c|c|c|c|}
\hline & & & & & & & & & \\
\hline $\begin{array}{l}\text { Sediment } \\
\text { Ireatment }\end{array}$ & Replicate & Batch & $\begin{array}{l}\text { Dry } \\
\text { Weight }\end{array}$ & $\begin{array}{l}\text { Aroclor } \\
1221\end{array}$ & $\begin{array}{l}\text { Aroclor } \\
1232 \\
\end{array}$ & $\begin{array}{l}\text { Aroclor } \\
1242\end{array}$ & $\begin{array}{l}\text { Aroclor } \\
1248\end{array}$ & $\begin{array}{l}\text { Aroclor } \\
1254 \\
\end{array}$ & $\begin{array}{l}\text { Aroclor } \\
1260 \\
\end{array}$ \\
\hline $\begin{array}{l}\text { Target OL (a) } \\
\text { Achieved High DL } \\
\text { Achieved Low OL }\end{array}$ & & & & $\begin{array}{l}20 \\
5.73 \\
1.61\end{array}$ & $\begin{array}{l}20 \\
5.73 \\
1.61\end{array}$ & $\begin{array}{l}20 \\
5.73 \\
1.61\end{array}$ & $\begin{array}{r}20 \\
5.73 \\
1.61\end{array}$ & $\begin{array}{l}20 \\
5.73 \\
1.61\end{array}$ & $\begin{array}{l}20 \\
5.73 \\
1.61\end{array}$ \\
\hline $\begin{array}{l}P C-1 \text { Comp } \\
P C-1 \\
P C-1 \\
P C-1 \\
P C-1 \\
P C-1\end{array}$ & $\begin{array}{l}1 \\
2 \\
3 \\
4 \\
5\end{array}$ & $\begin{array}{l}5 \\
5 \\
5 \\
4 \\
3\end{array}$ & $\begin{array}{l}14.424 \\
14.978 \\
14.257 \\
11.647 \\
10.453 \\
12.981\end{array}$ & $\begin{array}{l}3.30 U^{(b)} \\
1.99 U \\
1.97 U \\
1.87 U \\
1.86 U \\
3.23 U\end{array}$ & $\begin{array}{l}3.30 U \\
1.99 U \\
1.97 U \\
1.87 U \\
1.86 U \\
3.23 U\end{array}$ & $\begin{array}{l}3.30 \mathrm{U} \\
1.99 \mathrm{U} \\
1.97 \mathrm{U} \\
1.87 \mathrm{U} \\
1.86 \mathrm{U} \\
3.23 \mathrm{U}\end{array}$ & $\begin{array}{r}3.30 U \\
1.99 U \\
1.97 U \\
1.87 U \\
1.86 U \\
14.51\end{array}$ & $\begin{array}{r}12.24 \\
6.29 \\
6.19 \\
5.02 \\
16.43 \\
3.23 \mathrm{U}\end{array}$ & $\begin{array}{l}3.30 U \\
1.99 U \\
1.97 U \\
1.87 U \\
1.86 U \\
3.23 U\end{array}$ \\
\hline $\begin{array}{l}P C-1 A \text { Comp } \\
P C-1 A \\
P C-1 A \\
P C-1 A \text { Rep } 1 \\
P C-1 A \text { Rep } 2 \\
P C-1 A \text { Rep } 3 \\
P C-1 A \\
P C-1 A\end{array}$ & $\begin{array}{l}1 \\
2 \\
3 \\
3 \\
3 \\
4 \\
5\end{array}$ & $\begin{array}{l}5 \\
4 \\
4 \\
4 \\
4 \\
4 \\
5\end{array}$ & $\begin{array}{l}14.505 \\
13.331 \\
14.133 \\
12.944 \\
12.944 \\
12.944 \\
12.779 \\
12.122\end{array}$ & $\begin{array}{l}1.61 \mathrm{U} \\
1.95 \mathrm{U} \\
1.81 \mathrm{U} \\
4.86 \mathrm{U} \\
5.74 \mathrm{U} \\
5.10 \mathrm{U} \\
2.12 \mathrm{U} \\
2.40 \mathrm{U}\end{array}$ & $\begin{array}{l}1.61 \mathrm{U} \\
1.95 \mathrm{U} \\
1.81 \mathrm{U} \\
4.86 \mathrm{U} \\
5.74 \mathrm{U} \\
5.10 \mathrm{U} \\
2.12 \mathrm{U} \\
2.40 \mathrm{U}\end{array}$ & $\begin{array}{l}1.61 \mathrm{U} \\
1.95 \mathrm{U} \\
1.81 \mathrm{U} \\
4.86 \mathrm{U} \\
5.74 \mathrm{U} \\
5.10 \mathrm{U} \\
2.12 \mathrm{U} \\
2.40 \mathrm{U}\end{array}$ & $\begin{array}{l}1.61 \mathrm{U} \\
1.95 \mathrm{U} \\
1.81 \mathrm{U} \\
4.86 \mathrm{U} \\
5.74 \mathrm{U} \\
5.10 \mathrm{U} \\
2.12 \mathrm{U} \\
2.40 \mathrm{U}\end{array}$ & $\begin{array}{r}7.34 \\
3.81 \\
10.40 \\
20.72 \\
17.99 \\
18.96 \\
13.87 \\
4.21\end{array}$ & $\begin{array}{l}1.61 \mathrm{U} \\
1.95 \mathrm{U} \\
1.81 \mathrm{U} \\
4.86 \mathrm{U} \\
5.74 \mathrm{U} \\
5.10 \mathrm{U} \\
2.12 \mathrm{U} \\
2.40 \mathrm{U}\end{array}$ \\
\hline $\begin{array}{l}P C-2 \text { Comp } \\
P C-2 \\
P C-2 \\
P C-2 \\
P C-2 \\
P C-2\end{array}$ & $\begin{array}{l}1 \\
2 \\
3 \\
4 \\
5\end{array}$ & $\begin{array}{l}4 \\
4 \\
4 \\
4 \\
4\end{array}$ & $\begin{array}{l}14.158 \\
12.313 \\
12.488 \\
14.708 \\
14.903 \\
14.869\end{array}$ & $\begin{array}{l}1.65 \mathrm{U} \\
2.63 \mathrm{U} \\
2.12 \mathrm{U} \\
2.83 \mathrm{U} \\
2.80 \mathrm{U} \\
4.15 \mathrm{U}\end{array}$ & $\begin{array}{l}1.65 \mathrm{U} \\
2.63 \mathrm{U} \\
2.12 \mathrm{U} \\
2.83 \mathrm{U} \\
2.80 \mathrm{U} \\
4.15 \mathrm{U}\end{array}$ & $\begin{array}{l}1.65 U \\
2.63 U \\
2.12 U \\
2.83 U \\
2.80 U \\
4.15 U\end{array}$ & $\begin{array}{l}1.65 U \\
2.63 U \\
2.12 U \\
2.83 U \\
2.80 U \\
4.15 U\end{array}$ & $\begin{array}{r}5.77 \\
10.58 \\
12.38 \\
11.85 \\
14.17 \\
14.29\end{array}$ & $\begin{array}{l}1.65 U \\
2.63 U \\
2.12 U \\
2.83 U \\
2.80 U \\
4.15 U\end{array}$ \\
\hline $\begin{array}{l}P C-4 \text { Comp } \\
P C-4 \\
P C-4 \\
P C-4 \\
P C-4 \\
P C-4\end{array}$ & $\begin{array}{l}1 \\
2 \\
3 \\
4 \\
5\end{array}$ & $\begin{array}{l}4 \\
5 \\
3 \\
3 \\
4\end{array}$ & $\begin{array}{l}14.542 \\
12.851 \\
14.206 \\
12.937 \\
12.755 \\
12.989\end{array}$ & $\begin{array}{l}1.65 \mathrm{U} \\
2.47 \mathrm{U} \\
2.47 \mathrm{U} \\
3.01 \mathrm{U} \\
2.95 \mathrm{U} \\
2.42 \mathrm{U}\end{array}$ & $\begin{array}{l}1.65 U \\
2.47 U \\
2.47 U \\
3.01 U \\
2.95 U \\
2.42 U\end{array}$ & $\begin{array}{l}1.65 \mathrm{U} \\
2.47 \mathrm{U} \\
2.47 \mathrm{U} \\
3.01 \mathrm{U} \\
2.95 \mathrm{U} \\
2.42 \mathrm{U}\end{array}$ & $\begin{array}{l}1.65 U \\
2.47 U \\
2.47(U) \\
7.78(\mathrm{C}) \\
5.25(\mathrm{c}) \\
2.42 \mathrm{U}\end{array}$ & $\begin{array}{l}3.05 \\
8.25 \\
3.20 \\
3.01 \mathrm{U} \\
2.95 \mathrm{U} \\
8.33\end{array}$ & $\begin{array}{l}1.65 \mathrm{U} \\
2.47 \mathrm{U} \\
2.47 \mathrm{U} \\
3.01 \mathrm{U} \\
2.95 \mathrm{U} \\
2.42 \mathrm{U}\end{array}$ \\
\hline $\begin{array}{l}P C-5 \text { Comp } \\
P C-5 \\
P C-5 \\
P C-5 \\
P C-5 \\
P C-5\end{array}$ & $\begin{array}{l}1 \\
2 \\
3 \\
4 \\
5\end{array}$ & $\begin{array}{l}5 \\
4 \\
5 \\
4 \\
3\end{array}$ & $\begin{array}{l}14.684 \\
12.806 \\
14.186 \\
14.039 \\
13.276 \\
13.892\end{array}$ & $\begin{array}{l}1.65 U \\
2.30 U \\
5.60 U \\
2.13 U \\
2.27 U \\
3.25 U\end{array}$ & $\begin{array}{l}1.65 \mathrm{U} \\
2.30 \mathrm{U} \\
5.60 \mathrm{U} \\
2.13 \mathrm{U} \\
2.27 \mathrm{U} \\
3.25 \mathrm{U}\end{array}$ & $\begin{array}{l}1.65 U \\
2.30 U \\
5.60 U \\
2.13 U \\
2.27 U \\
3.25 U\end{array}$ & $\begin{array}{r}1.65 \mathrm{U} \\
2.30 \mathrm{U} \\
5.60 \mathrm{U} \\
2.13 \mathrm{U} \\
2.27 \mathrm{U}) \\
12.19(\mathrm{C})\end{array}$ & $\begin{array}{l}5.05 \\
3.07 \\
5.60 \mathrm{U} \\
3.08 \\
12.29 \\
3.25 \mathrm{U}\end{array}$ & $\begin{array}{l}1.65 \mathrm{U} \\
2.30 \mathrm{U} \\
5.60 \mathrm{U} \\
2.13 \mathrm{U} \\
2.27 \mathrm{U} \\
3.25 \mathrm{U}\end{array}$ \\
\hline $\begin{array}{l}\text { Reference Comp } \\
\text { Reference } \\
\text { Reference } \\
\text { Reference Rep } 1 \\
\text { Reference Rep } 2 \\
\text { Reference Rep } 3 \\
\text { Reference } \\
\text { Reference }\end{array}$ & $\begin{array}{l}1 \\
2 \\
3 \\
3 \\
3 \\
4 \\
5\end{array}$ & $\begin{array}{l}4 \\
4 \\
5 \\
5 \\
5 \\
3 \\
3\end{array}$ & $\begin{array}{l}13.976 \\
12.696 \\
14.103 \\
12.986 \\
12.986 \\
12.986 \\
12.212 \\
13.839\end{array}$ & $\begin{array}{l}1.65 U \\
4.65 U \\
3.86 U \\
4.85 U \\
4.92 U \\
3.60 U \\
3.20 U \\
3.18 U\end{array}$ & $\begin{array}{l}1.65 \mathrm{U} \\
4.65 \mathrm{U} \\
3.86 \mathrm{U} \\
4.85 \mathrm{U} \\
4.92 \mathrm{U} \\
3.60 \mathrm{U} \\
3.20 \mathrm{U} \\
3.18 \mathrm{U}\end{array}$ & $\begin{array}{l}1.65 U \\
4.65 U \\
3.86 U \\
4.85 U \\
4.92 U \\
3.60 U \\
3.20 U \\
3.18 U\end{array}$ & $\begin{array}{l}1.65 U \\
4.65 U \\
3.86 U \\
4.85 U \\
4.92 U \\
3.60 U \\
3.20(U) \\
8.09(C)\end{array}$ & $\begin{array}{l}1.65 \mathrm{U} \\
4.65 \mathrm{U} \\
3.86 \mathrm{U} \\
4.85 \mathrm{U} \\
4.92 \mathrm{U} \\
3.60 \mathrm{U} \\
3.20 \mathrm{U} \\
3.18 \mathrm{U}\end{array}$ & $\begin{array}{l}1.65 U \\
4.65 U \\
3.86 U \\
4.85 U \\
4.92 U \\
3.60 U \\
3.20 U \\
3.18 U\end{array}$ \\
\hline M. nasula Background Rep 1 & 1 & 5 & 16.303 & $3.83 \mathrm{U}$ & $3.83 \mathrm{U}$ & $3.83 \mathrm{U}$ & $3.83 \mathrm{U}$ & $3.83 \mathrm{U}$ & $3.83 \mathrm{U}$ \\
\hline M. nasuta Background Rep 2 & 2 & 5 & 16.303 & $4.79 \mathrm{U}$ & $4.79 \mathrm{U}$ & $4.79 \mathrm{U}$ & $4.79 \mathrm{U}$ & $4.79 \mathrm{U}$ & $4.79 \mathrm{U}$ \\
\hline M. nasuta Background Rep 3 & 3 & 5 & 16.303 & $3.08 \mathrm{U}$ & $3.08 \mathrm{U}$ & $3.08 \mathrm{U}$ & $3.08 \mathrm{U}$ & $3.08 \mathrm{U}$ & $3.08 \mathrm{U}$ \\
\hline
\end{tabular}


IABLE L.25. (contd)

Sediment

Ireatment

M. nasuta Control Comp

M. nasula Control

M. nasuta Control

M. nasuta Control

M. nasula Control

M. nasuta Control
Percent M. nasula PCBs ( $(\mathrm{kg} / \mathrm{kg}$ wet weight)

Dry Aroclor Aroclor Aroclor Aroclor Aroclor Aroclor

Replicate Batch Weight 1221 1232 $1242 \quad 1248 \quad 1254 \quad 1260$

$\begin{array}{llllllll}14.815 & 1.62 \cup & 1.62 \cup & 1.62 \cup & 1.62 \cup & 1.62 \cup & 1.62 U\end{array}$

$\begin{array}{llllllll}15.651 & 3.20 \mathrm{U} & 3.20 \mathrm{U} & 3.20 \mathrm{U} & 3.20 \mathrm{U} & 3.20 \mathrm{U} & 3.20 \mathrm{U}\end{array}$

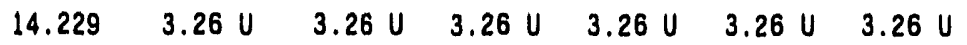

$\begin{array}{lllllll}13.711 & 3.80 \mathrm{U} & 3.80 \mathrm{U} & 3.80 \mathrm{U} & 3.80 \mathrm{U} & 3.80 \mathrm{U} & 3.80 \mathrm{U}\end{array}$

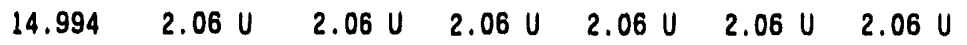

$\begin{array}{lllllll}12.860 & 1.85 \mathrm{U} & 1.85 \mathrm{U} & 1.85 \mathrm{U} & 1.85 \mathrm{U} & 1.85 \mathrm{U} & 1.85 \mathrm{U}\end{array}$

(a) DL Detection limit.

(b) U Analyte was not present above the associated value.

(c) Suspect value due to analytical laboratory contamination; tissue composite used in statistical analysis. 


\section{IABLELE26. Polychlorinated Biphenyl (PCB) Analysis, Dry Weight, in Tissue of M. nasuta, Panama City Harbor Project}

\begin{tabular}{|c|c|c|c|c|c|c|c|c|c|c|}
\hline \multirow[b]{2}{*}{ S } & \multirow[b]{2}{*}{$\begin{array}{l}\text { Sediment } \\
\text { Ireatment }\end{array}$} & \multirow[b]{2}{*}{ Beplicate } & \multirow[b]{2}{*}{ Batch } & \multirow[b]{2}{*}{$\begin{array}{l}\text { Dry } \\
\text { Welaht }\end{array}$} & \\
\hline & & & & & $\begin{array}{l}\text { Aroclor } \\
1221 \\
\end{array}$ & $\begin{array}{l}\text { Aroclor } \\
1232 \\
\end{array}$ & $\begin{array}{l}\text { Aroclor } \\
1242 \\
\end{array}$ & $\begin{array}{c}\text { Aroclor } \\
1248 \\
\end{array}$ & $\begin{array}{l}\text { Aroclor } \\
1254 \\
\end{array}$ & $\begin{array}{c}\text { Aroclor } \\
1260 \\
\end{array}$ \\
\hline $\begin{array}{l}p_{1} \\
P\end{array}$ & $\begin{array}{l}P C-1 \text { Comp } \\
P C-1 \\
P C-1 \\
P C-1 \\
P C-1 \\
P C-1\end{array}$ & $\begin{array}{l}1 \\
2 \\
3 \\
4 \\
5\end{array}$ & $\begin{array}{l}5 \\
5 \\
5 \\
4 \\
3\end{array}$ & $\begin{array}{l}14.424 \\
14.978 \\
14.257 \\
11.647 \\
10.453 \\
12.981\end{array}$ & $\begin{array}{l}22.86 U^{10} \\
13.29 U \\
13.82 U \\
16.06 U \\
17.79 U \\
24.88 U\end{array}$ & $\begin{array}{l}1)_{22.86} \mathrm{U} \\
13.29 \mathrm{U} \\
13.82 \mathrm{U} \\
16.06 \mathrm{U} \\
17.79 \mathrm{U} \\
24.88 \mathrm{U}\end{array}$ & $\begin{array}{l}22.86 \mathrm{U} \\
13.29 \mathrm{U} \\
13.82 \mathrm{U} \\
16.06 \mathrm{U} \\
17.79 \mathrm{U} \\
24.88 \mathrm{U}\end{array}$ & $\begin{array}{r}22.86 U \\
13.29 U \\
13.82 U \\
16.06 U \\
17.79 U \\
111.78\end{array}$ & $\begin{array}{r}84.86 \\
41.99 \\
43.42 \\
43.10 \\
157.18 \\
24.88 \mathrm{U}\end{array}$ & $\begin{array}{l}22.86 \\
13.29 \\
13.82 \\
16.06 \\
17.79 \\
24.88\end{array}$ \\
\hline PI & $\begin{array}{l}P C-1 A \text { Comp } \\
P C-1 A \\
P C-1 A \\
P C-1 A \text { Rep } 1 \\
P C-1 A \text { Rep } 2 \\
P C-1 A \text { Rep } 3 \\
P C-1 A \\
P C-1 A\end{array}$ & $\begin{array}{l}1 \\
2 \\
3 \\
3 \\
3 \\
4 \\
5\end{array}$ & $\begin{array}{l}5 \\
4 \\
4 \\
4 \\
4 \\
4 \\
5\end{array}$ & $\begin{array}{l}14.505 \\
13.331 \\
14.133 \\
12.944 \\
12.944 \\
12.944 \\
12.779 \\
12.122\end{array}$ & $\begin{array}{l}11.08 U \\
14.63 U \\
12.81 U \\
37.55 U \\
44.34 U \\
39.40 U \\
16.59 U \\
19.80 U\end{array}$ & $\begin{array}{l}11.08 U \\
14.63 U \\
12.81 U \\
37.55 U \\
44.34 U \\
39.40 U \\
16.59 U \\
19.80 U\end{array}$ & $\begin{array}{l}11.08 \mathrm{U} \\
14.63 \mathrm{U} \\
12.81 \mathrm{U} \\
37.55 \mathrm{U} \\
44.34 \mathrm{U} \\
39.40 \mathrm{U} \\
16.59 \mathrm{U} \\
19.80 \mathrm{U}\end{array}$ & $\begin{array}{l}11.08 U \\
14.63 U \\
12.81 U \\
37.55 U \\
44.34 U \\
39.40 U \\
16.59 U \\
19.80 U\end{array}$ & $\begin{array}{r}50.57 \\
28.58 \\
73.59 \\
160.07 \\
138.98 \\
146.48 \\
108.54 \\
34.73\end{array}$ & $\begin{array}{l}11.08 U \\
14.63 U \\
12.81 U \\
37.55 U \\
44.34 U \\
39.40 U \\
16.59 U \\
19.80 U\end{array}$ \\
\hline $\begin{array}{l}P 1 \\
P l \\
P l \\
P l \\
P(\end{array}$ & $\begin{array}{l}P C-2 \text { Comp } \\
P C-2 \\
P C-2 \\
P C-2 \\
P C-2 \\
P C-2\end{array}$ & $\begin{array}{l}1 \\
2 \\
3 \\
4 \\
5\end{array}$ & $\begin{array}{l}4 \\
4 \\
4 \\
4 \\
4\end{array}$ & $\begin{array}{l}14.158 \\
12.313 \\
12.488 \\
14.708 \\
14.903 \\
14.869\end{array}$ & $\begin{array}{l}11.65 U \\
21.36 U \\
16.98 U \\
19.24 U \\
18.79 U \\
27.91 U\end{array}$ & $\begin{array}{l}11.65 U \\
21.36 U \\
16.98 U \\
19.24 U \\
18.79 U \\
27.91 U\end{array}$ & $\begin{array}{l}11.65 U \\
21.36 U \\
16.98 U \\
19.24 U \\
18.79 U \\
27.91 U\end{array}$ & $\begin{array}{l}11.65 U \\
21.36 U \\
16.98 U \\
19.24 U \\
18.79 U \\
27.91 U\end{array}$ & $\begin{array}{l}40.74 \\
85.93 \\
99.14 \\
80.57 \\
95.08 \\
96.11\end{array}$ & $\begin{array}{l}1.65 U \\
1.36 U \\
6.98 U \\
9.24 U \\
8.79 U \\
7.91 U\end{array}$ \\
\hline c' & $\begin{array}{l}P C-4 \text { Comp } \\
P C-4 \\
P C-4 \\
P C-4 \\
P C-4 \\
P C-4\end{array}$ & $\begin{array}{l}1 \\
2 \\
3 \\
4 \\
5\end{array}$ & $\begin{array}{l}4 \\
5 \\
3 \\
3 \\
4\end{array}$ & $\begin{array}{l}14.542 \\
12.851 \\
14.206 \\
12.937 \\
12.755 \\
12.989\end{array}$ & $\begin{array}{l}11.34 U \\
19.22 U \\
17.39 U \\
23.27 U \\
23.13 U \\
18.63 U\end{array}$ & $\begin{array}{l}11.34 U \\
19.22 U \\
17.39 U \\
23.27 U \\
23.13 U \\
18.63 U\end{array}$ & $\begin{array}{l}11.34 U \\
19.22 U \\
17.39 U \\
23.27 U \\
23.13 U \\
18.63 U\end{array}$ & $\begin{array}{l}11.34 \mathrm{U} \\
19.22 \mathrm{U} \\
17.39(\mathrm{~b}) \\
60.14(\mathrm{~b}) \\
41.16 \mathrm{~b}) \\
18.63 \mathrm{U}\end{array}$ & $\begin{array}{l}20.98 \\
64.20 \\
22.53 \\
23.27 \mathrm{U} \\
23.13 \mathrm{U} \\
64.13\end{array}$ & $\begin{array}{l}11.34 \mathrm{U} \\
19.22 \mathrm{U} \\
17.39 \mathrm{U} \\
23.27 \mathrm{U} \\
23.13 \mathrm{U} \\
18.63 \mathrm{U}\end{array}$ \\
\hline 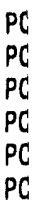 & $\begin{array}{l}P C-5 \text { Comp } \\
P C-5 \\
P C-5 \\
P C-5 \\
P C-5 \\
P C-5\end{array}$ & $\begin{array}{l}1 \\
2 \\
3 \\
4 \\
5\end{array}$ & $\begin{array}{l}5 \\
4 \\
5 \\
4 \\
3\end{array}$ & $\begin{array}{l}14.684 \\
12.806 \\
14.186 \\
14.039 \\
13.276 \\
13.892\end{array}$ & $\begin{array}{l}11.25 U \\
17.96 U \\
39.48 \mathrm{U} \\
15.17 \mathrm{U} \\
17.10 \mathrm{U} \\
23.39 \mathrm{U}\end{array}$ & $\begin{array}{l}11.25 \mathrm{U} \\
17.96 \mathrm{U} \\
39.48 \mathrm{U} \\
15.17 \mathrm{U} \\
17.10 \mathrm{U} \\
23.39 \mathrm{U}\end{array}$ & $\begin{array}{l}11.25 \mathrm{U} \\
17.96 \mathrm{U} \\
39.48 \mathrm{U} \\
15.17 \mathrm{U} \\
17.10 \mathrm{U} \\
23.39 \mathrm{U}\end{array}$ & $\begin{array}{l}11.25 U \\
17.96 U \\
39.48 U \\
15.17 U \\
17.10(b) \\
87.75(b)\end{array}$ & $\begin{array}{l}34.42 \\
23.97 \\
39.48 \mathrm{U} \\
21.94 \\
92.57 \\
23.39 \mathrm{U}\end{array}$ & $\begin{array}{l}11.25 \mathrm{U} \\
17.96 \mathrm{U} \\
39.48 \mathrm{U} \\
15.17 \mathrm{U} \\
17.10 \mathrm{U} \\
23.39 \mathrm{U}\end{array}$ \\
\hline $\begin{array}{l}\mathrm{Re} \\
\mathrm{Re} \\
\mathrm{Re} \\
\mathrm{Re}\end{array}$ & $\begin{array}{l}\text { Reference Comp } \\
\text { Reference } \\
\text { Reference } \\
\text { Reference Rep } 1 \\
\text { Reference Rep } 2 \\
\text { Reference Rep } 3 \\
\text { Reference } \\
\text { Reference }\end{array}$ & $\begin{array}{l}1 \\
2 \\
3 \\
3 \\
3 \\
4 \\
5\end{array}$ & $\begin{array}{l}4 \\
4 \\
5 \\
5 \\
5 \\
3 \\
3\end{array}$ & $\begin{array}{l}13.976 \\
12.696 \\
14.103 \\
12.986 \\
12.986 \\
12.986 \\
12.212 \\
13.839\end{array}$ & $\begin{array}{l}11.83 U \\
36.63 U \\
27.37 U \\
37.35 U \\
37.89 U \\
27.72 U \\
26.20 U \\
22.98 U\end{array}$ & $\begin{array}{l}11.83 \mathrm{U} \\
36.63 \mathrm{U} \\
27.37 \mathrm{U} \\
37.35 \mathrm{U} \\
37.89 \mathrm{U} \\
27.72 \mathrm{U} \\
26.20 \mathrm{U} \\
22.98 \mathrm{U}\end{array}$ & $\begin{array}{l}11.83 \mathrm{U} \\
36.63 \mathrm{U} \\
27.37 \mathrm{U} \\
37.35 \mathrm{U} \\
37.89 \mathrm{U} \\
27.72 \mathrm{U} \\
26.20 \mathrm{U} \\
22.98 \mathrm{U}\end{array}$ & $\begin{array}{l}11.83 U \\
36.63 U \\
27.37 U \\
37.35 U \\
37.89 U \\
27.72 U \\
26.20(b) \\
58.46(b)\end{array}$ & $\begin{array}{l}11.83 \mathrm{U} \\
36.63 \mathrm{U} \\
27.37 \mathrm{U} \\
37.35 \mathrm{U} \\
37.89 \mathrm{U} \\
27.72 \mathrm{U} \\
26.20 \mathrm{U} \\
22.98 \mathrm{U}\end{array}$ & $\begin{array}{l}11.83 \mathrm{U} \\
36.63 \mathrm{U} \\
27.37 \mathrm{U} \\
37.35 \mathrm{U} \\
37.89 \mathrm{U} \\
27.72 \mathrm{U} \\
26.20 \mathrm{U} \\
22.98 \mathrm{U}\end{array}$ \\
\hline & M. nasuta Background Rep 1 & 1 & 5 & 16.303 & 23.490 & 20.490 & 20.490 & 23.490 & $23.49 \mathrm{U}$ & 23.490 \\
\hline & M. nasuta Background Rep 2 & 2 & 5 & 16.303 & $29.38 \mathrm{U}$ & $29.38 \mathrm{U}$ & $29.38 \mathrm{U}$ & $29.38 \mathrm{U}$ & $29.38 \mathrm{U}$ & $29.38 \mathrm{U}$ \\
\hline & M. nasuta Background Rep 3 & 3 & 5 & 16.303 & $18.89 U$ & $18.89 \mathrm{U}$ & $18.89 \mathrm{U}$ & $18.89 \mathrm{U}$ & $18.89 \mathrm{U}$ & 18.89 \\
\hline
\end{tabular}




\section{IABLE L.26. (contd)}

Sediment

Ireatment

M. nasula Control Comp

$M$. nasuta Control

M. nasuta Control

M. nasuta Control

M. nasuta Control

$M$. nasuta Control

\begin{tabular}{|c|c|c|c|c|c|c|c|c|}
\hline \multirow[b]{2}{*}{ Replicate } & \multirow[b]{2}{*}{ Batch } & \multirow{2}{*}{$\begin{array}{l}\text { Percent } \\
\text { Dry } \\
\text { Welaht }\end{array}$} & \multicolumn{6}{|c|}{ M. nasula PCBs $(1 \mathrm{~g} / \mathrm{kg}$ dry weight $)$} \\
\hline & & & $\begin{array}{c}\text { Aroclor } \\
1221 \\
\end{array}$ & $\begin{array}{c}\text { Aroclor } \\
\quad 1232 \\
\end{array}$ & $\begin{array}{c}\text { Aroclor } \\
1242 \\
\end{array}$ & $\begin{array}{c}\text { Aroclor } \\
1248 \\
\end{array}$ & $\begin{array}{c}\text { Aroc lor } \\
1254 \\
\end{array}$ & $\begin{array}{c}\text { Aroclor } \\
1260 \\
\end{array}$ \\
\hline 1 & 3 & $\begin{array}{l}14.815 \\
15.651\end{array}$ & $\begin{array}{l}10.97 U \\
20.45 U\end{array}$ & $\begin{array}{l}10.97 U \\
20.45 U\end{array}$ & $\begin{array}{l}10.97 U \\
20.45 U\end{array}$ & $\begin{array}{l}10.97 U \\
20.45 U\end{array}$ & $\begin{array}{l}10.97 U \\
20.45 U\end{array}$ & $\begin{array}{l}10.97 U \\
20.45 U\end{array}$ \\
\hline 2 & 3 & 14.229 & $22.91 U$ & $22.91 \mathrm{U}$ & $22.91 \mathrm{U}$ & $22.91 U$ & $22.91 \mathrm{U}$ & $22.91 \mathrm{U}$ \\
\hline 3 & 5 & 13.711 & $27.71 \mathrm{U}$ & $27.71 \mathrm{U}$ & $27.71 \mathrm{U}$ & $27.71 \mathrm{U}$ & $27.71 \mathrm{U}$ & $27.71 \mathrm{U}$ \\
\hline 4 & 5 & 14.994 & $13.74 \mathrm{U}$ & $13.74 \mathrm{U}$ & $13.74 \mathrm{U}$ & $13.74 \mathrm{U}$ & $13.74 \mathrm{U}$ & $13.74 \mathrm{U}$ \\
\hline 5 & 5 & 12.860 & $14.39 \mathrm{U}$ & $14.39 \mathrm{U}$ & $14.39 \mathrm{U}$ & $14.39 \mathrm{U}$ & $14.39 \mathrm{U}$ & $14.39 \mathrm{U}$ \\
\hline
\end{tabular}

(a) U Analyte was not present above the associated value.

(b) Suspect value due to analytical laboratory contamination; tissue composite value used in statistical analysis. 
IABLE L.27. Quality Control Summary for Polychlorinated Biphenyl (PCB) Analysis, Wet Weight, in Tissue of M. nasuta, Panama City Harbor Project

Sediment

Ireatment

\begin{tabular}{|c|c|c|c|c|c|c|c|c|}
\hline \multirow[b]{2}{*}{ Replicate } & \multirow[b]{2}{*}{ Batch } & \multirow{2}{*}{$\begin{array}{l}\text { Parcent } \\
\text { Dry } \\
\text { Watght }\end{array}$} & \multicolumn{6}{|c|}{ M. nusule $\mathrm{PCBS}(1 \mathrm{~g} / \mathrm{kg}$ wet waloht) } \\
\hline & & & $\begin{array}{l}\text { Aroclor } \\
1221\end{array}$ & $\begin{array}{l}\text { Aroclor } \\
1232\end{array}$ & $\begin{array}{l}\text { Aroclor } \\
1242\end{array}$ & $\begin{array}{l}\text { Aroclor } \\
1248\end{array}$ & $\begin{array}{l}\text { Aroclor } \\
1254\end{array}$ & 1260 \\
\hline
\end{tabular}

Method Blanks

Blank

Blank

Blank

Blank

$\begin{array}{lllllllll} & 1.77 U(a) & 1.77 U & 1.77 U & 1.77 U & 1.77 U & 1.77 U \\ 3 & 3.28 U & 3.28 U & 3.28 U & 3.28 U & 3.28 U & 3.28 U \\ 4 & 2.90 U & 2.90 U & 2.90 U & 2.90 U & 2.90 U & 2.90 U \\ 5 & 2.59 U & 2.59 U & 2.59 U & 2.59 U & 2.59 U & 2.59 U\end{array}$

\section{Matrix Solkes}

$P C-5$

PC-5 MS

Concentration Recovered

Amount Spiked

Percent Recovery

Reference

Reference MS

Concentration Recovered

Amount Spiked

Percent Recovery

M. nasuta Control

$M$. nasuta Control MS

14.186

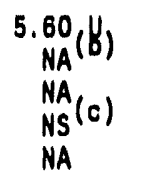

$5.60 \mathrm{U}$

NA
NA
NA

5.60 U
NA
NA
NS
NA

5.60 U
NA
NA
NS
NA

5.60

101.17

101.17

43.17

$5,60 \mathrm{U}$ $234 x^{(d)}$ NA

Concentration Recovered

Amount Spiked

Percent Recovery

Analytical Replicates

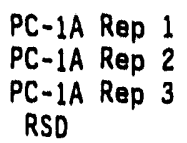

Reference Rep 1

Reference Rep 2

Reference Rep 3

RSD

M. nasuta Background Rep 1 $M$. nasula Background Rep 2 $M$. nasuta Background Rep 3 RSD
12.696

$4.65 U$
NA
NA
NS
NA

$4.65 \mathrm{U}$

$4.65 \mathrm{U}$

$4.65 \mathrm{U}$

NA
NS
NA

$N A$
$N A$
$N S$
$N A$

13.711

$3.80 U$
NA
NA
NS
NA

$3.80 \mathrm{U}$

$3.80 \mathrm{U}$

NA

NA

NA

NS

NA
NA
NS
NA

4.650
85.94
85.94
35.00
$246 \%$

$3.80 \mathrm{U}$

3.80

24.00

24.00

51.11

$47 \%$

$4.65 \mathrm{U}$

NS

NA

NS$$
47 \%
$$

20.72

20.72

17.99
18.96

$4.86 \mathrm{U}$

$\begin{array}{ll}12.944 & 4.86 U \\ 12.944 & 5.74 U \\ 12.944 & 5.10 \mathrm{U} \\ & \text { NA }\end{array}$

$4.86 U$

$4.86 \mathrm{U}$

4.86

5.74

$5.10 \mathrm{U}$

$5.10 \mathrm{U}$

5.10

8.96

$5.74 \mathrm{U}$

$5.10 \mathrm{U}$

\section{$12.986 \quad 4.85 \mathrm{U}$}

12.986

$4.92 \mathrm{U}$

$4.85 \mathrm{U}$

$4.92 \mathrm{U}$

$4.85 \mathrm{U}$

$4.92 \mathrm{U}$

$4.85 U$

$4.92 \mathrm{U}$

$4.85 U$

$4.92 \mathrm{U}$

$4.85 \mathrm{U}$

12.986

NA

NA

NA

NA

3.60
$N A$

$3.60 \mathrm{U}$

16.303

$3.83 \mathrm{U}$

$3.83 \mathrm{U}$

$3.83 \mathrm{U}$

$3.83 \mathrm{U}$

$3.83 \mathrm{U}$

$4.79 \mathrm{U}$

$3.83 \mathrm{U}$

16.303

$3.08 \mathrm{U}$

$3.08 \mathrm{U}$

$4.79 \mathrm{U}$

$4.79 \mathrm{U}$

$3.08 \mathrm{U}$

$4.79 \mathrm{U}$

NA

NA

NA

NA

NA

NA

(a) U Analyte was not present above the associated value.

(b) NA Not applicable.

(c) NS Not spiked.

(d) Recovery outside of quality control range $(40 \%-120 \%)$. 
IABLELL28. Surrogate Percent Recoverles and Quality Control Data for Chlorinated Pesticide and Polychlorinated Biphenyl (PCB) Analysis, Wet Weight, in Tissue of $M$. nasuta Panama City Harbor Project

\begin{tabular}{|c|c|c|c|c|c|}
\hline $\begin{array}{l}\text { Sediment } \\
\text { Ireatment }\end{array}$ & Beplicate & Batch & $\frac{\text { Surroc }}{\text { DBOEB }}$ & $\begin{array}{l}\text { M. nasuta } \\
\text { e Percent } \\
C L 5(103)\end{array}$ & $\frac{\text { Recoveries }}{\text { cL5(112) }}$ \\
\hline $\begin{array}{l}P C-1 \text { Comp } \\
P C-1 \\
P C-1 \\
P C-1 \\
P C-1 \\
P C-1\end{array}$ & $\begin{array}{l}1 \\
2 \\
3 \\
4 \\
5\end{array}$ & $\begin{array}{l}5 \\
5 \\
5 \\
4 \\
3\end{array}$ & $\begin{array}{r}64 \\
94 \\
83 \\
89 \\
118 \\
77\end{array}$ & $\begin{array}{l}61 \\
N A(a) \\
N A \\
N A \\
N A \\
N A\end{array}$ & $\begin{array}{l}58 \\
62 \\
58 \\
65 \\
45 \\
43\end{array}$ \\
\hline $\begin{array}{l}P C-1 A \text { Comp } \\
P C-1 A \\
P C-1 A \\
P C-1 A \text { Rep } 1 \\
P C-1 A \text { Rep } 2 \\
P C-1 A \text { Rep } 3 \\
P C-1 A \\
P C-1 A\end{array}$ & $\begin{array}{l}1 \\
2 \\
3 \\
3 \\
3 \\
4 \\
5\end{array}$ & $\begin{array}{l}5 \\
4 \\
4 \\
4 \\
4 \\
4 \\
5\end{array}$ & $\begin{array}{l}73 \\
89 \\
86 \\
91 \\
94 \\
98 \\
83 \\
89\end{array}$ & $\begin{array}{l}58 \\
N A \\
N A \\
N A \\
N A \\
N A \\
N A \\
N A\end{array}$ & $\begin{array}{l}56 \\
57 \\
41 \\
46 \\
56 \\
65 \\
41 \\
65\end{array}$ \\
\hline $\begin{array}{l}P C-2 \text { Comp } \\
P C-2 \\
P C-2 \\
P C-2 \\
P C-2 \\
P C-2\end{array}$ & $\begin{array}{l}1 \\
2 \\
3 \\
4 \\
5\end{array}$ & $\begin{array}{l}4 \\
4 \\
4 \\
4 \\
4\end{array}$ & $\begin{array}{r}71 \\
46 \\
101 \\
103 \\
98 \\
92\end{array}$ & $\begin{array}{l}56 \\
N A \\
N A \\
N A \\
N A \\
N A\end{array}$ & $\begin{array}{l}56 \\
25^{(b)} \\
47 \\
51 \\
50 \\
46\end{array}$ \\
\hline $\begin{array}{l}P C-4 \text { Comp } \\
P C-4 \\
P C-4 \\
P C-4 \\
P C-4 \\
P C-4\end{array}$ & $\begin{array}{l}1 \\
2 \\
3 \\
4 \\
5\end{array}$ & $\begin{array}{l}4 \\
5 \\
3 \\
3 \\
4\end{array}$ & $\begin{array}{r}93 \\
85 \\
88 \\
71 \\
80 \\
119\end{array}$ & $\begin{array}{l}70 \\
N A \\
N A \\
N A \\
N A \\
N A\end{array}$ & $\begin{array}{l}65 \\
43 \\
57 \\
26^{(b)} \\
41 \\
44\end{array}$ \\
\hline $\begin{array}{l}P C-5 \text { Comp } \\
P C-5 \\
P C-5 \\
P C-5 \\
P C-5 \\
P C-5\end{array}$ & $\begin{array}{l}1 \\
2 \\
3 \\
4 \\
5\end{array}$ & $\begin{array}{l}5 \\
4 \\
5 \\
4 \\
3\end{array}$ & $\begin{array}{l}84 \\
86 \\
86 \\
93 \\
89 \\
98\end{array}$ & $\begin{array}{l}67 \\
N A \\
N A \\
N A \\
N A \\
N A\end{array}$ & $\begin{array}{l}59 \\
61 \\
39(b) \\
60 \\
41 \\
40\end{array}$ \\
\hline PANAMA CITY HARBOR & \multicolumn{2}{|c|}{ L. 52} & & & \\
\hline
\end{tabular}


IABLE L.28. (contd)

\begin{tabular}{|c|c|c|c|c|c|}
\hline $\begin{array}{l}\text { Sedrment } \\
\text { Ireatment }\end{array}$ & Replicate & Batch & $\frac{\text { Surroge }}{\mathrm{DBOFB}}$ & $\frac{\begin{array}{r}M . \text { nasuta } \\
\text { ate Percent }\end{array}}{\text { CL5(103) }}$ & $\frac{\text { Recoveries }}{\text { CL5(112) }}$ \\
\hline $\begin{array}{l}\text { Reference Comp } \\
\text { Reference } \\
\text { Reference } \\
\text { Reference Rep } 1 \\
\text { Reference Rep } 2 \\
\text { Reference Rep } 3 \\
\text { Reference } \\
\text { Reference }\end{array}$ & $\begin{array}{l}1 \\
2 \\
3 \\
3 \\
3 \\
4 \\
5\end{array}$ & $\begin{array}{l}4 \\
4 \\
5 \\
5 \\
5 \\
3 \\
3\end{array}$ & $\begin{array}{l}70 \\
6(b) \\
100 \\
91 \\
96 \\
93 \\
88 \\
73\end{array}$ & $\begin{array}{l}72 \\
N A \\
N A \\
N A \\
N A \\
N A \\
N A \\
N A\end{array}$ & $\begin{array}{l}64 \\
4(b) \\
46 \\
80 \\
74 \\
63 \\
52 \\
25^{(b)}\end{array}$ \\
\hline $\begin{array}{l}\text { M. nasuta Background Rep } \\
\text { M. nasuta Background Rep } \\
\text { M. nasuta Background Rep }\end{array}$ & $\begin{array}{l}1 \\
2 \\
3\end{array}$ & $\begin{array}{l}5 \\
5 \\
5\end{array}$ & $\begin{array}{r}89 \\
90 \\
105\end{array}$ & $\begin{array}{l}\text { NA } \\
\text { NA } \\
\text { NA }\end{array}$ & $\begin{array}{l}56 \\
62 \\
66\end{array}$ \\
\hline 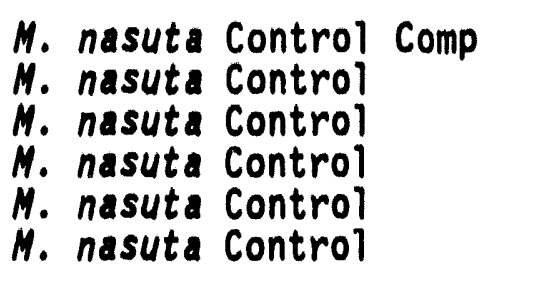 & $\begin{array}{l}1 \\
2 \\
3 \\
4 \\
5\end{array}$ & $\begin{array}{l}3 \\
3 \\
5 \\
5 \\
5\end{array}$ & $\begin{array}{l}70 \\
76 \\
129(b) \\
89 \\
97 \\
96\end{array}$ & $\begin{array}{l}67 \\
N A \\
N A \\
N A \\
N A \\
N A\end{array}$ & $\begin{array}{l}60 \\
27^{(b)} \\
31^{(b)} \\
66 \\
60 \\
56\end{array}$ \\
\hline \multicolumn{6}{|l|}{ Quality Control Data } \\
\hline \multicolumn{6}{|l|}{ Method Blanks } \\
\hline $\begin{array}{l}\text { Bl ank } \\
\text { BI ank } \\
\text { Bl ank } \\
\text { Bl ank }\end{array}$ & & $\begin{array}{l}3 \\
4 \\
5\end{array}$ & $\begin{array}{l}71 \\
121^{(b)} \\
72^{(b)} \\
55\end{array}$ & $\begin{array}{l}82 \\
N A \\
N A \\
N A\end{array}$ & $\begin{array}{l}69 \\
79^{(b)} \\
75 \\
52\end{array}$ \\
\hline \multicolumn{6}{|l|}{ Matrix Spikes } \\
\hline PC-5 MS & & 4 & 99 & NA & 48 \\
\hline Reference MS & & 4 & 103 & NA & 56 \\
\hline M. nasuta Control MS & & 5 & 90 & NA & 62 \\
\hline
\end{tabular}


TABLE L.29. Percent Lipid Results, Wet Weight, in Tissue of M. nasuta, Panama City Harbor Project

Sediment

Treatment

Target $O L^{(a)}$

Achieved DL

$P C-1$

$P C-1$

$P C-1$

$P C-1$

$P C-1$

$P C-1 A$

$P C-1 A$

PC-1A Rep 1

PC-1A Rep 2

PC-1A Rep 3

$P C-1 A$

$P C-1 A$

$P C-2$

$\mathrm{PC}-2$

$P C-2$

$\mathrm{PC}-2$

$P C-2$

$P C-4$

$P C-4$

$P C-4$

$P C-4$

$P C-4$

$P C-5$

$P C-5$

$P C-5$

$P C-5$

$P C-5$

Reference

Reference

Reference Rep 1

Reference Rep 2

Reference Rep 3

Reference

Reference

M. nasuta Background Rep 1

M. nasuta Background Rep 2

M. nasuta Background Rep 3

PANAMA CITY HARBOR

\section{Replicate}

1

2

3

4
5

5

1

2

3

3

3

4
5

1

2

3

4

5

1

2

3

4

5

1

2

3

4

5

1

2

3

3

3

4

5

1
2
3

L. 54
Batch

Percent

Lipid

0.1 $N A^{(b)}$

3.26

2.69

2. 30

3.03

1.85

2.78

2.03

8.76

5.57

4.87

4.01

3.07

3.75

1.83

2.84

2.97

6.52

3.11

3.05

1.75

1.60

1.78

3.10

6.68

2.20

2.65

2.01

7.69

10.69

5.57

5.37

2.99

1.43

1.79

6.85

8.56

7.52 
TABLE L.29. (contd)

Sediment

Treatment

M. nasuta Control

M. nasuta Control

M. nasuta Control

M. nasuta Control

$M$. nasuta Control

(a) DL Detection limit.

(b) NA Not applicable.

\section{Replicate}

1
2
3
4
5

Batch

3

3

5

5

5
Percent

Lipid

2.26

2.20

5.72

2.65

2.68 


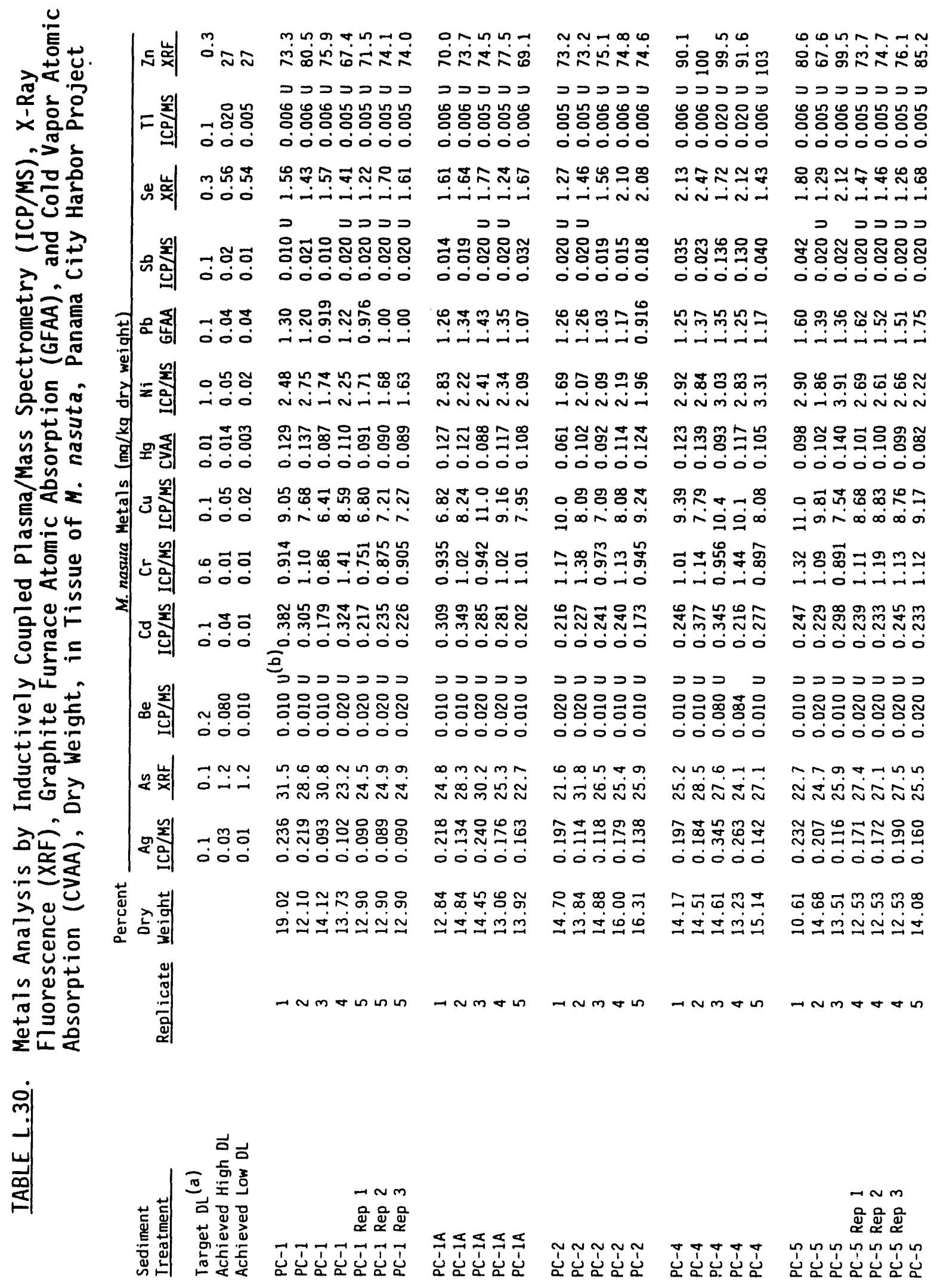




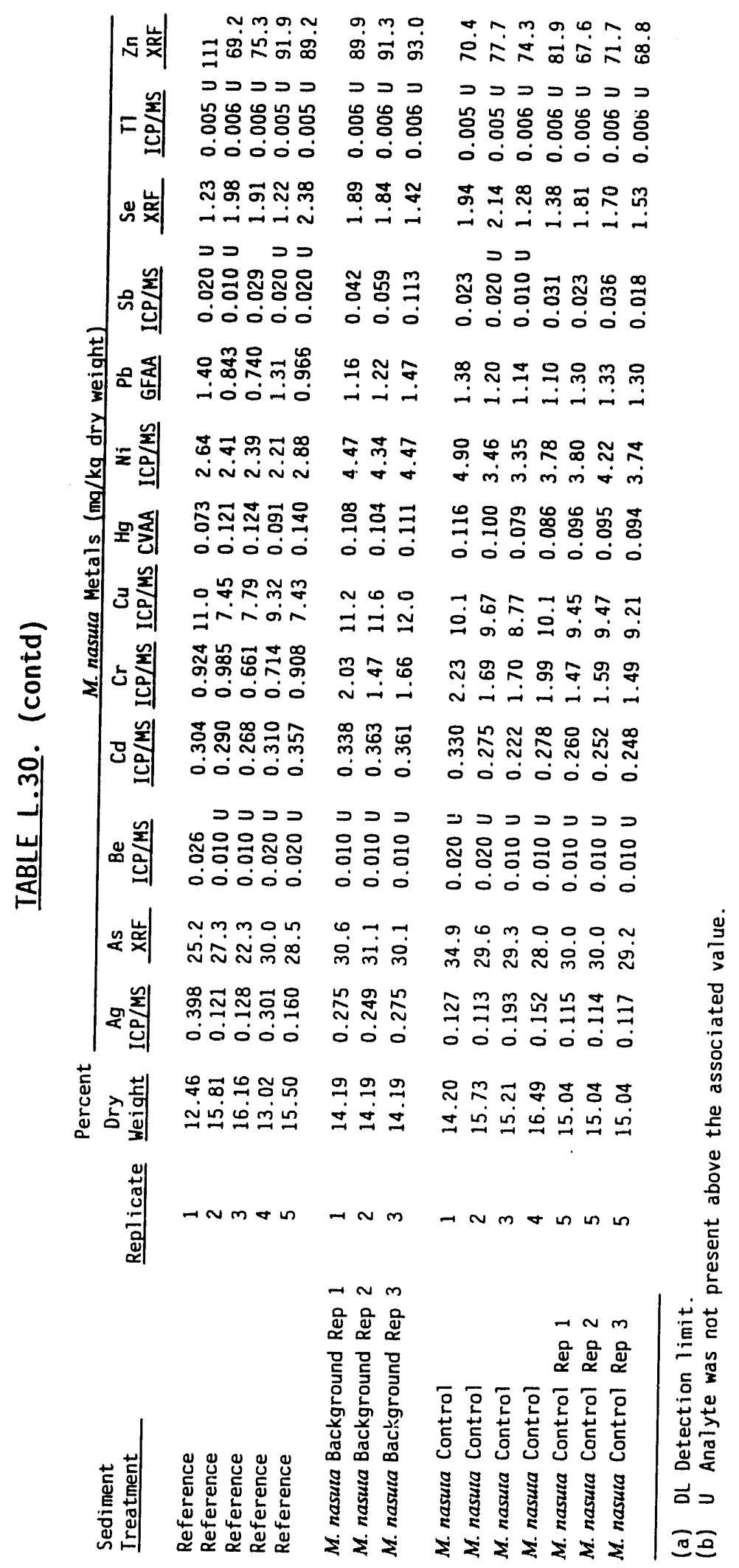




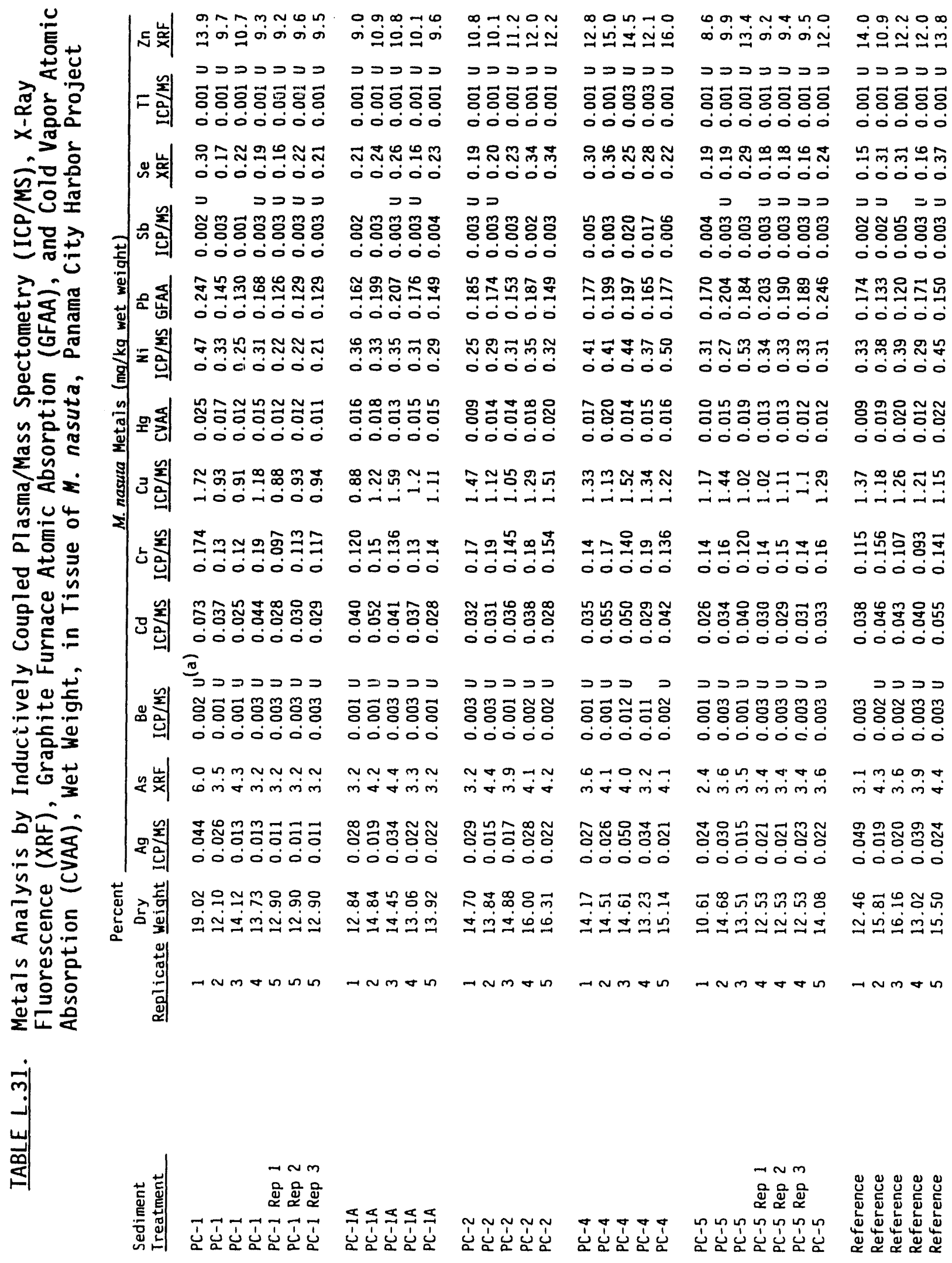

PANAMA CITY HARBOR 


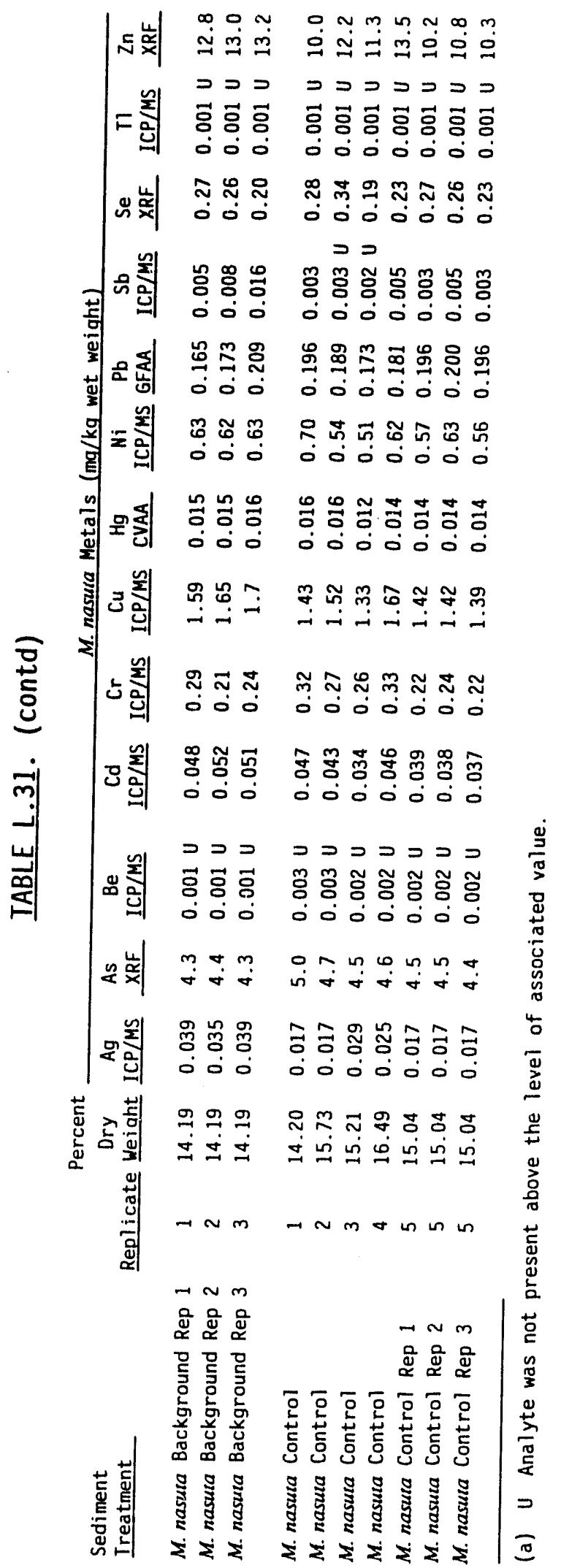




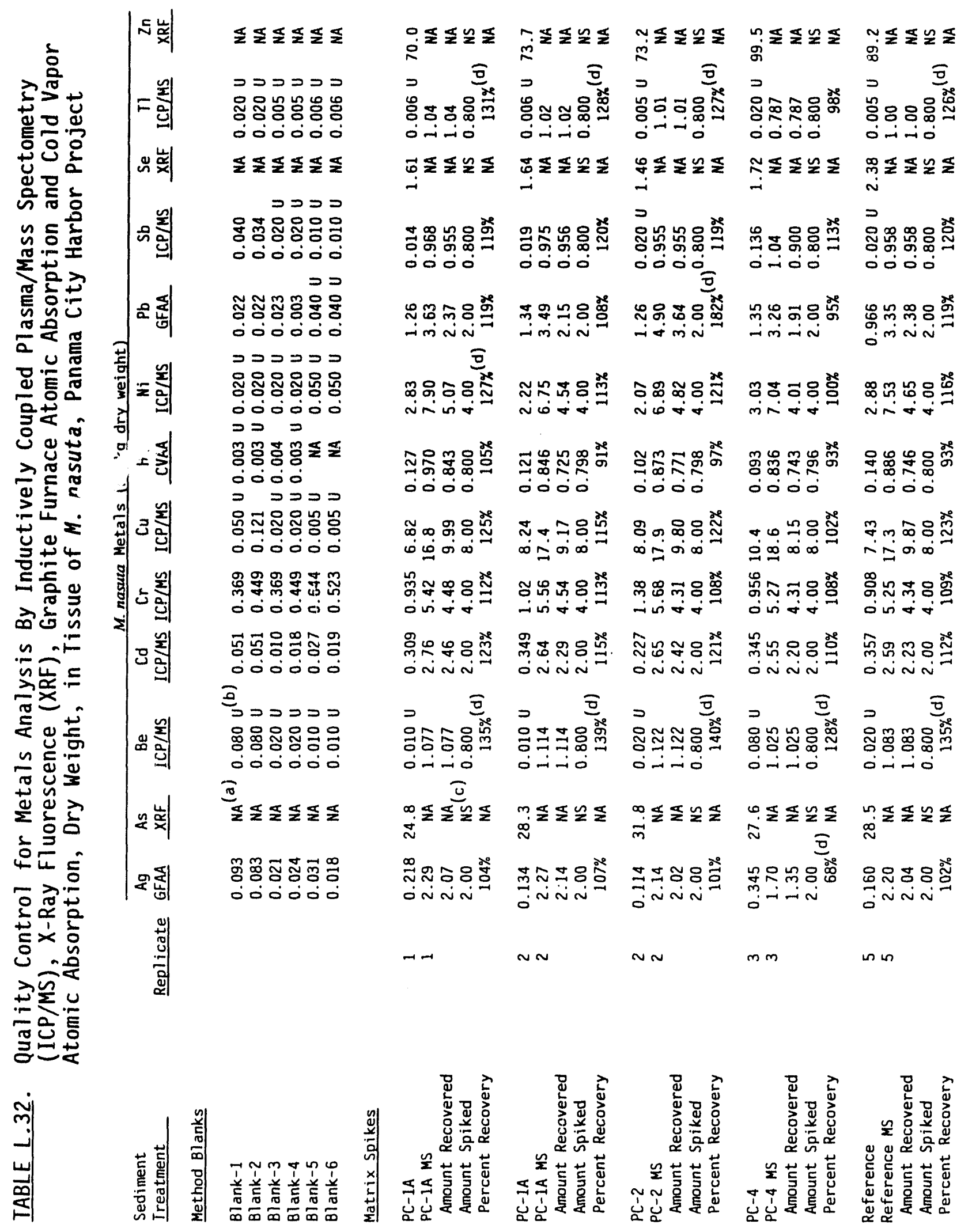

PANAMA CITY HARBOR

L. 60 


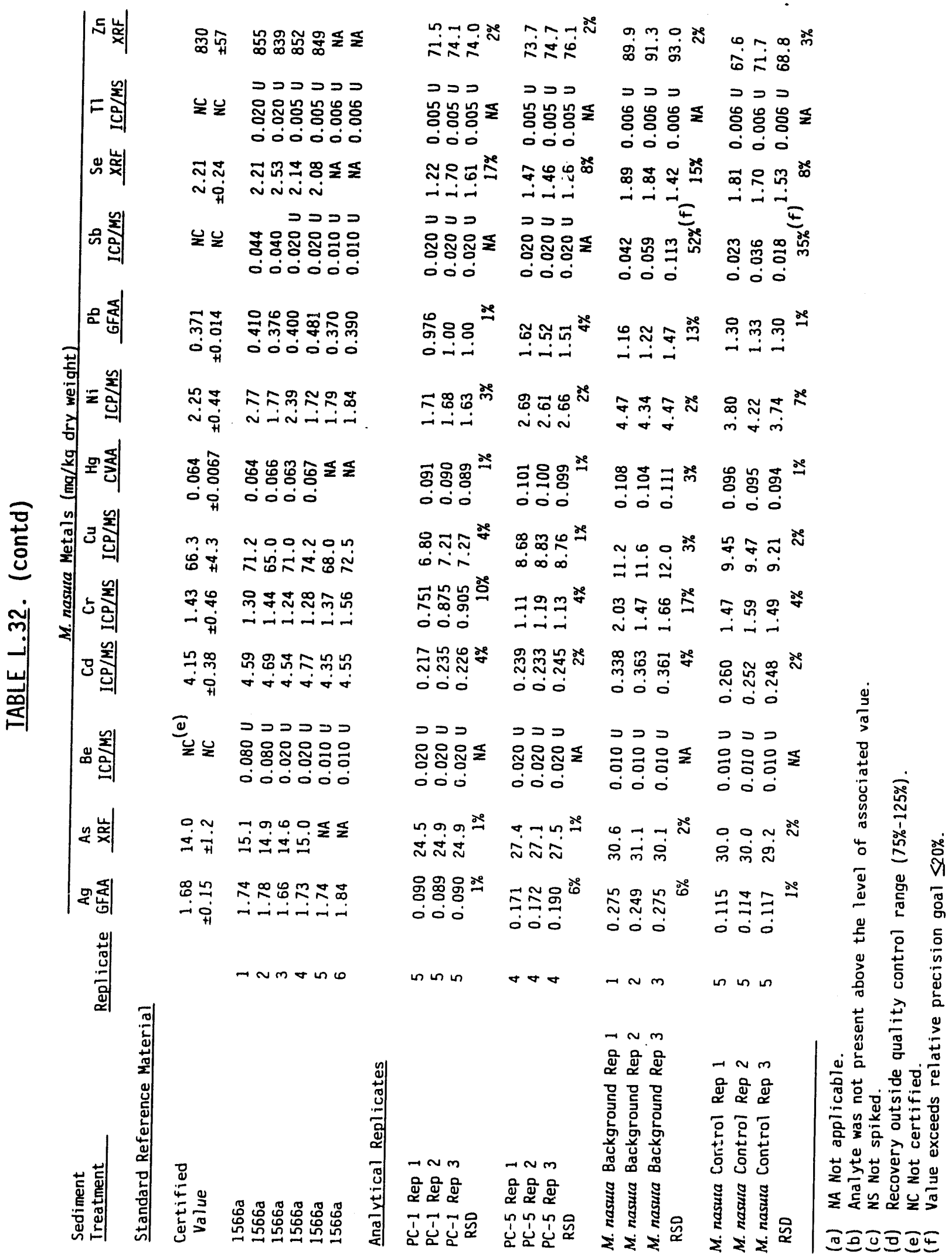

PANAMA CITY HARBOR 


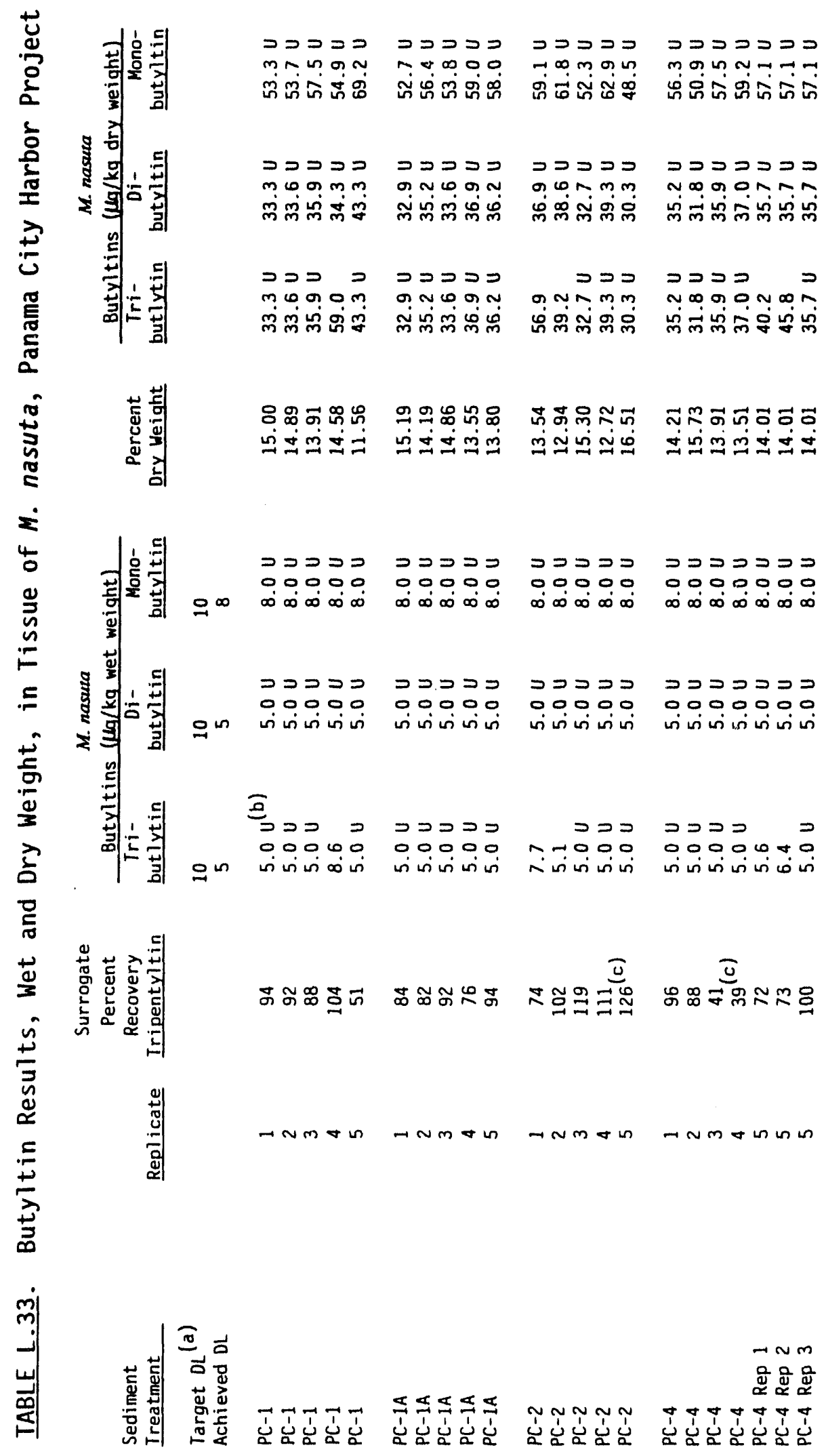

PANAMA CITY HARBOR L.62 


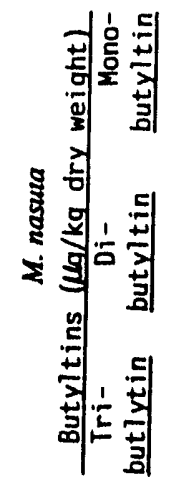

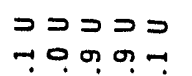

$\supset \supset \supset \supset \neg つ \supset$

ஸ்

ตก ?

$\supset \supset \supset$

$P>>D$

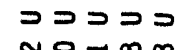

लिं户்

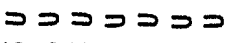

$>2$

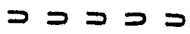

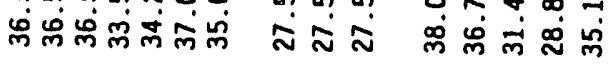

ก ก ก 0 ก

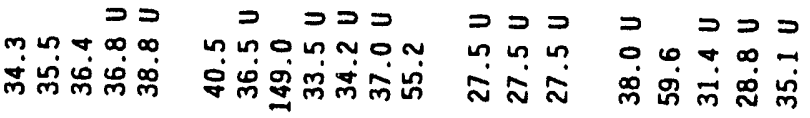

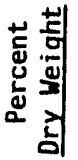

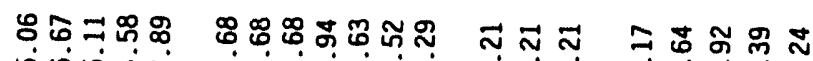

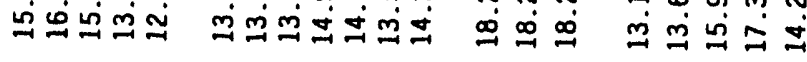

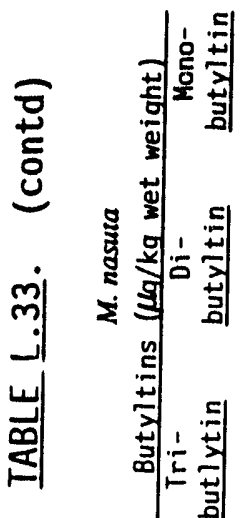

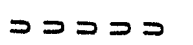

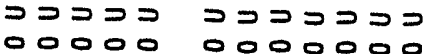

$\infty \infty \infty \infty \infty$

000000

ᄀ $\supset$

$\infty \begin{array}{lll}0 & 0 & 0 \\ \infty & \infty & \infty\end{array}$

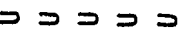

$\infty \infty \infty \infty \infty \infty$

$\begin{array}{lllll}0 & 0 & 0 & 0 & 0 \\ \infty & \infty & \infty & \infty & \infty \\ 0 & \infty & \infty\end{array}$

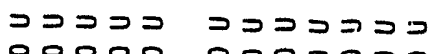

000000000000

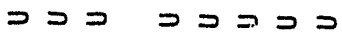

vivivivi

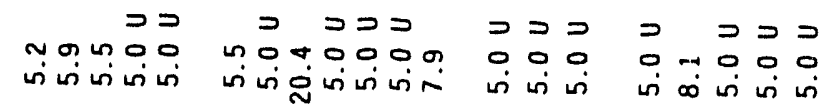

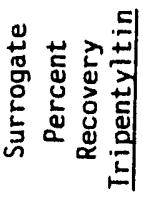

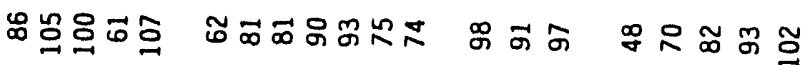

竎

$\rightarrow \sim m+n-4 n m-n$

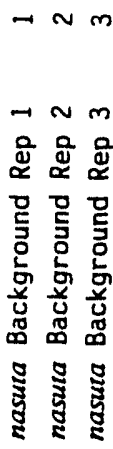

$\rightarrow \sim m+n$ 
IABLE L.34. Quality Control Summary for Butyltin Results, Wet Weight, in Tissue of $M$. nasuta, Panama City Harbor Project

Sediment

Ireatment

Method Blanks
Surrogate

Percent

Recovery

Replicate

M. nasula

Tripentyltin butlytin butyltin butyltin

Blank-1

Blank-2

Blank-3

Blank-4

Matrix Spikes

$P C-1$

$P C-1$ MS

Concentration Recovered

Amount Spiked

Percent Recovery

$P C-2$

PC-2 MS

Concentration Recovered

Amount Spiked

Percent Recovery

$P C-5$

PC-5 MS

Concentration Recovered Amount Spiked

Percent Recovery

M. nasuta Control

M. nasuta Control

Concentration Recovered

Amount Spiked

Percent Recovery

$\begin{array}{rl}44 & 5.0 U^{(a)} \\ 45 & 5.0 U^{(a)} \\ 96 & 5.0 U \\ 101 & 5.0 \mathrm{U}\end{array}$

$5.0 \mathrm{U}$

$5.0 \mathrm{U}$

$5.0 \mathrm{U}$

$8.0 \mathrm{U}$

$5.0 \mathrm{U}$

5.0

$8.0 \mathrm{U}$

$8.0 \mathrm{U}$

Analytical Replicates

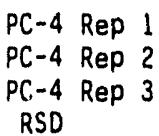

M. nasuta Background Rep 1 $M$. nasuta Background Rep 2 M. nasula Background Rep 3 RSD

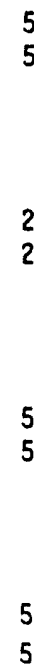

5

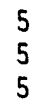

102

87

51

52

$5.0 \mathrm{U}$

57.1

57.1

46.1 (b)

2
2

5

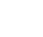

\section{1}

51.9

46.8

45.5

$103 \%$

107

71

$5.0 \mathrm{U}$

71.1

71.1

48.4 $147 \%(b)$

$5.0 \mathrm{U}$

78.5

78.5

94.5

$83 \%$

$\begin{array}{cc}72 & 5.6 \\ 73 & 6.4 \\ 100 & 5.0 \mathrm{U} \\ \mathrm{NA}(\mathrm{c}) & \mathrm{NA}\end{array}$

1

1

1

2

3

5
5
5
1
1
1
1
2
3

(a) U Analyte was not present above the level of associated value.

(b) Recovery outside quality control range (40\%-120\%).

(c) NA Not applicable.

PANAMA CITY HARBOR

$8.0 \mathrm{U}$

14.4

14.4

36.1 (b)

$8.0 \mathrm{U}$

11.5

11.5

45.5 (b)

$8.0 \mathrm{U}$

13.5

13.5

$28 \%$ (b)

$8.0 \mathrm{U}$

23.1

23.1

94.5 (b)
$8.0 \mathrm{U}$

$8.0 \mathrm{U}$

$8.0 \mathrm{U}$

NA

$8.0 \mathrm{U}$

$8.0 \mathrm{U}$

$8.0 \mathrm{U}$

NA

$8.0 \mathrm{U}$

$8.0 \mathrm{U}$

$8.0 \mathrm{U}$

NA

$\begin{array}{ccc}5.0 \mathrm{U} & 5.0 \mathrm{U} & 8.0 \mathrm{U} \\ 5.0 \mathrm{U} & 5.0 \mathrm{U} & 8.0 \mathrm{U} \\ 5.0 \mathrm{U} & 5.0 \mathrm{U} & 8.0 \mathrm{U} \\ \mathrm{NA} & \mathrm{NA} & \mathrm{NA}\end{array}$


TABLE L.35. Total Polychlorinated Dibenzodioxins (PCDD) and Dibenzofurans (PCDF) Analysis, Wet Weight, in Tissue of M. nasutal, Panama City Harbor Project

\begin{tabular}{|c|c|c|c|c|c|c|c|c|c|}
\hline \multirow[b]{2}{*}{$\begin{array}{l}\text { Sediment } \\
\text { Treatment }\end{array}$} & \multirow[b]{2}{*}{$\begin{array}{c}\text { Percent } \\
\text { Dry Welaht (a) }\end{array}$} & \multicolumn{8}{|c|}{ M. nasula Dioxins and Furans (ng/kg wet weight) } \\
\hline & & $\begin{array}{l}\text { Total } \\
\text { TCCO } \\
\end{array}$ & $\begin{array}{l}\text { Total } \\
\text { PeCDD } \\
\end{array}$ & $\begin{array}{l}\text { Total } \\
\mathrm{H} \times \mathrm{CDD} \\
\end{array}$ & $\begin{array}{l}\text { Total } \\
\text { HpCDD }\end{array}$ & $\begin{array}{l}\text { Total } \\
\text { TCDF } \\
\end{array}$ & $\begin{array}{l}\text { Total } \\
\text { PeCDF }\end{array}$ & $\begin{array}{l}\text { Tote. } 1 \\
\text { HacOF }\end{array}$ & $\begin{array}{l}\text { Total } \\
\text { HpCDF }\end{array}$ \\
\hline Target $\mathrm{OL}(\mathrm{b})$ & & 1.0 & 1.0 & 1.0 & 1.0 & 1.0 & 1.0 & 1.0 & 1.0 \\
\hline $\begin{array}{l}P C-1 \\
P C-2 \\
\text { Reference }\end{array}$ & $\begin{array}{l}13.769 \\
14.052 \\
13.979\end{array}$ & $\begin{array}{r}0.30 \\
0.21 \\
\text { NO }\end{array}$ & $\begin{array}{l}\text { ND }(c) \\
\text { ND } \\
\text { ND }\end{array}$ & $\begin{array}{l}1.59 \\
1.03 \\
0.72\end{array}$ & $\begin{array}{l}5.55 \\
3.60 \\
1.50\end{array}$ & $\begin{array}{r}1.15 \\
1.47 \\
\text { NO }\end{array}$ & $\begin{array}{l}\text { ND } \\
\text { ND } \\
\text { ND }\end{array}$ & $\begin{array}{l}0.65 \\
0.34 \\
0.23\end{array}$ & $\begin{array}{l}0.43 \\
0.27 \\
0.15\end{array}$ \\
\hline
\end{tabular}

(a) Value is average percent dry weight from PAH analysis.
(b) DL Detection limit.

(c) NO Not detected. 
TABLE L.36. Polychlorinated Dibenzodioxins (PCDD) Analysis and Quality Control Data (2378-TCDD - OCDD), Wet Weight, in Tissue of M. nasuta, Panama City Harbor Project

Sediment
Ireatment
Target $D L$ (b)
Achieved OL
PC-1
PC-2
Reference
Quality Control Data
Method Blank
Blank
Matrix Spikes
PC-1
PC-1 MS
Amount Spiked
Percent Recovery $(f)$
PC-1
PC-1 MSO
Amount Spiked
Percent Recovery $(f)$
RPD
I-Stat

\begin{tabular}{|c|c|c|c|c|c|c|c|}
\hline \multirow{2}{*}{$\begin{array}{l}\text { Percent } \\
\text { Ory } \\
\text { Weight (a) }\end{array}$} & \multicolumn{7}{|c|}{ M. nasuta Dioxins (ng/ $\mathrm{kg}$ wet weight) } \\
\hline & $\begin{array}{l}2378- \\
\text { TCOD }\end{array}$ & $\begin{array}{l}12378 \\
\text { PeCDD } \\
\end{array}$ & $\begin{array}{c}123478- \\
\mathrm{H} \times \mathrm{CDD} \\
\end{array}$ & $\begin{array}{l}123678- \\
H \times C D D \\
\end{array}$ & $\begin{array}{r}123789- \\
\mathrm{H} \times \mathrm{CDD} \\
\end{array}$ & $\begin{array}{l}1234678- \\
\mathrm{HDCDD}\end{array}$ & $O C D D$ \\
\hline & $\begin{array}{l}1.0 \\
0.2\end{array}$ & $\begin{array}{l}1.0 \\
0.1\end{array}$ & $\begin{array}{l}1.0 \\
0.1\end{array}$ & $\begin{array}{l}1.0 \\
0.1\end{array}$ & $\begin{array}{l}1.0 \\
0.2\end{array}$ & $\begin{array}{l}1.0 \\
0.7\end{array}$ & $\begin{array}{r}1.0 \\
<2.27\end{array}$ \\
\hline $\begin{array}{l}13.769 \\
14.052 \\
13.979\end{array}$ & $\begin{array}{l}0.4 U^{(c)} \\
0.3 U \\
0.2 U\end{array}$ & $\begin{array}{l}0.2 U \\
0.2 U \\
0.2 U\end{array}$ & $\begin{array}{l}0.1 U \\
0.2 U \\
0.1 \quad U\end{array}$ & $\begin{array}{l}0.4 U \\
0.3 U \\
0.1 U\end{array}$ & $\begin{array}{l}0.3 U \\
0.3 U \\
0.2 U\end{array}$ & $\begin{array}{l}1.47^{(d)(e)}(d) \\
2.9 y_{(d)} \\
0.50\end{array}$ & $\begin{array}{r}12.45 \\
9.53 \\
4.52\end{array}$ \\
\hline
\end{tabular}

(a) Value is average percent dry weight from PAH analysis.

(b) DL Detection Iimit.

(c) U Analyte was not present above the associated value.

(d) Calibration response factor at beginning of day out of limits.

(e) Mass ratio out of limits.

(f) Percerit recovery $=[$ (matrix spike concentration) $/($ amount spiked + origina $]$ sample concentration) $] * 100$ 


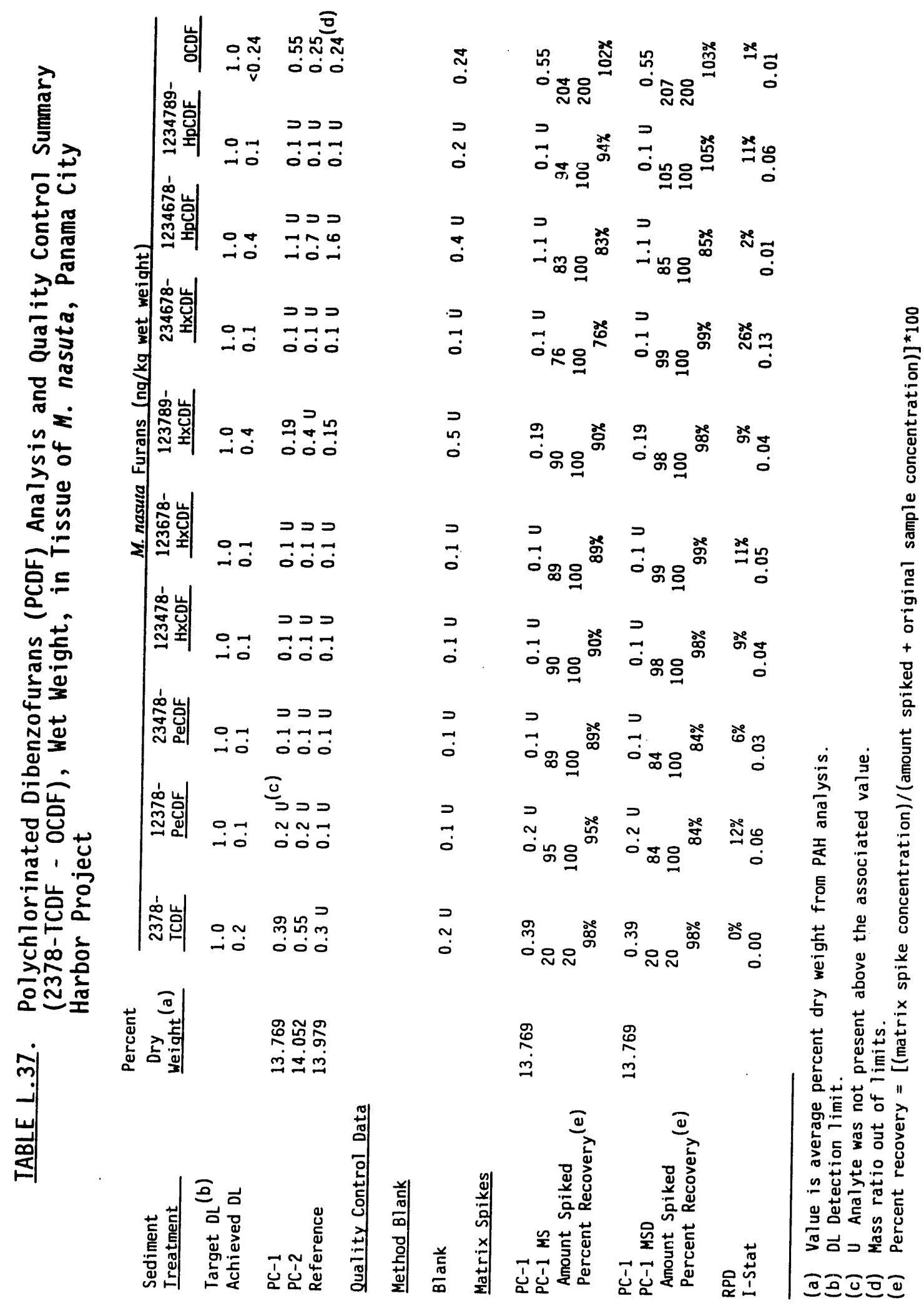

PANAMA CITY HARBOR 
TABLE L.38. Total Polychlorinated Dibenzodioxins (PCDD) and Dibenzofurans (PCDF) Analysis in Tissue of M. nasuta, Dry Weight, Panama City Harbor Project

\begin{tabular}{|c|c|c|c|c|c|c|c|c|c|}
\hline \multirow[b]{2}{*}{$\begin{array}{l}\text { Sediment } \\
\text { Ireatment }\end{array}$} & \multirow{2}{*}{$\begin{array}{c}\text { Percent } \\
\text { Dry } \\
\text { Weight (a) }\end{array}$} & \multicolumn{8}{|c|}{ M. nasuza Dioxins and Furans (ng/kg dry weight) } \\
\hline & & $\begin{array}{l}\text { Total } \\
\text { TCDD } \\
\end{array}$ & $\begin{array}{l}\text { Total } \\
\text { PeCDD }\end{array}$ & $\begin{array}{l}\text { Total } \\
\text { HxCDO }\end{array}$ & $\begin{array}{l}\text { Total } \\
\text { HpCDD }\end{array}$ & $\begin{array}{l}\text { Total } \\
\text { TCDF } \\
\end{array}$ & $\begin{array}{l}\text { Total } \\
\text { PeCDF }\end{array}$ & $\begin{array}{l}\text { Total } \\
\text { HXCDF }\end{array}$ & $\begin{array}{l}\text { Total } \\
\text { HpCDF }\end{array}$ \\
\hline $\begin{array}{l}P C-1 \\
P C-2 \\
\text { Reference }\end{array}$ & $\begin{array}{l}13.769 \\
14.052 \\
13.979\end{array}$ & $\begin{array}{r}2.18 \\
1.49 \\
\text { ND }\end{array}$ & $\begin{array}{l}\text { No }(b) \\
\text { ND } \\
\text { ND }\end{array}$ & $\begin{array}{r}11.55 \\
7.33 \\
5.15\end{array}$ & $\begin{array}{l}40.31 \\
25.62 \\
10.73\end{array}$ & $\begin{array}{r}8.35 \\
10.46 \\
\text { ND }\end{array}$ & $\begin{array}{l}\text { ND } \\
\text { ND } \\
\text { ND }\end{array}$ & $\begin{array}{l}4.72 \\
2.42 \\
1.65\end{array}$ & $\begin{array}{l}3.12 \\
1.92 \\
1.07\end{array}$ \\
\hline
\end{tabular}

(a) Value is average percent dry weight from PAH analysis.

(b) ND Not detected. 
IABLE L.39. Polychlorinated Dibenzodioxins (PCDD) Analysis and Quality Control Data (2378-TCDD - OCDD) in Tissue of M. nasuta, Dry Weight, Panama City Harbor Project

\begin{tabular}{|c|c|c|c|c|c|c|c|c|}
\hline \multirow[b]{2}{*}{$\begin{array}{l}\text { Sediment } \\
\text { Treatment }\end{array}$} & \multirow{2}{*}{$\begin{array}{l}\text { Percent } \\
\text { Dry } \\
\text { Weight (a) }\end{array}$} & \multicolumn{7}{|c|}{ M. nasuta Dioxins (ng/kg dry weight) } \\
\hline & & $\begin{array}{l}2378- \\
\text { ICDO } \\
\end{array}$ & $\begin{array}{l}12378- \\
\text { PeCDD }\end{array}$ & $\begin{array}{l}123478- \\
\mathrm{H} \times \mathrm{CDO} \\
\end{array}$ & $\begin{array}{c}123678- \\
\mathrm{H} \times \mathrm{CDD} \\
\end{array}$ & $\begin{array}{r}123789- \\
\mathrm{H} \times \mathrm{COD} \\
\end{array}$ & $\begin{array}{l}1234678- \\
\text { HpCDD }\end{array}$ & OCDD \\
\hline $\begin{array}{l}P C-1 \\
P C-2 \\
\text { Reference }\end{array}$ & $\begin{array}{l}13.769 \\
14.052 \\
13.979\end{array}$ & $\begin{array}{l}2.9 U(b) \\
2.1 U \\
1.4 U\end{array}$ & $\begin{array}{l}1.5 U \\
1.4 U \\
1.4 U\end{array}$ & $\begin{array}{l}0.7 \mathrm{U} \\
1.4 \mathrm{U} \\
0.7 \mathrm{U}\end{array}$ & $\begin{array}{l}2.9 U \\
2.1 U \\
0.7 U\end{array}$ & $\begin{array}{l}2.2 U \\
2.1 U \\
1.4 U\end{array}$ & $\begin{array}{l}10.7(c)(d) \\
20.6 u^{(c)} \\
3.6^{(c)}\end{array}$ & $\begin{array}{l}90.4 \\
67.8 \\
32.3\end{array}$ \\
\hline
\end{tabular}

\footnotetext{
(a) Value is average percent dry weight from PAH analysis.

(b) U Analyte was not present above the assoclated value.

(c) Calibration response factor at beginning of day out of limits.

(d) Mass ratio out of limits.
} 


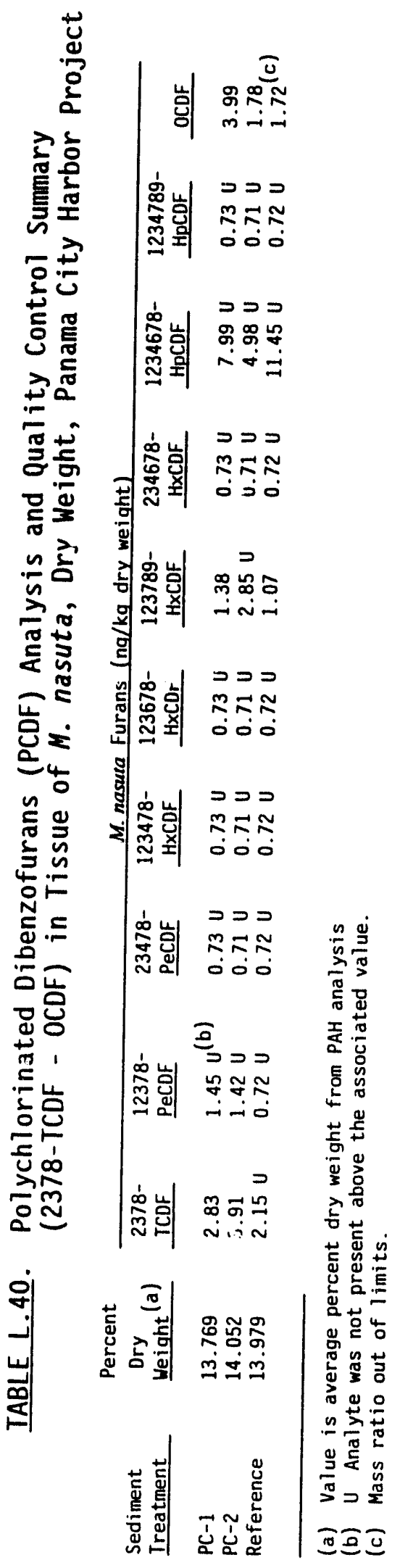


TABLE L.41. Surrogate Percent Recovery of Polychlorinated Dibenzodioxins (PCDD) in Tissue of M. nasuta, Wet Weight, Panama City Harbor Project

Sediment Surrogate Percent Recoveries

Treatment 23781234781236781234678$\underline{T C D D}-\mathrm{C} 13 \quad \mathrm{PeCDD}-\mathrm{C} 13$ HXCDD-C13 HXCDD-C13 HpCDD-C13 OCDD-C13

PC - 1

PC-2

88

82

96

101

82

Reference

93

106

90

94

84

60

89

65

65

106

104

54

Quality Control Data

Method Blank

Bl ank

62

71

59

60

62

53

Matrix Spikes

PC - 1 MS

PC-1 MSD
86

90
104

95
77

90
84

100
83

41
71 


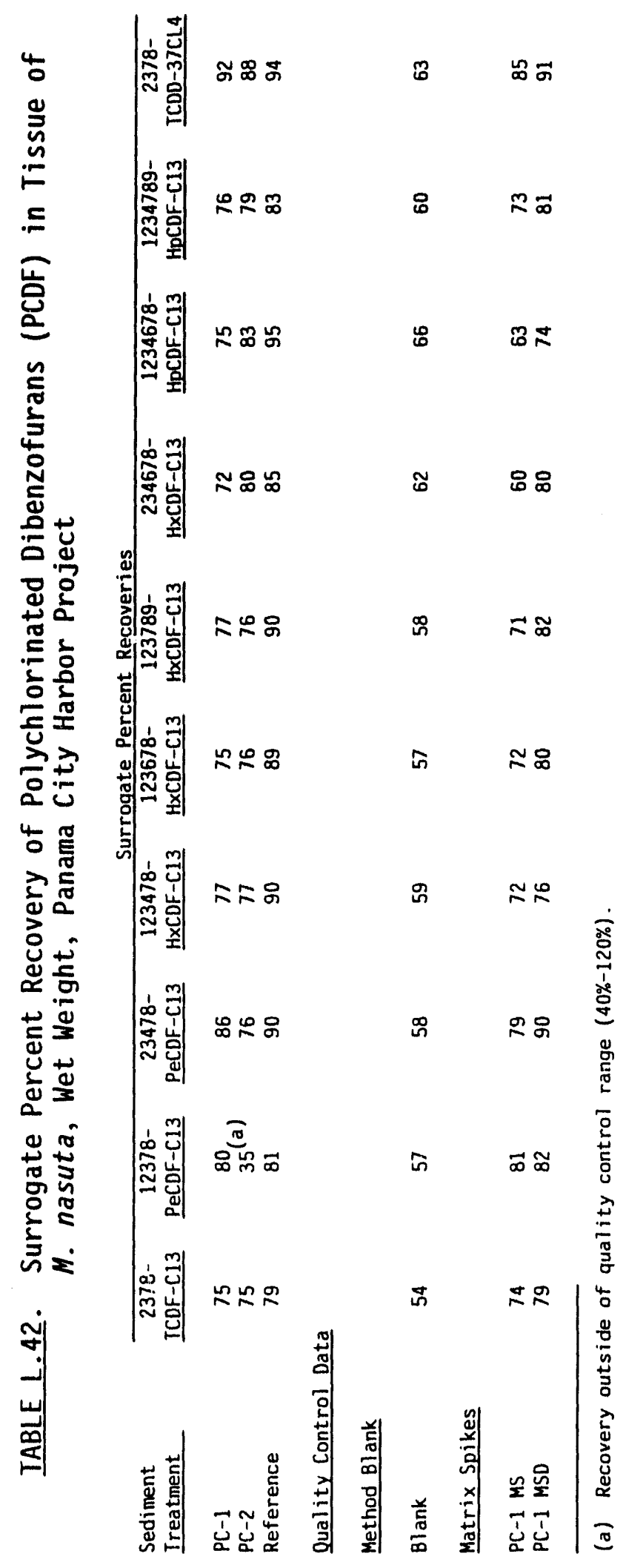

PANAMA CITY HARBOR 
APPENDIX $M$

N. VIRENS TISSUE CHEMISTRY

AND QUALITY CONTROL DATA 


\section{QA/QC SUMMARY}

PROGRAM:

PARAMETER:

LABORATORY:

MATRIX:
Panama City Harbor Program

Polynuclear Aromatic Hydrocarbons (PAHs)

Battelle Ocean Sciences, Duxbury, Massachusetts

N. virens Tissue

\section{QA/QC DATA QUALITY OBJECTIVES}

Reference
Method

EPA Method 8270 (1986a)

HOLDING TIMES

DETECTION LIMITS

METHOD BLANKS

MATRIX SPIKES

SRMs

REPLICATES

\section{Range of Recovery}

$40-120 \%$

\section{SRM Accuracy}

$\leq 30 \%$

\section{Relative Precision}

$\leq 30 \%$
Detection

Limit (wet wt)

$30 \mu \mathrm{g} / \mathrm{kg}$

All samples were stored frozen $\left(-20^{\circ} \mathrm{C}\right)$ in sealed containers until ready for extraction. The tissue samples were extracted within 2 months of receipt at the laboratory and were analyzed within 40 days.

The achieved detection limits for PAHs were all well below the target detection limits.

Four method blanks were analyzed with the tissue samples. At least one of the three blanks analyzed with the Batch 1,2, and 3 tissue samples were contaminated with the PAHs naphthalene, 2-methylnaphthalene, 1-methylnaphthalene, and phenanthrene at levels $>1 / 5$ the target detection limit. The data associated with these blanks were flagged with a "B."

The recovery of target PAHs in the matrix spikes ranged from $66 \%$ to $283 \%$. Ten of the 36 low-molecular-weight PAH (LPAH) matrix spike recoveries ranged from $121 \%$ to $283 \%$. The RPD between PC-4 COMP MS and MSD matrix splke recoveries ranged from $1 \%$ to $3 \%$, all within the target goal of $30 \%$. Twelve of the 60 high-molecularweight PAH (HPAH) matrix spike recoveries ranged from $121 \%$ to $129 \%$, most due to the fact that the concentrations of PAHs in the samples were suspect due to the analytical laboratory contamination.

The standard reference material NIST 1974 was analyzed with the PAH samples. The percent difference of certifled PAHs in the tissue SRMs were acceptable in 22 of the 32 reported SRM values.

Precision was measured by relative standard deviation (RSD) between triplicates. Fourteen of the calculable 21 LPAHS had RSD values that exceeded the $30 \%$ limit. These elevated RSD values ranged from $32 \%$ to $94 \%$, generally due to one of the replicates being suspect or associated with contamination from the blank sample. Thirteen of the calculable 33 HPAHs had RSD values that exceeded the $30 \%$ limit and ranged from $32 \%$ to $54 \%$. 
SURROGATES

Three surrogate compounds were analyzed with the samples:

naph thalene- $d_{8}$, acenaphthene- $d_{10}$, and benzo(a)-pyrene-d $d_{12}$. The recovery of the surrogate internal standard (SIS) compounds for 29 of the 153 tissue samples were outside the $40 \%$ to $120 \%$ acceptable range.

\section{ADDITIONAL INFORMATION}

The individual replicate tissue samples analyzed for PAHs in the $N$. virens tissues were contaminated in the analytical laboratory during analysis. Existing leftover uncontaminated tissue samples were combined into a single composite for each sediment treatment and reanalyzed. The composite and original data are presented in Appendix $M$. 


\section{QA/QC SUMMARY}

PROGRAM:

PARAMETER:

LABORATORY:

MATRIX:
Panama Clty Harbor Program

Phenols, Substituted Phenols, and Phthalate Esters

Battelle Ocean Sciences, Duxbury, Massachusetts

N. virens Tissue

QAMC DATA QUALITY OBJECTIVES

\begin{tabular}{|c|c|c|c|c|c|}
\hline & $\begin{array}{l}\text { Reference } \\
\text { Method } \\
\end{array}$ & $\begin{array}{l}\text { Range of } \\
\text { Recovery }\end{array}$ & $\begin{array}{c}\text { SRM } \\
\text { Accuracy }\end{array}$ & $\begin{array}{l}\text { Relative } \\
\text { Precislon }\end{array}$ & $\begin{array}{l}\text { Detectlon } \\
\text { Limit (wet wt) }\end{array}$ \\
\hline $\begin{array}{l}\text { henols } \\
\text { hthalate Ester }\end{array}$ & $\begin{array}{l}\text { EPA Method } 82 \\
\text { EPA Method } 82\end{array}$ & $\begin{array}{l}40-1 \\
40-1\end{array}$ & $\begin{array}{l}\text { NA } \\
\text { NA }\end{array}$ & $\begin{array}{l}\leq 30 \% \\
\leq 30 \%\end{array}$ & $\begin{array}{l}330 \mu \mathrm{g} / \mathrm{kg} \\
100 \mu \mathrm{g} / \mathrm{kg}\end{array}$ \\
\hline
\end{tabular}

HOLDING TIMES

DETECTION LIMITS

METHOD BLANKS

MATRIX SPIKES

SRMs

REPLICATES
All samples were stored frozen $\left(-20^{\circ} \mathrm{C}\right)$ in sealed containers until ready for extraction. The tissue samples were extracted within 2 months of receipt at the laboratory and were analyzed within the 40-day holding period.

The samples analyzed for phenols and phthalate esters were slightly elevated above the target detection limits. These elevations do not present a problem due to all but two samples having concentrations of phenols and phthalate esters that were undetected or detected below the method detection limit.

The method blanks analyzed with the samples had concentrations of phenols and phthalate esters that were either undetected or detected below the method detection limit.

Matrix spike recovery criteria for phenols and phthalate esters in tissues have not been established by the EPA. This may be due to the difficulty involved with recovering phenols both from the extraction procedures as well as the gas chromatograph. Nineteen of the 61 matrix spike recoveries ranged either from $121 \%$ to $226 \%$ or from $0 \%$ to $39 \%$, outside the target range of $40 \%$ to $120 \%$. These exceedences were generally due to relatively high concentrations of phenols and phthalate esters that were spiked into the samples.

NA

Precision was measured by relative standard deviation (RSDs) between triplicates. The concentrations of phenols and phthalate esters were either undetected or detected below the MDL so RSDs could not be calculated. 
SURROGATES

The surrogate compound 2.fluorophenol was analyzed with the samples. The recovery of the surrogate internal standard (SIS) compound exceeded the target goal of $30 \%$ for 12 of the 51 tissue samples processed with the analytical batches.

NA Not applicable. 


\section{QA/QC SUMMARY}

PROGRAM:

PARAMETER:

LABORATORY:

MATRIX:
Panama City Harbor Program

Chlorinated Pesticides and Polychlorinated Biphenyls (PCBs)

Battelle Ocean Sciences, Duxbury, Massachusetts

N. virens Tissue

\section{QAVC DATA QUALITY OBJECTIVES}

\begin{tabular}{ccccc}
$\begin{array}{c}\text { Reference } \\
\text { Method }\end{array}$ & $\begin{array}{c}\text { Range of } \\
\text { Becovery }\end{array}$ & $\begin{array}{c}\text { SRM } \\
\text { Accuracy }\end{array}$ & $\begin{array}{c}\text { Relative } \\
\text { Preclsion }\end{array}$ & $\begin{array}{c}\text { Detectlon } \\
\text { Limit (wet wt) }\end{array}$ \\
\hline EPA Method $8080(1986 \mathrm{a})$ & $40-120 \%$ & NA & $530 \%$ & $10-30 \mu \mathrm{g} / \mathrm{kg}$
\end{tabular}

HOLDING TIMES All samples were stored frozen $\left(-20^{\circ} \mathrm{C}\right)$ in sealed containers until ready for extraction. The tissue samples were extracted within 2 months of recelpt at the laboratory and were analyzed within the 40-day holding period.

DETECTION LIMITS The achieved detection limits for pesticides and PCBs were all within the target detection limits.

METHOD BLANKS The three method blanks analyzed with the samples were free of contamination.

MATRIX SPIKES The recovery of target pesticides and PCBs in the tissue samples were generally acceptable with the exception of 18 with ranges of $124 \%$ to $317 \%$ or $1 \%$ to $10 \%$.

SRMs

NA

REPLICATES

Precision was measured by relative standard deviation (RSDs) between triplicates. Nine of the calculable 19 RSD values exceeded the relative precision goal of $30 \%$, ranging from $31 \%$ to $140 \%$.

SURROGATES

Two surrogate compounds were analyzed with the samples: DBOFB and $\mathrm{Cl}_{5}(112)$. The recovery of the surrogate internal standard (SIS) compounds was acceptable, with the exception of 26 of the 102 tissue samples.

NA Not applicable. 


\section{QA/QC SUMMARY}
PROGRAM:
Panama City Harbor Program
PARAMETER:
Metals
LABORATORY: Battelle/Marine Sciences Laboratory, Sequim, Washington
MATRIX:
N. virens Tissues

\section{QANC DATA QUALITY OBJECTIVES}

\begin{tabular}{|c|c|c|c|c|c|}
\hline & $\begin{array}{l}\text { Reference } \\
\text { Method }\end{array}$ & $\begin{array}{l}\text { Range of } \\
\text { Recovery }\end{array}$ & $\begin{array}{c}\text { SRiM } \\
\text { Accuracy }\end{array}$ & $\begin{array}{l}\text { Relat } \\
\text { Precis }\end{array}$ & $\begin{array}{l}\text { Detection } \\
\text { Limit (dry wt) }\end{array}$ \\
\hline $\begin{array}{l}\text { ntimony } \\
\text { rsenic } \\
\text { eryllium } \\
\text { admium } \\
\text { hromium } \\
\text { opper } \\
\text { oad } \\
\text { ercury } \\
\text { ckel } \\
\text { elenium } \\
\text { lver } \\
\text { lallium } \\
\text { nc }\end{array}$ & $\begin{array}{l}\text { ICP/MS (EPA 1990b) } \\
\text { XRF (PNL SOP) } \\
\text { ICP/MS } \\
\text { ICP/MS } \\
\text { ICP/MS } \\
\text { ICP/MS } \\
\text { ICP/MS } \\
\text { CVAA (Bloom/Crecelius 1984) } \\
\text { ICP/MS } \\
\text { XRF } \\
\text { ICP/MS } \\
\text { ICP/MS } \\
\text { XRF }\end{array}$ & $\begin{array}{l}75-125 \\
75-125 \\
75-125 \\
75-125 \\
75-125 \\
75-125 \\
75-125 \\
75-125 \\
75-125 \\
75-125 \\
75-125 \\
75-125\end{array}$ & $\begin{array}{l}\leq 30 \% \\
\leq 30 \% \\
\leq 30 \% \\
\leq 30 \% \\
\leq 30 \% \\
\leq 30 \% \\
\leq 30 \% \\
\leq 30 \% \\
\leq 30 \% \\
\leq 30 \%\end{array}$ & & $\begin{array}{l}.1 \mathrm{mg} / \mathrm{kg} \\
.1 \mathrm{mg} / \mathrm{kg} \\
.2 \mathrm{mg} / \mathrm{kg} \\
.1 \mathrm{mg} / \mathrm{kg} \\
.6 \mathrm{mg} / \mathrm{kg} \\
.1 \mathrm{mg} / \mathrm{kg} \\
.1 \mathrm{mg} / \mathrm{kg} \\
.01 \mathrm{mg} / \mathrm{kg} \\
.0 \mathrm{mg} / \mathrm{kg} \\
.3 \mathrm{mg} / \mathrm{kg} \\
1 \mathrm{mg} / \mathrm{kg} \\
1 \mathrm{mg} / \mathrm{kg} \\
.3 \mathrm{mg} / \mathrm{kg}\end{array}$ \\
\hline
\end{tabular}

HOLDING TIMES

Recommended holding times for metals in tissues based on the 1991 Implementation Manual (EPAUSACE 1991) are 6 months $\left(<20^{\circ} \mathrm{C}\right)$ for all metals, except $\mathrm{Hg}$ which is 28 days. After receipt at MSL, $M$. nasuta tissue samples were held frozen and then freeze-dried and stored in sealed containers until ready for analysis.

DETECTION LIMITS

METHOD BLANKS

MATRIX SPIKES

SRMs
Achieved detection limits based on dry weight concentrations were lower than the target detection limits for all metals except As, $\mathrm{Hg}$, Se, and $\mathrm{Zn}$. These four metals were detected in all the tissue samples at concentrations above the target detection limit. Sample concentrations of these four metals were well above the achleved detection limits, therefore no corrective action was taken.

The method blank analyzed for metals had low levels of $\mathrm{Ag}, \mathrm{Cd}, \mathrm{Cr}$, $\mathrm{Cu}, \mathrm{Hg}, \mathrm{Pb}$, and $\mathrm{Sb}$. The data associated with these blanks were corrected for the amount in the method blank.

Four of the 30 calculable matrix splke recovery values were $49 \%$, $129 \%, 132 \%$, and $138 \%$, outside of the $75 \%$ to $125 \%$ range.

The oyster tissue standard reference material (SRM) 1566a was analyzed for all the metals. The values were all within the $30 \%$ limit set in the QA plan. 

Deviation (RSDs). Five of the calculable 44 RSDs ranged from $21 \%$ to $80 \%$, exceeding the target goal of $20 \%$. 


\section{QA/QC SUMMARY}

PROGRAM:

PARAMETER:

LABORATORY:

MATRIX:

\section{Panama City Harbor Program}

Butyltins

Battelle/Marine Sciences Laboratory, Sequim, Washington

N. virens Tissues

QAMC DATA QUALITY OBJECTIVES

\begin{tabular}{|c|c|c|c|c|}
\hline $\begin{array}{c}\text { Reference } \\
\text { Method }\end{array}$ & $\begin{array}{l}\text { Range of } \\
\text { Recovery }\end{array}$ & $\begin{array}{c}\text { SRM } \\
\text { Accuracy }\end{array}$ & $\begin{array}{r}\text { Pelative } \\
\text { Preclsion }\end{array}$ & $\begin{array}{r}\text { Detectlon } \\
\text { Limit (wet w }\end{array}$ \\
\hline $\begin{array}{l}\text { Unger et al. } 1986 \\
\text { Unger et al. } 1986 \\
\text { Unger et al. } 1986\end{array}$ & $\begin{array}{l}40-120 \\
40-120 \\
40-120\end{array}$ & $\begin{array}{l}\text { NA } \\
\text { NA } \\
\text { NA }\end{array}$ & $\begin{array}{l}\leq 30 \% \\
\leq 30 \% \\
\leq 30 \%\end{array}$ & $\begin{array}{l}10 \mu \mathrm{g} / \mathrm{kg} \\
10 \mu \mathrm{g} / \mathrm{kg} \\
10 \mu \mathrm{g} / \mathrm{kg}\end{array}$ \\
\hline
\end{tabular}

HOLDING TIMES Samples were extracted within the 14-day holding period and analyzed within 40 days of extraction.

DETECTION LIMITS The detection limit of $10 \mu \mathrm{g} / \mathrm{kg}$ was met for all samples.

METHOD BLANKS The method blanks analyzed with the samples were free of contamination.

MATRIX SPIKES Six of the monobutyltin matrix spike percent recoveries ranged from $11 \%$ to $24 \%$, outside the target range of $40 \%$ to $120 \%$. The matrix spike recoveries for dibutyltin and tributyltin were all within range. Low recoveries for monobutyltin are standard, due to inefficiency of the method used to extract this compound.

SRMs NA

REPLICATES Precision between triplicates was measured by Relative Standard Deviation (RSDs). There was at least one replicate that was undetected above the method detection limit; therefore, here were no calculable RSDs.

SURROGATES The surrogate internal standard (SIS) compound tripentyltin was analyzed with the samples. The recovery of six of the 44 sample percent recoveries ranged from $27 \%$ to $39 \%$, outside the $40 \%$ to $120 \%$ targeted range.

NA Not applicable. 
IABLE M.1. Total Polynuclear Aromatic Hydrocarbon (PAH) Analysis, Wet Weight, in Tissue of $N$. virens, Panama City Harbor Project

\begin{tabular}{|c|c|c|c|c|c|}
\hline $\begin{array}{l}\text { Sediment } \\
\text { Treatment }\end{array}$ & Replicate & Batch & $\begin{array}{l}\text { Total Low } \\
\text { Molecular } \\
\text { Welght PAH }\end{array}$ & $\begin{array}{l}\text { Total High } \\
\text { Molecular } \\
\text { Weight PAH } \\
\end{array}$ & $\begin{array}{c}\text { Total } \\
\text { PAH } \\
\end{array}$ \\
\hline $\begin{array}{l}P C-1 \text { COMP } \\
\text { PC-1 } \\
P C-1 \\
P C-1 \\
P C-1 \\
P C-1\end{array}$ & $\begin{array}{l}1 \\
2 \\
3 \\
4 \\
5\end{array}$ & $\begin{array}{l}2 \\
1 \\
2 \\
1 \\
2\end{array}$ & $\begin{array}{r}9 \\
42 \\
7 \\
17 \\
16 \\
13\end{array}$ & $\begin{array}{l}2 \\
5 \\
3 \\
6 \\
2 \\
4\end{array}$ & $\begin{array}{l}11 \\
47 \\
10 \\
23 \\
18 \\
17\end{array}$ \\
\hline $\begin{array}{l}P C-1 A \text { COMP } \\
P C-1 A \\
P C-1 A \\
P C-1 A \\
P C-1 A \\
P C-1 A\end{array}$ & $\begin{array}{l}1 \\
2 \\
3 \\
4 \\
5\end{array}$ & $\begin{array}{l}2 \\
1 \\
2 \\
2 \\
1\end{array}$ & $\begin{array}{r}6 \\
31 \\
9 \\
16 \\
10 \\
6\end{array}$ & $\begin{array}{l}2 \\
4 \\
2 \\
4 \\
3 \\
1\end{array}$ & $\begin{array}{r}8 \\
35 \\
11 \\
20 \\
13 \\
7\end{array}$ \\
\hline $\begin{array}{l}P C-2 \text { COMP } \\
P C-2 \\
P C-2 \\
P C-2 \\
P C-2 \\
P C-2\end{array}$ & $\begin{array}{l}1 \\
2 \\
3 \\
4 \\
5\end{array}$ & $\begin{array}{l}3 \\
2 \\
1 \\
1 \\
1\end{array}$ & $\begin{array}{r}9 \\
102 \\
32 \\
8 \\
6 \\
12\end{array}$ & $\begin{array}{l}2 \\
9 \\
5 \\
3 \\
1 \\
2\end{array}$ & $\begin{array}{r}11 \\
111 \\
37 \\
11 \\
7 \\
14\end{array}$ \\
\hline $\begin{array}{l}\text { PC-4 COMP } \\
\text { PC-4 } \\
\text { PC-4 Rep } 1 \\
\text { PC-4 Rep } 2 \\
\text { PC-4 Rep } 3 \\
\text { PC-4 } \\
\text { PC-4 Rep } 1 \\
\text { PC-4 Rep } 2 \\
\text { PC-4 Rep } 3 \\
\text { PC-4 }\end{array}$ & $\begin{array}{l}1 \\
2 \\
2 \\
2 \\
3 \\
4 \\
4 \\
4 \\
5\end{array}$ & $\begin{array}{l}1 \\
2 \\
2 \\
2 \\
1 \\
2 \\
2 \\
2 \\
3\end{array}$ & $\begin{array}{r}19 \\
18 \\
21 \\
49 \\
21 \\
8 \\
15 \\
29 \\
86 \\
463\end{array}$ & $\begin{array}{r}3 \\
0 \\
6 \\
7 \\
5 \\
1 \\
6 \\
6 \\
9 \\
17\end{array}$ & $\begin{array}{r}22 \\
18 \\
27 \\
56 \\
26 \\
9 \\
21 \\
35 \\
95 \\
480\end{array}$ \\
\hline $\begin{array}{l}P C-5 \text { COMP } \\
P C-5 \\
P C-5 \\
P C-5 \\
P C-5 \\
P C-5\end{array}$ & $\begin{array}{l}1 \\
2 \\
3 \\
4 \\
5\end{array}$ & $\begin{array}{l}2 \\
2 \\
1 \\
3 \\
1\end{array}$ & $\begin{array}{r}12 \\
49 \\
13 \\
9 \\
308 \\
7\end{array}$ & $\begin{array}{r}4 \\
7 \\
8 \\
7 \\
16 \\
3\end{array}$ & $\begin{array}{r}16 \\
56 \\
21 \\
16 \\
324 \\
10\end{array}$ \\
\hline $\begin{array}{l}\text { Reference COMP } \\
\text { Reference } \\
\text { Reference } \\
\text { Reference } \\
\text { Reference } \\
\text { Reference }\end{array}$ & $\begin{array}{l}1 \\
2 \\
3 \\
4 \\
5\end{array}$ & $\begin{array}{l}3 \\
2 \\
2 \\
1 \\
3\end{array}$ & $\begin{array}{r}11 \\
237 \\
39 \\
33 \\
12 \\
51\end{array}$ & $\begin{array}{r}2 \\
10 \\
4 \\
4 \\
3 \\
5\end{array}$ & $\begin{array}{r}13 \\
247 \\
43 \\
37 \\
15 \\
56\end{array}$ \\
\hline N. virens Background Rep 1 & 1 & 3 & 230 & 11 & 241 \\
\hline N. virens Background Rep 2 & 2 & 3 & 507 & 22 & 529 \\
\hline N. virens Background Rep 3 & 3 & 3 & 193 & 11 & 204 \\
\hline
\end{tabular}




\section{IABLE M.1. (contd)}

Sediment

Ireatment

Control COMP

$N$. virens Control

$N$. virens Control

$N$. virens Control

$N$. virens Control

N. virens Control Rep 1

$N$. virens Control Rep ?

N. virens Control Rep 3

\begin{tabular}{cc} 
Replicate & Batch \\
\hline 1 & \\
2 & 2 \\
3 & 3 \\
4 & 1 \\
5 & 1 \\
5 & 1 \\
5 & 1
\end{tabular}

Total Low

Molecular

Weight PAH

11

272

10

10

13

17

12
Total High

Molecular Total

Weight PAH.

PAH

14

13

286

12

11

22

22

17 


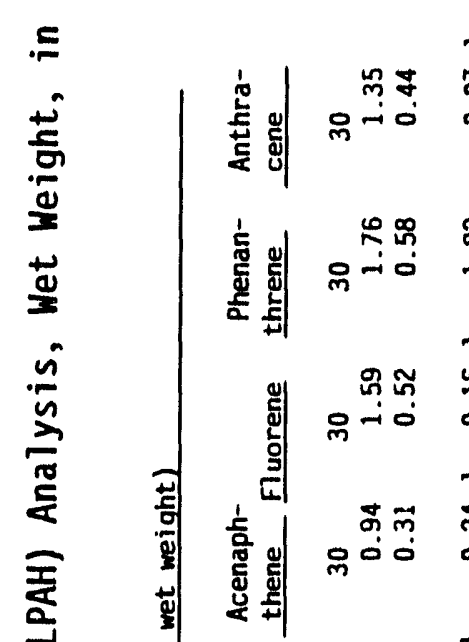

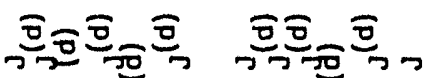

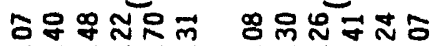
வ0000

జ

-

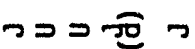

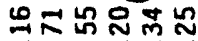

0ं0ல்

$\neg$ ᄀน

눙

○0000

흠ำ 훅

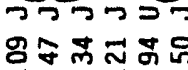
வ0000

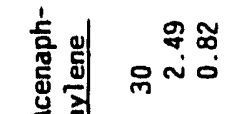

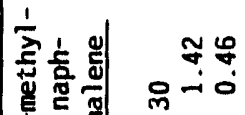

จ

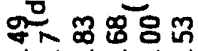

oniónó

로

$3=0$

m?

웅다융

o० -ímo

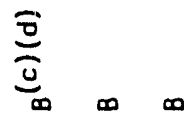

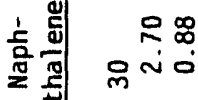

范不荳

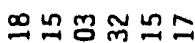

ஸ்ذญญ்

矛

눰

퐁

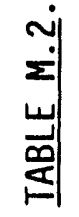

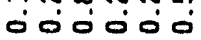

$\infty \infty \infty$

$N \rightarrow n-N$

०000

$\infty \infty \infty$

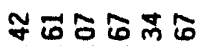

- -

ว 7 శ0

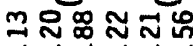

วนーว

กล ○。0

흐 흐

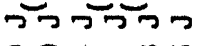

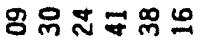

०0000

ग 20

舟必早品品

o-

$2 \pi 0$

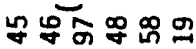

0ं

]

$\underbrace{\infty}_{\infty} \infty$

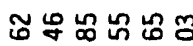

miñ

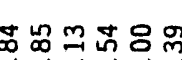

过的的

-

n-nNm

뭉

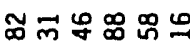

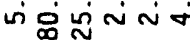

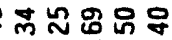

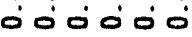

흐

品圆电

递

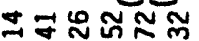

ن०

ว 2

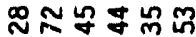

०00000

흠흐 흑

영잉응

○。ं

$\overline{0}_{\infty}$

命合界的告

0 n⿺辶0

$\neg$ 象

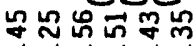

o-i-iñ

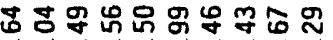

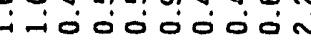

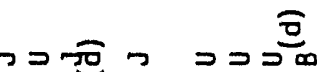

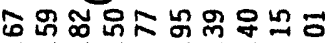

Dóñon-

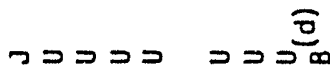

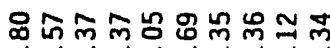

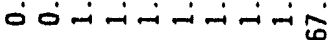

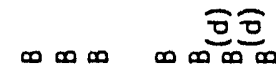

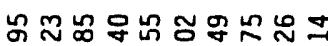
$\cong \cong \Xi \dot{m}$

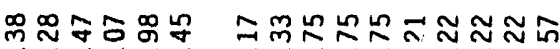

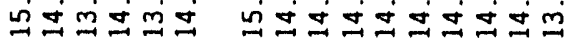

$-\sim \sim N-N \sim N m$

$-\sim m \forall n$

$\rightarrow \sim m+n$

$\rightarrow \sim m+\infty$

- n N n

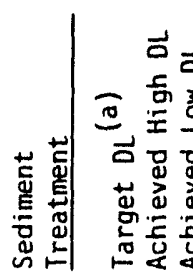

意

高

$\leq \leq \leq \leq \leq \leq$

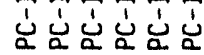

言

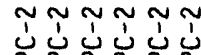

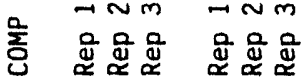

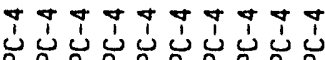

PANAMA CITY HARBOR

M.3 


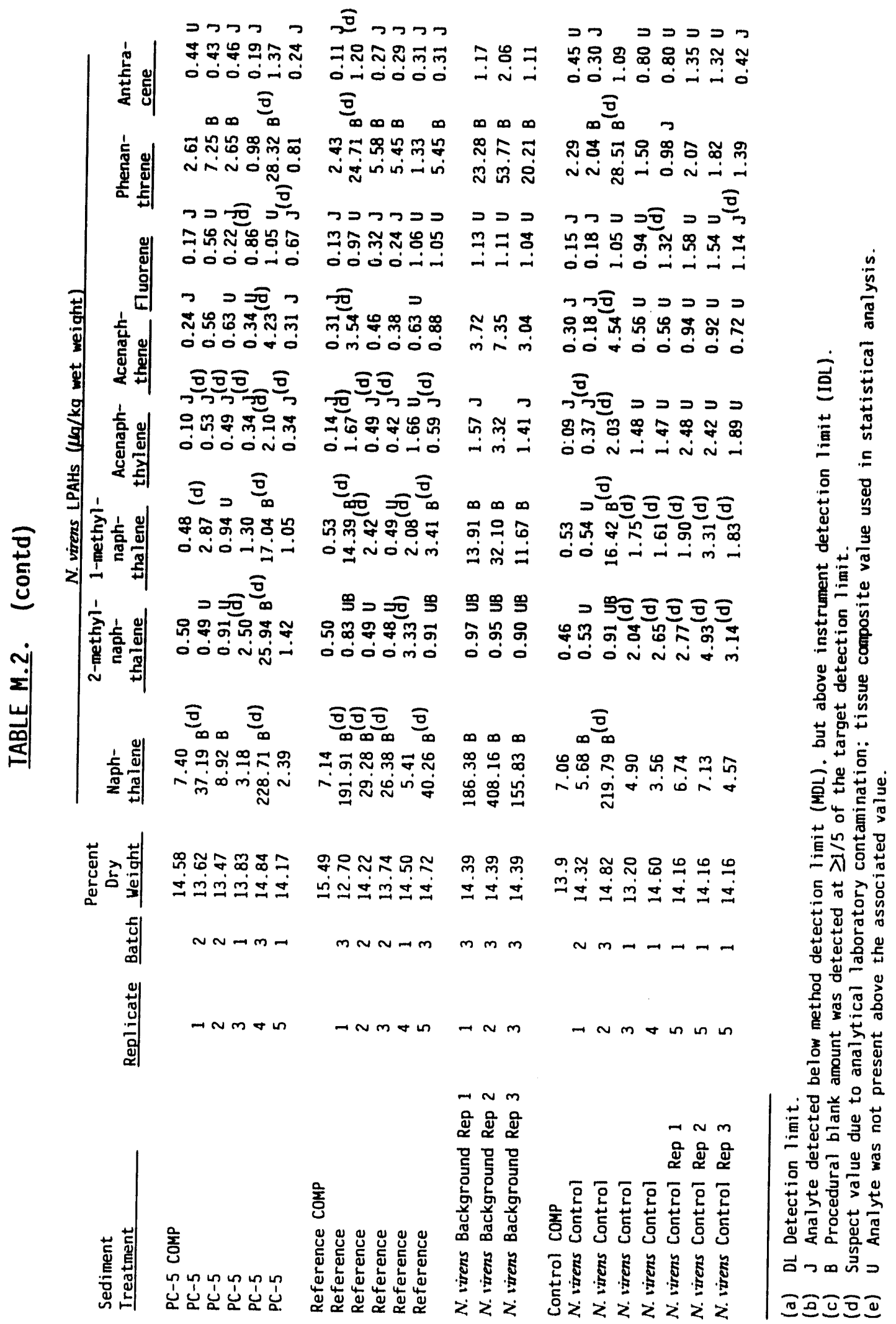


IABLE M.3. High Molecular Weight Polynuclear Aromatic Hydrocarbon (HPAH) Analysis (elution order, Fluoranthene - Benzo[b]fluoranthene), Wet Weight, in Tissue of N. Virens, Panama City Harbor Project

Sediment Ireatment

Target $D L$ (a)

Achieved HIgh DL

Achleved LOW DL.

PC-1 COMP

$P C-1$

$P C-1$

$P C-1$

$P C-1$

$P C-1$

$P C-1 A$ COMP

$P C-1 A$

PC-1A

$P C-1 A$

$P C-1 A$

$P C-1 A$

PC-2 COMP

$\mathrm{PC}-2$

$P C-2$

$P C-2$

$P C-2$

$P C-2$

PC-4 COMP

$P C-4$

PC-4 Rep 1

PC-4 Rep 2

$P C-4$ Rep 3

$P C-4$

PC-4 Rep 1

$P C-4$ Rep 2

$P C-4$ Rep 3

$P C-4$

PC-5 COMP

$P C-5$

PC -5

$P C-5$

PC -5

$P C-5$

Reference COMP

Reference

Reference

Reference

Reference

Reference

N. virens Background Rep 1 $N$. virens Background Rep 2 $N$. virens Background Rep 3
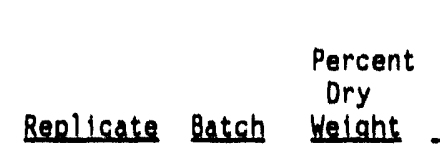

Fluor-
anthene

N. virens HPAHs $14 \mathrm{~g} / \mathrm{kg}$ wat weight

Welaht

30

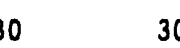

2.35

0.17

30

1.69
0.55

Benzo [a]

anthra-

cene Chrysene

Benzo [b]

fluor-

30
2.15
0.70

30

$\begin{array}{lll}2.15 & 2.45 & 2.42 \\ 0.70 & 0.80 & 0.79\end{array}$

30

15.18

$0.65 \mathrm{j}^{(\mathrm{b})}$

$0.42 \mathrm{~J}$

$0.14 \mathrm{~J}$

$0.38 \mathrm{~J}$

$0.34 \mathrm{~J} \quad 0.57 \mathrm{~J}$

0.190

14.15
14.03

12.32

14.15

1.34

1.05

0.92

$1.07 \mathrm{~J}$

0.68
0.76
0.98

$0.43 \mathrm{~J}$

$0.36 \mathrm{~J}$

$0.67 \mathrm{~J}$

$0.81 u^{(d)} 0.93 U$

$0.21 \mathrm{~J} \quad 0.81 \mathrm{~J}$

$0.19 \mathrm{~J}$

$0.52 \mathrm{~J}$

1.22
1.06

0.86

$0.11 \mathrm{~s}$

$0.36 \mathrm{~J}$

$0.26 \mathrm{~J}$

$0.47 \mathrm{~J}$

$0.54 \mathrm{~J}$

$0.66 \mathrm{~J}$

$0.38 \mathrm{~J}$

$0.29 \mathrm{~J}$

$0.13 \mathrm{~J}(\mathrm{c})$

$0.78 \mathrm{j}(\mathrm{c})$

$0.92 U$

$0.36 \mathrm{~J}$

12.85

13.54

14.00
13.39

1.05

0.73

0.65

$0.23 \mathrm{~J}$

$0.86 \mathrm{~J}$
$0.82 \mathrm{U}$

$0.49 \mathrm{~J}$

$0.15 \mathrm{~J}$

0.34 (d)

2.24 (c)

1.64
0.96

$0.12 \mathrm{~J}$

c) $0.33 \mathrm{~J}$

$0.70 \mathrm{~J}(\mathrm{c}) 0.97 \mathrm{~J}$

$0.31 \mathrm{~J}$

$0.56 \mathrm{~J}$

0.97

0.75

$0.18 \mathrm{~J}$

$0.31 \mathrm{~J}$

$0.86 \mathrm{U}$

$0.57 \mathrm{~J}$

$0.21 \mathrm{~J}$

$0.49 \mathrm{~J}$

$0.18 \mathrm{~J}$

$0.43 \mathrm{~J}$

$0.43 \mathrm{~J}$

$0.49 \mathrm{~J}$

$0.30 \mathrm{~J}$

$0.85 \mathrm{U}$

14.45

15.17

14.33

14.75

14.75

14.75

14.21

14.22

14.22

14.22

$0.94 \mathrm{~J}$

$0.49 \mathrm{~J}$

$0.31 \mathrm{~J}$

$0.61 \mathrm{~J}$

$0.19 \mathrm{~J}(\mathrm{c})$

$0.47 \mathrm{~J}$

$0.11 \mathrm{~J}$

$0.89 U$

$0.48 \mathrm{~J}$

$0.98 \mathrm{~J}$

$0.22 \mathrm{~J}$

$0.89 \mathrm{U}$

$0.43 \mathrm{~J}$

$0.66 \mathrm{~J}$

$1.02 \mathrm{U}$

$0.89 \mathrm{~J}$

$1.63 \mathrm{~J}$

$0.68 \mathrm{~J}$

$1.01 \mathrm{~J}$

$0.44 \mathrm{~J}$

$1.14 \mathrm{~J}$

$0.70 \mathrm{~J}$

$0.38 \mathrm{~J}$

$1.14 \mathrm{~J}$

$0.80 \mathrm{~J}$

$0.93 \mathrm{U}$

$0.52 \mathrm{~J}$

$0.85 \mathrm{U}$

$0.97 \mathrm{U}$

$1.12 \mathrm{~J}$

$1.32 \mathrm{~J}$

$0.98 \mathrm{~J}$

$0.41 \mathrm{~J}$

$0.69 \mathrm{~J}$

$0.47 \mathrm{~J} \quad 0.85 \mathrm{~J}$

2.15

1.47 (c)

$0.58 \mathrm{~J}$

$1.15 \mathrm{~J}$

$0.34 \mathrm{~J}$

$1.01 \mathrm{U}$

$0.62 \mathrm{~J}$

$0.82 \mathrm{~J}$

$0.50 \mathrm{~J}$

$0.96 \mathrm{U}$

$0.65 \mathrm{~J}$

$0.79 \mathrm{~J}$

13.57

14.58

1.01

$4.33(c)$

$1.17 \mathrm{~J}(\mathrm{c}) 2.03$

$1.04(\mathrm{c})$

13.62
13.47

1.61

1.62

$1.83(\mathrm{c})$

0.90

$0.16 \mathrm{~J}$

$0.64 \mathrm{~J}$

$0.45 \mathrm{~J}$

13.83

14.84

14.17

$1.03 \mathrm{U}$

2.05

$0.43 \mathrm{~J}$

$0.83 \mathrm{~J}$

0.90

$1.92(0)$

$1.31 \mathrm{~J}$

$0.97 \mathrm{~J}$

$0.43 \mathrm{~J}(\mathrm{c}) 1.14$

$0.99 \mathrm{~J}^{(\mathrm{c})} 2.13$

0.79 ( )

1.11

$0.27 \mathrm{~J}$

$0.64 \mathrm{~J}$

$0.56 \mathrm{~J}$

15.49

12.70

14.22

$3.03(\mathrm{c})$

$0.35, \mathrm{c})$

$0.07 \mathrm{~J}$ (c) $0.36 \mathrm{~J}(\mathrm{c}$

$0.23 \mathrm{~J}(c)$

1.14

$2.75^{(\mathrm{c})}$

$0.76 \mathrm{~J}(\mathrm{c}) \quad 1.29 \mathrm{~J}(\mathrm{c})$

$0.27 \mathrm{~J}(\mathrm{c}) 0.49 \mathrm{~J}$

$1.12 \mathrm{~J}(\mathrm{c})$

1.23

$1.33 \mathrm{~J}$

0.85

$0.41 \mathrm{~J}(\mathrm{c}) \quad 0.70 \mathrm{~J}$

$0.35 \mathrm{~J}$

14.50

$1.24 \mathrm{~J}$

$0.82 \mathrm{~J}$

$0.39 \mathrm{~J}$

$0.51 \mathrm{~J}$

$1.62 \mathrm{U}$

2.89

2.62

$0.75 \mathrm{~J}$

$1.39 \mathrm{~J}$

$0.50 \mathrm{~J}$

14.39

14.39

6.49

5.88

1.51

2.61

$1.08 \mathrm{~J}$

2.60

2.40

$1.28 \mathrm{~J}$

M. 5 


\section{IABLE M.3.}

\begin{tabular}{|c|c|c|c|c|c|c|c|c|c|}
\hline \multirow{2}{*}{\multicolumn{2}{|c|}{$\begin{array}{l}\text { Sediment } \\
\text { Ireatment }\end{array}$}} & \multirow[b]{2}{*}{ Beplucate } & \multirow[b]{2}{*}{ Batch } & \multirow[b]{2}{*}{$\begin{array}{c}\text { Percent } \\
\text { Dry } \\
\text { Welght }\end{array}$} & \multicolumn{5}{|c|}{$N$ virens HeAHs (Ua/kg wet welaht) } \\
\hline & & & & & $\begin{array}{l}\text { Fluor- } \\
\text { anthene }\end{array}$ & Pyrane & $\begin{array}{l}\text { Benzo [a] } \\
\text { anthra- } \\
\text { cene }\end{array}$ & Chrysene & $\begin{array}{l}\text { Benzo [b] } \\
\text { flucr- } \\
\text { anthene }\end{array}$ \\
\hline $\begin{array}{l}\text { Control } \\
N \text {. virens }\end{array}$ & $\begin{array}{l}\text { COMP } \\
\text { Control }\end{array}$ & 1 & 2 & $\begin{array}{l}13.90 \\
14.32\end{array}$ & $\begin{array}{l}0.84 \\
1.08\end{array}$ & $\begin{array}{l}0.57 \\
0.80\end{array}$ & $\begin{array}{l}0.14 \mathrm{~J} \\
0.20 \mathrm{~J}\end{array}$ & $\begin{array}{l}0.54 \mathrm{~J} \\
0.59 \mathrm{~J}\end{array}$ & $\begin{array}{l}0.24 \mathrm{~J} \\
0.36 \mathrm{~J}\end{array}$ \\
\hline N. virens & Control & 2 & 3 & 14.82 & $3.85^{(c)}$ & $3.53(c)$ & $0.97 \mathrm{j}^{1 \mathrm{C}}$ & $1.81(c)$ & $1.36 \mathrm{~J}^{(\mathrm{c})}$ \\
\hline$N$. virens & Control & 3 & 1 & 13.20 & $1.18 \mathrm{~J}$ & $0.90 \mathrm{~J}$ & $1.27 \mathrm{U}$ & $1.46 \mathrm{U}$ & $1.44 \mathrm{U}$ \\
\hline N. virens & Control & 4 & 1 & 14.60 & $1.38 \mathrm{U}$ & $0.87 \mathrm{~J}$ & $1.26 \mathrm{U}$ & $1.45 \mathrm{U}$ & $1.43 \mathrm{U}$ \\
\hline N. virens & Control Rep 1 & 5 & 1 & 14.16 & $2.16 \mathrm{~J}$ & $2.69(\mathrm{c})$ & $1.00 \mathrm{j}$ & c) $1.42 \mathrm{~J}$ & $0.99 \mathrm{~J}^{(\mathrm{c})}$ \\
\hline N. virens & Control Rep 2 & 5 & 1 & 14.16 & $1.69 \mathrm{~J}$ & $1.44 \mathrm{~J}$ & $0.65 \mathrm{j}(\mathrm{c}$ & $0.92 \mathrm{~J}$ & $0.74 \mathrm{j}^{10}$ \\
\hline N. virens & Control Rep 3 & 5 & 1 & 14.16 & $1.40 \mathrm{~J}$ & $1.20 \mathrm{~J}$ & $0.53 \mathrm{j}$ & $0.85 \mathrm{~J}$ & $0.63 \mathrm{~J}$ \\
\hline
\end{tabular}

\footnotetext{
(a) DL Detection Iimit.

(b) J Analyte detected below method detection $11 \mathrm{mit}$ (MDL), but above instrument detection 1 imit (IOL).

(c) Suspect value due to analytical laboratory contamination; tissue composite value used in statistical analysis.

(d) U Analyte was not present above the associated value.
} 
IABLE M.4. High Molecular Weight Polynuclear Aromatic Hydrocarbon (HPAH) Analys is (elution order, Benzo[k]fluoranthene Benzo[g,h,i]perylene), Wet Weight, in Tissue of $N$. virens, Panama City Harbor Project

\begin{tabular}{|c|c|c|c|c|c|c|c|c|}
\hline \multirow[b]{2}{*}{$\begin{array}{l}\text { Sediment } \\
\text { Irestment }\end{array}$} & \multirow[b]{2}{*}{ Replleate } & \multirow[b]{2}{*}{ Batch } & \multirow[b]{2}{*}{$\begin{array}{c}\text { Percent } \\
\text { Ory } \\
\text { Welaht } \\
\end{array}$} & \multicolumn{4}{|c|}{ N. virens HPAHs (Ma/ko wet wolaht) } & \multirow[b]{2}{*}{$\begin{array}{l}\text { Benzo } \\
{[g . h .1]} \\
\text { perylene }\end{array}$} \\
\hline & & & & $\begin{array}{l}\text { Benzo[k] } \\
\text { fluor- } \\
\text { anthene }\end{array}$ & $\begin{array}{l}\text { Benzo [a] } \\
\text { Derrene }\end{array}$ & $\begin{array}{l}\text { Indeno } \\
{[1,2,3-} \\
c, d] \\
\text { pxrene }\end{array}$ & $\begin{array}{c}\text { Dibenzo } \\
{[a, h]} \\
\text { anthra- } \\
\text { cene } \\
\end{array}$ & \\
\hline $\begin{array}{l}\text { Target OL (a) } \\
\text { Achloved High OL } \\
\text { Achloved Low OL }\end{array}$ & & & & $\begin{array}{l}30 \\
1.13 \\
0.37\end{array}$ & $\begin{array}{l}30 \\
0.90 \\
0.30\end{array}$ & $\begin{array}{l}30 \\
1.97 \\
0.65\end{array}$ & $\begin{array}{l}30 \\
1.78 \\
0.58\end{array}$ & $\begin{array}{l}30 \\
1.66 \\
0.54\end{array}$ \\
\hline $\begin{array}{l}P C-1 \text { COMP } \\
P C-1 \\
P C-1 \\
P C-1 \\
P C-1 \\
P C-1\end{array}$ & $\begin{array}{l}1 \\
2 \\
3 \\
4 \\
5\end{array}$ & $\begin{array}{l}2 \\
1 \\
2 \\
1 \\
2\end{array}$ & $\begin{array}{l}15.18 \\
14.15 \\
14.03 \\
12.32 \\
14.15 \\
14.17\end{array}$ & $\begin{array}{l}0.18 \mathrm{~J}^{(\mathrm{b})} \\
0.13 \mathrm{~J} \\
0.20 \mathrm{~J} \\
0.30 \mathrm{~J} \\
0.43 \mathrm{U} \\
0.11 \mathrm{~J}\end{array}$ & $\begin{array}{l}0.07 \mathrm{~J} \\
0.09 \mathrm{~J} \\
0.31 \mathrm{U}(\mathrm{d}) \\
0.24 \mathrm{~J} \\
0.34 \mathrm{U} \\
0.34 \mathrm{U}\end{array}$ & $\begin{array}{l}0.65 \mathrm{U}^{(\mathrm{c})} \\
0.28 \mathrm{~J} \\
0.69 \mathrm{U} \\
0.59 \mathrm{~J} \\
0.75 \mathrm{U} \\
0.21 \mathrm{~J}\end{array}$ & $\begin{array}{l}0.59 \mathrm{U} \\
0.09 \mathrm{~J} \\
0.62 \mathrm{U} \\
0.16 \mathrm{~J} \\
0.68 \mathrm{U} \\
0.67 \mathrm{II}\end{array}$ & $\begin{array}{l}0.25 \mathrm{~J} \\
0.38 \mathrm{~J} \\
0.58(\mathrm{y}) \\
0.86(\mathrm{~d}) \\
0.63 \mathrm{U} \\
0.31 \mathrm{~J}\end{array}$ \\
\hline $\begin{array}{l}P C-1 A \text { COMP } \\
P C-1 A \\
P C-1 A \\
P C-1 A \\
P C-1 A \\
P C-1 A\end{array}$ & $\begin{array}{l}1 \\
2 \\
3 \\
4 \\
5\end{array}$ & $\begin{array}{l}2 \\
1 \\
2 \\
2 \\
1\end{array}$ & $\begin{array}{l}14.84 \\
12.85 \\
14.13 \\
13.54 \\
14.00 \\
13.39\end{array}$ & $\begin{array}{l}0.13 \mathrm{~J} \\
0.12 \mathrm{~J} \\
0.42 \mathrm{U} \\
0.13 \mathrm{~J} \\
0.11 \mathrm{~J} \\
0.40 \mathrm{U}\end{array}$ & $\begin{array}{l}0.07 \mathrm{~J} \\
0.30 \mathrm{U} \\
0.33 \mathrm{U} \\
0.13 \mathrm{~J} \\
0.38 \mathrm{U} \\
0.32 \mathrm{U}\end{array}$ & $\begin{array}{l}0.66 \mathrm{U} \\
0.24 \mathrm{~J} \\
0.73 \mathrm{U} \\
0.32 \mathrm{~J} \\
0.18 \mathrm{~J} \\
0.69 \mathrm{U}\end{array}$ & $\begin{array}{l}0.59 \mathrm{U} \\
0.07 \mathrm{~J} \\
0.66 \mathrm{U} \\
0.09 \mathrm{~J} \\
0.06 \mathrm{~J} \\
0.62 \mathrm{U}\end{array}$ & $\begin{array}{l}0.39 \mathrm{~J} \\
0.38 \mathrm{~J} \\
0.61 \mathrm{U} \\
0.48 \mathrm{~J} \\
0.29 \mathrm{~J} \\
0.58 \mathrm{U}\end{array}$ \\
\hline $\begin{array}{l}P C-2 \text { COMP } \\
P C-2 \\
P C-2 \\
P C-2 \\
P C-2 \\
P C-2\end{array}$ & $\begin{array}{l}1 \\
2 \\
3 \\
4 \\
5\end{array}$ & $\begin{array}{l}3 \\
2 \\
1 \\
1 \\
1\end{array}$ & $\begin{array}{l}15.38 \\
14.28 \\
13.47 \\
14.07 \\
13.98 \\
14.45\end{array}$ & $\begin{array}{l}0.11 \mathrm{~J} \\
0.28 \mathrm{~J} \\
0.22 \mathrm{~J} \\
0.24 \mathrm{~J} \\
0.41 \mathrm{U} \\
0.68 \mathrm{U}\end{array}$ & $\begin{array}{l}0.30 U \\
0.86 U \\
0.12 \mathrm{~J} \\
0.36 U \\
0.33 U \\
0.54 U\end{array}$ & $\begin{array}{l}0.65 \mathrm{U} \\
0.67 \mathrm{~J} \\
0.32 \mathrm{~J} \\
0.80 \mathrm{U} \\
0.72 \mathrm{U} \\
1.19 \mathrm{U}\end{array}$ & $\begin{array}{l}0.59 \mathrm{U} \\
0.19 \mathrm{~J} \\
0.08 \mathrm{~J} \\
0.72 \mathrm{U} \\
0.65 \mathrm{U} \\
1.07 \mathrm{U}\end{array}$ & $\begin{array}{l}0.24 \mathrm{~J}(\mathrm{~d}) \\
0.77 \mathrm{~J} \\
0.47 \mathrm{~J} \\
0.67 \mathrm{U} \\
0.61 \mathrm{U} \\
1.00 \mathrm{U}\end{array}$ \\
\hline $\begin{array}{l}\text { PC-4 COMP } \\
\text { PC-4 } \\
\text { PC-4 Rep 1 } \\
\text { PC-4 ReP 2 } \\
\text { PC-4 Rep } 3 \\
\text { PC-4 } \\
\text { PC-4 Rep 1 } \\
\text { PC-4 ReP } 2 \\
\text { PC-4 ReP } 3 \\
\text { PC-4 }\end{array}$ & $\begin{array}{l}1 \\
2 \\
2 \\
2 \\
3 \\
4 \\
4 \\
4 \\
5\end{array}$ & $\begin{array}{l}1 \\
2 \\
2 \\
2 \\
1 \\
2 \\
2 \\
2 \\
3\end{array}$ & $\begin{array}{l}15.17 \\
14.33 \\
14.75 \\
14.75 \\
14.75 \\
14.21 \\
14.22 \\
14.22 \\
14.22 \\
13.57\end{array}$ & $\begin{array}{l}0.19 \mathrm{~J} \\
0.47 \mathrm{U} \\
0.22 \mathrm{~J} \\
0.27 \mathrm{~J} \\
0.26 \mathrm{~J} \\
0.45 \mathrm{U} \\
0.21 \mathrm{~J} \\
0.21 \mathrm{~J} \\
0.27 \mathrm{~J} \\
0.53 \mathrm{~J}\end{array}$ & $\begin{array}{l}0.59 \mathrm{U} \\
0.38 \mathrm{U} \\
0.16 \mathrm{~J} \\
0.17 \mathrm{~J} \\
0.14 \mathrm{~J} \\
0.36 \mathrm{U} \\
0.18 \mathrm{~J} \\
0.89 \mathrm{U} \\
0.24 \mathrm{~J} \\
0.68\end{array}$ & $\begin{array}{l}1.30 \mathrm{U} \\
0.82 \mathrm{U} \\
0.55 \mathrm{~J} \\
0.60 \mathrm{~J} \\
0.36 \mathrm{~J} \\
0.78 \mathrm{U} \\
0.55 \mathrm{~J} \\
0.61 \mathrm{~J} \\
0.65 \mathrm{~J} \\
0.79 \mathrm{~J}\end{array}$ & $\begin{array}{l}1.17 \mathrm{U} \\
0.74 \mathrm{U} \\
0.14 \mathrm{~J} \\
0.23 \mathrm{~J} \\
0.16 \mathrm{~J} \\
0.71 \mathrm{U} \\
0.17 \mathrm{~J} \\
0.16 \mathrm{~J} \\
0.21 \mathrm{~J} \\
0.18 \mathrm{~J}\end{array}$ & $\begin{array}{l}0.34 \mathrm{~J} \\
0.69 \mathrm{U} \\
0.88 \mathrm{~J}(\mathrm{~d}) \\
1.04 \mathrm{~J}(\mathrm{~J}) \\
0.53 \mathrm{~J} \\
0.66 \mathrm{U}(\mathrm{d}) \\
1.08 \mathrm{~J}(\mathrm{~J}) \\
0.83 \mathrm{~J} \\
0.94 \mathrm{~J} \\
0.88 \mathrm{~J}\end{array}$ \\
\hline $\begin{array}{l}P C-5 \text { COMP } \\
P C-5 \\
P C-5 \\
P C-5 \\
P C-5 \\
P C-5\end{array}$ & $\begin{array}{l}1 \\
2 \\
3 \\
4 \\
5\end{array}$ & $\begin{array}{l}2 \\
2 \\
1 \\
3 \\
1\end{array}$ & $\begin{array}{l}14.58 \\
13.62 \\
13.47 \\
13.83 \\
14.84 \\
14.17\end{array}$ & $\begin{array}{l}0.44 \\
0.36 \mathrm{~J} \\
0.50 \mathrm{~J} \\
0.74 \\
0.70 \mathrm{~J} \\
0.38 \mathrm{~J}\end{array}$ & $\begin{array}{l}0.17 \mathrm{~J} \\
0.31 \mathrm{~J} \\
0.60 \mathrm{U} \\
0.32 \mathrm{y}) \\
0.76(\mathrm{~d}) \\
0.30 \mathrm{~J}\end{array}$ & $\begin{array}{l}0.20 \mathrm{~J} \\
0.31 \mathrm{~J} \\
0.24 \mathrm{~J} \\
0.71 \mathrm{U}(d) \\
0.64 \mathrm{~J}(\mathrm{U}) \\
0.86 \mathrm{U}\end{array}$ & $\begin{array}{l}0.58 \mathrm{U} \\
0.11 \mathrm{~J} \\
0.13 \mathrm{~J} \\
0.64 \mathrm{U} \\
0.20 \mathrm{~J} \\
0.78 \mathrm{U}\end{array}$ & $\begin{array}{l}0.46 \mathrm{~J} \\
0.40 \mathrm{~J} \\
0.45 \mathrm{~J} \\
0.60 \mathrm{U} \\
0.77 \mathrm{~J} \\
0.13 \mathrm{~J}\end{array}$ \\
\hline $\begin{array}{l}\text { Reference comp } \\
\text { Reference } \\
\text { Reference } \\
\text { Reference } \\
\text { Reference } \\
\text { Reference }\end{array}$ & $\begin{array}{l}1 \\
2 \\
3 \\
4 \\
5\end{array}$ & $\begin{array}{l}3 \\
2 \\
2 \\
1 \\
3\end{array}$ & $\begin{array}{l}15.49 \\
12.70 \\
14.22 \\
13.74 \\
14.50 \\
14.72\end{array}$ & $\begin{array}{l}0.12 \mathrm{~J} \\
0.24 \mathrm{~J} \\
0.10 \mathrm{~J} \\
0.13 \mathrm{~J} \\
0.76 \mathrm{U} \\
0.16 \mathrm{~J}\end{array}$ & $\begin{array}{l}0.05 \mathrm{~J} \\
0.55 \mathrm{U} \\
0.32 \mathrm{U} \\
0.08 \mathrm{~J} \\
0.60 \mathrm{U} \\
0.60 \mathrm{U}\end{array}$ & $\begin{array}{l}0.66 \mathrm{U} \\
0.47 \mathrm{~J} \\
0.33 \mathrm{~J} \\
0.20 \mathrm{~J} \\
1.32 \mathrm{U} \\
0.29 \mathrm{~J}\end{array}$ & $\begin{array}{l}0.59 \mathrm{U} \\
0.15 \mathrm{~J} \\
0.09 \mathrm{~J} \\
0.07 \mathrm{~J} \\
1.19 \mathrm{U} \\
1.18 \mathrm{U}\end{array}$ & $\begin{array}{l}0.29 \mathrm{~J} \\
0.62 \mathrm{~J} \\
0.48 \mathrm{~J} \\
0.31 \mathrm{~J} \\
1.11 \mathrm{U} \\
0.44 \mathrm{~J}\end{array}$ \\
\hline
\end{tabular}


IABLEM.4. (contd)

\begin{tabular}{|c|c|c|c|c|c|c|c|c|}
\hline \multirow[b]{2}{*}{$\begin{array}{l}\text { Sediment } \\
\text { Irectment }\end{array}$} & \multirow[b]{2}{*}{ Beolleate } & \multirow[b]{2}{*}{ Batch } & \multirow[b]{2}{*}{$\begin{array}{c}\text { Percent } \\
\text { Ory } \\
\text { Waloht }\end{array}$} & \multicolumn{5}{|c|}{ N. virens HPAHs (Ha/ko wat welaht) } \\
\hline & & & & $\begin{array}{c}\text { Benzo [k] } \\
\text { fluor- } \\
\text { enthene }\end{array}$ & $\begin{array}{l}\text { Benzo [a] } \\
\text { Dyrene }\end{array}$ & $\begin{array}{c}\text { Indeno } \\
{[1,2,3-} \\
c, d] \\
\text { eyrene }\end{array}$ & $\begin{array}{l}\text { Dibenzo } \\
{[a, h]} \\
\text { anthra- } \\
\text { cene }\end{array}$ & $\begin{array}{l}\text { Benzo } \\
{[g, h .1]} \\
\text { Darylang }\end{array}$ \\
\hline N. virens Background Rep 1 & 1 & 3 & 14.39 & $0.38 \mathrm{~J}$ & $0.64 \mathrm{U}$ & $0.58 \mathrm{~J}$ & $0.15 \mathrm{~J}$ & $0.74 \mathrm{~J}$ \\
\hline N. virens Background Rep 2 & 2 & 3 & 14.39 & 0.89 & $0.63 \mathrm{U}$ & $1.10 \mathrm{~J}$ & $0.41 \mathrm{~J}$ & 1.21 \\
\hline N. virens Background Rep 3 & 3 & 3 & 14.39 & $0.45 \mathrm{~J}$ & $0.59 \mathrm{U}$ & $0.79 \mathrm{~J}$ & $0.22 \mathrm{~J}$ & $1.06 \mathrm{~J}$ \\
\hline $\begin{array}{l}\text { Contral COMP } \\
N \text {. virens Control }\end{array}$ & 1 & 2 & $\begin{array}{l}13.90 \\
14.32\end{array}$ & $\begin{array}{l}0.23 \mathrm{~J} \\
0.13 \mathrm{~J}\end{array}$ & $\begin{array}{l}0.30 U \\
0.35 U\end{array}$ & $\begin{array}{l}0.65 \mathrm{U} \\
0.17 \mathrm{~J}\end{array}$ & $\begin{array}{l}0.59 U \\
0.68 U\end{array}$ & $\begin{array}{l}0.25 \mathrm{~J} \\
0.31 \mathrm{~J}\end{array}$ \\
\hline N. virens Control & 2 & 3 & 14.82 & $0.39 \mathrm{~J}$ & $0.42 \mathrm{~J}$ & $0.61 \mathrm{~J}$ & $0.16 \mathrm{~J}$ & $0.75 \mathrm{~J}$ \\
\hline N. virens Control & 3 & 1 & 13.20 & $0.67 \mathrm{U}$ & $0.53 \mathrm{U}$ & $1.17 \mathrm{U}$ & $1.06 \mathrm{U}$ & $0.98 U$ \\
\hline N. virens Control & 4 & 1 & 14.60 & $0.67 \mathrm{U}$ & $0.53 U$ & $1.16 \mathrm{U}$ & $1.05 \mathrm{U}$ & $0.98 \mathrm{U}$ \\
\hline N. virens Control Rep 1 & 5 & 1 & 14.16 & $0.82 \mathrm{~J}$ & $0.90 \mathrm{U}$ & $1.97 \mathrm{U}$ & $1.77 \mathrm{U}$ & $1.65 \mathrm{U}$ \\
\hline N. virens Control Rap 2 & 5 & 1 & 14.16 & $1.10 \mathrm{U}$ & $0.88 U$ & $1.92 \cup$ & $1.73 \mathrm{U}$ & $1.61 \mathrm{U}$ \\
\hline N. vinens Control Rep 3 & 5 & 1 & 14.16 & $0.44 \mathrm{~J}$ & $0.69 \mathrm{U}$ & $1.50 \mathrm{U}$ & $1.35 U$ & $1.26 \mathrm{U}$ \\
\hline
\end{tabular}

(a) DL Datection $1 / \mathrm{m} 1 \mathrm{t}$.

(b) I Analyte detected below method detection $11 \mathrm{mit}$ (MOL), but above instrument detection $1 \mathrm{imit}$ (IOL).

(c) U Analyte was not present above the associated value.

(d) Suspect value due to analytical laboratory contamination; tissue composite value used in statitical analysis. 
IABLE M.5. Total Polynuclear Aromatic Hydrocarbon (P/AH) Analysis, Dry Weight, in Tissue of $N$. virens, Panama City Harbor Project

\begin{tabular}{|c|c|c|c|c|c|}
\hline $\begin{array}{l}\text { Sediment } \\
\text { Ireatment }\end{array}$ & Beplleats & Batch & $\begin{array}{l}\text { Total Low } \\
\text { Molecular } \\
\text { Yoloht PAH }\end{array}$ & $\begin{array}{l}\text { Total Nigh } \\
\text { Molecular } \\
\text { Welaht PAH }\end{array}$ & $\begin{array}{l}\text { Total } \\
\text { PAH }\end{array}$ \\
\hline $\begin{array}{l}P C-1 \text { COMP } \\
P C-1 \\
P C-1 \\
P C-1 \\
P C-1 \\
P C-1\end{array}$ & $\begin{array}{l}1 \\
2 \\
3 \\
4 \\
5\end{array}$ & $\begin{array}{l}2 \\
1 \\
2 \\
1 \\
2\end{array}$ & $\begin{array}{r}57 \\
291 \\
49 \\
137 \\
114 \\
88\end{array}$ & $\begin{array}{l}15 \\
34 \\
18 \\
47 \\
16 \\
28\end{array}$ & $\begin{array}{r}12 \\
328 \\
67 \\
184 \\
130 \\
116\end{array}$ \\
\hline $\begin{array}{l}P C-1 A \text { COMP } \\
P C-1 A \\
P C-1 A \\
P C-1 A \\
P C-1 A \\
P C-1 A\end{array}$ & $\begin{array}{l}1 \\
2 \\
3 \\
4 \\
5\end{array}$ & $\begin{array}{l}2 \\
1 \\
2 \\
2 \\
1\end{array}$ & $\begin{array}{r}44 \\
241 \\
61 \\
115 \\
72 \\
43\end{array}$ & $\begin{array}{l}15 \\
29 \\
14 \\
31 \\
2 ! \\
7\end{array}$ & $\begin{array}{r}59 \\
270 \\
75 \\
146 \\
93 \\
50\end{array}$ \\
\hline $\begin{array}{l}P C-2 \text { COMP } \\
P C-2 \\
P C-2 \\
P C-2 \\
P C-2 \\
P C-2\end{array}$ & $\begin{array}{l}1 \\
2 \\
3 \\
4 \\
5\end{array}$ & $\begin{array}{l}3 \\
2 \\
1 \\
1 \\
1\end{array}$ & $\begin{array}{r}60 \\
715 \\
236 \\
55 \\
46 \\
82\end{array}$ & $\begin{array}{r}13 \\
60 \\
36 \\
18 \\
9 \\
15\end{array}$ & $\begin{array}{r}73 \\
775 \\
272 \\
73 \\
55 \\
97\end{array}$ \\
\hline $\begin{array}{l}P C-4 \text { COMP } \\
P C-4 \\
P C-4 \text { Rep } 1 \\
P C-4 \text { Rep } 2 \\
P C-4 \text { Rep } 3 \\
P C-4 \\
P C-4 \text { Rep } 1 \\
P C-4 \text { Rep } 2 \\
P C-4 \text { Rep } 3 \\
P C-4\end{array}$ & $\begin{array}{l}1 \\
2 \\
2 \\
2 \\
3 \\
4 \\
4 \\
4 \\
5\end{array}$ & $\begin{array}{l}1 \\
2 \\
2 \\
2 \\
1 \\
2 \\
2 \\
2 \\
3\end{array}$ & $\begin{array}{r}126 \\
127 \\
145 \\
335 \\
141 \\
57 \\
105 \\
204 \\
607 \\
3412\end{array}$ & $\begin{array}{r}21 \\
0 \\
39 \\
50 \\
34 \\
4 \\
42 \\
42 \\
61 \\
125\end{array}$ & $\begin{array}{r}147 \\
127 \\
184 \\
385 \\
175 \\
61 \\
147 \\
246 \\
668 \\
3537\end{array}$ \\
\hline $\begin{array}{l}P C-5 \text { COMP } \\
P C-5 \\
P C-5 \\
P C-5 \\
P C-5 \\
P C-5\end{array}$ & $\begin{array}{l}1 \\
2 \\
3 \\
4 \\
5\end{array}$ & $\begin{array}{l}2 \\
2 \\
1 \\
3 \\
1\end{array}$ & $\begin{array}{r}79 \\
358 \\
95 \\
68 \\
2073 \\
51\end{array}$ & $\begin{array}{r}30 \\
49 \\
57 \\
50 \\
111 \\
24\end{array}$ & $\begin{array}{r}109 \\
407 \\
152 \\
118 \\
2184 \\
75\end{array}$ \\
\hline $\begin{array}{l}\text { Reference COMP } \\
\text { Reference } \\
\text { Reference } \\
\text { Reference } \\
\text { Reference } \\
\text { Reforence }\end{array}$ & $\begin{array}{l}1 \\
2 \\
3 \\
4 \\
5\end{array}$ & $\begin{array}{l}3 \\
2 \\
2 \\
1 \\
3\end{array}$ & $\begin{array}{r}73 \\
1869 \\
273 \\
241 \\
86 \\
346\end{array}$ & $\begin{array}{l}14 \\
82 \\
29 \\
29 \\
22 \\
31\end{array}$ & $\begin{array}{r}87 \\
1951 \\
302 \\
270 \\
108 \\
377\end{array}$ \\
\hline N. wirens Background Rep $\mid$ & 1 & 3 & 1598 & 73 & 1671 \\
\hline N. virens Background Rep 2 & 2 & 3 & 3519 & 153 & 3672 \\
\hline N. virens Background Rep 3 & 3 & 3 & 1342 & 77 & 1419 \\
\hline
\end{tabular}


IABLE M.5. (contd)

Sediment

Irretment

Control COMp

$N$. wirens Control

$N$. whens Control

$N$. vinens Control

$N$. whens Control

N. whens Control Rep 1

$N$. whens Control Rep 2

N. virens Control Rep 3

\section{Beoluate}

1

2

3

3

4

5

Total Low
Molecular
Batch Melaht PAH

2

3

3

1

1

$\begin{array}{cr}\begin{array}{l}\text { Total High } \\ \text { Molecular } \\ \text { Yelaht PAH }\end{array} & \begin{array}{r}\text { Total } \\ \text { PAH }\end{array} \\ 20 & \\ 25 & 98 \\ 93 & 86 \\ 16 & 1930 \\ 6 & 93 \\ 64 & 75 \\ 38 & 159 \\ 36 & 159 \\ & 124\end{array}$




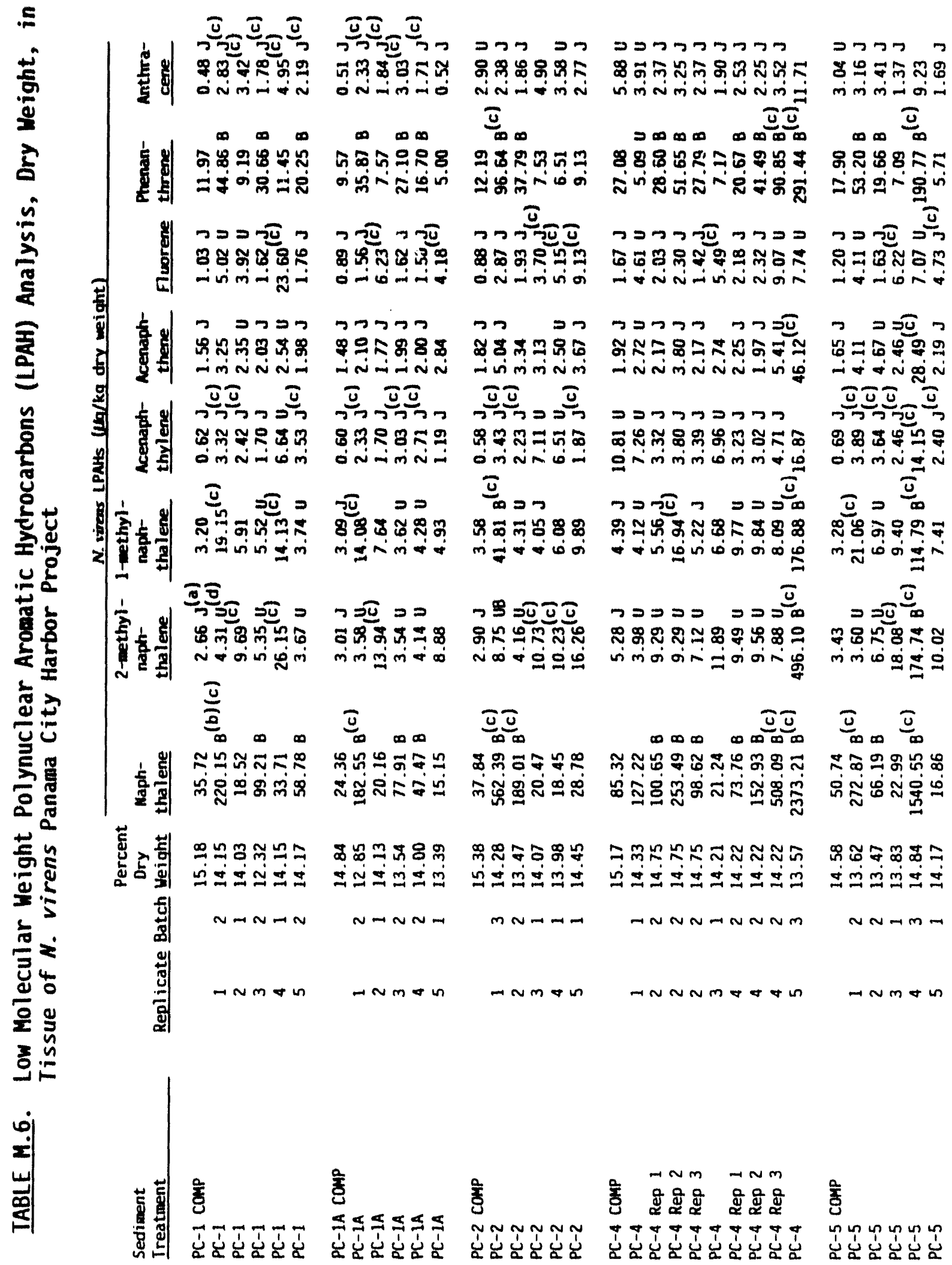

PANAMA CITY HARBOR

M.11 


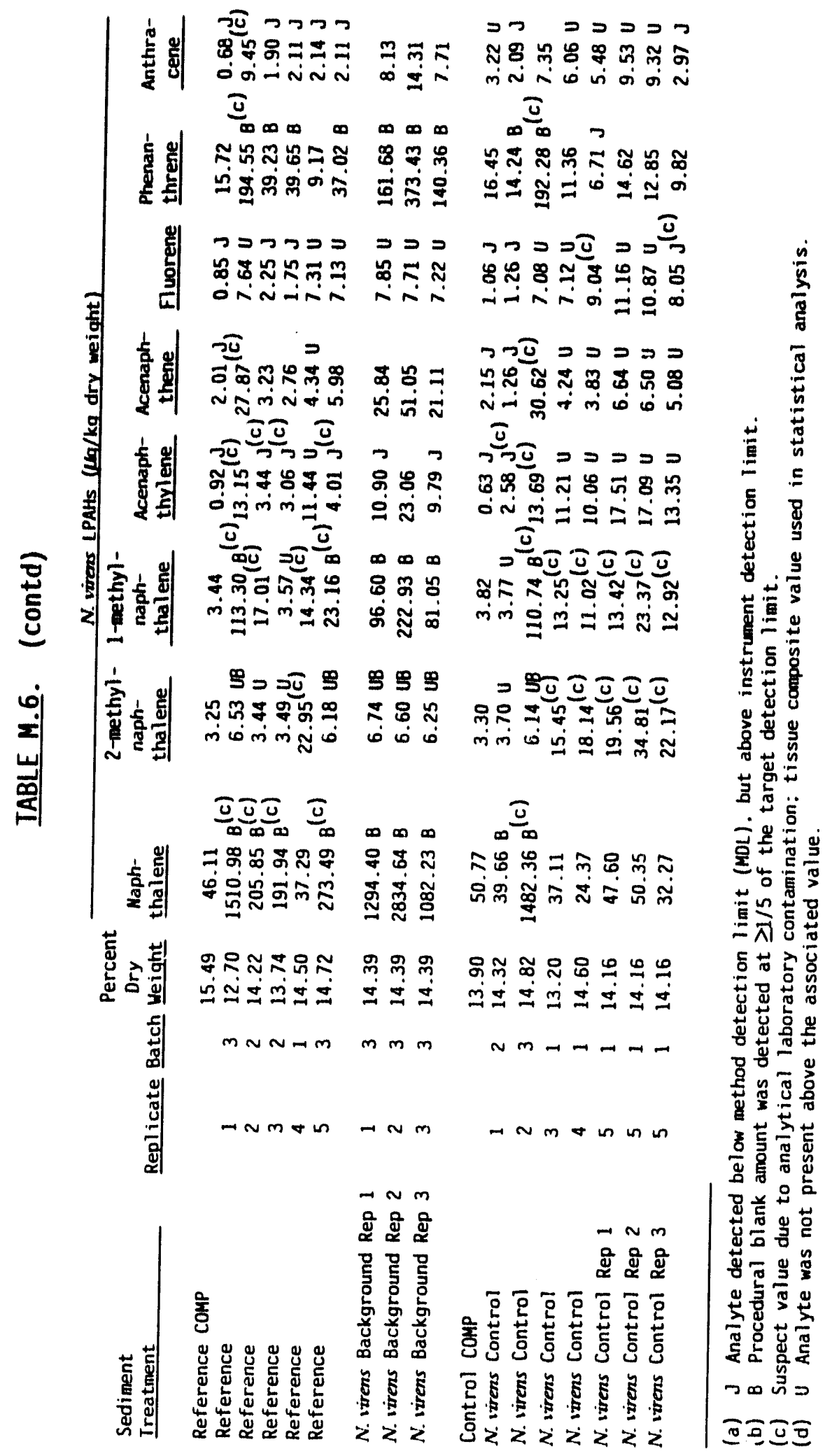


TABLE M.7. High Molecular Weight Polynuclear Aromatic Hydrocarbon (HPAH) Analysis (elution order, Fluoranthene - Benzo[b]fluoranthene), Dry Weight, in Tissue of N. virens, Panama City Harbor Project

\begin{tabular}{|c|c|c|c|c|c|c|c|c|}
\hline \multirow[b]{2}{*}{$\begin{array}{l}\text { Sediment } \\
\text { Treatment } \\
\end{array}$} & \multirow[b]{2}{*}{ Replicate } & \multirow[b]{2}{*}{ Batch } & \multirow[b]{2}{*}{$\begin{array}{l}\text { Percent } \\
\text { Dry } \\
\text { Weight } \\
\end{array}$} & \multicolumn{5}{|c|}{ N. virens HPAHs $(\mu \mathrm{g} / \mathrm{kg}$ dry weight $)$} \\
\hline & & & & $\begin{array}{l}\text { Fluor- } \\
\text { anthene }\end{array}$ & Pyrene & $\begin{array}{l}\text { Benzo [a] } \\
\text { anthra- } \\
\text { cene } \\
\end{array}$ & Chrysene & $\begin{array}{r}\text { Benzo [b] } \\
\text { fluor- } \\
\text { anthene }\end{array}$ \\
\hline $\begin{array}{l}P C-1 \quad \text { COMP } \\
P C-1 \\
P C-1 \\
P C-1 \\
P C-1 \\
P C-1\end{array}$ & $\begin{array}{l}1 \\
2 \\
3 \\
4 \\
5\end{array}$ & $\begin{array}{l}2 \\
1 \\
2 \\
1 \\
2\end{array}$ & $\begin{array}{l}15.18 \\
14.15 \\
14.03 \\
12.32 \\
14.15 \\
14.17\end{array}$ & $\begin{array}{l}4.29 \mathrm{~J}^{(\mathrm{a})} \\
9.47 \\
6.55 \\
8.68 \mathrm{~J} \\
8.62 \\
7.48\end{array}$ & $\begin{array}{l}2.76 \mathrm{~J} \\
7.42 \\
4.84 \\
6.16 \mathrm{~J} \\
6.93 \\
6.07\end{array}$ & $\begin{array}{l}0.94 \mathrm{~J} \\
2.40 \mathrm{~J} \\
1.57 \mathrm{~J} \\
2.92 \mathrm{~J}(\mathrm{c}) \\
5.72 \mathrm{U}(\mathrm{J} \\
1.48 \mathrm{~J}\end{array}$ & $\begin{array}{l}2.48 \mathrm{~J} \\
4.03 \mathrm{~J} \\
3.06 \mathrm{~J} \\
5.43 \mathrm{~J} \\
6.57 \mathrm{U} \\
5.72 \mathrm{~J}\end{array}$ & $\begin{array}{l}1.25 \mathrm{~J} \\
3.67 \mathrm{~J} \\
0.93 \mathrm{~J} \\
6.33 \mathrm{~J}(\mathrm{~b}) \\
6.50 \mathrm{U} \\
2.54 \mathrm{~J}\end{array}$ \\
\hline $\begin{array}{l}P C-1 A \text { COMP } \\
P C-1 A \\
P C-1 A \\
P C-1 A \\
P C-1 A \\
P C-1 A\end{array}$ & $\begin{array}{l}1 \\
2 \\
3 \\
4 \\
5\end{array}$ & $\begin{array}{l}2 \\
1 \\
2 \\
2 \\
1\end{array}$ & $\begin{array}{l}14.84 \\
12.85 \\
14.13 \\
13.54 \\
14.00 \\
13.39\end{array}$ & $\begin{array}{l}4.21 \mathrm{~J} \\
8.01 \\
6.16 \mathrm{U} \\
7.75 \\
6.14 \mathrm{~J} \\
6.12 \mathrm{U}\end{array}$ & $\begin{array}{l}2.56 \mathrm{~J} \\
5.68 \\
5.02 \\
4.80 \\
3.71 \mathrm{~J} \\
3.66 \mathrm{~J}\end{array}$ & $\begin{array}{l}0.73 \mathrm{~J} \\
2.02 \mathrm{~J} \\
1.63 \mathrm{~J} \\
1.70 \mathrm{~J} \\
1.50 \mathrm{~J} \\
1.12 \mathrm{~J}\end{array}$ & $\begin{array}{l}2.42 \mathrm{~J} \\
3.66 \mathrm{~J} \\
3.82 \mathrm{~J} \\
4.87 . \mathrm{J} \\
2.71 \mathrm{~J} \\
2.16 \mathrm{~J}\end{array}$ & $\begin{array}{l}1.21 \mathrm{~J} \\
3.35 \mathrm{~J} \\
3.04 \mathrm{~J} \\
3.62 \mathrm{~J} \\
2.14 \mathrm{~J} \\
6.34 \mathrm{U}\end{array}$ \\
\hline $\begin{array}{l}P C-2 \text { COMP } \\
P C-2 \\
P C-2 \\
P C-2 \\
P C-2 \\
P C-2\end{array}$ & $\begin{array}{l}1 \\
2 \\
3 \\
4 \\
5\end{array}$ & $\begin{array}{l}3 \\
2 \\
1 \\
1 \\
1\end{array}$ & $\begin{array}{l}15.38 \\
14.28 \\
13.47 \\
14.07 \\
13.98 \\
14.45\end{array}$ & $\begin{array}{l}4.15 \gamma_{(b)} \\
15.69 \\
10.17 \\
6.89 \\
6.15 U \\
9.75 U\end{array}$ & $\begin{array}{r}2.23 \mathrm{~d}(b) \\
11.48 \mathrm{~b} \\
7.13 \\
5.33 \\
4.08 \mathrm{~J} \\
5.81 \mathrm{~J}\end{array}$ & $\begin{array}{l}0.79 \mathrm{~J}(\mathrm{~b}) \\
4.90 \mathrm{~J}(\mathrm{~J} \\
2.30 \mathrm{~J} \\
1.28 \mathrm{~J} \\
1.50 \mathrm{~J} \\
2.14 \mathrm{~J}\end{array}$ & $\begin{array}{l}2.17 \mathrm{~J} \\
6.79 \mathrm{~J} \\
4.16 \mathrm{~J} \\
2.20 \mathrm{~J} \\
3.50 \mathrm{~J} \\
4.22 \mathrm{~J}\end{array}$ & $\begin{array}{l}1.21 \mathrm{~J}(b) \\
8.12 \mathrm{~J}(\mathrm{~J}) \\
3.49 \mathrm{~J} \\
0.78 \mathrm{~J} \\
6.37 \mathrm{U} \\
3.32 \mathrm{~J}\end{array}$ \\
\hline $\begin{array}{l}\text { PC-4 COMP } \\
\text { PC-4 } \\
\text { PC-4 Rep } 1 \\
\text { PC-4 Rep } 2 \\
\text { PC-4 Rep } 3 \\
\text { PC-4 } \\
\text { PC-4 Rep } 1 \\
\text { PC-4 Rep } 2 \\
\text { PC-4 Rep } 3 \\
\text { PC-4 }\end{array}$ & $\begin{array}{l}1 \\
2 \\
2 \\
2 \\
3 \\
4 \\
4 \\
4 \\
5\end{array}$ & $\begin{array}{l}1 \\
2 \\
2 \\
2 \\
1 \\
2 \\
2 \\
2 \\
3\end{array}$ & $\begin{array}{l}15.17 \\
14.33 \\
14.75 \\
14.75 \\
14.75 \\
14.21 \\
14.22 \\
14.22 \\
14.22 \\
13.57\end{array}$ & $\begin{array}{r}6.21 \mathrm{~J} \\
6.84 \mathrm{U} \\
7.79 \mathrm{~J} \\
11.05 \mathrm{~J} \\
7.73 \mathrm{~J} \\
6.54 \mathrm{U} \\
7.88 \mathrm{~J} \\
9.28 \mathrm{~J} \\
15.12 \\
34.48\end{array}$ & $\begin{array}{c}3.23 \mathrm{~J} \\
4.88 \mathrm{U} \\
4.61 \mathrm{~J} \\
6.85 \mathrm{~J} \\
4.74 \mathrm{~J} \\
3.66 \mathrm{~J} \\
6.89 \mathrm{~J} \\
5.41 \mathrm{(b)} \\
10.34 \quad(\mathrm{~b}) \\
31.90 \quad\end{array}$ & $\begin{array}{l}1.45 \mathrm{~J} \\
6.21 \mathrm{U} \\
2.91 \mathrm{~J} \\
2.98 \mathrm{~J} \\
2.58 \mathrm{~J} \\
5.98 \mathrm{U} \\
2.88 \mathrm{~J} \\
3.30 \mathrm{~J} \\
4.08 \mathrm{~J}(\mathrm{~b}) \\
8.62 \mathrm{~J}\end{array}$ & $\begin{array}{r}4.37 \mathrm{~J} \\
7.12 \mathrm{U} \\
6.03 \mathrm{~J} \\
7.73 \mathrm{~J} \\
5.42 \mathrm{~J} \\
6.82 \mathrm{U} \\
4.85 \mathrm{~J} \\
5.98 \mathrm{~J} \\
8.09 \mathrm{~J} \\
14.96\end{array}$ & $\begin{array}{l}2.23 \mathrm{~J} \\
7.05 \mathrm{U} \\
4.20 \mathrm{~J} \\
5.56 \mathrm{~J} \\
3.39 \mathrm{~J} \\
6.75 \mathrm{U} \\
4.57 \mathrm{~J} \\
5.55 \mathrm{~J}(\mathrm{~b}) \\
7.31 \mathrm{U}(\mathrm{b}) \\
12.30 \mathrm{~b})\end{array}$ \\
\hline $\begin{array}{l}P C-5 \text { COMP } \\
P C-5 \\
P C-5 \\
P C-5 \\
P C-5 \\
P C-5\end{array}$ & $\begin{array}{l}1 \\
2 \\
3 \\
4 \\
5\end{array}$ & $\begin{array}{l}2 \\
2 \\
1 \\
3 \\
1\end{array}$ & $\begin{array}{l}14.58 \\
13.62 \\
13.47 \\
13.83 \\
14.84 \\
14.17\end{array}$ & $\begin{array}{r}6.92 \\
11.81 \\
12.02 \\
13.23 \text { (b) } \\
29.71 \quad \text { U } \\
7.27 \mathrm{U}\end{array}$ & $\begin{array}{r}6.20 \\
10.05 \\
15.21 \\
13.88 \quad \text { (b) } \\
28.09 \\
7.83\end{array}$ & $\begin{array}{l}1.11 \mathrm{~J} \\
3.16 \mathrm{~J} \\
3.19 \mathrm{~J} \\
3.11 \mathrm{~J} \\
6.67 \mathrm{~J}(\mathrm{~b}) \\
1.90 \mathrm{~J}\end{array}$ & $\begin{array}{r}4.37 \mathrm{~J} \\
6.09 \mathrm{~J} \\
9.72 \mathrm{~J} \\
8.24 \\
14.35 \\
4.51 \mathrm{~J}\end{array}$ & $\begin{array}{c}3.12 \mathrm{~J} \\
6.60 \\
7.20 \mathrm{~J} \\
5.71 \mathrm{~J}(\mathrm{~b}) \\
11.52 \mathrm{~J} \\
3.95 \mathrm{~J}\end{array}$ \\
\hline $\begin{array}{l}\text { Reference cOMP } \\
\text { Reference } \\
\text { Reference } \\
\text { Reference } \\
\text { Reference } \\
\text { Reference }\end{array}$ & $\begin{array}{l}1 \\
2 \\
3 \\
4 \\
5\end{array}$ & $\begin{array}{l}3 \\
2 \\
2 \\
1 \\
3\end{array}$ & $\begin{array}{l}15.49 \\
12.70 \\
14.22 \\
13.74 \\
14.50 \\
14.72\end{array}$ & $\begin{array}{l}4.41 \mathrm{j}(b) \\
23.86(\mathrm{~b}) \\
8.01 \\
8.45 \\
9.17 \mathrm{~J} \\
8.42 \mathrm{~J}\end{array}$ & $\begin{array}{l}2.25 \mathrm{j}(\mathrm{b}) \\
21.65 \\
4.99 \\
6.18 \\
5.65 \mathrm{~J}(\mathrm{~b}) \\
7.13 \mathrm{~J}\end{array}$ & $\begin{array}{l}0.46 \mathrm{~J}(b) \\
5.98 \mathrm{~J}_{(b)} \\
1.90 \mathrm{~J}^{(b)} \\
1.96 \mathrm{~J}^{(b)} \\
2.83 \mathrm{~J}^{(b)} \\
2.65 \mathrm{~J}^{(b)}\end{array}$ & $\left\{\begin{array}{l}2.35 \mathrm{~J}(\mathrm{~b}) \\
10.16 \mathrm{~J} \\
4.15 \mathrm{~J} \\
3.57 \mathrm{~J} \\
4.83 \mathrm{~J} \\
3.46 \mathrm{~J}\end{array}\right.$ & $\begin{array}{l}1.47 \mathrm{~J}(\mathrm{~b}) \\
8.82 \mathrm{~J} \\
3.30 \mathrm{~J} \\
2.55 \mathrm{~J} \\
11.17 \mathrm{U} \\
3.40 \mathrm{~J}\end{array}$ \\
\hline N. virens Background Rep 1 & 1 & 3 & 14.39 & 20.07 & 18.20 & $5.21 \mathrm{~J}$ & $9.65 \mathrm{~J}$ & $7.50 \mathrm{~J}$ \\
\hline N. virens Background Rep 2 & 2 & 3 & 14.39 & 45.07 & 40.84 & 10.49 & 18.13 & 13.54 \\
\hline N. virens Background Rep 3 & 3 & 3 & 14.39 & 18.06 & 16.67 & $5.49 \mathrm{~J}$ & $10.07 \mathrm{~J}$ & $8.89 \mathrm{~J}$ \\
\hline
\end{tabular}




\section{TABLE M.7. (contd)}

\begin{tabular}{|c|c|c|c|c|c|c|c|c|}
\hline \multirow[b]{2}{*}{$\begin{array}{l}\text { Sediment } \\
\text { Ireatment }\end{array}$} & \multirow[b]{2}{*}{ Replicate } & \multirow[b]{2}{*}{ Batch } & \multirow[b]{2}{*}{$\begin{array}{l}\text { Percent } \\
\text { Dry } \\
\text { Weight } \\
\end{array}$} & \multicolumn{4}{|c|}{ N. virens HPAHs $(\mu \mathrm{g} / \mathrm{kg}$ dry weight $)$} & \multirow[b]{2}{*}{$\begin{array}{c}\text { Benzo [b] } \\
\text { fluor- } \\
\text { anthene }\end{array}$} \\
\hline & & & & $\begin{array}{l}\text { Fluor- } \\
\text { anthene }\end{array}$ & Pyrene & $\begin{array}{l}\text { Benzo [a] } \\
\text { anthra- } \\
\text { cene } \\
\end{array}$ & Chrysene & \\
\hline $\begin{array}{l}\text { Control COMP } \\
N \text {. virens Control }\end{array}$ & 1 & 2 & $\begin{array}{l}13.90 \\
14.32\end{array}$ & $\begin{array}{l}6.05 \\
7.54\end{array}$ & $\begin{array}{l}4.07 \\
5.59\end{array}$ & $\begin{array}{l}1.00 \mathrm{~J} \\
1.40 \mathrm{~J}\end{array}$ & $\begin{array}{l}3.91 \mathrm{~J} \\
4.12 \mathrm{H}\end{array}$ & $\begin{array}{l}1.71 \mathrm{~J} \\
2.51 \mathrm{~J}\end{array}$ \\
\hline N. virens Control & 2 & 3 & 14.82 & 25.97 (b) & $23.81(b)$ & $6.54 \mathrm{~J}^{(b}$ & 12.21 (b) & $9.17 \mathrm{j}^{\text {(t }}$ \\
\hline N. virens Control & 3 & 1 & 13.20 & $8.94 \mathrm{~J}$ & $6.82 \mathrm{~J}$ & $9.62 \mathrm{U}$ & $11.06 \mathrm{U}$ & $10.91 \mathrm{U}$ \\
\hline N. virens Control & 4 & 1 & 14.60 & $9.45 U$ & $5.96 \mathrm{y}$ & $8.63 U$ & $9.93 \mathrm{U}$ & $9.79 \mathrm{U}$ \\
\hline N. virens Control Rep 1 & 5 & 1 & 14.16 & $15.25 \mathrm{~J}$ & 19.00 (b) & $7.06 \mathrm{~J}^{(\mathrm{b}}$ & $10.03 \mathrm{~J}$ & $6.99 \mathrm{~J}^{(\mathrm{b}}$ \\
\hline N. virens Control Rep 2 & 5 & 1 & 14.16 & $11.93 \mathrm{~J}$ & $10.17 \mathrm{~J}$ & $4.59 \mathrm{~J}^{(\mathrm{b}}$ & $6.50 \mathrm{~J}$ & $5.23 \jmath^{(t}$ \\
\hline N. virens Control Rep 3 & 5 & 1 & 14.16 & $9.89 \mathrm{~J}$ & $8.47 \mathrm{~J}$ & $3.74 \mathrm{~J}^{(\mathrm{b}}$ & $6.00 \mathrm{~J}$ & $4.45 \mathrm{~J}$ \\
\hline
\end{tabular}

(a) J Analyte detected below method detection limit (MOL), but above instrument detection limit (IDL).

(b) Suspect value due to analytical laboratory contamination; tissue composite value used in statistical analysis.

(c) U Analyte was not present above the associated value. 
TABLE M.8. High Molecular Weight Polynuclear Aromatic Hydrocarbon (HPAH) Analysis (elution order, Benzo[K]fluoranthene Benzo[g, $h, i]$ perylene), Dry Weight, in Tissue of $N$. virens Panama City Harbor Project

\begin{tabular}{|c|c|c|c|c|c|c|c|c|}
\hline \multirow[b]{2}{*}{$\begin{array}{l}\text { Sediment } \\
\text { Ireatment }\end{array}$} & \multirow[b]{2}{*}{ Replicate } & \multirow[b]{2}{*}{ Batch } & \multirow[b]{2}{*}{$\begin{array}{l}\text { Percent } \\
\text { Ory } \\
\text { Weight } \\
\end{array}$} & \multicolumn{5}{|c|}{ N. virens HPAHs ( $\mu \mathrm{g} / \mathrm{kg}$ dry weight) } \\
\hline & & & & $\begin{array}{c}\text { Benzo }[k] \\
\text { fluor- } \\
\text { anthene }\end{array}$ & $\begin{array}{l}\text { Benzo [a] } \\
\text { pyrene }\end{array}$ & $\begin{array}{c}\text { Indeno } \\
{[1,2,3-} \\
c, d] \\
\text { pyrene }\end{array}$ & $\begin{array}{l}\text { Dibenzo } \\
{[a, h]} \\
\text { anthra- } \\
\text { cene } \\
\end{array}$ & $\begin{array}{l}\text { Benzo } \\
{[\mathrm{g} . \mathrm{J}, \mathrm{i}]} \\
\text { perylene }\end{array}$ \\
\hline $\begin{array}{l}P C-1 \text { COMP } \\
P C-1 \\
P C-1 \\
P C-1 \\
P C-1 \\
P C-1\end{array}$ & $\begin{array}{l}1 \\
2 \\
3 \\
4 \\
5\end{array}$ & $\begin{array}{l}2 \\
1 \\
2 \\
1 \\
2\end{array}$ & $\begin{array}{l}15.18 \\
14.15 \\
14.03 \\
12.32 \\
14.15 \\
14.17\end{array}$ & $\begin{array}{l}1.16 \mathrm{~J}^{(\mathrm{a})} \\
0.92 \mathrm{~J} \\
1.42 \mathrm{~J} \\
2.43 \mathrm{~J} \\
3.04 \mathrm{U} \\
0.78 \mathrm{~J}\end{array}$ & $\begin{array}{l}0.44 \mathrm{~J} \\
0.64 \mathrm{~J} \\
2.21 \mathrm{U}(\mathrm{c}) \\
1.95 \mathrm{~J}(\mathrm{U}) \\
2.40 \mathrm{U} \\
2.40 \mathrm{U}\end{array}$ & $\begin{array}{l}4.31 \mathrm{U}^{(b)} \\
1.98 \mathrm{~J} \\
4.92 \mathrm{U} \\
4.79 \mathrm{~J} \\
5.30 \mathrm{U} \\
1.48 \mathrm{~J}\end{array}$ & $\begin{array}{l}3.89 \mathrm{U} \\
0.64 \mathrm{~J} \\
4.42 \mathrm{U} \\
1.30 \mathrm{~J} \\
4.81 \mathrm{U} \\
4.73 \mathrm{U}\end{array}$ & $\begin{array}{l}1.63 \mathrm{~J} \\
2.68 \mathrm{~J} \\
4.13 \mathrm{U}(\mathrm{c}) \\
6.98 \mathrm{U} \\
4.45 \mathrm{~J} \\
2.19 \mathrm{~J}\end{array}$ \\
\hline $\begin{array}{l}P C-1 A \text { COMP } \\
P C-1 A \\
P C-1 A \\
P C-1 A \\
P C-1 A \\
P C-1 A\end{array}$ & $\begin{array}{l}1 \\
2 \\
3 \\
4 \\
5\end{array}$ & $\begin{array}{l}2 \\
1 \\
2 \\
2 \\
1\end{array}$ & $\begin{array}{l}14.84 \\
12.85 \\
14.13 \\
13.54 \\
14.00 \\
13.39\end{array}$ & $\begin{array}{l}0.89 \mathrm{~J} \\
0.93 \mathrm{~J} \\
2.97 \mathrm{U} \\
0.96 \mathrm{~J} \\
0.79 \mathrm{~J} \\
2.99 \mathrm{U}\end{array}$ & $\begin{array}{l}0.47 \mathrm{~J} \\
2.33 \mathrm{U} \\
2.33 \mathrm{U} \\
0.96 \mathrm{~J} \\
2.71 \mathrm{U} \\
2.39 \mathrm{U}\end{array}$ & $\begin{array}{l}4.44 \mathrm{U} \\
1.87 \mathrm{~J} \\
5.16 \mathrm{U} \\
2.36 \mathrm{~J} \\
1.28 \mathrm{~J} \\
5.15 \mathrm{U}\end{array}$ & $\begin{array}{l}4.00 \mathrm{U} \\
0.54 \mathrm{~J} \\
4.67 \mathrm{U} \\
0.66 \mathrm{~J} \\
0.43 \mathrm{~J} \\
4.63 \mathrm{U}\end{array}$ & $\begin{array}{l}2.63 \mathrm{~J} \\
2.96 \mathrm{~J} \\
4.32 \mathrm{U} \\
3.54 \mathrm{~J} \\
2.07 \mathrm{~J} \\
4.33 \mathrm{U}\end{array}$ \\
\hline $\begin{array}{l}P C-2 \text { COMP } \\
P C-2 \\
P C-2 \\
P C-2 \\
P C-2 \\
P C-2\end{array}$ & $\begin{array}{l}1 \\
2 \\
3 \\
4 \\
5\end{array}$ & $\begin{array}{l}3 \\
2 \\
1 \\
1 \\
1\end{array}$ & $\begin{array}{l}15.38 \\
14.28 \\
13.47 \\
14.07 \\
13.98 \\
14.45\end{array}$ & $\begin{array}{l}0.69 \mathrm{~J} \\
1.96 \mathrm{~J} \\
1.63 \mathrm{~J} \\
1.71 \mathrm{~J} \\
2.93 \mathrm{U} \\
4.70 \mathrm{U}\end{array}$ & $\begin{array}{l}1.93 U \\
5.74 U \\
0.89 \mathrm{~J} \\
2.56 \mathrm{U} \\
2.36 \mathrm{U} \\
3.74 \mathrm{U}\end{array}$ & $\begin{array}{l}4.22 \mathrm{U} \\
4.69 \mathrm{~J} \\
2.38 \mathrm{~J} \\
5.69 \mathrm{U} \\
5.15 \mathrm{U} \\
8.23 \mathrm{U}\end{array}$ & $\begin{array}{l}3.81 \mathrm{U} \\
1.33 \mathrm{~J} \\
0.59 \mathrm{~J} \\
5.12 \mathrm{U} \\
4.65 \mathrm{U} \\
7.40 \mathrm{U}\end{array}$ & $\begin{array}{l}1.54 \mathrm{~J}(\mathrm{c}) \\
5.39 \mathrm{~J} \\
3.49 \mathrm{~J} \\
4.76 \mathrm{U} \\
4.36 \mathrm{U} \\
6.92 \mathrm{U}\end{array}$ \\
\hline $\begin{array}{l}\text { PC-4 COMP } \\
\text { PC-4 } \\
\text { PC-4 Rep } 1 \\
\text { PC-4 Rep 2 } \\
\text { PC-4 Rep } 3 \\
\text { PC-4 } \\
\text { PC-4 Rep } 1 \\
\text { PC-4 Rep } 2 \\
\text { PC-4 Rep } 3 \\
\text { PC-4 }\end{array}$ & $\begin{array}{l}1 \\
2 \\
2 \\
2 \\
3 \\
4 \\
4 \\
4 \\
5\end{array}$ & $\begin{array}{l}1 \\
2 \\
2 \\
2 \\
1 \\
2 \\
2 \\
2 \\
3\end{array}$ & $\begin{array}{l}15.17 \\
14.33 \\
14.75 \\
14.75 \\
14.75 \\
14.21 \\
14.22 \\
14.22 \\
14.22 \\
13.57\end{array}$ & $\begin{array}{l}1.25 \mathrm{~J} \\
3.28 \mathrm{U} \\
1.49 \mathrm{~J} \\
1.83 \mathrm{~J} \\
1.76 \mathrm{~J} \\
3.17 \mathrm{U} \\
1.48 \mathrm{~J} \\
1.48 \mathrm{~J} \\
1.90 \mathrm{~J} \\
3.90 \mathrm{~J}\end{array}$ & $\begin{array}{l}3.91 \mathrm{U} \\
2.65 \mathrm{U} \\
1.08 \mathrm{~J} \\
1.15 \mathrm{~J} \\
0.95 \mathrm{~J} \\
2.53 \mathrm{U} \\
1.27 \mathrm{~J} \\
6.26 \mathrm{U} \\
1.69 \mathrm{~J} \\
5.01\end{array}$ & $\begin{array}{l}8.57 \mathrm{U} \\
5.72 \mathrm{U} \\
3.73 \mathrm{~J} \\
4.07 \mathrm{~J} \\
2.44 \mathrm{~J} \\
5.49 \mathrm{U} \\
3.87 \mathrm{~J} \\
4.29 \mathrm{~J} \\
4.57 \mathrm{~J} \\
5.82 \mathrm{~J}\end{array}$ & $\begin{array}{l}7.73 \mathrm{U} \\
5.16 \mathrm{U} \\
0.95 \mathrm{~J} \\
1.56 \mathrm{~J} \\
1.08 \mathrm{~J} \\
4.99 \mathrm{U} \\
1.20 \mathrm{~J} \\
1.13 \mathrm{~J} \\
1.48 \mathrm{~J} \\
1.33 \mathrm{~J}\end{array}$ & $\begin{array}{l}2.25 \mathrm{~J} \\
4.82 \mathrm{U} \\
5.96 \mathrm{~J}(\mathrm{c}) \\
7.05 \mathrm{~J}(\mathrm{~J} \\
3.59 \mathrm{~J} \\
4.64 \mathrm{U}(\mathrm{c}) \\
7.59 \mathrm{~J} \\
5.84 \mathrm{~J} \\
6.61 \mathrm{~J} \\
6.48 \mathrm{~J}\end{array}$ \\
\hline $\begin{array}{l}P C-5 \text { COMP } \\
P C-5 \\
P C-5 \\
P C-5 \\
P C-5 \\
P C-5\end{array}$ & $\begin{array}{l}1 \\
2 \\
3 \\
4 \\
5\end{array}$ & $\begin{array}{l}2 \\
2 \\
1 \\
3 \\
1\end{array}$ & $\begin{array}{l}14.58 \\
13.62 \\
13.47 \\
13.83 \\
14.84 \\
14.17\end{array}$ & $\begin{array}{l}3.03 \\
2.64 \mathrm{~J} \\
3.71 \mathrm{~J} \\
5.35 \\
4.72 \mathrm{~J} \\
2.68 \mathrm{~J}\end{array}$ & $\begin{array}{l}1.19 \mathrm{~J} \\
2.27 \mathrm{~J} \\
4.45 \mathrm{U} \\
2.31 \mathrm{Y}(\mathrm{c}) \\
5.12 \mathrm{~J} \\
2.12 \mathrm{~J}\end{array}$ & $\begin{array}{l}1.35 \mathrm{~J} \\
2.27 \mathrm{~J} \\
1.78 \mathrm{~J} \\
5.13 \mathrm{U}(\mathrm{c}) \\
4.31 \mathrm{~J}(\mathrm{U} \\
6.07 \mathrm{U}\end{array}$ & $\begin{array}{l}4.00 \mathrm{U} \\
0.81 \mathrm{~J} \\
0.96 \mathrm{~J} \\
4.63 \mathrm{U} \\
1.35 \mathrm{~J} \\
5.50 \mathrm{U}\end{array}$ & $\begin{array}{l}3.14 \mathrm{~J} \\
2.93 \mathrm{~J} \\
3.34 \mathrm{~J} \\
4.34 \mathrm{U} \\
5.19 \mathrm{~J} \\
0.92 \mathrm{~J}\end{array}$ \\
\hline $\begin{array}{l}\text { Reference COMP } \\
\text { Reference } \\
\text { Reference } \\
\text { Reference } \\
\text { Reference } \\
\text { Reference }\end{array}$ & $\begin{array}{l}1 \\
2 \\
3 \\
4 \\
5\end{array}$ & $\begin{array}{l}3 \\
2 \\
2 \\
1 \\
3\end{array}$ & $\begin{array}{l}15.49 \\
12.70 \\
14.22 \\
13.74 \\
14.50 \\
14.72\end{array}$ & $\begin{array}{l}0.79 \mathrm{~J} \\
1.89 \mathrm{~J} \\
0.70 \mathrm{~J} \\
0.95 \mathrm{~J} \\
5.24 \mathrm{U} \\
1.09 \mathrm{~J}\end{array}$ & $\begin{array}{l}0.34 \mathrm{~J} \\
4.33 \mathrm{U} \\
2.25 \mathrm{U} \\
0.58 \mathrm{~J} \\
4.14 \mathrm{U} \\
4.08 \mathrm{U}\end{array}$ & $\begin{array}{l}4.25 \mathrm{U} \\
3.70 \mathrm{~J} \\
2.32 \mathrm{~J} \\
1.46 \mathrm{~J} \\
9.10 \mathrm{U} \\
1.97 \mathrm{~J}\end{array}$ & $\begin{array}{l}3.84 \mathrm{U} \\
1.18 \mathrm{~J} \\
0.63 \mathrm{~J} \\
0.51 \mathrm{~J} \\
8.20 \mathrm{U} \\
8.02 \mathrm{U}\end{array}$ & $\begin{array}{l}1.90 \mathrm{~J} \\
4.88 \mathrm{~J} \\
3.37 \mathrm{~J} \\
2.26 \mathrm{~J} \\
7.65 \mathrm{U} \\
2.99 \mathrm{~J}\end{array}$ \\
\hline N. virens Background Rep 1 & 1 & 3 & 14.39 & $2.64 \mathrm{~J}$ & $4.44 \mathrm{U}$ & $4.03 \mathrm{~J}$ & $1.04 \mathrm{~J}$ & $5.14 \mathrm{~J}$ \\
\hline N. virens Background Rep 2 & 2 & 3 & 14.39 & 6.18 & $4.38 \mathrm{U}$ & $7.64 \mathrm{~J}$ & $2.85 \mathrm{~J}$ & 8.40 \\
\hline N. virens Background Rep 3 & 3 & 3 & 14.39 & $3.13 \mathrm{~J}$ & $4.10 \mathrm{U}$ & $5.49 \mathrm{~J}$ & $1.53 \mathrm{~J}$ & $7.36 \mathrm{~J}$ \\
\hline
\end{tabular}


TABLE M.8. (contd)

\begin{tabular}{|c|c|c|c|c|c|c|c|c|}
\hline \multirow[b]{2}{*}{$\begin{array}{l}\text { Sediment } \\
\text { Ireatment }\end{array}$} & \multirow[b]{2}{*}{ Replitcate } & \multirow[b]{2}{*}{ Batch } & \multirow[b]{2}{*}{$\begin{array}{l}\text { Percent } \\
\text { Ory } \\
\text { Weight }\end{array}$} & \multicolumn{4}{|c|}{$N$, virens HPAHs $(\mu \mathrm{g} / \mathrm{kg}$ dry weight $)$} & \multirow[b]{2}{*}{$\begin{array}{l}\text { Benzo } \\
{[g . j, i]} \\
\text { perylene }\end{array}$} \\
\hline & & & & $\begin{array}{c}\text { Benzo }[k] \\
\text { fluor- } \\
\text { anthene }\end{array}$ & $\begin{array}{l}\text { Benzo [a] } \\
\text { pyrene }\end{array}$ & $\begin{array}{c}\text { Indeno } \\
{[1,2,3-} \\
c, d] \\
\text { pyrene }\end{array}$ & $\begin{array}{c}\text { Dibenzo } \\
{[\mathrm{a}, \mathrm{h}]} \\
\text { anthra- } \\
\text { cene } \\
\end{array}$ & \\
\hline $\begin{array}{l}\text { Control COMP } \\
N \text {. virens Control }\end{array}$ & 1 & 2 & $\begin{array}{l}13.90 \\
14.32\end{array}$ & $\begin{array}{l}1.37 \mathrm{~J} \\
0.91 \mathrm{~J}\end{array}$ & $\begin{array}{l}2.15 \mathrm{U} \\
2.44 \mathrm{U}\end{array}$ & $\begin{array}{l}4.70 \mathrm{U} \\
1.19 \mathrm{~J}\end{array}$ & $\begin{array}{l}4.24 \mathrm{U} \\
4.75 \mathrm{U}\end{array}$ & $\begin{array}{l}1.83 \mathrm{~J} \\
2.16 \mathrm{~J}\end{array}$ \\
\hline N. virens Control & 2 & 3 & 14.82 & $2.63 \mathrm{~J}$ & $2.83 \mathrm{~J}$ & $4.11 \mathrm{~J}$ & $1.08 \mathrm{~J}$ & $5.06 \mathrm{~J}^{1 \mathrm{c}}$ \\
\hline N. virens Control & 3 & 1 & 13.20 & $5.07 \mathrm{U}$ & $4.01 \mathrm{U}$ & $8.86 \mathrm{U}$ & $8.03 \mathrm{U}$ & $7.42 \mathrm{U}$ \\
\hline N. virens Contral & 4 & 1 & 14.60 & $4.59 \mathrm{U}$ & $3.63 \mathrm{U}$ & $7.94 \mathrm{U}$ & $7.19 \mathrm{U}$ & $6.71 \mathrm{U}$ \\
\hline N. virens Control Rep 1 & 5 & 1 & 14.16 & $5.79 \mathrm{~J}$ & $6.36 \mathrm{U}$ & $13.91 \mathrm{U}$ & $12.50 \mathrm{U}$ & $11.65 \mathrm{U}$ \\
\hline N. virens Control Rep 2 & 5 & 1 & 14.16 & $7.77 \mathrm{U}$ & $6.21 \mathrm{U}$ & $13.56 \mathrm{U}$ & $12.22 \mathrm{U}$ & $11.37 \mathrm{U}$ \\
\hline N. virens Control Rep 3 & 5 & 1 & 14.16 & $3.11 \mathrm{~J}$ & $4.87 U$ & $10.59 \mathrm{U}$ & $9.53 \mathrm{U}$ & $8.90 \mathrm{U}$ \\
\hline
\end{tabular}

(a) J Analyte detected below method detection limit (MOL), but above instrument detection limit (IDL).

(b) U Analyte was not present above the assoclated value.

(c) Suspect value due to analytical laboratory contamination: tissue composite value used in statistical analysis. 


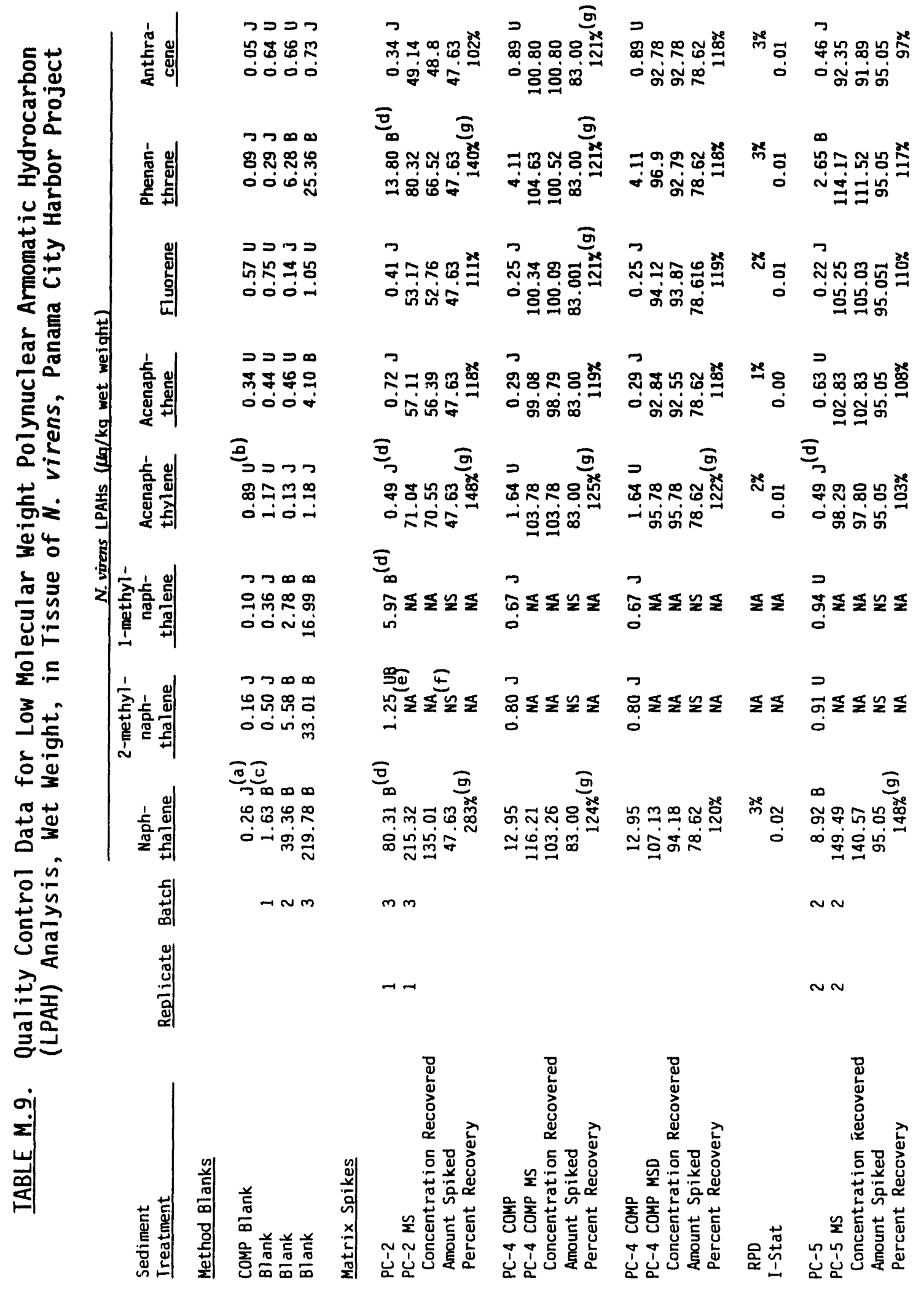

PANAMA CITY HARBOR

M. 17 


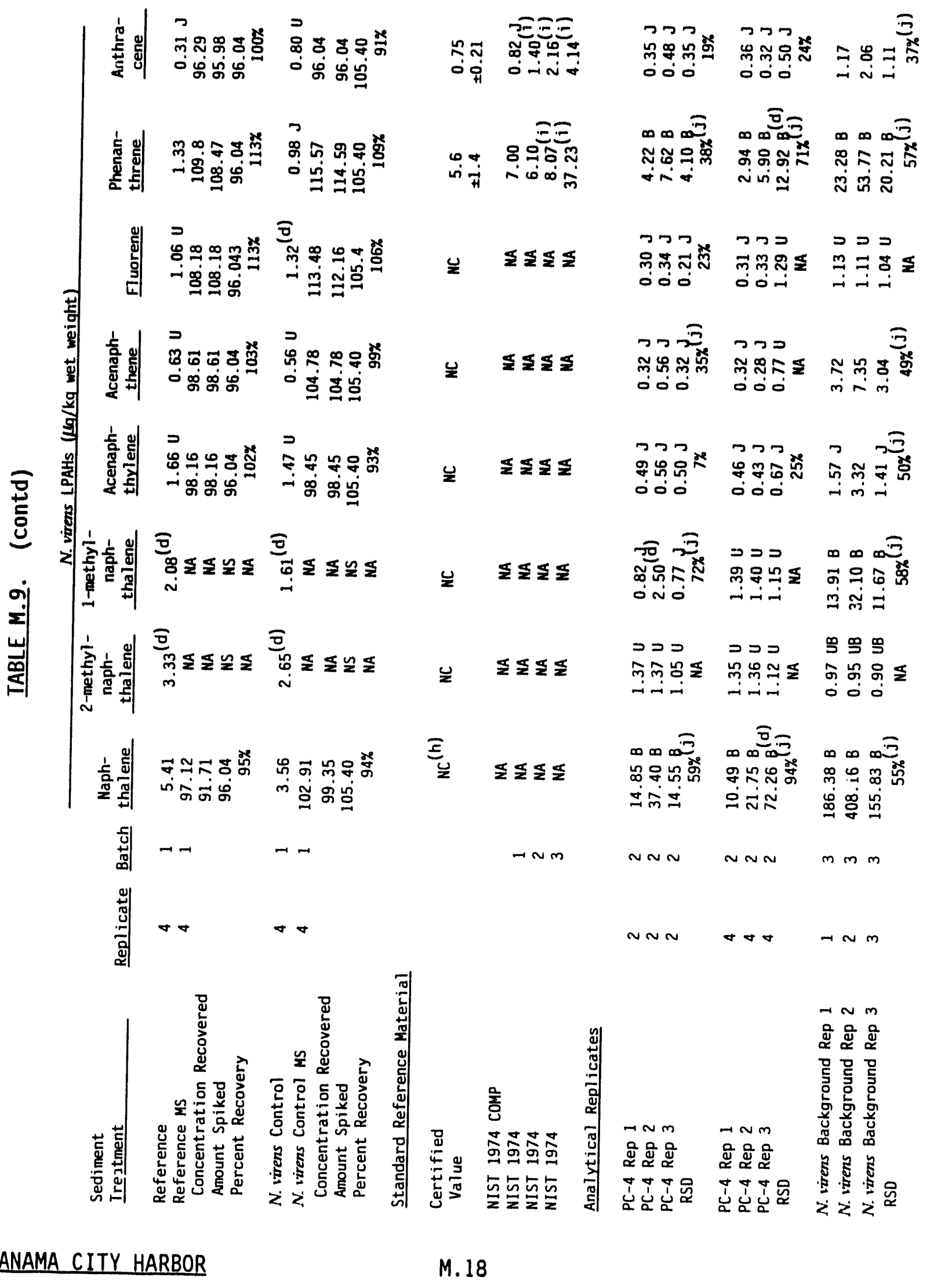




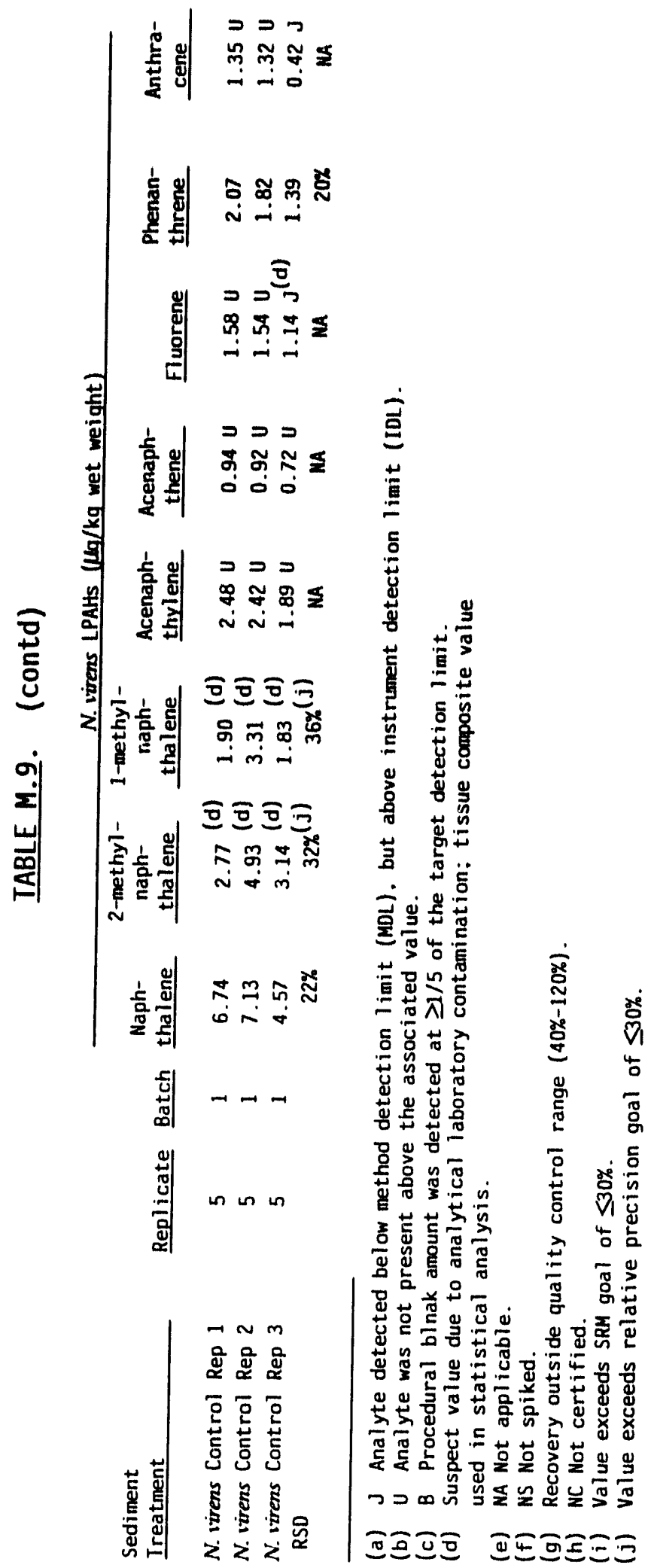


IABLE M.10. Quality Control Data for High Molecular Weight Polynuclear Aromatic Hydrocarbon (HPAH) Analysis (elution order, Fluoranthene - Benzo[b]fluoranthene), Wet Weight, in Tissue of N. Virens, Panama City Harbor Project

\begin{tabular}{|c|c|c|c|c|c|c|c|}
\hline \multirow[b]{2}{*}{$\begin{array}{l}\text { Sediment } \\
\text { Ireatment. }\end{array}$} & \multirow[b]{2}{*}{ Replleate } & \multirow[b]{2}{*}{ Batch } & \multicolumn{5}{|c|}{ N. virens HPAHs ( $1 \mathrm{~g} / \mathrm{kg}$ wet weight $)$} \\
\hline & & & $\begin{array}{l}\text { Fluor- } \\
\text { anthene }\end{array}$ & Pyrane & $\begin{array}{l}\text { Benzo [a] } \\
\text { anthra- } \\
\text { cene }\end{array}$ & Chrysene & $\begin{array}{l}\text { Benzo [b] } \\
\text { fluor- } \\
\text { anthene }\end{array}$ \\
\hline \multicolumn{8}{|l|}{ Method Blanks } \\
\hline $\begin{array}{l}\text { COMP Blank } \\
\text { Blank } \\
\text { Blank } \\
\text { Blank }\end{array}$ & & $\begin{array}{l}1 \\
2 \\
3\end{array}$ & $\begin{array}{l}0.10 \mathrm{~J}(\mathrm{a}) \\
0.22 \mathrm{~J} \\
0.79 \mathrm{~J}(\mathrm{c}) \\
2.78 \mathrm{~B}\end{array}$ & $\begin{array}{l}0.16 \mathrm{~J} \\
0.25 \mathrm{~J} \\
0.78 \mathrm{~J} \\
2.68 \mathrm{~B}\end{array}$ & $\begin{array}{l}0.76 u^{(b)} \\
1.01 \mathrm{U} \\
0.28 \mathrm{~J} \\
0.77 \mathrm{~J}\end{array}$ & $\begin{array}{l}0.06 \mathrm{~J} \\
1.15 \mathrm{U} \\
0.44 \mathrm{~J} \\
1.20 \mathrm{~J}\end{array}$ & $\begin{array}{l}0.86 \mathrm{U} \\
1.14 \mathrm{U} \\
0.47 \mathrm{~J} \\
1.04 \mathrm{~J}\end{array}$ \\
\hline \multicolumn{8}{|l|}{ Matrix Splkes } \\
\hline $\begin{array}{l}\text { PC-2 } \\
\text { PC-2 MS } \\
\text { Concentration Recovered } \\
\text { Amount Splked } \\
\text { Percent Recovery }\end{array}$ & $\begin{array}{l}1 \\
1\end{array}$ & $\begin{array}{l}3 \\
3\end{array}$ & $\begin{array}{l}2.24^{(d)} \\
62.17 \\
59.93 \\
47.63 \\
126 \%(\theta)\end{array}$ & $\begin{array}{l}1.64(d) \\
62.14 \\
63.50 \\
47.63 \\
127 x^{(e)}\end{array}$ & $\begin{array}{l}0.70 J^{(d)} \\
56.03 \\
55.33 \\
47.63 \\
116 \%\end{array}$ & $\begin{array}{l}0.97 \mathrm{~J} \\
60.37 \\
59.40 \\
47.63 \\
125 \%(\mathrm{e})\end{array}$ & $\begin{array}{l}1.16 j(d) \\
50.62 \\
49.46 \\
47.63 \\
104 \%\end{array}$ \\
\hline $\begin{array}{l}\text { PC-4 COMP } \\
\text { PC-4 COMP MS } \\
\text { Concentration Recovered } \\
\text { Amount Spiked } \\
\text { Percent Recovery }\end{array}$ & & & $\begin{array}{c}0.94 \mathrm{~J} \\
100.50 \\
99.56 \\
83.00 \\
120 \%\end{array}$ & $\begin{array}{l}0.49 \mathrm{~J} \\
99.64 \\
99.15 \\
83.00 \\
119 \%\end{array}$ & $\begin{array}{l}0.22 \mathrm{~J} \\
103.40 \\
103.18 \\
83.001 \\
124 \%(0)\end{array}$ & $\begin{array}{c}0.66 \mathrm{~J} \\
100.23 \\
99.57 \\
83.001 \\
120 \%\end{array}$ & $\begin{array}{l}0.34 \mathrm{~J} \\
103.00 \\
102.66 \\
83.00 \\
124 \%(8)\end{array}$ \\
\hline $\begin{array}{l}\text { PC-4 COMP } \\
\text { PC-4 COMP MSD } \\
\text { Concentration Recovered } \\
\text { Amount Splked } \\
\text { Percent Recovery }\end{array}$ & & & $\begin{array}{l}0.94 \mathrm{~J} \\
95.37 \\
94.43 \\
78.62 \\
120 \%\end{array}$ & $\begin{array}{c}0.49 \mathrm{~J} \\
93.39 \\
92.90 \\
78.62 \\
118 \%\end{array}$ & $\begin{array}{l}0.22 \mathrm{~J} \\
96.86 \\
96.64 \\
78.62 \\
123 \%(\mathrm{e})\end{array}$ & $\begin{array}{c}0.66 \mathrm{~J} \\
93.81 \\
93.15 \\
78.62 \\
118 \%\end{array}$ & $\begin{array}{l}0.34 \mathrm{~J} \\
95.16 \\
94.82 \\
78.62 \\
121 \%(\mathrm{e})\end{array}$ \\
\hline $\begin{array}{l}\text { RPD } \\
\text { I-Stat }\end{array}$ & & & 0.00 & $0.00^{1 \%}$ & 0.00 & 0.01 & 0.01 \\
\hline $\begin{array}{l}P C-5 \\
\text { PC-5 MS } \\
\text { Concentration Recovered } \\
\text { Amount Splked } \\
\text { Percent Recovery }\end{array}$ & $\begin{array}{l}2 \\
2\end{array}$ & $\begin{array}{l}2 \\
2\end{array}$ & $\begin{array}{r}1.62 \\
112.65 \\
111.03 \\
95.05 \\
117 \%\end{array}$ & $\begin{array}{r}2.05 \\
112.73 \\
110.68 \\
95.05 \\
116 \%\end{array}$ & $\begin{array}{c}0.43 \mathrm{~J} \\
104.66 \\
104.23 \\
95.05 \\
110 \%\end{array}$ & $\begin{array}{c}1.31 \mathrm{~J} \\
103.91 \\
102.60 \\
95.05 \\
108 \%\end{array}$ & $\begin{array}{c}0.97 \mathrm{~J} \\
105.24 \\
104.27 \\
95.05 \\
110 \%\end{array}$ \\
\hline $\begin{array}{l}\text { Reference } \\
\text { Reference MS } \\
\text { Concentration Recovered } \\
\text { Amount Splked } \\
\text { Percent Recovery }\end{array}$ & $\begin{array}{l}4 \\
4\end{array}$ & $\begin{array}{l}1 \\
1\end{array}$ & $\begin{array}{r}1.33 \mathrm{~J} \\
110.22 \\
108.89 \\
96.04 \\
113 \%\end{array}$ & $\begin{array}{r}0.82 \mathrm{~J} \\
106.57 \\
105.75 \\
96.04 \\
110 \%\end{array}$ & $\begin{array}{c}0.41 \mathrm{j}(\mathrm{d}) \\
102.47 \\
102.06 \\
96.04 \\
106 \%\end{array}$ & $\begin{array}{c}0.70 \mathrm{~J} \\
104.87 \\
104.17 \\
96.04 \\
108 \%\end{array}$ & $\begin{array}{l}1.62 \mathrm{U} \\
97.50 \\
97.50 \\
96.04 \\
102 \%\end{array}$ \\
\hline N. virens Control & 4 & 1 & $1.38 \mathrm{U}$ & $0.87 \mathrm{~J}$ & $1.26 U$ & $1.45 \mathrm{U}$ & $1.43 \mathrm{U}$ \\
\hline N. virens Control MS & 4 & 1 & 112.81 & 108.46 & 105.89 & 109.31 & 105.86 \\
\hline $\begin{array}{l}\text { Concentration Recovered } \\
\text { Amount Spiked } \\
\text { Percent Recovery }\end{array}$ & & & $\begin{array}{l}112.81 \\
105.40 \\
107 \%\end{array}$ & $\begin{array}{l}107.59 \\
105.40 \\
102 \%\end{array}$ & $\begin{array}{l}105.89 \\
105.40 \\
100 \%\end{array}$ & $\begin{array}{l}109.31 \\
105.40 \\
104 \%\end{array}$ & $\begin{array}{l}105.86 \\
105.40 \\
100 \%\end{array}$ \\
\hline
\end{tabular}


IABLE M.10. (contd)

\begin{tabular}{|c|c|c|c|c|c|c|c|}
\hline \multirow{2}{*}{$\begin{array}{l}\text { Sediment } \\
\text { Ireatment }\end{array}$} & \multirow[b]{2}{*}{ Replicate } & \multirow[b]{2}{*}{ Batch } & \multicolumn{5}{|c|}{ Nuvirens HPAHs ( $\mathrm{g}_{\mathrm{g}} / \mathrm{kg}$ wet wolght) } \\
\hline & & & $\begin{array}{l}\text { Fluor- } \\
\text { enthene }\end{array}$ & Pyrene & $\begin{array}{l}\text { Benzo [a] } \\
\text { anthra- } \\
\text { cene }\end{array}$ & Chrysene & $\begin{array}{l}\text { Benzo [b] } \\
\text { fluor- } \\
\text { enthene }\end{array}$ \\
\hline \multicolumn{8}{|c|}{ Standard Reference Material } \\
\hline $\begin{array}{l}\text { Certified } \\
\text { Value }\end{array}$ & & & $\begin{array}{r}33.6 \\
\pm 58\end{array}$ & $\begin{array}{l}34.1 \\
\pm 3.7\end{array}$ & $N C^{(f)}$ & NC & $\begin{array}{r}6.5 \\
\pm 1.2\end{array}$ \\
\hline $\begin{array}{l}\text { NIST } 1974 \text { COMP } \\
\text { NIST } 1974 \\
\text { NIST } 1974 \\
\text { NIST } 1974\end{array}$ & & $\begin{array}{l}1 \\
2 \\
3\end{array}$ & $\begin{array}{l}33.15 \\
32.17 \\
34.64 \\
36.03\end{array}$ & $\begin{array}{l}31.29 \\
30.99 \\
34.77 \\
35.36\end{array}$ & $\begin{array}{l}N A(g) \\
N A \\
N A \\
N A\end{array}$ & $\begin{array}{l}N A \\
N A \\
N A \\
N A\end{array}$ & $\begin{array}{l}6.05 \\
5.82(h) \\
9.71 \\
8.18\end{array}$ \\
\hline \multicolumn{8}{|l|}{ Analytical Reolicates } \\
\hline $\begin{array}{l}\text { PC-4 Rep } 1 \\
\text { PC-4 Rep } 2 \\
\text { PC-4 Rep } 3 \\
\text { RSD }\end{array}$ & $\begin{array}{l}2 \\
2 \\
2\end{array}$ & $\begin{array}{l}2 \\
2 \\
2\end{array}$ & $\begin{array}{l}1.15 \mathrm{~J} \\
1.63 \mathrm{~J} \\
1.14 \mathrm{~J} \\
21 \%\end{array}$ & $\begin{array}{l}0.68 \mathrm{~J} \\
1.01 \mathrm{~J} \\
0.70 \mathrm{~J} \\
23 \%\end{array}$ & $\begin{array}{c}0.43 \mathrm{~J} \\
0.44 \mathrm{~J} \\
0.38 \mathrm{~J} \\
8 \%\end{array}$ & $\begin{array}{c}0.89 \mathrm{~J} \\
1.14 \mathrm{~J} \\
0.80 \mathrm{~J} \\
19 \%\end{array}$ & $\begin{array}{l}0.62 \mathrm{~J} \\
0.82 \mathrm{~J} \\
0.50 \mathrm{~J} \\
25 \%\end{array}$ \\
\hline $\begin{array}{l}\text { PC-4 Rep } 1 \\
\text { PC-4 Rep } 2 \\
\text { PC-4 Rep } 3 \\
\text { RSD }\end{array}$ & $\begin{array}{l}4 \\
4 \\
4\end{array}$ & $\begin{array}{l}2 \\
2 \\
2\end{array}$ & $\begin{array}{l}1.12 \mathrm{~J} \\
1.32 \mathrm{~J} \\
2.15 \mathrm{~s}(1) \\
\quad 36 \%\end{array}$ & $\begin{array}{l}0.98 \mathrm{~J} \\
0.77 \mathrm{Jd} \\
1.47 \mathrm{~d} \\
33 \mathrm{C}^{(1)}\end{array}$ & $\begin{array}{l}0.41 \mathrm{~J} \\
0.47 \mathrm{~J} \\
0.58 \mathrm{~J} \\
18 \mathrm{x}\end{array}$ & $\begin{array}{c}0.69 \mathrm{~J} \\
0.85 \mathrm{~J} \\
1.15 \mathrm{~J} \\
26 \%\end{array}$ & $\begin{array}{l}0.65 \mathrm{~J} \\
0.79 \mathrm{~J}(d) \\
1.04 \mathrm{~J}(\mathrm{~d}) \\
24 \mathrm{x}\end{array}$ \\
\hline N. virens Background Rep 1 & 1 & 3 & 2.89 & 2.62 & $0.75 \mathrm{~J}$ & $1.39 \mathrm{~J}$ & $1.08 \mathrm{~J}$ \\
\hline N. virens Background Rep 2 & 2 & 3 & 6.49 & 5.88 & 1.51 & 2.61 & 1.95 \\
\hline $\begin{array}{l}\text { N. virens Background Rep } 3 \\
\text { RSD }\end{array}$ & 3 & 3 & $\begin{array}{l}2.60 \\
54 x^{(1)}\end{array}$ & $\begin{array}{l}2.40 \\
54 x^{(1)}\end{array}$ & ${ }_{42 \%}^{0.79}(1)$ & $1.45 \mathrm{~J}_{38 \times}(1)$ & $1.283(1)$ \\
\hline $\begin{array}{l}\text { N. virens Control Rep } 1 \\
\text { N. virens Control Rep } 2 \\
\text { N. virens Control Rep } 3 \\
\text { RSO }\end{array}$ & $\begin{array}{l}5 \\
5 \\
5\end{array}$ & $\begin{array}{l}1 \\
1 \\
1\end{array}$ & $\begin{array}{l}2.16 \mathrm{~J} \\
1.69 \mathrm{~J} \\
1.40 \mathrm{~J} \\
22 \%\end{array}$ & $\begin{array}{l}2.69(d) \\
1.44 \mathrm{~J} \\
1.20 \mathrm{~J} \\
45 \%(1)\end{array}$ & $\begin{array}{l}1.00 j(d) \\
0.65 j(d) \\
0.53 j(d) \\
34 \%\end{array}$ & $\begin{array}{l}1.42 \mathrm{~J} \\
0.92 \mathrm{~J} \\
0.85 \mathrm{~J} \\
29 \%\end{array}$ & $\begin{array}{l}0.99 J^{(d)} \\
0.74 J^{(d)} \\
0.63 \mathrm{~J} \\
\quad 23 \%\end{array}$ \\
\hline
\end{tabular}

(a) J Analyte detected below method detection 1 imit (MDL), but above instrument detection limit (IDL).

(b) $U$ Analyte was not present above the associated value.

(c) B Procedural blank amount was detected at $\geq 1 / 5$ of the target detection $1 / m i t$.

(d) Suspect value due to analytical laboratory contamination: tissue compsite value used in statistical analysis.

(e) Recovery outside quality control range $(40 \%-120 \%)$.

(f) NC Not certified.

(g) NA Not applicable.

(h) Value exceeds SRM goal of $\leq 30 \%$.

(i) Value exceeds relative precision goal of $\leq 30 \%$, 
IABLE M.11. Quality Control Data for High Molecular Weight Polynuclear Aromatic Hydrocarbon (HPAH) Analys is (elution order,

Benzo[k]fluoranthene - Benzo[g, $h, t]$ perylene), Wet Weight, in Tissue of $N$. virens, Panama City Harbor Project

\begin{tabular}{|c|c|c|c|c|c|c|c|}
\hline \multirow[b]{2}{*}{$\begin{array}{l}\text { Sedtment } \\
\text { Ireatment }\end{array}$} & \multirow[b]{2}{*}{ Replioate } & \multirow[b]{2}{*}{ Batch } & \multicolumn{5}{|c|}{ Nevirens HPAHs ( $/ \mathrm{g} / \mathrm{kg}$ wat welaht) } \\
\hline & & & $\begin{array}{l}\text { Benzo [k] } \\
\text { fluor- } \\
\text { anthene }\end{array}$ & $\begin{array}{l}\text { Benzo [a] } \\
\text { Dyrene }\end{array}$ & $\begin{array}{c}\text { Indeno } \\
{[1,2,3 \text { - }} \\
c, d] \\
\text { Rurene }\end{array}$ & $\begin{array}{c}\text { Dibanzo } \\
\text { [a, } h] \\
\text { anthra- } \\
\text { cene }\end{array}$ & $\begin{array}{l}\text { Benzo } \\
\text { [g.h.i] } \\
\text { perylene }\end{array}$ \\
\hline \multicolumn{8}{|l|}{ Mathod Blanks } \\
\hline $\begin{array}{l}\text { COMP Blank } \\
\text { Blank } \\
\text { Blank } \\
\text { Blank }\end{array}$ & & $\begin{array}{l}1 \\
2 \\
3\end{array}$ & $\begin{array}{l}0.40 u^{(a)} \\
0.53 U^{(b)} \\
0.16 j(b) \\
0.34 J\end{array}$ & $\begin{array}{l}0.32 \mathrm{U} \\
0.42 \mathrm{U} \\
0.12 \mathrm{~J} \\
0.36 \mathrm{~J}\end{array}$ & $\begin{array}{l}0.70 \mathrm{U} \\
0.93 \mathrm{U} \\
0.31 \mathrm{~J} \\
0.48 \mathrm{~J}\end{array}$ & $\begin{array}{l}0.63 \mathrm{U} \\
0.84 \mathrm{U} \\
0.14 \mathrm{~J} \\
0.18 \mathrm{~J}\end{array}$ & $\begin{array}{l}0.59 \mathrm{U} \\
0.78 \mathrm{U} \\
0.52 \mathrm{~J} \\
0.78 \mathrm{~J}\end{array}$ \\
\hline \multicolumn{8}{|l|}{ Matrix Solkes } \\
\hline $\begin{array}{l}\text { PC-2 } \\
\text { PC-2 MS } \\
\text { Concentration Recovered } \\
\text { Anount Splked } \\
\text { Percent Recovery }\end{array}$ & 1 & $\begin{array}{l}3 \\
3\end{array}$ & $\begin{array}{l}0.28 \mathrm{~J} \\
55.22 \\
54.94 \\
47.83 \\
115 \%\end{array}$ & $\begin{array}{l}0.82 U \\
43.23 \\
43.23 \\
47.63 \\
91 \times\end{array}$ & $\begin{array}{l}0.67 \mathrm{~J} \\
45.59 \\
44.92 \\
47.63 \\
94 \%\end{array}$ & $\begin{array}{r}0.19 \mathrm{~J} \\
45.72 \\
45.53 \\
47.63 \\
96 \%\end{array}$ & $\begin{array}{l}0.77 \mathrm{~J}^{(c)} \\
32.23 \\
31.46 \\
47.63 \\
66 \%\end{array}$ \\
\hline $\begin{array}{l}\text { PC-4 COMP } \\
\text { PC- } 4 \text { COMP MS } \\
\text { Concentration Recovered } \\
\text { Amount Splked } \\
\text { Percent Recovery }\end{array}$ & & & $\begin{array}{l}0.19 \mathrm{~J} \\
105.47 \\
105.28 \\
83.00 \\
127 \%^{(d)}\end{array}$ & $\begin{array}{c}0.59 \mathrm{U} \\
101.62 \\
101.62 \\
83.00 \\
122 x^{(d)}\end{array}$ & $\begin{array}{l}1.30 \mathrm{U} \\
96.80 \\
96.80 \\
83.00 \\
117 \%\end{array}$ & $\begin{array}{l}1.17 \mathrm{U} \\
107.44 \\
107.44 \\
83.00 \\
129 x(d)\end{array}$ & $\begin{array}{c}0.34 \mathrm{~J} \\
100.23 \\
99.89 \\
83.00 \\
120 \%\end{array}$ \\
\hline $\begin{array}{l}\text { PC- } 4 \text { COMP } \\
\text { PC- } 4 \text { COMP MSO } \\
\text { Concentration Recovered } \\
\text { Amount Spiked } \\
\text { Percent Recovery }\end{array}$ & & & $\begin{array}{l}0.19 \mathrm{~J} \\
96.86 \\
96.67 \\
78.62 \\
123 \%(\mathrm{~d})\end{array}$ & $\begin{array}{l}0.59 U \\
94.90 \\
94.90 \\
78.62 \\
121 x^{(d)}\end{array}$ & $\begin{array}{c}1.30 \mathrm{U} \\
80.92 \\
80.92 \\
78.616 \\
103 \%\end{array}$ & $\begin{array}{l}1.17 \mathrm{U} \\
87.97 \\
87.97 \\
78.62 \\
112 \%\end{array}$ & $\begin{array}{l}0.34 \mathrm{~J} \\
92.92 \\
92.58 \\
78.62 \\
118 \%\end{array}$ \\
\hline $\begin{array}{l}\text { RPD } \\
1-\text { Stat }\end{array}$ & & & $0.02^{3 x}$ & $0.00^{1 \%}$ & $\begin{array}{l}13 \% \\
0.06\end{array}$ & $\begin{array}{l}14 x \\
0.07\end{array}$ & $0.01^{2 x}$ \\
\hline $\begin{array}{l}P C-5 \\
P C-5 \text { MS } \\
\text { Concentration Recovered } \\
\text { Amount Spiked } \\
\text { Percent Recovery }\end{array}$ & $\begin{array}{l}2 \\
2\end{array}$ & $\begin{array}{l}2 \\
2\end{array}$ & $\begin{array}{c}0.50 \mathrm{~J} \\
101.21 \\
100.71 \\
95.05 \\
106 \%\end{array}$ & $\begin{array}{l}0.60 \mathrm{U} \\
91.54 \\
91.54 \\
95.05 \\
96 \%\end{array}$ & $\begin{array}{r}0.24 \mathrm{~J} \\
91.38 \\
91.14 \\
95.051 \\
96 \%\end{array}$ & $\begin{array}{l}0.13 \mathrm{~J} \\
85.31 \\
85.18 \\
95.05 \\
90 \%\end{array}$ & $\begin{array}{l}0.45 \mathrm{~J} \\
75.86 \\
75.41 \\
95.05 \\
79 \%\end{array}$ \\
\hline $\begin{array}{l}\text { Reference } \\
\text { Reference MS } \\
\text { Concentration Recovered } \\
\text { Amount Splked } \\
\text { Percent Recovery }\end{array}$ & $\begin{array}{l}4 \\
4\end{array}$ & $\begin{array}{l}1 \\
1\end{array}$ & $\begin{array}{c}0.76 \mathrm{U} \\
104.33 \\
104.33 \\
96.04 \\
109 \%\end{array}$ & $\begin{array}{l}0.60 \mathrm{U} \\
92.76 \\
92.76 \\
96.04 \\
97 \%\end{array}$ & $\begin{array}{c}1.32 U \\
96.79 \\
96.79 \\
96.043 \\
101 \%\end{array}$ & $\begin{array}{r}1.19 \mathrm{U} \\
101.27 \\
101.27 \\
96.04 \\
105 \%\end{array}$ & $\begin{array}{l}1.11 \cup \\
76.80 \\
76.80 \\
96.04 \\
80 \%\end{array}$ \\
\hline N. virens Control & 4 & 1 & $0.67 \mathrm{U}$ & $0.53 \mathrm{U}$ & $1.16 \mathrm{U}$ & $1.05 \mathrm{U}$ & $0.98 \mathrm{U}$ \\
\hline N. virens Control MS & 4 & 1 & 103.29 & 92.69 & 99.25 & 102.37 & 79.4 \\
\hline $\begin{array}{l}\text { Concentration Recovered } \\
\text { Amount Splked } \\
\text { Percent Recovery }\end{array}$ & & & $\begin{array}{r}103.29 \\
105.40 \\
98 \%\end{array}$ & $\begin{array}{r}92.69 \\
105.40 \\
88 \%\end{array}$ & $\begin{array}{r}99.25 \\
105.40 \\
94 \%\end{array}$ & $\begin{array}{l}102.37 \\
105.40 \\
97 \%\end{array}$ & $\begin{array}{r}79.40 \\
105.40 \\
75 \%\end{array}$ \\
\hline
\end{tabular}

PANAMA CITY HARBOR

M. 22 
IABLEM.11. (contd)

\begin{tabular}{|c|c|c|c|c|c|c|c|}
\hline \multirow{2}{*}{$\begin{array}{l}\text { Sediment } \\
\text { Ireatmant }\end{array}$} & \multirow[b]{2}{*}{ Ienluate } & \multirow[b]{2}{*}{ Batch } & \multicolumn{5}{|c|}{ iN virens HPAHs (1/n/ko wat welaht) } \\
\hline & & & $\begin{array}{l}\text { Benzo [k] } \\
\text { fluor- } \\
\text { anthene }\end{array}$ & $\begin{array}{l}\text { Benzo[a] } \\
\text { Dyrene }\end{array}$ & $\begin{array}{l}\text { Indeno } \\
{[1,2,3 \text {. }} \\
c, d] \\
\text { exrens }\end{array}$ & $\begin{array}{l}\text { Dibenzo } \\
{[a, h]} \\
\text { anthra- } \\
\text { cene }\end{array}$ & $\begin{array}{l}\text { Benzo } \\
\text { [g.h.l] } \\
\text { perylene }\end{array}$ \\
\hline \multicolumn{8}{|c|}{ Standard Reforence Materlal } \\
\hline $\begin{array}{l}\text { Certified } \\
\text { Value }\end{array}$ & & & $N C^{(0)}$ & $\begin{array}{r}2.29 \\
\pm 0.47\end{array}$ & $\begin{array}{r}1.8 \\
\pm .33\end{array}$ & NC & $\begin{array}{l}2.47 \\
\pm .28\end{array}$ \\
\hline $\begin{array}{l}\text { NIST } 1974 \text { COMP } \\
\text { NIST } 1974 \\
\text { NIST } 1974 \\
\text { NIST } 1974\end{array}$ & & $\begin{array}{l}1 \\
2 \\
3\end{array}$ & $\begin{array}{l}N A(f) \\
N A \\
N A \\
N A\end{array}$ & $\begin{array}{l}1.61 \\
2.30 \\
2.70 \\
2.35\end{array}$ & $\begin{array}{l}1.75 \\
1.76(9) \\
2.73(9) \\
2.08\end{array}$ & $\begin{array}{l}\text { NA } \\
\text { NA } \\
\text { NA } \\
\text { NA }\end{array}$ & $\begin{array}{l}3.17(0) \\
5.49(0) \\
7.04(0) \\
4.29(0)\end{array}$ \\
\hline \multicolumn{8}{|l|}{ Analytical Replianten } \\
\hline $\begin{array}{l}\text { PC-4 Rep } 1 \\
\text { PC-4 Rep } 2 \\
\text { PC-4 ReP } 3 \\
\text { RSD }\end{array}$ & $\begin{array}{l}2 \\
2 \\
2\end{array}$ & $\begin{array}{l}2 \\
2 \\
2\end{array}$ & $\begin{array}{l}0.22 \mathrm{~J} \\
0.27 \mathrm{~J} \\
0.28 \mathrm{~J} \\
11 \mathrm{x}\end{array}$ & $\begin{array}{l}0.16 \mathrm{~J} \\
0.17 \mathrm{~J} \\
0.14 \mathrm{~J} \\
10 \%\end{array}$ & $\begin{array}{l}0.55 \mathrm{~J} \\
0.60 \mathrm{~J} \\
0.36 \mathrm{~J} \\
25 \times\end{array}$ & $\begin{array}{l}0.14 \mathrm{~J} \\
0.23 \mathrm{~J} \\
0.16 \mathrm{~J} \\
278\end{array}$ & $\begin{array}{l}0.88 \mathrm{~J}(c) \\
1.04 \mathrm{j}(\mathrm{c}) \\
0.53 \mathrm{j}(\mathrm{h}) \\
322 \mathrm{~h})\end{array}$ \\
\hline $\begin{array}{l}P C-4 \text { Rep } 1 \\
P C-4 \text { Rap } 2 \\
\text { PC-4 Rap } 3 \\
\text { RSD }\end{array}$ & $\begin{array}{l}4 \\
4 \\
4\end{array}$ & $\begin{array}{l}2 \\
2 \\
2\end{array}$ & $\begin{array}{l}0.21 \mathrm{~J} \\
0.21 \mathrm{~J} \\
0.27 \mathrm{~J} \\
15 x\end{array}$ & $\begin{array}{l}0.18 \mathrm{~J} \\
0.89 \mathrm{U} \\
0.24 \mathrm{~J} \\
\mathrm{NA}\end{array}$ & $\begin{array}{c}0.55 \mathrm{~J} \\
0.61 \mathrm{~J} \\
0.65 \mathrm{~J} \\
8 \%\end{array}$ & $\begin{array}{l}0.17 \mathrm{~J} \\
0.16 \mathrm{~J} \\
0.21 \mathrm{~J} \\
15 x\end{array}$ & $\begin{array}{l}1.08 \mathrm{j}(\mathrm{c}) \\
0.83 \mathrm{~J} \\
0.94 \mathrm{~J} \\
13 \mathrm{x}\end{array}$ \\
\hline N. wirens Background Rep 1 & 1 & 3 & $0.38 \mathrm{~J}$ & $0.64 \mathrm{U}$ & $0.58 \mathrm{~J}$ & $0.15 \mathrm{~J}$ & $0.74 \mathrm{~J}$ \\
\hline N. virens Background Rep 2 & 2 & 3 & 0.89 & $0.63 \mathrm{U}$ & $1.10 \mathrm{~J}$ & $0.41 \mathrm{~J}$ & 1.21 \\
\hline $\begin{array}{l}\text { N. virens Background Rep } 3 \\
\text { RSO }\end{array}$ & 3 & 3 & $0.45 \mathrm{~J}_{48 \mathrm{~K}}(\mathrm{~h})$ & $\begin{array}{c}0.59 U \\
N A\end{array}$ & $\begin{array}{l}0.79 \\
32 \%\end{array}(\mathrm{~h})$ & $\begin{array}{l}0.22 \mathrm{~J} \\
52 \times\end{array}$ & $\begin{array}{l}1.06 \mathrm{~J} \\
24 \mathrm{x}\end{array}$ \\
\hline N. virens Control Rep 1 & 5 & 1 & $0.82 \mathrm{~J}$ & $0.90 \mathrm{U}$ & $: 97 \mathrm{U}$ & $1.77 \mathrm{U}$ & $1.65 \mathrm{U}$ \\
\hline N. virens Control Rep 2 & 5 & 1 & $1.10 \mathrm{U}$ & $0.88 \mathrm{U}$ & $1.92 \mathrm{U}$ & $1.73 \mathrm{U}$ & $1.61 \mathrm{U}$ \\
\hline $\begin{array}{l}\text { N. virens Control Rep } 3 \\
\text { RSD }\end{array}$ & 5 & 1 & $\begin{array}{c}0.44 \mathrm{~J} \\
\mathrm{NA}\end{array}$ & $\begin{array}{c}0.69 \mathrm{U} \\
\mathrm{NA}\end{array}$ & $\begin{array}{l}1.50 \mathrm{U} \\
\mathrm{NA}\end{array}$ & $\begin{array}{c}1.35 \mathrm{U} \\
\mathrm{NA}\end{array}$ & $\begin{array}{l}1.26 \mathrm{U} \\
\mathrm{NA}\end{array}$ \\
\hline
\end{tabular}

(a) U Analyte was not present above the associated value.

(b) J Analyte detected below method detection $1 \mathrm{imit}$ (MOL), but above instrument detection 1 imit (IDL).

(c) Suspect value due to analytical laboratory contamination: tissue compsite value used in statistical analysis.

(d) Recovery outside quality control range $(40 \%-120 \%)$.

(e) NC Not certified.

(f) NA Not applicable.

(g) Value exceeds SRM goal of S30\%.

(h) Value exceeds relative precision goal of $530 x$. 


\section{IABLE M.12. Phenol and Substftuted Phenol Analysis, (phenol. 2-chlorophenol), Wet Weight, in Tissue of $N$. virens,}

Panama City Harbor Project

\begin{tabular}{|c|c|c|c|c|c|c|c|c|}
\hline \multirow{2}{*}{$\begin{array}{l}\text { Sediment } \\
\text { Irrentmant } \\
\text { Target OL (a) } \\
\text { Achieved OL HIgh } \\
\text { Achieved OL Low }\end{array}$} & \multirow[t]{2}{*}{ Bepllants } & \multirow[t]{2}{*}{ Batch } & $\begin{array}{l}\text { Percent } \\
\text { Dry Whtoht }\end{array}$ & Phenol and & $\begin{array}{l}\text { Subatjesut } \\
2,4_{1} \cdot d 1- \\
\text { methyl } \\
\text { ghenol }\end{array}$ & $\begin{array}{l}\text { N. wirens } \\
\text { ted phenele } \\
2,4,6- \\
\text { tri- } \\
\text { chloro- } \\
\text { phenol }\end{array}$ & $\begin{array}{l}\text { (Ma/ka mo } \\
\text { Para- } \\
\text { chloro- } \\
\text { meta- } \\
\text { arreol }\end{array}$ & t. welaht) \\
\hline & & & & $\begin{array}{l}330 \\
998.60 \\
331.96\end{array}$ & $\begin{array}{l}330 \\
998.60 \\
331.96\end{array}$ & $\begin{array}{l}330 \\
998.60 \\
331.96\end{array}$ & $\begin{array}{l}330 \\
998.60 \\
331.96\end{array}$ & $\begin{array}{l}330 \\
998.60 \\
331.96\end{array}$ \\
\hline $\begin{array}{l}P C-1 \\
P C-1 \\
P C-1 \\
P C=1 \\
P C=1\end{array}$ & $\begin{array}{l}1 \\
2 \\
3 \\
4 \\
5\end{array}$ & $\begin{array}{l}2 \\
1 \\
2 \\
1 \\
2\end{array}$ & $\begin{array}{l}14.15 \\
14.04 \\
12.33 \\
14.15 \\
14.17\end{array}$ & $\begin{array}{r}275.78 \mathrm{~J}(\mathrm{~b}) \\
260.69 \mathrm{U}(\mathrm{c}) \\
91.40 \mathrm{~J} \\
284.06 \mathrm{U} \\
75.31 \mathrm{~J}\end{array}$ & $\begin{array}{l}88.12 \mathrm{~J} \\
260.69 \mathrm{U} \\
478.35 \mathrm{U} \\
284.08 \mathrm{U} \\
376.86 \mathrm{U}\end{array}$ & $\begin{array}{r}93.34 \mathrm{~J} \\
260.69 \mathrm{U} \\
478.35 \mathrm{U} \\
284.06 \mathrm{U} \\
376.86 \mathrm{U}\end{array}$ & $\begin{array}{l}108,49 \mathrm{~J} \\
280,69 \mathrm{U} \\
478,35 \mathrm{U} \\
284.06 \mathrm{U} \\
378.86 \mathrm{U}\end{array}$ & $\begin{array}{r}37.91 \mathrm{~J} \\
260.69 \mathrm{U} \\
478.35 \mathrm{U} \\
284.06 \mathrm{U} \\
376.86 \mathrm{U}\end{array}$ \\
\hline $\begin{array}{l}P C-1 A \\
P C-1 A \\
P C-1 A \\
P C-1 A \\
P C-1 A\end{array}$ & $\begin{array}{l}1 \\
2 \\
3 \\
4 \\
5\end{array}$ & $\begin{array}{l}2 \\
1 \\
2 \\
2 \\
1\end{array}$ & $\begin{array}{l}12.85 \\
14.13 \\
13.54 \\
14.01 \\
13.40\end{array}$ & $\begin{array}{r}81.24 \mathrm{~J} \\
277.35 \mathrm{U} \\
87.11 \mathrm{~J} \\
32.37 \mathrm{~J} \\
53.74 \mathrm{~J}\end{array}$ & $\begin{array}{l}331.96 \mathrm{U} \\
277.35 \mathrm{U} \\
348.00 \mathrm{U} \\
420.98 \mathrm{U} \\
262.86 \mathrm{U}\end{array}$ & $\begin{array}{l}331.96 U \\
277.35 U \\
348.00 U \\
420.96 U \\
262.86 U\end{array}$ & $\begin{array}{l}331.96 U \\
277.35 U \\
348.00 U \\
420.96 U \\
262.86 U\end{array}$ & $\begin{array}{l}331.96 U \\
277.35 U \\
348.00 U \\
420.96 U \\
262.86 U\end{array}$ \\
\hline $\begin{array}{l}P C-2 \\
P C-2 \\
P C-2 \\
P C-2 \\
P C-2\end{array}$ & $\begin{array}{l}1 \\
2 \\
3 \\
4 \\
3\end{array}$ & $\begin{array}{l}3 \\
2 \\
1 \\
1 \\
1\end{array}$ & $\begin{array}{l}14.28 \\
13.47 \\
14.07 \\
13.98 \\
14.48\end{array}$ & $\begin{array}{r}84.58 \mathrm{~J} \\
46.35 \mathrm{~J} \\
13.61 \mathrm{~J} \\
273.89 \mathrm{U} \\
450.72 \mathrm{U}\end{array}$ & $\begin{array}{l}910.66 U \\
408.78 U \\
302.13 U \\
273.89 U \\
450.72 U\end{array}$ & $\begin{array}{l}910.86 U \\
408.78 U \\
302.13 U \\
273.89 U \\
450.72 U\end{array}$ & $\begin{array}{l}910.66 U \\
408.78 U \\
302.13 U \\
273.89 U \\
450.72 U\end{array}$ & $\begin{array}{r}910.66 U \\
408.78 U \\
302.13 \mathrm{U} \\
2.56 \mathrm{~J} \\
3.81 \mathrm{~J}\end{array}$ \\
\hline $\begin{array}{l}P C-4 \\
P C-4 \text { Rep } 1 \\
P C-4 \text { Rep } 2 \\
P C-4 \text { Rep } 3 \\
P C-4 \\
P C-4 \text { Rep } 1 \\
P C-4 \text { Rep } 2 \\
P C-4 \text { ReP } 3 \\
P C-4\end{array}$ & $\begin{array}{l}1 \\
2 \\
2 \\
2 \\
3 \\
4 \\
4 \\
4 \\
5\end{array}$ & $\begin{array}{l}1 \\
2 \\
2 \\
2 \\
1 \\
2 \\
2 \\
2 \\
3\end{array}$ & $\begin{array}{l}14.33 \\
14.75 \\
14.75 \\
14.75 \\
14.22 \\
14.22 \\
14.22 \\
14.22 \\
13.57\end{array}$ & $\begin{array}{r}311.62 \mathrm{U} \\
110.62 \mathrm{~J} \\
97.11 \mathrm{~J} \\
62.83 \mathrm{~J} \\
7.00 \mathrm{~J} \\
60.73 \mathrm{~J} \\
145.10 \mathrm{~J} \\
98.55 \mathrm{~J} \\
37.69 \mathrm{~J}\end{array}$ & $\begin{array}{l}311.62 U \\
995.42 U \\
998.60 U \\
760.80 U \\
297.48 U \\
980.68 U \\
989.90 U \\
0.86 \mathrm{~J} \\
661.07 U\end{array}$ & $\begin{array}{l}311.62 U \\
995.42 U \\
998.60 U \\
760.80 U \\
297.48 U \\
980.68 U \\
989.90 U \\
812.22 U \\
861.01 U\end{array}$ & $\begin{array}{r}311.62 U \\
995.42 U \\
998.60 U \\
760.80 U \\
0.60 \mathrm{~J} \\
980.08 \mathrm{U} \\
989.90 \mathrm{U} \\
812.22 \mathrm{U} \\
661.07 \mathrm{U}\end{array}$ & $\begin{array}{l}311.62 U \\
995.42 U \\
998.60 U \\
760.80 U \\
297.48 U \\
980.68 U \\
989.90 U \\
812.22 U \\
661.07 U\end{array}$ \\
\hline $\begin{array}{l}P C-5 \\
P C=-5 \\
P C-5 \\
P C=5 \\
P C=5\end{array}$ & $\begin{array}{l}1 \\
2 \\
3 \\
4 \\
5\end{array}$ & $\begin{array}{l}2 \\
2 \\
1 \\
3 \\
1\end{array}$ & $\begin{array}{l}13.63 \\
13.48 \\
13.83 \\
14.85 \\
14.17\end{array}$ & $\begin{array}{r}171.45 \mathrm{~J} \\
60.86 \mathrm{~J} \\
39.43 \mathrm{~J} \\
48.93 \mathrm{~J} \\
71.35 \mathrm{~J}\end{array}$ & $\begin{array}{r}355.08 \mathrm{U} \\
665.91 \mathrm{U} \\
269.07 \mathrm{U} \\
660.81 \mathrm{U} \\
6.50 \mathrm{~J}\end{array}$ & $\begin{array}{r}8.16 \mathrm{~J} \\
665.91 \mathrm{U} \\
269.07 \mathrm{U} \\
660.81 \mathrm{U} \\
327.43 \mathrm{U}\end{array}$ & $\begin{array}{l}355.08 \mathrm{U} \\
665.91 \mathrm{U} \\
269.07 \mathrm{U} \\
660.81 \mathrm{U} \\
327.43 \mathrm{U}\end{array}$ & $\begin{array}{l}355.08 U \\
665.91 U \\
269.07 U \\
660.81 U \\
327.43 U\end{array}$ \\
\hline $\begin{array}{l}\text { Reforence } \\
\text { Refarence } \\
\text { Reference } \\
\text { Refarence } \\
\text { Referance }\end{array}$ & $\begin{array}{l}1 \\
2 \\
3 \\
4 \\
5\end{array}$ & $\begin{array}{l}3 \\
2 \\
2 \\
1 \\
3\end{array}$ & $\begin{array}{l}12.70 \\
14.22 \\
13.74 \\
14.51 \\
14.72\end{array}$ & $\begin{array}{r}28.95 \mathrm{~J} \\
358.38 \mathrm{U} \\
71.89 \mathrm{~J} \\
499.63 \mathrm{U} \\
61.75 \mathrm{~J}\end{array}$ & $\begin{array}{l}607.28 \cup \\
358.38 \cup \\
347.05 \cup \\
499.63 \cup \\
661.55 \cup\end{array}$ & $\begin{array}{l}607.28 U \\
358.38 U \\
347.05 U \\
499.63 U \\
661.55 U\end{array}$ & $\begin{array}{l}607.28 U \\
358.38 U \\
347.05 U \\
499.63 U \\
661.55 U\end{array}$ & $\begin{array}{l}607.28 U \\
358.38 U \\
347.05 U \\
499.63 U \\
661.55 U\end{array}$ \\
\hline N. Wrens dackgrouna kep a & 1 & 3 & 14.40 & $292.49 \mathrm{~J}$ & $707.36 \mathrm{U}$ & $2.61 \mathrm{~J}$ & $707.36 \mathrm{U}$ & $707.36 \mathrm{U}$ \\
\hline N. virens Background Rep 2 & 2 & 3 & 14.40 & $236.40 \mathrm{~J}$ & $694.64 \mathrm{U}$ & $694.64 \mathrm{U}$ & $694.64 \mathrm{U}$ & $694.64 \mathrm{U}$ \\
\hline N. virens Background Rep 3 & 3 & 3 & 14.40 & $235.13 \mathrm{~J}$ & $656.38 \mathrm{U}$ & $656.38 \mathrm{U}$ & $656.38 \mathrm{U}$ & $656.38 \mathrm{U}$ \\
\hline
\end{tabular}


IBALE M.12. (contd)

\begin{tabular}{|c|c|c|c|c|c|c|c|c|}
\hline $\begin{array}{l}\text { Sedimant } \\
\text { Ireutment }\end{array}$ & Benlugate & Batah & $\begin{array}{l}\text { Percent } \\
\text { Dey Yeloht }\end{array}$ & Phanols & $\begin{array}{l}\text { Substitut } \\
2,4,-d i- \\
\text { methyl } \\
\text { ohenel }\end{array}$ & $\begin{array}{l}N . \text { virens } \\
\text { ted Phenols } \\
2,4,6- \\
\text { tri- } \\
\text { chloro- } \\
\text { phenol }\end{array}$ & $\begin{array}{l}\text { Lo/kg we } \\
\text { Para- } \\
\text { chloro- } \\
\text { mata- } \\
\text { eresol }\end{array}$ & $\begin{array}{l}\text { 2-chloro- } \\
\text { phonol }\end{array}$ \\
\hline N. virens Control & 1 & 2 & 14.32 & $65.29 \mathrm{~J}$ & $383.94 \mathrm{U}$ & $383.94 \mathrm{U}$ & $383.94 \mathrm{U}$ & $383.94 U$ \\
\hline N. Whens Control & 2 & 3 & 14.83 & $51.73 \mathrm{~J}$ & $662.78 \mathrm{U}$ & $662.78 \mathrm{U}$ & $682.78 \mathrm{U}$ & $662.78 \mathrm{U}$ \\
\hline N. Vinens Control & 3 & 1 & 13.20 & $173.90 \mathrm{~J}$ & $444.15 \mathrm{U}$ & 444.1511 & $2.15 \mathrm{~J}$ & $444.15 \mathrm{U}$ \\
\hline N. wirens Control & 4 & 1 & 14.61 & $441.23 \mathrm{U}$ & $441.23 \mathrm{U}$ & $441.23 \mathrm{U}$ & $441.23 \mathrm{U}$ & $4.93 \mathrm{~J}$ \\
\hline N. whens Control Rap 1 & 5 & 1 & 14.16 & $745.97 \mathrm{U}$ & $745.97 U$ & $745.97 U$ & $745.97 \mathrm{U}$ & $745.97 \mathrm{U}$ \\
\hline N. whens Control Rep 2 & 5 & 1 & 14.16 & $52.11 \mathrm{~J}$ & $728.08 \mathrm{U}$ & $728.08 \mathrm{U}$ & $728.08 \mathrm{U}$ & $728.08 \mathrm{U}$ \\
\hline N. whens Control Rep 3 & 5 & 1 & 14.16 & $569.52 \mathrm{U}$ & $569.52 \mathrm{U}$ & $569.52 \cup$ & $569.52 \mathrm{U}$ & $569.52 \mathrm{U}$ \\
\hline
\end{tabular}

(a) OL Detection limit.

(b) J Analyte detected below mathod detection 1 imit (MOL), but above instrument detection 1 imit (IOL).

(c) U Analyte was not present above the assoclated value. 
IABLE M.13 Phenol and Substituted Phenol Analysis, (2,4-dichlorophenol Pentachloropheno1), Wet Weight, in Tissue of $N$. virens, Panama City Harbor Project

\begin{tabular}{|c|c|c|c|c|c|c|c|c|c|}
\hline \multirow[b]{2}{*}{$\begin{array}{l}\text { Sediment } \\
\text { Ireatment }\end{array}$} & \multirow{2}{*}{\multicolumn{3}{|c|}{$\begin{array}{c}\text { Percent } \\
\text { Ory } \\
\text { Weloht }\end{array}$}} & \multicolumn{6}{|c|}{ N. virens } \\
\hline & & & & $\begin{array}{l}\text { 2,4-di- } \\
\text { chloro- } \\
\text { ohenol }\end{array}$ & $\begin{array}{l}\text { 2-nitro- } \\
\text { phenol }\end{array}$ & $\begin{array}{l}\text { - 4-nitro- } \\
\text { - phenol }\end{array}$ & $\begin{array}{l}2,4-d t- \\
\text { nitro- } \\
\text { phenol }\end{array}$ & $\begin{array}{c}4,6-d i- \\
\text { nitro- } \\
\text { o-cresol }\end{array}$ & $\begin{array}{l}\text { Penta- } \\
\text { chloro- } \\
\text { phenol }\end{array}$ \\
\hline $\begin{array}{l}\text { Target OL (a) } \\
\text { Achleved DL HIgh } \\
\text { Achleved DL Low }\end{array}$ & & & & $\begin{array}{l}330 \\
998.60 \\
331.96\end{array}$ & $\begin{array}{l}330 \\
998.60 \\
331.96\end{array}$ & $\begin{array}{l}330 \\
998.60 \\
331.96\end{array}$ & $\begin{array}{l}330 \\
998.60 \\
331.96\end{array}$ & $\begin{array}{l}330 \\
998.60 \\
331.96\end{array}$ & $\begin{array}{l}330 \\
998.60 \\
331.96\end{array}$ \\
\hline $\begin{array}{l}P C-1 \\
P C-1 \\
P C-1 \\
P C-1 \\
P C-1\end{array}$ & $\begin{array}{l}1 \\
2 \\
3 \\
4 \\
5\end{array}$ & $\begin{array}{l}2 \\
1 \\
2 \\
1 \\
2\end{array}$ & $\begin{array}{l}14.15 \\
14.04 \\
12.33 \\
14.15 \\
14.17\end{array}$ & $\begin{array}{r}59.98 \mathrm{~J} \\
260.69 \\
478.35 \\
284.06 \\
376.86\end{array}$ & $\begin{array}{lr}J(b) & 19.47 \\
U & 260.69 \\
U & 478.35 \\
U & 284.06 \\
U & 376.86\end{array}$ & 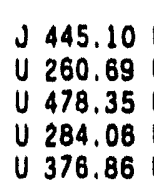 & $\begin{array}{lr}U(c) & 445.10 \\
U & 260.69 \\
U & 478.35 \\
U & 284.06 \\
U & 376.86\end{array}$ & $\begin{array}{lll}U & 445.10 & U \\
U & 260.69 & U \\
U & 478.35 & U \\
U & 284.06 & U \\
U & 376.86 & U\end{array}$ & 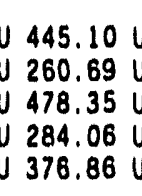 \\
\hline $\begin{array}{l}P C-1 A \\
P C-1 A \\
P C-1 A \\
P C-1 A \\
P C-1 A\end{array}$ & $\begin{array}{l}1 \\
2 \\
3 \\
4 \\
5\end{array}$ & $\begin{array}{l}2 \\
1 \\
2 \\
2 \\
1\end{array}$ & $\begin{array}{l}12.85 \\
14.13 \\
13.54 \\
14.01 \\
13.40\end{array}$ & $\begin{array}{l}331.96 \cup \\
277.35 \cup \\
348.00 \cup \\
420.96 \cup \\
262.86 U\end{array}$ & $\begin{array}{l}331.96 \\
277.35 \\
348.90 \\
420.96 \\
262.86\end{array}$ & $\begin{array}{ll}\text { U } & 331.96 \\
\text { U } & 277.35 \\
U & 348.00 \\
U & 420.96 \\
U & 262.86\end{array}$ & $\begin{array}{l}331.96 \\
277.35 \\
348.00 \\
423.96 \\
282.86\end{array}$ & $\begin{array}{lll}U & 331.96 & U \\
U & 277.35 & U \\
U & 348.00 & U \\
U & 420.96 & U \\
U & 262.86 & U\end{array}$ & $\begin{array}{l}331.96 \\
U \\
277.35 \\
348.00 \\
U \\
420.96 \\
262.86\end{array}$ \\
\hline $\begin{array}{l}P C-2 \\
P C-2 \\
P C-2 \\
P C=2 \\
P C-2\end{array}$ & $\begin{array}{l}1 \\
2 \\
3 \\
4 \\
5\end{array}$ & $\begin{array}{l}3 \\
2 \\
1 \\
1 \\
1\end{array}$ & $\begin{array}{l}14.28 \\
13.47 \\
14.07 \\
13.98 \\
14.46\end{array}$ & $\begin{array}{l}910.66 U \\
408.78 U \\
302.13 U \\
273.89 U \\
450.72 U\end{array}$ & $\begin{array}{l}910.66 \\
408.78 \\
302.13 \\
273.89 \\
450.72\end{array}$ & $\begin{array}{ll}\cup & 910.66 \\
U & 408.78 \\
U & 302.13 \\
U & 273.89 \\
U & 450.72\end{array}$ & $\begin{array}{l}910.66 \\
408.78 \\
302.13 \\
273.89 \\
450.72\end{array}$ & $\begin{array}{lll}U & 910.16 & U \\
U & 408.78 \text { U } \\
U & 302.13 \text { U } \\
U & 273.89 \text { U } \\
U & 450.72 U\end{array}$ & $\begin{array}{l}910.66 \\
U 408.78 \\
302.13 \\
273.89 \\
450.72\end{array}$ \\
\hline $\begin{array}{l}P C-4 \\
P C-4 \text { Rep } 1 \\
P C-4 \text { Rep } 2 \\
P C-4 \text { Rep } 3 \\
P C-4 \\
P C-4 \text { Rep } 1 \\
P C-4 \text { Rep } 2 \\
P C-4 \text { Rep } 3 \\
P C-4\end{array}$ & $\begin{array}{l}1 \\
2 \\
2 \\
2 \\
3 \\
4 \\
4 \\
4 \\
5\end{array}$ & $\begin{array}{l}1 \\
2 \\
2 \\
2 \\
1 \\
2 \\
2 \\
2 \\
3\end{array}$ & $\begin{array}{l}14.33 \\
14.75 \\
14.75 \\
14.75 \\
14.22 \\
14.22 \\
14.22 \\
14.22 \\
13.57\end{array}$ & $\begin{array}{r}311.62 U \\
995.42 U \\
998.60 U \\
760.80 U \\
3.96 \mathrm{~J} \\
980.68 \mathrm{U} \\
989.90 \mathrm{U} \\
812.22 \mathrm{U} \\
661.07 \mathrm{U}\end{array}$ & $\begin{array}{l}311.62 \\
995.42 \\
998.60 \\
760.80 \\
297.48 \\
980.68 \\
989.90 \\
812.22 \\
661.07\end{array}$ & $\begin{array}{ll}\cup & 311.62 \\
U & 995.42 \\
U & 998.60 \\
\cup & 760.80 \\
U & 297.48 \\
U & 980.68 \\
U & 989.90 \\
\cup & 812.22 \\
U & 661.07\end{array}$ & $\begin{array}{l}311.62 \\
995.42 \\
998.60 \\
760.80 \\
297.48 \\
980.68 \\
989.90 \\
812.22 \\
661.07\end{array}$ & $\begin{array}{lll}U & 311.62 & U \\
U & 995.42 & U \\
U & 998.60 & U \\
U & 760.80 & U \\
U & 297.48 & U \\
U & 980.68 U \\
U & 989.90 U \\
U & 812.22 U \\
U & 661.07 & U\end{array}$ & 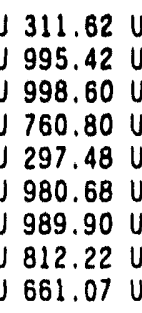 \\
\hline $\begin{array}{l}P C-5 \\
P C-5 \\
P C-5 \\
P C-5 \\
P C-5\end{array}$ & $\begin{array}{l}1 \\
2 \\
3 \\
4 \\
5\end{array}$ & $\begin{array}{l}2 \\
2 \\
1 \\
3 \\
1\end{array}$ & $\begin{array}{l}13.63 \\
13.48 \\
13.83 \\
14.85 \\
14.17\end{array}$ & $\begin{array}{l}355.08 U \\
665.91 U \\
269.07 \cup \\
660.81 U \\
327.43 U\end{array}$ & $\begin{array}{l}355.08 \\
665.91 \\
269.07 \\
660.81 \\
327.43\end{array}$ & $\begin{array}{ll}U & 355.08 \\
U & 665.91 \\
U & 269.07 \\
U & 660.81 \\
U & 327.43\end{array}$ & $\begin{array}{l}355.08 \\
665.91 \\
269.07 \\
660.81 \\
327.43\end{array}$ & $\begin{array}{lll}U & 355.08 & U \\
U & 665.91 & U \\
U & 269.07 & U \\
U & 660.81 & U \\
U & 327.43 & U\end{array}$ & $\begin{array}{l}355.08 \\
665.91 \\
J \\
269.07 \\
660.81 \\
327.43\end{array}$ \\
\hline $\begin{array}{l}\text { Reference } \\
\text { Reference } \\
\text { Reference } \\
\text { Reference } \\
\text { Reference }\end{array}$ & $\begin{array}{l}1 \\
2 \\
3 \\
1 \\
5\end{array}$ & $\begin{array}{l}3 \\
2 \\
2 \\
1 \\
3\end{array}$ & $\begin{array}{l}12.70 \\
14.22 \\
13.74 \\
14.51 \\
14.72\end{array}$ & $\begin{array}{l}607.28 U \\
358.38 U \\
347.05 U \\
499.63 U \\
661.55 U\end{array}$ & $\begin{array}{l}607.28 \\
358.38 \\
347.05 \\
499.63 \\
661.55\end{array}$ & $\begin{array}{ll}U & 607.28 \\
U & 358.38 \\
U & 347.05 \\
U & 499.63 \\
U & 661.55\end{array}$ & $\begin{array}{l}607.28 \\
358.38 \\
347.05 \\
499.63 \\
661.55\end{array}$ & $\begin{array}{lll}U & 607.28 & U \\
U & 358.38 & U \\
U & 347.05 & U \\
U & 499.63 \text { U } \\
U & 661.55 \text { U }\end{array}$ & $\begin{array}{l}607.28 \\
358.38 \\
347.05 \\
499.63 \\
4961.55 \\
661\end{array}$ \\
\hline N. virens Background Rep 1 & 1 & 3 & 14.40 & $707.36 \mathrm{U}$ & 707.36 & $\cup 707.36$ & 707.36 & $U 707.36 \mathrm{U}$ & J $707.36 U$ \\
\hline N. virens Background Rep 2 & 2 & 3 & 14.40 & $694.64 \mathrm{U}$ & 694.64 & U 694.64 & 694.64 & U 694.64 U & J $694.64 U$ \\
\hline N. virens Background Rep 3 & 3 & 3 & 14.40 & $656.38 \mathrm{U}$ & 656.38 & $\cup 656.38$ & 656.381 & U $656.38 \mathrm{U}$ & J $656.38 \mathrm{U}$ \\
\hline
\end{tabular}




\section{TABLE M.13. (contd)}

Sediment

Treatment

N. virens Control

$N$. virens Control

N. virens Control

$N$. virens Control

N. virens Control Rep 1

N. virens Control Rep 2

N. virens Control Rep 3
N. virens

Percent 2,4-di-

Dry chloro-

Replicate Batch Weight

phenol

2-nitro- 4-nitro-

phenol phenol

$383.94 \cup 383.94 \cup$

$662.78 \cup 662.78 \cup$

$444.15 \cup 444.15 \mathrm{U}$

$441.23 \cup 441.23 \mathrm{U}$

$745.97 \cup 745.97 \mathrm{U}$

$728.08 \cup 728.08 \mathrm{U}$

569.52 U 569.52 U (ug/kg wet weight) 2,4-di- 4,6-di- Pentanitro- nitro- chlorophenol o-cresol phenol

$383.94 \cup 383.94 \cup 383.94 \cup$ $662.78 \cup 662.78 \cup 662.78 \cup$

$5.20 \mathrm{~J} 444.15 \cup 444.15 \mathrm{U}$ $441.23 \cup 441.23 \cup 441.23 \cup$ $745.97 \cup 745.97 \cup 745.97 \cup$ $728.08 \cup 728.08 \cup 728.08 \cup$ $569.52 \cup 569.52 \cup 569.52 \cup$

(a) OL Detection Iimit.

(b) J Analyte detected below method detection 1 imit (MOL), but above instrument detection 1 imit (IDL).

(c) U Analyte was not present above the associated value. 
IABLE M.14. Phenol and Substituted Phenol Analysis, (phenol 2-chlorophenol), Dry Weight, in Tissue of $N$. virens, Panama City Harbor Project

\begin{tabular}{|c|c|c|c|c|c|c|c|c|}
\hline \multirow[b]{2}{*}{$\begin{array}{l}\text { Sediment } \\
\text { Ireatment }\end{array}$} & \multirow[b]{2}{*}{ Replicate } & \multirow{2}{*}{\multicolumn{2}{|c|}{$\begin{array}{c}\text { Percent } \\
\text { Dry } \\
\text { h Weight } \\
\end{array}$}} & \multicolumn{5}{|c|}{$\begin{array}{l}\text { N. virens } \\
\text { ted Phenc }\end{array}$} \\
\hline & & & & Phenol & $\begin{array}{l}\text { 2.4-di- } \\
\text { methyl- } \\
\text { phenol }\end{array}$ & $\begin{array}{c}2.4 .6- \\
\text { tri- } \\
\text { chloro- } \\
\text { phenol } \\
\end{array}$ & $\begin{array}{l}\text { Para- } \\
\text { chioro- } \\
\text { meta- } \\
\text { cresol } \\
\end{array}$ & $\begin{array}{l}\text { 2- } \\
\text { chloro- } \\
\text { phenol }\end{array}$ \\
\hline $\begin{array}{l}P C-1 \\
P C-1 \\
P C-1 \\
P C-1 \\
P C-1\end{array}$ & $\begin{array}{l}1 \\
2 \\
3 \\
4 \\
5\end{array}$ & $\begin{array}{l}2 \\
1 \\
2 \\
1 \\
2\end{array}$ & $\begin{array}{l}14.15 \\
14.03 \\
12.32 \\
14.15 \\
14.17\end{array}$ & $\begin{array}{r}1948.42 \mathrm{~J} \\
1857.03 \mathrm{U} \\
741.40 \mathrm{~J} \\
2007.35 \mathrm{U} \\
531.40 \mathrm{~J}\end{array}$ & $\begin{array}{r}\text { (a) } 622.58 \mathrm{~J} \\
\text { J(b) } 1857.03 \mathrm{U} \\
3880.19 \mathrm{U} \\
\mathbf{3} \\
2007.35 \mathrm{U} \\
2659.19 \mathrm{U}\end{array}$ & $\begin{array}{r}659.46 \mathrm{~J} \\
1857.03 \mathrm{U} \\
3880.19 \mathrm{U} \\
2007.35 \mathrm{U} \\
2659.19 \mathrm{U}\end{array}$ & $\begin{array}{r}752.37 \mathrm{~J} \\
1857.03 \mathrm{U} \\
3880.19 \mathrm{U} \\
2007.35 \mathrm{U} \\
2659.19 \mathrm{U}\end{array}$ & 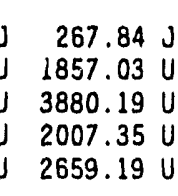 \\
\hline $\begin{array}{l}P C-1 A \\
P C-1 A \\
P C-1 A \\
P C-1 A \\
P C-1 A\end{array}$ & $\begin{array}{l}1 \\
2 \\
3 \\
4 \\
5\end{array}$ & $\begin{array}{l}2 \\
1 \\
2 \\
2 \\
1\end{array}$ & $\begin{array}{l}12.85 \\
14.13 \\
13.54 \\
14.00 \\
13.39\end{array}$ & $\begin{array}{r}632.17 \mathrm{~J} \\
1962.29 \mathrm{U} \\
643.26 \mathrm{~J} \\
231.08 \mathrm{~J} \\
401.07 \mathrm{~J}\end{array}$ & $\begin{array}{l}2583.15 U \\
1962.29 U \\
2569.78 U \\
3005.14 U \\
1961.79 U\end{array}$ & $\begin{array}{l}2583.15 U \\
1962.29 U \\
2569.78 U \\
3005.14 U \\
1961.79 U\end{array}$ & $\begin{array}{l}2583.15 U \\
1962.29 U \\
2569.78 U \\
3005.14 U \\
1961.79 U\end{array}$ & $\begin{array}{l}2583.15 U \\
1962.29 U \\
J \\
2569.78 U \\
3005.14 U \\
J \\
1961.79 U\end{array}$ \\
\hline $\begin{array}{l}P C-2 \\
P C-2 \\
P C-2 \\
P C-2 \\
P C-2\end{array}$ & $\begin{array}{l}1 \\
2 \\
3 \\
4 \\
5\end{array}$ & $\begin{array}{l}3 \\
2 \\
1 \\
1 \\
1\end{array}$ & $\begin{array}{l}14.28 \\
13.47 \\
14.07 \\
13.98 \\
14.45\end{array}$ & $\begin{array}{r}592.30 \mathrm{~J} \\
344.10 \mathrm{~J} \\
96.72 \mathrm{~J} \\
1959.02 \mathrm{U} \\
3117.87 \mathrm{U}\end{array}$ & $\begin{array}{l}6377.17 U \\
3034.74 U \\
2147.03 U \\
1959.02 U \\
3117.87 U\end{array}$ & $\begin{array}{l}6377.17 U \\
3034.74 U \\
2147.03 U \\
1959.02 U \\
3117.87 U\end{array}$ & $\begin{array}{l}6377.17 U \\
3034.74 U \\
2147.03 U \\
1359.02 U \\
3117.87 U\end{array}$ & $\begin{array}{r}6377.17 \mathrm{U} \\
3034.74 \mathrm{U} \\
2147.03 \mathrm{U} \\
18.31 \mathrm{~J} \\
26.36 \mathrm{~J}\end{array}$ \\
\hline 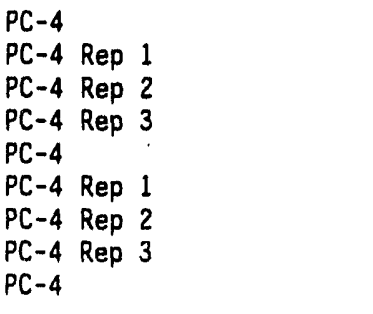 & $\begin{array}{l}1 \\
2 \\
2 \\
2 \\
3 \\
4 \\
4 \\
4 \\
5\end{array}$ & $\begin{array}{l}1 \\
2 \\
2 \\
2 \\
1 \\
2 \\
2 \\
2 \\
3\end{array}$ & $\begin{array}{l}14.33 \\
14.75 \\
14.75 \\
14.75 \\
14.21 \\
14.22 \\
14.22 \\
14.22 \\
13.57\end{array}$ & $\begin{array}{r}2174.60 \mathrm{U} \\
749.76 \mathrm{~J} \\
658.19 \mathrm{~J} \\
425.85 \mathrm{~J} \\
49.24 \mathrm{~J} \\
427.01 \mathrm{~J} \\
1020.25 \mathrm{~J} \\
692.94 \mathrm{~J} \\
277.66 \mathrm{~J}\end{array}$ & $\begin{array}{r}2174.60 U \\
6746.78 U \\
6768.33 U \\
5156.57 U \\
2092.42 U \\
6895.51 U \\
6960.34 U \\
6.05 \mathrm{~J} \\
4870.12 U\end{array}$ & $\begin{array}{l}2174.60 U \\
6746.78 U \\
6768.33 U \\
5156.57 U \\
2092.42 U \\
6895.51 U \\
6960.34 U \\
5711.01 U \\
4870.12 U\end{array}$ & $\begin{array}{r}2174.60 U \\
6746.78 U \\
6768.33 U \\
5156.57 U \\
4.22 U \\
6895.51 U \\
6960.34 U \\
5711.01 U \\
4870.12 U\end{array}$ & $\begin{array}{l}2174.60 U \\
6746.78 U \\
6768.33 U \\
5156.57 U \\
2092.42 U \\
6895.51 U \\
6960.34 U \\
5711.01 U \\
4870.12 U\end{array}$ \\
\hline $\begin{array}{l}P C-5 \\
P C-5 \\
P C-5 \\
P C-5 \\
P C-5\end{array}$ & $\begin{array}{l}1 \\
2 \\
3 \\
4 \\
5\end{array}$ & $\begin{array}{l}2 \\
2 \\
1 \\
3 \\
1\end{array}$ & $\begin{array}{l}13.62 \\
13.47 \\
13.83 \\
14.84 \\
14.17\end{array}$ & $\begin{array}{r}1257.98 \mathrm{~J} \\
451.58 \mathrm{~J} \\
285.10 \mathrm{~J} \\
329.61 \mathrm{~J} \\
503.35 \mathrm{~J}\end{array}$ & $\begin{array}{r}2605.33 U \\
4941.08 U \\
1945.55 U \\
4451.40 U \\
45.86 \mathrm{~J}\end{array}$ & $\begin{array}{r}59.87 \mathrm{~J} \\
4941.08 \mathrm{U} \\
1945.55 \mathrm{U} \\
4451.40 \mathrm{U} \\
2309.91 \mathrm{U}\end{array}$ & $\begin{array}{l}2605.33 U \\
4941.08 U \\
1945.55 U \\
4451.40 U \\
2309.91 U\end{array}$ & $\begin{array}{l}2605.33 U \\
4941.08 U \\
1945.55 U \\
4451.40 U \\
2309.91 U\end{array}$ \\
\hline $\begin{array}{l}\text { Reference } \\
\text { Reference } \\
\text { Reference } \\
\text { Reference } \\
\text { Reference }\end{array}$ & $\begin{array}{l}1 \\
2 \\
3 \\
4 \\
5\end{array}$ & $\begin{array}{l}3 \\
2 \\
2 \\
1 \\
3\end{array}$ & $\begin{array}{l}12.70 \\
14.22 \\
13.74 \\
14.50 \\
14.72\end{array}$ & $\begin{array}{r}227.93 \mathrm{~J} \\
2519.54 \mathrm{U} \\
523.06 \mathrm{~J} \\
3444.06 \mathrm{U} \\
419.47 \mathrm{~J}\end{array}$ & $\begin{array}{l}4781.36 U \\
2519.54 U \\
2525.10 U \\
3444.06 U \\
4493.92 U\end{array}$ & $\begin{array}{l}4781.36 U \\
2519.54 U \\
2525.10 U \\
3444.06 U \\
4493.92 U\end{array}$ & $\begin{array}{l}4781.36 U \\
2519.54 U \\
2525.10 U \\
3444.06 U \\
4493.92 U\end{array}$ & $\begin{array}{l}4781.36 U \\
2519.54 U \\
2525.10 U \\
3444.06 U \\
4493.92 U\end{array}$ \\
\hline N. virens Background Rep 1 & 1 & 3 & 14.39 & $2031.32 \mathrm{~J}$ & $4912.56 \mathrm{U}$ & $18.13 \mathrm{~J}$ & $4912.56 \mathrm{U}$ & $4912.56 \mathrm{U}$ \\
\hline N. virens Background Rep 2 & 2 & 3 & 14.39 & $1641.78 \mathrm{~J}$ & $4824.22 U$ & $4824.22 \mathrm{U}$ & $4824.22 U$ & 4824.22 \\
\hline N. virens Background Rep 3 & 3 & 3 & 14.39 & $1632.96 \mathrm{~J}$ & $4558.51 U$ & $4558.51 U$ & $4558.51 \mathrm{U}$ & 4558.51 \\
\hline
\end{tabular}

PANAMA CITY HARBOR 
TABLE M.14. (contd)

Sediment

Treatment

N. virens Control

$N$. virens Control

$N$. virens Control

N. viresis Control

N. virens Control Rep 1

N. virens Control Rep 2

$N$. virens Control Rep 3

\begin{tabular}{|c|c|c|c|c|c|c|c|}
\hline \multirow[b]{2}{*}{ Replicate } & \multirow[b]{2}{*}{ Batch } & \multirow[b]{2}{*}{$\begin{array}{c}\text { Percent } \\
\text { Dry } \\
\text { Weight }\end{array}$} & \multicolumn{5}{|c|}{$\begin{array}{l}\text { N. virens } \\
\text { hstituted Phenols (ua/kg dry weight) }\end{array}$} \\
\hline & & & Phenol & $\begin{array}{l}\text { 2,4-di- } \\
\text { methyl- } \\
\text { phenol }\end{array}$ & $\begin{array}{c}2.4 .6- \\
\text { tri- } \\
\text { chioro- } \\
\text { phenol } \\
\end{array}$ & $\begin{array}{c}\text { Para- } \\
\text { chloro- } \\
\text { meta- } \\
\text { cresol } \\
\end{array}$ & $\begin{array}{l}\text { 2- } \\
\text { chloro- } \\
\text { phenol }\end{array}$ \\
\hline 1 & 2 & 14.32 & $455.90 \mathrm{~J}$ & $2680.96 U$ & $2680.96 U$ & $2680.96 U$ & $2680.96 U$ \\
\hline 2 & 3 & 14.82 & $348.89 \mathrm{~J}$ & $4470.09 \mathrm{U}$ & $4470.09 \mathrm{U}$ & $4470.09 \mathrm{U}$ & $4470.09 \mathrm{U}$ \\
\hline 3 & 1 & 13.20 & $1317.03 \mathrm{~J}$ & $3363.75 \mathrm{U}$ & $3363.75 \mathrm{U}$ & $16.28 \mathrm{~J}$ & $3363.75 \mathrm{U}$ \\
\hline 4 & 1 & 14.60 & $3020.47 \mathrm{U}$ & $3020.47 \mathrm{U}$ & $3020.47 \mathrm{U}$ & $3020.47 \mathrm{U}$ & $33.75 \mathrm{~J}$ \\
\hline 5 & 1 & 14.16 & $5267.78 U$ & $5267.78 \mathrm{U}$ & $5267.78 \mathrm{U}$ & $5267.78 \mathrm{U}$ & $5267.78 \mathrm{U}$ \\
\hline 5 & 1 & 14.16 & $367.98 \mathrm{~J}$ & $5141.44 U$ & $5141.44 \mathrm{U}$ & $5141.44 \mathrm{U}$ & $5141.44 \mathrm{U}$ \\
\hline 5 & 1 & 14.16 & $4021.75 \mathrm{U}$ & $4021.75 U$ & $4021.75 \mathrm{U}$ & $4021.75 \mathrm{U}$ & $4021.75 U$ \\
\hline
\end{tabular}

(a) J Analyte detected below method detection 1 imit (MDL), but above instrument detection 1 imit (IDL).

(b) U Analyte. was not present above the associated value. 


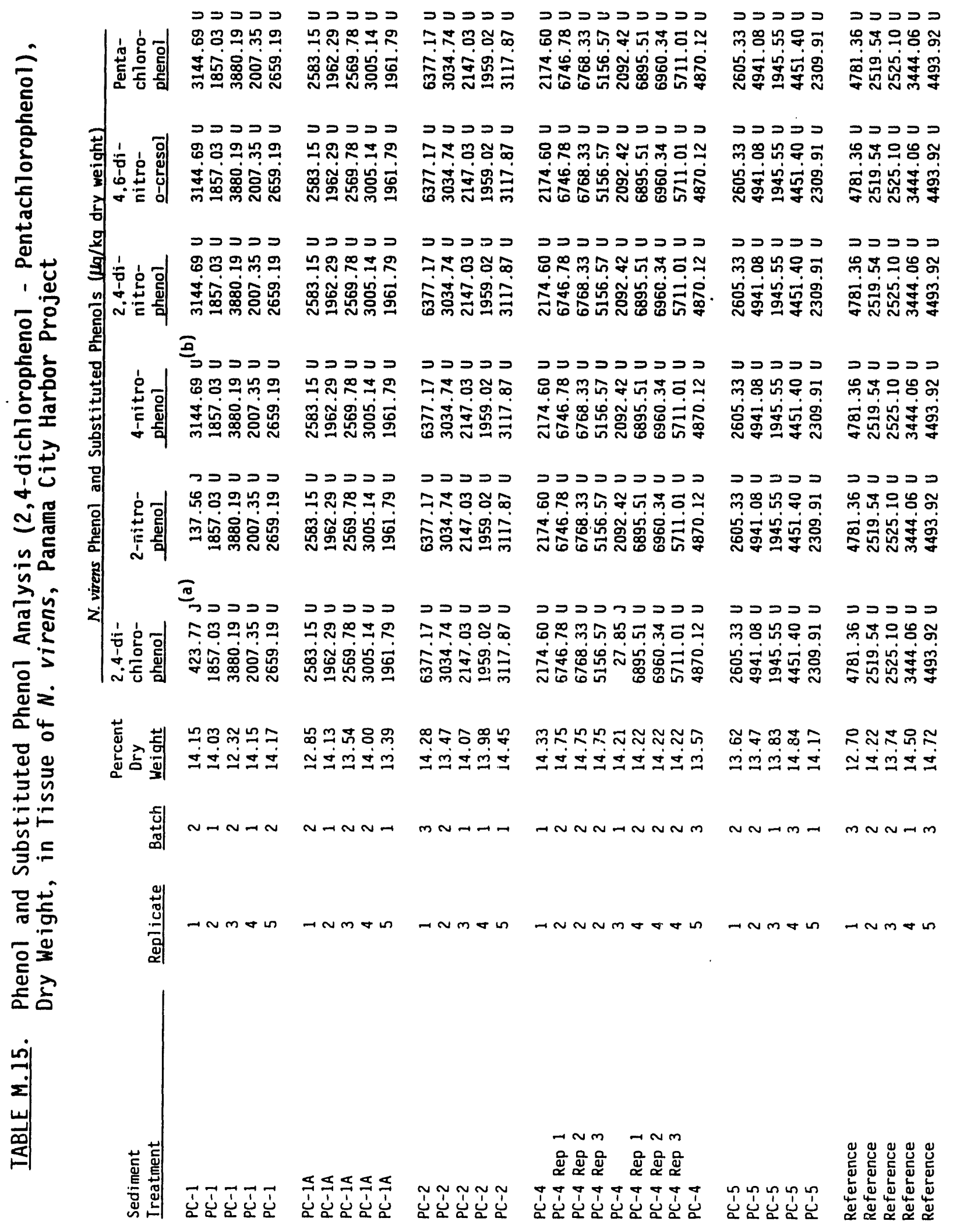

PANAMA CITY HARBOR

M. 30 


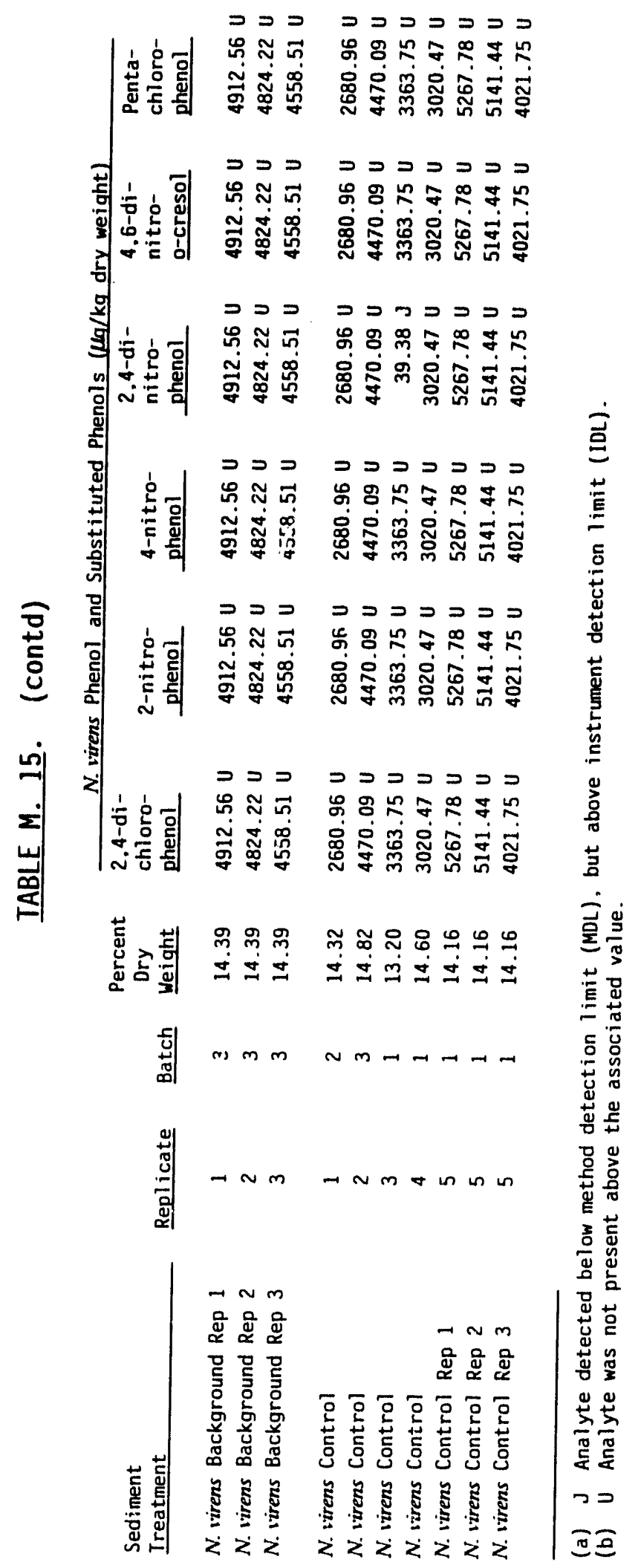


IABLE M.16. Quality Control Data for Phenol and Substituted Phenol Analysis, (Phenol - 2-chlorophenol), Wet Weight, in Tissue of N. virens, Panama City Harbor Project

\begin{tabular}{|c|c|c|c|c|c|c|c|}
\hline $\begin{array}{l}\text { Sediment } \\
\text { Ireatment }\end{array}$ & Replicate & Batch & Phenol & $\begin{array}{l}\text { and Substitut } \\
2,4-d \text { - } \\
\text { methyl } \\
\text { phenol }\end{array}$ & $\begin{array}{l}\text { N. virens } \\
\text { ed Phenols } \\
2,4,6- \\
\text { tri- } \\
\text { chloro } \\
\text { phenol }\end{array}$ & $\begin{array}{l}(1 \mathrm{ga} / \mathrm{kg} \text { wet } \\
\text { Para- } \\
\text { chloro- } \\
\text { meta- } \\
\text { cresol }\end{array}$ & $\begin{array}{l}\text { 2-chloro- } \\
\text { phenol }\end{array}$ \\
\hline \multicolumn{8}{|l|}{ Method Blanks } \\
\hline $\begin{array}{l}\text { Blank } \\
\text { Blank } \\
\text { Blank }\end{array}$ & & $\begin{array}{l}1 \\
2 \\
3\end{array}$ & $\begin{aligned} 57.99 & J^{(a)} \\
488.14 & U^{(b)} \\
59.04 \mathrm{~J} & \end{aligned}$ & $\begin{array}{r}2.71 \mathrm{~J} \\
488.14 \mathrm{U} \\
659.89 \mathrm{U}\end{array}$ & $\begin{array}{r}7.03 \mathrm{~J} \\
488.14 \mathrm{U} \\
659.89 \mathrm{U}\end{array}$ & $\begin{array}{r}8.35 \mathrm{~J} \\
488.14 \mathrm{U} \\
659.89 \mathrm{U}\end{array}$ & $\begin{array}{r}9.05 \mathrm{~J} \\
488.14 \mathrm{U} \\
659.89 \mathrm{U}\end{array}$ \\
\hline \multicolumn{8}{|l|}{ Matrix Solkes } \\
\hline $\begin{array}{l}\text { PC-2 } \\
\text { PC-2 MS } \\
\text { Concentration Recovered } \\
\text { Amount Spiked } \\
\text { Percent Recovery }\end{array}$ & 1 & $\begin{array}{l}3 \\
3\end{array}$ & $\begin{array}{l}84.58 \mathrm{~J} \\
5643.73 \\
5559.15 \\
4344.10 \\
128 \%(\mathrm{c})\end{array}$ & $\begin{array}{r}910.66 U \\
4996.88 \\
4996.88 \\
4344.10 \\
115 \%\end{array}$ & $\begin{array}{c}910.66 \mathrm{U} \\
5013.01 \\
5013.01 \\
4476.71 \\
112 \%\end{array}$ & $\begin{array}{c}910.66 U \\
3402.78 \\
3402.78 \\
4344.10 \\
78 \%\end{array}$ & $\begin{array}{l}910.66 \mathrm{U} \\
6070.32 \\
6070.32 \\
4344.10 \\
140 \%(\mathrm{c})\end{array}$ \\
\hline $\begin{array}{l}\text { PC }-5 \\
\text { PC-5 MS } \\
\text { Concentration Recovered } \\
\text { Amount Splked } \\
\text { Percent Recovery }\end{array}$ & $\begin{array}{l}2 \\
2\end{array}$ & $\begin{array}{l}2 \\
2\end{array}$ & $\begin{array}{l}60.86 \mathrm{~J} \\
5787.30 \\
5726.44 \\
2889.55 \\
198 \%(\mathrm{c})\end{array}$ & $\begin{array}{r}665.91 U \\
52.84 \\
52.84 \\
2889.55(c) \\
2 \%(c)\end{array}$ & $\begin{array}{c}665.91 U \\
1440.53 \\
1440.53 \\
2977.76 \\
48 \%\end{array}$ & $\begin{array}{r}665.91 U \\
1436.74 \\
1436.74 \\
2889.55 \\
50 \%\end{array}$ & $\begin{array}{l}665.91 U \\
6536.46 \\
6536.46 \\
2889.55 \\
226 \%(c)\end{array}$ \\
\hline $\begin{array}{l}\text { Reference } \\
\text { Reference MS } \\
\text { Concentration Recovered } \\
\text { Amount Splked } \\
\text { Percent Recovery }\end{array}$ & $\begin{array}{l}4 \\
4\end{array}$ & $\begin{array}{l}1 \\
1\end{array}$ & $\begin{array}{r}499.63 U \\
1952.94 \\
1952.94 \\
2919.71 \\
67 \%\end{array}$ & $\begin{array}{c}499.63 \mathrm{U} \\
136.19 \\
136.19 \\
2919.71 \\
5 \%(\mathrm{c})\end{array}$ & $\begin{array}{c}499.63 U \\
3085.79 \\
3085.79 \\
3008.84 \\
103 \%\end{array}$ & $\begin{array}{c}499.63 U \\
3129.72 \\
3129.72 \\
2919.71 \\
107 \%\end{array}$ & $\begin{array}{c}499.63 \mathrm{U} \\
3804.87 \\
3804.87 \\
2919.71 \text { (c) } \\
130 \% \text { ( }\end{array}$ \\
\hline N. virens Control & 4 & 1 & $441.23 \mathrm{U}$ & $441.23 U$ & $441.23 \mathrm{U}$ & $441.23 \mathrm{U}$ & $4.93 \mathrm{~J}$ \\
\hline N. virens Control MS & 4 & 1 & 3826.68 & 259.31 & 3669.92 & 3499.18 & 3791.46 \\
\hline $\begin{array}{l}\text { Concentration Recovered } \\
\text { Amount Spiked } \\
\text { Percent Recovery }\end{array}$ & & & $\begin{array}{r}3826.68 \\
3204.27 \\
119 \%\end{array}$ & $\begin{array}{r}259.31 \\
3204.27 \\
8 \%\end{array}$ & $\begin{array}{r}3669.92 \\
3302.09 \\
111 \%\end{array}$ & $\begin{array}{r}3499.18 \\
3204.27 \\
109 \%\end{array}$ & $\begin{array}{r}3786.53 \\
3204.27 \\
118 \%\end{array}$ \\
\hline \multicolumn{8}{|l|}{ Analytical Replicates } \\
\hline $\begin{array}{l}\text { PC-4 } \operatorname{Rep} 1 \\
\text { PC-4 } \operatorname{Rep} 2 \\
\text { PC-4 } \operatorname{Rep} 3 \\
\text { RSD }\end{array}$ & $\begin{array}{l}2 \\
2 \\
2\end{array}$ & $\begin{array}{l}2 \\
2 \\
2\end{array}$ & $\begin{array}{l}110.62 \mathrm{~J} \\
97.11 \mathrm{~J} \\
62.83 \mathrm{~J} \\
27 \%\end{array}$ & $\begin{array}{l}995.42 U \\
998.60 U \\
760.80(\mathrm{U}) \\
\mathrm{NA}\end{array}$ & $\begin{array}{l}995.42 \mathrm{U} \\
998.60 \mathrm{U} \\
760.80 \mathrm{U} \\
\text { NA }\end{array}$ & $\begin{array}{l}995.42 U \\
998.60 U \\
760.80 \mathrm{U} \\
\text { NA }\end{array}$ & $\begin{array}{l}995.42 U \\
998.60 \cup \\
760.81) U \\
\text { NA }\end{array}$ \\
\hline 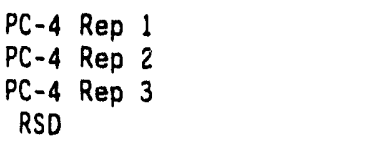 & $\begin{array}{l}4 \\
4 \\
4\end{array}$ & $\begin{array}{l}2 \\
2 \\
2\end{array}$ & $\begin{array}{r}60.73 \mathrm{~J} \\
145.10 \mathrm{~J} \\
98.55 \mathrm{~J} \\
42 \%\end{array}$ & $\begin{array}{c}980.68 \mathrm{U} \\
989.90 \mathrm{U} \\
0.86 \mathrm{~J} \\
N A\end{array}$ & $\begin{array}{c}980.68 \mathrm{U} \\
989.90 \mathrm{U} \\
812.22 \mathrm{U} \\
\text { NA }\end{array}$ & $\begin{array}{c}980.68 U \\
989.90 U \\
812.22 U \\
\text { NA }\end{array}$ & $\begin{array}{c}980.68 U \\
989.90 U \\
812.22 U \\
\text { NA }\end{array}$ \\
\hline N. virens Background Rep 1 & 1 & 3 & $292.49 \mathrm{~J}$ & $707.36 \mathrm{U}$ & $2.61 \mathrm{~J}$ & $707.36 \mathrm{U}$ & $707.36 \mathrm{U}$ \\
\hline N. virens Background Rep 2 & 2 & 3 & $236.40 \mathrm{~J}$ & $694.64 \mathrm{U}$ & $694.64 \mathrm{U}$ & $694.64 \mathrm{U}$ & $694.64 \mathrm{U}$ \\
\hline $\begin{array}{l}\text { N. virens Background Rep } 3 \\
\text { RSD }\end{array}$ & 3 & 3 & $\begin{array}{c}235.13 \mathrm{~J} \\
13 \%\end{array}$ & $\begin{array}{c}656.38 U \\
N A\end{array}$ & $\begin{array}{c}656.38 \mathrm{U} \\
\text { NA }\end{array}$ & $\begin{array}{c}656.38 \mathrm{U} \\
\text { NA }\end{array}$ & $\begin{array}{c}656.38 \mathrm{U} \\
. \mathrm{NA}\end{array}$ \\
\hline
\end{tabular}


IABLE M.15. (contd)

\begin{tabular}{|c|c|c|c|c|c|c|c|}
\hline \multirow[b]{2}{*}{$\begin{array}{l}\text { Sediment } \\
\text { Ireatment }\end{array}$} & \multirow[b]{2}{*}{ Replicate } & \multirow[b]{2}{*}{ Batch } & \multicolumn{5}{|c|}{$\begin{array}{l}\text { N. virens } \\
\text { Phenol and Subst/tuted Phenols ( } \mu_{\mathrm{a}} / \mathrm{kg} \text { wet we/ght) }\end{array}$} \\
\hline & & & Phenol & $\begin{array}{l}\text { 2,4-di- } \\
\text { methyl } \\
\text { phenol- }\end{array}$ & $\begin{array}{c}2,4,6- \\
\text { tri- } \\
\text { chloro } \\
\text { phenol }\end{array}$ & $\begin{array}{l}\text { Para- } \\
\text { chloro- } \\
\text { meta- } \\
\text { cresol }\end{array}$ & $\begin{array}{l}\text { 2-chloro- } \\
\text { phenol }\end{array}$ \\
\hline N. virens Control Rep 1 & 5 & 1 & $745.97 \mathrm{U}$ & $745.97 U$ & $745.97 \mathrm{U}$ & $745.97 \mathrm{U}$ & $745.97 U$ \\
\hline N. virens Control Rep 2 & 5 & 1 & $52.11 \mathrm{~J}$ & $728.08 \mathrm{U}$ & $728.08 \mathrm{U}$ & $728.08 \mathrm{U}$ & $728.08 \mathrm{U}$ \\
\hline $\begin{array}{l}\text { N. virens Control Rep } 3 \\
\text { RSD }\end{array}$ & 5 & 1 & $\begin{array}{c}569.52 U \\
\text { NA }\end{array}$ & $\underset{N A}{569.52 U}$ & $\begin{array}{c}569.52 U \\
N A\end{array}$ & $\begin{array}{c}569.52 U \\
N A\end{array}$ & $\begin{array}{l}569.5 ? \text { U U } \\
\text { NA }\end{array}$ \\
\hline
\end{tabular}

(a) J Analyte detected below method detection 1 imit (MOL), but above instrument delection 1 imit (IDL).

(b) U Analyte was not present above the associated value.

(c) Recovery outside quality control range $(40 \%-120 \%)$.

(d) NA Not applicable.

(e) Value exceeds relative precision goal of $\leq 30 \%$. 


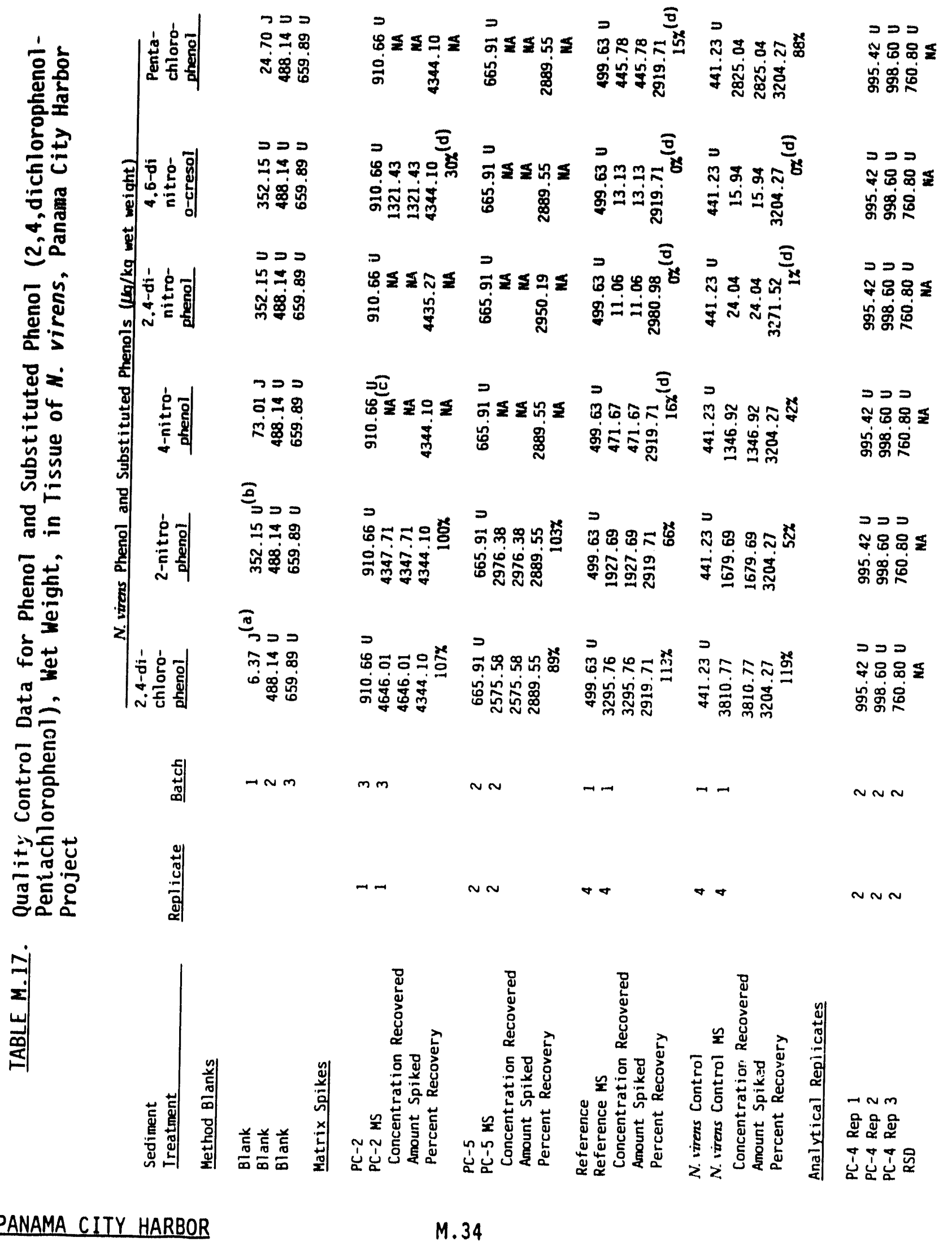




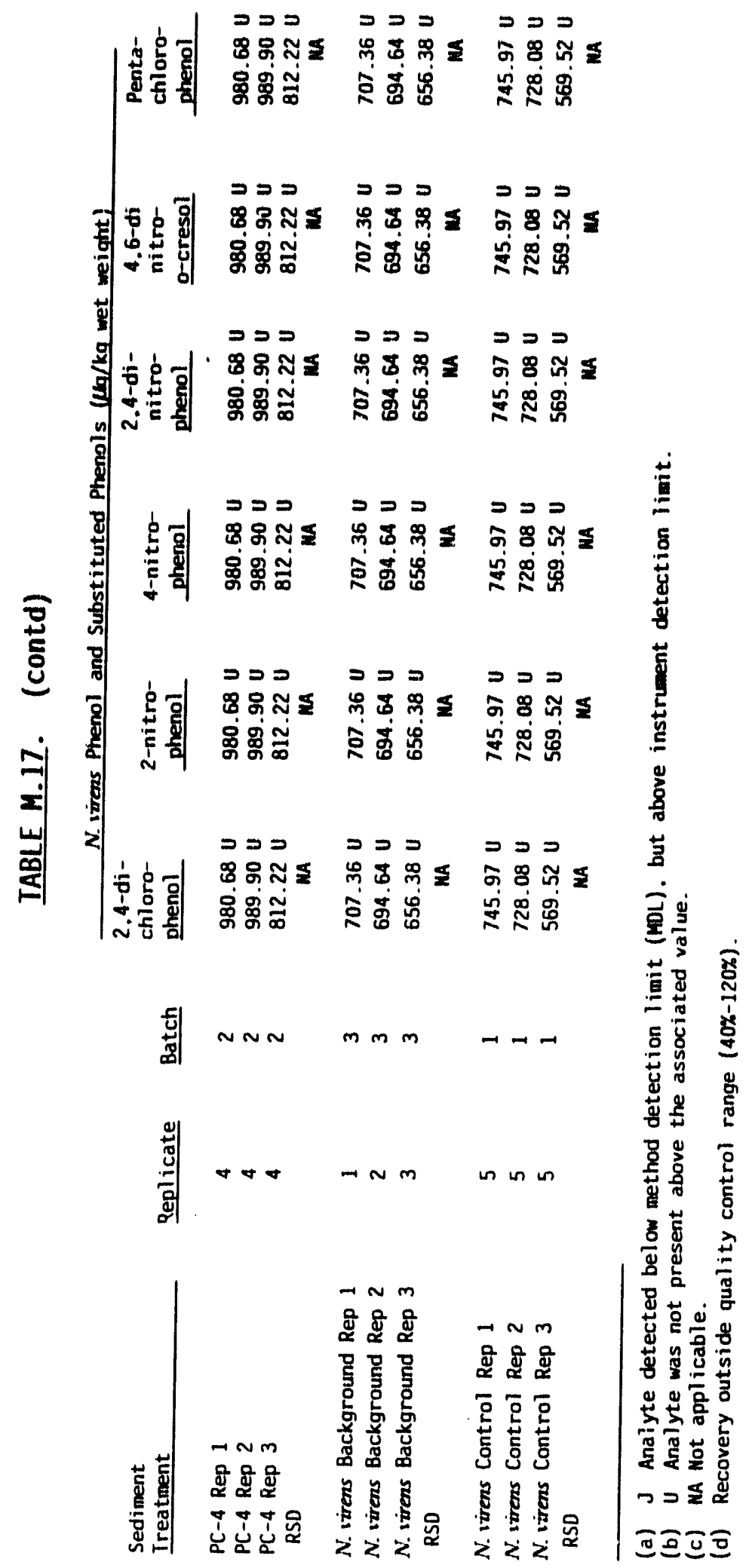




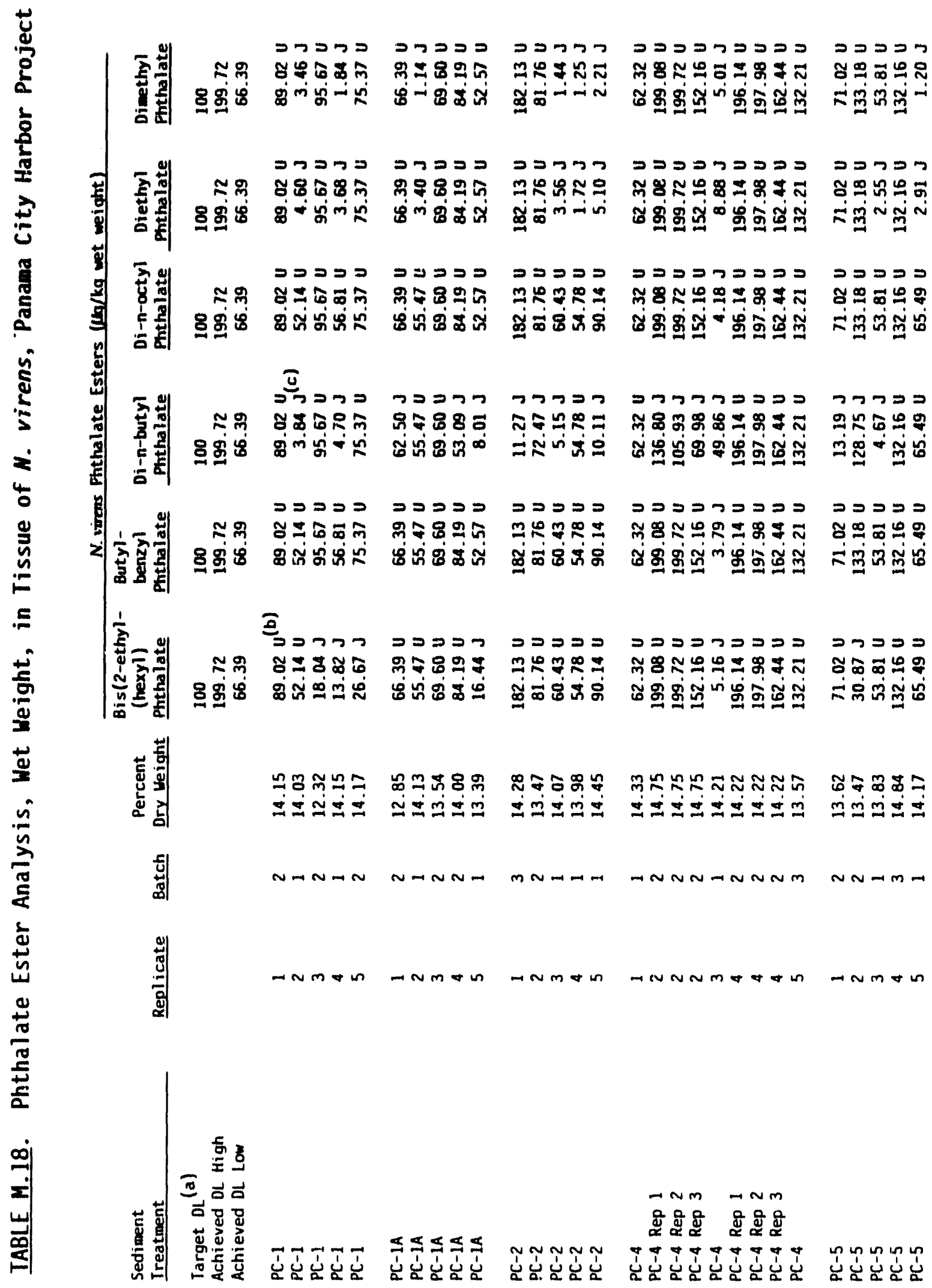

PANAMA CITY HARBOR 


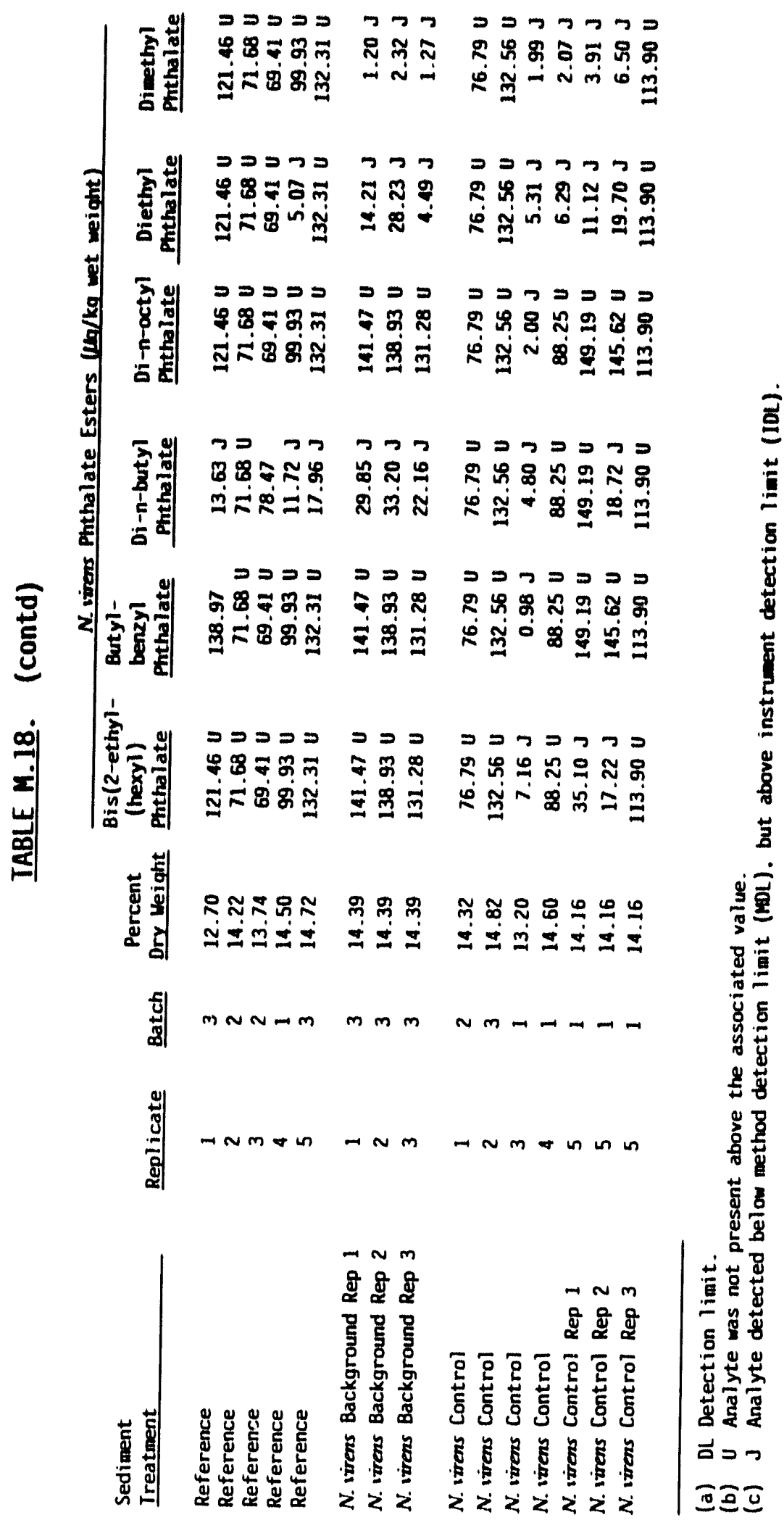




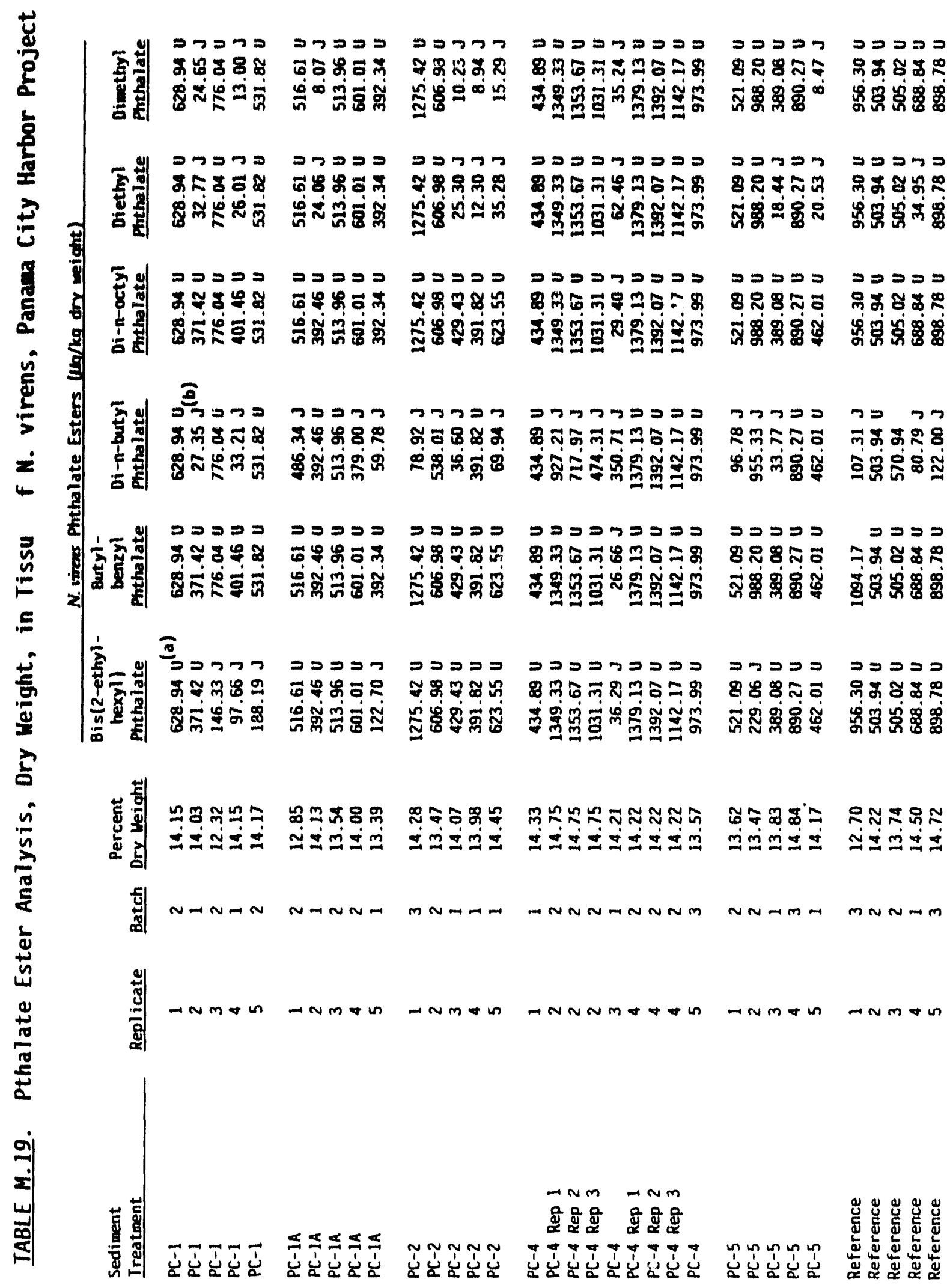

PANAMA CITY HARBOR 


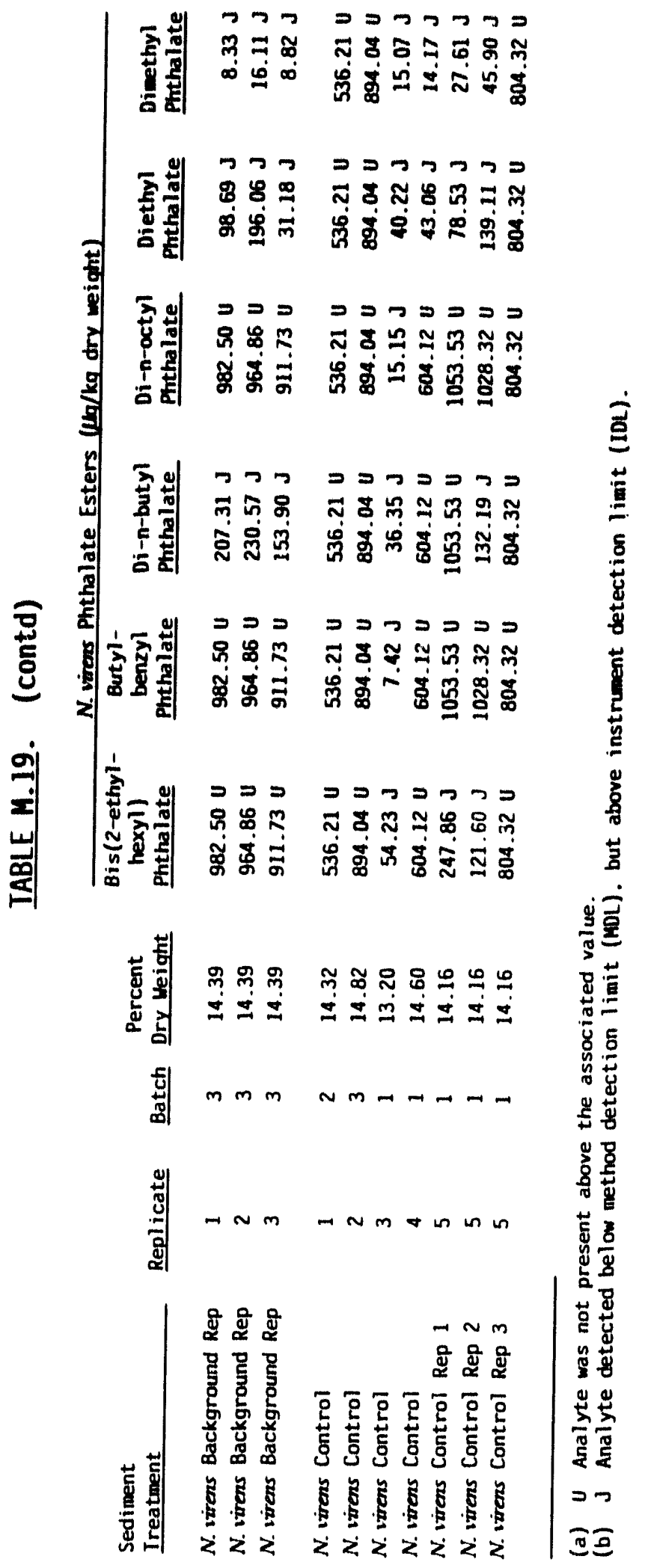




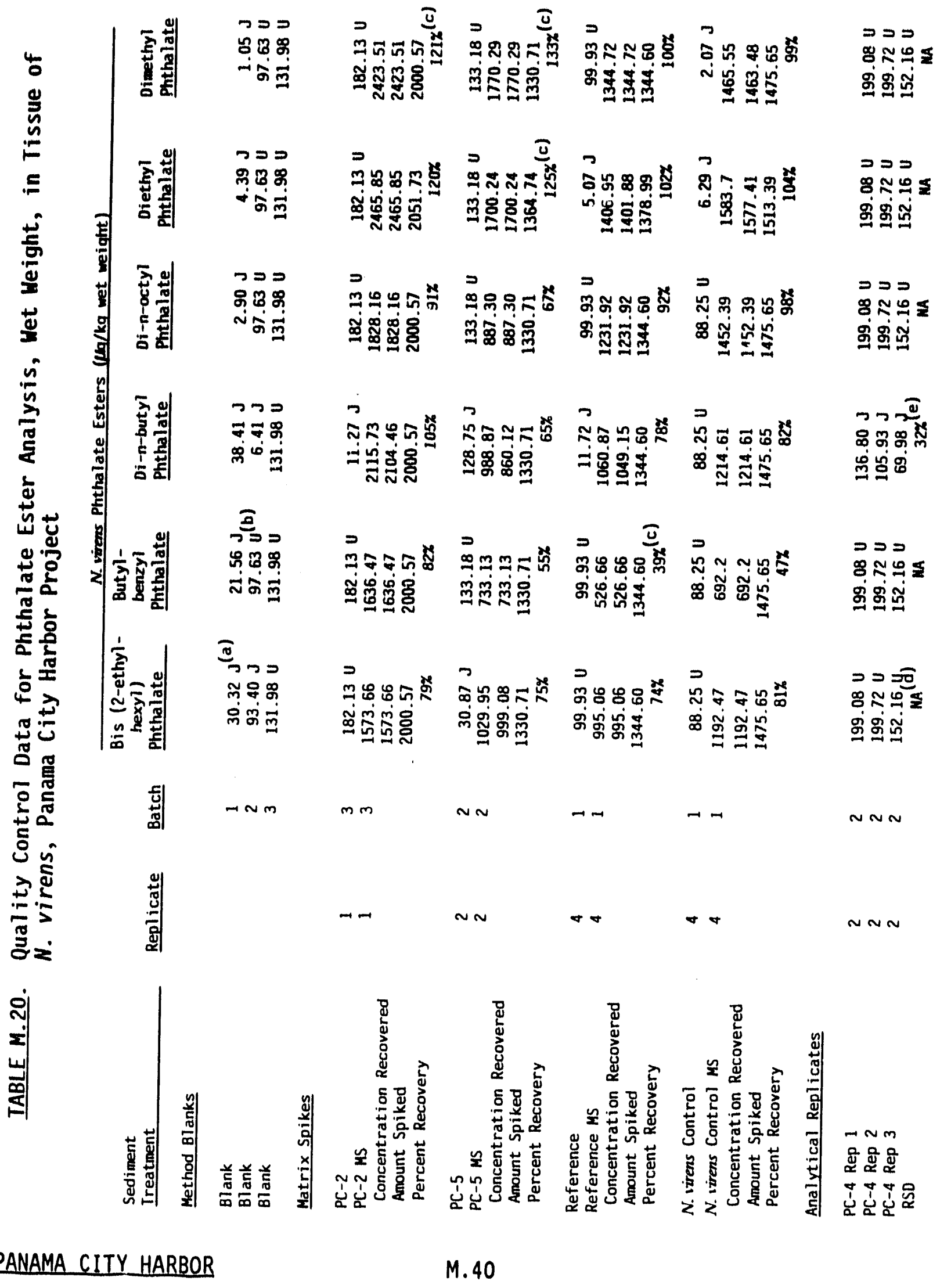




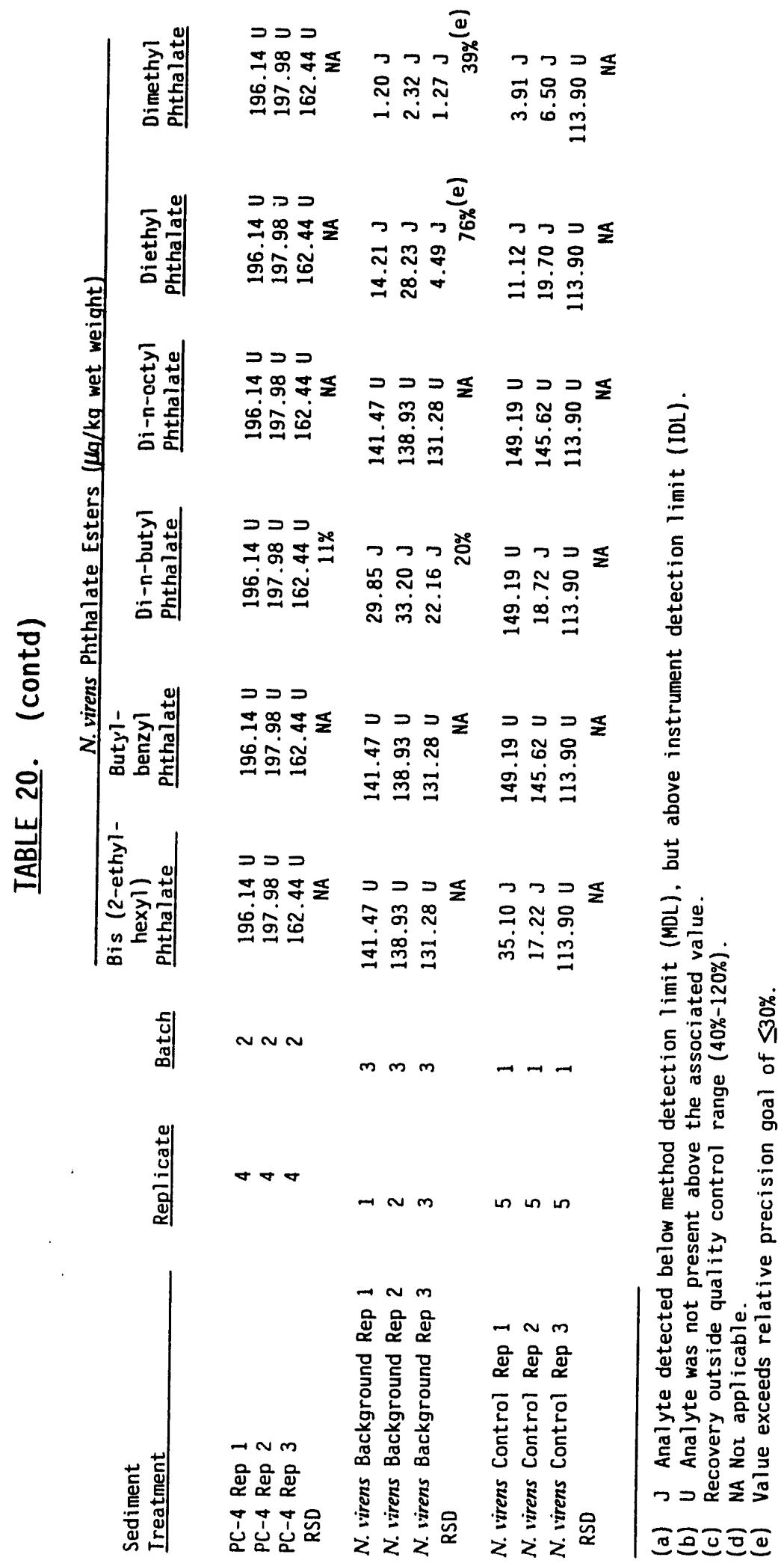




\section{TABLE M.21. Surrogate Percent Recoveries and Quality Control Data for Polynuclear Aromatic Hydrocarbon (PAH), Phenol and Substituted Phenol Analysis, in Tissue of N. virens, Panama City Harbor Project}

Sediment Ireatment

$\mathrm{PC}-1$

$P C-1$

$P C-1$

$P C-1$

$P C-1$

$P C-1 A$

$P C-1 A$

$P C-1 A$

$P C-1 A$

$P C-1 A$

$\mathrm{PC}-2$

$P C-2$

$\mathrm{PC}-2$

$\mathrm{PC}-2$

$\mathrm{PC}-2$

PC-4

PC-4 Rep 1

PC-4 Rep 2

PC-4 Rep 3

$P C-4$

PC-4 Rep 1

PC-4 Rep 2

PC-4 Rep 3

$P C-4$

$P C-5$

$P C-5$

$P C-5$

$P C-5$

PC-5

Reference

Reference

Reference

Reference

Reference

N. virens Background Rep 1 $N$. virens Background Rep 2 $N$. virens Background Rep 3

$N$. virens Control

$N$. virens Control

$N$. virens Control

$N$. virens Control

$N$. virens Control Rep 1

$N$. virens Control Rep 2

N. virens Control Rep 3

N. virens Surrogate Percent Recovery

2-fluoro- Naph- $\quad$ Acenaph- $\quad$ Benzo[a]

Replicate Batch

$\begin{array}{ll}1 & 2 \\ 2 & 1 \\ 3 & 2 \\ 4 & 1 \\ 5 & 2 \\ 1 & 2 \\ 2 & 1 \\ 3 & 2 \\ 4 & 2 \\ 5 & 1\end{array}$

1

2

3

(2)

$\begin{array}{ll}1 & 1 \\ 2 & 2 \\ 2 & 2 \\ 2 & 2 \\ 3 & 1 \\ 4 & 2 \\ 4 & 2 \\ 4 & 2 \\ 5 & 3\end{array}$

1
2
3
4
5

\section{2}

66
58
41
47
36
(a)
$37(a)$
$59(a)$
$34(a)$
57
44
thalene-d8

thene-d10 pyrene-dl?

105
54
58
45
49

108

70
67

69

45

${ }_{30}^{42}(a)$

${ }_{133}^{69}(a)$

71
80
57
65
53
64
61
53
79
69

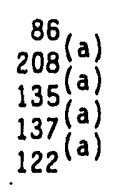

94

71

84

51

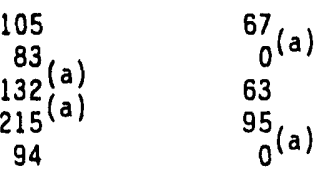

58
114
174
88
83

76

69

69

81

64
66

68

76

78

80

73

49 (a)

38
86

92

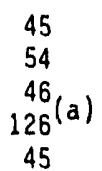

59

75

60

93

114

50
54
$518(a)$
98

85

71

70

68

68
45

94 (a)

$138(a)$
$166(a)$
$178(a)$

111

88

${ }_{211}^{78}(\mathrm{a})$

64

68
$112(a)$
146
67
103

${ }^{67}$ (a)

161 (a)

91

40

81

86

86

$136^{(a)}$

65 (a)

$145^{(a)}$
89

114

110

$142^{(a)}$

77
79

75
$0(a)$
0

$0^{(a)}$

71

74

66

67 ${ }_{34}^{57}(\mathrm{a})$

96

64

61

88

61

${ }_{0}^{96}(a)$

80
77
$72(a)$
0
66
76
83
68

01
80
$29(a)$
$132(a)$
63
60
56

PANAMA CITY HARBOR 
TABLE M.21. (contd)

\begin{tabular}{|c|c|c|c|c|c|c|}
\hline \multirow[b]{2}{*}{$\begin{array}{l}\text { Sediment } \\
\text { Treatment }\end{array}$} & \multirow[b]{2}{*}{ Replicate } & \multirow[b]{2}{*}{ Batch } & \multicolumn{4}{|c|}{$\begin{array}{l}\text { N. virens } \\
\text { Surrogate Percent Recoverv }\end{array}$} \\
\hline & & & $\begin{array}{l}\text { 2-fluoro- } \\
\text { phenol }\end{array}$ & $\begin{array}{c}\text { Naph- } \\
\text { thalene-d8 }\end{array}$ & $\begin{array}{l}\text { Acenaph- } \\
\text { thene-d10 }\end{array}$ & $\begin{array}{c}\text { Benzo [a] } \\
\text { pyrene-d12 }\end{array}$ \\
\hline \multicolumn{7}{|l|}{ Qual ity Control Data } \\
\hline \multicolumn{7}{|l|}{ Method Blanks } \\
\hline $\begin{array}{l}\text { Blank } \\
\text { Bl ank } \\
\text { Blank }\end{array}$ & & $\begin{array}{l}1 \\
2 \\
3\end{array}$ & $\begin{array}{l}21(a) \\
32(a) \\
75\end{array}$ & $\begin{array}{l}49 \\
54 \\
64\end{array}$ & $\begin{array}{l}58 \\
54 \\
65\end{array}$ & $\begin{array}{l}50 \\
49 \\
85\end{array}$ \\
\hline \multicolumn{7}{|l|}{ Matrix Spikes } \\
\hline PC-2 MS & & 3 & 78 & 53 & 87 & 73 \\
\hline PC-5 MS & & 2 & $31^{(a)}$ & 62 & 100 & 74 \\
\hline Reference MS & & 1 & 87 & 67 & 88 & $0^{(a)}$ \\
\hline N. virens Control MS & & 1 & 51 & 65 & 85 & 105 \\
\hline
\end{tabular}

(a) Recovery outside quality control range (40\%-120\%).

(b) NA Not applicable. 


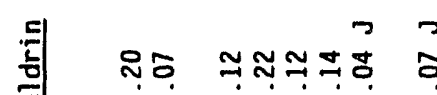
이 0000 ファコー

끙능능조 o0000

วコวนว

오ำำ 00000 웅

ำ $80^{\circ}$

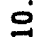

$\stackrel{\frac{1}{0}}{1}$

$\frac{5}{6}$

ธี่

$\sim-n-n$

N⿴N

8885

0ं0ं0

므명ㅇㅇ

$\cong \dot{\square} \dot{\dot{m}}$

$\Rightarrow 2523$

ลำำป

orman

வ0ं00

7

舟유

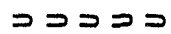

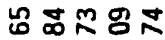

-i-in-

วงフコン

용용

00000

วนว

옹ำำ

00000

的 ०0000

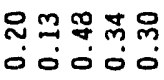

고근

กับ

0ं00

フココーファコ

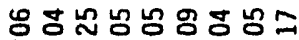

000000000

วコフ ว ว

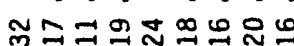

0000

고

능ㅎㅇㅇㅇㅇㅇㅡ

०००00

フココフコフง

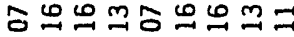

00000000

象安品

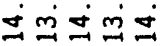

mำกำก ำกำ

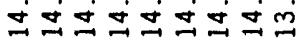

గొ

$\dot{m} \dot{m} \dot{m}$

$-N m \&$

$-\sim m \forall n$

-Nm

$\pi N N \sim m \forall \forall \forall$

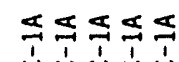
这它宫宫
$-N$

느m

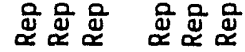

Tกนก

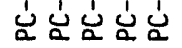

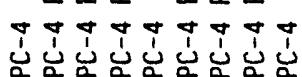

แn $\sin$ in 妄这造造 


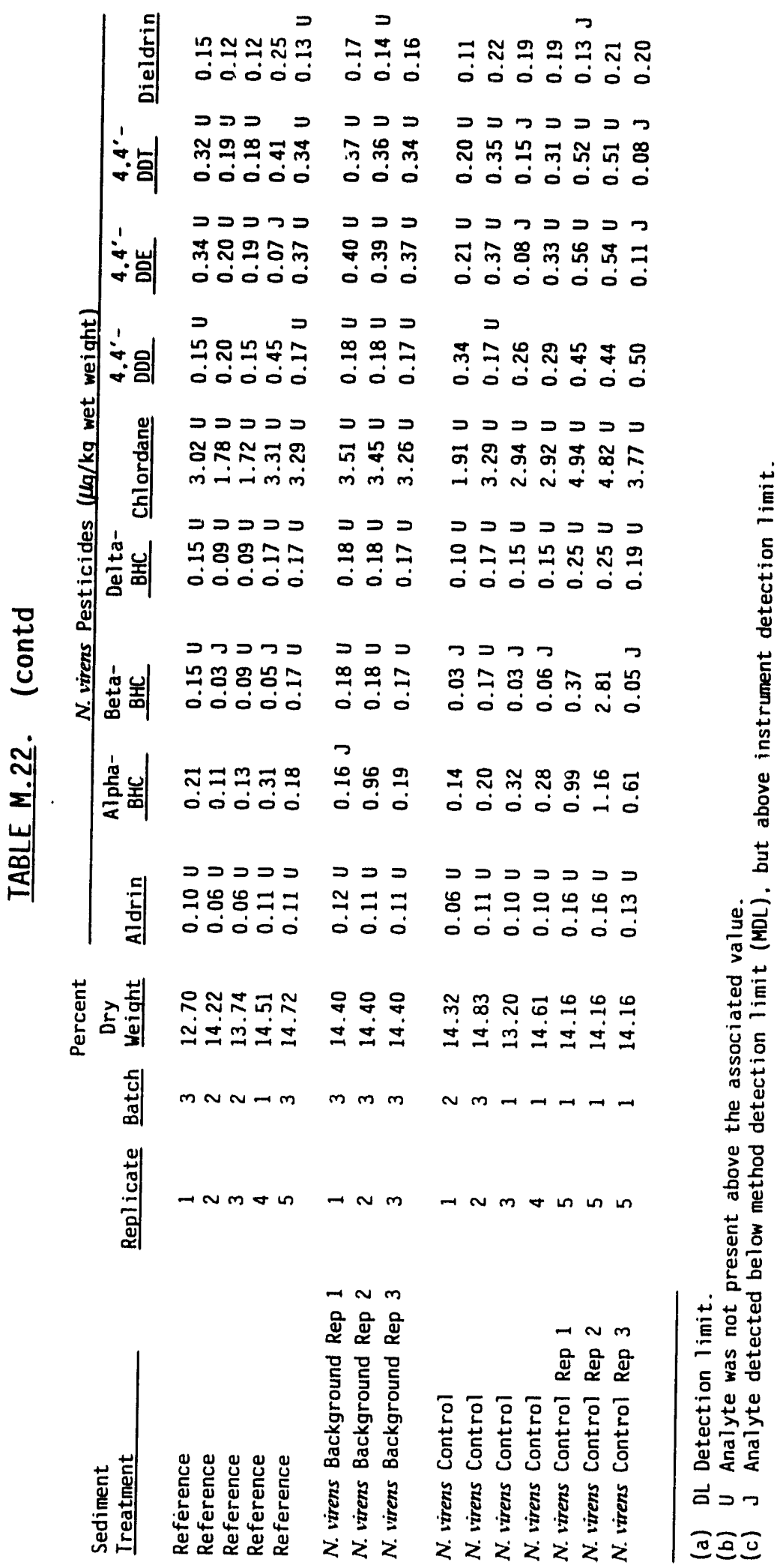




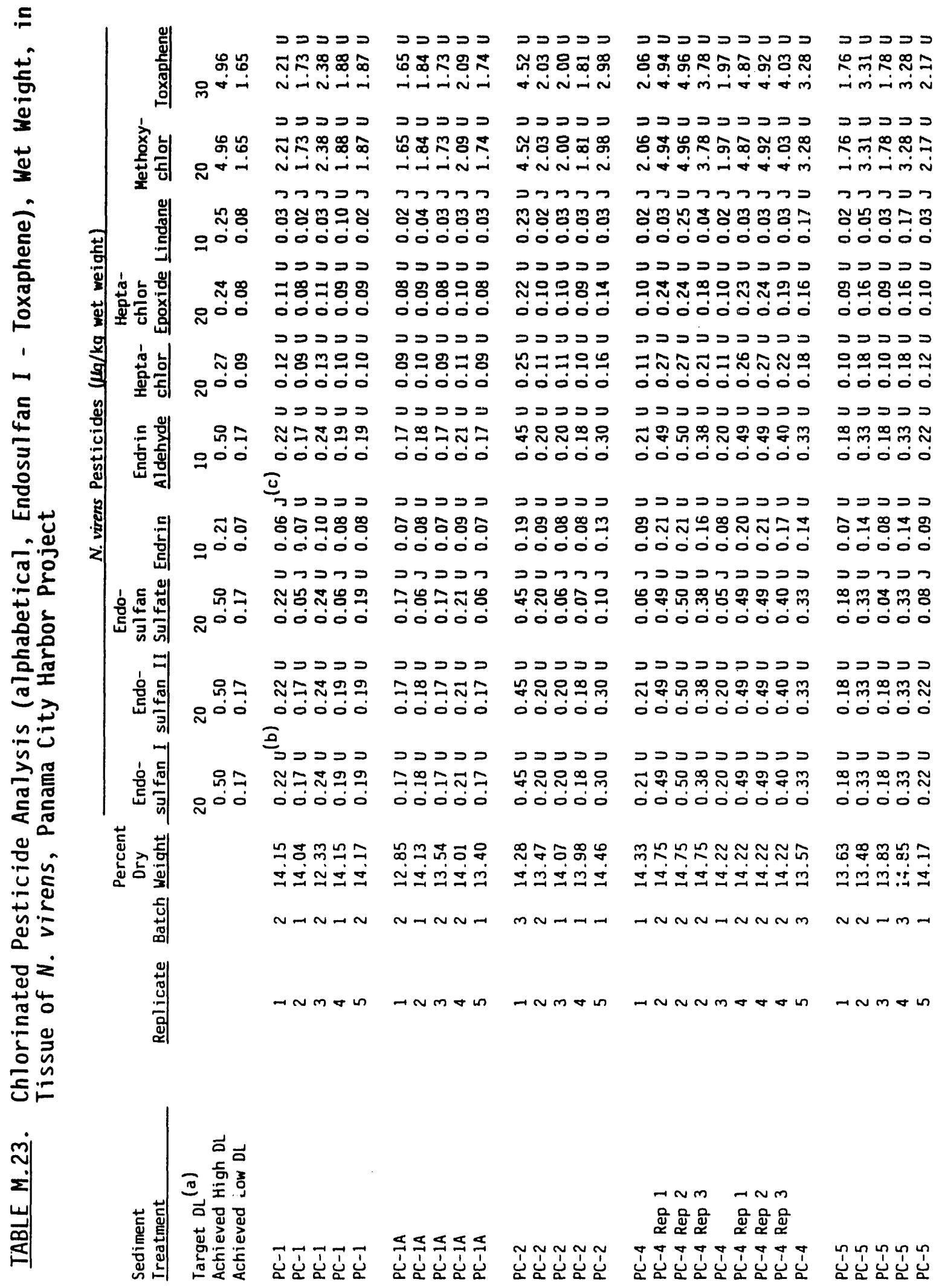

PANAMA CITY HARBOR 


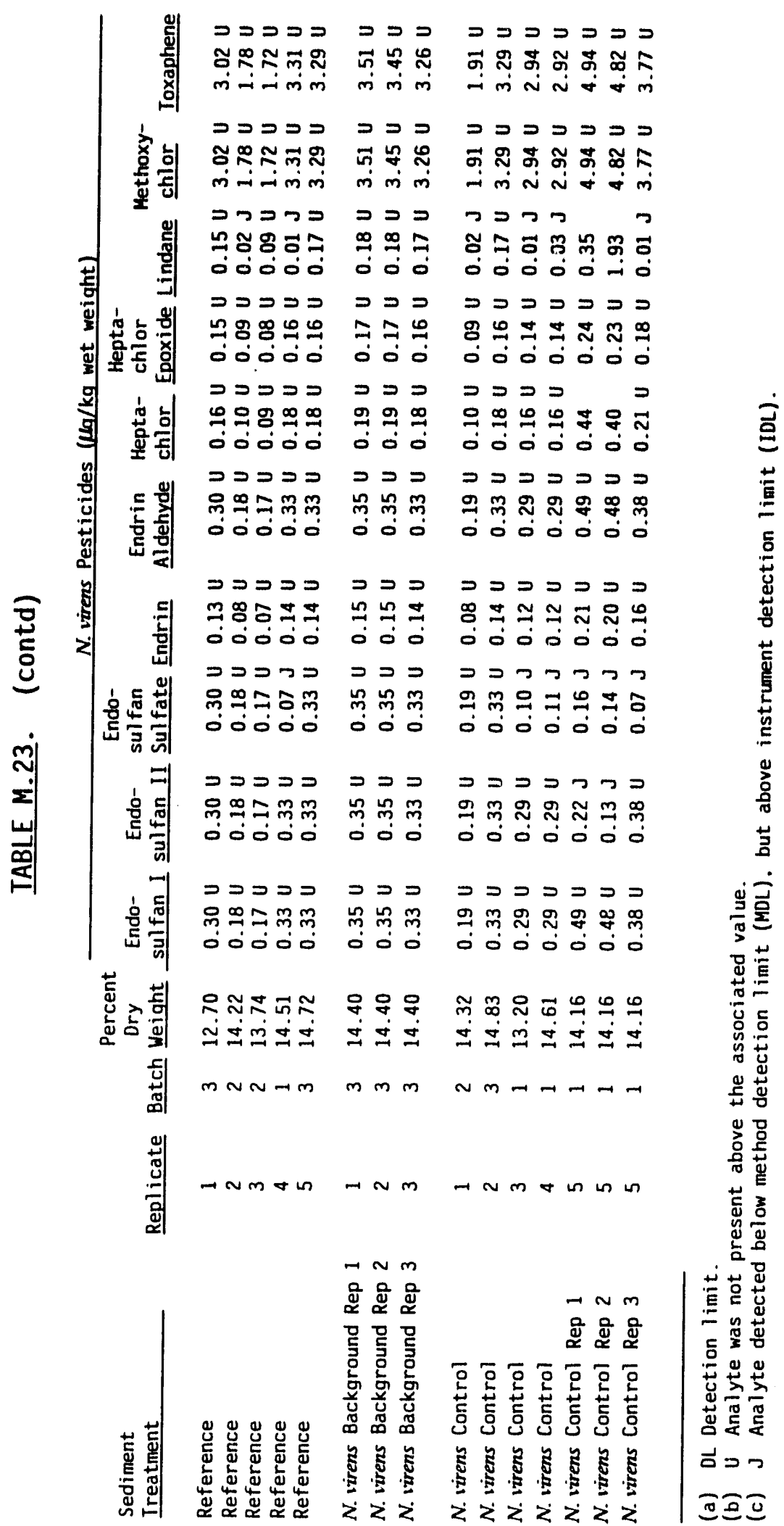




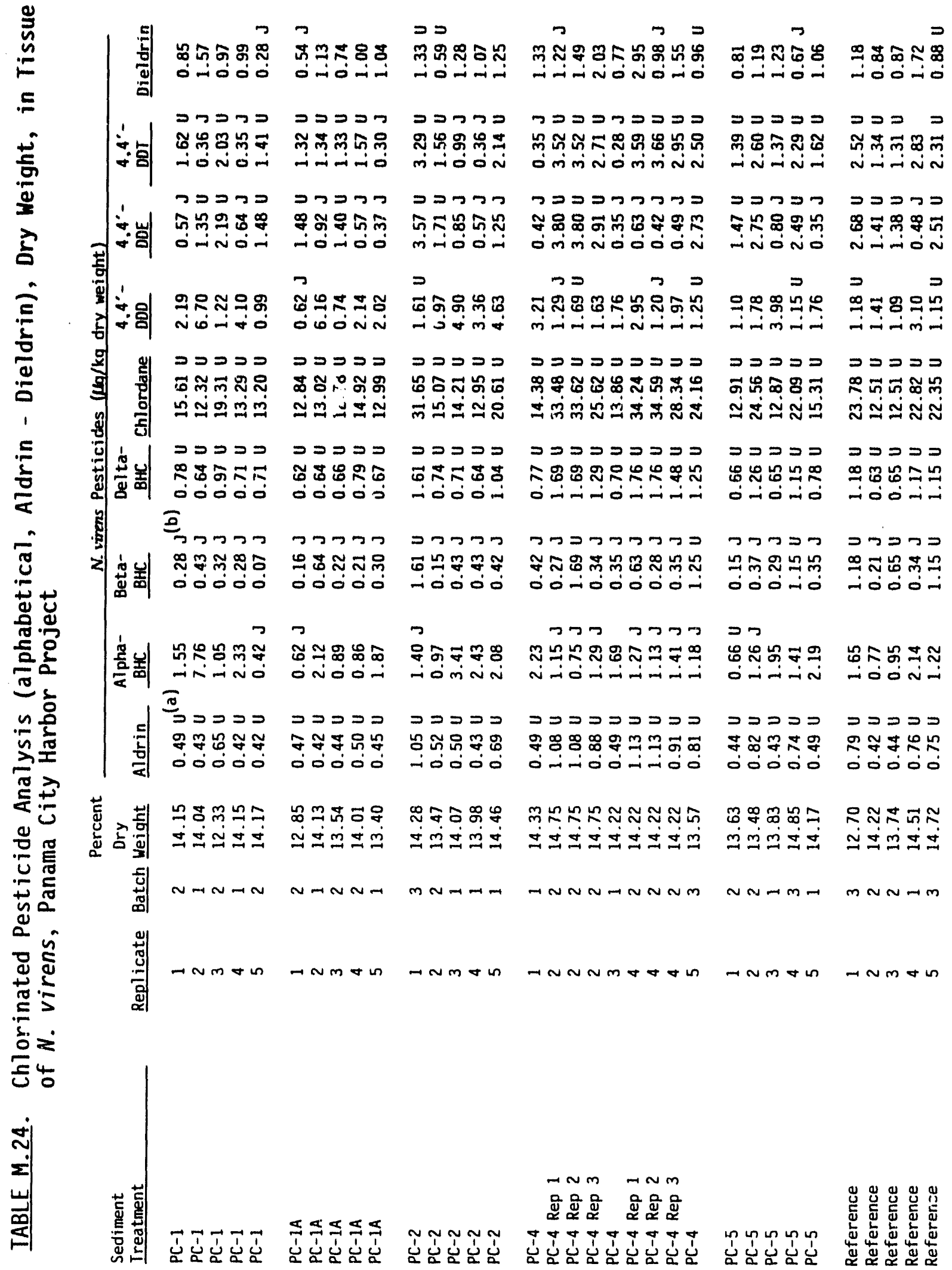

PANAMA CITY HARBOR

M. 48 


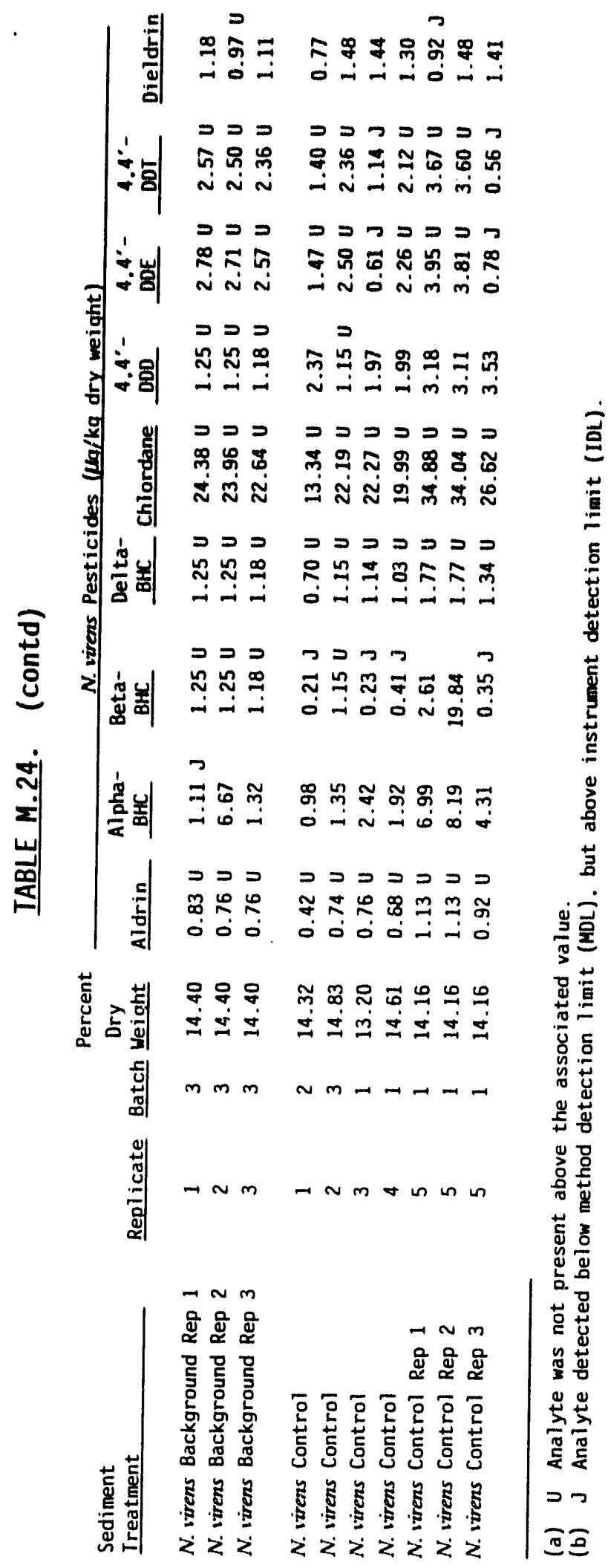




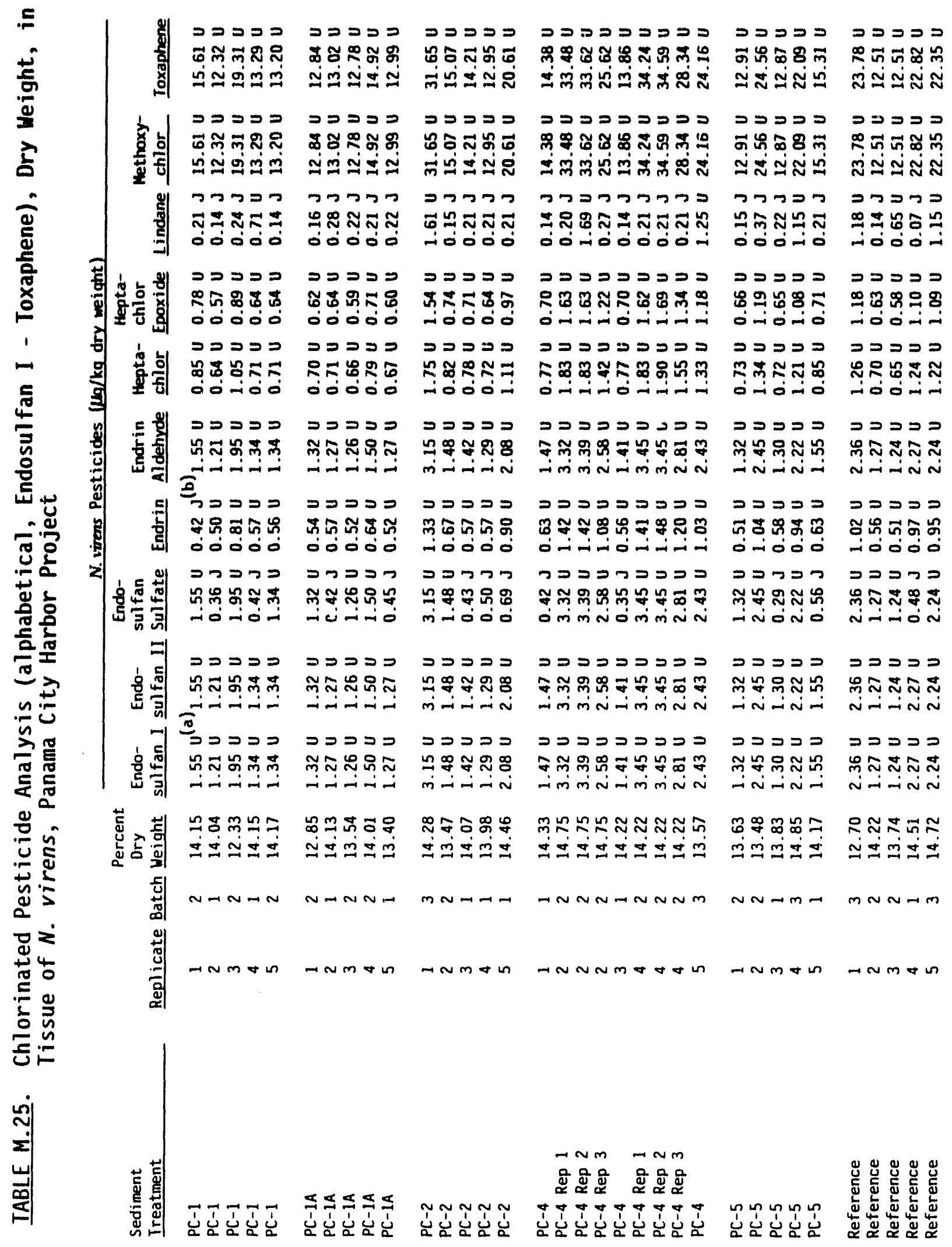

PANAMA CITY HARBOR 


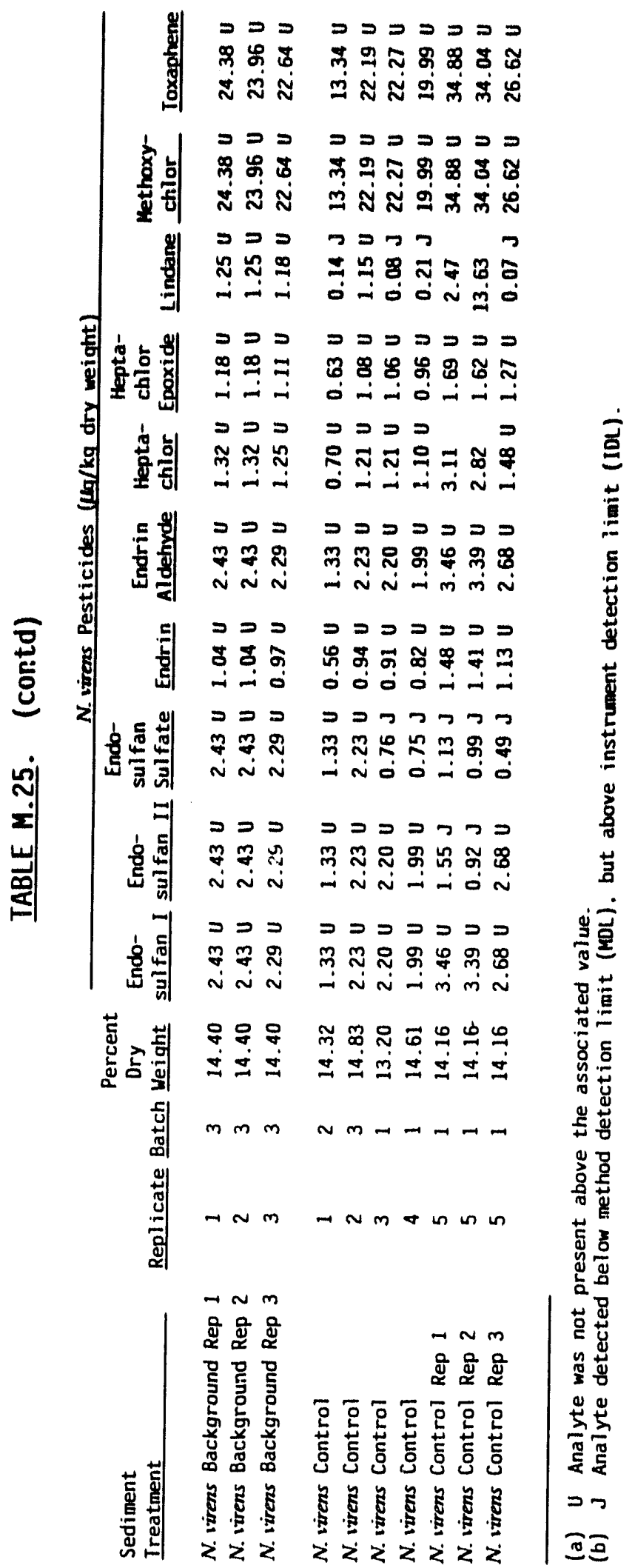




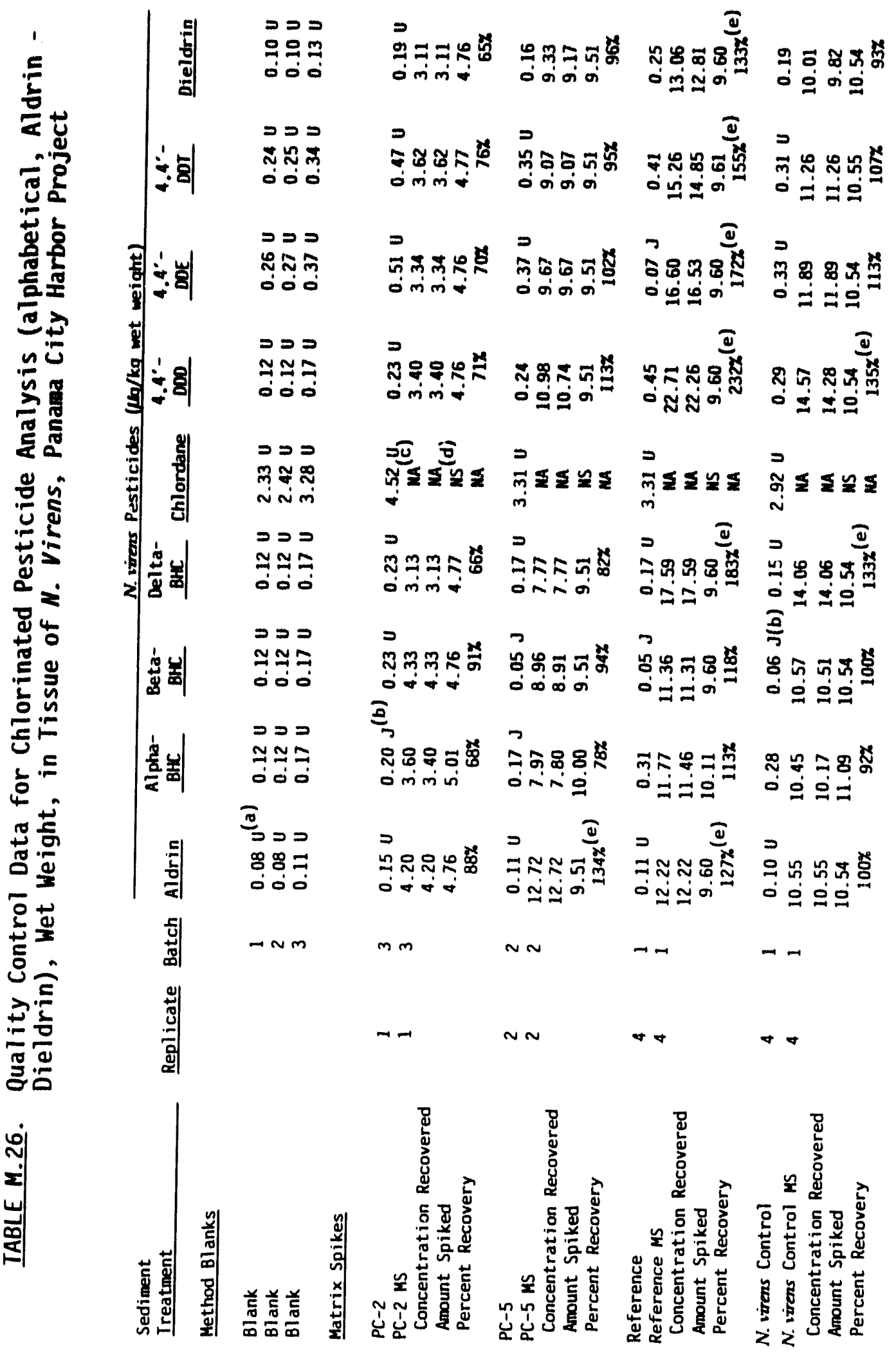

PANAMA CITY HARBOR

M. 52 


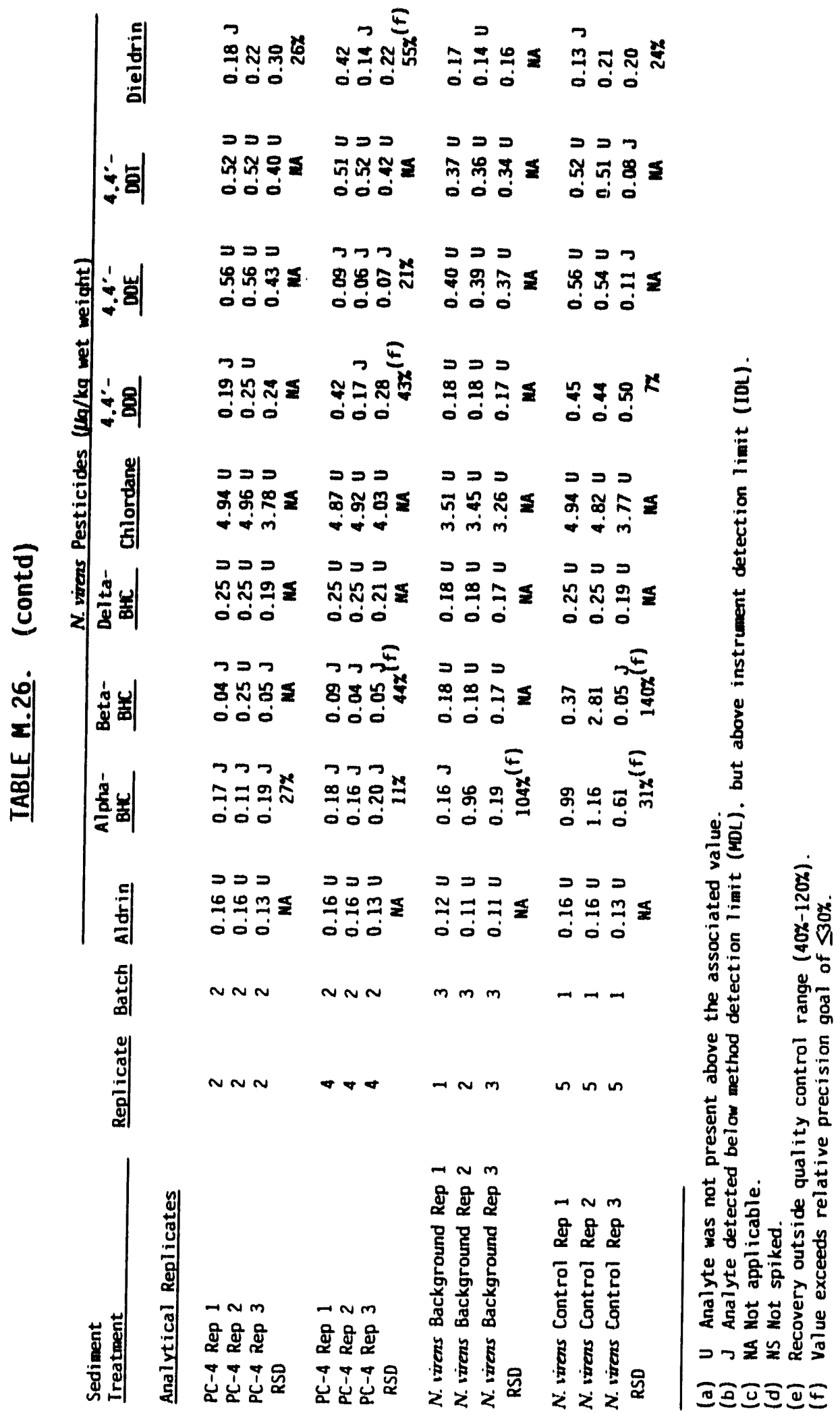

PANAMA CITY HARBOR

M. 53 


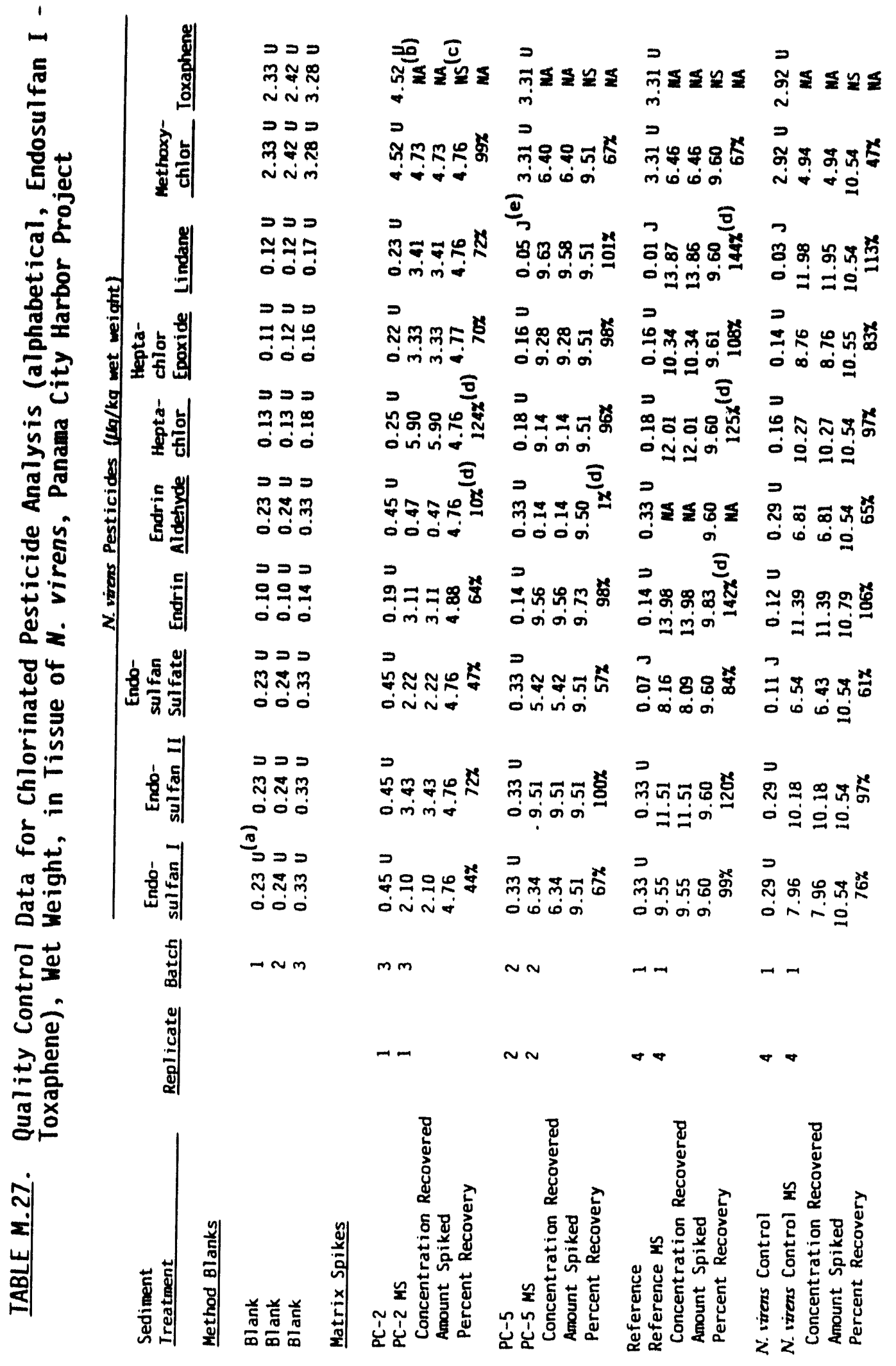

PANAMA CITY HARBOR 


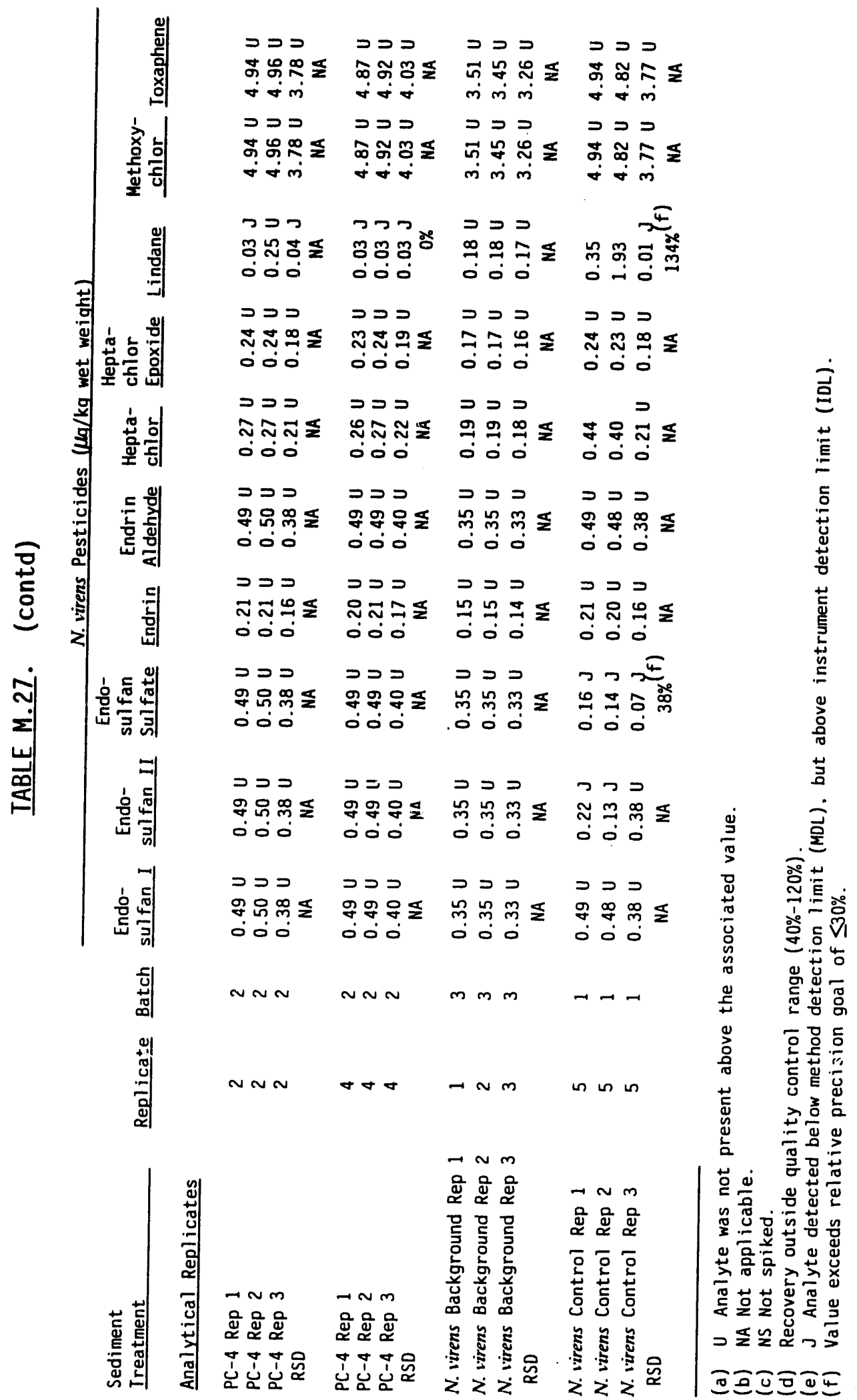

\section{PANAMA CITY HARBOR}

M.55 
TABLE M.28. Polychlorinated Biphenyl (PCB) Analysis, Wet Weight, in Tissue of $N$. virens, Panama City Harbor Project

\begin{tabular}{|c|c|c|c|c|c|c|c|c|c|}
\hline \multirow[b]{2}{*}{$\begin{array}{l}\text { Sediment } \\
\text { Ireatment }\end{array}$} & \multirow[b]{2}{*}{ Replicate } & \multirow[b]{2}{*}{ Batch } & \multirow{2}{*}{$\begin{array}{l}\text { Percent } \\
\text { Dry } \\
\text { Weight } \\
\end{array}$} & \multicolumn{6}{|c|}{$N$. virens $P C B s(1 \mathrm{~kg} / \mathrm{kg}$ wet weight) } \\
\hline & & & & $\begin{array}{l}\text { Aroclor } \\
1221\end{array}$ & $\begin{array}{c}\text { Aroclor } \\
1232 \\
\end{array}$ & $\begin{array}{c}\text { Aroclor } \\
1242 / 1016\end{array}$ & $\begin{array}{l}\text { Aroclor } \\
1248 \\
\end{array}$ & $\begin{array}{l}\text { Aroclor } \\
1254 \\
\end{array}$ & $\begin{array}{l}\text { Aroclor } \\
1260\end{array}$ \\
\hline $\begin{array}{l}\text { Target } D L \text { (a) } \\
\text { Achieved High OL } \\
\text { Achieved Low OL }\end{array}$ & & & & $\begin{array}{r}20 \\
4.96 \\
1.65\end{array}$ & $\begin{array}{r}20 \\
4.96 \\
1.65\end{array}$ & $\begin{array}{l}20 \\
4.96 \\
1.65\end{array}$ & $\begin{array}{l}20 \\
4.96 \\
1.65\end{array}$ & $\begin{array}{l}20 \\
4.96 \\
1.65\end{array}$ & $\begin{array}{l}20 \\
4.96 \\
1.65\end{array}$ \\
\hline $\begin{array}{l}P C-1 \\
P C-1 \\
P C-1 \\
P C-1 \\
P C-1\end{array}$ & $\begin{array}{l}1 \\
2 \\
3 \\
4 \\
5\end{array}$ & $\begin{array}{l}2 \\
1 \\
2 \\
1 \\
2\end{array}$ & $\begin{array}{l}14.15 \\
14.04 \\
12.33 \\
14.15 \\
14.17\end{array}$ & $\begin{array}{l}2.21 U^{(b)} \\
1.73 U \\
2.38 U \\
1.88 U \\
1.87 U\end{array}$ & $\begin{array}{l}2.21 U \\
1.73 U \\
2.38 U \\
1.88 U \\
1.87 U\end{array}$ & $\begin{array}{l}2.21 U \\
1.73 U \\
2.38 U \\
1.88 U \\
1.87 U\end{array}$ & $\begin{array}{l}2.21 \mathrm{U} \\
1.73 \mathrm{U} \\
2.38 \mathrm{U} \\
1.88 \mathrm{U} \\
1.87 \mathrm{U}\end{array}$ & $\begin{array}{l}2.21 \mathrm{U} \\
1.73 \mathrm{U} \\
2.38 \mathrm{U} \\
1.88 \mathrm{U} \\
1.87 \mathrm{U}\end{array}$ & $\begin{array}{r}13.86 \\
29.53 \\
13.88 \\
22.44 \\
7.47\end{array}$ \\
\hline $\begin{array}{l}P C-1 A \\
P C-1 A \\
P C-1 A \\
P C-1 A \\
P C-1 A \\
P C-2 \\
P C-2 \\
P C-2 \\
P C-2 \\
P C-2\end{array}$ & $\begin{array}{l}1 \\
2 \\
3 \\
4 \\
5 \\
1 \\
2 \\
3 \\
4 \\
5\end{array}$ & $\begin{array}{l}2 \\
1 \\
2 \\
2 \\
1 \\
3 \\
2 \\
1 \\
1 \\
1\end{array}$ & $\begin{array}{l}12.85 \\
14.13 \\
13.54 \\
14.01 \\
13.40 \\
14.28 \\
13.47 \\
14.07 \\
13.98 \\
14.46\end{array}$ & $\begin{array}{l}1.65 U \\
1.84 U \\
1.73 U \\
2.09 U \\
1.74 U \\
4.52 U \\
2.03 U \\
2.00 U \\
1.81 U \\
2.98 U\end{array}$ & $\begin{array}{l}1.65 U \\
1.84 U \\
1.73 U \\
2.09 U \\
1.74 U \\
4.52 U \\
2.03 U \\
2.00 U \\
1.81 U \\
2.98 U\end{array}$ & $\begin{array}{l}1.65 U \\
1.84 U \\
1.73 U \\
2.09 U \\
1.74 U \\
4.52 U \\
2.03 U \\
2.00 U \\
1.81 U \\
2.98 U\end{array}$ & $\begin{array}{l}1.65 U \\
1.84 U \\
1.73 U \\
2.09 U \\
1.74 U \\
4.52 U \\
2.03 U \\
2.00 U \\
1.81 U \\
2.98 U\end{array}$ & $\begin{array}{l}1.65 U \\
1.84 U \\
1.73 U \\
2.09 U \\
1.74 U \\
4.52 U \\
2.03 U \\
2.00 U \\
1.81 U \\
2.98 U\end{array}$ & $\begin{array}{r}7.20 \\
27.30 \\
9.83 \\
12.38 \\
25.15 \\
8.93 \\
9.78 \\
31.13 \\
28.18 \\
30.41\end{array}$ \\
\hline $\begin{array}{l}P C-4 \\
P C-4 \text { Rep } 1 \\
\text { PC-4 Rep } 2 \\
\text { PC-4 Rep } 3 \\
\text { PC-4 } \\
\text { PC-4 Rep } 1 \\
\text { PC-4 Rep } 2 \\
\text { PC-4 Rep } 3 \\
\text { PC-4 }\end{array}$ & $\begin{array}{l}1 \\
2 \\
2 \\
2 \\
3 \\
4 \\
4 \\
4 \\
5\end{array}$ & $\begin{array}{l}1 \\
2 \\
2 \\
2 \\
1 \\
2 \\
2 \\
2 \\
3\end{array}$ & $\begin{array}{l}14.33 \\
14.75 \\
14.75 \\
14.75 \\
14.22 \\
14.22 \\
14.22 \\
14.22 \\
13.57\end{array}$ & $\begin{array}{l}2.06 U \\
4.94 U \\
4.96 U \\
3.78 U \\
1.97 U \\
4.87 U \\
4.92 U \\
4.03 U \\
3.28 U\end{array}$ & $\begin{array}{l}2.06 U \\
4.94 U \\
4.96 U \\
3.78 U \\
1.97 U \\
4.87 U \\
4.92 U \\
4.03 U \\
3.28 U\end{array}$ & $\begin{array}{l}2.06 U \\
4.94 U \\
4.96 U \\
3.78 U \\
1.97 U \\
4.87 U \\
4.92 U \\
4.03 U \\
3.28 U\end{array}$ & $\begin{array}{l}2.06 U \\
4.94 U \\
4.96 U \\
3.78 U \\
1.97 U \\
4.87 U \\
4.92 U \\
4.03 U \\
3.28 U\end{array}$ & $\begin{array}{l}2.06 U \\
4.94 U \\
4.96 U \\
3.78 U \\
1.97 U \\
4.87 U \\
4.92 U \\
4.03 U \\
3.28 U\end{array}$ & $\begin{array}{l}27.92 \\
14.29 \\
30.34 \\
18.03 \\
25.26 \\
18.89 \\
14.48 \\
18.69 \\
17.21\end{array}$ \\
\hline $\begin{array}{l}P C-5 \\
P C-5 \\
P C-5 \\
P C-5 \\
P C-5\end{array}$ & $\begin{array}{l}1 \\
2 \\
3 \\
4 \\
5\end{array}$ & $\begin{array}{l}2 \\
2 \\
1 \\
3 \\
1\end{array}$ & $\begin{array}{l}13.63 \\
13.48 \\
13.83 \\
14.85 \\
14.17\end{array}$ & $\begin{array}{l}1.76 U \\
3.31 U \\
1.78 U \\
3.28 U \\
2.17 U\end{array}$ & $\begin{array}{l}1.76 U \\
3.31 U \\
1.78 U \\
3.28 U \\
2.17 U\end{array}$ & $\begin{array}{l}1.76 U \\
3.31 U \\
1.78 U \\
3.28 U \\
2.17 U\end{array}$ & $\begin{array}{l}1.76 U \\
3.31 U \\
1.78 U \\
3.28 U \\
2.17 U\end{array}$ & $\begin{array}{l}1.76 \mathrm{U} \\
3.31 \mathrm{U} \\
1.78 \mathrm{U} \\
3.28 \mathrm{U} \\
2.17 \mathrm{U}\end{array}$ & $\begin{array}{r}8.94 \\
15.37 \\
22.61 \\
19.06 \\
22.49\end{array}$ \\
\hline $\begin{array}{l}\text { Reference } \\
\text { Reference } \\
\text { Reference } \\
\text { Reference } \\
\text { Reference }\end{array}$ & $\begin{array}{l}1 \\
2 \\
3 \\
4 \\
5\end{array}$ & $\begin{array}{l}3 \\
2 \\
2 \\
1 \\
3\end{array}$ & $\begin{array}{l}12.70 \\
14.22 \\
13.74 \\
14.51 \\
14.72\end{array}$ & $\begin{array}{l}3.02 \cup \\
1.78 U \\
1.72 U \\
3.31 U \\
3.29 U\end{array}$ & $\begin{array}{l}3.02 U \\
1.78 U \\
1.72 U \\
3.31 U \\
3.29 U\end{array}$ & $\begin{array}{l}3.02 U \\
1.78 U \\
1.72 U \\
3.31 U \\
3.29 U\end{array}$ & $\begin{array}{l}3.02 U \\
1.78 U \\
1.72 U \\
3.31 U \\
3.29 U\end{array}$ & $\begin{array}{l}3.02 \mathrm{U} \\
1.78 \mathrm{U} \\
1.72 \mathrm{U} \\
3.31 \mathrm{U} \\
3.29 \mathrm{U}\end{array}$ & $\begin{array}{l}20.15 \\
10.33 \\
11.60 \\
39.38 \\
13.42\end{array}$ \\
\hline N. virens Background Rep 1 & 1 & 3 & 14.40 & $3.51 \mathrm{U}$ & $3.51 \mathrm{U}$ & $3.51 \mathrm{U}$ & $3.51 \mathrm{U}$ & $3.51 U$ & 21.44 \\
\hline N. virens Background Rep 2 & 2 & 3 & 14.40 & $3.45 \mathrm{U}$ & $3.45 U$ & $3.45 \mathrm{U}$ & $3.45 \mathrm{U}$ & $3.45 \mathrm{U}$ & 19.50 \\
\hline N. virens Background Rep 3 & 3 & 3 & 14.40 & $3.26 \mathrm{U}$ & $3.26 \mathrm{U}$ & $3.26 \mathrm{U}$ & $3.26 \mathrm{U}$ & $3.26 \mathrm{U}$ & 22.05 \\
\hline
\end{tabular}


TABLE M.28. (contd)

Sediment Ireatment

N. virens Control

N. virens Control

N. virens Control

N. virens Control

N. virens Control Rep 1

N. virens Control Rep 2

N. virens Control Rep 3
Percent

Replicate Batch Weight

14.32

14.83

13.20

14.61

14.16

14.16

14.16
N. virens PCBs ( $\mu \mathrm{g} / \mathrm{kg}$ wet weight)

Aroclor Aroclor Aroclor Aroclor Aroclor Aroclor $1221 \quad 1232 \quad 1242 / 1016 \quad 1248 \quad 1254 \quad 1260$

\begin{tabular}{|c|c|c|c|c|c|}
\hline $91 \mathrm{~V}$ & $1.91 \cup$ & $1.91 \mathrm{U}$ & $1.91 U$ & $1.91 U$ & 3 \\
\hline 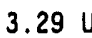 & $3.29 \mathrm{U}$ & $3.29 \mathrm{U}$ & $3.29 \cup$ & $3.29 \mathrm{U}$ & 25.02 \\
\hline .94 & $2.94 U$ & $2.94 U$ & $2.94 U$ & $2.94 \mathrm{U}$ & 23.56 \\
\hline 2.92 & 2.92 & $2.92 \mathrm{U}$ & $2.92 U$ & 2.92 & 27.91 \\
\hline 4.94 & 4.94 & $4.94 U$ & $4.94 U$ & $4.94 U$ & 27.84 \\
\hline 4.82 & 4.82 & $4.82 U$ & $4.82 \mathrm{U}$ & 4.82 & 28.75 \\
\hline 3.77 & 3.77 & $3.77 \cup$ & $3.77 \mathrm{U}$ & $3.77 \mathrm{U}$ & 28.26 \\
\hline
\end{tabular}

(a) OL Detection limit.

(b) U Analyte was not present above the associated value. 
TABLE M.29. Polychlorinated Biphenyl (PCB) Analysis, Dry Weight, in Tissue or $N$. virens, Panama City Harbor Project

\begin{tabular}{|c|c|c|c|c|c|c|c|c|c|}
\hline \multirow[b]{2}{*}{$\begin{array}{l}\text { Sediment } \\
\text { Ireatment }\end{array}$} & \multirow[b]{2}{*}{ Replicate } & \multirow[b]{2}{*}{ Batch } & \multirow{2}{*}{$\begin{array}{c}\text { Percent } \\
\text { Dry } \\
\text { Weight }\end{array}$} & \multicolumn{6}{|c|}{ N. virens PCBs ( $\mathrm{kg} / \mathrm{kg}$ dry Weight) } \\
\hline & & & & $\begin{array}{l}\text { Aroclor } \\
1221\end{array}$ & $\begin{array}{l}\text { Aroclor } \\
1232 \\
\end{array}$ & $\begin{array}{c}\text { Aroclor } \\
1242 / 1016\end{array}$ & $\begin{array}{l}\text { Aroclor } \\
1248 \\
\end{array}$ & $\begin{array}{l}\text { Aroclor } \\
1254 \\
\end{array}$ & $\begin{array}{l}\text { Aroclor } \\
1260\end{array}$ \\
\hline $\begin{array}{l}P C-1 \\
P C-1 \\
P C-1 \\
P C-1 \\
P C-1\end{array}$ & $\begin{array}{l}1 \\
2 \\
3 \\
4 \\
5\end{array}$ & $\begin{array}{l}2 \\
1 \\
2 \\
1 \\
2\end{array}$ & $\begin{array}{l}14.15 \\
14.04 \\
12.33 \\
14.15 \\
14.17\end{array}$ & $\begin{array}{l}15.61 U^{(a)} \\
12.32 U \\
19.31 U \\
13.29 U \\
13.20 U\end{array}$ & $\begin{array}{l}15.61 U \\
12.32 U \\
19.31 U \\
13.29 U \\
13.20 U\end{array}$ & $\begin{array}{l}15.61 U \\
12.32 U \\
19.31 U \\
13.29 U \\
13.20 U\end{array}$ & $\begin{array}{l}15.61 U \\
12.32 U \\
19.31 U \\
13.29 U \\
13.20 U\end{array}$ & $\begin{array}{l}15.61 U \\
12.32 U \\
19.31 U \\
13.29 U \\
13.20 U\end{array}$ & $\begin{array}{r}97.92 \\
210.36 \\
112.59 \\
158.58 \\
52.71\end{array}$ \\
\hline $\begin{array}{l}P C-1 A \\
P C-1 A \\
P C-1 A \\
P C-1 A \\
P C-1 A\end{array}$ & $\begin{array}{l}1 \\
2 \\
3 \\
4 \\
5\end{array}$ & $\begin{array}{l}2 \\
1 \\
2 \\
2 \\
1\end{array}$ & $\begin{array}{l}12.85 \\
14.13 \\
13.54 \\
14.01 \\
13.40\end{array}$ & $\begin{array}{l}12.84 U \\
13.02 U \\
12.78 U \\
14.92 U \\
12.99 U\end{array}$ & $\begin{array}{l}12.84 U \\
13.02 U \\
12.78 U \\
14.92 U \\
12.99 U\end{array}$ & $\begin{array}{l}12.84 U \\
13.02 U \\
12.78 U \\
14.92 U \\
12.99 U\end{array}$ & $\begin{array}{l}12.84 \mathrm{U} \\
13.02 \mathrm{U} \\
12.78 \mathrm{U} \\
14.92 \mathrm{U} \\
12.99 \mathrm{U}\end{array}$ & $\begin{array}{l}12.84 U \\
13.02 U \\
12.78 U \\
14.92 U \\
12.99 U\end{array}$ & $\begin{array}{r}56.03 \\
193.15 \\
72.59 \\
88.38 \\
187.70\end{array}$ \\
\hline $\begin{array}{l}P C-2 \\
P C-2 \\
P C-2 \\
P C-2 \\
P C-2\end{array}$ & $\begin{array}{l}1 \\
2 \\
3 \\
4 \\
5\end{array}$ & $\begin{array}{l}3 \\
2 \\
1 \\
1 \\
1\end{array}$ & $\begin{array}{l}14.28 \\
13.47 \\
14.07 \\
13.98 \\
14.46\end{array}$ & $\begin{array}{l}31.65 U \\
15.07 U \\
14.21 U \\
12.95 U \\
20.61 U\end{array}$ & $\begin{array}{l}31.65 U \\
15.07 U \\
14.21 U \\
12.95 U \\
20.61 U\end{array}$ & $\begin{array}{l}31.65 U \\
15.07 U \\
14.21 U \\
12.95 U \\
20.61 U\end{array}$ & $\begin{array}{l}31.65 U \\
15.07 U \\
14.21 U \\
12.95 U \\
20.61 U\end{array}$ & $\begin{array}{l}31.65 U \\
15.07 U \\
14.21 U \\
12.95 U \\
20.61 U\end{array}$ & $\begin{array}{r}62.54 \\
72.61 \\
221.22 \\
201.56 \\
210.36\end{array}$ \\
\hline $\begin{array}{l}\text { PC-4 } \\
\text { PC-4 Rep } 1 \\
\text { PC-4 Rep } 2 \\
\text { PC-4 Rep } 3 \\
\text { PC-4 } \\
\text { PC-4 Rep } 1 \\
\text { PC-4 } \\
\text { Rep } 2 \\
\text { PC-4 Rep } 3 \\
\text { PC-4 }\end{array}$ & $\begin{array}{l}1 \\
2 \\
2 \\
2 \\
3 \\
4 \\
4 \\
4 \\
5\end{array}$ & $\begin{array}{l}1 \\
2 \\
2 \\
2 \\
1 \\
2 \\
2 \\
2 \\
3\end{array}$ & $\begin{array}{l}14.33 \\
14.75 \\
14.75 \\
14.75 \\
14.22 \\
14.22 \\
14.22 \\
14.22 \\
13.57\end{array}$ & $\begin{array}{l}14.38 U \\
33.48 U \\
33.62 U \\
25.62 U \\
13.86 U \\
34.24 U \\
34.59 U \\
28.34 U \\
24.16 U\end{array}$ & $\begin{array}{l}14.38 U \\
33.48 U \\
33.62 U \\
25.62 U \\
13.86 U \\
34.24 U \\
34.59 U \\
28.34 U \\
24.16 \cdot U\end{array}$ & $\begin{array}{l}14.38 U \\
33.48 U \\
33.62 U \\
25.62 U \\
13.86 . U \\
34.24 U \\
34.59 U \\
28.34 U \\
24.16 U\end{array}$ & $\begin{array}{l}14.38 U \\
33.48 U \\
33.62 U \\
25.62 U \\
13.86 U \\
34.24 U \\
34.59 U \\
28.34 U \\
24.16 U\end{array}$ & $\begin{array}{l}14.38 U \\
33.48 U \\
33.62 U \\
25.62 U \\
13.86 U \\
34.24 U \\
34.59 U \\
28.34 U \\
24.16 U\end{array}$ & $\begin{array}{r}194.84 \\
96.86 \\
205.64 \\
122.20 \\
177.67 \\
132.82 \\
101.81 \\
131.42 \\
126.79\end{array}$ \\
\hline $\begin{array}{l}P C-5 \\
P C-5 \\
P C-5 \\
P C-5 \\
P C-5\end{array}$ & $\begin{array}{l}1 \\
2 \\
3 \\
4 \\
5\end{array}$ & $\begin{array}{l}2 \\
2 \\
1 \\
3 \\
1\end{array}$ & $\begin{array}{l}13.63 \\
13.48 \\
13.83 \\
14.85 \\
14.17\end{array}$ & $\begin{array}{l}12.91 U \\
24.56 U \\
12.87 U \\
22.09 U \\
15.31 U\end{array}$ & $\begin{array}{l}12.91 U \\
24.56 U \\
12.87 U \\
22.09 U \\
15.31 U\end{array}$ & $\begin{array}{l}12.91 U \\
24.56 U \\
12.87 U \\
22.09 U \\
15.31 U\end{array}$ & $\begin{array}{l}12.91 U \\
24.56 U \\
12.87 U \\
22.09 U \\
15.31 U\end{array}$ & $\begin{array}{l}12.91 U \\
24.56 U \\
12.87 U \\
22.09 U \\
15.31 U\end{array}$ & $\begin{array}{r}65.60 \\
114.05 \\
163.49 \\
128.39 \\
158.66\end{array}$ \\
\hline $\begin{array}{l}\text { Reference } \\
\text { Reference } \\
\text { Reference } \\
\text { Reference } \\
\text { Reference }\end{array}$ & $\begin{array}{l}1 \\
2 \\
3 \\
4 \\
5\end{array}$ & $\begin{array}{l}3 \\
2 \\
2 \\
1 \\
3\end{array}$ & $\begin{array}{l}12.70 \\
14.22 \\
13.74 \\
14.51 \\
14.72\end{array}$ & $\begin{array}{l}23.78 \mathrm{U} \\
12.51 \mathrm{U} \\
12.51 \mathrm{U} \\
22.82 \mathrm{U} \\
22.35 \mathrm{U}\end{array}$ & $\begin{array}{l}23.78 U \\
12.51 U \\
12.51 U \\
22.82 U \\
22.35 U\end{array}$ & $\begin{array}{l}23.78 U \\
12.51 U \\
12.51 U \\
22.82 U \\
22.35 U\end{array}$ & $\begin{array}{l}23.78 U \\
12.51 U \\
12.51 U \\
22.82 U \\
22.35 U\end{array}$ & $\begin{array}{l}23.78 U \\
12.51 U \\
12.51 U \\
22.82 U \\
22.35 U\end{array}$ & $\begin{array}{r}158.65 \\
72.62 \\
84.40 \\
271.46 \\
91.16\end{array}$ \\
\hline N. virens Background Rep 1 & 1 & 3 & 14.40 & $24.38 \mathrm{U}$ & $24.38 \mathrm{U}$ & $24.38 \mathrm{U}$ & $24.38 \mathrm{U}$ & $24.38 \mathrm{U}$ & 148.90 \\
\hline N. virens Background Rep 2 & 2 & 3 & 14.40 & $23.96 U$ & $23.96 \mathrm{U}$ & $23.96 \mathrm{U}$ & $23.96 \mathrm{U}$ & $23.96 \mathrm{U}$ & 135.43 \\
\hline N. virens Background Rep 3 & 3 & 3 & 14.40 & $22.64 \mathrm{U}$ & $22.64 \mathrm{U}$ & $22.64 U$ & $22.64 \mathrm{U}$ & $22.64 \mathrm{U}$ & 153.14 \\
\hline N. virens Control & 1 & 2 & 14.32 & $13.34 \mathrm{U}$ & $13.34 \mathrm{U}$ & $13.34 \mathrm{U}$ & $13.34 \mathrm{U}$ & $13.34 \mathrm{U}$ & 233.71 \\
\hline N. virens Control & 2 & 3 & 14.83 & $22.19 \mathrm{U}$ & $22.19 \mathrm{U}$ & $22.19 \mathrm{U}$ & $22.19 \mathrm{U}$ & $22.19 \mathrm{U}$ & 168.75 \\
\hline N. virens Control & 3 & 1 & 13.20 & $22.27 \mathrm{U}$ & $22.27 \mathrm{U}$ & $22.27 \mathrm{U}$ & $22.27 \mathrm{U}$ & $22.27 \mathrm{U}$ & 178.43 \\
\hline N. virens Control & 4 & 1 & 14.61 & $19.99 \mathrm{U}$ & $19.99 U$ & $19.99 U$ & $19.99 \mathrm{U}$ & $19.99 \mathrm{U}$ & 191.06 \\
\hline N. virens Control Rep 1 & 5 & 1 & 14.16 & $34.88 \mathrm{U}$ & $34.88 \mathrm{U}$ & $34.88 \mathrm{U}$ & $34.88 \mathrm{U}$ & $34.88 \mathrm{U}$ & 196.60 \\
\hline N. virens Control Rep 2 & 5 & 1 & 14.16 & $34.04 \mathrm{U}$ & $34.04 \mathrm{U}$ & $34.04 \mathrm{U}$ & $34.04 \mathrm{U}$ & $34.04 \mathrm{U}$ & 203.02 \\
\hline N. virens Control Rep 3 & 5 & 1 & 14.16 & $26.62 \mathrm{U}$ & $26.62 U$ & $26.62 \mathrm{U}$ & $26.62 \mathrm{U}$ & $26.62 \mathrm{U}$ & 199.56 \\
\hline
\end{tabular}

(a) Analyte was not present above the associated value.

PANAMA CITY HARBOR 
IABLE M.30. Quality Control Data for Polychlorinated Biphenyl (PCB) Analysis, Wet Weight, in Tissue of $N$. virens, Panama City Harbor Project

Sedim
Ireat
Metho
Blank
Blank
Blank

Matrix Spikes

$P C-2$

PC-2 MS

Concentration Recovered

Amount Spiked

Percent Recovery

$P C-5$

PC-5 MS

Concentration Recovered

Amount Spiked

Percent Recovery

Reference

Reference MS

Concentration Recovered

Amount Splked

Percent Recovery

$N$ virens Control

N. virens Control MS

Concentration Recovered

Amount Splked

Percent Recovery

Analytical Replicates

PC-4 Rep 1

PC-4 Rep 2

PC-4 Rep 3

RSD

PC-4 Rep 1

PC-4 Rep 2

PC-4 Rep 3

RSD

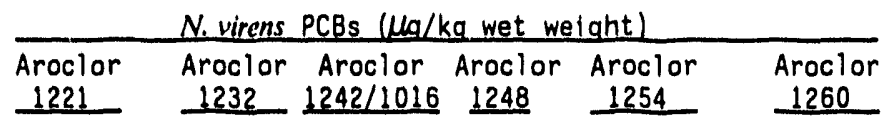

Replicate Batch

$2.33 U^{(a)}$

$2.42 \mathrm{U}$

$2.33 \mathrm{U}$

$2.33 \mathrm{U}$

$2.33 \mathrm{U}$

$2.33 \mathrm{U}$

$2.33 U$

$3.28 \mathrm{U}$

$3.28 \mathrm{U}$

$3.28 \mathrm{U}$

$2.42 \mathrm{U}$

$2.42 \mathrm{U}$

$3.28 \mathrm{U}$

$3.28 \mathrm{U}$

$3.28 \mathrm{U}$

\begin{tabular}{|c|c|c|}
\hline $\begin{array}{l}1 \\
1\end{array}$ & $\begin{array}{l}3 \\
3\end{array}$ & $\begin{array}{l}4.52(b) \\
N A \\
N A \\
N S(c) \\
N A\end{array}$ \\
\hline $\begin{array}{l}2 \\
2\end{array}$ & $\begin{array}{l}2 \\
2\end{array}$ & $\begin{array}{c}3.31 U \\
N A \\
N A \\
N S \\
N A\end{array}$ \\
\hline
\end{tabular}

4.52
NA
NA
NS
NA

4.52
NA
NA
NS
NA

4.52
NA
NA
NS
NA

$4.52 U$

75.86

75.86

53.59

$142 \%$ (d)

8.93

NA

NA

NS

$3.31 \mathrm{U}$

3.31 U
NA
NA
NS
NA

$3.31 \mathrm{U}$

$3.31 U$

15.37

NA
NS
NA

NA $\quad 33.52$

NA $\quad 33.52$

$\begin{array}{ll}\text { NS } & 43.57 \\ \text { NA } & 77 \%\end{array}$

NA

NA

NS

$3.31 \mathrm{U}$

$3.31 \mathrm{U}$

$3.31 \mathrm{U}$

$3.31 \mathrm{U}$

$3.31 \mathrm{U}$

39.38

NA
NA
NS
NA

NA
NA
NS
$\cdots$

NA
NA
NS
NA

NA $\quad 139.4$

NA $\quad 139.4$

NS $\quad 44.02$

$317 \%(\mathrm{~d})$

NA

NA

NS

$2.92 U$

$2.92 \mathrm{U}$

$2.92 U$

$2.92 \mathrm{U}$

$2.92 U$

27.91

NA

NA

NA

NA

73.88

NA

NA

NA

NS

NA

NA

NA

$153 \%$
(d)

NA

NA

NS

$\begin{array}{lccccc}4.94 U & 4.94 U & 4.94 U & 4.94 U & 4.94 U & 14.29 \\ 4.96 U & 4.96 U & 4.96 U & 4.96 U & 4.96 U & 30.34 \\ 3.78 U & 3.78 U & 3.78 U & 3.78 U & 3.78 U & 18.03 \\ \text { NA } & \text { NA } & \text { NA } & \text { NA } & \text { NA } & 40 \%(e) \\ & & & & & \\ 4.87 U & 4.87 U & 4.87 U & 4.87 U & 4.87 U & 18.89 \\ 4.92 U & 4.92 U & 4.92 U & 4.92 U & 4.92 U & 14.48 \\ 4.03 U & 4.03 U & 4.03 U & 4.03 U & 4.03 U & 18.69 \\ \text { NA } & \text { NA } & \text { NA } & \text { NA } & \text { NA } & 14 \%\end{array}$


IABLE M.30. (contd)

Sediment

Treatment

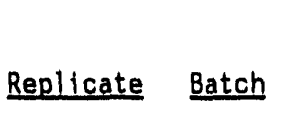

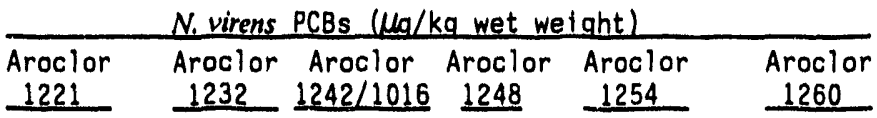

N. virens Background Rep 1

$N$. virens Background Rep 2

$\begin{array}{ll}1 & 3 \\ 2 & 3 \\ 3 & 3\end{array}$

$3.51 \mathrm{U}$

$3.51 \mathrm{U}$

$3.51 \mathrm{U}$

$3.51 U$

$3.51 \mathrm{U}$

21.44

$3.45 \mathrm{U}$

$3.45 \mathrm{U}$

$3.45 \mathrm{U}$

$3.45 \mathrm{U}$

$3.45 \mathrm{U}$

19.50

$3.26 \mathrm{U}$

3.26
NA

$3.26 U$

$3.26 \mathrm{U}$

$3.26 \mathrm{U}$

RSD

NA

NA

NA

NA

22.05

N. virens Control Rep 1

$N$. virens Control Rep 2

$N$. virens Control Rep 3

$\begin{array}{ll}5 & 1 \\ 5 & 1 \\ 5 & 1\end{array}$

$4.94 \mathrm{U}$
$4.82 \mathrm{U}$
$3.77 \mathrm{U}$

$4.94 \mathrm{U}$

$4.94 \mathrm{U}$

$4.94 U$

$4.94 U$

27.84 RSD

$4.82 \mathrm{U}$

$3.77 \mathrm{U}$

NA

$4.82 \mathrm{U}$

$3.77 \mathrm{U}$

NA

$4.82 U$

$3.77 \mathrm{U}$

NA

$4.82 \mathrm{U}$

$3.77 \mathrm{U}$

NA

28.75

28.26

$2 \%$

(a) $U$ Analyte was not present above the associated value.

(b) NA Not applicable.

(c) NS Not spiked.

(d) Recovery outside quality control range (40\%-120\%).

(e) Value exceeds relative precision goal of $\leq 30 \%$. 
IABLE M.31. Surrogate Recoveries and Quality Control Data for Polychlorinated Biphenyl (PCB) and Chlorinated Pesticide Analysis, Wet Weight, in Tissue of N. virens, Panama City Harbor Project

\section{Sediment}

Treatment

$P C-1$

$P C-1$

$P C-1$

$P C-1$

$P C-1$

$P C-1 A$

$P C-1 A$

PC-1A

PC- $1 A$

$P C-1 A$

$P C-2$

PC - 2

PC - 2

$P C-2$

$P C-2$

PC - 4

PC-4 Rep 1

PC-4 Rep 2

PC -4 Rep 3

PC- 4

PC-4 Rep 1

PC-4 Rep 2

PC -4 Rep 3

$P C-4$

$P C-5$

$P C-5$

$P C-5$

$P C-5$

PC -5

Reference

Reference

Reference

Reference

Reference

N. virens Background Rep 1

$N$. virens Background Rep 2

$N$. virens Background Rep 3

\section{Replicate Batch}

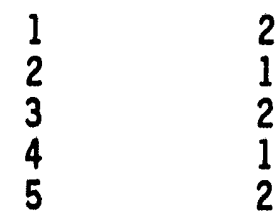

1
2
3
4
5

1
2
3
4
5

1

2

2

3

4

4

4

5

1

2

4
5

1

2

3

4
5

1
2
3
N. virens

$\frac{\text { Surrogate Percent Recovery }}{\text { DBOFB }}$

93
111
54
71
43

44

75

$31^{(a)}$

50

$22^{(a)}$

49

$125^{(a)}$

$28^{(a)}$

67

40

$37^{(a)}$

67

$32^{(a)}$
$35^{(a)}$
70
66
60

86

$32^{7}(a)$

$142^{(a)}$

56

97

91

110

77

100

88

$20^{(a)}$

$38^{(a)}$

60

46

$26^{(a)}$

40

$33^{(a)}$

64

$142^{\text {(a) }}$

96

105

84

${ }_{37}^{49}$ a)

63

$36^{(a)}$

53

96
63
86
101
55

$36^{(a)}$

40

44

67

$22^{(a)}$

84

61

78 $31^{(a)}$

$14^{(a)}$

$30^{(a)}$

PANAMA CITY HARBOR

M. 61 
TABLE M.31. (contd)

Sediment

Ireatment

N. virens Control

N. virens Control

N. virens Control

N. virens Control

N. virens Control Rep 1

N. virens Control Rep 2

N. virens Control Rep 3

Quality Control Data

Method Blanks

Bl ank

Blank

Bl ank

\section{Matrix Soikes}

PC-2 MS

3

PC-5 MS

Reference MS

N. virens Control MS
Replicate Batch

$\begin{array}{ll}1 & 2 \\ 2 & 3 \\ 3 & 1 \\ 4 & 1 \\ 5 & 1 \\ 5 & 1 \\ 5 & 1\end{array}$

N. virens

Surrogate Percent Recovery DBOFB

51
100
95
96
78
109
107

(a) Recovery outside quality control range (40\%-120\%). 
IABLE M.32. Percent Lipid Results, Wet Weight, in Tissue of N. virens, Panama City Harbor Project

Sediment Ireatment

Target $D L^{(a)}$
Achieved $D L$

$\mathrm{PC}-1$

$P C-1$

PC-1

PC- 1

PC-1

PC-1A

$P C-1 A$

$P C-1 A$

$P C-1 A$

PC- $1 A$

$P C-2$

PC-2

$\mathrm{PC}-2$

$\mathrm{PC}-2$

PC-2

PC- 4 :

PC-4 Rep 1

PC-4 Rep 2

$\mathrm{PC}-4$ Rep 3

PC- 4

PC-4 Rep 1

PC-4 Rep 2

PC-4 Rep 3

PC-4

PC -5

PC -5

PC-5

PC -5

PC-5

Reference

Reference

Reference

Reference

Reference

N. virens Background Rep 1

N. virens Background Rep 2

$N$. virens Background Rep 3

PANAMA CITY HARBOR
Replicate

1

3

4
5

5

1

3

4

5

1

2

3

4

5

1

2

2

2

3

4

4

4

5

1

2

3

4

5

1

2

3

4
Batch

Percent Lipid

0.1 $N A^{(b)}$

3.01

3.53

5.32

7.88

4.25

2.37

5.86

3.23

9.06

10.45

5.19

4.08

5.74

13.73

5.13

6.18

6.58

7.11

5.16

3.82

5.89

6.10

5.00

2.86

2.53

6.06

3.05

2.87

5.06

2.62

2.54

3.27

4.59

2.71

3.91

3.74

2.84 
IABLE M.32. (contd)

Sediment

Ireatment

N. virens Control

N. virens Control

N. virens Control

N. virens Control

N. virens Control Rep 1

N. virens Control Rep 2

N. virens Control Rep 3

\section{Replicate}

1
2
3
4
5
5
5

Batch

2

3

1

1

1

1
Percent Lipid

3.85

4.00

4.25

5.11

4.43

NA

3.22

(a) DL Detection 1imit.

(b) NA Not applicable. 


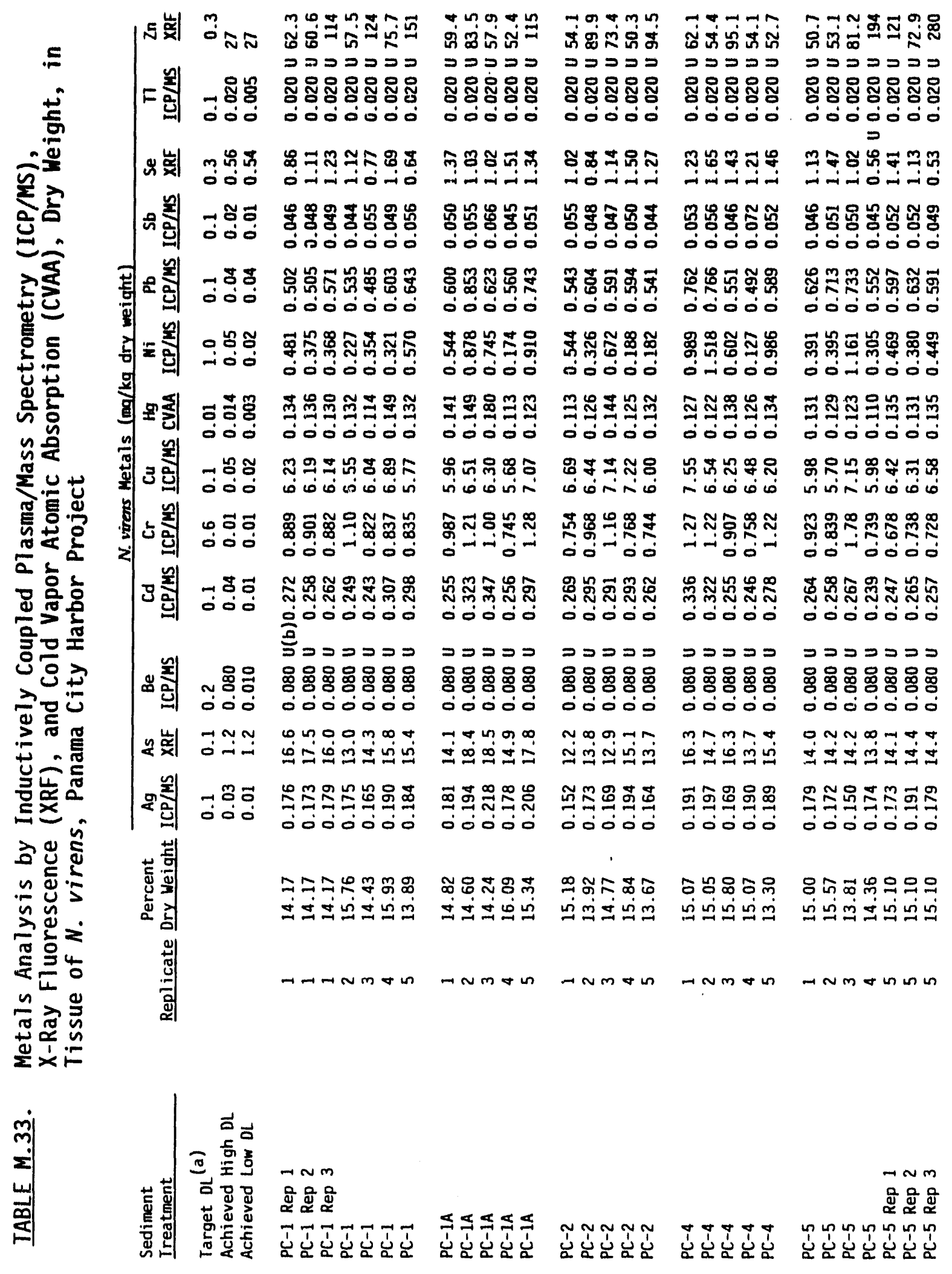

PANAMA CITY HARBOR

M.65 


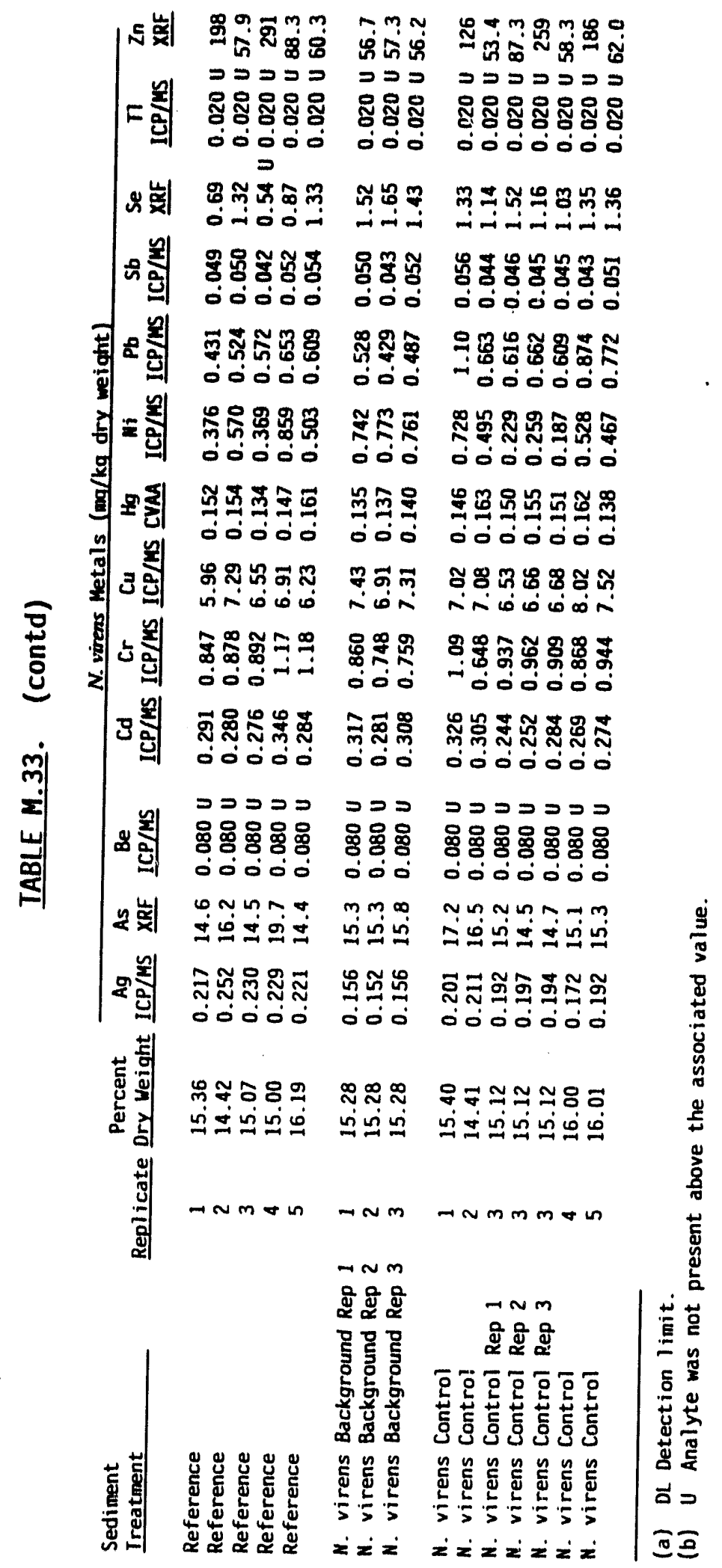

PANAMA CITY HARBOR

M. 66 


\begin{tabular}{|c|c|c|c|c|c|c|c|}
\hline & | 5 紋 & 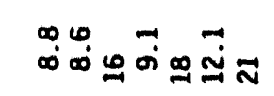 & $\begin{array}{l}\infty \\
\infty \\
\infty \\
\infty\end{array}$ & 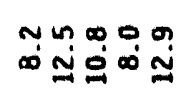 & 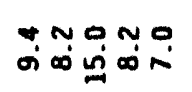 & 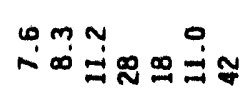 & 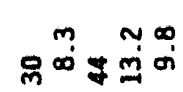 \\
\hline$x .5$ & & 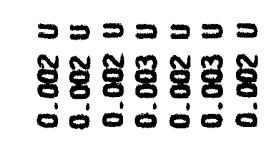 & 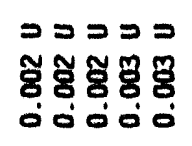 & 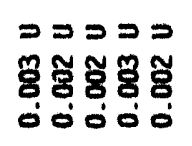 & 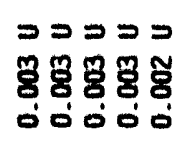 & 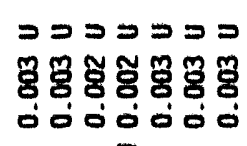 & 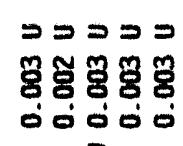 \\
\hline & & 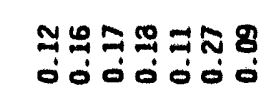 & 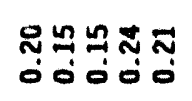 & 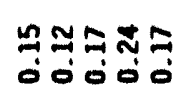 & 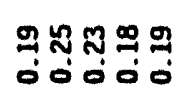 & 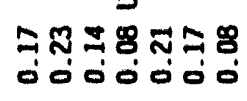 & $\begin{array}{l}79.98 \\
000 \\
000\end{array}$ \\
\hline & & 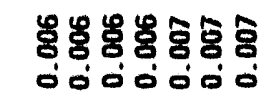 & 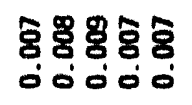 & 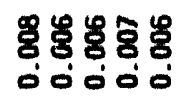 & 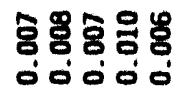 & 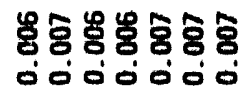 & 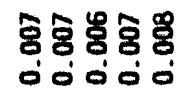 \\
\hline & & 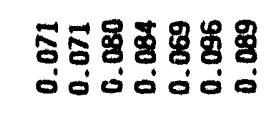 & 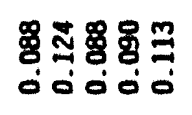 & 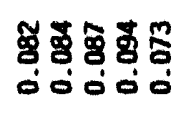 & 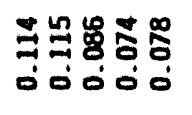 & 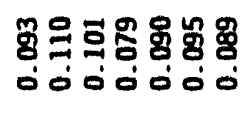 & 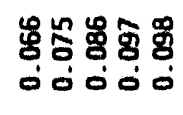 \\
\hline & & 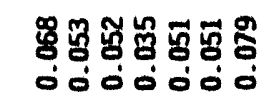 & 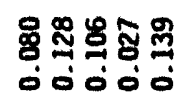 & 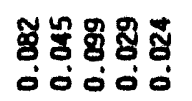 & 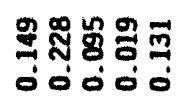 & 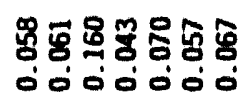 & 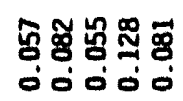 \\
\hline & & 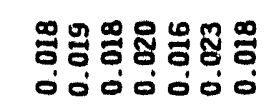 & 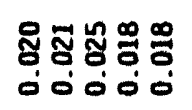 & 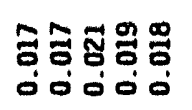 & 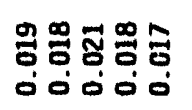 & 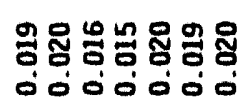 & 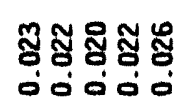 \\
\hline & & 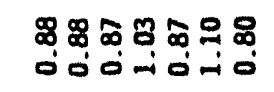 & 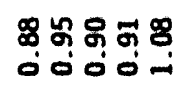 & 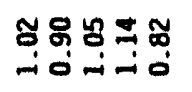 & 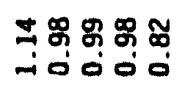 & 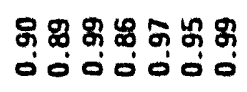 & 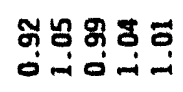 \\
\hline & & 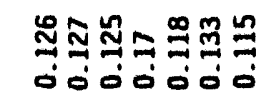 & 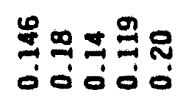 & 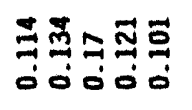 & 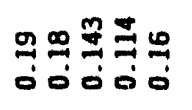 & 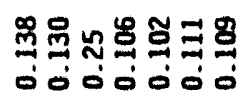 & 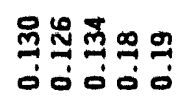 \\
\hline & & 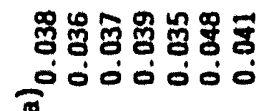 & 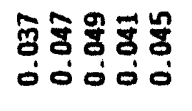 & 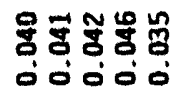 & 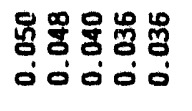 & 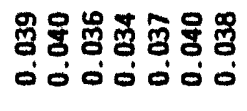 & 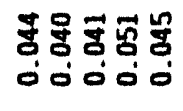 \\
\hline & $\Phi$ & 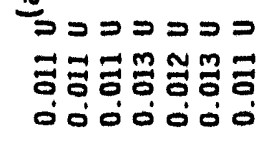 & 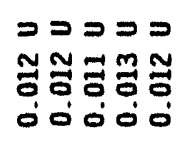 & 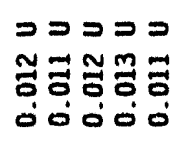 & 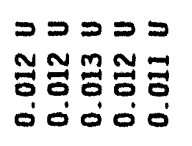 & 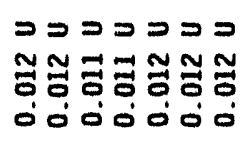 & 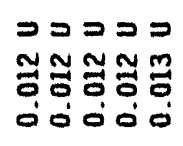 \\
\hline & 得 & نْ & $\overline{i N i N i N i ~}$ & 999 9 9 & نี & 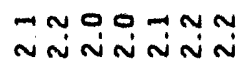 & 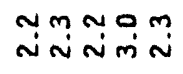 \\
\hline & 29: & 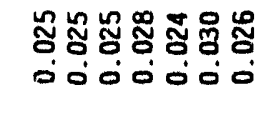 & 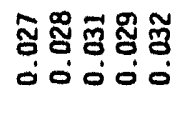 & 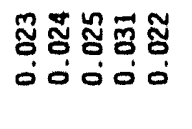 & 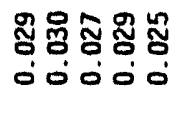 & 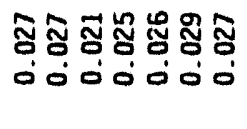 & 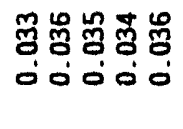 \\
\hline & 蒿 & 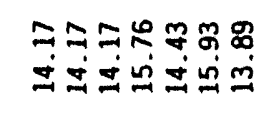 & 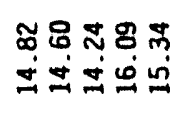 & 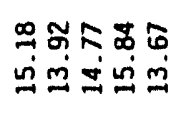 & 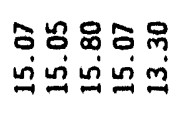 & 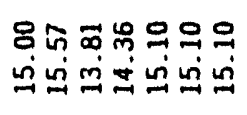 & 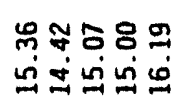 \\
\hline & & & $u \rightarrow$ in & $N m$ on & & חמ n & \\
\hline
\end{tabular}




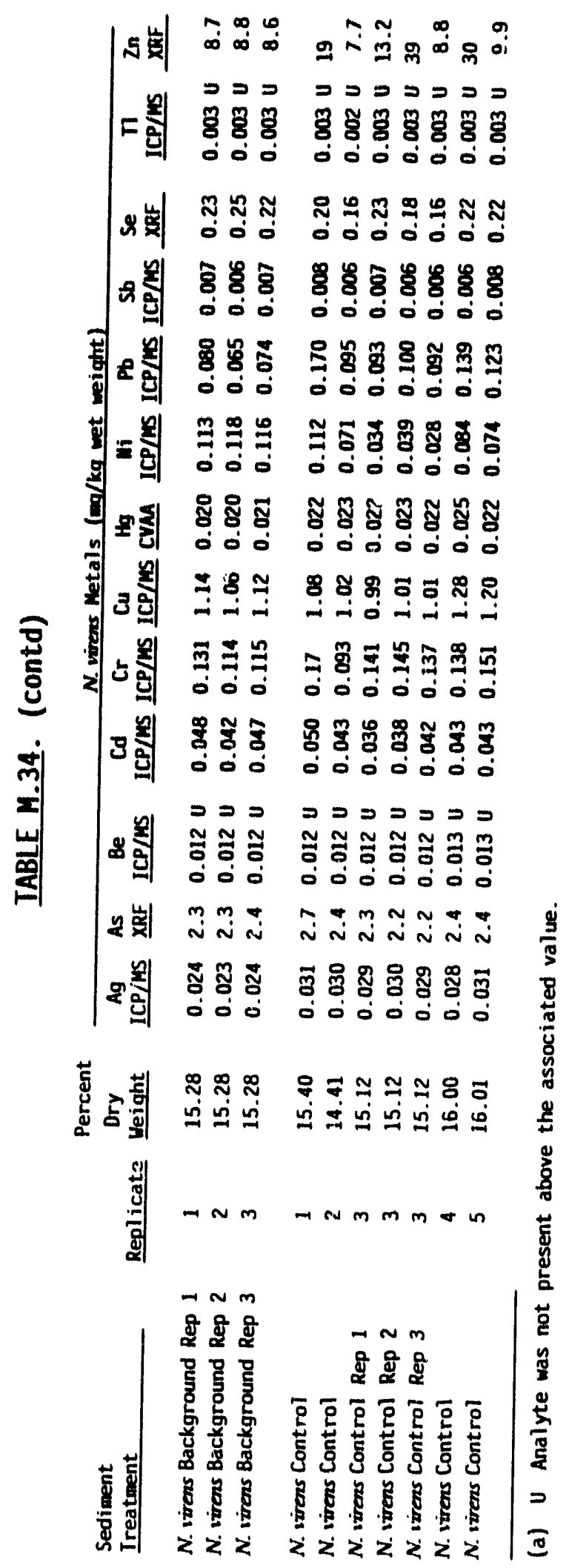

PANAMA CITY HARBOR

M. 68 


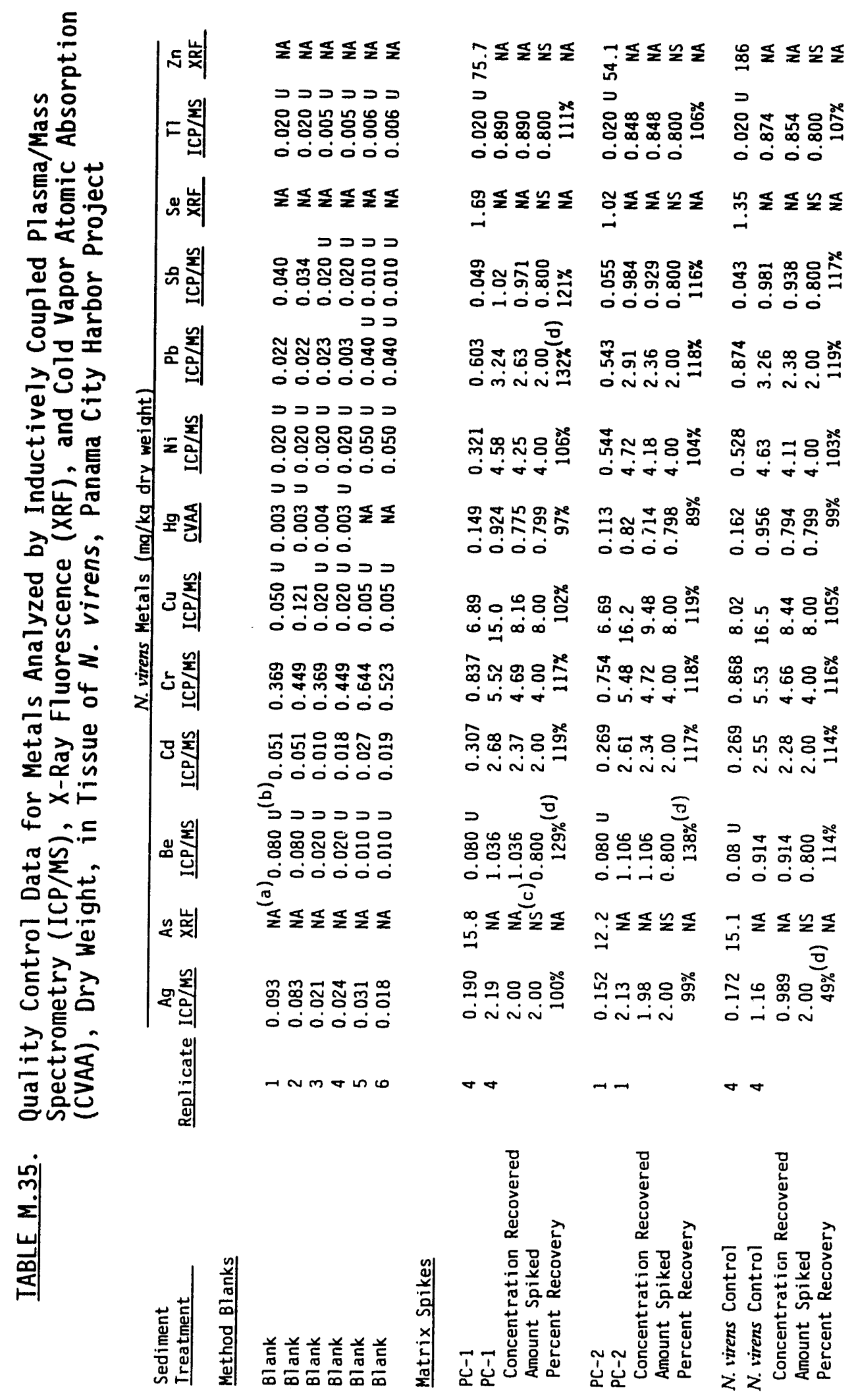




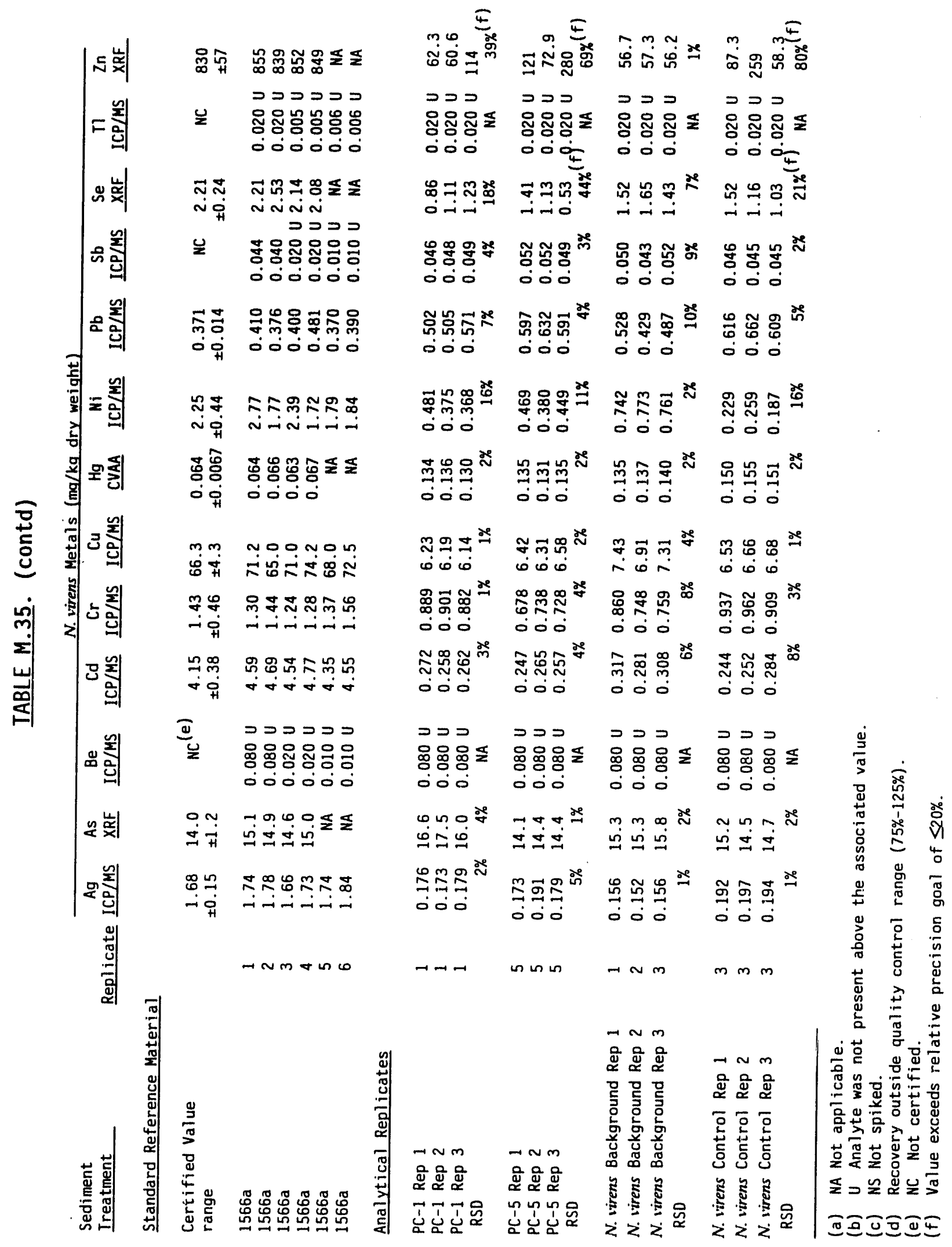

PANAMA CITY HARBOR

M. 70 


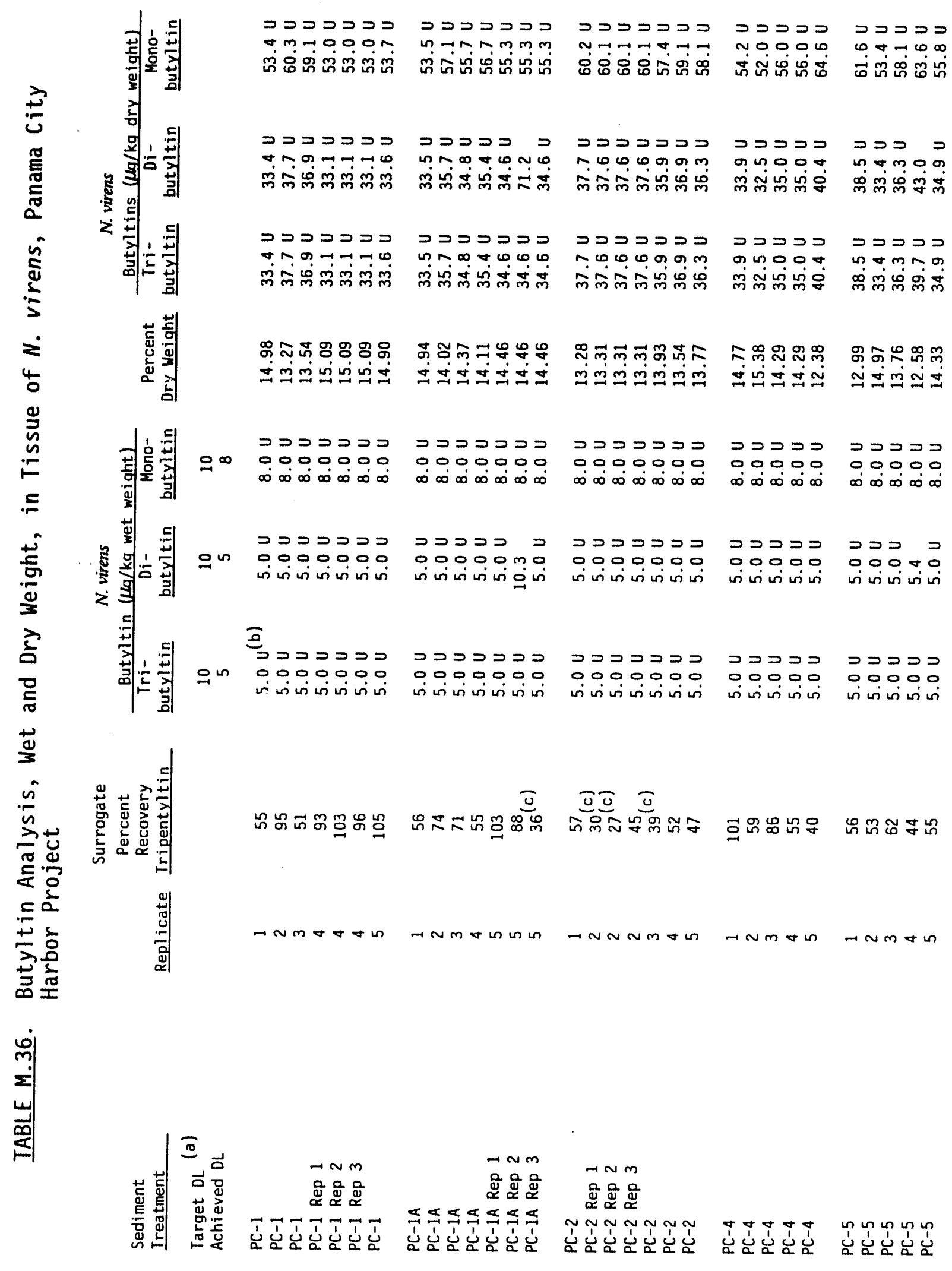

PANAMA CITY HARBOR

M.71 

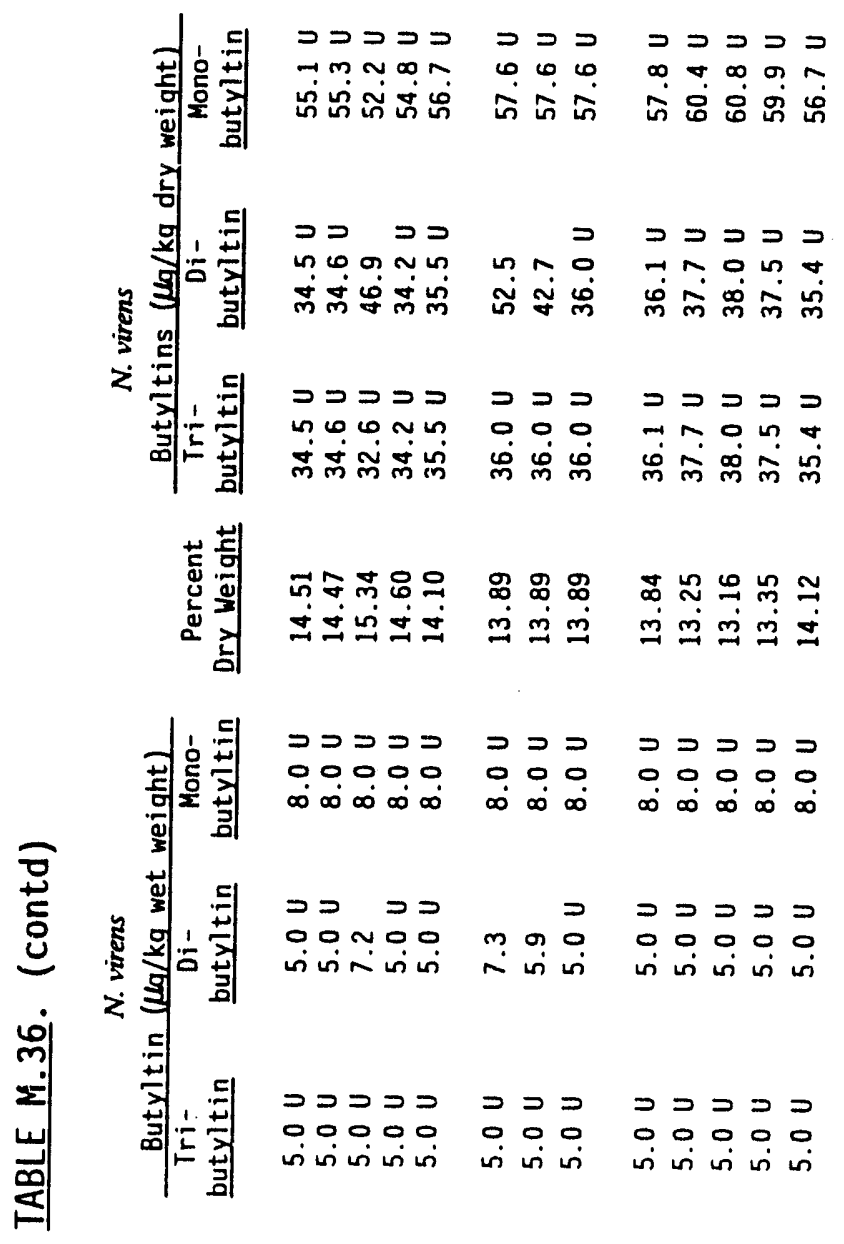

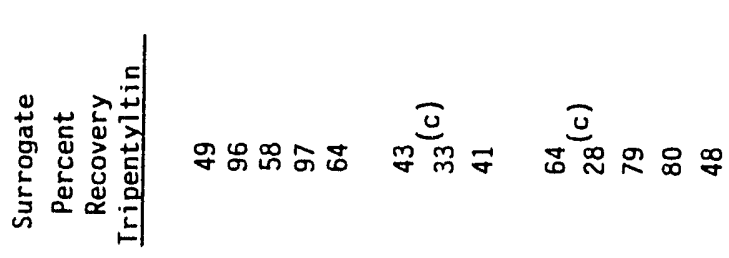

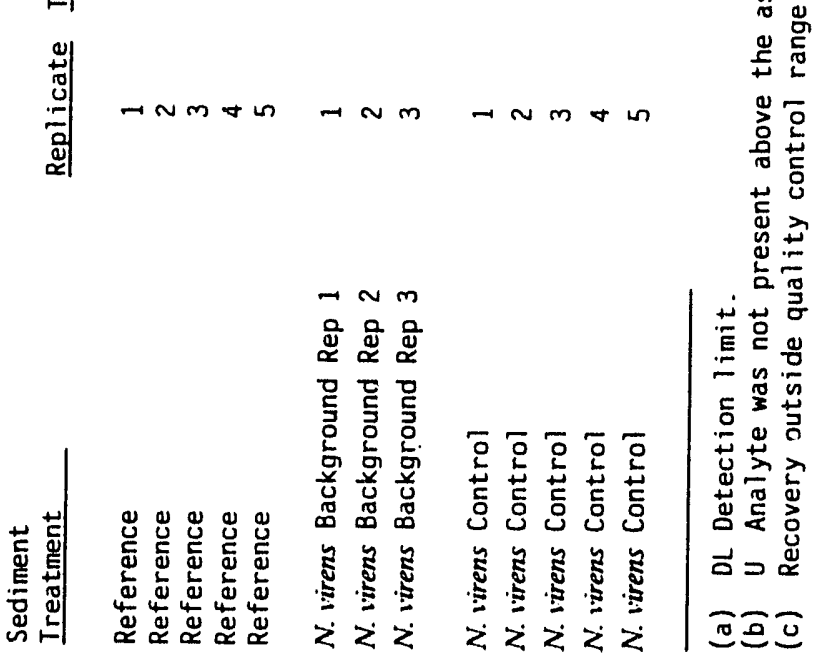


TABLE M.37. Quality Control Data for Butyltin Analysis, Wet Weight, in Tissue of N. virens, Panama City Harbor Project

Sediment

Treatment

Method Blanks

Blank

Blank

Blank

Blank

Matrix Spikes

$P C-1$

$P C-1$ MS

Concentration Recovered

Amount Spiked

Percent Recovery

$P C-1$

PC-1 MSO

Concentration Recovered Amount Spiked

Percent Recovery

RPD

I-Stat

$P C-5$

PC-5 MS

Concentration Recovered Amount Spiked

Percent Recovery

$P C-5$

PC-5 MSD

Concentration Recovered Amount Spiked

Percent Recovery

RPO

I-Stat

Reference

Reference MS

Concentration Recovered Amount Spiked

Percent Recovery

Reference

Reference MSD

Concentration Recovered Amount Spiked

Percent Recovery

RPD

I-Stat
Surrogate

Percent

Recovery

Replicate Iripentyltin

$\begin{array}{lr}1 & 44 \\ 2 & 45 \\ 3 & 96 \\ 4 & 101\end{array}$

5
5

5

5

105
78
NA
NA
NA

105

105
86
$N A$

NA

NA

NA

NA

NA

1

56

53

NA

NA

NA

1

56

56

NA

NA

NA

NA

NA

4

4

97

97

NA

NA

NA

97

105

NA

NA

NA

NA

NA

\begin{tabular}{|c|c|c|}
\hline Butylt & $\begin{array}{l}\text { N. virens } \\
(\mu \mathrm{g} / \mathrm{kg} \text { wet }\end{array}$ & ht) \\
\hline $\begin{array}{c}\text { Tri- } \\
\text { butyltin }\end{array}$ & $\begin{array}{c}\text { Di- } \\
\text { butyltin }\end{array}$ & $\begin{array}{c}\text { Mono- } \\
\text { butyltin }\end{array}$ \\
\hline
\end{tabular}

$\begin{array}{lll}5.0 U^{(a)} & 5.0 U & 8.0 U \\ 5.0 U & 5.0 U & 5.0 U \\ 5.0 U & 5.0 U & 8.0 U \\ 5.0 \mathrm{U} & 5.0 \mathrm{U} & 8.0 \mathrm{U}\end{array}$

$5.0 \mathrm{U}$

50.6

50.6

48.7

$104 \%$

$5.0 \mathrm{U}$

45.0

45.0

48.7

$92 \%$

$8.0 \mathrm{U}$

5.4

48.7 (c)

$5.0 \mathrm{U}$

$5.0 \mathrm{U}$

41.9

41.9

46.6

46.9

46.6

$101 \%$

$90 \%$

$8.0 \mathrm{U}$

5.6

5.6

46.6
$12 \%$

$3 \%$

0.02

$2 \%$

$0.9 \%$

$5.0 \mathrm{U}$

51.6

51.6

47.9

$108 \%$

$5.0 \mathrm{U}$

48.1

48.1

47.9

$100 \%$$$
0.04
$$

$8.0 \mathrm{U}$

7.5

7.5

47.9 (b)

$5.0 \mathrm{U}$

55.2

55.2

50.0

$110 \%$

$5.0 \mathrm{U}$
48.9

48.9

50.0

$98 \%$

$8.0 \mathrm{U}$

7.2

7.2

50.0
$14 \%$ (c)

$2 \%$

0.01

$0.01 \%$

$13 \%$
0.07

$5.0 \mathrm{U}$

51.8

51.8

49.4

$105 \%$

$5.0 \mathrm{U}$

49.6

49.6

49.4

$100 \%$

$$
\begin{aligned}
& 8.0 \mathrm{U} \\
& 11.9 \\
& 11.9 \\
& 49.4 \\
& 24 \%(\mathrm{c})
\end{aligned}
$$

$5.0 \mathrm{U}$

53.1

53.1

48.4

$110 \%$

$5.0 \mathrm{U}$

49.3

49.3

48.4

$102 \%$
$8.0 \mathrm{U}$
11.5
11.5
48.4 (c)

$5 \%$

0.02

$2 \%$

0.01

$0 \%$

PANAMA CITY HARBOR 
TABLE M.37. (contd)

Sediment

Treatment

Analytical Replicates

PC-1A Rep 1

$P C-1 A$ Rep 2

PC-1A Rep 3

RSD

PC-1 Rep 1

$P C-1$ Rep 2

$P C-1 \operatorname{Rep} 3$

RSD

PC-2 Rep 1

PC-2 Rep 2

$P C-2$ Rep 3

RSD

N. virens Background Rep 1

$N$. virens Background Rep 2

$N$. virens Background Rep 3 RSD
Surrogate

Percent

Recovery

Replicate

Iripentyitin

$\begin{array}{ll}5 & 103 \\ 5 & 88 \\ 5 & 36 \\ & \text { NA }\end{array}$

$5.0 U$
$5.0 U$
$5.0 U$
$N A$

$5.0 \mathrm{U}$

10.3

$5.0 \mathrm{U}$

NA

$8.0 \mathrm{U}$

$8.0 \mathrm{U}$

$8.0 \mathrm{U}$

NA

$5.0 \mathrm{U}$

$5.0 \mathrm{U}$

$5.0 \mathrm{U}$

NA

$5.0 \mathrm{U}$

$5.0 \mathrm{U}$

$5.0 \mathrm{U}$

NA

$8.0 \mathrm{U}$

$8.0 \mathrm{U}$

$8.0 \mathrm{U}$

NA

$5.0 \mathrm{U}$

$5.0 \mathrm{U}$

$5.0 \mathrm{U}$

NA

$5.0 \mathrm{U}$

$5.0 \mathrm{U}$

$5.0 \mathrm{U}$

NA

$8.0 \mathrm{U}$

$8.0 \mathrm{U}$

$8.0 \mathrm{U}$

NA

${ }_{33}^{43}(\mathrm{c})$

$5.0 \mathrm{U}$

$5.0 \mathrm{U}$

$5.0 \mathrm{U}$

41

NA

NA

7.3

5.9

$5.0 \mathrm{U}$

NA

$8.0 \mathrm{U}$

$8.0 \mathrm{U}$

$8.0 \mathrm{U}$

NA

(a) U Analyte was not present above the associated value.

(b) NA Not applicable.

(c) Recovery outside quality control range (40\%-120\%). 
APPENDIX N

ORGANIZATION CHART 


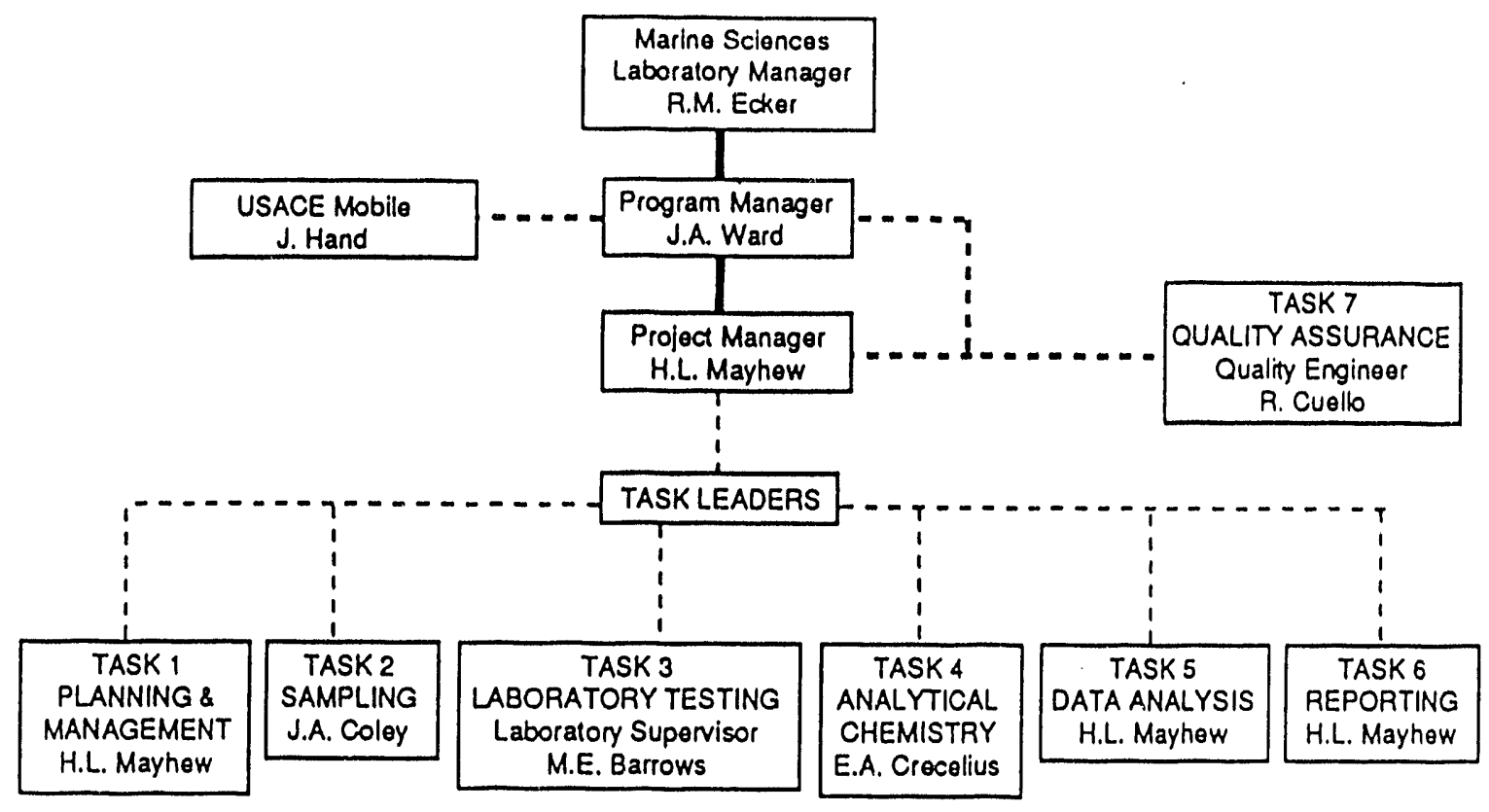

FIGURE N.1. Organizational Chart of Technical Staff, Panama City Harbor Project 
PNL-8894

UC-000

\section{DISTRIBUTION}

No. of

Copjes

OFFSITE

2 DOE/Office of Scientific and Technical Information

15 Mr. Joseph Hand

U.S. Army Corps of Engineers

Mobile District

109 St. Joseph Street

Mobile, AL 36628-0001

Attn: J. Hand/PD-EC

\section{ONSITE}

DOE Richland Field Office

\section{P.W. Kruger}

25 Pacific Nerthwest_Laboratony

R. Cuello

W.R. Gorst

L.M. Karle

N.P. Kohn

H.L. Mayhew (5)

M.R. Pinza

J.A. Trelstad (2)

J.A. Ward

J.Q. Word (5)

Publishing Coordination

Technical Report Files (5)

Bouting

M.J. Graham

P.M. Irving

C.S. Sloane

P.C. Hays (last)

Distr. 1 

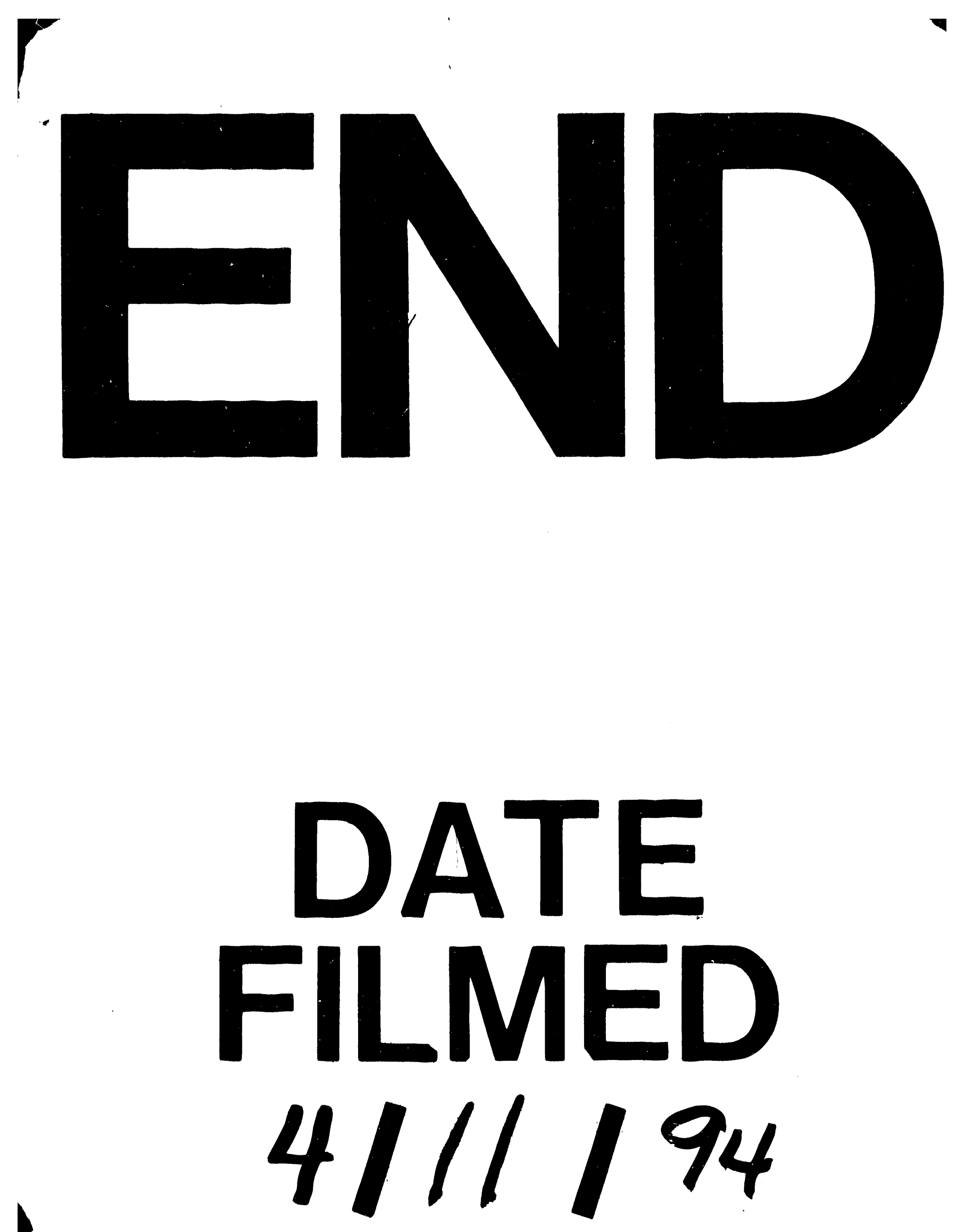

1 